\title{
Development of a Cobinamide-Based Optical Sensor for Hydrogen Cyanide and Hydrogen Sulfide
}

\author{
Lee Ann Greenawald
}

Follow this and additional works at: https://researchrepository.wvu.edu/etd

\section{Recommended Citation}

Greenawald, Lee Ann, "Development of a Cobinamide-Based Optical Sensor for Hydrogen Cyanide and Hydrogen Sulfide" (2016). Graduate Theses, Dissertations, and Problem Reports. 5710.

https://researchrepository.wvu.edu/etd/5710

This Dissertation is protected by copyright and/or related rights. It has been brought to you by the The Research Repository @ WVU with permission from the rights-holder(s). You are free to use this Dissertation in any way that is permitted by the copyright and related rights legislation that applies to your use. For other uses you must obtain permission from the rights-holder(s) directly, unless additional rights are indicated by a Creative Commons license in the record and/ or on the work itself. This Dissertation has been accepted for inclusion in WVU Graduate Theses, Dissertations, and Problem Reports collection by an authorized administrator of The Research Repository @ WVU.

For more information, please contact researchrepository@mail.wvu.edu. 


\title{
Development of a Cobinamide-Based Optical Sensor for Hydrogen Cyanide and Hydrogen Sulfide
}

\author{
Lee Ann Greenawald \\ Dissertation submitted \\ to the Eberly College of Arts and Sciences \\ at West Virginia University \\ Doctor of Philosophy in \\ Chemistry \\ Suzanne Bell, Ph.D., Chair \\ Christopher Coffey, Ph.D. \\ Jeremy Dawson, Ph.D. \\ Harry Finklea, Ph.D. \\ Glen Jackson, Ph.D. \\ Stephen Valentine, Ph.D. \\ Department of Chemistry
}

in partial fulfillment of the requirements for the degree of

Morgantown, West Virginia

2016

Keywords: End-of-Service-Life Indicator; Respirator; Diffuse Reflectance; Paper Sensor;

Monocyanocobinamide; Color Sensor

Copyright (C) 2016 Lee Ann Greenawald 
Development of a Cobinamide-Based Optical Sensor for Hydrogen Cyanide and Hydrogen Sulfide

\section{Lee Ann Greenawald}

Dissertation submitted to the Eberly College of Arts and Sciences at West Virginia University in partial fulfillment of the requirements for the degree of

\section{Doctor of Philosophy in Chemistry}

C. Eugene Bennett Department of Chemistry

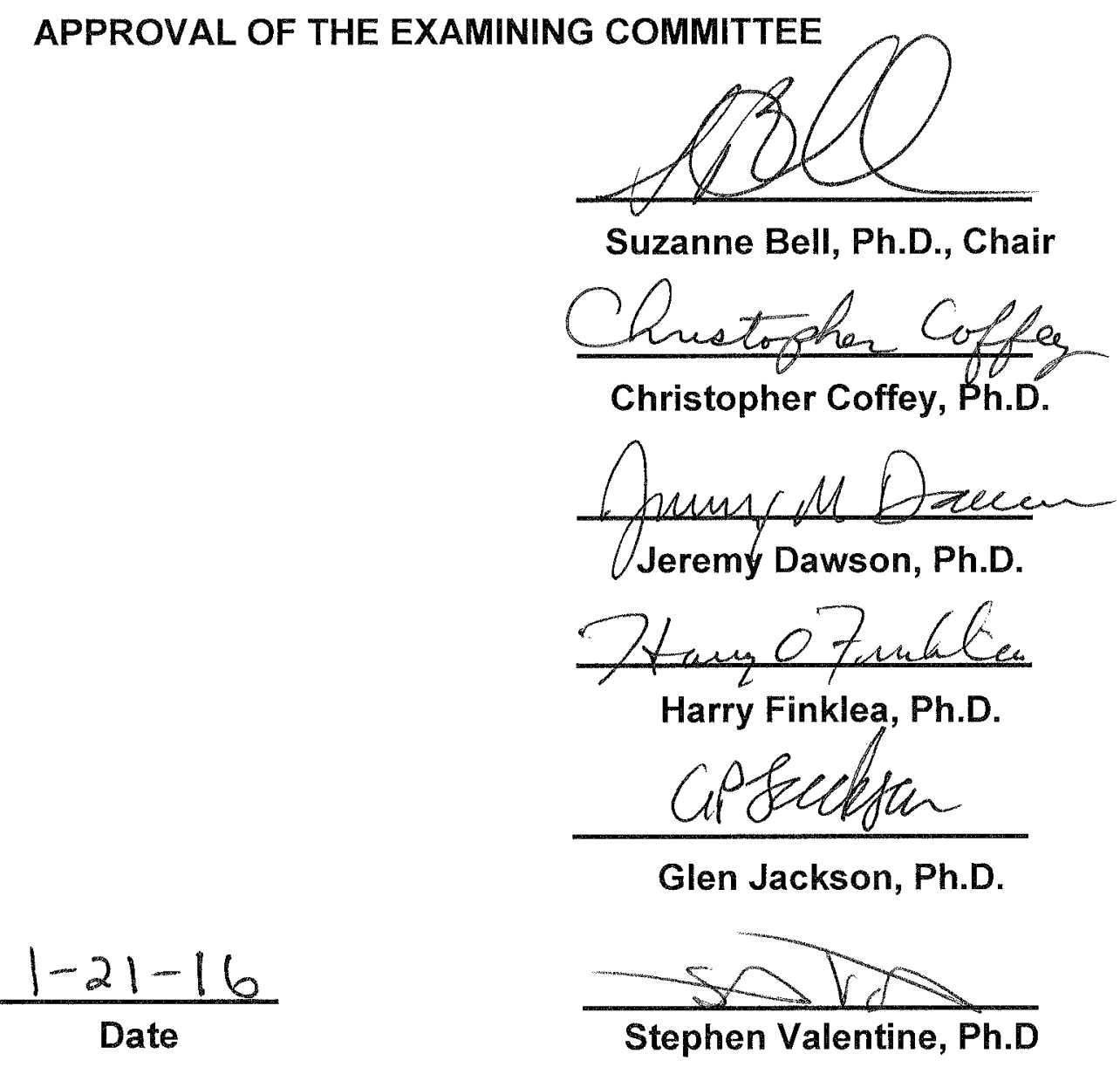




\section{Abstract \\ Development of a Cobinamide-Based Optical Sensor for Hydrogen Cyanide and Hydrogen Sulfide}

\section{Lee Ann Greenawald}

In an occupational or military environment, a personal air-purifying respirator must be provided when breathing-air is contaminated by harmful dust, fumes, gases, aerosols, or vapors. Too often, a respirator user does not have enough information to know when to change his/her cartridge/canister and thus is potentially exposed to toxic gases. Currently, there is no definitive way to determine when respirators' carbon beds have begun to fail. When an end-of-service-life indicator (ESLI) is incorporated into the carbon bed, it informs one, in real-time, when imminent breakthrough is occurring and to replace the cartridge/canister. ESLIs are a more reliable and safer way to determine respirator end-of-service-life. To date, there are no commercially available active ESLIs for inorganic gases.

The objective of this research is to develop an inexpensive, optical sensor for the detection of hydrogen cyanide $(\mathrm{HCN})$ and hydrogen sulfide $\left(\mathrm{H}_{2} \mathrm{~S}\right)$ gas, which can be used to determine the end-of-service-life of a respirator carbon bed. The sensor relies on diffuse reflectance from a paper substrate fixed with cobinamide, a Vitamin $\mathrm{B}_{12}$ derivative. Cobinamide undergoes a metal-ligand binding interaction with $\mathrm{HCN}$, whereas both a binding and reduction reaction may occur with exposure to $\mathrm{H}_{2} \mathrm{~S}$. Characteristic and different spectral shifts rapidly occurred after exposure to $\mathrm{HCN}$ and $\mathrm{H}_{2} \mathrm{~S}$, implying a dual ESLI could be developed to simultaneously detect both gases. Upon increasing the relative humidity from 25 to $85 \%$, the sensitivity was found to increase $7 \mathrm{x}$ for cobinamide-immobilized cellulose fiber filter paper and 50x for glass fiber filter paper upon exposure to 5.0 parts-per-million (ppm) $\mathrm{HCN}$ - the NIOSH recommended exposure limit for $\mathrm{HCN}$. The cobinamide-immobilized paper sensor successfully detected low concentrations of $\mathrm{HCN}$ and $\mathrm{H}_{2} \mathrm{~S}$ upon imminent breakthrough of respirator canisters and cartridges (respectively). The breakthrough curves of the cobinamide paper sensor correlated well with commercial electrochemical detectors, implying that cobinamide may be used to detect both gases at a certain location in the respirator carbon bed and inform the user to replace his or her cartridge/canister.

Additionally, a low-power, inexpensive 3-color (RGB) sensor was prototyped to actively monitor the total change in color of the cobinamide complex on paper upon $\mathrm{HCN}$ exposure. The photodiodes detected, in real-time, a rapid change in the red, green, and blue values of the cobinamide compound upon exposure to $\mathrm{HCN}$ at various concentrations and relative humidity levels. Total change in color from initial cobinamide on paper increased as a function of $\mathrm{HCN}$ concentration, where faster reaction kinetics were observed at higher relative humidity. Response times at all relative humidity levels were within 20 seconds for $5.0 \mathrm{ppm} \mathrm{HCN}$ exposure. The color sensor offers an economical and more quantitative approach to determining color change compared to current, subjective end-of-service-life indicators. 


\section{Dedication}

For my parents and sister for their unconditional love and support.

And my cheerleader and best friend, Grayling, for all of his encouragement and patience. 


\section{Acknowledgments}

I would like to express gratitude and acknowledge the following individuals and groups:

My committee members, Dr. Suzanne Bell, Dr. Chris Coffey, Dr. Jeremy Dawson, Dr. Harry Finklea, Dr. Glen Jackson, and Dr. Stephen Valentine for reviewing my document, serving on my graduate committee, and always being encouraging and supportive.

My colleagues at both Morgantown and Pittsburgh NIOSH facilities - peers, mentors, friends, leaders, and collaborators - who have supported my early-career journey and for allowing me to grow as a scientist, expert, and professional.

The United States Office of Personnel Management Pathways Program for the opportunity to achieve a higher education while pursuing a Federal career.

Dr. Constinia Charbonnette and the Office of Graduate Education \& Life for tuition assistance.

The past and current members of the Bell Research Group in the Chemistry Department at West Virginia University for their advice, support, and friendship. 


\section{Table of Contents}

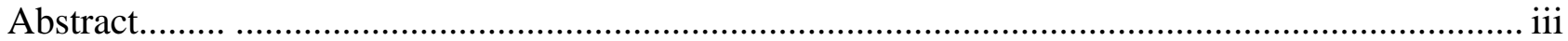

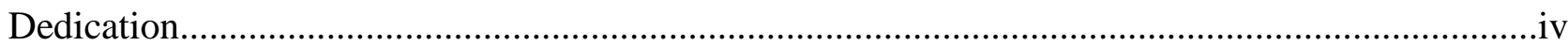

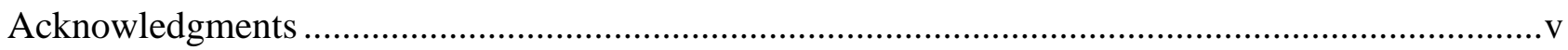

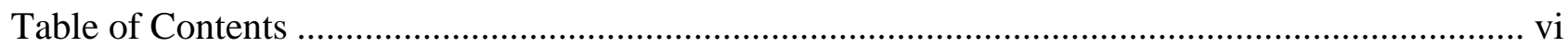

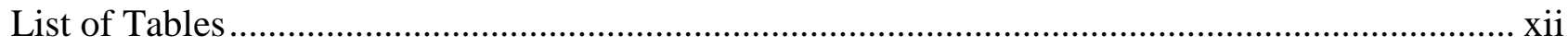

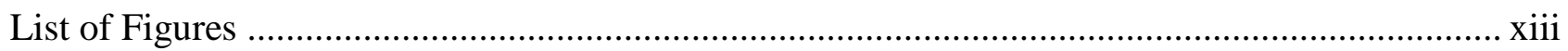

List of Abbreviations, Symbols, and Nomenclature ........................................................ xvii

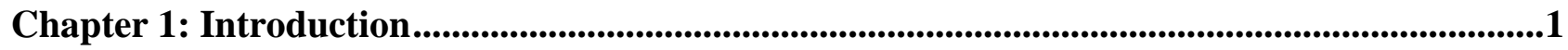

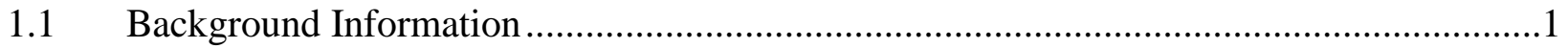

1.1.1 User Determination of Carbon Bed Service-Life .............................................2

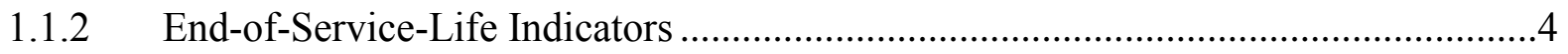

1.1.3 Hydrogen Cyanide ...................................................................................

1.1.4 Cyanide and HCN Detectors.................................................................... 12

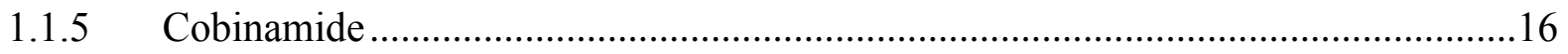

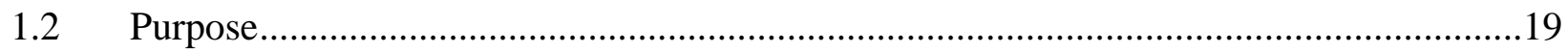

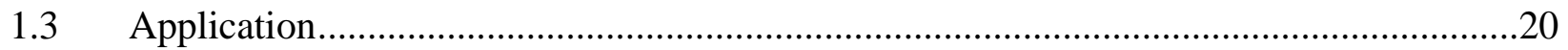

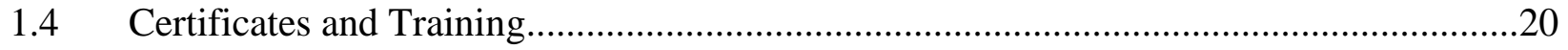

Chapter 2: Cobinamide-Based Detection of Hydrogen Cyanide Gas.........................................21

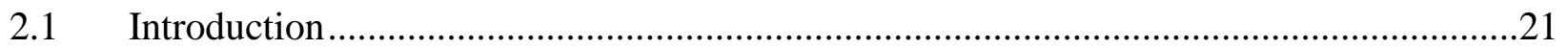

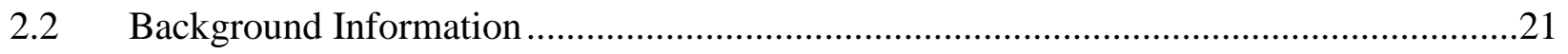

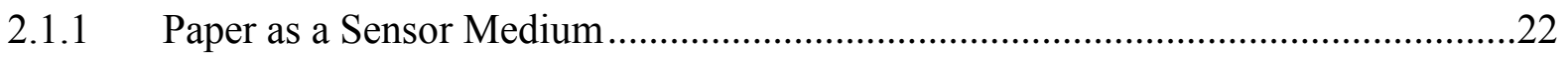

2.2.2 Diffuse Reflectance Spectrometry .............................................................29

2.2.3 The Kubelka-Munk Function.................................................................. 34

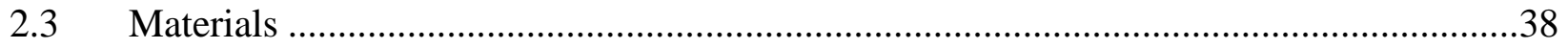




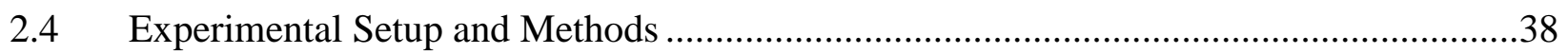

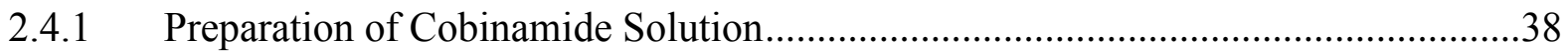

2.4.2 Preparation of Cbi Sensor Substrate …………..........................................................39

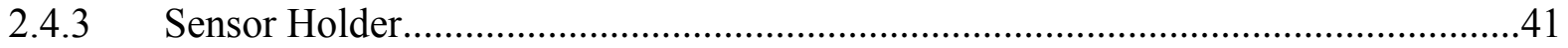

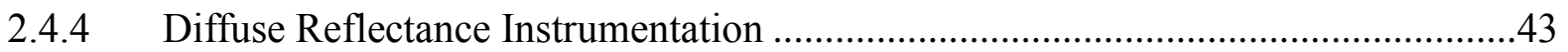

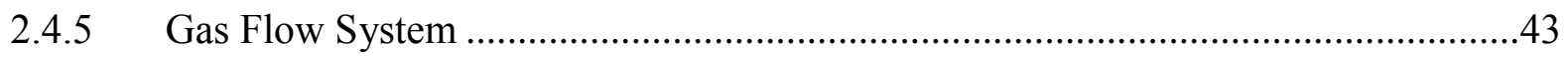

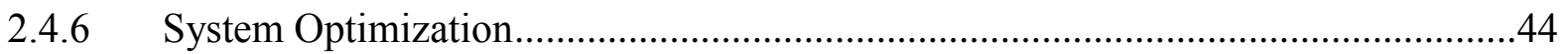

2.4.7 Repeatability and Reproducibility of Cobinamide on Filter Paper............................47

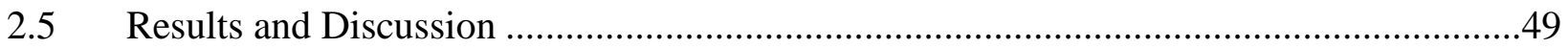

2.5.1 UV-VIS Spectra of Cobinamide …………………................................................49

2.5.2 Comparison of Absorbance and Diffuse Reflectance Spectra ...................................52

2.5.3 Cellulose Filter Paper.............................................................................................54

2.5.3.1 Repeatability of Cobinamide on Cellulose Paper ...................................................54

2.5.3.2 Monocyanocobinamide Detection of HCN Gas ......................................................55

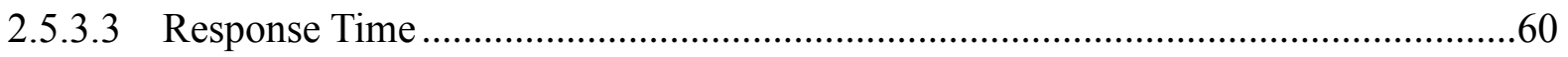

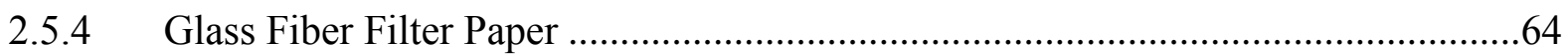

2.5.4.1 Monocyanocobinamide Detection of HCN Gas …………....................................65

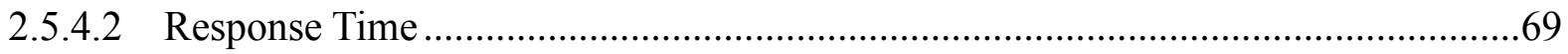

2.5.5 Reproducibility of Cobinamide on Glass Fiber Paper ............................................71

2.5.6 Comparison of Cellulose and Glass Fiber Filter Paper.............................................76

2.5.7 Effect of Percent Relative Humidity …………………………...............................78

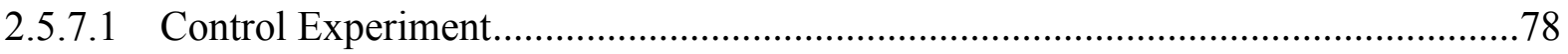

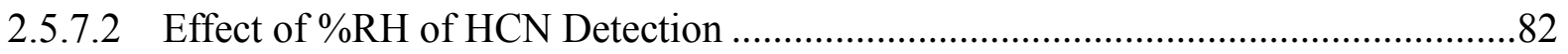

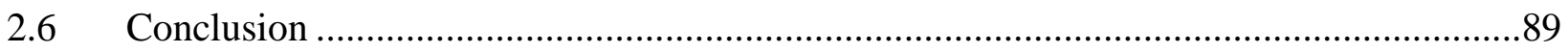

Chapter 3: Cobinamide-Based Detection of Hydrogen Sulfide Gas..................................................90 


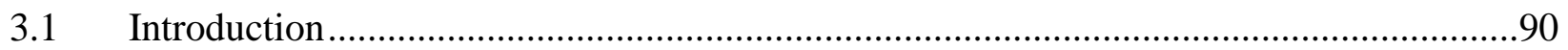

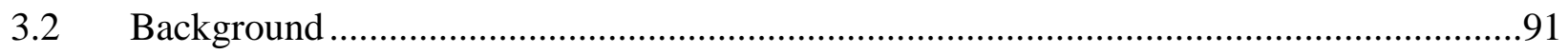

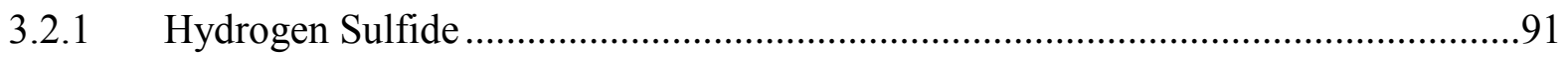

3.2.2 Reaction(s) of Cobinamide and Sulfide ..................................................................

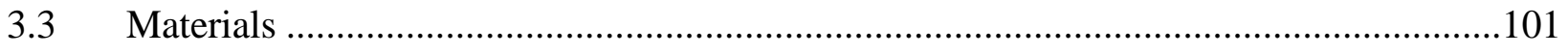

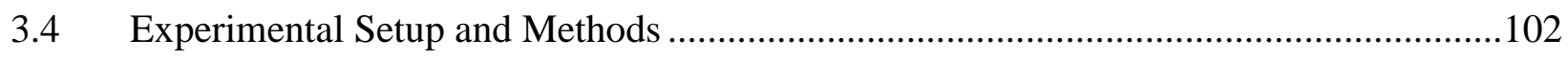

3.4.1 Preparation of Cobinamide Solution....................................................................102

3.4.2 Preparation of Cbi Sensor Substrate ………………...........................................102

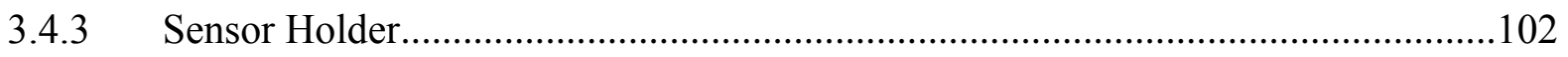

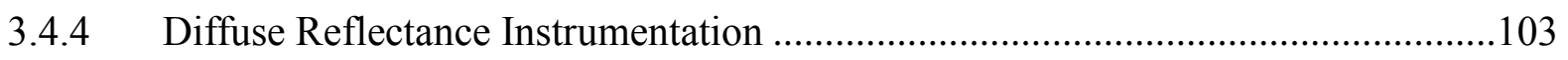

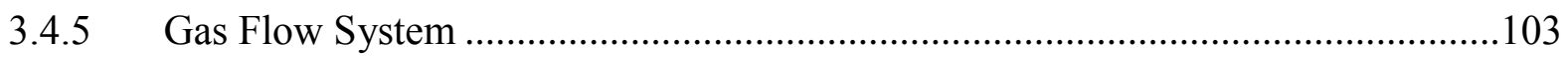

3.4.6 System Optimization.........................................................................................104

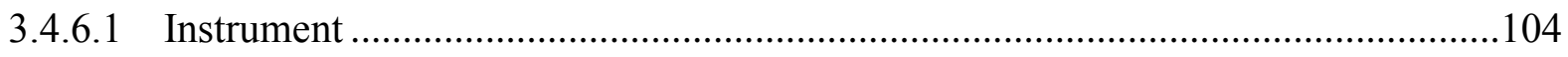

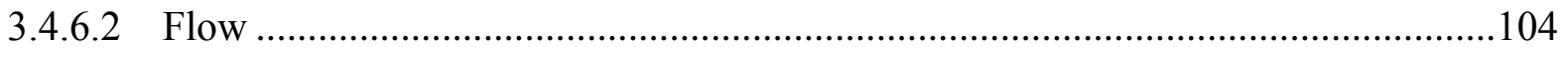

3.4.6.3 Volume and Concentration of Cobinamide ...............................................................105

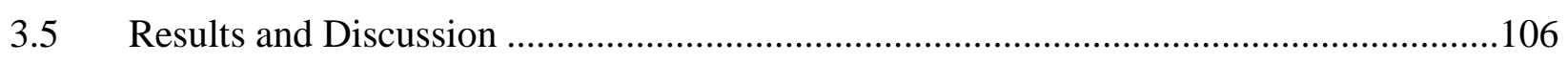

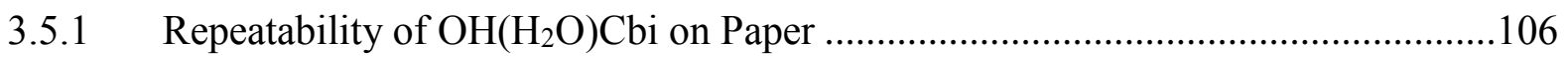

3.5.2 UV-VIS Spectra of Cobinamide with $\mathrm{Na}_{2} \mathrm{~S}$ and Ascorbic Acid..............................107

3.5.3 Comparison of Absorbance and Diffuse Reflectance Spectra ................................111

3.5.4 Aquohydroxocobinamide Detection of $\mathrm{H}_{2} \mathrm{~S}$ Gas .............................................112

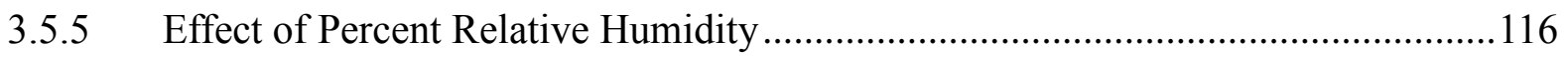

3.5.6 Discussion - Data interpretation and Literature Comparison..................................120

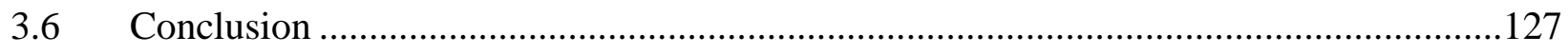

Chapter 4: Detection of $\mathrm{HCN}$ and $\mathrm{H}_{2} \mathrm{~S}$ Breakthrough from Respirator Canisters and Cartridges.........................................................................................................................................128 


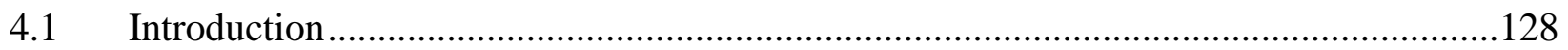

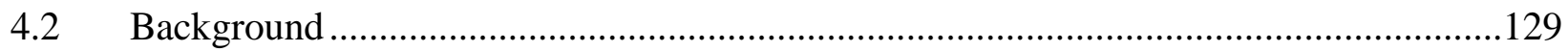

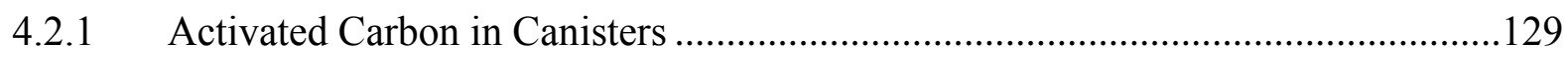

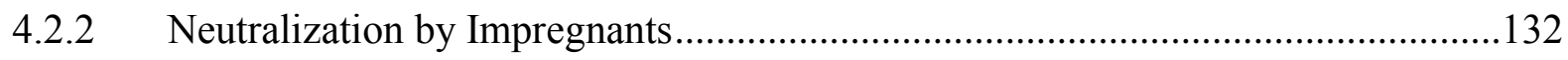

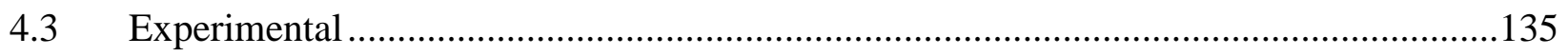

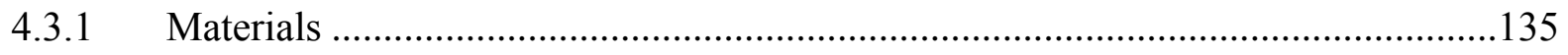

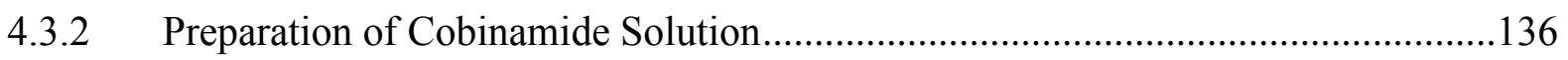

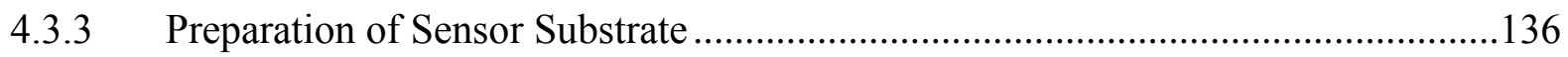

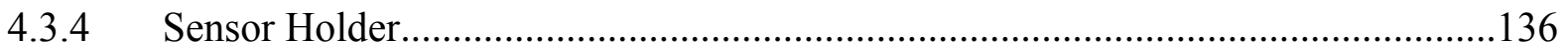

4.3.5 Diffuse Reflectance Instrumentation ………………………………………........136

4.3.6 Gas Flow System and Instrumentation: HCN....................................................137

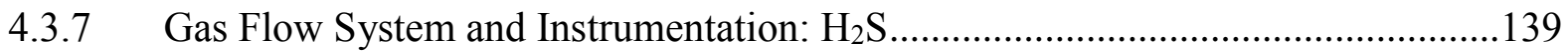

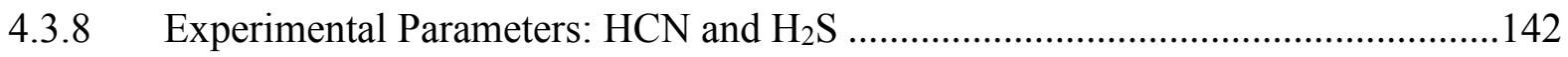

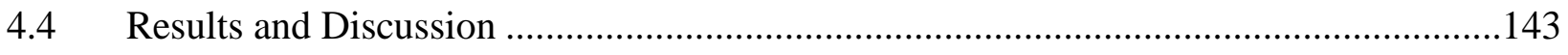

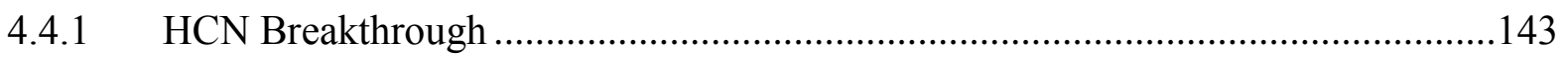

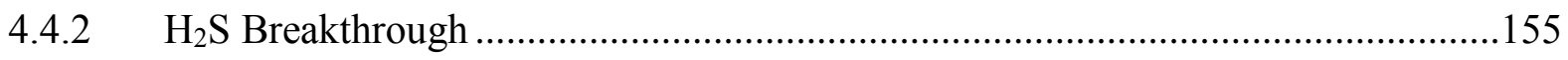

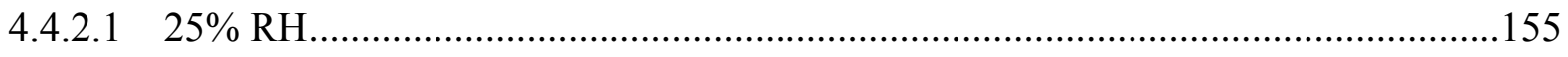

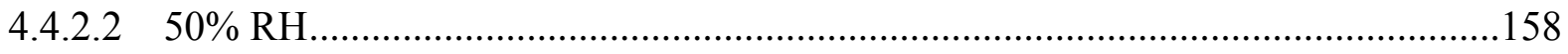

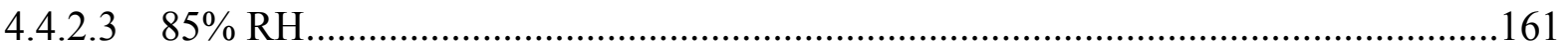

4.4.2.4 Comparison of $\mathrm{H}_{2} \mathrm{~S}$ Breakthrough as a Function of \% $\mathrm{RH}$....................................163

4.4.2.5 Cbi Detection of Breakthrough a of Pre-Exhausted Cartridge ...............................165

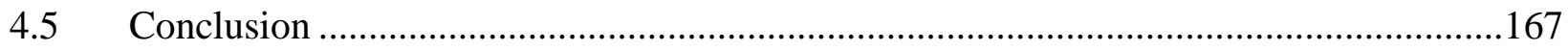

Chapter 5: Color Sensor Prototype Development ......................................................................................169

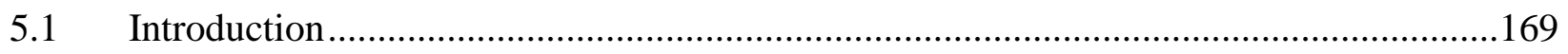

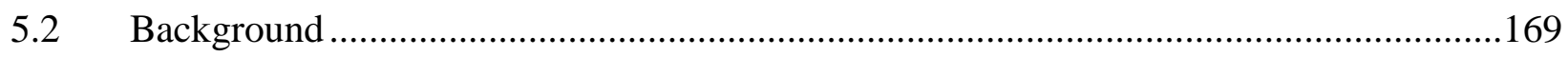




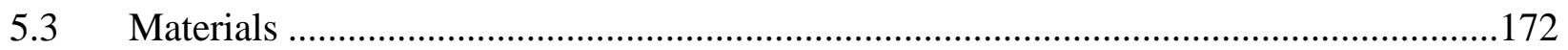

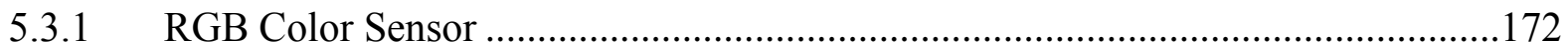

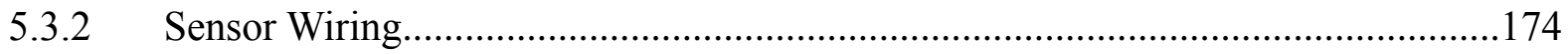

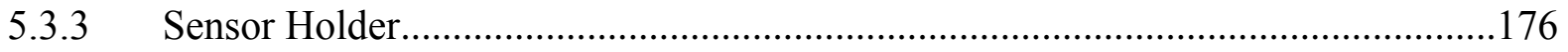

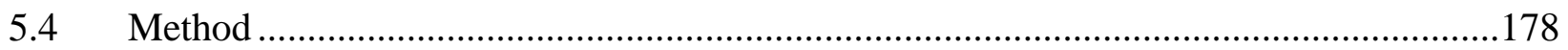

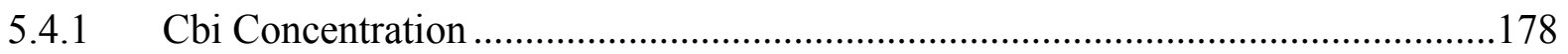

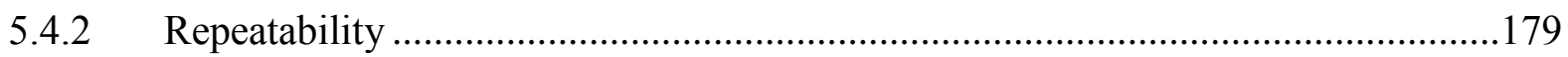

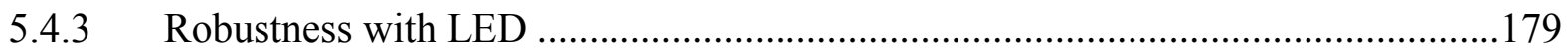

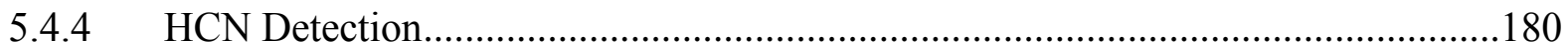

$5.5 \quad$ Results and Discussion ........................................................................................180

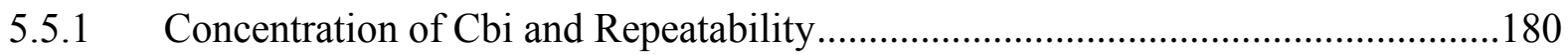

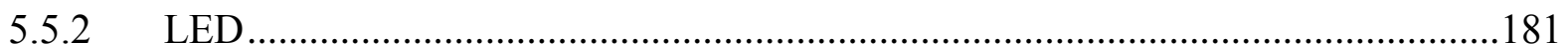

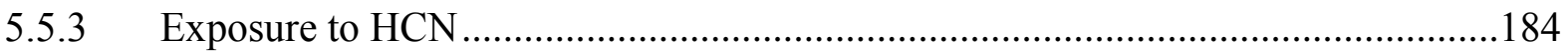

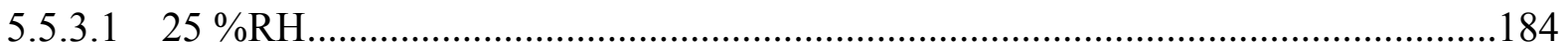

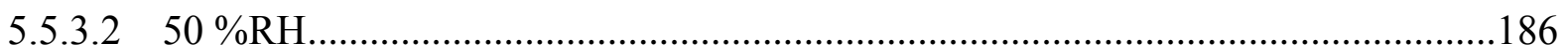

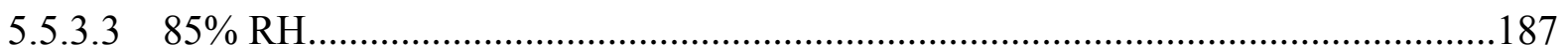

5.5.4 Comparison of HCN Concentrations as a Function of \% RH ................................189

5.5.5 Preliminary Findings for HCN Breakthrough.....................................................192

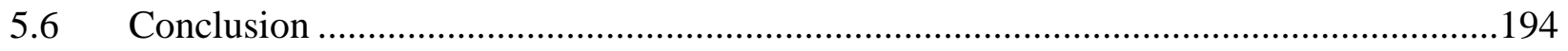

Chapter 6: Research Summary, Implications, and Future Work .....................................................195

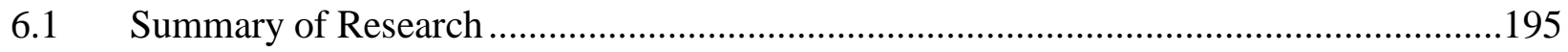

6.2 Research Implications and Future Work ....................................................................... 197

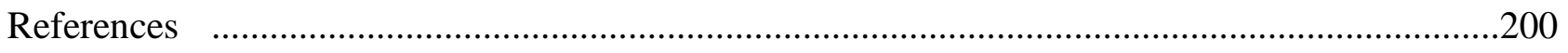

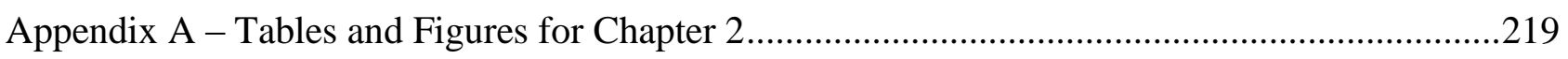

Appendix B - Tables and Figures for Chapter 3 ………...........................................................226 


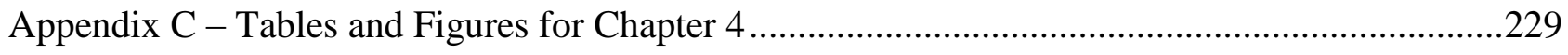

Appendix D - Tables and Figures for Chapter 5 ................................................................23 


\section{List of Tables}

Table 1.1 - Symbols and definitions for the Wood Model............................................ 4

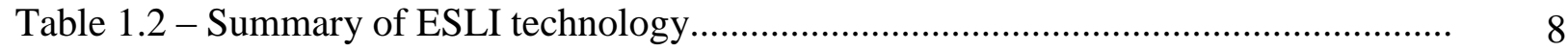

Table 1.3 - HCN properties............................................................................. 9

Table 1.4 - Colorimetric and optical sensors for $\mathrm{CN}^{-}$and $\mathrm{HCN}$..................................... 13

Table 2.1 - Examples of paper sensors ................................................................ 26

Table 2.2 - MFC calculations............................................................................ 46

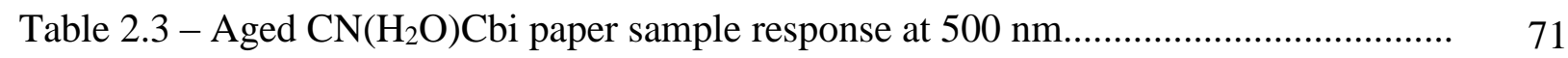

Table 2.4 - Aged $\left(\mathrm{H}_{2} \mathrm{O}\right)$ Cbi paper sample $\mathrm{F}(\mathrm{R})$ responses at $583 \mathrm{~nm}$ when exposed to 5.0

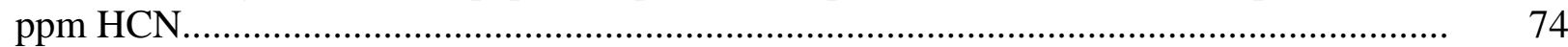

Table $3.1-\mathrm{H}_{2} \mathrm{~S}$ properties and symptoms......................................................... 93

Table 3.2 - General comparison of common $\mathrm{H}_{2} \mathrm{~S}$ detection methods............................. 97

Table 3.3 - Comparison of spectral shifts of Cbi exposed to $\mathrm{H}_{2} \mathrm{~S}, \mathrm{Na}_{2} \mathrm{~S}$, ascorbic acid, and NaHS.

Table 3.4 - Comparison of slopes for the initial response of $10.0 \mathrm{ppm}_{2} \mathrm{~S}$ to $\mathrm{OH}\left(\mathrm{H}_{2} \mathrm{O}\right) \mathrm{Cbi}$ at 25,50 , and $85 \% \mathrm{RH}$..

Table 4.1 - Common chemical impregnants....

Table 4.2 - Summary of $F(R)$ response times of Cbi on glass fiber paper, time corresponding to an increase in slope, and correlating HCN concentrations at each time... Table 5.1 - RGB values of blank glass fiber paper and 200.0 $\mu \mathrm{M}$ Cbi on glass fiber paper......

164

Table 5.2 - Normalized response compared to white LED spectrum (A) and comparison between spectral response of the photodiodes and response to paper as a function of maximum wavelength/color.

Table 5.3 - Comparison of HCN concentrations as a function of $\% \mathrm{RH}$. 


\section{List of Figures}

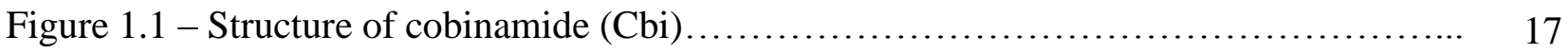

Figure 2.1 - Cbi encapsulated in sol-gel monoliths................................ 23

Figure 2.2 - Comparison of diffuse and specular reflection........................... 30

Figure 2.3 - Possible interactions between light and paper............................. 30

Figure 2.4 - Illustration of optical fiber (with permission) ............................ 32

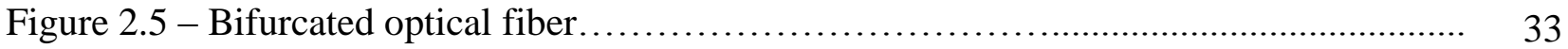

Figure 2.6 - General schematic of chemical sensor................................... 34

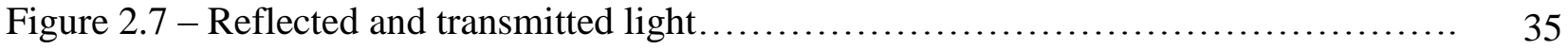

Figure 2.8 - Two flux model of the Kubelka-Munk function......................... 36

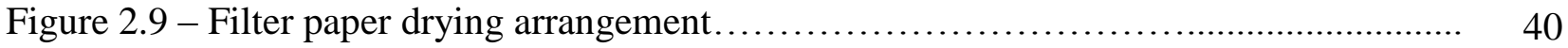

Figure 2.10 - Top down view of sensor holder (A), side view with bifurcated fiber optic

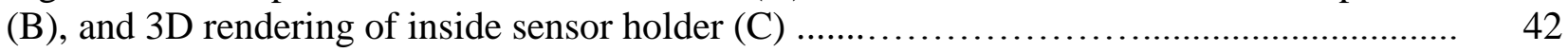

Figure 2.11 - Schematic of the experimental setup for HCN gas exposure................ 44

Figure 2.12 - MFCs used for HCN gas-flow .................................. 46

Figure 2.13 - Absorption spectra of the three cobinamide complexes (A), $20.0 \mu \mathrm{M}$

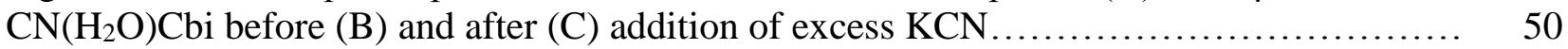

Figure 2.14 - Spectra of $\mathrm{CN}\left(\mathrm{H}_{2} \mathrm{O}\right) \mathrm{Cbi}$ with increasing amounts of $\mathrm{KCN} \ldots \ldots \ldots \ldots \ldots \ldots \ldots \ldots . \quad 51$

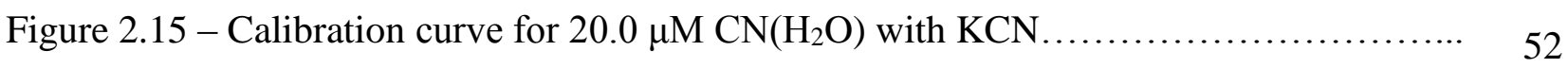

Figure 2.16 - Monocyanocobinamide solution spectra and diffuse reflectance spectra........ 53

Figure 2.17 - Comparison of monocyanocobinamide solution spectra and diffuse reflectance spectra on glass fiber paper.......................................... 54

Figure $2.18-\mathrm{CN}\left(\mathrm{H}_{2} \mathrm{O}\right) \mathrm{Cbi}$ on cellulose filter paper response to $1.0 \mathrm{ppm} \mathrm{HCN} \ldots \ldots \ldots \ldots \ldots . . . .65$

Figure $2.19-\mathrm{CN}\left(\mathrm{H}_{2} \mathrm{O}\right) \mathrm{Cbi}$ on cellulose filter paper response to $5.0 \mathrm{ppm} \mathrm{HCN} \ldots \ldots \ldots \ldots \ldots . . .66$

Figure 2.20 - Kubelka-Munk function applied to 5.0 ppm HCN exposure.......................... 57

Figure 2.21 - Difference spectra in terms of the Kubelka-Munk function......................... 58

Figure 2.22 - Comparison of the average response of $\mathrm{CN}\left(\mathrm{H}_{2} \mathrm{O}\right) \mathrm{Cbi}$ on cellulose filter paper

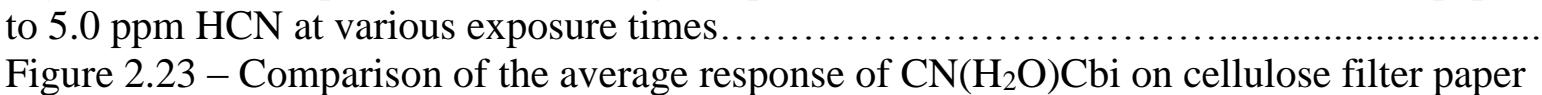
to various HCN concentrations for 5 minutes................................................ 60

Figure 2.24 - Difference spectra for aquohydroxocobinamide on cellulose filter paper....... 61

Figure $2.25-\mathrm{CN}\left(\mathrm{H}_{2} \mathrm{O}\right) \mathrm{Cbi}$ and $\mathrm{OH}\left(\mathrm{H}_{2} \mathrm{O}\right) \mathrm{Cbi}$ response to $5.0 \mathrm{ppm} \mathrm{HCN}$ on cellulose filter paper.................................................................................................... 62

Figure 2.26 - Initial response of $\mathrm{CN}\left(\mathrm{H}_{2} \mathrm{O}\right) \mathrm{Cbi}$ and $\mathrm{OH}\left(\mathrm{H}_{2} \mathrm{O}\right) \mathrm{Cbi}$ to $5.0 \mathrm{ppm} \mathrm{HCN}(25 \% \mathrm{RH})$

Figure $2.27-\mathrm{CN}\left(\mathrm{H}_{2} \mathrm{O}\right) \mathrm{Cbi}$ on cellulose filter paper response to 1.0 and $5.0 \mathrm{ppm} \mathrm{HCN}$ (A)

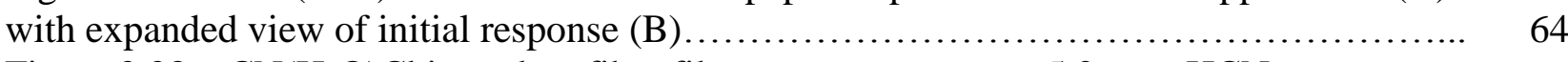

Figure $2.28-\mathrm{CN}\left(\mathrm{H}_{2} \mathrm{O}\right) \mathrm{Cbi}$ on glass fiber filter paper response to $5.0 \mathrm{ppm} \mathrm{HCN} \ldots \ldots \ldots \ldots . .65$

Figure 2.29 - Difference spectra of $\mathrm{CN}\left(\mathrm{H}_{2} \mathrm{O}\right) \mathrm{Cbi}$ on glass fiber filter paper response to 5.0 ppm HCN

Figure 2.30 - Average $\mathrm{F}(\mathrm{R})$ response of $\mathrm{CN}\left(\mathrm{H}_{2} \mathrm{O}\right) \mathrm{Cbi}$ on glass fiber filter paper to $5.0 \mathrm{ppm}$ $\mathrm{HCN}$ 
Figure 2.31 - Average $\mathrm{F}(\mathrm{R})$ response of $\mathrm{CN}\left(\mathrm{H}_{2} \mathrm{O}\right) \mathrm{Cbi}$ on glass fiber filter paper to $\mathrm{HCN}$

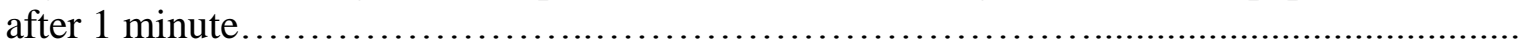

Figure 2.32 - Average $\mathrm{F}(\mathrm{R})$ response of $\mathrm{CN}\left(\mathrm{H}_{2} \mathrm{O}\right) \mathrm{Cbi}$ on glass fiber filter paper to $\mathrm{HCN}$ after 15 minutes

Figure 2.33 - Response of $\mathrm{CN}\left(\mathrm{H}_{2} \mathrm{O}\right) \mathrm{Cbi}$ on glass fiber filter paper to 1.0 and $5.0 \mathrm{ppm} \mathrm{HCN}$ (A) with expanded view of initial response (B) ...

Figure 2.34 - Box-and-Whisker plot (A) and bar graph (B) of fresh and aged Cbi paper samples

Figure 2.35 - Fresh and aged Cbi paper samples exposed to $5.0 \mathrm{ppm}$ for 1 minute (A) and 15 minutes $(\mathrm{B})$

Figure 2.36 - Comparison of $\mathrm{CN}\left(\mathrm{H}_{2} \mathrm{O}\right) \mathrm{Cbi}$ on cellulose and glass fiber filter paper to 5.0 ppm HCN (A) with expanded view of initial response (B)

Figure 2.37 - Effect of \% RH on cellulose filter paper

Figure 2.38 - Effect of \% RH on glass fiber filter

Figure 2.39 - Transparency of cellulose and glass fiber filter paper when wet.

Figure 2.40 - Response of $\mathrm{CN}\left(\mathrm{H}_{2} \mathrm{O}\right) \mathrm{Cbi}$ on cellulose filter paper to $5.0 \mathrm{ppm} \mathrm{HCN}$ at various $\% \mathrm{RH}$

Figure $2.41-$ Response of $\mathrm{CN}\left(\mathrm{H}_{2} \mathrm{O}\right) \mathrm{Cbi}$ on glass fiber filter paper to $5.0 \mathrm{ppm} \mathrm{HCN}$ at various $\% \mathrm{RH}$

Figure 2.42 - Difference spectra of $\mathrm{CN}\left(\mathrm{H}_{2} \mathrm{O}\right) \mathrm{Cbi}$ on glass fiber filter paper response to 5.0 ppm $\mathrm{HCN}$ at $85 \% \mathrm{RH}$

Figure 2.43 - Average initial response of $\mathrm{CN}\left(\mathrm{H}_{2} \mathrm{OCbi}\right.$ on cellulose filter paper (A) and glass fiber filter paper (B) to $5.0 \mathrm{ppm} \mathrm{HCN}$ at various $\% \mathrm{RH}$

Figure 2.44 - Effect of \%RH on Cbi cellulose filter paper to $5.0 \mathrm{ppm} \mathrm{HCN}$

Figure 2.45 - Effect of $\% \mathrm{RH}$ on Cbi glass fiber filter paper to $5.0 \mathrm{ppm} \mathrm{HCN}$

Figure 3.1 - MSA Altair $\mathrm{H}_{2} \mathrm{~S}$ detector (with permission)

Figure 3.2 - Sensor flow setup

Figure 3.3 - Comparison of absorbance and Kubelka-Munk function to $\mathrm{OH}\left(\mathrm{H}_{2} \mathrm{O}\right) \mathrm{Cbi}$ on glass fiber filter paper.

Figure 3.4 - Absorbance spectrum of $\mathrm{OH}\left(\mathrm{H}_{2} \mathrm{O}\right) \mathrm{Cbi}$ with $\mathrm{Na}_{2} \mathrm{~S}$

Figure 3.5 - Absorbance spectrum of $\mathrm{OH}\left(\mathrm{H}_{2} \mathrm{O}\right) \mathrm{Cbi}$ with ascorbic acid ("a.a"); anaerobic conditions.

Figure $3.6-50.0 \mu \mathrm{M} \mathrm{OH}\left(\mathrm{H}_{2} \mathrm{O}\right)$ Cbi before (A) and after (B) addition of 5:1 ascorbic acid.... Figure 3.7 - Absorbance spectrum of $\mathrm{OH}\left(\mathrm{H}_{2} \mathrm{O}\right)$ Cbi before $(\mathrm{A})$ and after $(\mathrm{B})$ addition of 5:1 ascorbic acid (anaerobic conditions)

Figure 3.8 - Addition of $50.0 \mu \mathrm{M} \mathrm{Na} 2 \mathrm{~S}$ to $\mathrm{OH}\left(\mathrm{H}_{2} \mathrm{O}\right)$ Cbi solution (A) and exposure of 10.0

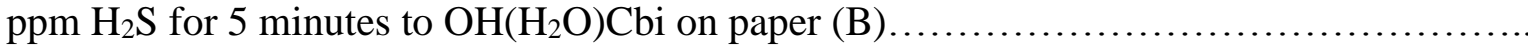
Figure $3.9-\mathrm{OH}\left(\mathrm{H}_{2} \mathrm{O}\right) \mathrm{Cbi}$ on glass fiber filter paper response to $10.0 \mathrm{ppm} \mathrm{H}_{2} \mathrm{~S}$.

Figure 3.10 - Difference spectra of $\mathrm{OH}\left(\mathrm{H}_{2} \mathrm{O}\right) \mathrm{Cbi}$ on glass fiber filter paper response to 10.0 ppm $\mathrm{H}_{2} \mathrm{~S}$

Figure 3.11 - Average response of $\mathrm{OH}\left(\mathrm{H}_{2} \mathrm{O}\right) \mathrm{Cbi}$ on glass fiber filter paper to $10.0 \mathrm{ppm} \mathrm{H}_{2} \mathrm{~S}$ at various exposure times $(25 \% \mathrm{RH})$

Figure 3.12 - Comparison of Cbi response to $5.0 \mathrm{ppm} \mathrm{HCN}$ and $10.0 \mathrm{ppm} \mathrm{H}_{2} \mathrm{~S}$ on glass fiber filter paper. 
Figure 3.13 - Response of $\mathrm{OH}\left(\mathrm{H}_{2} \mathrm{O}\right) \mathrm{Cbi}$ on glass fiber filter paper to $10.0 \mathrm{ppm} \mathrm{H}_{2} \mathrm{~S}$ at

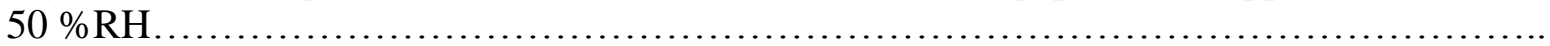

Figure 3.14 - Comparison of Cbi response to $5.0 \mathrm{ppm} \mathrm{HCN}$ and $10.0 \mathrm{ppm} \mathrm{H}_{2} \mathrm{~S}$ at $50 \% \mathrm{RH}$...

Figure 3.15 - Average response of $\mathrm{OH}\left(\mathrm{H}_{2} \mathrm{O}\right) \mathrm{Cbi}$ to $10.0 \mathrm{ppm} \mathrm{H}_{2} \mathrm{~S}$ at $85 \% \mathrm{RH}$ (A) difference spectra (B)

Figure 3.16 - Comparison of Cbi response to $5.0 \mathrm{ppm} \mathrm{HCN}$ and $10.0 \mathrm{ppm} \mathrm{H}_{2} \mathrm{~S}$ at $85 \% \mathrm{RH}$...

Figure 3.17 - Comparison of $\mathrm{OH}\left(\mathrm{H}_{2} \mathrm{O}\right) \mathrm{Cbi}$ with $\mathrm{Na}_{2} \mathrm{~S}$, ascorbic acid, and $25 / 50 \% \mathrm{RH}$

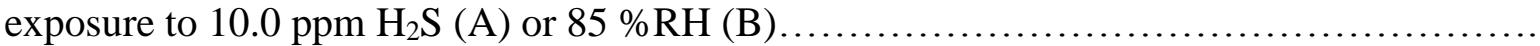

Figure 3.18 - Comparison of $\mathrm{OH}\left(\mathrm{H}_{2} \mathrm{O}\right) \mathrm{Cbi}$ to $10.0 \mathrm{ppm} \mathrm{H}_{2} \mathrm{~S}$ at 25, 50, and $85 \% \mathrm{RH} \ldots \ldots \ldots$...

Figure 4.1 - Reaction steps in gas adsorption by activated carbon

Figure 4.2 - Experimental setup showing placement of the diffuse reflectance sensor and RGB color sensor.

Figure $4.3-\mathrm{H}_{2} \mathrm{~S}$ cartridge testing chamber (A), with fiber optic, light source, spectrometer,

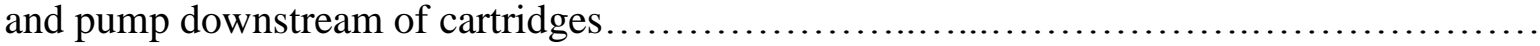

Figure 4.4 - Comparison of two CBRN canisters

Figure 4.5 - Cbi paper sensor and electrochemical sensor breakthrough curves.

Figure $4.6-\mathrm{F}(\mathrm{R})$ spectrum at breakthrough.

Figure 4.7 - Breakthrough curves for Cbi paper sensor and electrochemical sensor plotted as 6-order polynomials (A) and second derivatives (B)....

Figure $4.8-\mathrm{F}(\mathrm{R})$ spectra during $\mathrm{HCN}$ breakthrough experiment.

Figure 4.9 - Expanded view of $\mathrm{F}(\mathrm{R})$ spectra during $\mathrm{HCN}$ breakthrough experiment.

Figure $4.10-\mathrm{F}(\mathrm{R})$ spectra of $50.0 \mu \mathrm{M} \mathrm{CN}\left(\mathrm{H}_{2} \mathrm{O}\right) \mathrm{Cbi}$ on glass fiber filter paper to $5.0 \mathrm{ppm}$ cyanogen

Figure 4.11 - Comparison of $\mathrm{CN}\left(\mathrm{H}_{2} \mathrm{O}\right) \mathrm{Cbi}$ on paper when exposed to $5.0 \mathrm{ppm}$ cyanogen and after 15 and 164 minutes into $\mathrm{HCN}$ breakthrough experiment (A). Comparison of $\mathrm{CN}\left(\mathrm{H}_{2} \mathrm{O}\right) \mathrm{Cbi}$ on paper when exposed to $5.0 \mathrm{ppm}$ cyanogen and $5.0 \mathrm{ppm} \mathrm{HCN}$ (separate experiments).....

Figure 4.12 - Average difference spectra of $\mathrm{OH}\left(\mathrm{H}_{2} \mathrm{O}\right)$ Cbi response to $\mathrm{H}_{2} \mathrm{~S}$ breakthrough at $25 \% \mathrm{RH}$

Figure $4.13-\mathrm{F}(\mathrm{R})$ and electrochemical detector response to $\mathrm{H}_{2} \mathrm{~S}$ breakthrough at $25 \% \mathrm{RH}$...

Figure 4.14 - Electrochemical detector response to $\mathrm{H}_{2} \mathrm{~S}$ breakthrough at $25 \% \mathrm{RH}$.

Figure 4.15 - Average difference spectra of $\mathrm{OH}\left(\mathrm{H}_{2} \mathrm{O}\right)$ Cbi response to $\mathrm{H}_{2} \mathrm{~S}$ breakthrough at $50 \% \mathrm{RH}$

Figure 4.16 - Comparison of average $\mathrm{F}(\mathrm{R})$ spectra at $\mathrm{H}_{2} \mathrm{~S}$ breakthrough (blue line) and exposure to 10.0 ppm $\mathrm{H}_{2} \mathrm{~S}$ (red line).

Figure $4.17-\mathrm{F}(\mathrm{R})$ and electrochemical detector response to $\mathrm{H}_{2} \mathrm{~S}$ breakthrough at $50 \% \mathrm{RH}$...

Figure $4.18-\mathrm{F}(\mathrm{R})$ and electrochemical detector response to $\mathrm{H}_{2} \mathrm{~S}$ breakthrough at $85 \% \mathrm{RH}$...

Figure 4.19 - Electrochemical detector response to $\mathrm{H}_{2} \mathrm{~S}$ breakthrough for 25, 50, and $85 \%$ RH.

Figure $4.20-\mathrm{F}(\mathrm{R})$ and electrochemical detector response to $\mathrm{H}_{2} \mathrm{~S}$ breakthrough at $25 \% \mathrm{RH}$ for a pair of spent cartridges

Figure 5.1 - Pictorial representation of an RGB color sensor based on variations in photodiode depletion region (A) or incorporation of absorption filter (B) 
Figure 5.3 - Side view of the RGB color sensor with soldered sensor pins (A), backside view of color sensor with soldered ribbon cable (B), connection of the RGB color sensor to the microcontroller via ribbon cable and breadboard $(\mathrm{C})$

Figure 5.4 - Top view of the RGB color sensor (A and B), middle section of sensor holder with glass window for LED illumination of Cbi paper

Figure 5.5 - Complete RGB color sensor prototype

Figure 5.6 - Normalized response to the white LED spectrum (A) and comparison between spectral response of the photodiodes and response to paper as a function of maximum wavelength/color (B).

Figure 5.7 - Response of the separate R, G, and B values upon 5.0 ppm HCN exposure at $25 \% \mathrm{RH}$

Figure 5.8 - RGB color sensor total change in color during HCN exposure at $25 \% \mathrm{RH}(\mathrm{A})$, expanded view of initial response (B).

Figure 5.9- RGB color sensor total change in color during HCN exposure at $50 \% \mathrm{RH} . . . . . .$.

Figure 5.10 - Response of the separate R, G, and B values upon 5.0 ppm HCN exposure at $50 \%$ RH.

Figure 5.11 - RGB color sensor total change in color during HCN exposure at $85 \% \mathrm{RH}$ (A), expanded view of initial response (B).

Figure 5.12 - Average total change in color during 5.0 ppm HCN exposure at various \%RH; HCN was cycled on and off, $n=3$ (A), expanded view of initial response (B).. Figure 5.13 - RGB color sensor response to $\mathrm{HCN}$ breakthrough from a respirator canister compared with the Cbi fiber optic sensor configuration 


\section{List of Abbreviations, Symbols, and Nomenclature}

Percent Relative humidity

Diaquacobinamide

Total color difference

Microgram

Microliters

Three-dimensional

Absorbance

Amperes

Ascorbic acid

American Conference of Governmental Industrial

Hygienists

Analog-to-digital converter

Active end-of-service-life indicator

Agglomerative hierarchical clustering

Ceiling

Concentration

Confidence interval

Cobinamide

Chemical, Biological, Radiological, Nuclear

Centers for Disease Control and Prevention

Commission Internationale de l'Éclairage

Centimeter

Dicyanocobinamide

Carbon monoxide

Cobalt

Carbon dioxide

Cross-section of the scatterer

Copper oxide

Digital value

Dimethylbenzimidazole

Emission rate (ng/min)

Environmental protection agency

End-of-service-life indicator

Remission function

Food and Drug Administration

Primary dilution flow rate $(\mathrm{sccm})$

Fourier Transform Infrared
$\% \mathrm{RH}$

$\left(\mathrm{H}_{2} \mathrm{O}\right)_{2} \mathrm{Cbi}$

$\Delta \mathrm{C}$

$\mu \mathrm{g}$

$\mu \mathrm{L}$

3D

A

A

a.a.

ACGIH

ADC

AESLI

AHC

C

c

CI

Cbi

CBRN

CDC

CIE

$\mathrm{cm}$

$\mathrm{CN}\left(\mathrm{H}_{2} \mathrm{O}\right) \mathrm{Cbi}$

$\mathrm{CO}$

$\mathrm{Co}$

$\mathrm{CO}_{2}$

$\mathrm{C}_{\text {sca }}$

$\mathrm{Cu}_{2} \mathrm{O}$

D.V.

DMB

$\mathrm{E}_{\mathrm{ng} / \mathrm{min}}$

EPA

ESLI

$\mathrm{F}(\mathrm{R})$

FDA

$\mathrm{F}_{\mathrm{pd}}$

FTIR 
gram

$\mathrm{g}$

Molecular weight

$\mathrm{g} / \mathrm{mol}$

Gas chromatography/mass spectrometry

GC/MS

Water

$\mathrm{H}_{2} \mathrm{O}$

Hydrogen sulfide

$\mathrm{H}_{2} \mathrm{~S}$

Hydrochloric acid

$\mathrm{HCl}$

Hydrogen cyanide

$\mathrm{HCN}$

High performance liquid chromatography

HPLC

Inter-Integrated Circuit

$\mathrm{I}^{2} \mathrm{C}$

Immediately dangerous to life and health

IDLH

Light entering medium

$\mathrm{I}_{\text {in }}$

Indium gallium nitride

InGaN

Incident light

Light exiting medium

$\mathrm{I}_{\mathrm{o}}$

Infrared

$\mathrm{I}_{\text {out }}$

IR

Reflected light

$\mathrm{I}_{\mathrm{r}}$

Reflect light (Kubelka-Munk function)

Absorption coefficient

$\mathrm{J}_{\mathrm{r}}$

K

Rate constant

$k$

Binding affinity

$\mathrm{Ka}$

Potassium cyanide

$\mathrm{KCN}$

Light dimension

$\mathrm{L}$

Light emitting diode

LED

Limit of detection

LOD

Liters per minute

LPM

Molarity

$\mathrm{M}$

Microelectrochemical system

MEMS

Mass flow controller

MFC

milligram per liter

$\mathrm{mg} / \mathrm{L}$

millimeter

$\mathrm{mm}$

millisecond

$\mathrm{ms}$

Impregnant concentration

$n$

Number of samples

$\mathrm{n}$

Refractive index

$\mathrm{n}$

Volume density of scatterers in the medium

$\mathrm{N}$

Nitrogen

$\mathrm{N}_{2}$

Sodium sulfide

$\mathrm{Na}_{2} \mathrm{~S}$

Sodium hydrosulfide

$\mathrm{NaHS}$

Refractive index of air

$\mathrm{n}_{\text {air }}$

Sodium hydroxide

$\mathrm{NaOH}$ 
Refractive index of the fluid $\quad \mathrm{n}_{\mathrm{f}}$

Ammonia

$\mathrm{NH}_{3}$

National Institute for Occupational Safety and Health

NIOSH

nanometer

$\mathrm{nm}$

nanomolar

$\mathrm{nM}$

Nitric oxide

NO

National Personal Protective Technology Laboratory

NPPTL

Degrees Celsius

${ }^{\circ} \mathrm{C}$

Aquohydroxocobinamide

Occupational Safety and Health Administration

$\mathrm{OH}\left(\mathrm{H}_{2} \mathrm{O}\right) \mathrm{Cbi}$

Organic vapor

OSHA

Powered air-purifying respirator

OV

Permissible exposure limit

PAPR

parts-per-billion

PEL

parts-per-million

$\mathrm{ppb}$

parts-per-million by volume

ppm

Polytetrafluoroethylene

$\mathrm{ppm}_{\mathrm{V}}$

Polyvinyl chloride

PTFE

Quartz crystal microbalance

PVC

Reflectance

QCM

Recommended exposure limit

$\mathrm{R}$

Red, green, blue

REL

Relative standard deviation

RGB

Sample standard deviation

RSD

Scattering coefficient

$\mathrm{S}$

Standard Deviation

$\mathrm{S}$

Signal-to-noise

S.D.

Self-contained breathing apparatus

$\mathrm{S} / \mathrm{N}$

Standard cubic centimeters

SCBA

Short-term recommended exposure limit

sccm

Standard test procedure

STEL

Student's t-value

STP

Transmittance coefficient characteristic of the paper

$\mathrm{t}$

$\mathrm{T}_{\mathrm{c}}$

Triethylenediamine

TEDA

Tetraethyl orthosilicate

TEOS

Total internal reflection

TIR

Test representative agent

TRA

Time-weighted average

TWA

Universal Serial Board

USB 
Ultraviolet- visible

Voltage

Watt

Thickness / optical path length

Attenuation coefficient of the medium

Molar extinction coefficient

Incident angle

Wavelength

micromolar

nicrofluidic and analytical devices

Transmission coefficient for air-paper interface

Transmission coefficient for paper-air interface

Time dependent volume fraction
UV-VIS

$\mathrm{V}$

W

$z$

$\alpha$

$\varepsilon$

$\theta$

$\lambda$

$\mu \mathrm{M}$

$\mu \mathrm{PADs}$

$\tau_{i n}$

$\tau_{\text {out }}$

$\varphi(t)$ 


\section{Chapter 1: Introduction}

\subsection{Background Information}

Respirators offer the last line of defense by filtering air contaminated with harmful dust, fumes, gases, sprays, or vapors. ${ }^{1}$ If respirators fail to protect the user, significant and severe consequences may occur. Unfortunately, respirator carbon beds (i.e. cartridges or canisters ${ }^{\dagger}$ ) have a limited service-life before they must be disposed and replaced with a new one. ${ }^{3}$ The term "end-of-service-life" or "service-life" refers to the point at which a respirator no longer provides adequate protection to the user. Service-life is a measurement or estimate of breakthrough time under specified conditions, which is defined as the elapsed time between the initial contact of a reported gas/vapor concentration on the upstream surface of the adsorbent bed and the downstream side. ${ }^{4,5}$ The breakthrough concentration is the downstream ("effluent") concentration above which the sorbent is considered to be performing inadequately. For activated carbon-based filtering media, breakthrough occurs when the filtering medium becomes saturated and can no longer retain the chemical that the cartridge or canister is intended to adsorb. If the user does not replace the carbon bed before breakthrough occurs, harmful gases and vapors will enter the inside of the respirator, i.e. the breathing zone of the user.

Service-lives are affected by a number of factors including the following: type of contaminant, number of contaminants, concentration, ambient temperature, percent relative humidity (\%RH), airflow (i.e. worker exertion level), volume of carbon bed (canister vs. cartridge), and selected breakthrough value. ${ }^{3}$ Before being worn, the service-life must be

\footnotetext{
${ }^{\dagger}$ Because both cartridges and canisters are used in later chapters, the primary difference between these two carbon beds are the sorbent volume and construction. ${ }^{2}$ The sorbent volume of a cartridge is small (50$200 \mathrm{~cm}^{3}$ ) so service-lives are shorter. ${ }^{3}$ Use of cartridges are typically reserved for low concentrations of vapors and gases. Canisters have typical sorbent volumes of $1000-2000 \mathrm{~cm}^{3}$ and are typically worn for high/unknown concentrations of gases and vapors (e.g., military, First Responders, etc.). ${ }^{3}$
} 
determined so that an appropriate change-schedule can be implemented. Change-schedules ensure that the cartridge/canister is replaced before downstream concentration inside the respirator exceeds a predetermined breakthrough value. ${ }^{3}$ The Occupational Safety and Health Association (OSHA) respiratory protection regulation (29 CFR 1910.134) requires that if an endof-service-life indicator (ESLI) is not incorporated into the carbon bed of a respirator, employers are required to implement change-schedules. ${ }^{1}$

\subsubsection{User Determination of Carbon Bed Service-Life}

There are a number of methods available to the user to determine canister/cartridge service-life; these directly apply to gases and vapors and not particulates. ${ }^{3}$ In the past, users would rely on the smell or irritation of a gas to indicate breakthrough, but by the time a user can smell a gas, dangerous concentrations may already be present. According to OSHA 1910.134, sensory warning properties cannot be used to determine cartridge/canister change-out due to genetic factors and olfactory fatigue. ${ }^{1}$ The first method is to conduct experimental tests in a laboratory. Laboratory testing can be performed by respirator manufacturers and private testing laboratories. Testing involves measuring the actual breakthrough time for a specific cartridge with a specific chemical or test representative agent (TRA). ${ }^{6}$ This method may be more reliable in the case of multiple contaminants in comparison to relying on conservative assumptions. Experimental tests can also be used to validate an existing change-out method. A drawback is the amount of time and money used to perform these tests. The second is field-testing, where air from the workplace is drawn through a cartridge and the downstream air is monitored to determine breakthrough time. ${ }^{6}$ A cartridge surrogate (i.e. carbon tube) is also used. The third and most commonly used method are software programs derived from mathematical models. Most of these software programs are similar in that users provide information about the environment 
(e.g., contaminant type(s), concentration, relative humidity, temperature, etc.), the cartridge type (e.g., carbon bed weight, packed bed volume, micropore volume, etc.), and use conditions (e.g., work load signifying breathing rate). The software provides an estimate - not exact predictionof the service-life. However, each manufacturer's software applies to its own cartridges and unique carbon properties. ${ }^{7}$ Models are currently available by $\mathrm{CD}$ or online through respirator manufacturers $\left(\mathrm{MSA}^{\circledR 8}, 3 \mathrm{M}^{\circledR 9}\right.$, Honeywell $\left.{ }^{\circledR 10}\right)$.

These software programs are largely based on formulas improved by Gerry Wood who is considered an expert in this field. Models developed for calculation of carbon bed service-lives have been continuously evolving since 1969 , with significant contributors such as Wheeler, ${ }^{11}$ Nelson, ${ }^{12-14}$ Jonas, ${ }^{15-17}$ Yoon and Nelson, ${ }^{18-22}$ and Wood. ${ }^{23-35}$ The widely used "Wood Model" is founded from the Reaction Kinetic equation and specifically used in the $3 \mathrm{M}^{\circledR}$ software and MultiVapor $^{\mathrm{TM}}$ software, where breakthrough time $\left(\mathrm{t}_{\mathrm{b}}\right)$ is calculated by ${ }^{36}$ :

$$
\begin{aligned}
& t_{b}=\left(\frac{W_{e} W}{C_{o} Q}\right)-\left(\frac{W_{e} \rho_{B}}{k_{v} C_{o}}\right) \ln \left[\frac{\left(C_{o}-C_{x}\right)}{C_{x}}\right] \\
& \text { Equation } 1.1 \\
& \text { where } \\
& W_{e}=W_{o} d_{L} \exp \left[-b^{\prime} W_{o} P_{e}^{-1.8} R^{2} T^{2}\left(\ln \left\{\frac{\rho}{\rho_{s a t}}\right\}\right)^{2}\right] \\
& P_{e}=\left(\frac{\left(n_{o}-1\right)}{\left(n_{o}^{2}+2\right)}\right) \frac{M_{w}}{d_{L}} \\
& \frac{1}{k_{v}}=\left(\left(\frac{1}{V_{L}}\right)+0.027\right)\left(I+\frac{s}{P_{e}}\right)
\end{aligned}
$$

The symbols and definitions can be found in Table 1.1. Equation 1.2 is the DubininRadushkevich equation used to calculate the equilibrium adsorption capacity of individual vapors. 
Table 1.1 Symbols and definitions for the Wood Model

\begin{tabular}{|c|l|}
\hline Symbol & \multicolumn{1}{|c|}{ Definition $^{36}$} \\
\hline $\mathrm{t}_{\mathrm{b}}$ & Breakthrough time (min) \\
\hline $\mathrm{W}_{\mathrm{e}}$ & Equilibrium adsorption capacity $(\mathrm{g} / \mathrm{g}$ carbon) \\
\hline $\mathrm{W}$ & Weight of carbon adsorbent \\
\hline $\mathrm{r}_{\mathrm{b}}$ & Bulk density of the packed bed $\left(\mathrm{g} / \mathrm{cm}^{3}\right)$ \\
\hline $\mathrm{Q}$ & Volumetric flow rate $\left(\mathrm{cm}^{3} / \mathrm{min}\right)$ \\
\hline $\mathrm{C}_{\mathrm{o}}$ & Inlet concentration $\left(\mathrm{g} / \mathrm{cm}^{3}\right)$ \\
\hline $\mathrm{C}_{\mathrm{x}}$ & Exit concentration $\left(\mathrm{g} / \mathrm{cm}^{3}\right)$ \\
\hline $\mathrm{W}_{\mathrm{o}}$ & Carbon micropore volume $\left(\mathrm{cm}^{3} / \mathrm{g}\right)$ \\
\hline $\mathrm{d}_{\mathrm{L}}$ & Liquid density of adsorbate $\left(\mathrm{g} / \mathrm{cm}^{3}\right)$ \\
\hline $\mathrm{T}$ & Absolute temperature $\left({ }^{\circ} \mathrm{K}\right)$ \\
\hline$\rho$ & Partial pressure corresponding to concentration $\mathrm{C}_{\mathrm{x}}$ \\
\hline$\rho_{\mathrm{sat}}$ & Saturation vapor pressure at temperature $\mathrm{T}$ \\
\hline $\mathrm{P}_{\mathrm{e}}$ & Molar polarization \\
\hline $\mathrm{R}$ & Ideal gas constant $(1.987 \mathrm{cal} / \mathrm{K} * \mathrm{~mol})$ \\
\hline $\mathrm{b}$ & An empirical coefficient with value $3.56 \mathrm{x} 10^{-5}$ \\
\hline $\mathrm{M}_{\mathrm{w}}$ & Molecular weight $(\mathrm{g} / \mathrm{mol})$ \\
\hline $\mathrm{n}_{\mathrm{o}}$ & Refractive index \\
\hline $\mathrm{V}_{\mathrm{L}}$ & Linear airflow velocity $(\mathrm{cm} / \mathrm{sec})$ \\
\hline $\mathrm{S}$ & Empirical coefficients fitted to data \\
\hline $\mathrm{k}_{\mathrm{V}}$ & Adsorption rate coefficient \\
\hline & \\
\hline
\end{tabular}

Although software programs are an improvement relative to guesswork, the number of variables that play a role in predicting the end-of-service-life can have a great effect on the accuracy of the software. Models are generally less accurate than experimental testing, varying in service-times as much as $\pm 50 \% .{ }^{7,10}$ One contribution is the vague definition of airflow based on work rates, which vary between manufacturer. ${ }^{7}$ Likewise, the user may not be knowledgeable of the workplace conditions that must be incorporated.

\subsubsection{End-of-Service-Life Indicators}

In 1976, the National Institute for Occupational Safety and Health (NIOSH) began accepting applications for certification of air-purifying respirators with active ESLIs (AESLIs), those that invoke an automatic and spontaneous warning signal (e.g., flashing lights, vibration, 
etc.) upon imminent breakthrough. ${ }^{2}$ Respirator manufacturers, regulatory agencies, and general industry raised concerns that NIOSH only accepted active ESLIs. Therefore, in 1984, NIOSH incorporated these recommendations into new, published standards for certification of both passive and active ESLIs to encourage their development. ${ }^{2}$ Passive ESLIs require the user to monitor an indicator incorporated within the carbon bed (e.g., a color change) with no automatic warning signal. Both active and passive ESLIs would inform the user with a more accurate, realtime prediction of when imminent breakthrough is near. When an ESLI is available, the user does not need to be cognizant of all the parameters and environmental conditions associated with change-out schedules. ESLIs can also eliminate premature disposal of respirator carbon beds. ESLIs are especially advantageous for First Responders who are in unknown environments where change-out schedules are virtually nonexistent.

Minimum certification standards for passive and active ESLIs are listed in NIOSH Standard Test Procedure (STP)-0066. ${ }^{37}$ For both types of ESLIs, the applicant must provide NIOSH with the following information: data demonstrating the ESLI can reliably indicate sorbent depletion less than or equal to $90 \%$ service-life (including testing at various temperatures, humidity, and contaminant concentrations), data on desorption of any impregnating agents used in the indicator, data on effects of industrial interferences found in the anticipated workplace, data on any reaction products produced during chemical reactions, and data which predicts the storage life of the indicator. All passive ESLIs should meet the following summarized criteria: the ESLI should be incorporated into the respirator so that it is readily visible to the wearer, the color change must be detectable to people with physical impairments (e.g., color blindness), and reference colors for the initial and final colors should be placed adjacent to the indicator. ${ }^{37}$ Lastly, all ESLIs must not interfere with the effectiveness of the face 
seal or vision of the user, change the weight distribution of the respirator, must withstand cleaning and a drop from a 6-foot height, must not create any hazard to the wearer's health or safety, and lastly must be "intrinsically safe" according to the National Electrical Code. ${ }^{37}$

Although drawbacks have been recognized, numerous challenges still exist which hinders the development of commercial ESLIs. Current challenges include the effects of humidity, temperature, flow rate, as well as the size, weight, and power requirements to incorporate ESLIs into respirators. In 2004, NIOSH conducted a teleconference with five large respirator manufacturers to obtain information and opinions on ESLIs. ${ }^{38}$ All manufacturers agreed that ESLIs would be beneficial but raised questions on how achievable a sensor would be in the near future. ${ }^{38}$ Manufacturers were concerned about costs and shelf-life. They preferred to limit costs to no more than $\$ 1 /$ cartridge for the sensor and $\$ 20-\$ 50$ on any sensor-related electronics per respirator. The manufacturers noted that niche markets would be a good place to begin introducing new types of technology.

Following World War I and considered the first ESLI, a canister was patented with a built-in color indicating system for measuring "poisoning or obnoxious gas".39,40 Since then, many other prototypes were patented. Most of these prototypes focus on colorimetric indicators, which are still used today. Colorimetric indicators are considered "passive ESLIs" and present a visual color change which warns the user that the carbon bed is close to its saturation point. These indicators are integrated inside a cartridge, where a clear window allows the user to observe a color change as the gas progresses from the front of the carbon bed to the back.

A review of promising ESLIs that have reached more advanced stages of development can be seen in Table 1.2. The results are displayed in reverse chronological order; the highlighted 
rows are ESLIs that are currently commercially available. Parts-per-million (ppm) is defined here and throughout this document as one molecule in one million molecules. The literature review conducted was restricted to those found that directly apply to determination of servicelife for personal respiratory equipment (i.e. not general technology for gas sensors). Additionally, included are those after the year 2000 (inclusion). An exception are references for Maclay and Moyer, who are considered to be the first to publish ESLI research in peer-reviewed journals. Much research is proprietary by manufacturers or government agencies. Patents were excluded from this review but can be seen elsewhere. ${ }^{38,39}$ 
Table 1.2 - Summary of ESLI technology

\begin{tabular}{|c|c|c|c|c|c|}
\hline Manufacturer & Technology & $\begin{array}{l}\text { Compounds } \\
\text { Detected }\end{array}$ & $\begin{array}{c}\text { Type of } \\
\text { Respirator }\end{array}$ & $\begin{array}{c}\text { On } \\
\text { Market? }\end{array}$ & Notes \\
\hline $3 \mathbf{M}^{\circledR 41}$ & $\begin{array}{l}\text { P; Colorimetric } \\
\text { Indicator: visual }\end{array}$ & $\begin{array}{l}\text { Organic } \\
\text { vapors } \\
\text { (multiple) }\end{array}$ & $\begin{array}{c}\text { APR } \\
\text { cartridges }\end{array}$ & Yes & $\begin{array}{l}\text { Newest on market (2015); cannot see portion of cartridge } \\
\text { where ESLI located; poor lighting, red-green color deficiency, } \\
\text { tinted eyewear, glare may be an issue. }\end{array}$ \\
\hline $\begin{array}{l}\text { Honeywell }^{\circledR 42} \\
\text { and } 3 \mathrm{M}^{\circledR 43}\end{array}$ & $\begin{array}{l}\text { P; Colorimetric } \\
\text { Indicator: visual }\end{array}$ & $\begin{array}{l}\text { Mercury } \\
\text { vapor and } \\
\text { chlorine }\end{array}$ & $\begin{array}{c}\text { APR } \\
\text { cartridges }\end{array}$ & Yes & \\
\hline $\begin{array}{l}\text { Sailor and } \\
\text { Snyder } \text { et } a l .{ }^{44,45}\end{array}$ & $\begin{array}{l}\text { Porous silicon } \\
\text { photonic crystals }\end{array}$ & \multicolumn{2}{|c|}{ Organic vapors (multiple) } & No & $\begin{array}{l}\text { Exposures of } 50-800 \mathrm{ppm} \text { of isopropyl alcohol and heptane; } \\
\text { effects of humidity observed; thermally oxidized and } \\
\text { dichlorodimethylsilane-modified materials show greatest } \\
\text { stability; U.S. Patent } 7,889,952 \text { B2 }\end{array}$ \\
\hline $\begin{array}{l}\text { Garg, Snyder, } \\
\text { Fedder, et al. }\end{array}$ & $\begin{array}{l}\text { Gold nanoparticles } \\
\text { coated with organic } \\
\text { monolayer for } \\
\text { chemiresistive sensor }\end{array}$ & \multicolumn{2}{|c|}{ Organic vapors (multiple) } & No & $\begin{array}{l}\text { Nanoparticles capped with trithiol ligands for enhanced } \\
\text { stability; Sensitive to } 300 \mathrm{ppm} \text { toluene. }\end{array}$ \\
\hline $\begin{array}{l}\text { Li, Snyder, and } \\
\text { Fedder } \text { et } \\
\text { al. }^{47,48,49}\end{array}$ & $\begin{array}{l}\text { Chemically sensitive } \\
\text { nanostructured } \\
\text { polymers with } \\
\text { CMOS-MEMS }\end{array}$ & \multicolumn{2}{|c|}{ Organic vapors (multiple) } & No & $\begin{array}{l}\text { Sensors designed to detect conductivity, gravimetric, and } \\
\text { stress changes in the polymers. Authors developed a CMOS- } \\
\text { MEMS capacitive humidity sensor as a compensation piece } \\
\text { for the referenced ESLI research. }{ }^{50}\end{array}$ \\
\hline Pinet et al..$^{51}$ & $\begin{array}{l}\text { Birefringent porous } \\
\text { glass fibers }\end{array}$ & \multicolumn{2}{|c|}{ Organic vapors (multiple) } & No & $\begin{array}{l}\text { Optical anisotropy modified in presence of solvent vapors, } \\
\text { sensitive to } 50 \mathrm{ppm} \text { toluene. }\end{array}$ \\
\hline Caron $^{52}$ & $\begin{array}{l}\text { Porous glass optical } \\
\text { fibers }\end{array}$ & \multicolumn{2}{|l|}{ Toluene } & No & $\begin{array}{l}\text { Transmittance drop upon exposure to solvent vapors; } \\
\text { nonselective; sensitive to toluene at a few thousand ppm }\end{array}$ \\
\hline $\begin{array}{l}\text { Park and } \\
\text { Zellers }^{53}\end{array}$ & $\begin{array}{l}\text { Surface Acoustic } \\
\text { Wave (SAW) sensors }\end{array}$ & \multicolumn{2}{|c|}{ Organic vapors (multiple) } & No & $\begin{array}{l}\text { Array of three SAW sensors; capable of recognizing and } \\
\text { quantifying low-and sub-ppm concentrations of } 16 \text { organic } \\
\text { vapors. }\end{array}$ \\
\hline $\begin{array}{l}\text { Maclay et } a l .{ }^{54} \\
\text { and Moyer } \text { et } \\
\text { al. }\end{array}$ & Chemiresistors & \multicolumn{2}{|c|}{ Organic vapors (multiple) } & No & $\begin{array}{l}\text { One of first published articles first exploring ESLIs for } \\
\text { respirator cartridges, although found suitable, more research } \\
\text { needed to compensate for relative humidity effects and } \\
\text { sensitivity improvement, and baseline stability }\end{array}$ \\
\hline
\end{tabular}


Previously, North Safety Products ${ }^{\circledR}$ (now Honeywell Safety Products ${ }^{\circledR}$ ) offered a realtime colorimetric strip indicator for hydrogen chloride, hydrogen fluoride, sulfur dioxide, and hydrogen sulfide, and a separate one for ammonia. ${ }^{38}$ Although the product still circulates the Internet, they are no longer commercially available from the manufacturer. As can be seen by the first two rows of Table 1.2, there are limited amount of ESLIs on the market; however, the United States Federal health and occupational agencies, as well as Homeland Security, are heavily encouraging the development of commercially available, low-powered ESLIs.

\subsubsection{Hydrogen Cyanide}

Cyanide is a colorless and extremely toxic compound typically found in the gaseous form as hydrogen cyanide $(\mathrm{HCN})$. Table 2.1 summarizes physical properties and toxicity symptoms of $\mathrm{HCN}$.

Table 1.3: HCN Properties

\begin{tabular}{|c|c|c|c|}
\hline $\begin{array}{c}\text { Molecular } \\
\text { Weight }^{56}\end{array}$ & \multicolumn{3}{|l|}{$27.03 \mathrm{~g} / \mathrm{mol}$} \\
\hline Boiling Point ${ }^{56}$ & \multicolumn{3}{|l|}{$25.6^{\circ} \mathrm{C}$} \\
\hline Melting Point ${ }^{56}$ & \multicolumn{3}{|c|}{$-13.4^{\circ} \mathrm{C}$} \\
\hline $\begin{array}{c}\text { Vapor } \\
\text { Pressure }^{56}\end{array}$ & \multicolumn{3}{|c|}{630 Torr at $20^{\circ} \mathrm{C}$} \\
\hline $\begin{array}{l}\text { Conversion } \\
\text { Factor }^{56}\end{array}$ & \multicolumn{3}{|c|}{$1 \mathrm{ppm}=1.10 \mathrm{mg} / \mathrm{m}^{3}$ at $25^{\circ} \mathrm{C}$} \\
\hline Gas Density $^{57}$ & \multicolumn{3}{|l|}{$0.94 \mathrm{~kg} / \mathrm{m}^{3}$} \\
\hline pKa & \multicolumn{3}{|l|}{9.3} \\
\hline Toxic Dose ${ }^{58}$ & \multicolumn{3}{|c|}{ Lethal dose in blood $50-200 \mathrm{mg}$ (adult) } \\
\hline \multirow[t]{5}{*}{$\begin{array}{l}\text { Symptoms if } \\
\text { Inhaled }^{59}\end{array}$} & \multicolumn{3}{|c|}{$\begin{array}{l}\text { General: cognitive dysfunction (confusion, anxiety, headache), permanent brain } \\
\text { damage due to lack of oxygen, coma, respiratory arrest, cardiovascular collapse. }\end{array}$} \\
\hline & Exposure Time & 10 min. & 8 hours \\
\hline & Discomfort/non-disabling & $2.5 \mathrm{ppm}$ & $1.0 \mathrm{ppm}$ \\
\hline & Irreversible or other serious, long-lasting effects & $17 \mathrm{ppm}$ & $2.5 \mathrm{ppm}$ \\
\hline & Life-threatening effects or death & $27 \mathrm{ppm}$ & $6.6 \mathrm{ppm}$ \\
\hline
\end{tabular}

Cyanide and $\mathrm{HCN}$ are used or are a byproduct in a number of industrial applications including production of plastics, polymers, insecticides, pharmaceuticals, mining, jewelry 
manufacturing, dyeing, photography, and chelating agents and are reactive intermediates in chemical synthesis. Approximately 1.1 million tons of cyanide are used annually. ${ }^{56,60} \mathrm{HCN}$ is currently a major interest to the United States Homeland Security where it has been assigned a Schedule 3 substance of the Chemical Weapons Convention, a category in which chemicals have been produced or used as a chemical weapon, have the toxicity or lethality to be a chemical weapon, and/or are being produced in large commercial quantities for industrial applications. ${ }^{61}$ In addition to being used as an industrial reagent or byproduct, $\mathrm{HCN}$ is produced when synthetic material combusts, especially under high temperatures and low oxygen conditions. With the increase in chemically manufactured materials in modern homes, firefighters experience what is known as "the breath from hell". ${ }^{62}$ This term refers to the quick combustion of materials such as acetyls (e.g., aerosol containers), acrylics (e.g., glues), polyesters (e.g., computers and appliances), polypropylene (e.g., furniture), polyurethane (e.g., wall insulations and cushions), and polyvinyl chlorides (PVC, e.g., carpet and clothes) producing toxic levels of $\mathrm{HCN}^{62,63}$ Smoke inhalation during house or industrial fires is the most common source of HCN exposure and poisoning in the U.S., followed by industrial and terrorist attack exposures, and suicidal ingestion (cyanide). ${ }^{60}$

Accordingly, firefighters are most regularly exposed to HCN. Being more lethal than carbon monoxide (CO), HCN may be the leading cause of the estimated 5,000-10,000 deaths associated with smoke inhalation each year. ${ }^{60}$ The cyanide ion, $\mathrm{CN}^{-}$, inhibits nearly 40 enzyme systems, with high affinity for cobalt, $\mathrm{Fe}^{3+}$ in methemoglobin, and $\mathrm{Fe}^{2+}$ in hemoglobin. ${ }^{64}$ Primarily, $\mathrm{HCN}$ acts a cellular asphyxiant by reversibly binding to $\mathrm{Fe}^{3+}$ in cytochrome c oxidase, preventing its reduction, and inhibiting electron transport and interrupting cellular respiration at the cellular level. ${ }^{65}$ This process prevents tissues from extracting oxygen from hemoglobin in 
blood.$^{65}$ Exposure particularly affects the organs that are most sensitive to low oxygen levels such as the central nervous system (e.g., brain), the cardiovascular system (e.g., heart), and the pulmonary system (e.g., lungs). ${ }^{66}$ NIOSH recommends the immediately dangerous to life and health concentration (IDLH), or the level that interferes with the ability to escape, for HCN to be $50 \mathrm{ppm} .{ }^{67}$ However, NIOSH's short-term recommended exposure limit (STEL) for HCN is 4.7 ppm. STEL is defined as a " 15 minute time-weighted average (TWA) exposure that should not be exceeded at any time during the workday" without suffering irritation, chronic tissue damage, or narcosis. ${ }^{67,68}$

Too frequently, firefighters experience symptoms of HCN exposure (e.g., dizziness, weakness, hypotension at $\sim 1$ milligram/liter $(\mathrm{mg} / \mathrm{L}$ ) cyanide in blood) often confused with $\mathrm{CO}$ poisoning due to the similarity of symptoms. This is problematic when choosing the appropriate antidote for an exposed victim. A HCN antidote kit sold in the U.S. ("Taylor", "Lilly", or "Pasadena Kit") containing amyl nitrate, thiosulfate, and sodium nitrite may be administrated by inhalation or intravenously. ${ }^{57,69} \mathrm{~A}$ problem with this kit is that the nitrite forms methemoglobin, which reduces the blood's ability to transmit oxygen (more lethal in already CO poisoned victims) ${ }^{69}$ In 2006, the Food and Drug Administration (FDA) approved Cyanokit ${ }^{\mathrm{TM}}$ for treatment of suspected $\mathrm{HCN}$ exposure containing hydroxocobalamin, which binds $\mathrm{CN}^{-}$with high affinity to form cyanocobalamin and is excreted through the urine. Hydroxocobalamin is an effective antidote with mild side effects (skin discoloration or allergy) and does not reduce the blood's oxygen carrying capacity. ${ }^{64}$ The third type of antidote includes sulfur donors (thiosulfate) that convert $\mathrm{CN}^{-}$to $\mathrm{SCN}^{-}$(thiocyanate) which is excreted in the urine. 


\subsubsection{Cyanide and HCN Detectors}

Cyanide and HCN sensors have recently expanded to develop detection methods for safe working conditions, terrorist attacks situations, and blood/breath concentration levels of poisoned victims. Methods of determination of cyanide can be difficult as it is affected by $\mathrm{pH}$, temperature, and presence of sulfur compounds. ${ }^{70}$ Optical sensors have been particularly studied due to their simplicity and low-cost. ${ }^{71,72}$ Numerous detailed reviews on cyanide detection can be found, with the most recent by Randviir and Banks. ${ }^{71,73,74}$ A non-exhaustive list of colorimetric/optical sensors for $\mathrm{HCN} / \mathrm{CN}^{-}$is summarized in Table 1.4. These approaches are primarily based on two characteristic properties of cyanide: its strong nucleophilicity and strong binding affinity for transition metals. ${ }^{71}$ For comparison, a few corrin-based (heterocyclic molecules) $\mathrm{CN}^{-}$detection applications are also displayed in this table, but will be discussed in greater detail in Section 1.1.5. 
Table 1.4 - Colorimetric and optical sensors for $\mathrm{CN}^{-}$and $\mathrm{HCN}$

\begin{tabular}{|c|c|c|c|c|c|}
\hline Analyte & Reagent & Detection System & LOD & Interferences & References \\
\hline $\mathrm{CN}^{-}$and $\mathrm{HCN}$ & $\begin{array}{l}\text { Chloramine-T and pyridine- } \\
\text { barbituric acid }\end{array}$ & UV-VIS spectrometer & $0.005 \mathrm{mg} / \mathrm{L}$ & $\begin{array}{l}\text { Sulfide/sulfur containing } \\
\text { species, fatty acids, carbonate, } \\
\text { aldehydes, nitrate/nitrite }\end{array}$ & USEPA Method $335.4^{75}$ \\
\hline $\mathrm{CN}^{-}$in water & $\begin{array}{l}\text { 1. Aquocyanocobinamide } \\
\text { 2. Aquocobyrinic acid } \\
\text { 3. Aquocyanocobester }\end{array}$ & UV-VIS spectrometer & $\begin{array}{l}\text { Aquocobyrinic: } 1.5 \\
\mu \mathrm{M}\end{array}$ & $\mathrm{SCN}^{-}$ & Männel-Croisé and Zelder, $2009^{76}$ \\
\hline $\mathrm{CN}^{-}$in water & Crystal violet & $\begin{array}{l}\text { Immobilization on } \\
\text { transparent triacetyl } \\
\text { cellulose membranes }\end{array}$ & $5 \mathrm{ppm}$ & $\begin{array}{l}\mathrm{Co}(\mathrm{II}), \mathrm{Ni}(\mathrm{II}), \mathrm{Fe}(\mathrm{III}), \mathrm{Fe}(\mathrm{II}), \\
\mathrm{Cr}(\mathrm{III}), \mathrm{Cu}(\mathrm{II}), \mathrm{Zn}(\mathrm{II}), \mathrm{Ag}(\mathrm{I})\end{array}$ & Chamjangali et al., $2010^{77}$ \\
\hline $\begin{array}{l}\mathrm{CN}^{-} \text {in tobacco } \\
\text { smoke and } \\
\text { cassava plant }\end{array}$ & $\begin{array}{l}\beta \text {-Aquo- } \alpha \text {-cyanocobyrinic acid } \\
\text { and } \beta \text {-Aquo- } \alpha \text {-cyanocobyrinic } \\
\text { acid heptamethyl ester }\end{array}$ & $\begin{array}{l}\text { UV-VIS } \\
\text { spectrometer, diffuse } \\
\text { reflectance UV-VIS } \\
\text { spectrometer, and } \\
\text { hand-help color } \\
\text { difference } \\
\text { spectrophotometer }\end{array}$ & DRUV-VIS: $1 \mu \mathrm{g} / \mathrm{L}$ & $\mathrm{SCN}^{-}, \mathrm{I}^{-}, \mathrm{OCN}^{-}$ & Männel-Croisé et al., 2012 78 \\
\hline $\begin{array}{l}\mathrm{CN}^{-} \text {in water } \\
\text { converted to } \\
\text { HCN }\end{array}$ & $\begin{array}{l}\text { p-Nitrobenzaldehdye and o- } \\
\text { Dinitrobenzene }\end{array}$ & UV-VIS spectrometer & $1 \mathrm{mg} / \mathrm{L}$ & Mentioned, not list & Untang, et al., $2010^{79}$ \\
\hline $\mathrm{HCN}$ & $\begin{array}{l}\mathrm{N}- \\
\text { chlorosuccinamide/succinamide } \\
\text { oxidizing agent and barbituric } \\
\text { acid/pyridine coupling agent }\end{array}$ & UV-VIS spectrometer & $1 \mu \mathrm{g} \mathrm{CN}^{-}$ & Hydrogen sulfide & $\begin{array}{l}\text { NIOSH Manual of Analytical } \\
\text { Methods }^{80}\end{array}$ \\
\hline $\mathrm{CN}^{-}$and $\mathrm{HCN}$ & Triphenylmethanes & $\begin{array}{l}\text { Digital Supermode } \\
\text { distributed Bragg } \\
\text { reflector (DS-DBR) }\end{array}$ & $\begin{array}{l}\mathrm{HCN}: 2 \mathrm{ppm} \\
\mathrm{CN}^{-}: 1 \times 10^{-5} \mathrm{M}\end{array}$ & None & Gotor et al., 2013 \\
\hline $\mathrm{HCN}$ & 4-nitrobenzil & $\begin{array}{l}\text { Naked-eye using gas } \\
\text { detection tube }\end{array}$ & $0.05 \mathrm{mg} / \mathrm{m}^{3}$ & $\begin{array}{l}\text { Ammonia (false positive), } \\
\text { phosgene, hydrogen chloride, } \\
\text { acetic acid (false negative) }\end{array}$ & Pitschmann et al., 2014 \\
\hline
\end{tabular}


Although many techniques are available for the detection of $\mathrm{CN}^{-}$, there is not as wide a variety for gaseous $\mathrm{HCN}$ detection. Electrochemical sensors are a common means for $\mathrm{HCN}$ detection. Electrochemical detection occurs using a gold, silver, or platinum electrode by the reactions $^{82}$ :

$$
\begin{array}{lr}
2 \mathrm{HCN}+\mathrm{Au}_{(\mathrm{s})} \rightarrow \mathrm{HAu}(\mathrm{CN})_{2}+\mathrm{H}^{+}+\mathrm{e}^{-} & \text {Equation 1.5 } \\
2 \mathrm{HCN}+\mathrm{Ag}_{(\mathrm{s})} \rightarrow \mathrm{HAg}(\mathrm{CN})_{2}+\mathrm{H}^{+}+\mathrm{e}^{-} & \text {Equation 1.6 }
\end{array}
$$

where the standard potential for Equation 1.5 is $0.61 \mathrm{~V}$ and that of Equation 1.6 is 0.31 V. ${ }^{107}$ First, the gas passes through a gas-permeable membrane (hydrophobic barrier) within the electrochemical instrument. This barrier allows the proper amount of gas to reach the sensing electrode and prevents the electrolyte from leaking and drying out the sensor. ${ }^{82}$ The porosity of this membrane affects the sensitivity of the electrochemical instrument: lower porosity membranes are used for instruments that monitor higher gas concentrations by limiting the amount of gas passing through, while lower concentration monitors have a higher porosity, allowing more gas to reach the sensing electrode. ${ }^{82}$ After a reduction or oxidation reactions occurs at the electrode, an electrical signal is produced and is proportional to the gas concentration. Electrochemical sensors for $\mathrm{CN}^{-} / \mathrm{HCN}$ include potentiometric cyanide-selective electrodes $^{83}$, amperometric sensor using a gold electrode ${ }^{84}$, and indirect measurement using stripping voltammetry at a mercury drop electrode. ${ }^{85}$ Portable and robust electrochemical sensors are available by a number of manufacturers for occupational personal air-sampling devices that may be clipped to the user's backpack or belt. The devices are designed for single HCN gas or multigas detection ranging from $\$ 500$ to over $\$ 3500 .{ }^{86-88}$ Most devices can detect up to $100 \mathrm{ppm}$ HCN with step increases of $1 \mathrm{ppm}$. An audible, visual, or vibrating alarm can be set once a certain threshold (usually the STEL) is reached. Advantages of electrochemical sensors include 
good repeatability/accuracy, low-cost with low-power requirements (among the lowest for gas monitoring), linear output, and can be specific for gases in parts-per-billion (ppb), based on selectivity of the sensor. Drawbacks include cost, battery life, limited temperature range, interferences ( $\mathrm{CO}$ and nitric oxide (NO)), limited sensor shelf-life (leading to a slow response with aged sensor), and negative effects from very dry/hot or very humid environments. ${ }^{82,89}$ To date, these sensors have not been incorporated into a canister's carbon bed.

Microcantilevers, ${ }^{72}$ gas chromatography/mass spectrometry (GC/MS; headspace for whole blood), ${ }^{91}$ quartz crystal microbalance (QCM), ${ }^{90}$ Fourier transform infrared spectrometry (FTIR), fiber optic chemical sensors, ${ }^{92}$ and colorimetric gas sampling tubes ${ }^{93}$ are also common detection methods used for gaseous HCN. Microcantilevers, the simplest type of microelectromechanical system (MEMS), act as a physical, biological, or chemical sensor. The microcantilever detects changes in bending or vibrational frequency by mass change due to analyte adsorption on a coated sensing medium. ${ }^{94}$ These sensors offer many advantages such as quick response, high sensitivity for trace levels ( $\mathrm{ppb}$ ) of gases, low-power requirements, and low-cost. ${ }^{94}$ Microcantilevers are able to detect water vapor (i.e. humidity), but must be done on a compensating sensor differently than the sensor for the gas of interest. The main disadvantage, in terms of portability, is robustness, which is required for an ESLI due to respirators and associated canisters often thrown or dropped. A NIOSH standard (RCT-APR-STP-0060) for approving air-purifying respirators requires a drop test of 6 feet: "Any ESLI that is permanently installed in the respirator facepiece shall withstand cleaning and a drop from a height of 6-feet. Replaceable ESLI must be able to easily removed and able to withstand a drop from this height. ${ }^{95}$ Additionally, the requirement of electrical read-out interfaces for microcantilevers hinder portable sensing applications and commercialization, although recent studies have shown 
improvement by using lock-in amplifiers with a microcontroller and power supply to overcome this issue. ${ }^{96}$ Advantages including sensitivity and selectivity of HPLC and GC/MS detection methods are well known, but current methods require complex, bulky instrumentation, and unsuitable power requirements, characteristics inappropriate for ESLIs. A QCM was developed for detection of $\mathrm{HCN}$ using various copper oxide $(\mathrm{CuO})$ nanoparticle morphologies as the sensing medium. Detection relies on the change in frequency of an oscillating quartz crystal and mass-balance detection method, resulting in a limit of detection (LOD) of 0.265 ppm HCN. ${ }^{97}$ Portable FTIR analyzers are available and able to detect sub-ppm levels of HCN. ${ }^{98,99}$ Currently, these analyzers are relatively large and bulky, and are not as commonly used as the portable electrochemical monitors. ${ }^{99}$ Gas sampling tubes, nicknamed the "length of stain" tubes, are glass tubes filled with a chemical reagent that undergo a color change when exposed to the gas of interest. ${ }^{100} \mathrm{~A}$ hand pump manually draws 0.1 liters per minute (LPM) of the sample into the tube. The length of the color change in the glass tube correlates with the concentration of the gas. ${ }^{100}$ Common embedded reagents for $\mathrm{HCN}$ detection include $\mathrm{HgCl}_{2}$ ( $\mathrm{pH}$ indicator), sodium picrate, $\mathrm{Na}_{2}\left[\mathrm{Pd}\left(\mathrm{SO}_{3}\right)_{2}\right]$, chloramine, and $p$-nitrobenzaldehyde. ${ }^{101}$ Detector tubes are widely available for hundreds of gases, and are relatively inexpensive. Unfortunately, this detection method is not very accurate (reported accuracies $\pm 20-30 \%$ ) and is prone to numerous interfering gases causing false positives. ${ }^{102}$ The gas tubes are also sensitive to temperature and humidity fluctuations and must be stored in cold temperatures during their short shelf-life.

\subsubsection{Cobinamide}

Cobinamide (Cbi) is a cobalt-centered hydroxocobalamin precursor characterized by its corrin macrocyclic structure ligated by four nitrogen groups (Figure 1.1). ${ }^{103}$ Unlike its precursor cobalamin (Vitamin $\left.\mathrm{B}_{12}\right)$, the cobalt $\left(\mathrm{Co}^{3+}\right)$ metal center offers two axial coordination sites as 
opposed to one. For cobalamin, the lower axial site $(\alpha)$ is occupied by a nucleotide loop (dimethylbenzimidazole, DMB) ligand, which is removed during the preparation of Cbi. ${ }^{103} \mathrm{The}$ DMB ligand on cobalamin acts as a negative trans-effect on the upper binding site, reducing cobalamin's affinity for ligands. ${ }^{104}$ When this bulky ligand is removed, Cbi has over a $10^{10}$ greater affinity for $\mathrm{CN}^{-}$than cobalamin. ${ }^{104}$ Because Cbi has the ability to bind two ligands, it can also more easily undergo redox reactions.

Figure 1.1 - Structure of Cbi

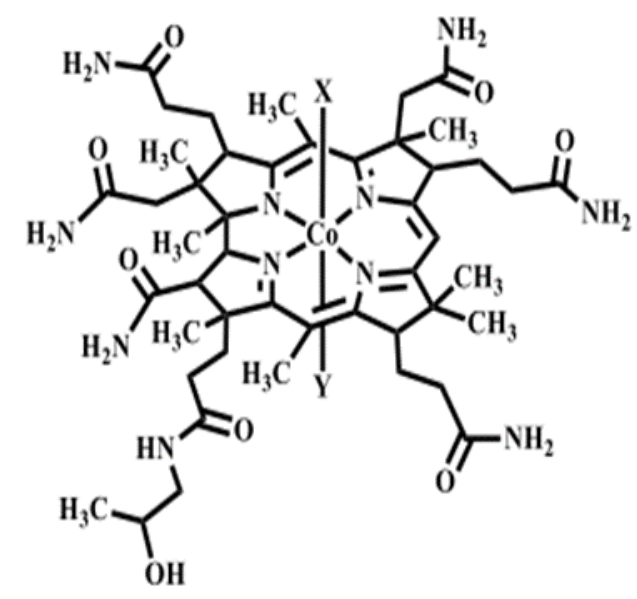

The $\mathrm{X}$ and $\mathrm{Y}$ ligands in Figure 1.1 can be neutral (e.g., water $\left(\mathrm{H}_{2} \mathrm{O}\right)$, ammonia $\left(\mathrm{NH}_{3}\right)$, $\mathrm{NO}$ ), or anionic groups (e.g., $\left.\mathrm{OH}^{-}, \mathrm{CN}^{-}, \mathrm{SCN}^{-}\right) .{ }^{105,106} \mathrm{Cbi}$ is particularly sensitive to $\mathrm{CN}^{-}$, forming a charge-transfer complex where the electron-donor group $\left(\mathrm{CN}^{-}\right)$binds to the electron-acceptor group (Cbi) creating absorbance spectra with a large molar absorptivity $\left(\varepsilon>10,000 \mathrm{~L} \mathrm{~mol}^{-}\right.$ $\left.{ }^{1} \mathrm{~cm}^{1}\right) \cdot{ }^{107}$ At neutral $\mathrm{pH}$ in water, Cbi exists as the mixed hydroxy-aquo complex $\left(\left[\mathrm{OH}\left(\mathrm{H}_{2} \mathrm{O}\right) \mathrm{Cbi}\right]\right.$, pKa $10.3 \pm 0.2)$, termed aquohydroxocobinamide. ${ }^{108}$ Diaquacobinamide $\left(\left[\left(\mathrm{H}_{2} \mathrm{O}\right)_{2} \mathrm{Cbi}\right]\right.$, pKa $5.9 \pm$ $0.1)$ and dihydroxocobinamide $\left[(\mathrm{OH})_{2} \mathrm{Cbi}\right]$ exist in acidic $(\mathrm{pH}<6)$ and basic $(\mathrm{pH}>11)$ environments, respectively. ${ }^{109}$ Binding of $\mathrm{CN}^{-}$to Cbi occurs with an overall binding affinity $\left(\mathrm{K}_{\mathrm{a}}\right)$ 
value of $10^{22}$ Molarity $^{-2}(\mathrm{M})$ (compared to a $\mathrm{K}_{\mathrm{a}}$ value of $10^{12} \mathrm{M}^{-1}$ for hydroxocobalamin) as shown below. ${ }^{110}$

$$
\mathrm{OH}\left(\mathrm{H}_{2} \mathrm{O}\right) \mathrm{Cbi} \stackrel{10^{14} \mathrm{M}^{-1}}{\longrightarrow} \mathrm{CN}\left(\mathrm{H}_{2} \mathrm{O}\right) \mathrm{Cbi} \stackrel{10^{8} \mathrm{M}^{-1}}{\longrightarrow}(\mathrm{CN})_{2} \mathrm{Cbi}
$$

The water ligand is substituted by $\mathrm{CN}^{-}$, and the $\mathrm{OH}^{-}$is subsequently protonated under most $\mathrm{pH}$ conditions. Cbi can be produced through base hydrolysis of hydroxocobalamin acetate using cerium (III) hydroxide, or through heated acid hydrolysis to remove the nucleotide group. ${ }^{111,112}$ The products are purified on cellulose cation exchange columns and concentrated/desalted on reversed-phase $\mathrm{C} 18$ columns. ${ }^{109}$

Although hydroxocobalamin is an FDA-approved cyanide antidote, 4-5 grams (g) are required to treat smoke inhalation victims. ${ }^{104}$ However, due to cobinamide's high binding affinity, fast kinetics, and ability to bind two $\mathrm{CN}^{-}$ions, it has been studied with successful results as a cyanide antidote as well as promising results for $\mathrm{H}_{2} \mathrm{~S}$ and $\mathrm{NO}$ antidotes. ${ }^{104,113-116}$ In addition to use as an effective antidote, $\mathrm{Cbi}$ (specifically $\mathrm{OH}\left(\mathrm{H}_{2} \mathrm{O}\right) \mathrm{Cbi}$ ) has been used in a variety of other applications. Cobinamide (and its precursor cobalamin) is most frequently used in absorption spectrometry applications. This is due to the corrinoids' highly colored characteristics upon ligand binding, varying from red (e.g., cobinamide/cobalamin), to yellow/brown (e.g., methylcobalamin), to purple (e.g., dicyanocobinamide/cobalamin), or even greenish (e.g., super reduced cobalamin (I) ${ }^{117}$ These compounds are sensitive to the changes and nature axial ligands, but relatively insensitive to changes in side-chains or outer ring carbon atoms of the corrinoid. ${ }^{117}$ The diverse and characteristic absorbance spectra and high extinction coefficients (which enables experiments with small amounts of material) are key advantages for using absorption spectrometry. Specifically, the change from $\mathrm{CN}\left(\mathrm{H}_{2} \mathrm{O}\right) \mathrm{Cbi}$ to dicyanocobinamide $\left[(\mathrm{CN})_{2} \mathrm{Cbi}\right]$ 
yields a significant color change from orange (peak absorbance at $\sim 510$ nanometers $(\mathrm{nm})$ ) to violet $(583 \mathrm{~nm})$ that is easily observed. This $\alpha$-band is typically used as the reference standard to determine concentration, although the $\gamma$ - band can also be used. ${ }^{117}$ This rapid spectral change has been used in various applications such as establishing Henry's Law constant by aqueous solubility of $\mathrm{HCN}$, reversing cyanide toxicity of experimental animals, detecting endogenous biological cyanide through diffuse reflectance spectrometry (LOD of 1 microgram/liter, $\mu \mathrm{g} / \mathrm{L}$ ), detecting blood cyanide concentrations (LOD of 0.25 nanomolar, nM), analyzing cyanide concentration by liquid-core waveguide injection systems (LOD of $30 \mathrm{nM}$ ), and field-portable detection of cyanide in blood by transmission through a Cbi-impregnated filter paper (LOD of 0.5 micromolar $(\mu \mathrm{M}))^{78,104,109,113,118-121}$

As noted by Baldwin et al. and further shown by Ma et al., more rapid and pronounced spectral changes occur on $\mathrm{CN}^{-}$binding when the starting reagent is monocyanocobinamide $\left[\mathrm{CN}\left(\mathrm{H}_{2} \mathrm{O}\right) \mathrm{Cbi}\right]$ than when starting with either diaquacobinamide or aquohydroxocobinamide. ${ }^{111,108}$ The more rapid and sensitive binding kinetics is attributed to the stronger trans-labilizing effect of $\mathrm{CN}^{-}$compared to $\mathrm{OH}^{-}$. After this recent discovery, the liquidcore waveguide system was improved with use of $\mathrm{CN}\left(\mathrm{H}_{2} \mathrm{O}\right) \mathrm{Cbi}$ as the reagent and a LOD of 8 $\mathrm{nM}$ was reported. ${ }^{108}$

\subsection{Purpose}

For more than a decade, NIOSH has allocated funds towards the development of ESLIs. The objective of this research is to identify technology that shows potential for an ESLI that respirator manufacturers can further mature. In general, these sensors must be small, simple, inexpensive, selective, and robust. It is advantageous to begin with a niche market. The work described here focuses on the detection of inorganic gases. These gases have limited service-time 
estimates because most algorithms used in end-of-service-life determination software programs were developed for OV interaction with activated carbon, which behaves differently for acidic, basic, and chemical, biological, radiological, and nuclear (CBRN) gases. This may be due, for example, to the difficulty of predicting breakthrough when chemical impregnants are embedded into the activated carbon. Accordingly, existing algorithms may not be reliable in the context of $\mathrm{HCN}$ and hydrogen sulfide $\left(\mathrm{H}_{2} \mathrm{~S}\right)$. Supplied-air respirators are typically recommended for inorganic chemicals, which are more expensive and cumbersome for the user. Developing ESLIs for inorganic compounds may allow air-purifying respirators to be adequate, greatly reducing the cost to both employers and users. ${ }^{38}$ In general, the further development and maturity of ESLIs will provide a more accurate and safer way to inform the user to replace the respirator canister or cartridge(s), thus improving the health and safety of respirator users.

\subsection{Application}

This research focused on the development of an optical sensor is developed for the detection of $\mathrm{HCN}$ and $\mathrm{H}_{2} \mathrm{~S}$ gas. Cobinamide was used as a colorimetric indicator that is immobilized on cellulose or glass fiber filter paper. The minimum detectable concentrations of interest for these two gases are their respective RELs, $4.7 \mathrm{ppm} \mathrm{HCN}$ and $10.0 \mathrm{ppm}_{2} \mathrm{~S}$. Response to these gases should occur rapidly so the user has adequate time to replace the cartridge/canister. The targeted response time is within 1 minute for both gases, but was found to be significantly less.

\subsection{Certificates and Training}

The research was performed in the laboratories at NIOSH/National Personal Protective Technology Laboratory (NPPTL) Morgantown and Pittsburgh facilities under supervision of Dr. 
Chris Coffey, Mr. Terry Thornton, Mr. Frank Palya, Mr. Jonathan Szalajda, and Dr. James Harris. Specific certifications and training were required for storing and handling high concentrations of toxic gases. NIOSH, a facility under the Centers for Disease Control and Prevention (CDC), required completion of training such as "Hazard Communication", "Hazardous Chemical Waste Management", "Chemical Storage”, "Radiation Safety-Sealed Source", among others. The training requirements were fulfilled prior to commencement of this research.

\section{Chapter 2: Cobinamide-Based Detection of Hydrogen Cyanide Gas}

\subsection{Introduction}

Monocyanocobinamide has a high affinity for $\mathrm{CN}^{-}$and offers great potential as a $\mathrm{HCN}$ gas sensor. To study the effects of monocyanocobinamide with low concentrations of $\mathrm{HCN}$, a gas-flow system was assembled and methods were optimized to fix cobinamide onto paper. Specifically, two types of filter paper were tested and compared for their response to HCN: a cellulose-based filter paper and a thicker, borosilicate glass fiber paper. During HCN exposure, the paper circles were housed in a light-tight holder that allowed HCN to flow over the paper circle. A bifurcated fiber optic directed the diffuse reflected light from the paper circle to a miniature spectrometer. Resulting apparent absorbance was monitored as a function of wavelength, $\mathrm{HCN}$ concentration, and exposure time. Apparent absorbance was converted to diffuse reflectance values using the Kubelka-Munk function.

\subsection{Background Information}

Respirators are worn in a wide variety of dry and humid climates with water vapor concentrations ranging from $<2000$ to $>20,000$ parts-per-million by volume $\left(\mathrm{ppm}_{\mathrm{v}}\right)$ or 
approximately 10 to $100 \% \mathrm{RH}$, respectively. ${ }^{122}$ For an ESLI to be suitable for diverse environmental conditions, the sensor must not be negatively affected by water vapor or extreme temperature changes. Water vapor is a potential interference for many sensor technologiesincluding electrochemical-based sensors (without humidity compensators) and photonic crystals (among others)-, which is a significant concern in the context of ESLI sensors. ${ }^{44}$ For a sensor to be practical for use as an ESLI, it must meet the appropriate size and power requirements to be incorporated into respirator canister. Unlike the bulky laboratory-based detection methods for HCN (Chapter 1), the sensor must be small, simple, and cost-effective to be marketable by respirator manufacturers.

\subsubsection{Paper as a Sensor Medium}

Initial experiments with sol-gel

Cbi is chosen as the optical indicator for $\mathrm{HCN}$ due to its high affinity for $\mathrm{CN}^{-}$, but it must first be concentrated onto an inexpensive and porous medium to facilitate rapid detection of HCN. Initially, sol-gel (a porous, transparent glass-like material) was used to immobilize Cbi. Sol-gel requires inexpensive reagents and can be tailored to various shapes and thicknesses depending on the application. A significant feature of sol-gel technology is its ability to immobilize various compounds. Small molecules (e.g., dyes) and larger molecules (e.g., enzymes) are able to be encapsulated in the silicon dioxide network during the sol-gel manufacturing process. ${ }^{123-125}$ The sol-gel matrix acts as a host for the embedded compounds; its various pore sizes $(\mathrm{nm}-\mu \mathrm{m})$ allow diffusion and detection of analytes in both solution or gas phase.

Tetraethyl orthosilicate (TEOS) was used as the silica matrix. In controlled molar ratios, ethanol, water, hydrochloric acid $(\mathrm{HCl})$, and $\mathrm{Cbi}$ were added to this solution and allowed to dry 
in a molding. Ultimately, the sol-gel was difficult to prepare with sufficient amounts of Cbi that would remain intact. In the sol-gel community, it is known that thicker sol-gel materials are more susceptible to cracking, which was observed. ${ }^{124,126-128}$ Although initial experiments were promising, the cracking led to issues with reproducibility. Cracking is due to non-uniform pore sizes throughout the matrix creating a gradient upon solvent removal. Even with the addition of surfactants, which is reported to reduce cracking, the uncontrollable pore size of the sol-gel led to an essentially non-porous monolith that did not allow sufficient amount of $\mathrm{HCN}$ to diffuse through the pores in the desired response time. Sol-gel monoliths encapsulated with Cbi can be seen in Figure 2.1 with cracked monoliths (with surfactants, no Cbi) upon drying in Figure A.1. Most applications use sol-gel with thin layers $(\mathrm{nm}-\mu \mathrm{m})$ using spin-coating or dip-coating techniques. These methods were also attempted, but the layers were too thin and no $\mathrm{Cbi}$ absorbance spectrum could be observed.

Figure 2.1 - Cbi encapsulated in sol-gel monoliths

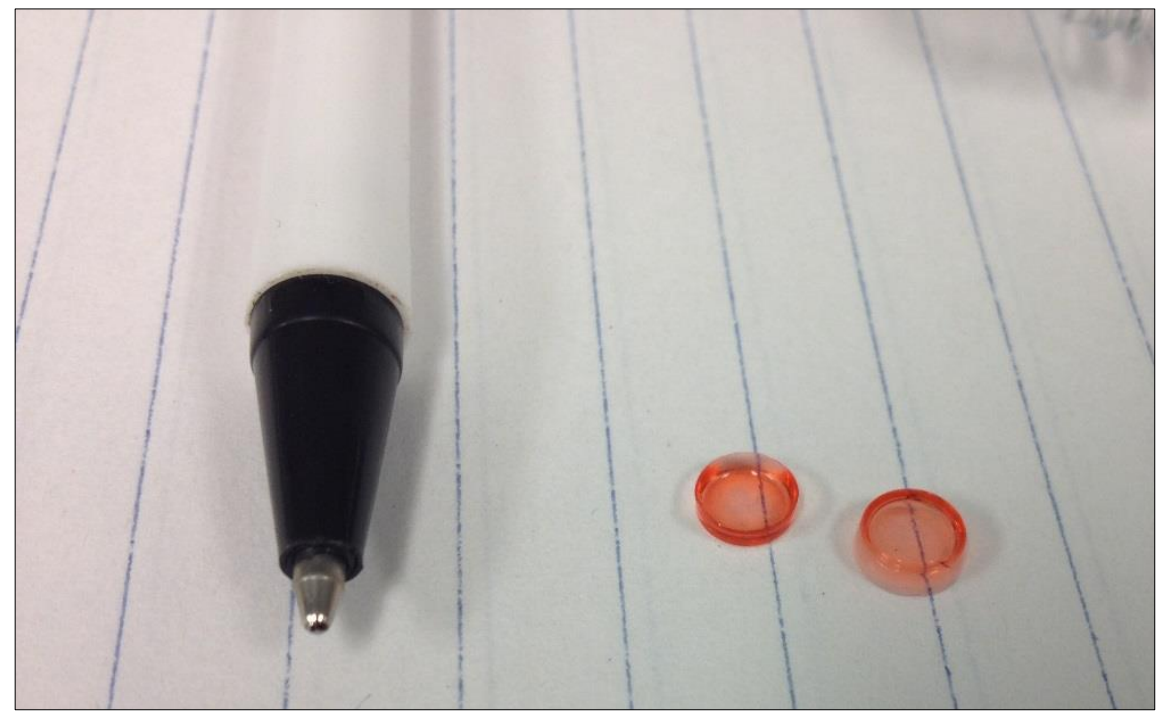




\section{Paper}

An alternative sensor medium to meet the requirements of an ESLI is paper. The physical properties of paper make this medium desirable when seeking to develop an inexpensive, flexible, portable, and biodegradable/disposable sensor. Made of multiple fiber layers, the intrinsic hydrophilic matrix allows aqueous solutions to penetrate quickly without the need of an external pump. ${ }^{129}$ Additionally, the fibers can be functionalized to change the hydrophobicity, reactivity, or permeability, making paper compatible with a variety of chemicals. Paper is highly porous with uniform pores and a large surface area, which is advantageous for rapid adsorption of gas-phase analytes. Most paper-based sensor devices in literature use Whatman ${ }^{\circledR}$ No. 1 or No. 4, depending on the desired porosity, particle retention, and flow rate. ${ }^{129}$ Additional types of paper used for sensors include nitrocellulose membranes with uniform pore size, glossy paper with inorganic fillers, or composite papers made of the combination of cellulose and polyester. ${ }^{130,131}$ Common fabrication techniques include cutting, printing (wax or ink-jet), dipcoating, and photolithography. ${ }^{132}$ Wax printing assists in concentrating the reagent by keeping it in a specific location, thereby inhibiting diffusion.

Paper offers a bright, high-contrast backing for color change readings. Accordingly, the most common and inexpensive analytical technique used with paper is colorimetric and optical detection. ${ }^{132}$ This can be a simple subjective "yes/no" color-change observable by the naked eye, or a more quantitative color change when using a smartphone or flatbed scanner coupled with image processing software. The first semi-quantitative paper device was developed in 1956 for the detection of glucose, where enzymes immobilized on analytical grade filter paper produced a color change after urine introduction. ${ }^{133}$ This was the first time paper was viewed as an inexpensive and simple sensor medium suitable for commercial production. Twenty years later, 
another milestone was reached when the first commercial immunoassay became available in 1977: the e.p.t. ${ }^{\text {TM }}$ home pregnancy test kit. ${ }^{134}$ Since then, paper has become a promising substrate for real-time, low-cost sensors and the applications using paper as an analytical device have rapidly expanded. ${ }^{132}$

A discussion on paper sensors is incomplete without introducing George Whitesides. Often cited as the breakthrough in paper-based diagnostics, Whitesides' group paved the way in patterning paper-based microfluidic and analytical devices, or $\mu$ PADs, when their work and first scientific journal publication on the topic was published in $2007 .{ }^{132}$ Their work has included various paper fabrication techniques, bioassay diagnostics for developing worlds, digitalization of intensity of color on paper using a smartphone, and quantifying colorimetric assays through transmission of paper. ${ }^{135-138}$ Table 2.1 displays a summary focused on colorimetric sensors using paper as the sensor medium. This table is not inclusive to colorimetric paper devices as a whole, but an attempt to showcase a variety of analyte classes, fabrication techniques, and detection systems. Included in this table are examples of small gaseous analytes that were detected by a colorimetric indicator fixed on paper followed by red, green, blue (RGB) color difference analysis once manually scanned into the computer, which will be further discussed in Chapter 5 . Detectable analytes on paper include volatile organic amines, formaldehyde, ethanol, alcohols, aldehydes, carboxylic acids, and toxic compounds including hydrogen sulfide, hydrogen cyanide, chlorine, and phosgene. ${ }^{122,139-142}$ 
Table 2.1 - Examples of paper sensors

\begin{tabular}{|c|c|c|c|c|c|c|c|}
\hline Fabrication & Analyte Class & $\begin{array}{l}\text { Analyte of } \\
\text { Interest }\end{array}$ & Reagent & $\begin{array}{c}\text { Detection } \\
\text { System }\end{array}$ & LOD & Quantitative? & References \\
\hline \multirow[t]{2}{*}{$\begin{array}{c}\text { Hydrophobic } \\
\text { photoresist (SU-8 } \\
\text { polymer) }\end{array}$} & \multirow[t]{2}{*}{ Proteins/Biomolecules } & \multirow[t]{2}{*}{ BSA, glucose } & \multirow[t]{2}{*}{$\begin{array}{l}\text { TBPB, potassium iodide, } \\
\text { horseradish peroxidase/ } \\
\text { glucose oxidase }\end{array}$} & $\begin{array}{l}\text { Epson Perfection } \\
\text { 1640SU scanner } \\
\text { (default settings) }\end{array}$ & $\begin{array}{l}0.38 \mu \mathrm{M} \text { BSA, } 2.5 \\
\mathrm{mM} \text { glucose }\end{array}$ & Semi-quantitative & $\begin{array}{l}\text { Martinez et } \\
a l, .2007^{143}\end{array}$ \\
\hline & & & & $\begin{array}{l}2 \text { smartphones, } \\
\text { scanner, digital } \\
\text { camera }\end{array}$ & $\begin{array}{l}25 \mu \mathrm{M} \text { BSA, } 2.5 \mathrm{mM} \\
\text { glucose }\end{array}$ & Quantitative & $\begin{array}{l}\text { Martinez et } \\
\text { al., } 2008^{137}\end{array}$ \\
\hline Wax printing & Microorganisms & E. Coli $\mathrm{O} 157: \mathrm{H} 7$ & $\begin{array}{l}\text { Chlorophenol red and } \beta \text { - } \\
\text { Galactosidases }\end{array}$ & $\begin{array}{l}\text { Flatbed scanner; } \\
\text { grey intensities } \\
\text { using NIH ImageJ }\end{array}$ & $\begin{array}{l}10 \text { colony units } / \mathrm{cm}^{2} \\
\text { after } 12 \text { hours }\end{array}$ & Semi-quantitative & $\begin{array}{l}\text { Jokerst et al., } \\
2012^{144}\end{array}$ \\
\hline Patterned cutting & \multirow{2}{*}{ Metals } & $\mathrm{Cu}^{2+}$ & $\begin{array}{l}\text { Modified silver } \\
\text { nanoparticles }\end{array}$ & $\begin{array}{l}\text { Calibration plot } \\
\text { based on standards; } \\
\text { Adobe Photoshop } \\
\text { CS2 }\end{array}$ & $7.8 \mu \mathrm{M}$ & Quantitative & $\begin{array}{l}\text { Ratnarathorn } \\
\text { et al., } 2012^{145}\end{array}$ \\
\hline Ink-jetted sol-gel & & $\begin{array}{l}\mathrm{Hg}(\mathrm{II}), \mathrm{Ag}(\mathrm{I}), \\
\mathrm{Cu}(\mathrm{II}), \mathrm{Cd}(\mathrm{II}), \\
\mathrm{Pb}(\mathrm{II}), \mathrm{Cr}(\mathrm{VI}), \\
\mathrm{Ni}(\mathrm{II})\end{array}$ & Various $\beta$-Galactosidases & $\begin{array}{l}\text { Human eye, Canon } \\
\text { G11 } 12 \text { MegaPixel } \\
\text { camera and office } \\
\text { scanner with } \\
\text { ImageJ software }\end{array}$ & $\begin{array}{l}\mathrm{Hg}(\mathrm{II}), 0.001 \mathrm{ppm} \\
\mathrm{Ag}(\mathrm{I}): 0.002 \mathrm{ppm} \\
\mathrm{Cu}(\mathrm{II}): 0.020 \mathrm{ppm} \\
\mathrm{Cd}(\mathrm{II}), 0.020 \mathrm{ppm} \\
\mathrm{Pb}(\mathrm{II}): 0.140 \mathrm{ppm} \\
\mathrm{Cr}(\mathrm{VI}): 0.150 \mathrm{ppm} \\
\mathrm{Ni}(\mathrm{II}): 0.230 \mathrm{ppm}\end{array}$ & Quantitative & $\begin{array}{c}\text { Hossain and } \\
\text { Brennan, } \\
2011^{146}\end{array}$ \\
\hline RBC agglutination & Whole Blood & Whole Blood & $\begin{array}{l}\mathrm{RBC} \text { antigens for blood } \\
\text { typing }\end{array}$ & $\begin{array}{l}\text { Color change with } \\
\text { UV-VIS at } 595 \mathrm{~nm}\end{array}$ & N/A & Semi-quantitative & $\begin{array}{c}\text { Jarujamrus et } \\
\text { al., } 2012^{147}\end{array}$ \\
\hline $\begin{array}{l}\text { Photolithography/ } \\
\text { patterned channels }\end{array}$ & Small Molecules & $\begin{array}{l}\text { Urinary ketones, } \\
\text { glucose and } \\
\text { salivary nitrite }\end{array}$ & $\begin{array}{l}\text { Potassium iodide, } \\
\text { horseradish peroxidase/ } \\
\text { glucose oxidase, glycine, } \\
\text { nitroprusside, } \\
\text { sulfanilamide, citric acid, } \\
\text { n-(1- } \\
\text { napthyl)ethylenediamine }\end{array}$ & $\begin{array}{l}\text { Flatbed scanner } \\
\text { (Microtek } \\
\text { Scanmaker 4800)/ } \\
\text { CMYK color } \\
\text { analysis in Adobe } \\
\text { Photoshop CS4 }\end{array}$ & $\begin{array}{l}\text { Acetoacetate: } 0.5 \mathrm{mM} \\
\text { Salivary nitrite: } 5 \mu \mathrm{M} \\
\text { Urinary ketone: } 5 \mathrm{mM}\end{array}$ & Quantitative & $\begin{array}{l}\text { Klasner } \text { et al., } \\
\quad 2010^{148}\end{array}$ \\
\hline $\begin{array}{l}\text { Photolithography/ } \\
\text { Index-matching fluid }\end{array}$ & Protein & BSA & $\begin{array}{l}\text { Vegetable oil, PMPS, } \\
\text { mineral oil }\end{array}$ & $\begin{array}{l}\text { Transmittance } \\
\text { Colorimeter }\end{array}$ & N/A Range: $0-20 \mu \mathrm{M}$ & Quantitative & $\begin{array}{l}\text { Ellerbee } e t \\
a l ., 2009^{138}\end{array}$ \\
\hline
\end{tabular}


A model can be adopted for paper assuming fibers of uniform scattering properties separated by air voids. The general transmittance theory states that light entering a medium ( $\left.\mathrm{I}_{\text {in }}\right)$ of thickness $z(\mathrm{~cm})$ may attenuate $\left(\mathrm{I}_{o u t}\right)$ if the medium absorbs or contains scattering particles large relative to the wavelength of light. $Z$ and the attenuation coefficient of the medium due to absorption and scattering $\left(\alpha, \mathrm{cm}^{-1}\right)$ are related by ${ }^{149}$ :

$$
\mathrm{I}_{\text {out }}=10^{-\alpha z} \mathrm{I}_{\text {in }}
$$

The scattering coefficient is a function of the cross-section of the scatterer $\left(\mathrm{C}_{\text {sca }}, \mathrm{cm}^{2}\right)$ and the volume density of scatterers in the medium $\left(\mathrm{N}, \mathrm{cm}^{-3}\right)$. When a dye is fixed on paper, the transmission of light is attenuated much like the Beer-Lambert Law ${ }^{138}$ :

$$
\mathrm{I}_{\text {out }}=\mathrm{I}_{\text {in }} 10^{-\varepsilon c z}
$$

Equation 2.2

where $\varepsilon\left(\mathrm{M}^{-1} \mathrm{~cm}^{-1}\right)$ is the molar extinction coefficient of the dye, c $(\mathrm{M})$ is the concentration of the dye, and $z(\mathrm{~cm})$ is the optical path length of the paper (i.e. thickness). The total transmission from the source to the detector (taking into account the air-paper, paper-air boundaries) can be described by ${ }^{138}$ :

$$
\mathrm{I}=\tau_{\text {in }} 10^{-\alpha_{s c a} z} 10^{-\alpha_{s a m p} z} 10^{-\varepsilon c z} \tau_{\text {out }} \mathrm{I}_{\mathrm{o}}=\mathrm{T}_{\mathrm{c}} 10^{-\alpha_{s a m p} z} 10^{-\varepsilon c z} \mathrm{I}_{\mathrm{o}}
$$

further simplified to:

$$
\mathrm{T}=\frac{I}{I_{o}}=\mathrm{T}_{\mathrm{c}} 10^{-\alpha_{s a m p} z} 10^{-\varepsilon c z}
$$

where $\mathrm{I}\left(\mathrm{W} / \mathrm{cm}^{2}\right)$ is the final intensity at the detector, $\mathrm{I}_{\mathrm{o}}$ is the source intensity, $\alpha_{\text {samp }}\left(\mathrm{cm}^{-1}\right)$ which accounts for attenuation of the liquid sample, $\alpha_{s c a}\left(\mathrm{~cm}^{-1}\right)$ is the scattering coefficient of the paper, $\tau_{\text {in }}$ and $\tau_{\text {out }}$ are the transmission coefficients for the air-paper and paper-air interface, respectively, and $\mathrm{T}_{\mathrm{c}}$ (unitless) is the characteristic transmittance of the paper (before applying the colorimetric dye). ${ }^{138}$ More sensitive detection occurs when attenuation is caused by light extinction by the 
fixed-dye, rather than scattering. This can be achieved by minimizing scattering of the paper or maximizing the transmission coefficients; a larger $T_{\mathfrak{c}}$ correlates with increased sensitivity. To maximize transmission, the boundary indexes must match. Whitesides (Ellerbee et al.) attempted to quantify the transmission of light through paper for a colorimetric assay of a microfluidic device. ${ }^{138}$ Incorporating a fluid to replace the air-filled pores (better matching the refractive index of the paper) reduces the effects of scattering. Oils including vegetable and mineral oil were applied to the paper to replace the air voids in the filter paper with oil, with R.I. values ranging from 1.4 to $1.5{ }^{138}$ The overall transmittance increases as a perfect index-matching condition is reached: $:^{138}$

$$
n_{f}(t)=\varphi(t) n_{\text {air }}+(1-\varphi(t)) n_{f}
$$

where $n_{f}$ is the refractive index of the fluid, $n_{\text {air }}$ is the refractive index of air (i.e. 1.00), and $\varphi(t)$ is a time dependent volume fraction.

Irreproducibility is a potential limitation of paper that can occur when the detection system is placed in close proximity to the paper surface. This can be attributed to inhomogeneous coating of the indicator and the resulting diffusion of the indicator across the paper. Sensitivity therefore suffers due to the concentration of the compound delivered to the paper. The increase in surface area may also cause an increased evaporation rate. ${ }^{129}$ Additionally, indicators fixed on the paper may be trapped too deeply in the porous matrix, causing inaccessibility to the analyte of interest. ${ }^{150}$ In a diffuse reflectance configuration, scattering may be an issue when interpreting data due to the paper's non-uniform and porous surface morphology. ${ }^{129}$ Overall, the advantages of using paper (e.g., simple, flexible, universal) offer a promising media for the development of an inexpensive sensor. 


\subsubsection{Diffuse Reflectance Spectrometry}

When light interacts with a sample's surface, the incident light can be reflected, interreflected, refracted, absorbed, transmitted, or a combination of these events. Specular reflectance occurs when the angle of outgoing reflected light matches the incident angle with respect to the surface normal, as described by the law of reflection. Specular reflectance can be observed for polished, mirror-like surfaces. Diffuse reflected light reflected at many different angles and occurs with rough surfaces, although surface roughness is not the only contributor to scattering. The angle of reflected light depends on the sample surface, lattice structure, and size of particles within the matrix, among other factors. The multiple reflection and refraction occurrences are due to the microscopic irregularities within the material. ${ }^{151}$ Diffuse reflected light is typically the color of the material it is reflected from, whereas specular light is dependent on the color of the incident light (Figure 2.2). Common sample media that exhibit diffuse reflectance include soil, paint, body tissues, powders, meat, crystals, and organic material composed of cellulose fibers-e.g., paper. ${ }^{152-156}$ 
Figure 2.2 - Comparison of diffuse and specular reflection

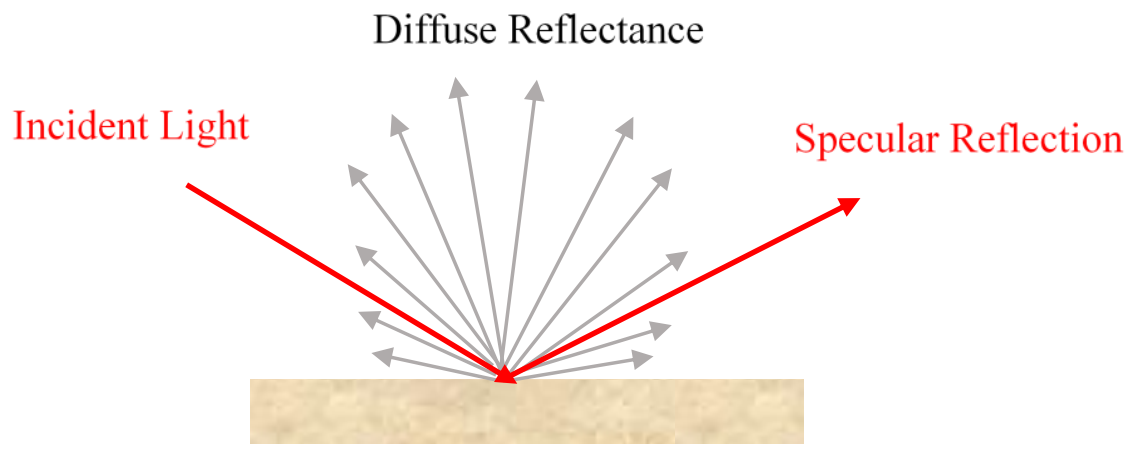

In addition to cellulose fibers, paper may consist of fillers, pigments, and additives. ${ }^{157}$

When light strikes paper, many interaction events are possible before the light ray exits the paper. Possible interaction events are shown in Figure 2.3 with explanation in text, adapted from V.

Džimbeg-Malčić et al. ${ }^{157}$

Figure 2.3 - Possible interactions between light and paper

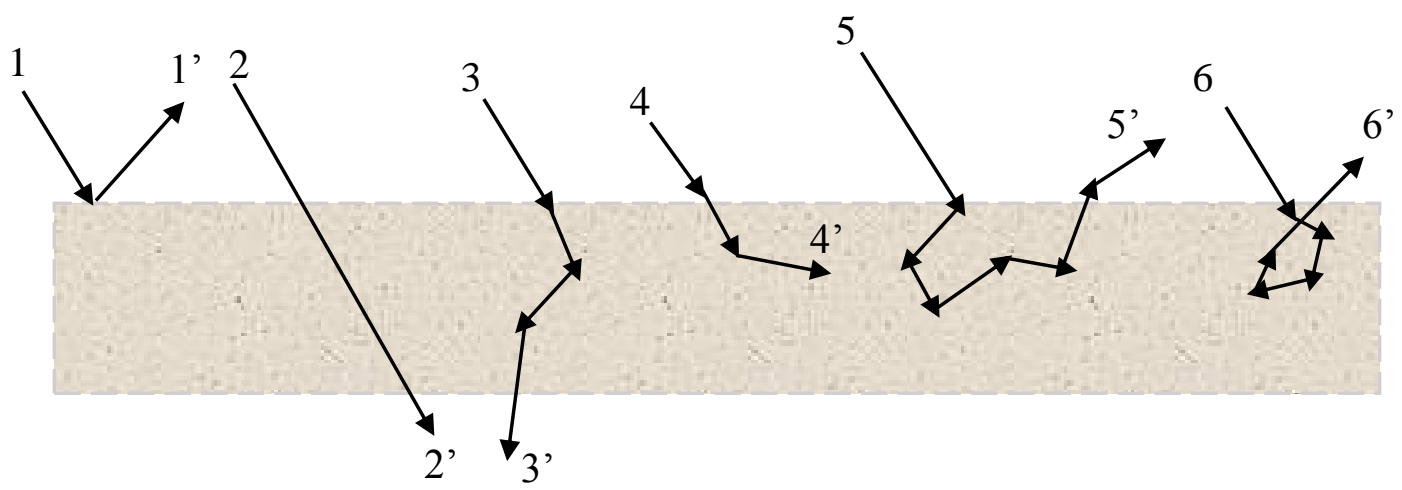

The direction of specular reflectance depends on the incident angle defined by the surface normal. The surface of paper is often rough, so there may be many "surface normals" and diffuse reflectance primarily occurs. Specular reflectance can occur, but it is rare (Ray 1,1'). Uncommon for thick paper, but possible for thinner, transparent paper, Ray 2,2' occurs when the incident 
light passes straight through the paper. For thin paper, internal scattering of the incident light may occur, and the ray may exit the opposite end, in a "diffuse transmittance" form (Ray 3,3'). Multiple light scattering events occur in the bulk of the paper. Scattering occurs several times before the light is either absorbed (Ray 4,4') or exited (Ray 5,5'), not necessarily at the incidence angle. Surface reflection occurs between an interface of two media with different refractive indexes. Internal surface reflection can occur within the paper before finally exiting (Ray 6,6'), common for glossy or smooth paper. ${ }^{157}$

Two arrangements are generally used for diffuse reflectance spectrometry. The first is an integrating sphere where the inner walls are made of a highly reflective, smooth material (e.g., PTFE or barium sulfate), which uniformly scatters the incident light over the entire surface of the sphere. ${ }^{158} \mathrm{~A}$ sample is placed within the sphere and a photodiode or fiber optic is connected to a detector port to monitor reflectance from the sample's surface. The sphere provides a $180^{\circ}$ fieldof-view to allow total collection of light reflected from the sample. ${ }^{159}$ Because integrating spheres are designed for diffuse reflectance measurements, light can be directed towards the sample at an angle of $0^{\circ}$, and the specular reflected light exits the sphere and is not detected. ${ }^{158}$ Spheres are often used for LED total light output, color, or irradiance measurements. ${ }^{160}$ Integrating spheres can be customized in a variety of configurations, and are widely available by many optical product companies.

The second arrangement for collection of diffuse reflectance is the optical fiber. Snell's Law (Equation 2.6), the theoretical basis of how the optical fiber works, states that when light travels from one material to another, it refracts (changes in direction and velocity), which depends on the incident angle $(\theta)$ relative to the normal and the refractive index (n) of the material. ${ }^{161}$ 


$$
\mathrm{n}_{1} \sin \theta_{1}=\mathrm{n}_{2} \sin \theta_{2}
$$

When light travels from a medium of high n (e.g., glass) to lower n (e.g., air), the light refracts towards the normal. This is called total internal reflection (TIR). At or above the critical angle (the angle of incidence necessary for TIR to occur) transmission is $0 \%$ and reflection is $100 \%$ (Figure 2.4). ${ }^{162}$

Figure 2.4 - Illustration of optical fiber (with permission)

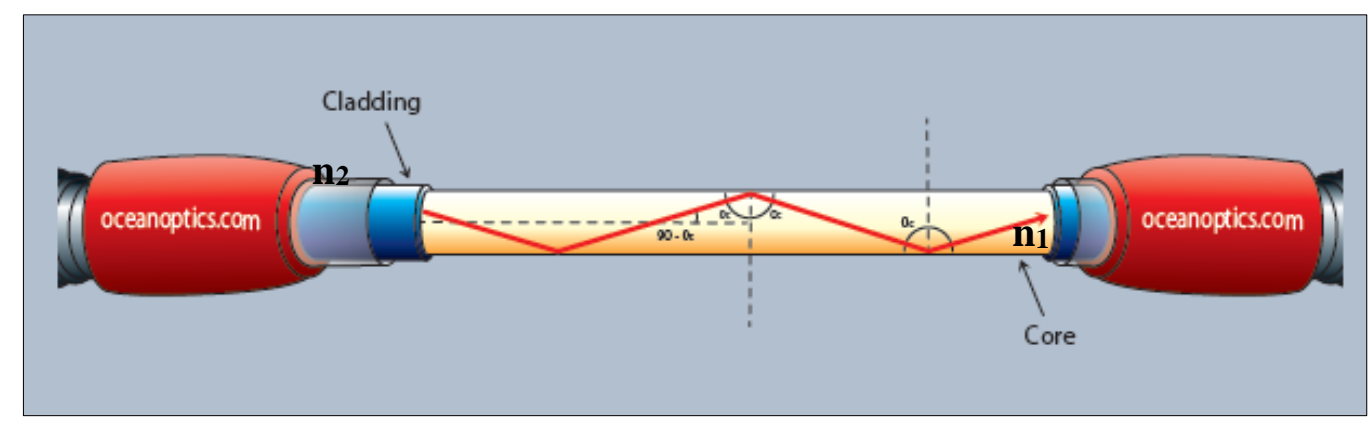

In this figure, $\mathrm{n}_{1}$ (Equation 2.5) is the refractive index of the core, while $\mathrm{n}_{2}$ is the refractive index of the fiber's cladding, which is lower than $\mathrm{n}_{1}$. The cladding, usually made of polyimide or urethane acrylate, keeps light confined to the core of the fiber (usually made of silica or plastic) and allows light to propagate down the length of the fiber without loss of energy. This is because the cladding has a lower refractive index than the glass core. Lastly, a resin coating is applied to protect against environmental factors such as humidity, and to provide overall strength to the cable.

A specific type of optical fiber used for diffuse reflectance is the bifurcated fiber optic where multiple fibers are encased in a single cable. The "six-around-one" is a popular bifurcated fiber design where six fibers direct light towards the sample, and the light reflected from the sample is directed towards the detector leg using one fiber. Bifurcated fiber optics can be used 
for directing equal amounts of light from a light source to two different locations, or from a single sample to two different detectors. ${ }^{163}$ The present research uses the common end of a bifurcated fiber to couple the sample, while the two spliced ends are individually coupled to a light source and a detector, depicted by Figure 2.5 .

Figure 2.5 - Bifurcated optical fiber

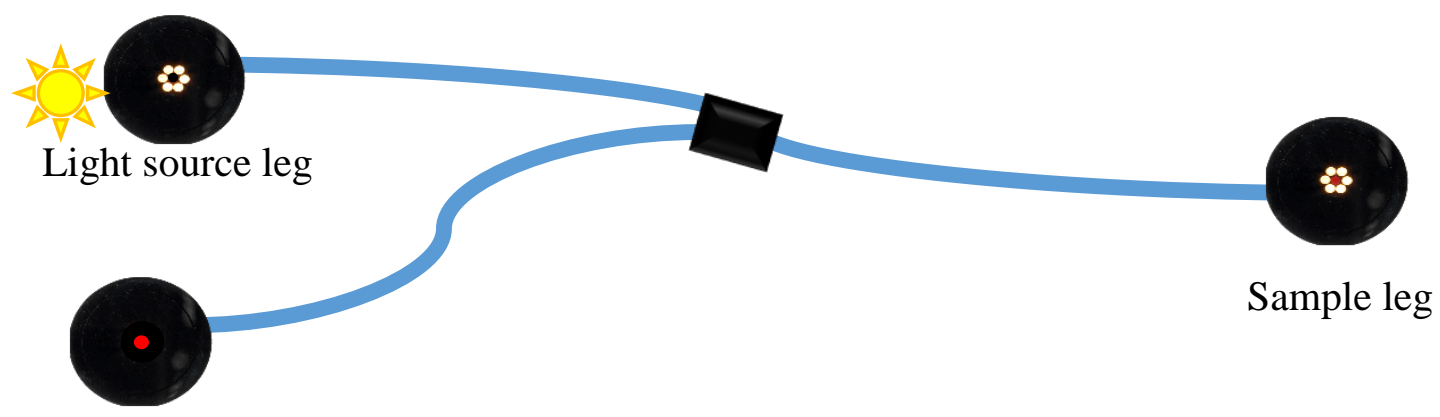

Detector leg

Materials such as beads, strips, or PVC membranes have been used to immobilize reagents at the end of a bifurcated fiber optic for sensing purposes. ${ }^{151}$ Relatively little research has been done where paper is directly coupled to the end of a bifurcated fiber optic for real-time gas-sensing applications. One example (1991) includes the detection of chlorine gas by immobilizing a reagent onto nylon tape and monitoring the change in diffuse reflectance $(\mathrm{K} / \mathrm{S}$ values) in real-time. ${ }^{164}$

In the present chemical sensor, a reflectance orientation-i.e. illumination and collection of light performed on the same side of the sample-is used to collect colored light reflected from a piece of paper. This orientation was selected to reduce the overall footprint of the design with miniaturization in forethought. A transmission orientation, which would likely be more quantitative and accurate, would require a light source and detector on opposing sides of the sample and would result in a larger footprint. The paper acts as the support medium/solid-gas 
interface for the fixed indicator (the receptor) and gaseous analyte. The paper is directly coupled to the common end of the bifurcated fiber optic (e.g., passive fiber configuration) and the chemical signals are directed to a UV-VIS spectrometer (the transducer). A general schematic of this type of chemical sensor is depicted by Figure 2.6 (adapted from Lobnik in Optical Chemical Sensors). ${ }^{165}$

Figure 2.6 - General schematic of chemical sensor

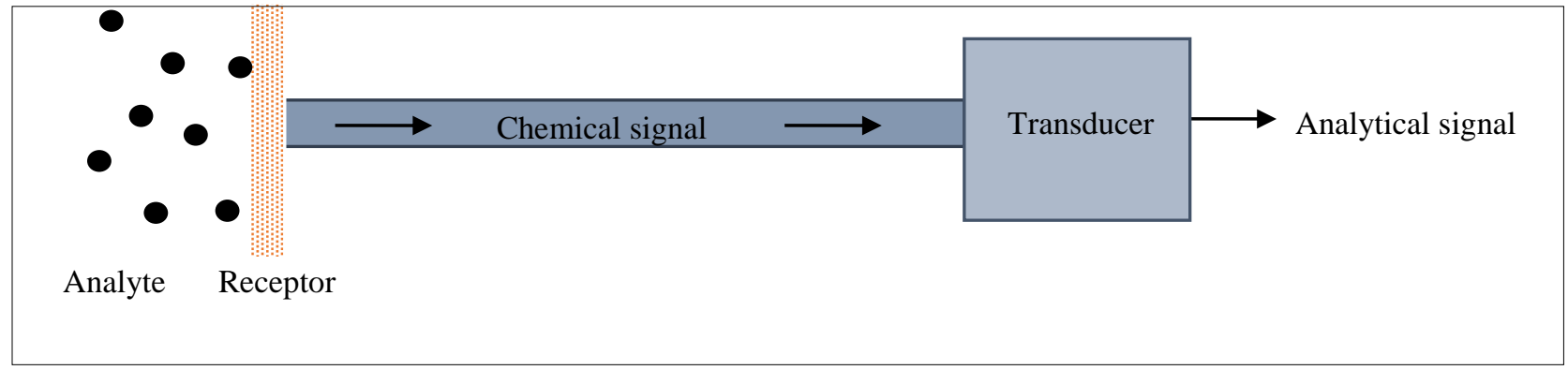

Chapters $2-4$, the chemical signals are initially processed as apparent absorbance values by the spectrometer, and further converted into diffuse reflectance values using the Kubelka-Munk equation.

\subsubsection{The Kubelka-Munk Function}

The simplest model for describing light's interaction with paper is based on the KubelkaMunk function. ${ }^{157}$ The model was initially developed in 1931 for the paper industry, and is widely used today for paper optics, printed paper, paper coatings, food science, paints, plastics, wood, and textiles. ${ }^{166,167,168,156,}$, The model is commonly used for data processing with infrared spectroscopy, including fourier transform infrared spectroscopy (FTIR) and diffuse reflectance infrared fourier transform (DRIFT), along with fiber optic-based detection systems. ${ }^{156,167,169-171}$ The Kubelka-Munk function is the most common approach to interpret diffuse reflectance. The function assists in extracting the absorption properties of a sample from reflected light and makes the data comparable to that of its transmittance counterpart. ${ }^{172}$ That is, the model is used to relate 
the intensity of bands in the reflectance spectrum with the concentration of the analyte, similar to Beer's Law which uses absorbance rather than reflectance. ${ }^{170}$ A comparison between reflected and transmitted light can be seen in Figure 2.7a and Figure 2.7b, respectively, where $\mathrm{I}_{\mathrm{o}}$ is incident light, $\mathrm{I}_{\mathrm{r}}$ is reflected light, and $\mathrm{I}_{\mathrm{t}}$ is transmitted light.

Figure 2.7 - Reflected and transmitted light

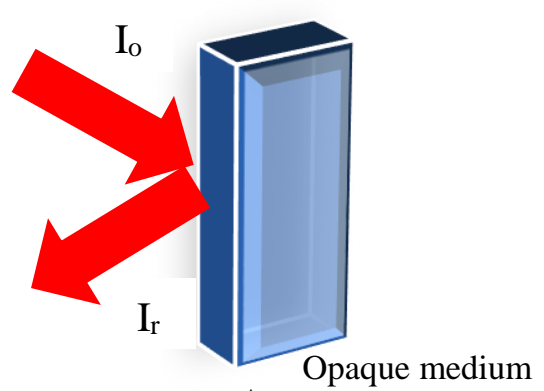

A

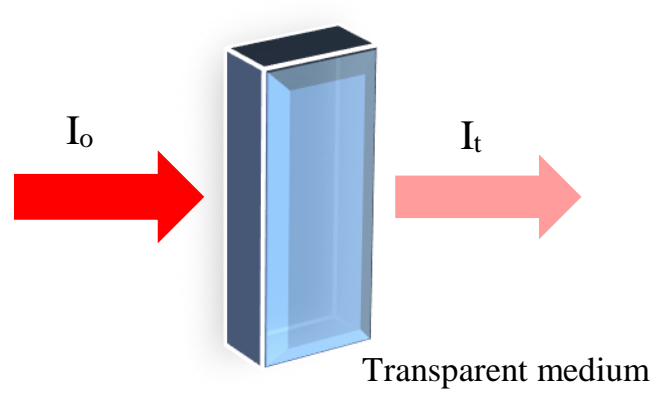

B

The Kubelka-Munk equation correlates the remission function $(\mathrm{F}(\mathrm{R}))$ with the concentration of the species (c) as a linear relationship. The Kubelka-Munk equation can be seen in Equation 2.6. Many resources are available that focus on the derivation of the Kubelka-Munk function but is not within the scope of this summary; readers interested should look elsewhere. ${ }^{157,166,172,173}$

$$
\begin{aligned}
& F(R)=\frac{(1-R)^{2}}{2 R}=\frac{\varepsilon c}{S}=\frac{K}{S} \\
& R=10^{-A}
\end{aligned}
$$

where $\mathrm{R}$ is reflectance, $\mathrm{K}$ is the absorption coefficient, $\mathrm{S}$ is the scattering coefficient, $\varepsilon$ is the molar absorptivity of species, and $\mathrm{c}$ is the concentration of the species. ${ }^{151}$ As can be seen by Equation 2.7, $\mathrm{F}(\mathrm{R})$ is directly related to sample concentration, much like absorbance is related to sample concentration in Beer's Law. Absorbance values (A) can be converted to reflectance (R) by Equation 2.7. A higher value of $\mathrm{K}$, in units of $1 / \mathrm{mm}$, means that a photon has a higher probability of being absorbed. ${ }^{157}$ The scattering coefficient, also in units of $1 / \mathrm{mm}$, describes the 
direction change of scattering when light interacts with paper. The scattering coefficient can be obtained from the slope of a plot against material thickness. ${ }^{166}$ It is assumed that bulk materials have infinite lateral dimensions. This assumption allows the horizontal light flux to be ignored and only upwards and downwards directions are of interest, as portrayed by the two-flux model in Figure 2.8. ${ }^{157}$ The substrate with reflectance R, can be divided into a series of layers with equal thickness $(\mathrm{dx})$. The incident light traveling downwards is denoted $\mathrm{I}_{\mathrm{o}}$, where the reflected light travels upward, donated by $\mathrm{J}_{\mathrm{r}}$. Reflectance can be defined as $\mathrm{J}_{\mathrm{r}} / \mathrm{I}_{0}$.

Figure 2.8 - Two flux model of Kubelka-Munk function

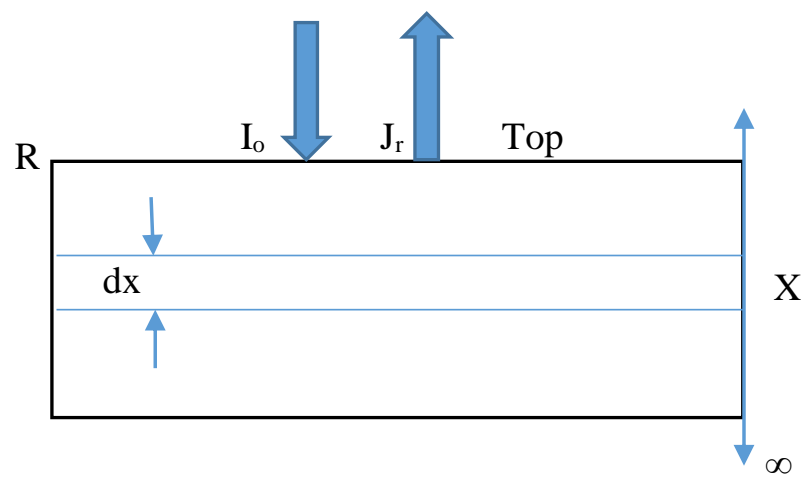

The Kubelka-Munk function is applied to variety of analytes and detector orientations, and is often plotted as $\mathrm{K} / \mathrm{S}$ or $\mathrm{F}(\mathrm{R})$ vs. wavelength $(\lambda), \lambda^{-1}, \% \mathrm{R}$, and concentration (termed a KubelkaMunk plot). ${ }^{167,170,171,174,175}$

The Kubelka-Munk equation is based on several assumptions. The first is that the material under consideration is of infinite thickness. ${ }^{157}$ This assumption means that a further increase in thickness of the media would cause no change in reflectance. ${ }^{166}$ The second assumption is that a perfectly diffuse illumination hits the surface of the sample. ${ }^{157}$ The third assumes that the only interactions of light with the sample are scattering and absorption (polarization and fluorescence are ignored). ${ }^{157}$ The fourth assumption is that the sample is homogenous, containing particles that are small compared to the thickness of the paper, and able 
to disperse light. The fifth assumption is that no external or internal surface reflections occur. ${ }^{157}$ The last assumption is that parameters $\mathrm{S}$ and $\mathrm{K}$ are constant independent of the sample layer thickness. $^{157}$

The intrinsic characteristics of paper when used as the sample medium prevent paper to satisfy all of the assumptions, though the model remains the most used in practice. General shortcomings include the misinterpretation of S and K since they are mutually dependent and the vague definition of measuring reflectance. ${ }^{166}$ Other limitations of the model include imprecision when strongly absorbing media (i.e. heavily dyed media) interact with light. The second assumption thus becomes invalid. Revisions have been proposed for the Kubelka-Munk model, including more accurately describing the effects of internal scattering of light within the medium and applying the model to optically inhomogeneous samples. ${ }^{176,177}$ Nonlinearity of KubelkaMunk plots can be attributed to the absorption by the matrix and specular reflection from the sample surface. ${ }^{174}$ Methods have been performed to eliminate specular reflectance, mostly by polarization. ${ }^{178-180}$ There is also a complex dependence of the model with particle size. An increase in particle size decreases the value K. Light penetrates deeper into the sample and increases the absorbance. ${ }^{166}$

Although the Kubelka-Munk function provides only an estimate to relate reflectance signals to absorbance, it is the most commonly used approach and best approximation for diffuse reflectance from materials such as paper. The function will be used here as a proxy for absorbance data, with limitations considered for both the sensor medium and mathematical function. 


\subsection{Materials}

Aquohydroxocobinamide ([OH( $\left.\left.\mathrm{H}_{2} \mathrm{O}\right) \mathrm{Cbi}\right]$, $\left.\mathrm{Co}(\mathrm{III})\right)$ was synthesized through acid hydrolysis from hydroxocobalamin and donated from Gerry Boss at the University of California, San Diego. ${ }^{116}$ The purity of $\mathrm{OH}\left(\mathrm{H}_{2} \mathrm{O}\right) \mathrm{Cbi}$ is reported to be $>98 \%$ and assessed by conversion of $\mathrm{OH}\left(\mathrm{H}_{2} \mathrm{O}\right) \mathrm{Cbi}$ to $(\mathrm{CN})_{2} \mathrm{Cbi}$ (with excess $\mathrm{KCN}$ in the solvent) and elution as a single peak by HPLC on a reversed-phase column. Results were also compared spectrophotometrically to reported values. ${ }^{12,181}$ Potassium cyanide $(\mathrm{KCN})$ was purchased from Fisher Scientific (granular; certified ACS) and was dissolved in $1 \mathrm{M}$ sodium hydroxide ( $\mathrm{NaOH}$, Fisher Scientific; certified). Stock HCN gas was purchased from Butler Gas (Pittsburgh) at a concentration of $495.0( \pm 2 \%)$ ppm balanced in clean, dry air. Two different types of filter paper were used as the support media: Fisherbrand ${ }^{\circledR}$ P8 Qualitative filter paper (200 $\mu \mathrm{m}$ thick, $20-25 \mu \mathrm{m}$ particle retention) and Gelman Sciences A/E Borosilicate Glass fiber filter paper (binder-free, $330 \mu \mathrm{m}$ thick, $1 \mu \mathrm{m}$ pore size). Deionized water (18 M $\Omega-\mathrm{cm})$ was from an in-line water system (Thermo Scientific Micropure). Diluent air used in the gas flow system was compressed house air which filters $100 \%$ oil (aerosol, liquid, vapor). ${ }^{182}$

\subsection{Experimental Setup and Methods}

\subsubsection{Preparation of Cobinamide Solution}

A bench-top UV-VIS spectrometer (Thermo Scientific Evolution 300) was used to determine the concentration of cobinamide stock solutions using a molar extinction coefficient of $10450 \mathrm{M}^{-1} \mathrm{~cm}^{-1}$ at $583 \mathrm{~nm} .{ }^{112}$ To prepare stock solutions of cobinamide, a small amount (2-4 mg) of solid aquohydroxocobinamide was weighed and diluted in deionized water. The concentration of dicyanocobinamide $\left[\left(\mathrm{CN}_{2}\right) \mathrm{Cbi}\right]$ was determined using the molar extinction coefficient at 583 nm when excess KCN was added to the aqueous aquohydroxocobinamide solution in a cuvette. 
The original concentration of aquohydroxocobinamide was back calculated from these results. As explained in Chapter 1, a more rapid and distinct spectral change occurs upon $\mathrm{CN}^{-}$binding when the reagent is monocyanocobinamide $\left[\mathrm{CN}\left(\mathrm{H}_{2} \mathrm{O}\right) \mathrm{Cbi}\right]$ than when starting with either diaquacobinamide or aquohydroxocobinamide. The binding of one cyanide ion to $\mathrm{OH}\left(\mathrm{H}_{2} \mathrm{O}\right) \mathrm{Cbi}$ was accomplished by incubating equimolar amounts of $\mathrm{OH}\left(\mathrm{H}_{2} \mathrm{O}\right) \mathrm{Cbi}$ and $\mathrm{KCN}$ overnight at 4 degrees Celsius $\left({ }^{\circ} \mathrm{C}\right)$. After equilibration, efficiency of $\mathrm{CN}^{-}$loading to $\mathrm{Cbi}$ should be $>99 \%$ due to the high binding affinity. $\mathrm{CN}\left(\mathrm{H}_{2} \mathrm{O}\right)$ Cbi stock solutions were diluted in deionized water and used for fixing onto the paper substrates.

\subsubsection{Preparation of Cbi Sensor Substrate}

Both types of filter paper were cut into uniform $6.0 \pm 0.5$ millimeter $(\mathrm{mm})$ diameter circles using a standard hole punch (accuracy found from the International Standards Organization Standard 838). ${ }^{183}$ The optimal concentration of $\mathrm{CN}\left(\mathrm{H}_{2} \mathrm{O}\right) \mathrm{Cbi}$ to pipette onto the paper substrate was found to be $50.0 \mu \mathrm{M}$, leading to approximately 0.9 micrograms $(\mu \mathrm{g})$ $\mathrm{CN}\left(\mathrm{H}_{2} \mathrm{O}\right)$ Cbi per paper. This concentration produced a diffuse reflectance spectrum with a high signal to noise $(\mathrm{S} / \mathrm{N})$ ratio without being too concentrated, which would result in lower sensitivity in detecting small changes of the reflectance spectrum.

The optimal volume of $\mathrm{CN}\left(\mathrm{H}_{2} \mathrm{O}\right) \mathrm{Cbi}$ placed onto the paper circles was $15.00 \pm 0.02$ microliters $(\mu \mathrm{L})$, which completely wicked over the surface of the paper without oversaturating and leaving $\mathrm{CN}\left(\mathrm{H}_{2} \mathrm{O}\right) \mathrm{Cbi}$ residue outside the paper. This volume was appropriate because the paper substrates were able to completely dry in a reasonable amount of time (1 hour).

$\mathrm{CN}\left(\mathrm{H}_{2} \mathrm{O}\right) \mathrm{Cbi}$ was manually pipetted onto the center of each piece of paper. The $\mathrm{CN}\left(\mathrm{H}_{2} \mathrm{O}\right)$ Cbi solution diffused uniformly over the paper substrate. After application of $\mathrm{CN}\left(\mathrm{H}_{2} \mathrm{O}\right) \mathrm{Cbi}$, individual pieces of paper were allowed to dry by placing each on top plastic 
pipettes so that the center of the papers - where the fiber optic was fixed directly below - were unaffected. The paper dried fully at room temperature $\left(\sim 21^{\circ} \mathrm{C}\right)$ after $\sim$ one hour. Prior to this setup, the glass fiber filter papers were placed on aluminum or glass weigh dishes to dry. Paper residue and excess Cbi was left behind on the dishes. This was not the case for cellulose filter paper (most likely due to the addition of binders). For uniformity, both cellulose and glass filter paper were placed on top of the pipettes to dry (Figure 2.9).

Figure 2.9 - Filter paper drying arrangement

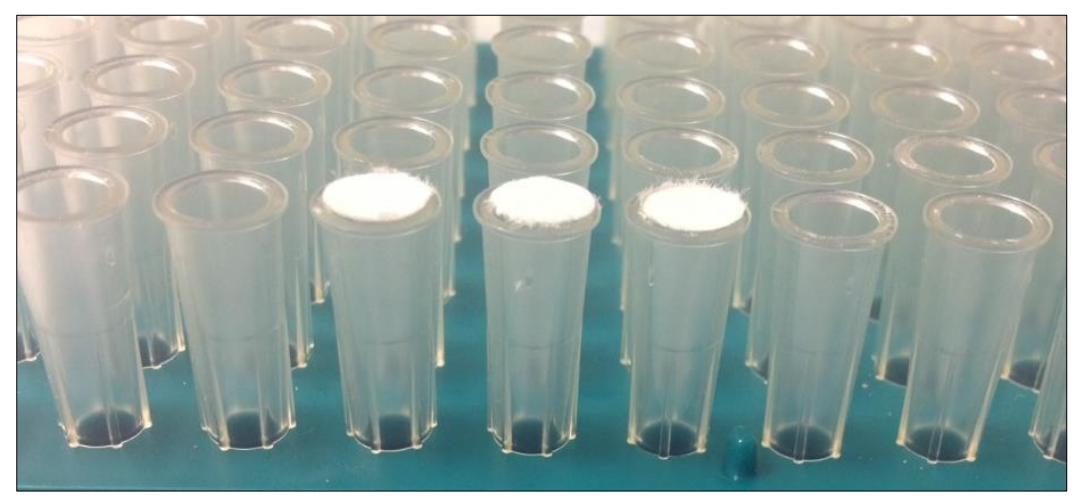

For observation of the $\mathrm{CN}\left(\mathrm{H}_{2} \mathrm{O}\right) \mathrm{Cbi}$ response at various \%RH, some Cbi-spotted paper samples were incubated at their respective $\% \mathrm{RH}$ for 4 hours at $21.0^{\circ} \mathrm{C}$ using an environmental chamber (Caron Model 6010-1) prior to the experiment.

Entire pieces of paper were soaked in $50.0 \mu \mathrm{M} \mathrm{CN}\left(\mathrm{H}_{2} \mathrm{O}\right) \mathrm{Cbi}$ solution with the attempt to increase uniformity across the individual paper pieces. However, this method created greater uncertainty on the final amount of $\mathrm{CN}\left(\mathrm{H}_{2} \mathrm{O}\right)$ Cbi on each piece of paper as well as resulting in more waste of the $\mathrm{CN}\left(\mathrm{H}_{2} \mathrm{O}\right)$ Cbi solution as it took approximately $2 \mathrm{~mL}$ to cover the entire piece of filter paper. 


\subsubsection{Sensor Holder}

The custom-made sensor holder was designed to securely hold a $6.0 \mathrm{~mm}$ diameter paper circle. Each monocyanocobinamide pre-spotted paper circle was inserted into the holder that was constructed of black, Delrin ${ }^{\circledR}$ acetal homopolymer. Acetal was chosen as a thermoplastic because it will not degrade when exposed to low concentrations of HCN gas. ${ }^{184} \mathrm{~A} 12.7 \mathrm{~mm}$ in diameter mirror (Thor Labs BB05-E02) was incorporated into the screw-top lid at the top of the holder, above the paper circle, to ensure maximum light was reflected and collected by the detector. Two holes in each side of the holder allowed $\mathrm{HCN}$ to flow above the paper without disturbing it.

Figure 2.10a depicts a top-down view of the paper circle inserted into the holder. Figure 2.10b is a side-view of the holder with the lid on top and bifurcated fiber optic connected to the bottom, directly underneath the paper circle. Figure $2.10 \mathrm{c}$ is a three-dimensional (3D) rendering of an initial prototype of the holder (lacking the second flow-through hole, which was added later). The sensor holder dimensions can be seen in Figure A.1 and Table A.1 (Appendix), with measurements in $\mathrm{mm}$. 
Figure 2.10 - Top down view of sensor holder (A), side view with bifurcated fiber optic (B), and $3 \mathrm{D}$ rendering of inside sensor holder (C)
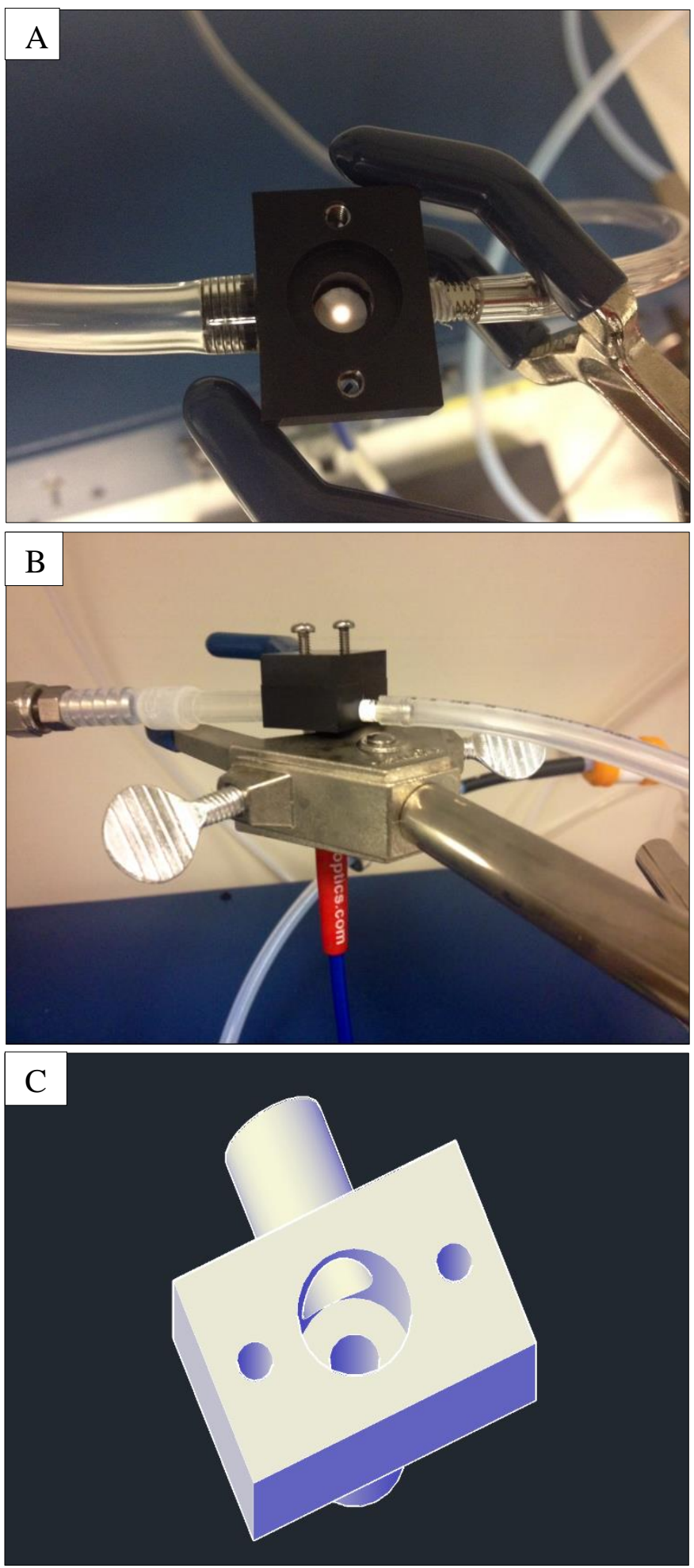


\subsubsection{Diffuse Reflectance Instrumentation}

An Ocean Optics USB4000 UV-VIS-ES miniature spectrometer (200-850 nm, optical resolution of $1.4 \mathrm{~nm}$ full width at half maximum) was used for diffuse reflectance measurements. The common end of a bifurcated fiber optic (Ocean Optics ${ }^{\circledR}$, core diameter $600 \mu \mathrm{m}$, fused silica) was connected (via SMA connector) to the bottom of the holder directly under the filter paper. The bifurcated fiber has a numerical aperture of 0.22 , translating into an acceptance angle of $12.7^{\circ}\left(25.4^{\circ}\right.$ full angle). The light from the fiber optic diffuses over the paper surface. The two distal branches of the fiber were connected to a tungsten halogen light source (Ocean Optics ${ }^{\circledR}$ LLS, 215-2500 nm) and a miniature USB Ocean Optics ${ }^{\circledR}$ UV-VIS-ES spectrometer, respectively. The spectrometer was controlled by Ocean Optics ${ }^{\circledR}$ software, Oceanview. After acquiring a reference spectrum (blank piece of paper) and dark reference spectrum (light source blocked at origin), the software converts data into apparent absorbance in real-time. The software also allows averaging data over a wavelength range and monitoring the apparent absorbance over time (referred later to as "trends"). Average of values from 700 to 750 were used as the reference for all experiments.

\subsubsection{Gas Flow System}

The experimental setup is illustrated in Figure 2.11. Three mass flow controllers (MFCs; Alicat Scientific) regulate airflow, $\mathrm{HCN}$ concentration, and the $\% \mathrm{RH}$ based on air passing through a water bubbler. The accuracy and repeatability of the MFCs (reported by the manufacturers) are $\pm 1.0 \%$ and $\pm 0.2 \%$ of full scale, respectively. $\mathrm{HCN}$ gas from the cylinder was diluted with compressed air to the desired HCN concentration (1.0-10.0 ppm), and the final concentration was verified using an electrochemical detector (Interscan ${ }^{\circledR}$ Model RM, 0-50.0 \pm $0.1 \mathrm{ppm})$. Prior the start of each experiment, the $\% \mathrm{RH}$ was measured with a humidity sensor. 
Experiments were performed at a carrier gas flow rate of $1.00 \pm 0.01$ liter per minute (LPM) at $25 \% \mathrm{RH}$ (unless otherwise specified) at room temperature. A concentration of $1.0 \mathrm{ppm}$ was the lowest concentration at which an accurate dilution could be obtained. All tubing was made of Teflon (polytetrafluoroethylene, PTFE) material.

Figure 2.11 - Schematic of the experimental setup for $\mathrm{HCN}$ gas exposure

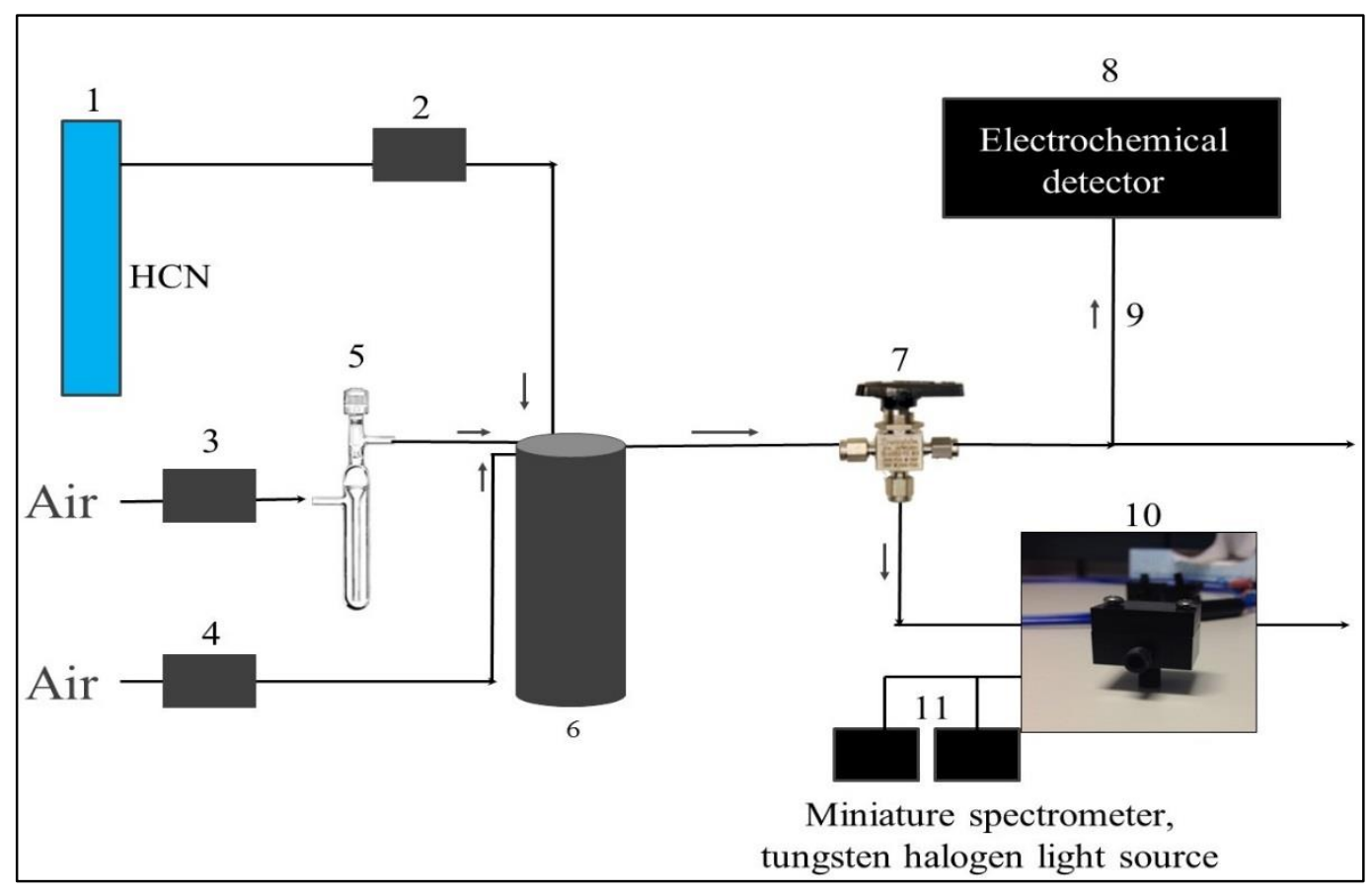

1. Stock HCN $(495 \pm 2 \%$ ppm). 2. MFC $1(0.000-1.000 \pm 0.8 \%$ LPM $)$. 3. MFC $2(0.00-$ $10.00 \pm 0.8 \%$ LPM $) .4$. MFC $3(0.00-10.00 \pm 0.8 \%$ LPM $) .5$. Water bubbler for $\%$ RH control. 6. $1 \mathrm{~L}$ gas mixing vessel. 7. 3-way valve. 8. Interscan ${ }^{\circledR} \mathrm{HCN}$ electrochemical detector $\left(0.0-50.0 \mathrm{ppm}, \pm 2 \%\right.$. 9. Interscan ${ }^{\circledR}$ draws air at 0.5 LPM. 10. Sensor holder. 11 . Ocean Optics ${ }^{\circledR}$ miniature USB spectrometer and light source.

\subsubsection{System Optimization}

\section{Instrument}

The integration time for an individual scan was selected to give a signal $85 \%$ of the spectrometer's saturation level (limited by the $\mathrm{A} / \mathrm{D}$ converter to $65 \mathrm{k}$ counts). The number of scans-to-average was chosen to improve $\mathrm{S} / \mathrm{N}$, which improves with the square root to the number 
of averages taken. ${ }^{185}$ The boxcar width reduces noise from the spectrum. The boxcar value of 5 will average an additional 5 pixels on each side (10 total) and assigns that average to the center pixel. For the glass fiber filter paper, which was thicker than the cellulose paper and allowed more light to be reflected back to the detector, the integration time was set to $300 \mathrm{~ms}$ with a boxcar width and scans-to-average set to 5. Apparent absorbance was converted to reflectance by Equation 2.8 to be used with the Kubelka-Munk function, Equation 2.7.

Flow

The flow rate over the paper was set to $1.00 \pm 0.01 \mathrm{LPM}$ to avoid backpressure build-up in the sensor holder. This flow rate has no correlation to the airflow through a respirator carbon bed, but was chosen to focus on studying the binding between $\mathrm{HCN}$ and $\mathrm{CN}\left(\mathrm{H}_{2} \mathrm{O}\right) \mathrm{Cbi}$. As previously stated, three MFCs were used to control the appropriate ratio of dry air, humidified air, and concentrated $\mathrm{HCN}$ to yield the flow rate, desired concentration, and \%RH. Each MFC was controlled via RS-232 interface with a computer and Alicat Scientific ${ }^{\circledR}$ software, Flow Vision SC 1.1.44.0. Using this software, the user can add up to six MFCs and easily set the desired flow for each MFC. Each MFC has an LED display screen, which represents the display function of the instrument including the flow set point, temperature, and pressure (Figure 2.12). 
Figure 2.12 - MFCs used for HCN gas-flow

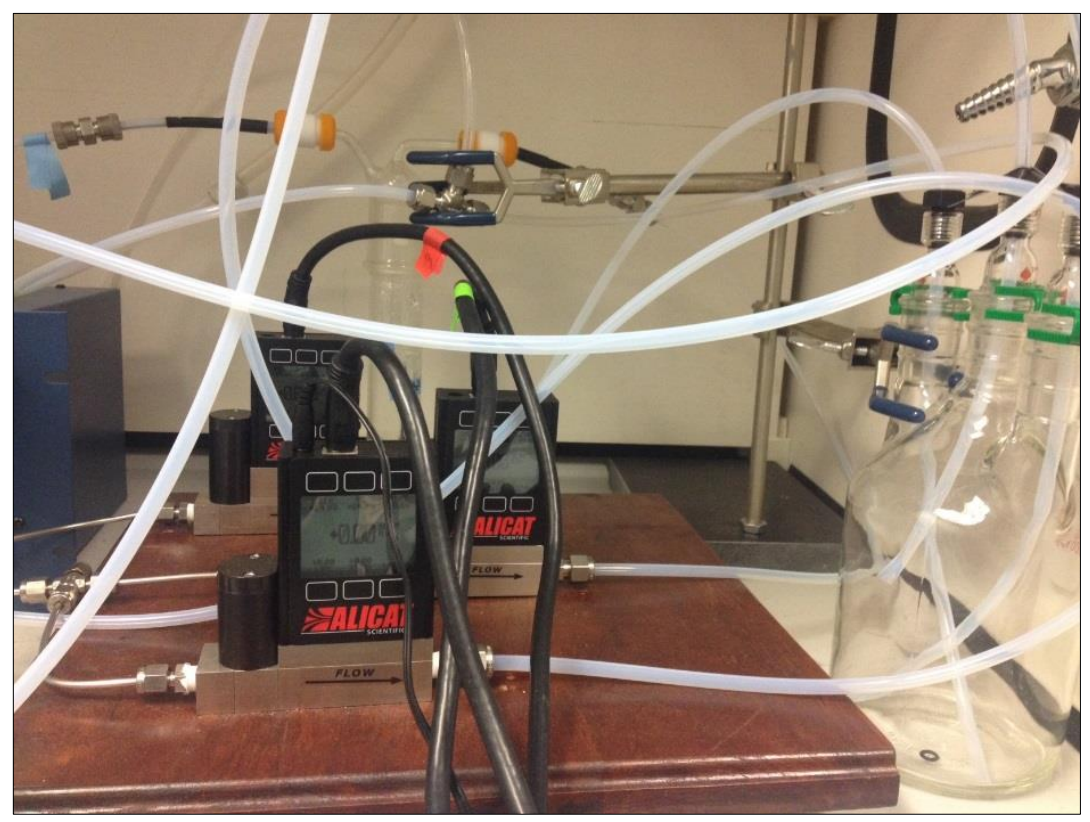

The following dilution calculations (displayed in Table 2.2) were used for each MFC where flow is in LPM, desired total flow is $1.00 \mathrm{LPM}$, and HCN concentration is in ppm:

Table 2.2 - MFC Calculations

\begin{tabular}{|c|c|c|}
\hline MFC \# & Purpose & Equation \\
\hline 1 & Control dry air & Desired total flow - MFC2 \\
\hline 2 & $\begin{array}{c}\text { Control air going to } \\
\text { bubbler (\%RH) }\end{array}$ & Desired total flow x (desired \% RH / maximum \%RH) \\
\hline 3 & Control HCN flow & $\begin{array}{c}\text { (MFC1 + MFC2) } \mathrm{x} \text { (desired HCN concentration/stock } \\
\text { HCN concentration) }\end{array}$ \\
\hline
\end{tabular}

The system was initially flushed with compressed air at the desired \%RH (no $\mathrm{HCN}$ ) for 1-2 hours before each experiment. The system was evaluated by the electrochemical detector to ensure a reading of $0.0 \mathrm{ppm} \mathrm{HCN}$. A blank paper circle was then placed in the holder. The reflectance signal from the blank was defined as $100 \%$ reflectance at each wavelength. A piece of $\mathrm{CN}\left(\mathrm{H}_{2} \mathrm{O}\right)$ Cbi-immobilized paper was then placed in the holder. The paper circles were allowed 
to equilibrate with the desired $\% \mathrm{RH}$ for 30 minutes in the holder prior to beginning the experiment. In some experiments, the reflectance spectrum of $\mathrm{CN}\left(\mathrm{H}_{2} \mathrm{O}\right) \mathrm{Cbi}$-immobilized paper was designated as the "blank" when the goal was to monitor changes in the $\mathrm{CN}\left(\mathrm{H}_{2} \mathrm{O}\right) \mathrm{Cbi}$ spectrum and obtain a "difference spectrum". Initially, a three-way valve was set to allow air to flow to the HCN electrochemical detector. Once desired HCN concentration was reached, the valve was switched to direct the air to flow over the sensor. The valve switching time was designated as the start of the experiment (i.e. $\mathrm{t}=0$ ).

The small size of the sensor holder combined with the 1.0 LPM flow rate yields a time constant of a few seconds for a step change in $\mathrm{HCN}$ concentration. The tubing from the 3-way valve to the sensor holder measured $73.7 \mathrm{~cm}$ in length. Using $1 / 4$ " diameter tubing and a flow rate of 1.0 LPM, it was theoretically calculated to take 1.4 seconds for air to get from the three-way valve to the sensor holder.

\subsubsection{Repeatability and Reproducibility of Cobinamide on Filter Paper}

30 samples of both cellulose and glass fiber paper with $15.0 \mu \mathrm{L}$ of $50.0 \mu \mathrm{M} \mathrm{CN}\left(\mathrm{H}_{2} \mathrm{O}\right) \mathrm{Cbi}$ were evaluated for their repeatability when consecutive spectra were taken. Each paper was run in triplicate and the resulting apparent absorbance spectra were averaged. Repeatability, or the "closeness of the agreement between the results of successive measurements of the same measurand carried out in the same conditions" is represented here by the percent relative standard deviation (\%RSD) where the standard deviation (S.D.) and mean were taken of the apparent absorbance or the Kubelka-Munk function $(\mathrm{F}(\mathrm{R}))$ values at $500 \mathrm{~nm}$.

Additionally, 15 samples of $\mathrm{CN}\left(\mathrm{H}_{2} \mathrm{O}\right) \mathrm{Cbi}$-immobilized glass fiber paper were evaluated for reproducibility. Reproducibility, or the "closeness of the agreement between the results of successive measurements of the same measurand, where the measurements are carried out under 
different conditions" is also represented by \%RSD but conducted using different conditions. ${ }^{186}$ Here, spectra were taken after 1, 3, and 6 months of initial Cbi-immobilized paper preparation. The samples were kept in individual vials at $4^{\circ} \mathrm{C}$ with a few $\mathrm{NaOH}$ pellets in each vial to remove excess carbon dioxide $\left(\mathrm{CO}_{2}\right)$. A table of the reproducibility plan can be seen in the Table A.2. Errors bars in all measurements (unless otherwise stated) were defined using 95\% confidence interval $(95 \% \mathrm{CI})$. A Student's t-test was conducted to determine if there was a significant difference between the fresh samples and aged paper samples. For 3 samples, a Student's t-value of 4.303 was used as the multiplier, and for 6 samples a t-value of 2.571 was used. $^{186}$ 


\subsection{Results and Discussion}

\subsubsection{UV-VIS Spectra of Cobinamide}

The absorbance spectra (using the benchtop spectrometer) of $20.0 \pm 0.2 \mu \mathrm{M}$ solutions of $\mathrm{OH}\left(\mathrm{H}_{2} \mathrm{O}\right) \mathrm{Cbi}, \mathrm{CN}\left(\mathrm{H}_{2} \mathrm{O}\right) \mathrm{Cbi}$, and $(\mathrm{CN})_{2} \mathrm{Cbi}$ are shown in Figure 2.13a. As expected, the absorbance spectra for $\mathrm{OH}\left(\mathrm{H}_{2} \mathrm{O}\right) \mathrm{Cbi}$ (red line) and $\mathrm{CN}\left(\mathrm{H}_{2} \mathrm{O}\right) \mathrm{Cbi}$ (green line) are similar, thus the changes in absorbance spectrum when trace amounts of $\mathrm{CN}^{-}$bind to $\mathrm{OH}\left(\mathrm{H}_{2} \mathrm{O}\right) \mathrm{Cbi}$ are not significant. When a second cyanide ion binds to $\mathrm{CN}\left(\mathrm{H}_{2} \mathrm{O}\right) \mathrm{Cbi}$, an absorbance peak appears at $583 \mathrm{~nm}$, absorption at 450-500 nm decreases, and an isosbestic point occurs near $531 \mathrm{~nm}$. The characteristic peak at $583 \mathrm{~nm}$ and observable color change is thus rate-limited by the first $\mathrm{CN}^{-}$ binding. Development of $(\mathrm{CN})_{2} \mathrm{Cbi}$ (blue line) occurs when excess $\mathrm{KCN}$ in $1 \mathrm{mM} \mathrm{NaOH}$ is

added to the cuvette. An observable violet color rapidly occurs upon addition of KCN (Figures $2.13 \mathrm{~b}$ and $\mathrm{c})$. 
Figure 2.13 - Absorption spectra of the three cobinamide complexes (A), $20.0 \mu \mathrm{M} \mathrm{OH}\left(\mathrm{H}_{2} \mathrm{O}\right) \mathrm{Cbi}$ (B), $20.0 \mu \mathrm{M} \mathrm{OH}\left(\mathrm{H}_{2} \mathrm{O}\right) \mathrm{Cbi}+30 \mu \mathrm{M} \mathrm{KCN}$ in $1 \mathrm{mM} \mathrm{NaOH}(\mathrm{C})$.
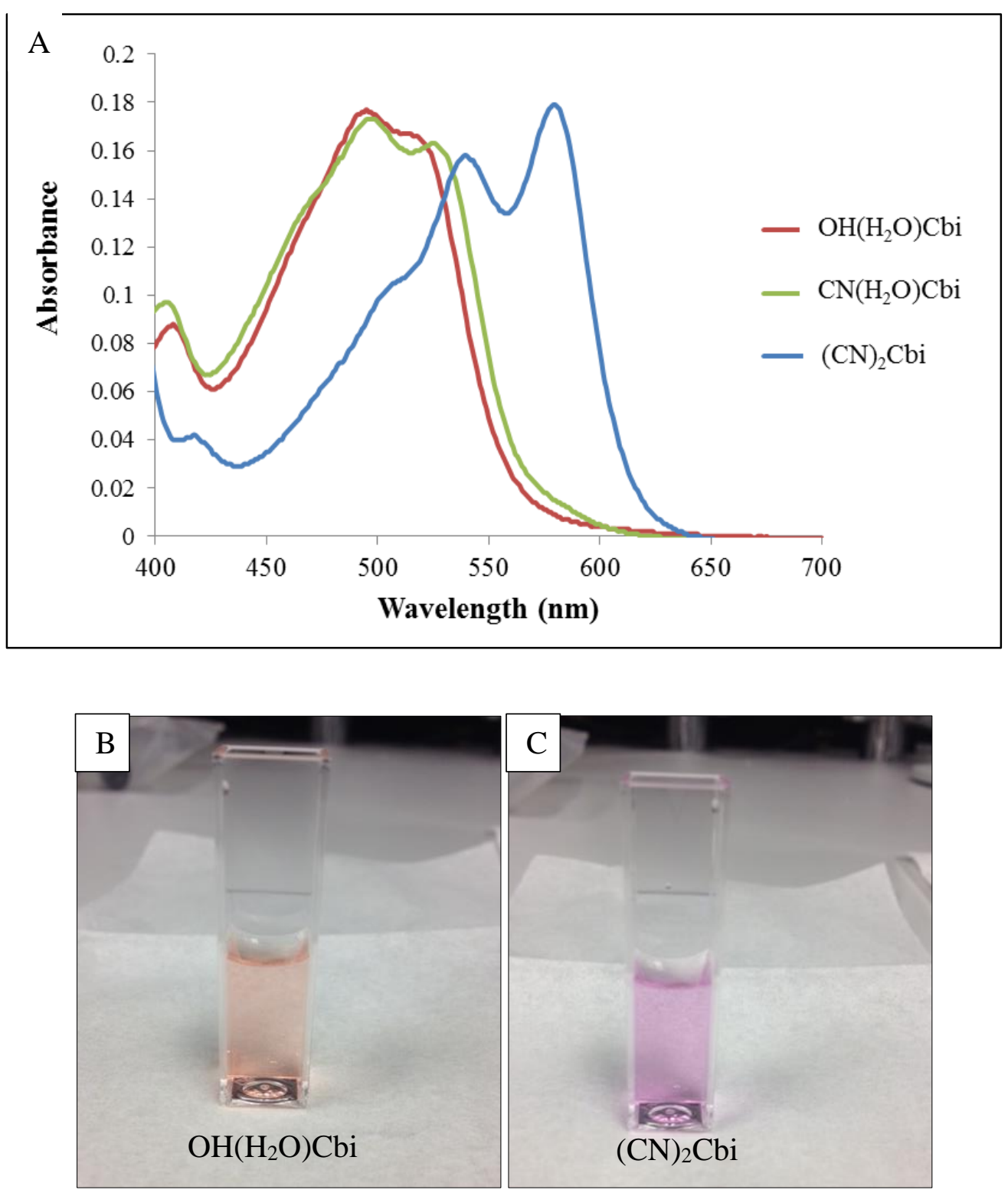

The increasing absorbance peak at $583 \mathrm{~nm}$ and simultaneous decrease in absorbance near $500 \mathrm{~nm}$ appears when incremental amounts of $\mathrm{KCN}$ are added to the $20.0 \mu \mathrm{M} \mathrm{CN}\left(\mathrm{H}_{2} \mathrm{O}\right) \mathrm{Cbi}$ solution. Addition of 5.0, 10.0, 15.0, 20.0, 25.0, and 30.0 $\mu \mathrm{M} \mathrm{KCN} \mathrm{in} 1 \mathrm{mM} \mathrm{NaOH}$ to the $\mathrm{CN}\left(\mathrm{H}_{2} \mathrm{O}\right) \mathrm{Cbi}$ solution produced the spectra shown in Figure 2.14. When the absorbance at 583 $\mathrm{nm}$ was plotted against $\mathrm{KCN}$ concentration, a linear correlation $\left(\mathrm{R}^{2}=0.9966\right)$ was observed, deviating from linearity at higher concentrations (Figure $2.15 ; \mathrm{n}=3 ; 95 \% \mathrm{CI}$ ). 
Figure 2.14 - Spectra of $\mathrm{CN}\left(\mathrm{H}_{2} \mathrm{O}\right)$ Cbi with increasing amounts of $\mathrm{KCN}$

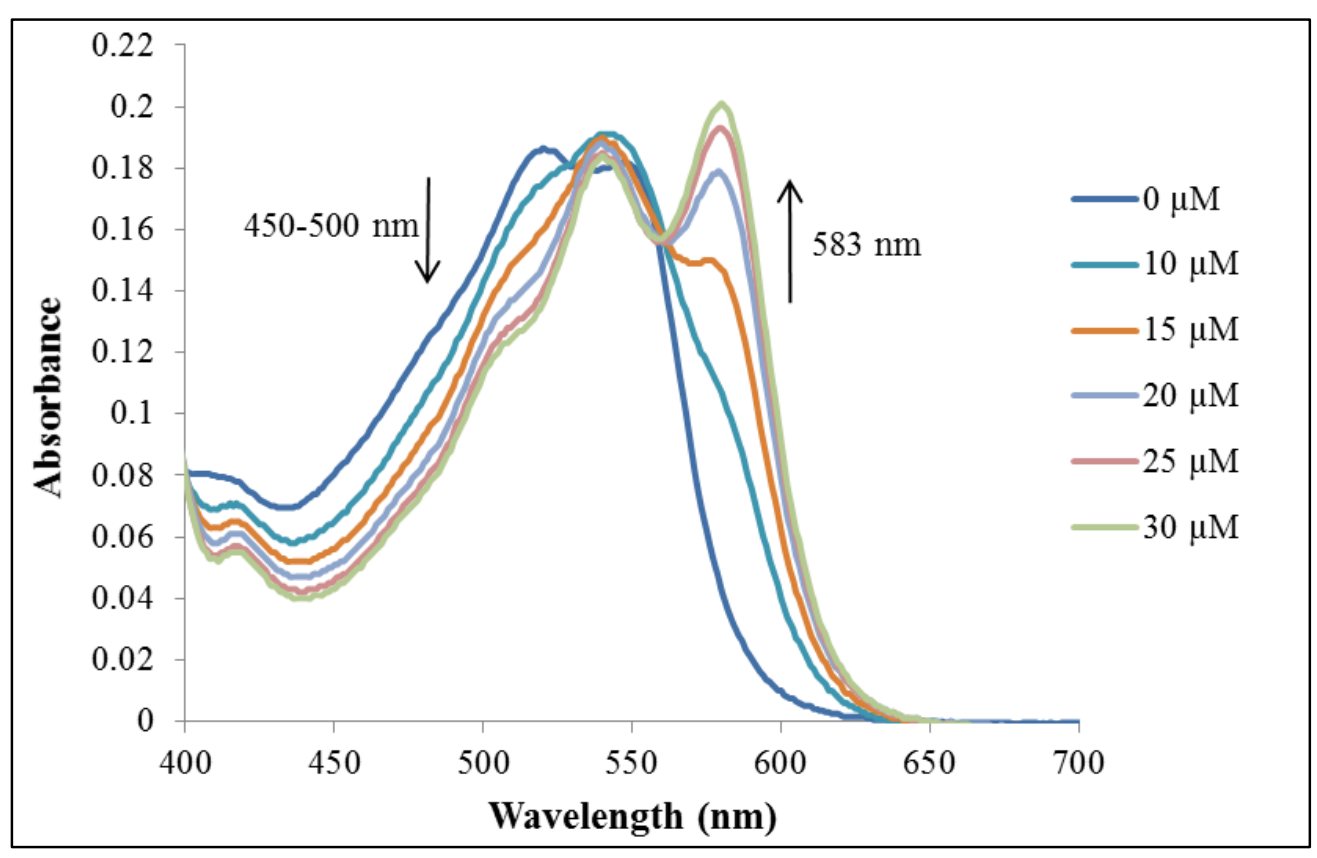


Figure 2.15 - Calibration curve for $20.0 \mu \mathrm{M} \mathrm{CN}\left(\mathrm{H}_{2} \mathrm{O}\right) \mathrm{Cbi}$ with $\mathrm{KCN}$

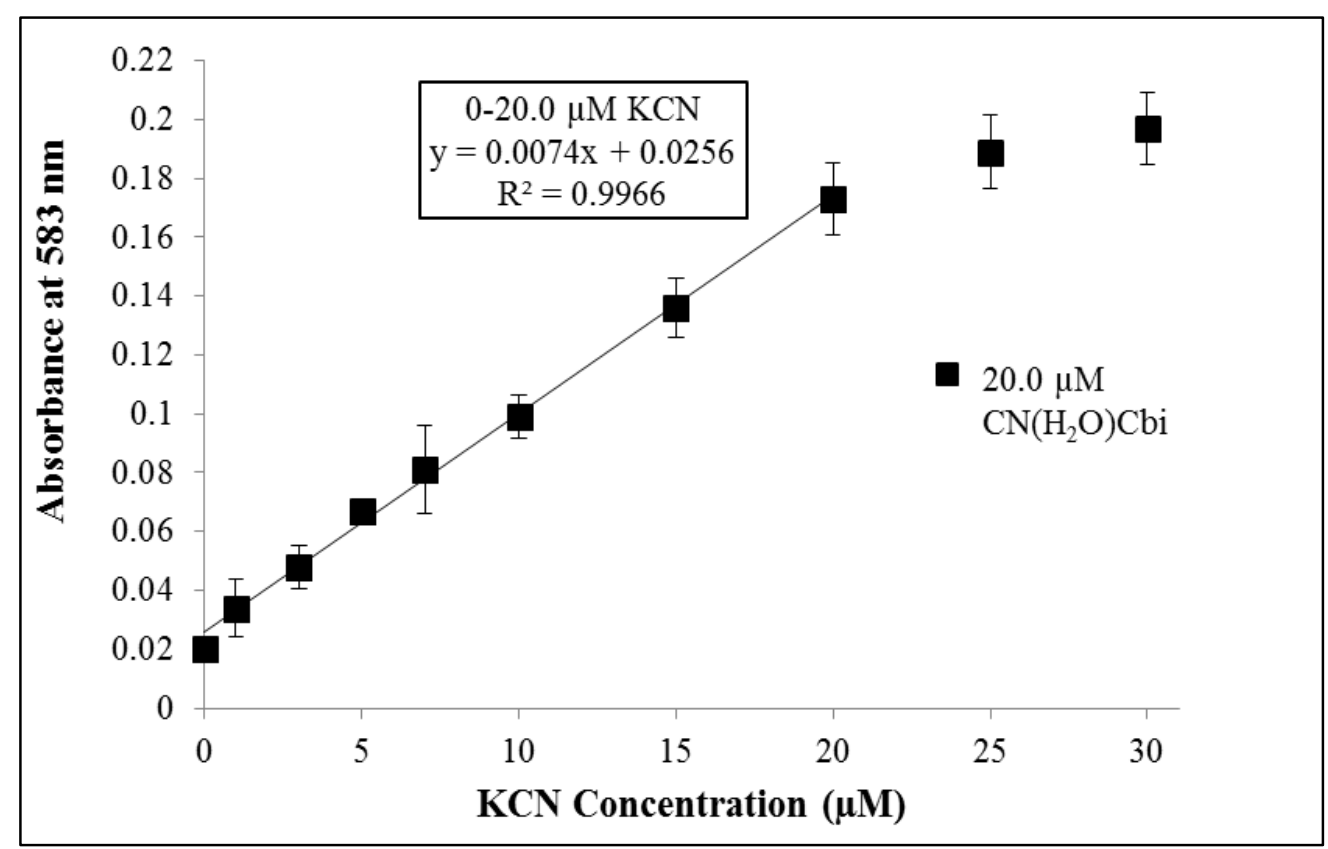

\subsubsection{Comparison of Absorbance and Diffuse Reflectance Spectra}

The absorbance spectrum of monocyanocobinamide obtained from a benchtop UV-VIS spectrometer was compared with the spectrum when $15.00 \mu \mathrm{L}$ of $50.0 \mu \mathrm{M}$

monocyanocobinamide was immobilized on a piece of filter paper. The absorbance spectrum of a $20.0 \mu \mathrm{M} \mathrm{CN}\left(\mathrm{H}_{2} \mathrm{O}\right) \mathrm{Cbi}$ solution (benchtop UV-VIS; left y-axis) was compared with the diffuse reflectance spectra (in terms of the Kubelka-Munk function) of $\mathrm{CN}\left(\mathrm{H}_{2} \mathrm{O}\right) \mathrm{Cbi}$ on both cellulose and glass fiber papers in terms of $F(R)$ (right $y$-axis) and can be seen in Figure 2.16. Both absorbance and diffuse reflectance spectra are similar with differences most likely due to intrinsic scattering from the paper. A higher $\mathrm{F}(\mathrm{R})$ value for $\mathrm{CN}\left(\mathrm{H}_{2} \mathrm{O}\right) \mathrm{Cbi}$ was observed on glass fiber paper compared to the cellulose filter paper. This could be attributed to more light being lost from transmission through the thinner, cellulose filter paper. Both pieces of paper were spiked with the same amount of $\mathrm{CN}\left(\mathrm{H}_{2} \mathrm{O}\right)$ Cbi deposited, so the difference in reflected spectra 
intensity was likely due to the greater thickness of the glass fiber paper reflecting more light back to the detector.

Figure 2.16 - Monocyanocobinamide solution spectra and diffuse reflectance spectra

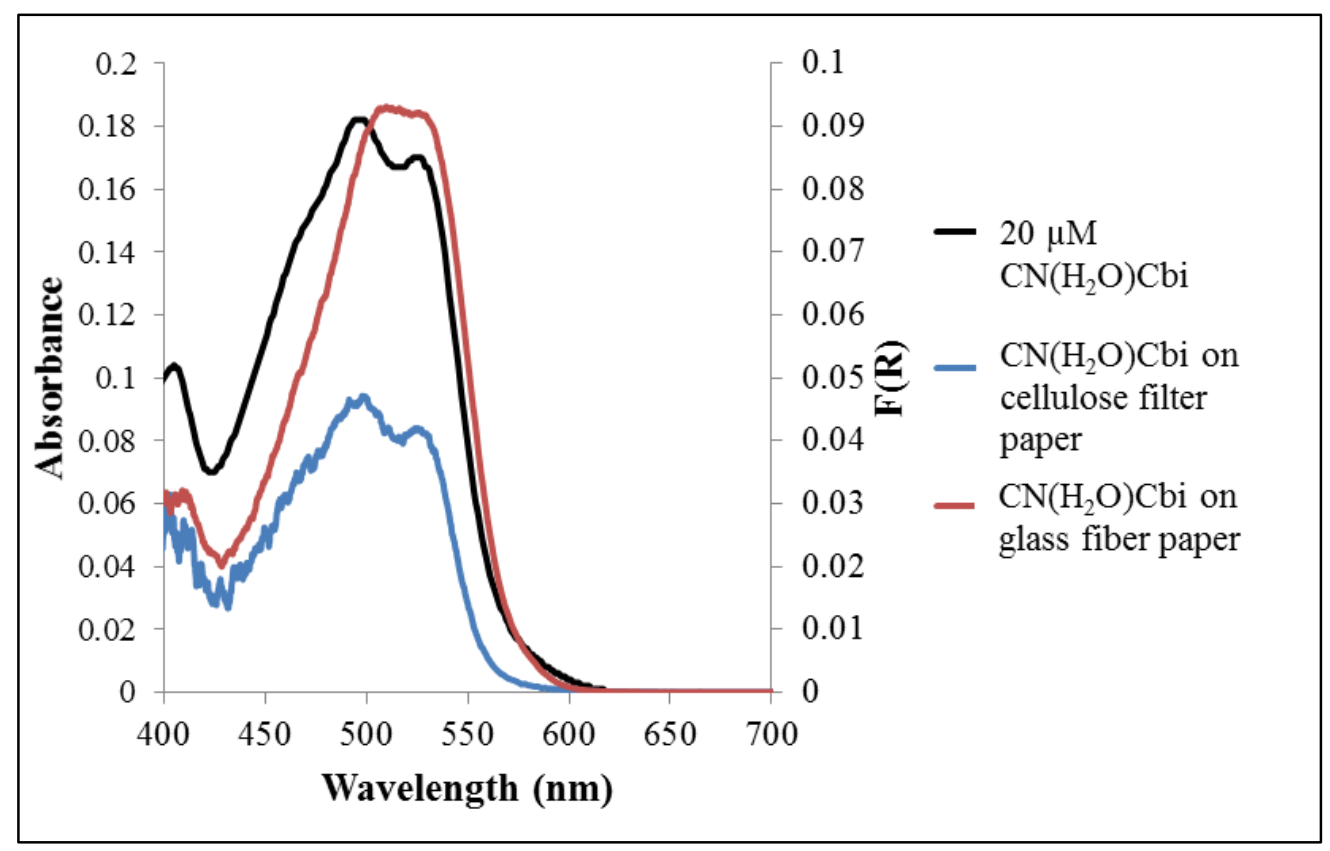

Spectral changes resulting from the conversion of $\mathrm{CN}\left(\mathrm{H}_{2} \mathrm{O}\right) \mathrm{Cbi}$ to $(\mathrm{CN})_{2} \mathrm{Cbi}$ in solution and in the gas phase on paper are also comparable. Excess $\mathrm{KCN}$ in $1 \mathrm{mM} \mathrm{NaOH}$ was added to a $\mathrm{CN}\left(\mathrm{H}_{2} \mathrm{O}\right)$ Cbi solution in a cuvette and plotted as the absorbance spectrum. Exposure of $15.0 \mathrm{ppm}$ $\mathrm{HCN}$ to a Cbi-fixed glass fiber paper for 15 minutes is plotted as diffuse reflectance. This comparison is shown in Figure 2.17. There is slight variation between the absorbance spectrum and diffuse reflectance spectrum, which is most likely attributed to scattering of light from the matte surface of paper, but the characteristic features of the dicyano complex are apparent by diffuse reflectance. Thus, substitution of the water ligand by cyanide occurs readily for the $\mathrm{CN}\left(\mathrm{H}_{2} \mathrm{O}\right) \mathrm{Cbi}$ on the paper. 
Figure 2.17 - Comparison of monocyanocobinamide solution spectra and diffuse reflectance spectra on glass fiber paper

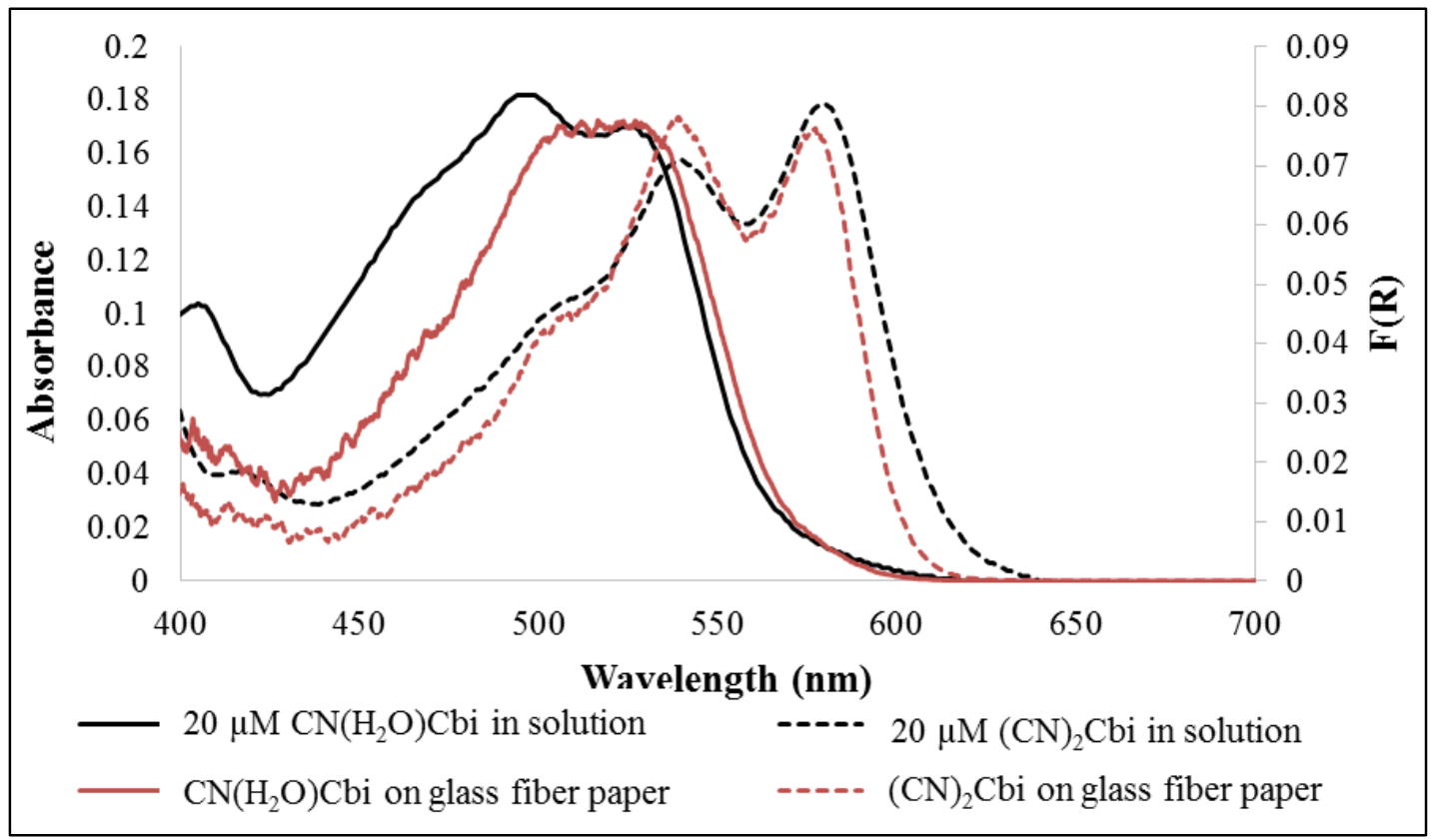

\subsubsection{Cellulose Filter Paper}

\subsubsection{Repeatability of Cobinamide on Cellulose Paper}

The average absorbance of $\mathrm{CN}\left(\mathrm{H}_{2} \mathrm{O}\right)$ Cbi on cellulose filter paper (measured at $500 \mathrm{~nm}$ ) is $0.14 \pm 0.02 \mathrm{~nm}(\mathrm{a} F(\mathrm{R})$ value equal to $0.049 \pm 0.001)$ with a $16 \% \mathrm{RSD}$. These values are based on 30 samples with \pm values calculated by sample standard deviation.

When an entire piece of cellulose filter paper was soaked in $50.0 \mu \mathrm{M} \mathrm{CN}\left(\mathrm{H}_{2} \mathrm{O}\right) \mathrm{Cbi}$ solution, a $12 \% \mathrm{RSD}$ is calculated $(\mathrm{n}=30)$. Even though a lower \%RSD is found for this technique when compared to individual paper loading, this lower value may be attributed to having a more concentrated $\mathrm{CN}\left(\mathrm{H}_{2} \mathrm{O}\right)$ Cbi paper with a larger absorbance signal (a larger denominator when calculating \%RSD). Thus (and for reasons mentioned previously), pipetting aliquots to individual pieces of paper was adopted as the loading method. 


\subsubsection{Monocyanocobinamide Detection of HCN Gas}

The $\mathrm{CN}\left(\mathrm{H}_{2} \mathrm{O}\right)$ Cbi pre-spotted paper was placed into the sensor holder in preparation for $\mathrm{HCN}$ exposure at 1.0 LPM in the $\mathrm{HCN}$ gas-flow system. When $\mathrm{CN}\left(\mathrm{H}_{2} \mathrm{O}\right) \mathrm{Cbi}$ on cellulose filter paper is considered the blank, the average blank signal from $570-590 \mathrm{~nm}$ in terms of the Kubelka-Munk function is $6( \pm 1) \times 10^{-7}$, or in terms of absorbance: $0.0005 \pm 0.0002(\mathrm{n}=10) .1 .0$ ppm $\mathrm{HCN}$ is the lowest concentration in which an accurate dilution could be obtained due to the constraints of the HCN stock concentration and dilution capabilities of the mass flow controllers. Figure 2.18 shows the average apparent absorbance response of $\mathrm{CN}\left(\mathrm{H}_{2} \mathrm{O}\right) \mathrm{Cbi}$ on cellulose filter paper when exposed to $1.0 \mathrm{ppm} \mathrm{HCN}$ after 1 and 5 minutes at $25 \% \mathrm{RH}(\mathrm{n}=3)$. An observable response of $\mathrm{CN}^{-}$binding to $\mathrm{CN}\left(\mathrm{H}_{2} \mathrm{O}\right) \mathrm{Cbi}$ to form the dicyano complex $(583 \mathrm{~nm})$ occurs within one minute at $1.0 \mathrm{ppm}$-below the NIOSH STEL of $4.7 \mathrm{ppm} \mathrm{HCN}$.

Figure $2.18-\mathrm{CN}\left(\mathrm{H}_{2} \mathrm{O}\right) \mathrm{Cbi}$ on cellulose filter paper response to $1.0 \mathrm{ppm} \mathrm{HCN}$

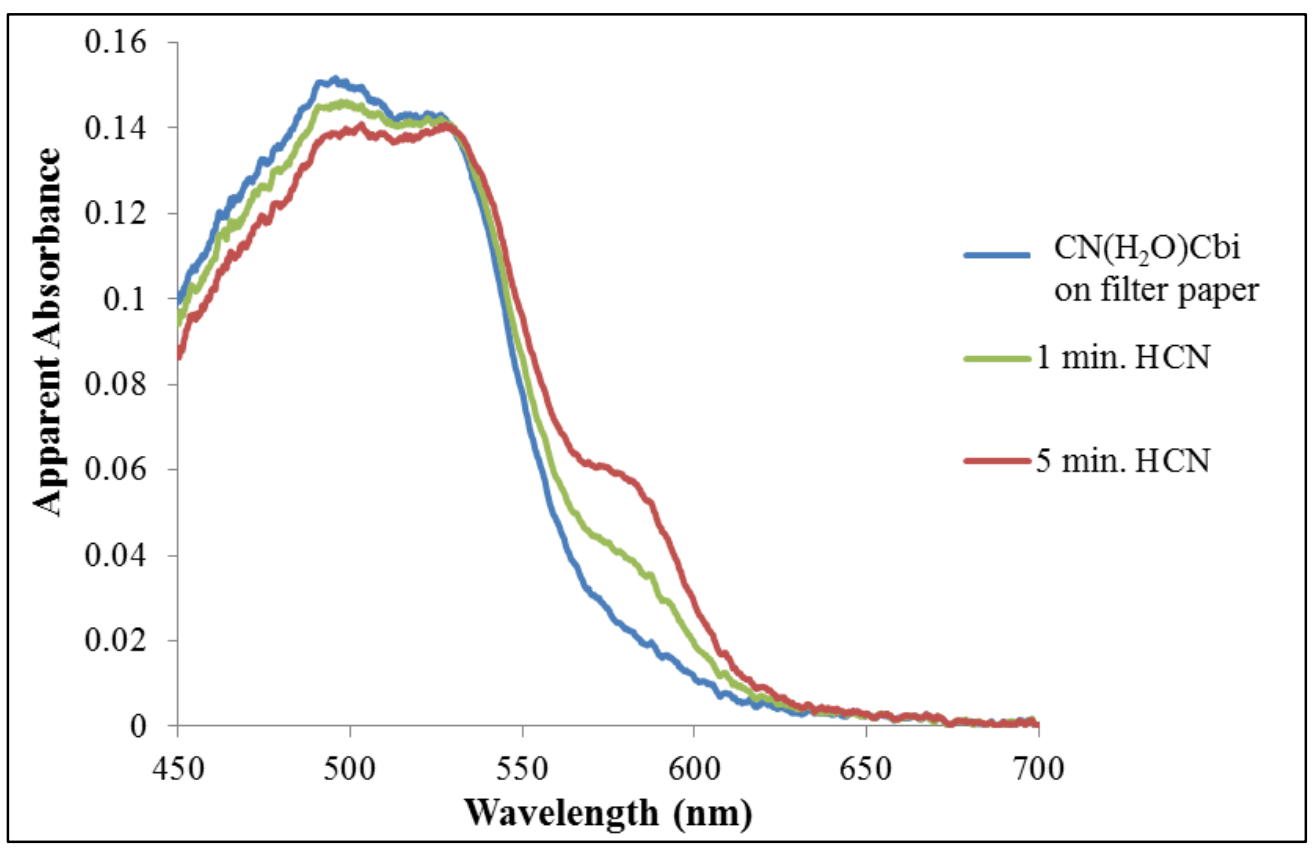


Similar spectral shifts occur upon exposure of $\mathrm{CN}\left(\mathrm{H}_{2} \mathrm{O}\right) \mathrm{Cbi}$ on cellulose filter paper to $5.0 \mathrm{ppm}$ $\mathrm{HCN}$ after 1 and 5 minutes at $25 \% \mathrm{RH}$ (Figure 2.19). Although other HCN concentrations are studied throughout this research, $5.0 \mathrm{ppm} \mathrm{HCN}$ is the concentration of interest since it is close to the NIOSH STEL. Apparent absorbance was converted to diffuse reflectance by the KubelkaMunk equation and can be seen in Figure 2.20. The increased signal at $583 \mathrm{~nm}$, decreased signal at $450-500 \mathrm{~nm}$ and isosbestic point at $531 \mathrm{~nm}$ are apparent and characteristic of $(\mathrm{CN})_{2} \mathrm{Cbi}$.

Figure 2.19- $\mathrm{CN}\left(\mathrm{H}_{2} \mathrm{O}\right) \mathrm{Cbi}$ on cellulose filter paper response to $5.0 \mathrm{ppm} \mathrm{HCN}$

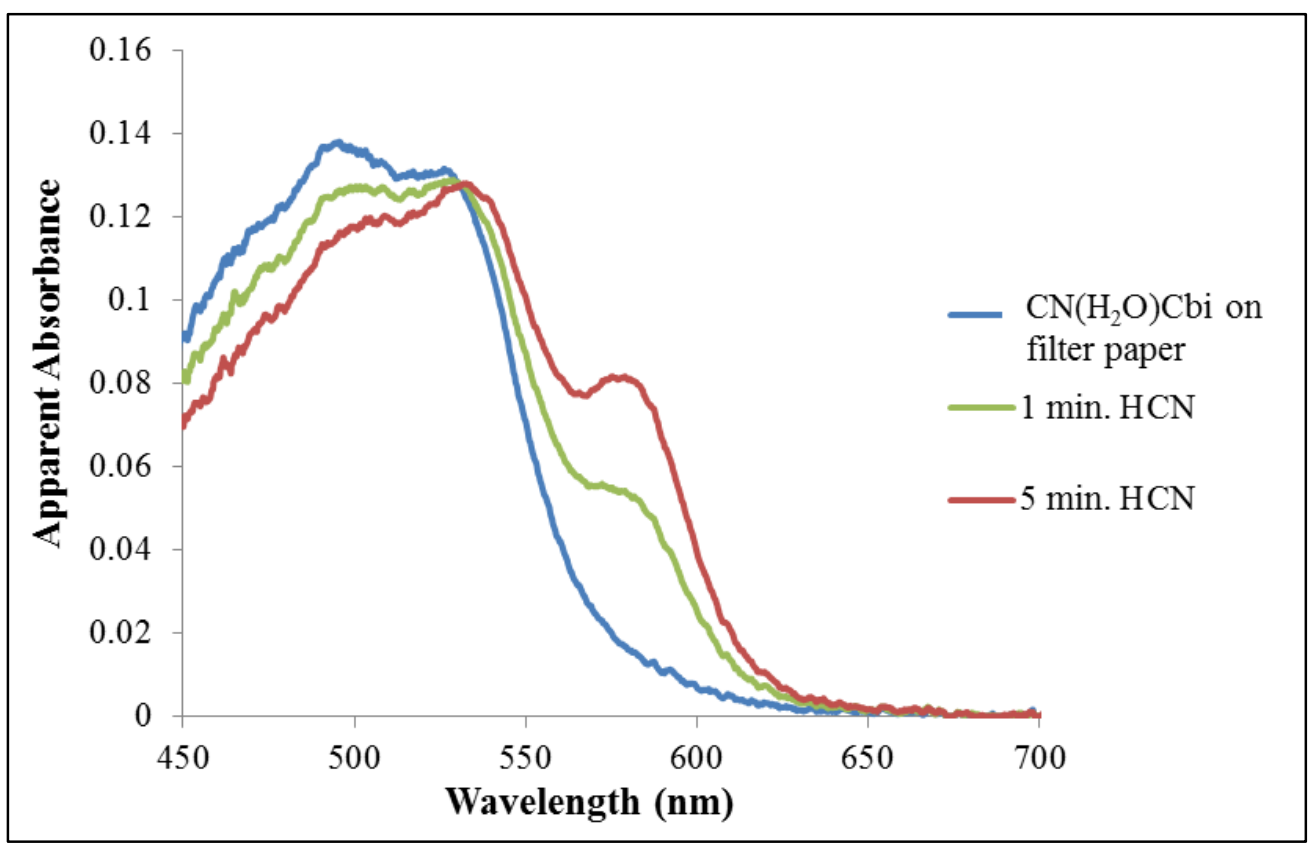


Figure 2.20 - Kubelka-Munk function applied to $5.0 \mathrm{ppm} \mathrm{HCN}$ exposure

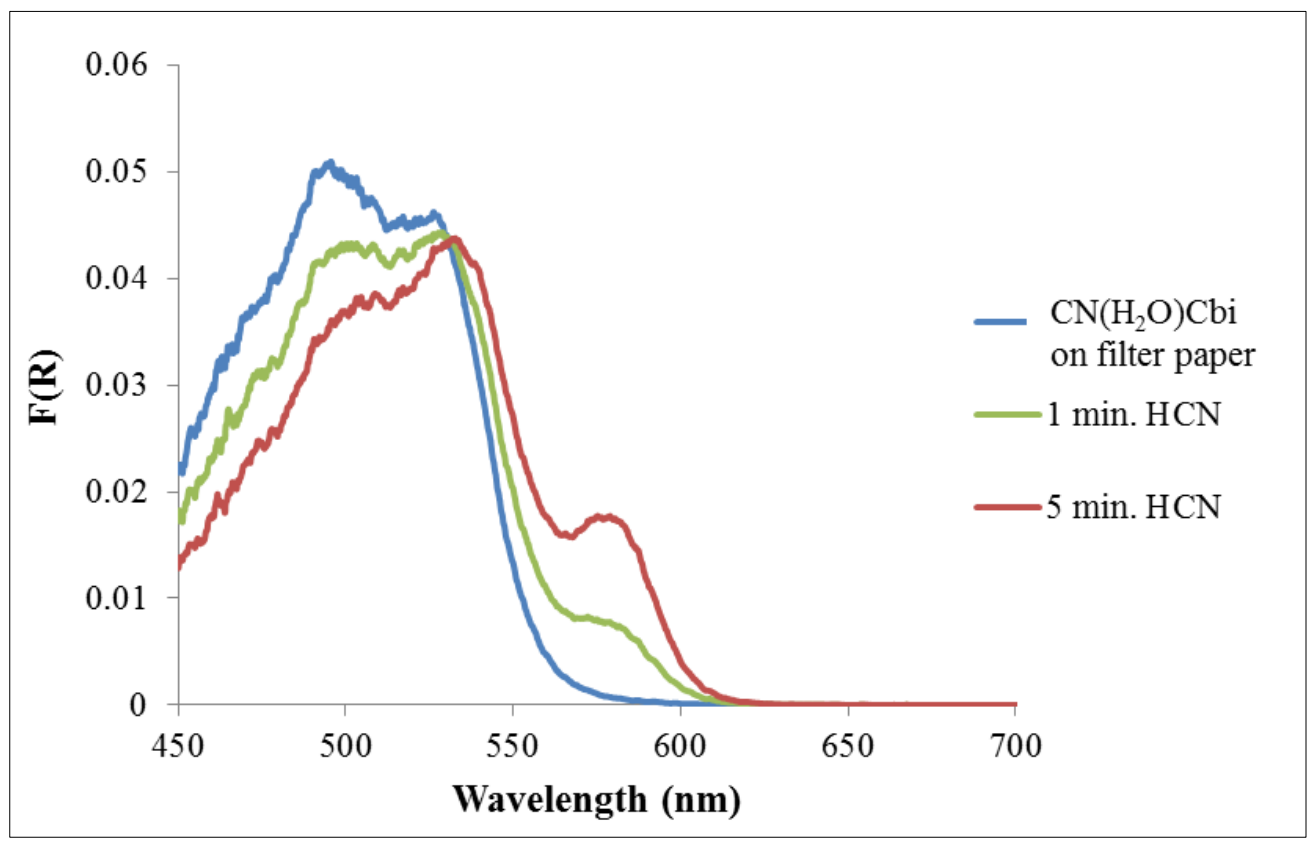

To more easily visualize these characteristic wavelength trends, the spectrum of $\mathrm{CN}\left(\mathrm{H}_{2} \mathrm{O}\right) \mathrm{Cbi}$ on cellulose filter paper is considered the blank, creating difference spectra. This can be observed in Figure 2.21, where the average Kubelka-Munk spectra is shown $(\mathrm{n}=3)$. The response to 60 minute exposure time is shown on the secondary-axis. Unless otherwise noted, the KubelkaMunk function will be applied and presented in the remaining figures of this and subsequent chapters. 
Figure 2.21 - Difference spectra in terms of the Kubelka-Munk function

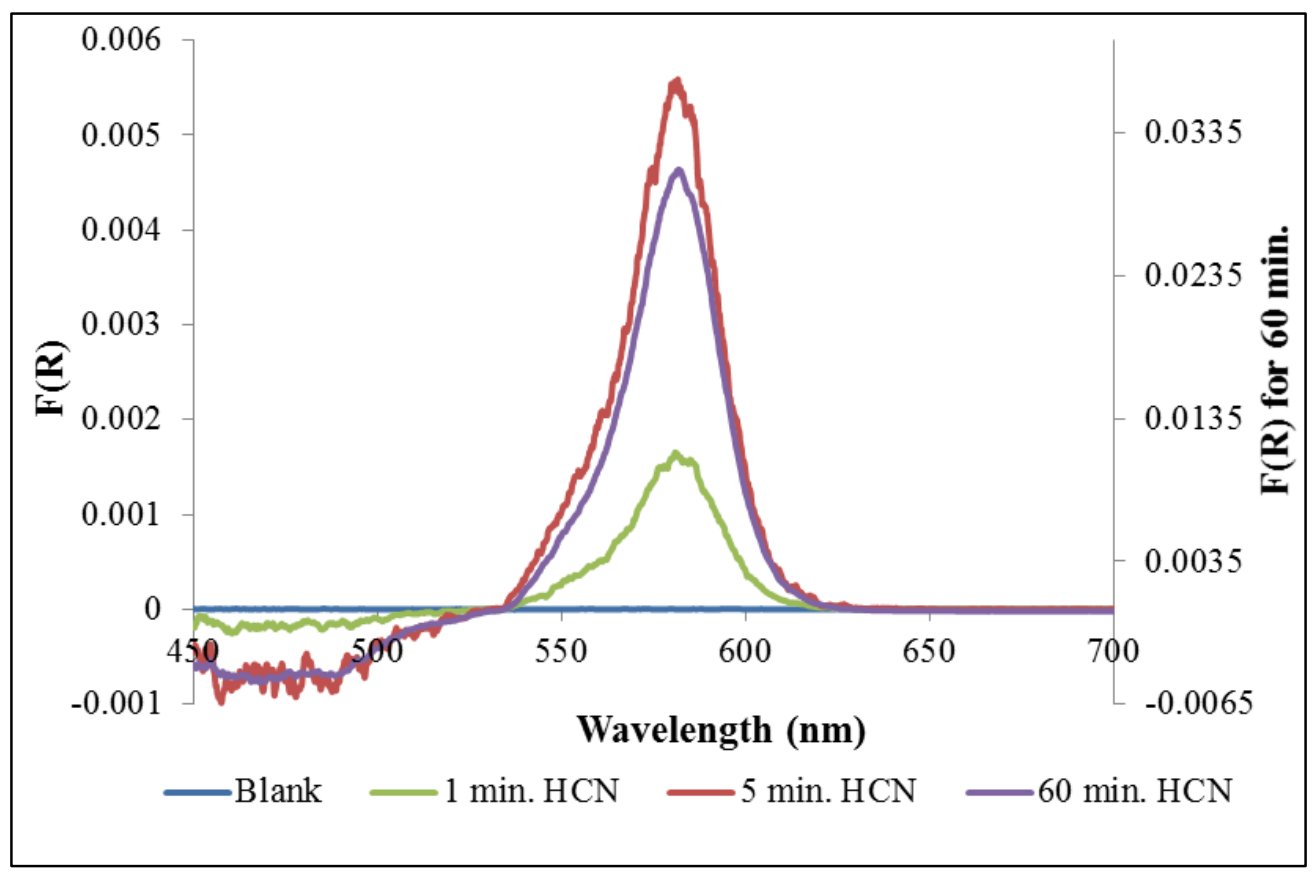

As explained in Section 2.2.3, the Kubelka-Munk function is used to transform reflectance data into transmittance. The conversion often assists in linearizing data for a calibration curve. This can be observed when the Kubelka-Munk function is applied for values at $583 \mathrm{~nm}$ when $5.0 \mathrm{ppm}$ HCN was exposed to the cellulose filter paper for 1, 5, 10, and 15 minutes (Figure 2.22). The apparent absorbance begins to plateau as the binding sites on Cbi on the paper become saturated with $\mathrm{CN}^{-}$. When the Kubelka-Munk function is applied, a more linear trend is observed. A LINEST Excel function provides a linear fit with slope $9.1 \pm 0.4 \times 10^{-4}$ and y-intercept $5 \pm 3 \times 10^{-4}$ with an $\mathrm{R}^{2}$ value of 0.994 . The values for Figure 2.22 are displayed in Table A.3. 
Figure 2.22 - Comparison of the average response of $\mathrm{CN}\left(\mathrm{H}_{2} \mathrm{O}\right) \mathrm{Cbi}$ on cellulose filter paper to $5.0 \mathrm{ppm} \mathrm{HCN}$ at various exposure times

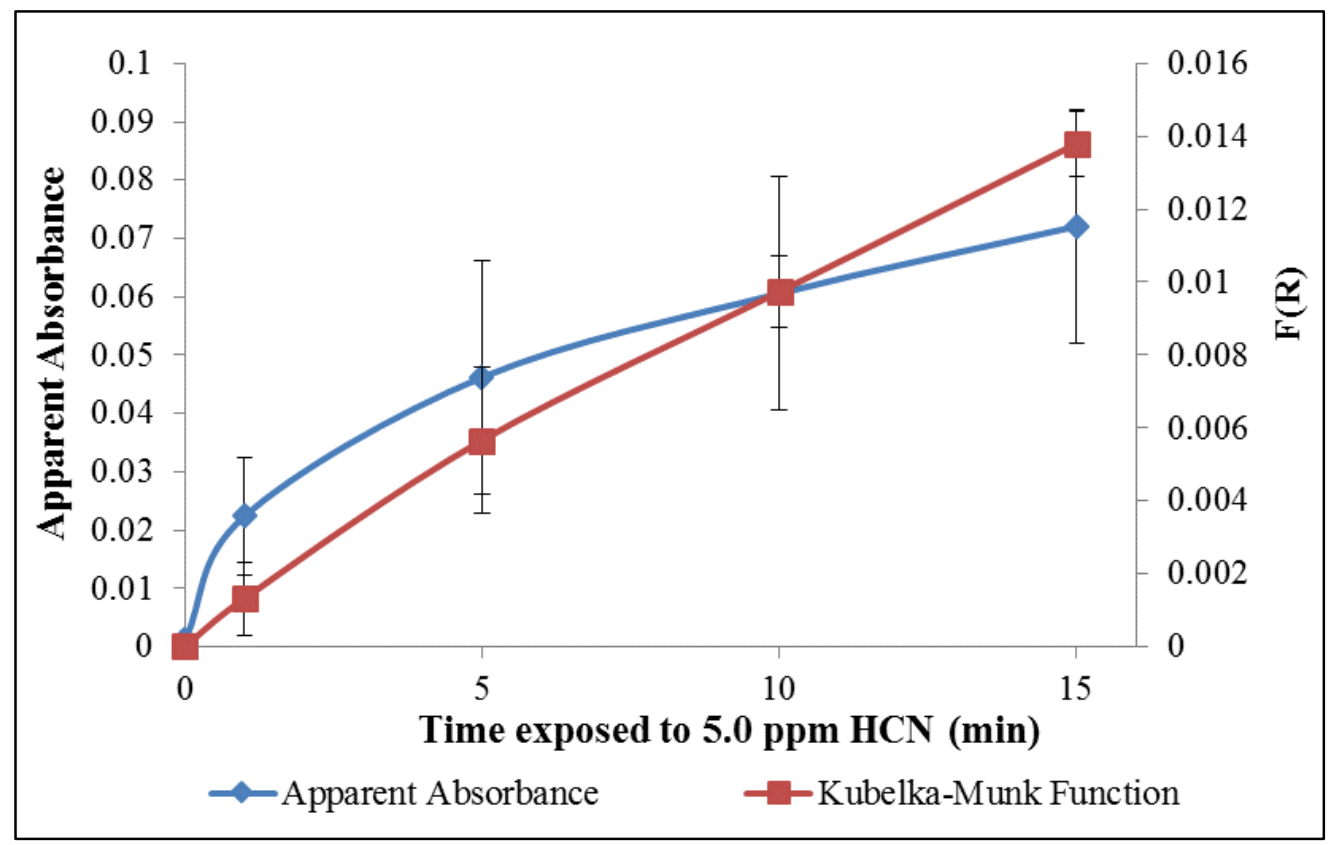

Similarly, the Kubelka-Munk function was applied to the average apparent absorbance values as a function of $\mathrm{HCN}$ concentration $(0.0,1.0,3.0,5.0,7.0,9.0,15.0 \mathrm{ppm})$ when the cellulose filter paper was exposed to $\mathrm{HCN}$ for 5 minutes (Figure 2.23, n=3). A linear trend is observed until 10.0 ppm $\left(\mathrm{R}^{2}=0.999\right)$ and deviates for $15.0 \mathrm{ppm} \mathrm{HCN}$. Values for Figure 2.23 are displayed in Table A.4. A LINEST Excel function for $\mathrm{HCN}$ concentrations $0.0-10.0 \mathrm{ppm}$ provides a linear equation of $y=\left(1.12 \pm 0.002 \times 10^{-3}\right) x+4 \pm 0.1 \times 10^{-5}$. 
Figure 2.23 - Comparison of the average response of $\mathrm{CN}\left(\mathrm{H}_{2} \mathrm{O}\right)$ Cbi on cellulose filter paper various $\mathrm{HCN}$ concentrations for 5 minutes

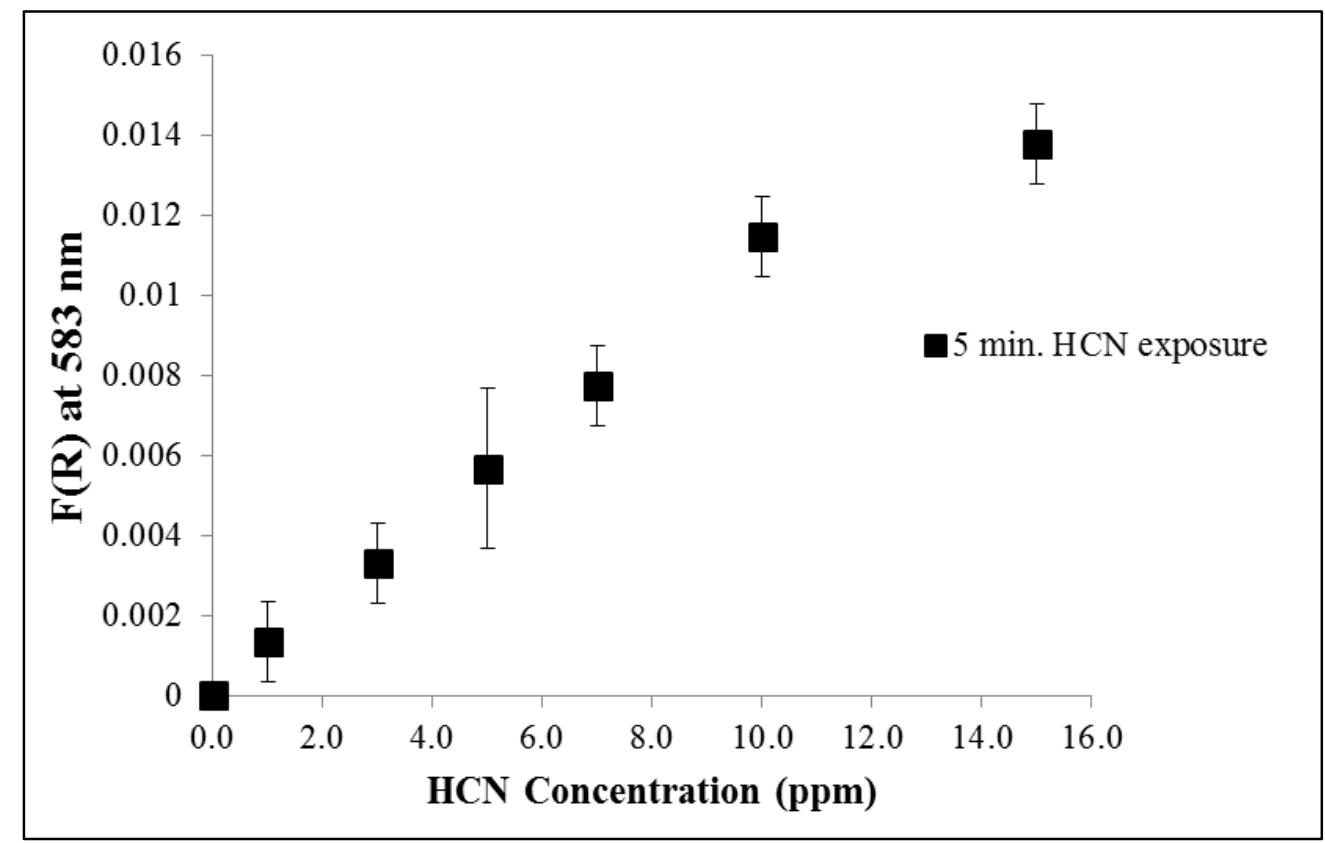

\subsubsection{Response Time}

For the sensor to be capable of detecting impending breakthrough, Cbi on paper must indicate the presence of $\mathrm{HCN}$ with a fast response time-i.e. within one minute. For all trends, the average of the blank from $700-750 \mathrm{~nm}$ is used as the reference.

\section{Comparison of Aquohydroxocobinamide and Monocyanocobinamide Response to HCN Gas}

To appreciate the kinetics of monocyanocobinamide on cellulose filter paper, $15.0 \mu \mathrm{L}$ of $50.0 \mu \mathrm{M}$ aquohydroxocobinamide $\left[\mathrm{OH}\left(\mathrm{H}_{2} \mathrm{O}\right) \mathrm{Cbi}\right]$ was pipetted onto cellulose filter paper, allowed to dry, and exposed to $5.0 \mathrm{ppm} \mathrm{HCN}$ at $25 \% \mathrm{RH}$ at various time exposures. As expected, the reflectance signal is lower than the signals observed when monocyanocobinamide was spotted on cellulose filter paper, in fact an order of magnitude lower. Figure 2.24 shows the response of $\mathrm{OH}\left(\mathrm{H}_{2} \mathrm{O}\right)$ Cbi pre-spotted on cellulose filter paper to $5.0 \mathrm{ppm} \mathrm{HCN}$. Exposure to 5.0 ppm $\mathrm{HCN}$ for 1 minute has an almost unobservable $\mathrm{F}(\mathrm{R})$ spectrum. For comparison, a 5 minute 
exposure using $\mathrm{CN}\left(\mathrm{H}_{2} \mathrm{O}\right)$ Cbi has a response at $583 \mathrm{~nm}$ an order of a magnitude larger than $\mathrm{OH}\left(\mathrm{H}_{2} \mathrm{O}\right) \mathrm{Cbi}$.

Figure 2.24 - Difference spectra for aquohydroxocobinamide on cellulose filter paper

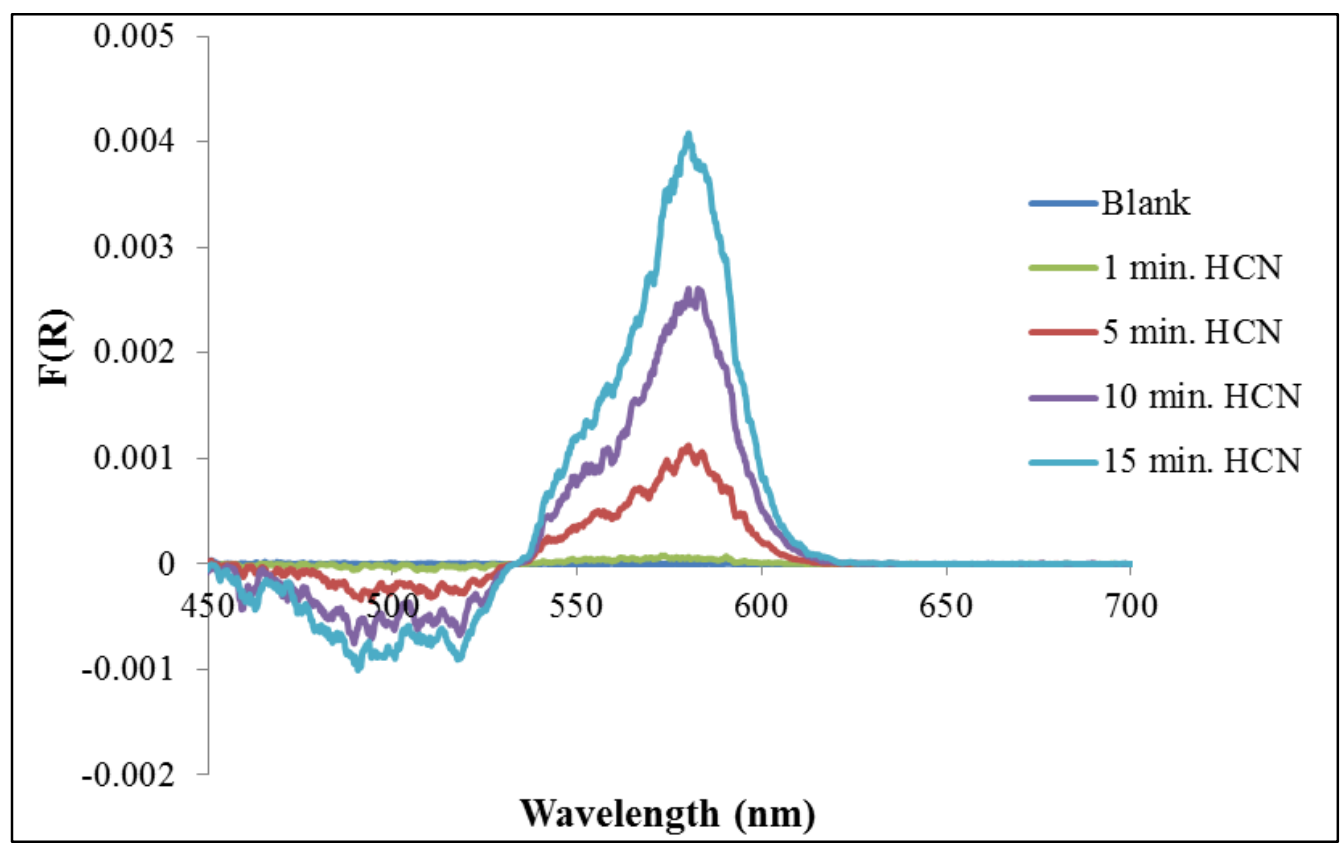

Additionally, when the signal at $583 \mathrm{~nm}$ for $\mathrm{OH}\left(\mathrm{H}_{2} \mathrm{O}\right) \mathrm{Cbi}$ is monitored over time in the presence of $5.0 \mathrm{ppm} \mathrm{HCN} \mathrm{(25 \% RH),} \mathrm{a} \mathrm{near} \mathrm{linear} \mathrm{response} \mathrm{is} \mathrm{observed} \mathrm{over} \mathrm{twenty} \mathrm{minutes} \mathrm{(} \mathrm{R}^{2}$ value of 0.9927). The responses of initial reagents $\mathrm{OH}\left(\mathrm{H}_{2} \mathrm{O}\right) \mathrm{Cbi}$ and $\mathrm{CN}\left(\mathrm{H}_{2} \mathrm{O}\right)$ Cbi when exposed to 5.0 ppm $\mathrm{HCN}(25 \% \mathrm{RH})$ are compared and shown in Figure 2.25. The signal at $583 \mathrm{~nm}$ is monitored for 15 minutes. 
Figure $2.25-\mathrm{CN}\left(\mathrm{H}_{2} \mathrm{O}\right) \mathrm{Cbi}$ and $\mathrm{OH}\left(\mathrm{H}_{2} \mathrm{O}\right) \mathrm{Cbi}$ response to $5.0 \mathrm{ppm} \mathrm{HCN}$ on cellulose filter paper

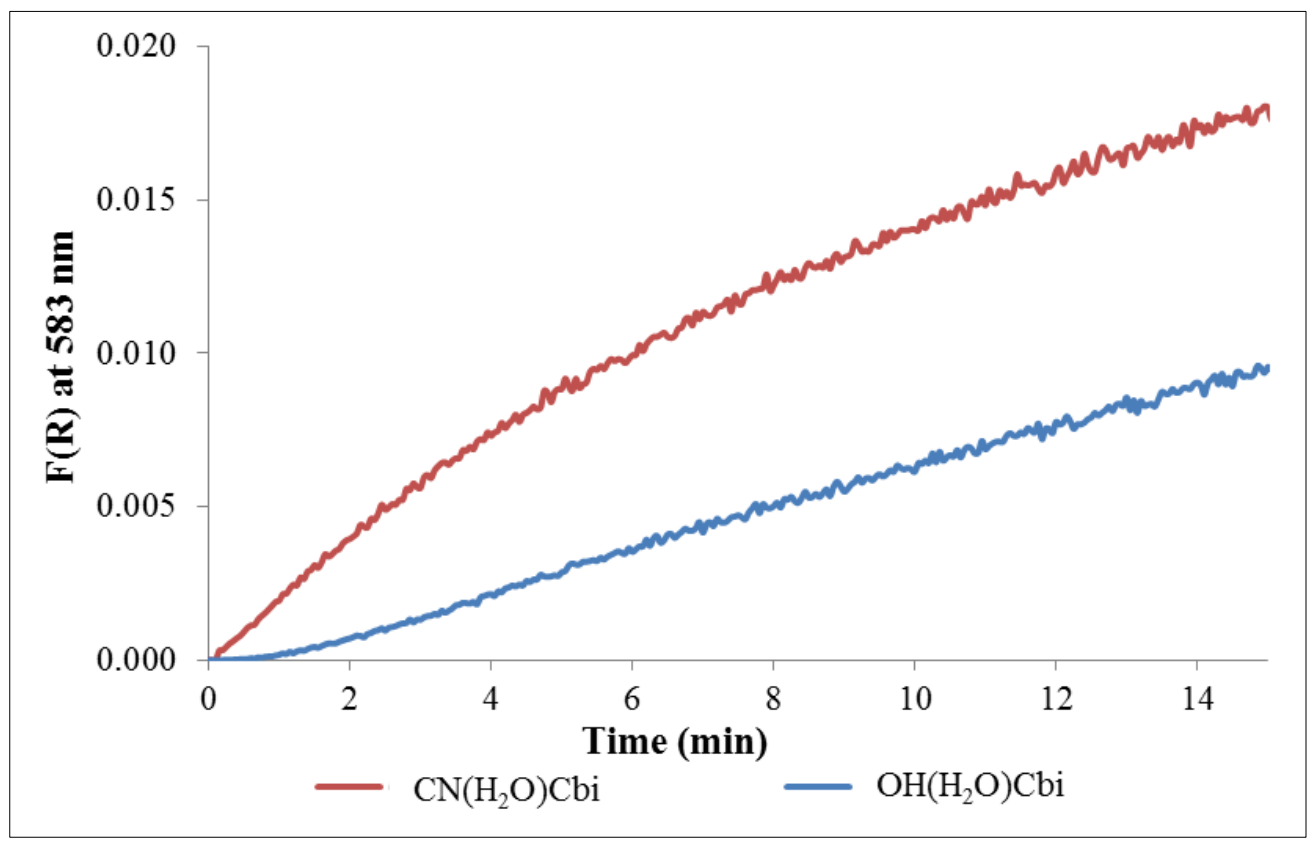

An expanded view of the initial responses of $5.0 \mathrm{ppm} \mathrm{HCN}$ exposure to $\mathrm{OH}\left(\mathrm{H}_{2} \mathrm{O}\right) \mathrm{Cbi}$ and $\mathrm{CN}\left(\mathrm{H}_{2} \mathrm{O}\right) \mathrm{Cbi}$ is shown in Figure 2.26a and Figure 2.26b, respectively. The response for $\mathrm{CN}\left(\mathrm{H}_{2} \mathrm{O}\right) \mathrm{Cbi}$ is much higher than $\mathrm{OH}\left(\mathrm{H}_{2} \mathrm{O}\right) \mathrm{Cbi}$. The fast response of $\mathrm{CN}\left(\mathrm{H}_{2} \mathrm{O}\right) \mathrm{Cbi}$ is evident and shows significant response starting in $\sim 10$ seconds, while at least 30 seconds is required for response for $\mathrm{OH}\left(\mathrm{H}_{2} \mathrm{O}\right) \mathrm{Cbi}$. 
Figure 2.26 - Initial response of $\mathrm{OH}\left(\mathrm{H}_{2} \mathrm{O}\right) \mathrm{Cbi}$ and $\mathrm{CN}\left(\mathrm{H}_{2} \mathrm{O}\right) \mathrm{Cbi}$ to $5.0 \mathrm{ppm} \mathrm{HCN}(25 \% \mathrm{RH})$
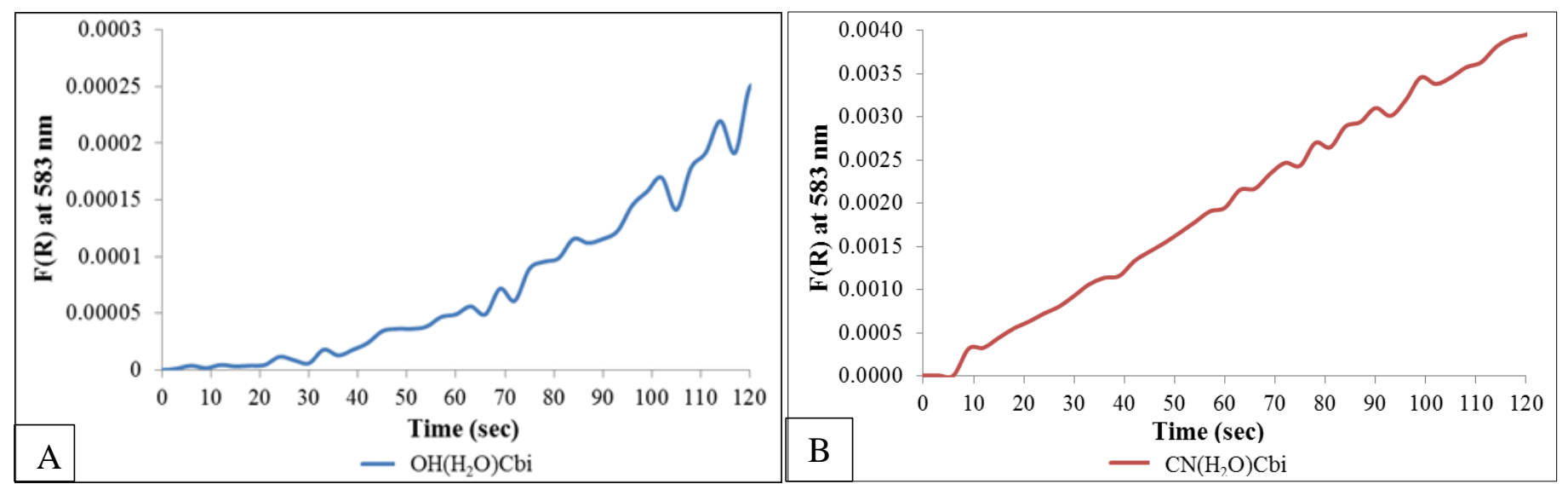

The characteristic peak at $583 \mathrm{~nm}$ and observable color change is therefore rate-limited by the first $\mathrm{CN}^{-}$binding to $\mathrm{Cbi}$. This data supports using $\mathrm{CN}\left(\mathrm{H}_{2} \mathrm{O}\right) \mathrm{Cbi}$ as the initial immobilization reagent for the development of the $\mathrm{HCN}$ sensor as a faster response time is desired.

Two $\mathrm{F}(\mathrm{R})$ vs. time trends - one at $583 \mathrm{~nm}$ and the other of the average response between 450-500 nm - can be observed in Figure 2.27a. $\mathrm{T}=0$ corresponds to the time at which the valve was turned to direct the $\mathrm{HCN}$ gas over the sensor. A dead time of $<2$ seconds is calculated based on the sizing of the tubing in the gas flow setup. As expected, exposure to $5.0 \mathrm{ppm} \mathrm{HCN}$ shows a higher signal at $583 \mathrm{~nm}$ (and decreased signal at 450-500 nm) than exposure to $1.0 \mathrm{ppm} \mathrm{HCN}$. Figure 2.27b displays an expansion of the initial response when HCN passes over the sensor. With an estimated dead time of less than 2 seconds, a measurable response at $583 \mathrm{~nm}$ appears near 10 seconds for $5.0 \mathrm{ppm}$ exposure. A slower response is observed for $1.0 \mathrm{ppm}$ exposure, with an increase in signal occurring at approximately 20 seconds. 
Figure $2.27-\mathrm{CN}\left(\mathrm{H}_{2} \mathrm{O}\right) \mathrm{Cbi}$ on cellulose paper response to 1.0 and $5.0 \mathrm{ppm} \mathrm{HCN}$ (A) with expanded view of initial response (B)
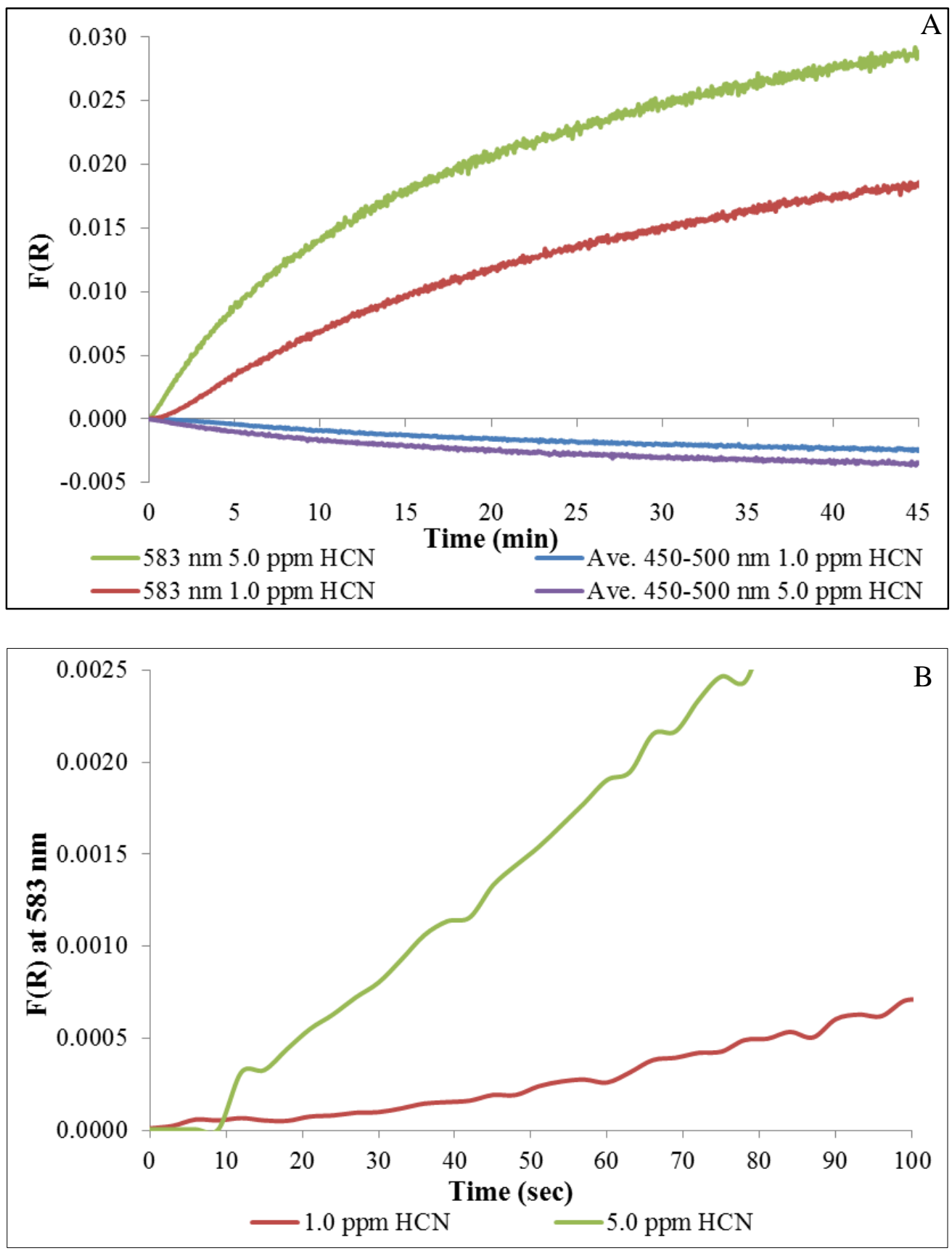

\subsubsection{Glass Fiber Filter Paper}

The same instrumentation and methods described for cellulose filter paper are applied for immobilizing $\mathrm{CN}\left(\mathrm{H}_{2} \mathrm{O}\right) \mathrm{Cbi}$ on borosilicate glass fiber filter paper and exposing to various 
concentrations of $\mathrm{HCN}$ gas. The average absorbance of $\mathrm{CN}\left(\mathrm{H}_{2} \mathrm{O}\right) \mathrm{Cbi}$ on glass fiber paper (measured at $500 \mathrm{~nm}$ ) is $0.18 \pm 0.03 \mathrm{~nm}(\mathrm{a} \mathrm{F}(\mathrm{R})$ value equal to $0.089 \pm 0.002)$. These values are based on 30 samples with \pm values calculated by sample standard deviation.

\subsubsection{Monocyanocobinamide Detection of HCN Gas}

Similar spectral shifts for $\mathrm{CN}\left(\mathrm{H}_{2} \mathrm{O}\right)$ Cbi on cellulose filter paper are observed for glass fiber paper: i.e. the $583 \mathrm{~nm}$ signal increases and the $450-500 \mathrm{~nm}$ signal decreases when $5.0 \mathrm{ppm}$ $\mathrm{HCN}$ is present at $25 \% \mathrm{RH}$. The Kubelka-Munk function is plotted for the diffuse reflectance spectra (Figure 2.28; $\mathrm{n}=6$ ).

Figure $2.28-\mathrm{CN}\left(\mathrm{H}_{2} \mathrm{O}\right) \mathrm{Cbi}$ on glass fiber filter paper response to $5.0 \mathrm{ppm} \mathrm{HCN}$

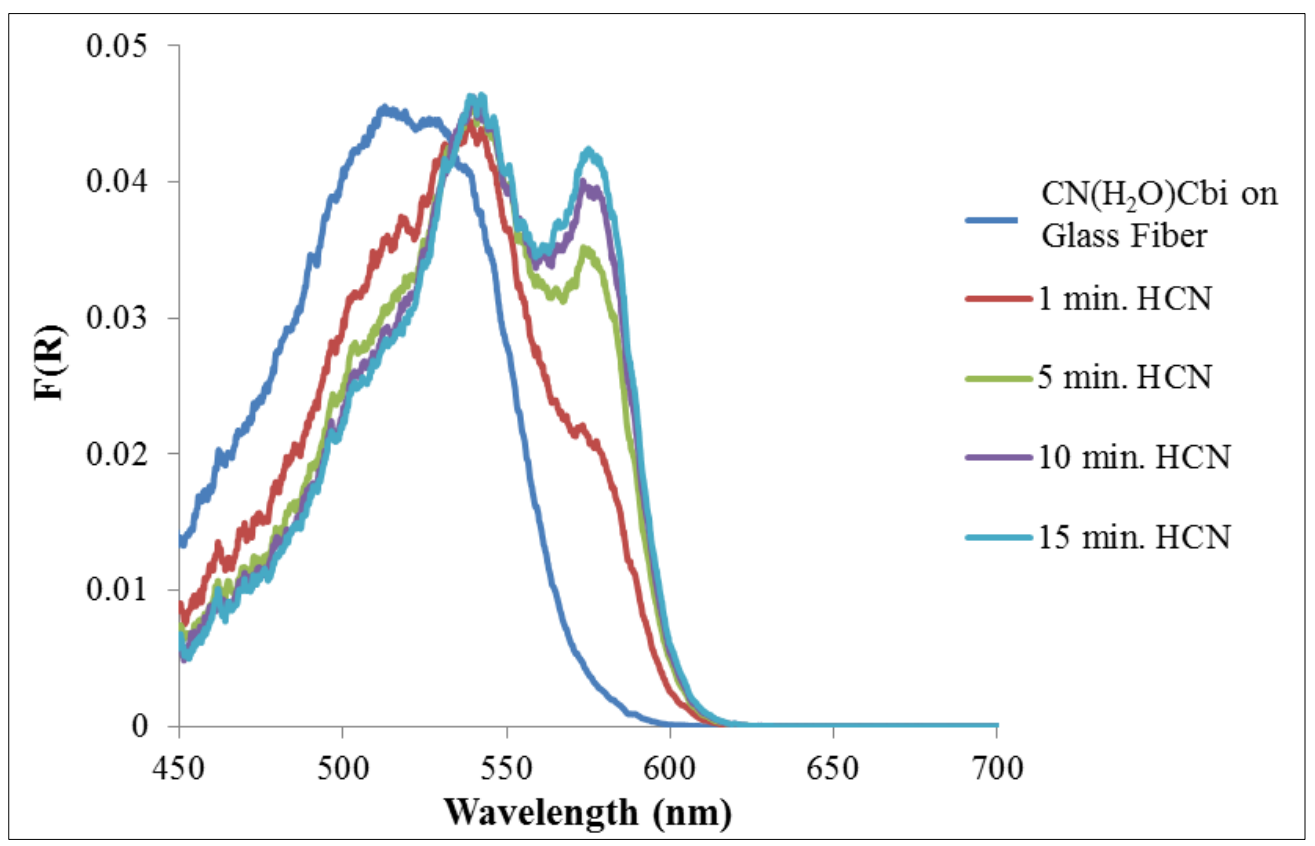

Compared to cellulose paper, larger F(R) signals for the glass fiber paper are observed, which plateaus at longer $\mathrm{HCN}$ exposure times with a near steady-state signal established near 10 minutes of exposure. This observation is likely attributed to the larger surface area of the thicker glass fiber paper and more cobinamide available to complex with $\mathrm{CN}^{-}$. Additionally, the thicker 
paper could increase $F(R)$ values as expected from Beer's Law. This can be more easily viewed in Figure 2.29 where the average spectrum of $\mathrm{CN}\left(\mathrm{H}_{2} \mathrm{O}\right) \mathrm{Cbi}$ on glass fiber filter paper is the blank, creating difference spectra $(n=6)$. The response using the glass fiber paper is higher at each time interval when compared to cellulose paper. For example, a $F(R)$ value for 5 minute exposure of $5.0 \mathrm{ppm} \mathrm{HCN}$ for cellulose filter paper is $0.006 \pm 0.002$ (Table A.4; $\mathrm{n}=3$ ), whereas the same conditions for glass fiber paper yield an $F(R)$ value of $0.015 \pm 0.001(n=6)$.

Figure 2.29 - Difference spectra of $\mathrm{CN}\left(\mathrm{H}_{2} \mathrm{O}\right) \mathrm{Cbi}$ on glass fiber filter paper response to $5.0 \mathrm{ppm}$ $\mathrm{HCN}$

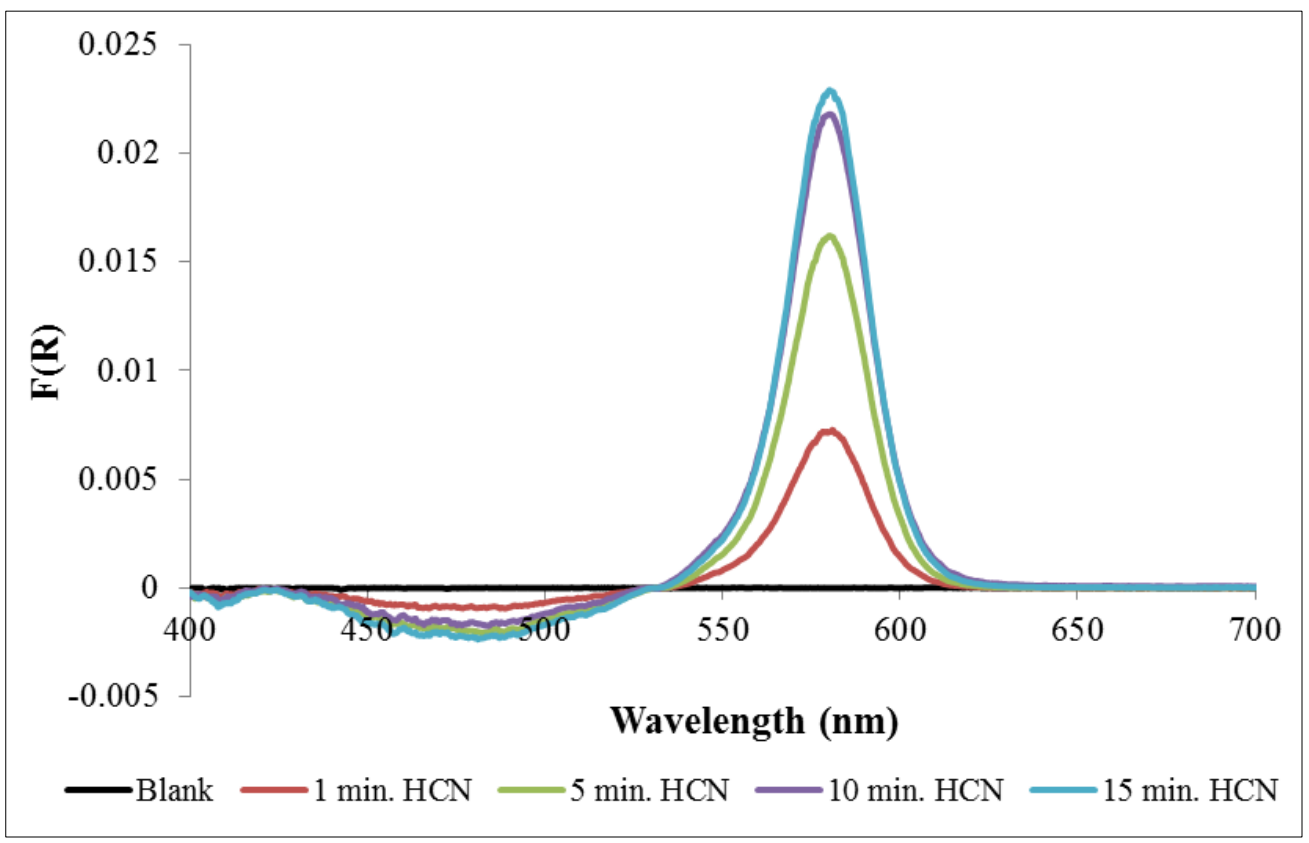

The Kubelka-Munk function is plotted against various time exposures to $5.0 \mathrm{ppm} \mathrm{HCN}$. This function assisted in linearizing the data for cellulose paper but is still nonlinear for glass fiber paper with respect to time (Figure 2.30, $\mathrm{n}=6$ ). Data for Figure 2.30 is shown in Table A.5. 
Figure 2.30 - Average $\mathrm{F}(\mathrm{R})$ response of $\mathrm{CN}\left(\mathrm{H}_{2} \mathrm{O}\right) \mathrm{Cbi}$ on glass fiber filter paper to $5.0 \mathrm{ppm} \mathrm{HCN}$ at various exposure times

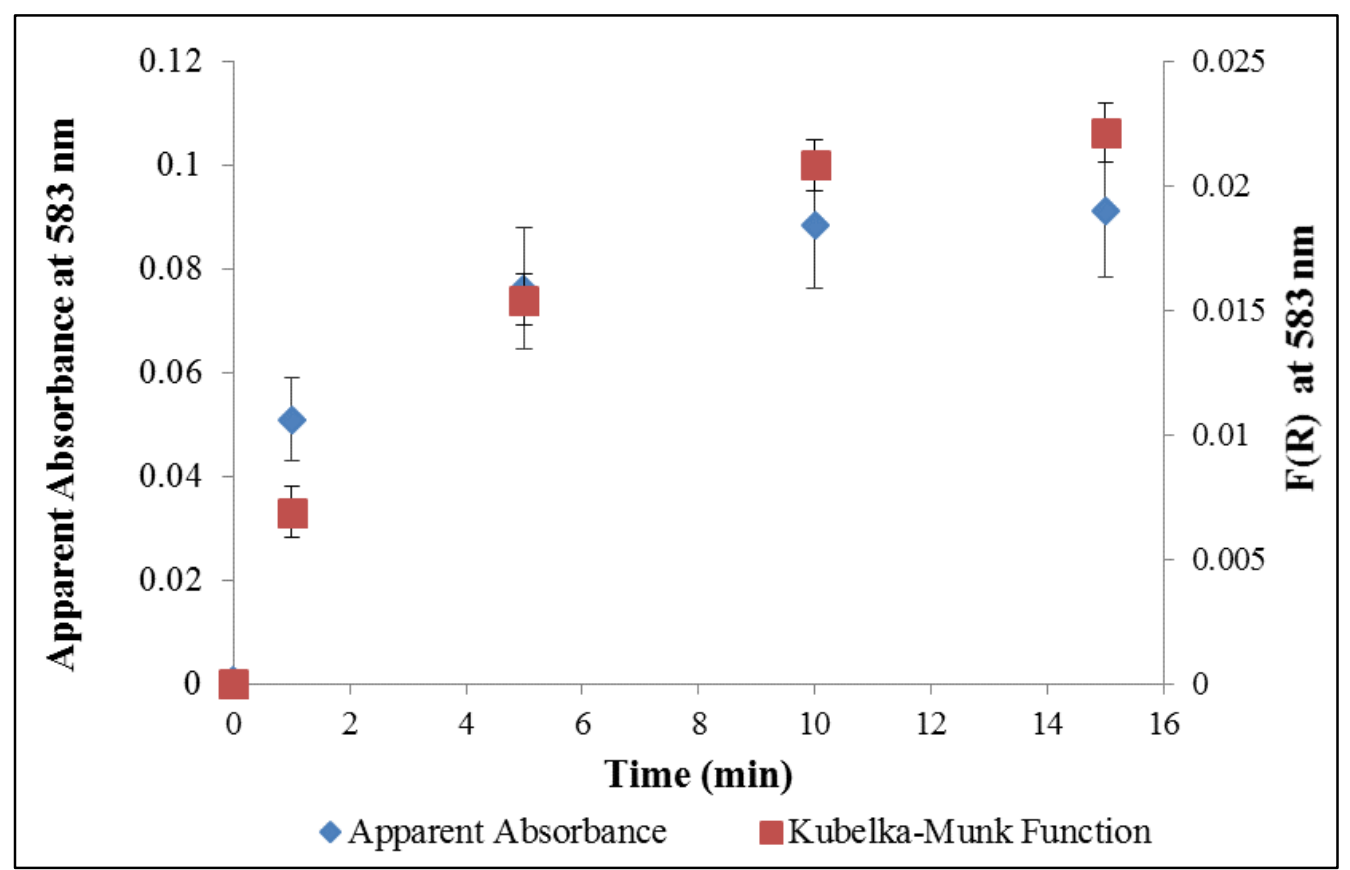

The saturation of the response suggests that the amount of reacted cobinamide complex is approaching the total amount of cobinamide immobilized on the glass fiber paper. The linear behavior for cellulose paper indicates that the amount of reacted cobinamide is small with respect to the total amount of cobinamide over the 15 minutes of exposure. These differences suggest that the interaction of $\mathrm{CN}\left(\mathrm{H}_{2} \mathrm{O}\right) \mathrm{Cbi}$ with the substrate affects its response to $\mathrm{HCN}$. The Kubelka-Munk function signal is approximately linear with respect to $\mathrm{HCN}$ concentration after 1 minute (Figure 2.31) as well as after 15 minutes (Figure 2.32) with $\mathrm{R}^{2}$ values equal to 0.989 and 0.994, respectively. A LINEST Excel function was performed for both Kubelka-Munk plots, which provided a linear fit with slope $1.65 \pm 0.09 \times 10^{-3}$ and y intercept $-7 \pm 5 \times 10^{-4}$ for 1 minute, and slope $4.4 \pm 0.2 \times 10^{-3}$ and y-intercept $4 \pm 9 \times 10^{-4}$ for 15 minutes. Data values for Figure 2.31 and Figure 2.32 can be seen in Table A.6. Error bars are represented by $95 \%$ CI for $\mathrm{n}=3$ ( $\mathrm{n}=6$ for $5.0 \mathrm{ppm})$. 
Figure 2.31 - Average $\mathrm{F}(\mathrm{R})$ response of $\mathrm{CN}\left(\mathrm{H}_{2} \mathrm{O}\right) \mathrm{Cbi}$ on glass fiber filter paper to $\mathrm{HCN}$ after 1 minute

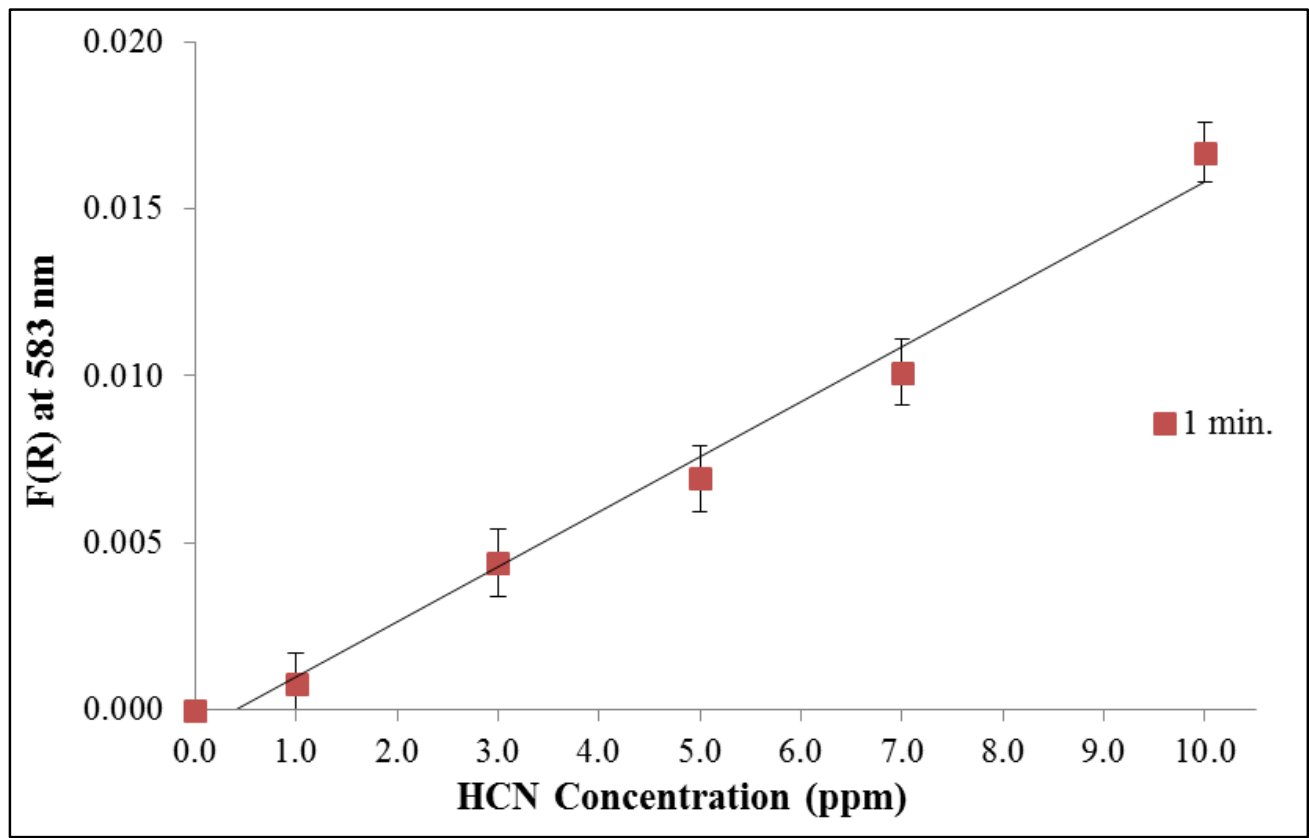

Figure 2.32 - Average $\mathrm{F}(\mathrm{R})$ response of $\mathrm{CN}\left(\mathrm{H}_{2} \mathrm{O}\right) \mathrm{Cbi}$ on glass fiber filter paper to $\mathrm{HCN}$ after 15 minutes

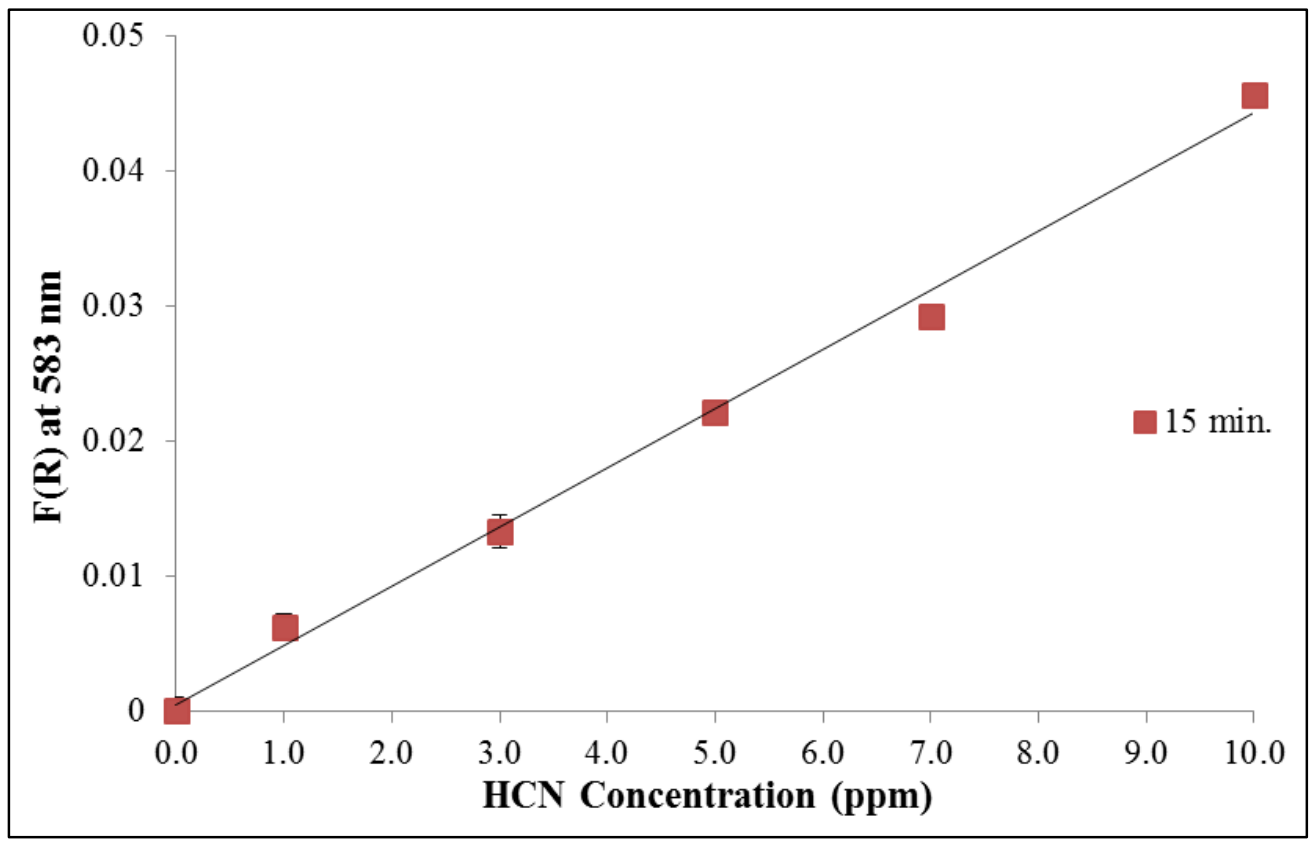

Deviations are likely due to the nonhomogeneous paper medium. One of the assumptions of the Kubelka-Munk function is that the substrate is isotropic and homogenous, which is not 
necessarily the case when using paper. ${ }^{157}$ A more linear response using the Kubelka-Munk function is observed after 15 minutes $\mathrm{HCN}$ exposure, most likely due to the system being at steady state at each concentration. Although the Cbi-immobilized filter papers can detect $\mathrm{HCN}$ concentrations of less than $5.0 \mathrm{ppm}$, the focus of this study is the STEL of HCN. HCN at 5.0 ppm can be detected rapidly using the $\mathrm{CN}\left(\mathrm{H}_{2} \mathrm{O}\right)$ Cbi-immobilized glass fiber paper.

\subsubsection{Response Time}

Figure 2.33a shows the $\mathrm{F}(\mathrm{R})$ values at $583 \mathrm{~nm}$ for $\mathrm{CN}\left(\mathrm{H}_{2} \mathrm{O}\right) \mathrm{Cbi}$ on glass fiber paper for $5.0 \mathrm{ppm}$ (red line) and $1.0 \mathrm{ppm}$ (blue line) $\mathrm{HCN}$ exposure. A larger signal is observed for the 5.0 ppm HCN exposure, although 1.0 ppm HCN exposure provides a significant and rapid response. Figure 2.33 b shows a rapid initial response occurring within 5 seconds for 5.0 ppm HCN exposure, while the initial rapid rise occurs after 10 seconds for the $1.0 \mathrm{ppm}$ exposure. 
Figure 2.33 - Response of $\mathrm{CN}\left(\mathrm{H}_{2} \mathrm{O}\right) \mathrm{Cbi}$ on glass fiber filter paper to 1.0 and $5.0 \mathrm{ppm} \mathrm{HCN}$ (A) with expanded view of initial response (B)
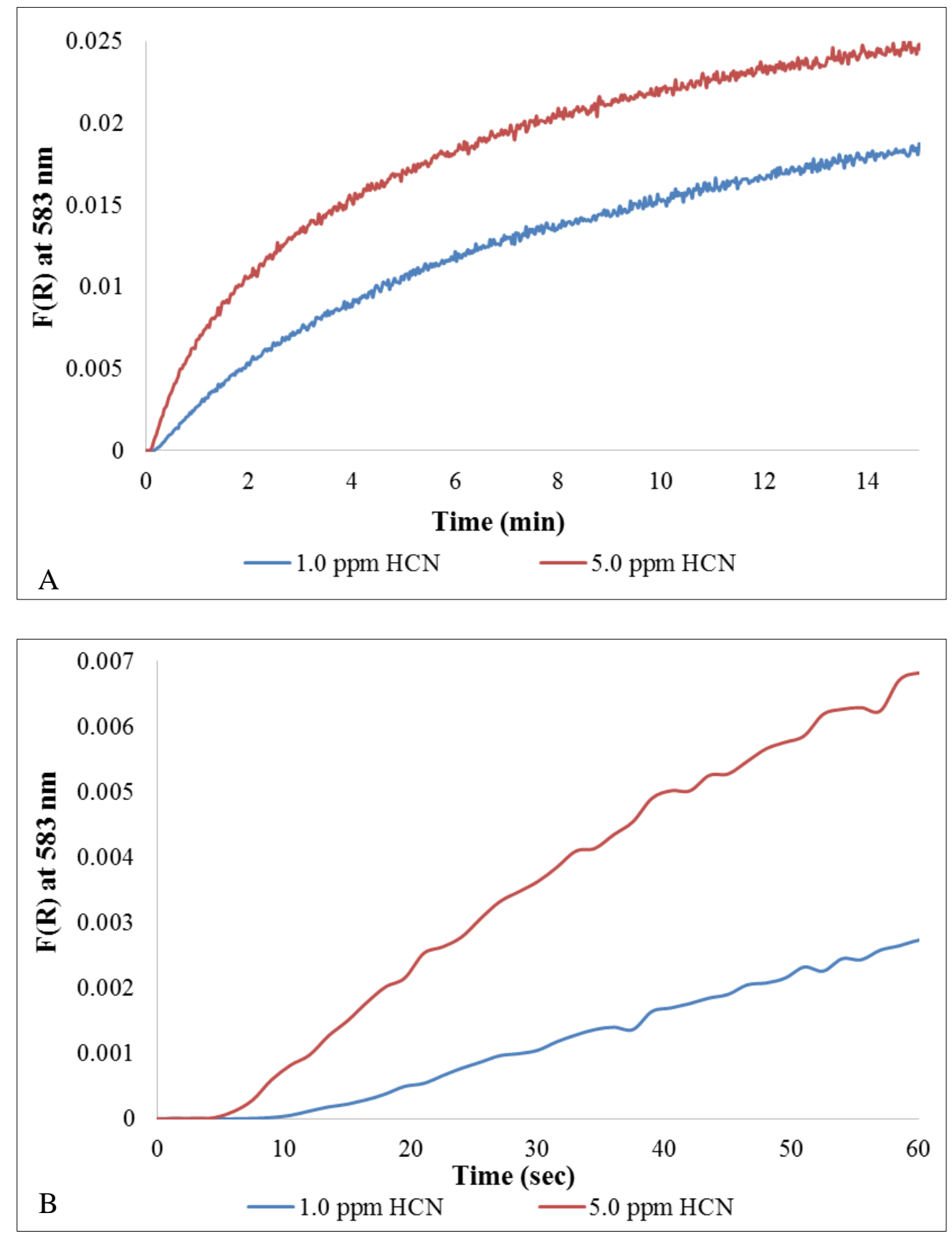


\subsubsection{Reproducibility of Cobinamide on Glass Fiber Paper}

Table 2.3 shows the average $\mathrm{F}(\mathrm{R})$ values of $\mathrm{CN}\left(\mathrm{H}_{2} \mathrm{O}\right)$ Cbi observed at $500 \mathrm{~nm}$ on glass fiber filter paper as a function of aging. Uncertainty is in terms of $95 \%$ CI with percent error relative to the fresh samples in parentheses. Fresh samples refer those when $\mathrm{CN}\left(\mathrm{H}_{2} \mathrm{O}\right) \mathrm{Cbi}$ was pipetted onto the paper and, once dry, were immediately placed in the holder for HCN exposure. $\mathrm{F}(\mathrm{R})$ values slightly decrease as a function of time, but not significantly. The error may be attributed to the paper placement: the exact paper placement in the sensor holder was uncontrollable and may not be the same each time. Because of this, a slight shift in the paper's placement may result in a different apparent absorbance spectrum and altered value of $F(R)$ at $500 \mathrm{~nm}$. Therefore, it is difficult to determine if the change in $\mathrm{F}(\mathrm{R})$ values are due to degradation of Cbi on paper over time or paper placement. More controlled experiments must be performed where the paper is allowed to remain in one position during testing and storage.

Table 2.3 - Aged $\mathrm{CN}\left(\mathrm{H}_{2} \mathrm{O}\right)$ Cbi paper sample response at $500 \mathrm{~nm}$

\begin{tabular}{|c|c|c|c|c|}
\hline $\begin{array}{c}\text { Samples used for } \\
\text { comparison (n) }\end{array}$ & Fresh F(R) values & $\begin{array}{c}1 \text { month F(R) } \\
\text { values (\%)bias from } \\
\text { fresh sample) }\end{array}$ & $\begin{array}{c}3 \text { months } \\
\mathrm{F}(\mathrm{R}) \text { values } \\
(\% \text { bias from } \\
\text { fresh sample) }\end{array}$ & $\begin{array}{c}6 \text { months } \mathrm{F}(\mathrm{R}) \\
\text { values (\%bias } \\
\text { from fresh } \\
\text { sample) }\end{array}$ \\
\hline 10 & $0.06 \pm 0.01$ & $\begin{array}{c}0.055 \pm 0.008 \\
(-2.9 \%)\end{array}$ & - & - \\
\hline 10 & $0.06 \pm 0.01$ & - & $\begin{array}{c}0.056 \pm 0.007 \\
(-8.0 \%)\end{array}$ & - \\
\hline 9 & $0.06 \pm 0.02$ & - & - & $\begin{array}{c}0.06 \pm 0.01 \\
(-2.8 \%)\end{array}$ \\
\hline
\end{tabular}


A Student's two sample T-test was conducted to determine if there was a statistically significant difference between the fresh and aged Cbi samples. The two-tailed critical values for T with significance levels of $\alpha=0.05$ are $2.10,2.10$, and 2.11 for the comparison between fresh and 1 month, fresh and 3 month, and fresh and 6 month samples, respectively. Degrees of freedom were 18 (e.g., 10+10-2), 18, and 17, respectively. No significant difference is found for any of the aging conditions. Two visual representations of the spread of the data can be seen in the "Box-and-Whisker" plot and bar graph in Figure 2.34. The Box-and-Whisker plot (Figure 2.34a) depicts the maximum values, the medians, the upper and lower quartiles $(25 \%$ of data greater and less than the median), and the minimum values for each set of data. The asterisk represents an outlier with a value of 0.031 , which was verified by the Grubbs Test $(\mathrm{n}=15$, critical value $=2.548$ at $95 \%$ C.I). This value was removed from the data set. Thus, 14 Cbi samples are represented in the "fresh" category. Another representation of the data can be observed in the bar graph in Figure 2.34b (uncertainty in terms of S.D). 
Figure 2.34 - Box-and-Whisker plot (A) and bar graph (B) of fresh and aged Cbi paper samples
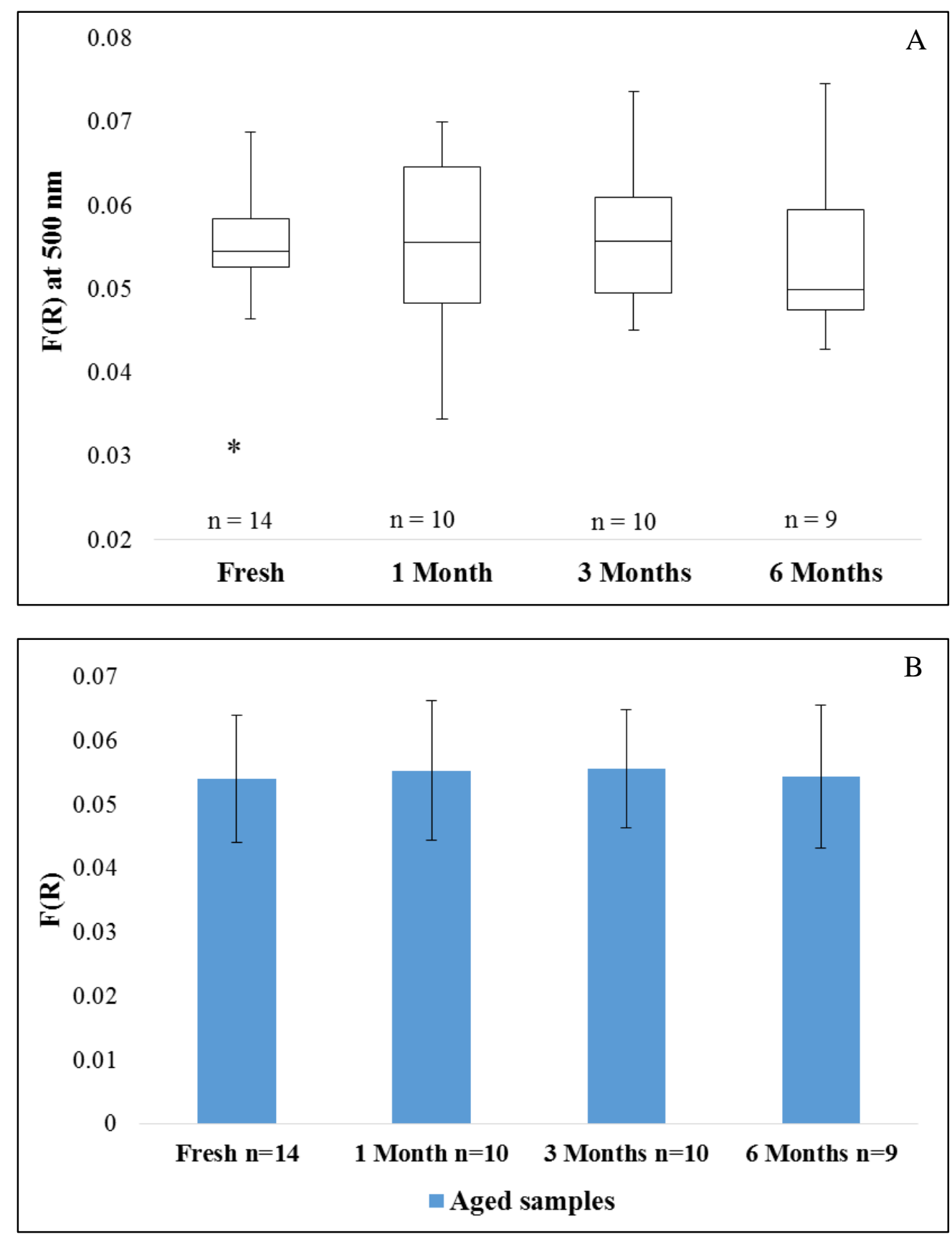
The aged papers were also evaluated by their detection of $5.0 \mathrm{ppm} \mathrm{HCN}$ based on $\mathrm{F}(\mathrm{R})$ values at $583 \mathrm{~nm}(25 \% \mathrm{RH})$. Table 2.5 shows the results of average $\mathrm{F}(\mathrm{R})$ values for samples aged for 1,3 , and 6 months $(n=3)$ compared to fresh $\mathrm{CN}\left(\mathrm{H}_{2} \mathrm{O}\right)$ Cbi paper samples $(n=6)$. Uncertainty is in terms of $95 \%$ CI. In 1 month-aged samples, the signal at 583 slightly increases for 1 and 5 minutes (relative to the fresh sample), but decreases at 10 minutes and for all exposure times for 3 and 6 months. As mentioned previously, the attenuated signal may not be attributed to degradation of Cbi, but due to paper placement in the sensor holder. Regardless, HCN is still rapidly detected at the concentration of interest by aged samples.

Table 2.4 - Aged $\mathrm{CN}\left(\mathrm{H}_{2} \mathrm{O}\right)$ Cbi paper sample $\mathrm{F}(\mathrm{R})$ responses at $583 \mathrm{~nm}$ when exposed to 5.0 ppm HCN

\begin{tabular}{|c|c|c|c|c|}
\hline Time (min) & $\begin{array}{c}\text { Fresh } \\
\mathrm{n}=6\end{array}$ & $\begin{array}{c}1 \text { month } \\
\mathrm{n}=3\end{array}$ & $\begin{array}{c}3 \text { months } \\
\mathrm{n}=3\end{array}$ & $\begin{array}{c}6 \text { months } \\
\mathrm{n}=3\end{array}$ \\
\hline 0 & $9.5 \pm 0.3 . \times 10^{-7}$ & $1.0 \pm 0.1 \times 10^{-6}$ & $1.11 \pm 0.04 \times 10^{-6}$ & $1 \pm 3 \times 10^{-10}$ \\
\hline 1 & $0.007 \pm 0.001$ & $0.009 \pm 0.004$ & $0.005 \pm 0.002$ & $0.0050 \pm 0.0006$ \\
\hline 5 & $0.015 \pm 0.001$ & $0.016 \pm 0.006$ & $0.011 \pm 0.004$ & $0.011 \pm 0.002$ \\
\hline 10 & $0.021 \pm 0.001$ & $0.019 \pm 0.009$ & $0.016 \pm 0.005$ & $0.014 \pm 0.003$ \\
\hline
\end{tabular}


Figure 2.35 - Fresh and aged Cbi paper samples exposed to 5.0 ppm HCN for 1 minute (A) and 15 minutes $(\mathrm{B})$
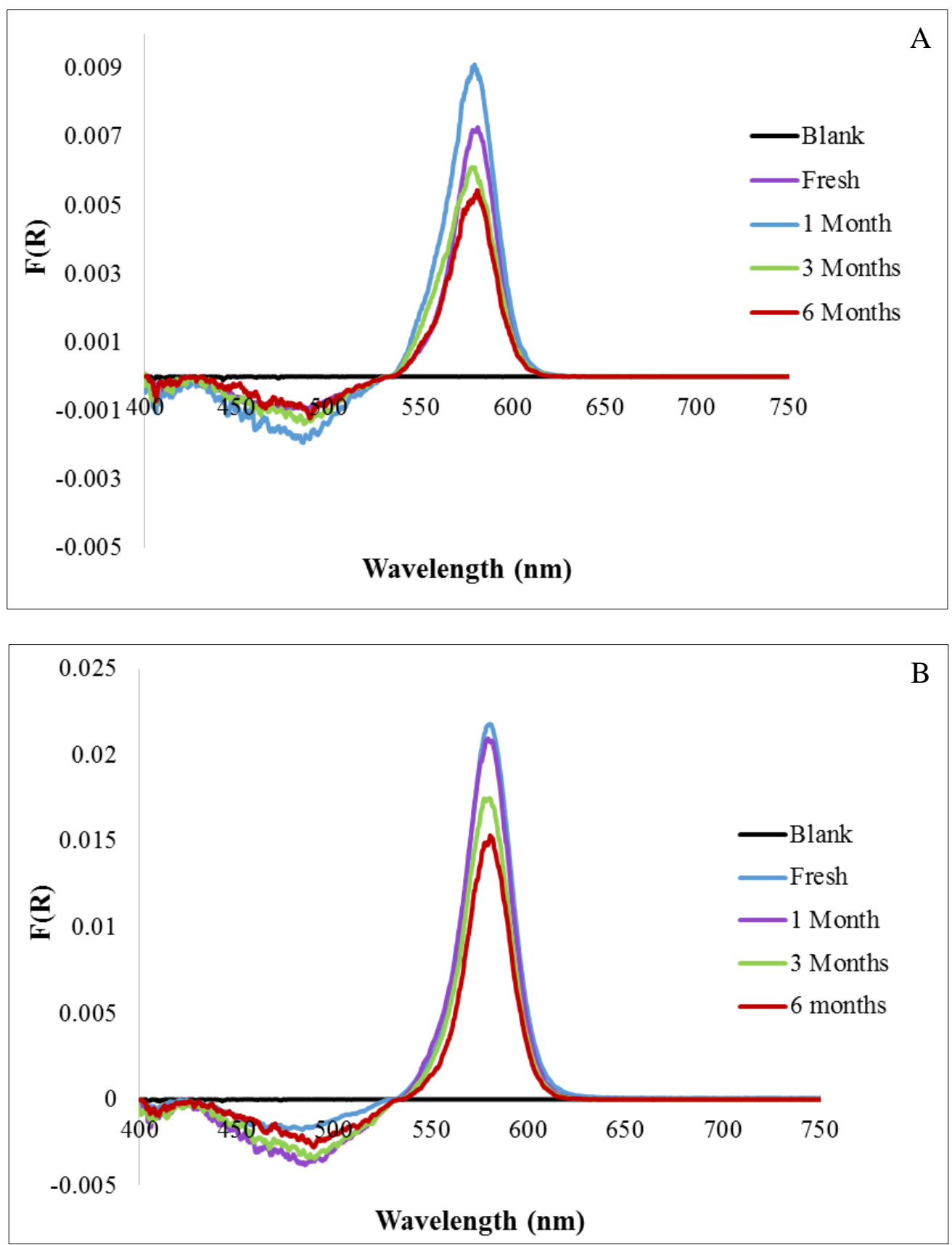

The reproducibility results suggest $\mathrm{Cbi}$ is stable on paper if kept at $4^{\circ} \mathrm{C}$. No significant difference was observed in the Cbi spectra, however it is difficult to determine if the response to HCN suffers as a result of aging. 


\subsubsection{Comparison of Cellulose and Glass Fiber Filter Paper}

The average time trends at $583 \mathrm{~nm}$ for 1.0 and $5.0 \mathrm{ppm} \mathrm{HCN}$ for cellulose and glass fiber filter paper are compared. The results can be seen in Figure 2.36. The glass fiber filter paper $F(R)$ responses to 1.0 and $5.0 \mathrm{ppm} \mathrm{HCN}$ are significantly larger than the cellulose filter paper. Again, this is most likely due to the thicker glass fiber paper allowing more light to be reflected back to the detector compared to the thinner, more porous cellulose filter paper. Additionally, a comparison between the $\mathrm{F}(\mathrm{R})$ values for both types of papers when exposed to $5.0 \mathrm{ppm} \mathrm{HCN}$ for

up to $1,5,10$, and 15 minutes is shown in Figure A.3. Glass fiber paper displays initial response times approximately half those of the cellulose paper. Data for Figure A.3 can be seen in Table A.8. 
Figure 2.36 - Comparison of $\mathrm{CN}\left(\mathrm{H}_{2} \mathrm{O}\right) \mathrm{Cbi}$ on cellulose and glass fiber filter paper to $5.0 \mathrm{ppm}$ $\mathrm{HCN}$ (A) with expanded view of initial response (B)
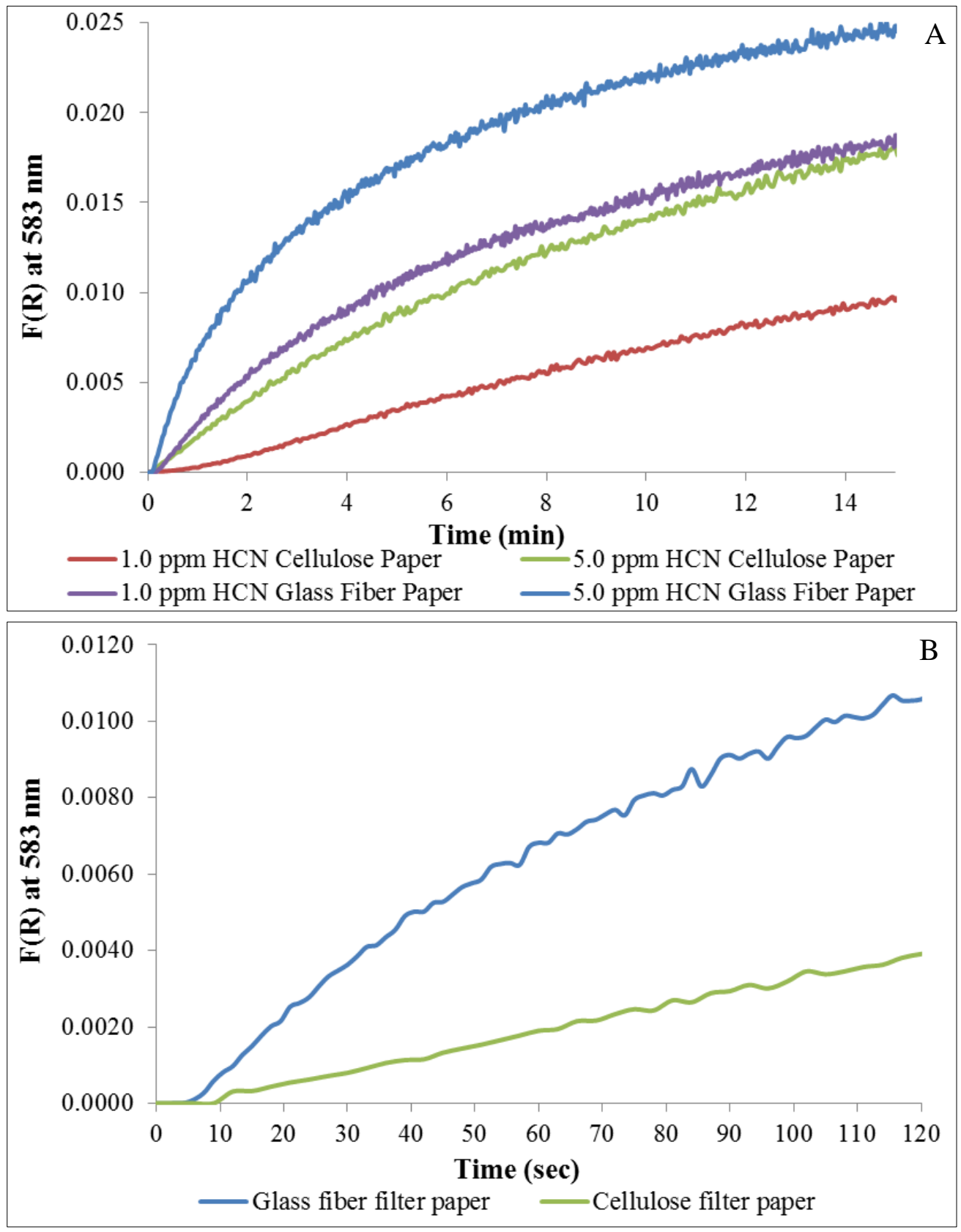


\subsubsection{Effect of Percent Relative Humidity 2.5.7.1 Control Experiment}

The effect of $\%$ RH on the paper's performance was quantified for additional RH values of 50 and $85 \%$. These humidity values were evaluated because respirators are used in a wide range of climates with various levels of humidity. Additionally, these specific values were selected as they are standard protocol for certification STPs at NIOSH.

A control experiment was conducted to observe the effect of $\% \mathrm{RH}$ on both types of paper without Cbi or HCN. Blank cellulose and glass fiber papers (no $\mathrm{CN}\left(\mathrm{H}_{2} \mathrm{O}\right) \mathrm{Cbi}$ ) were individually placed into the sensor holder and exposed to $25 \% \mathrm{RH}$ clean air for 30 minutes. Without moving the paper, $\% \mathrm{RH}$ were changed to allow $50 \% \mathrm{RH}$ air to flow over the paper for 30 minutes, and again changed for $85 \% \mathrm{RH}$ air to flow for 30 minutes. The $\% \mathrm{RH}$ was reduced to $25 \% \mathrm{RH}$ after 30 minutes exposure to $85 \% \mathrm{RH}$. Figure 2.37 displays these results for cellulose paper, where the average $F(R)$ values from 700 to $750 \mathrm{~nm}$ (i.e. the baseline) are plotted against time. The baseline appeared to be stable for $25 \% \mathrm{RH}$ exposure. Almost immediately after the MFCs were changed for $50 \% \mathrm{RH}$ flow, the signal decreases and stabilizes. A rapid and large decrease in signal is immediately observed for $85 \% \mathrm{RH}$ (at 60 minutes), which then rapidly increases when the air flow was reduced back to $25 \% \mathrm{RH}$ (at 90 minutes). 
Figure 2.37 - Effect of \%RH on cellulose filter paper

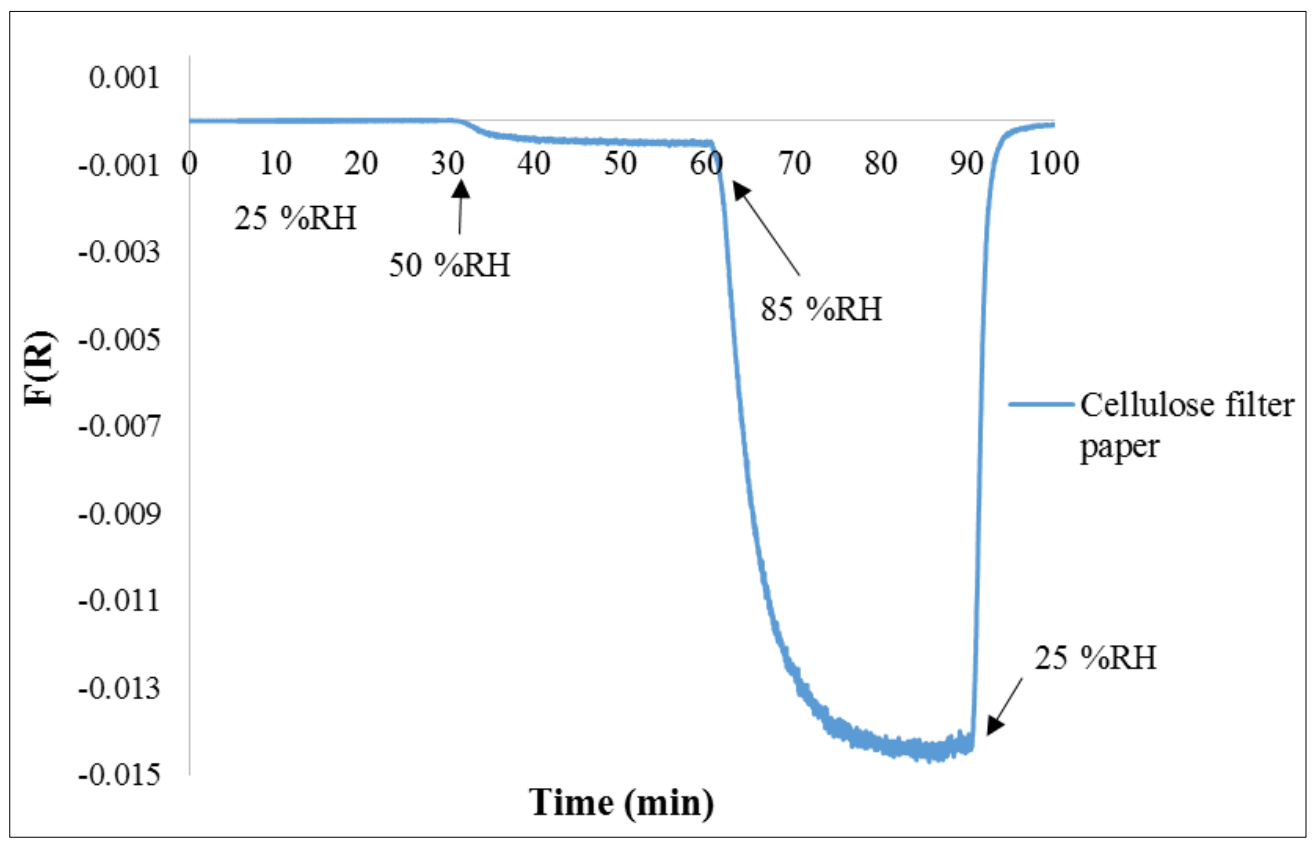

A similar experiment was conducted for glass fiber filter paper. Figure 2.38 displays these results where the average $F(R)$ values from 700 to $750 \mathrm{~nm}$ are plotted against time. Although difficult to see, the baseline decreases slightly for $25 \% \mathrm{RH}$ exposure, while it slightly increases for $50 \% \mathrm{RH}$ exposure (at 30 minutes). Both signals stabilize after a few minutes. Opposite that of cellulose paper, a rapid increase in signal is immediately observed for $85 \% \mathrm{RH}$ (at 60 minutes), which then quickly decreases when the \%RH was reduced back to $25 \% \mathrm{RH}$ (at 90 minutes). 
Figure 2.38 - Effect of \%RH on glass fiber filter paper

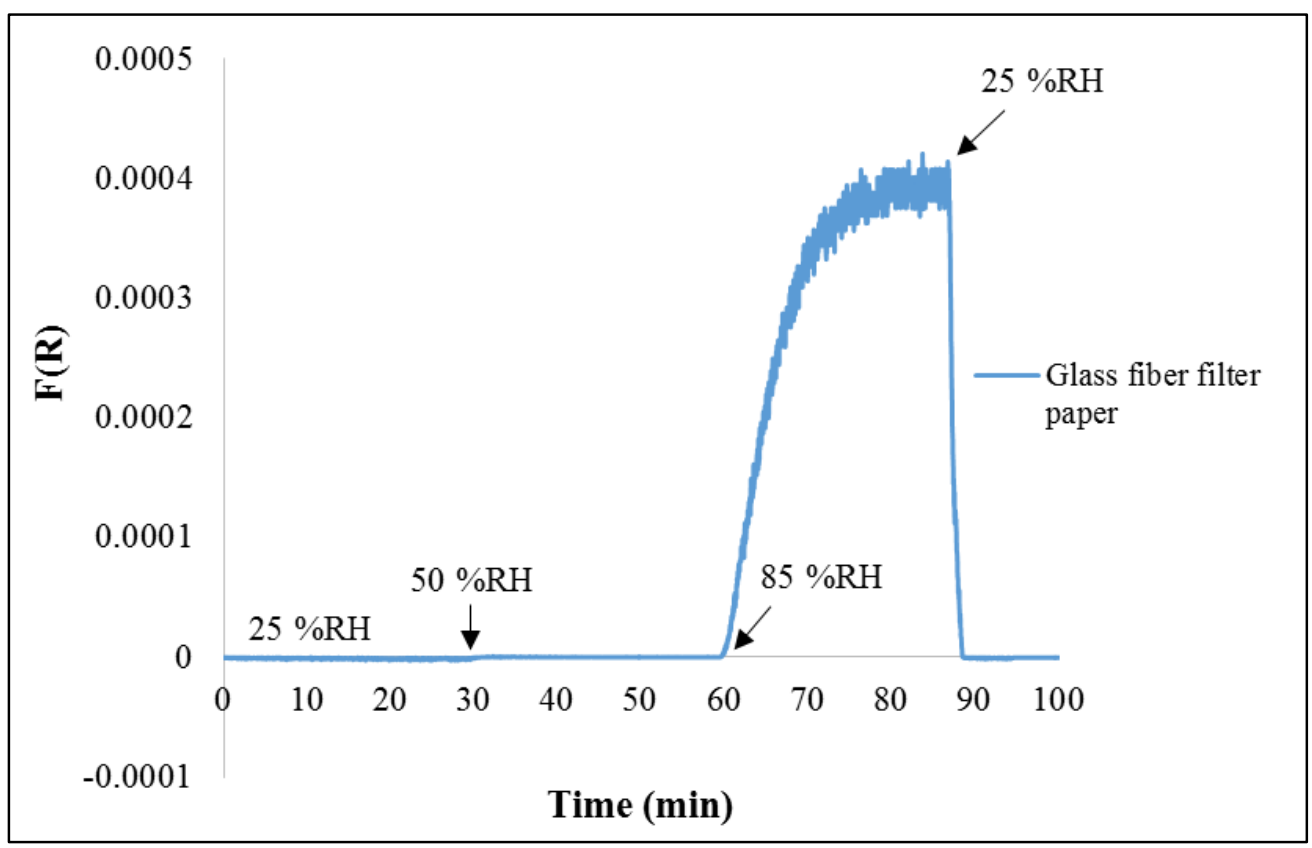

The opposing observations may be attributed to the light's interaction with water on the surface of each type of paper. For cellulose paper, a higher concentration of water vapor in the air leads to a decreased $\mathrm{F}(\mathrm{R})$ (i.e. decrease in apparent absorbance), or more light reaching the detector in the spectrometer. This observation may be attributed to better index-matching between the paper and the water vapor adsorbed to the paper, described in Section 2.2.1, where transmission through the paper is increased and the mirror reflects light back to the detector. When the piece of paper is dry, the pores are filled with air with a refractive index (R.I.) of $1.00 .{ }^{161}$ With increased \%RH, water (R.I. 1.33) fills the paper pores and better matches the R.I. of paper (i.e. “index matching”), reported to be $1.45-1.62$ for cellulose filter paper. ${ }^{138}$ Water in the paper's pores change the scattering properties of the material, where the average scattering is reduced. ${ }^{187}$ Water quickly wicks over the surface of the paper, possibly creating a smoother surface and allowing specular reflectance due to the air-water interface. This is similar to that of water on a 
road's surface. This phenomenon would allow more light to reach the spectrometer, causing a lower $\mathrm{F}(\mathrm{R})$ signal. $^{187}$

Figure 2.39 - Transparency of cellulose and glass fiber filter paper when wet
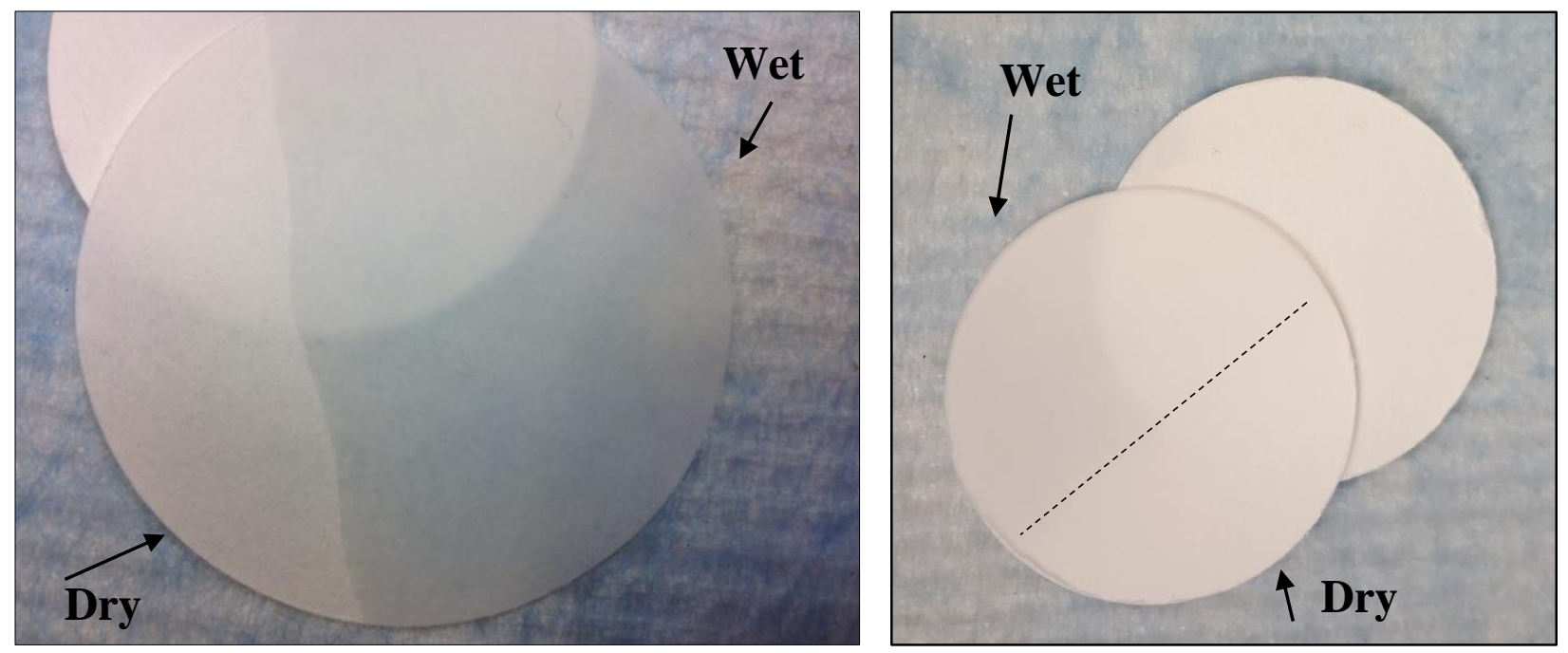

Glass fiber paper appears to be less affected to \% RH as cellulose filter paper by comparing their respective $F(R)$ intensities. The increase in $F(R)$ for the thicker glass fiber paper may be attributed to less light reaching the detector and more light absorbed by the thicker paper. Water adsorbed on a Lambertian surface (i.e. diffusely reflecting surface) often appears darker. ${ }^{187}$ This is attributed to the possibility of total internal reflection at the water-air interface, leading to multiple sequences of absorption within the paper matrix before reflection back to the spectrometer can occur. ${ }^{187}$

The increasing or decreasing baseline must be accounted for with the development of an ESLI using paper as a sensor medium. Algorithms for correction and alarm thresholds must be in place. Mathematical models as examples are presented in the NIOSH technical report: Components for Evaluation of Direct-Reading Monitors for Gases and Vapors. ${ }^{188} \mathrm{~A}$ false positive 
(caused by the glass fiber paper) would trigger an alarm and cause unnecessary costs for canister replacement, anxiety, and sense of mistrust of the sensor to the user.

\subsubsection{Effect of \%RH of HCN Detection}

$\mathrm{CN}\left(\mathrm{H}_{2} \mathrm{O}\right) \mathrm{Cbi}$ was fixed onto the paper circles and exposed to 25,50 , and $85 \% \mathrm{RH}$. Figure 2.40 shows the response on cellulose filter paper as a function of time for 25,50 , and $85 \% \mathrm{RH}$, with the data in Table A.8. A data point is added indicating the average $F(R)$ at $583 \mathrm{~nm}$ for $25 \%$ RH after 60 minutes $(0.0303 \pm 0.0002)$, similar to the $F(R)$ values of 50 and $85 \% R H$ after only 15 minutes ( $0.035 \pm 0.001$ and $0.0358 \pm 0.0001$, respectively).

Figure 2.40 - Response of $\mathrm{CN}\left(\mathrm{H}_{2} \mathrm{O}\right) \mathrm{Cbi}$ on cellulose filter paper to $5.0 \mathrm{ppm} \mathrm{HCN}$ at various $\%$ RH

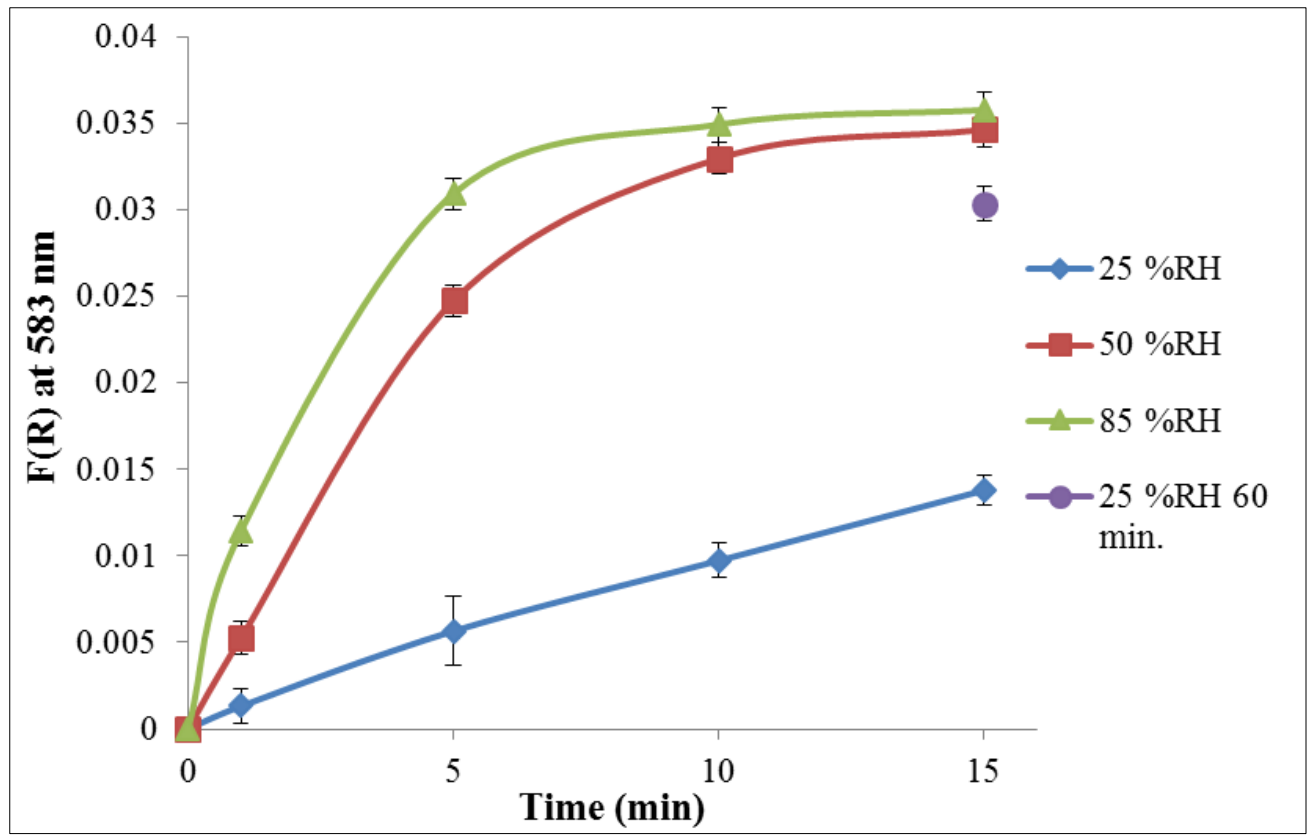

Figure 2.41 shows the effect of $\% \mathrm{RH}$ on glass fiber filter paper at $583 \mathrm{~nm}$ as a function of time for 25,50 , and $85 \% \mathrm{RH}$, with the data in Table A.10. Exposure to $25 \% \mathrm{RH}$ has a lower $\mathrm{F}(\mathrm{R})$ 
value than 50 or $85 \% \mathrm{RH}$ at each time interval. The response for $25 \% \mathrm{RH}$ begins to plateau after 10 min, while the response for 50 and $85 \%$ RH begins to plateau after 5 minutes for $50 \%$ and close to 1 minute for $85 \% \mathrm{RH}$, reaching steady-state more rapidly than cellulose paper.

Figure 2.41 - Response of $\mathrm{CN}\left(\mathrm{H}_{2} \mathrm{O}\right) \mathrm{Cbi}$ on glass fiber filter paper to $5.0 \mathrm{ppm} \mathrm{HCN}$ at various $\%$ RH

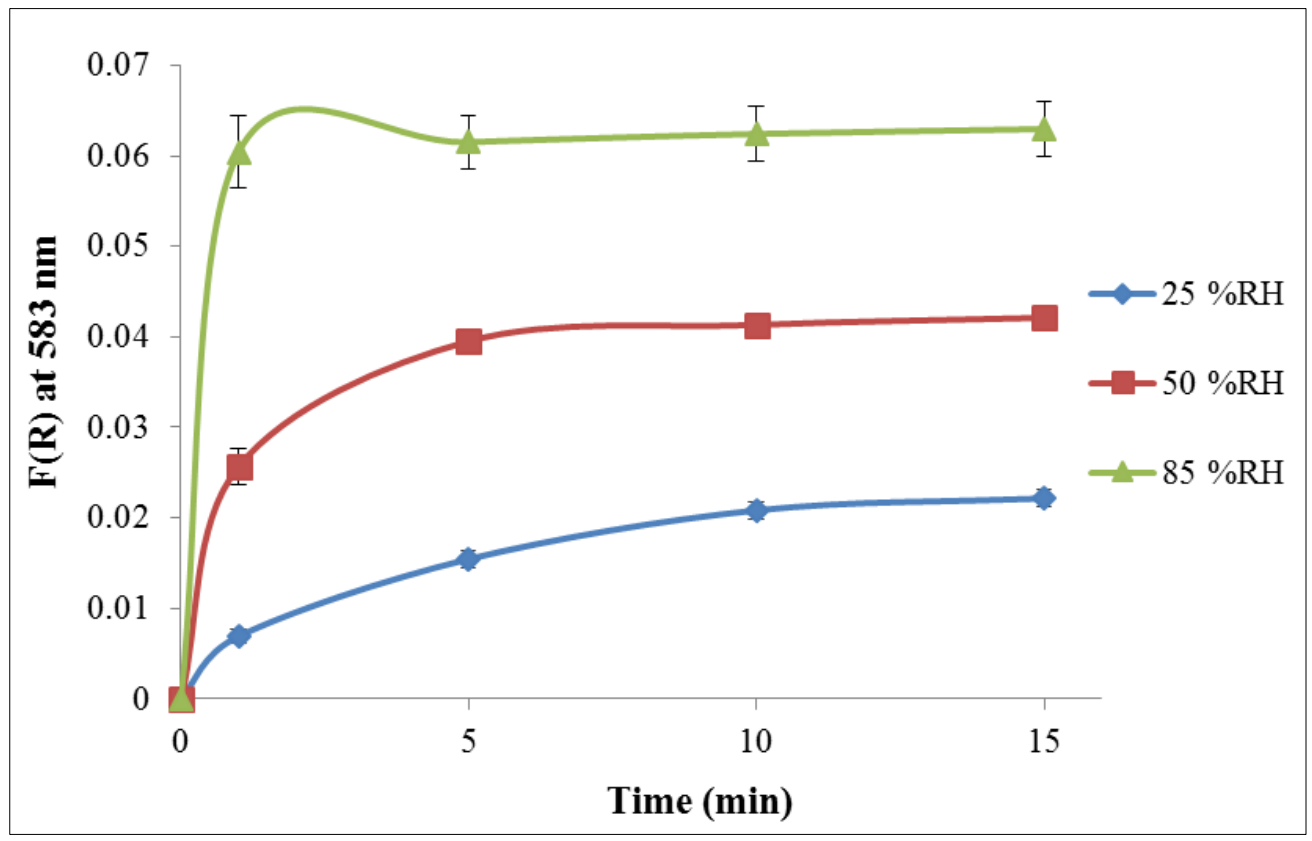

The $\mathrm{F}(\mathrm{R})$ signal for $85 \% \mathrm{RH}$ when exposed to $\mathrm{HCN}$ becomes saturated quickly, as can be seen by the difference spectra in Figure 2.42, where spectra were taken 1, 5, 10, and 15 minutes after exposure to $5.0 \mathrm{ppm} \mathrm{HCN}$. Little change is observed between these time intervals at the higher \%RH. The reaction of $\mathrm{CN}\left(\mathrm{H}_{2} \mathrm{O}\right) \mathrm{Cbi}$ on paper is affected by the moisture content on the paper: a dry paper $(25 \% \mathrm{RH})$ reacts slower while a more rapid reaction is observed with wetter paper ( 85 $\% \mathrm{RH})$. 
Figure 2.42 - Difference spectra of $\mathrm{CN}\left(\mathrm{H}_{2} \mathrm{O}\right) \mathrm{Cbi}$ on glass fiber paper response to $5.0 \mathrm{ppm} \mathrm{HCN}$ at $85 \% \mathrm{RH}$

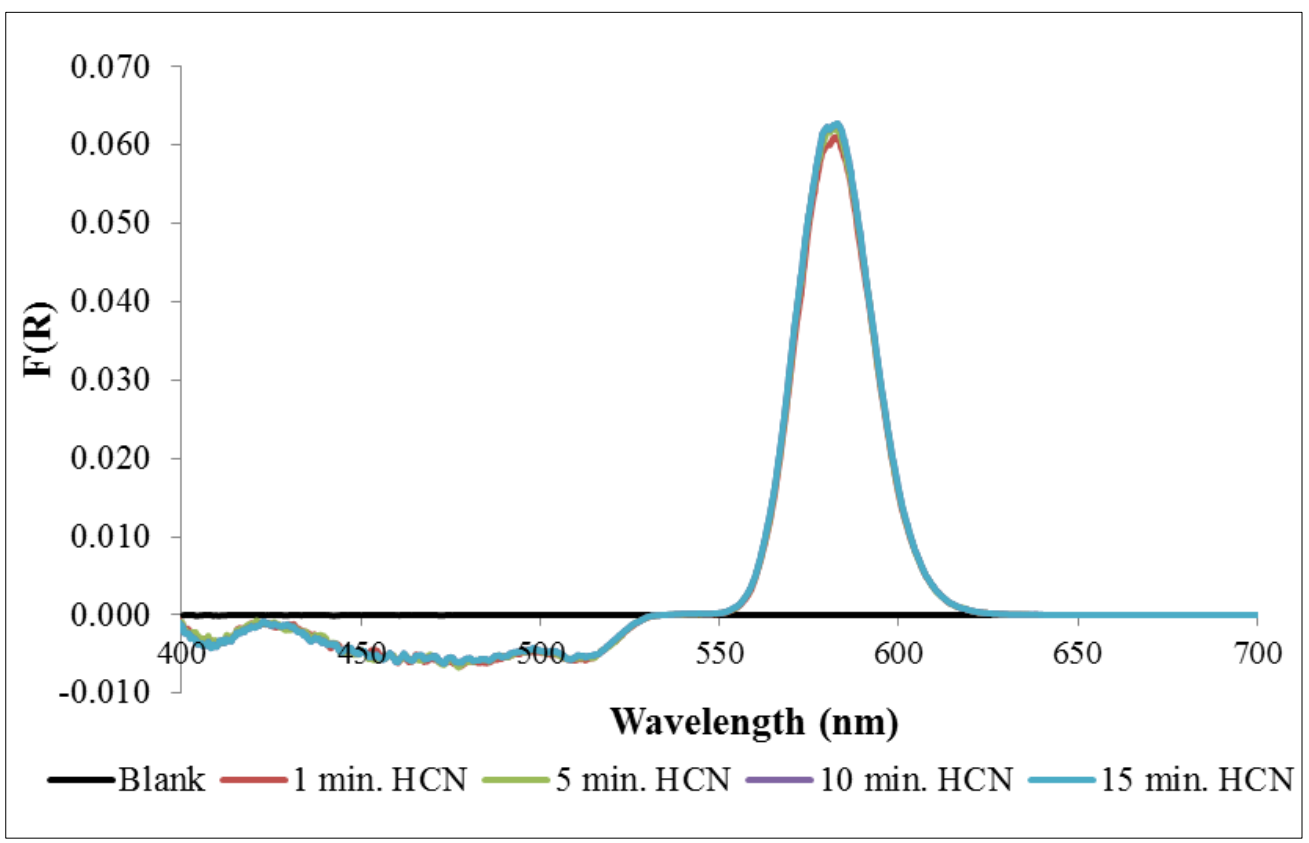

At each \% $\% H$ for both types of paper, the signal responds at approximately the same time ( $\sim 10$ seconds) after exposure to $\mathrm{HCN}$. The higher sensitivity of the $\mathrm{CN}\left(\mathrm{H}_{2} \mathrm{O}\right)$ Cbi-immobilized paper at higher relative humidity is clearly evident when comparing the initial responses (Figure 2.43a and b). Data for the initial responses of cellulose and glass fiber paper can be seen in Table A.10 and A.11, respectively. For cellulose filter paper, the sensitivity increases $3 \mathrm{x}$ and $7 \mathrm{x}$ for 50 and $85 \% \mathrm{RH}$, respectively (compared to $25 \% \mathrm{RH}$ ). For glass fiber filter paper, the sensitivity increases $6 \mathrm{x}$ and $50 \mathrm{x}$ for $50 \% \mathrm{RH}$ and $85 \% \mathrm{RH}$, respectively. 
Figure 2.43 - Average initial response of $\mathrm{CN}\left(\mathrm{H}_{2} \mathrm{O}\right)$ Cbi on cellulose filter paper (A) glass fiber filter paper (B) to $5.0 \mathrm{ppm} \mathrm{HCN}$ at various $\% \mathrm{RH}$
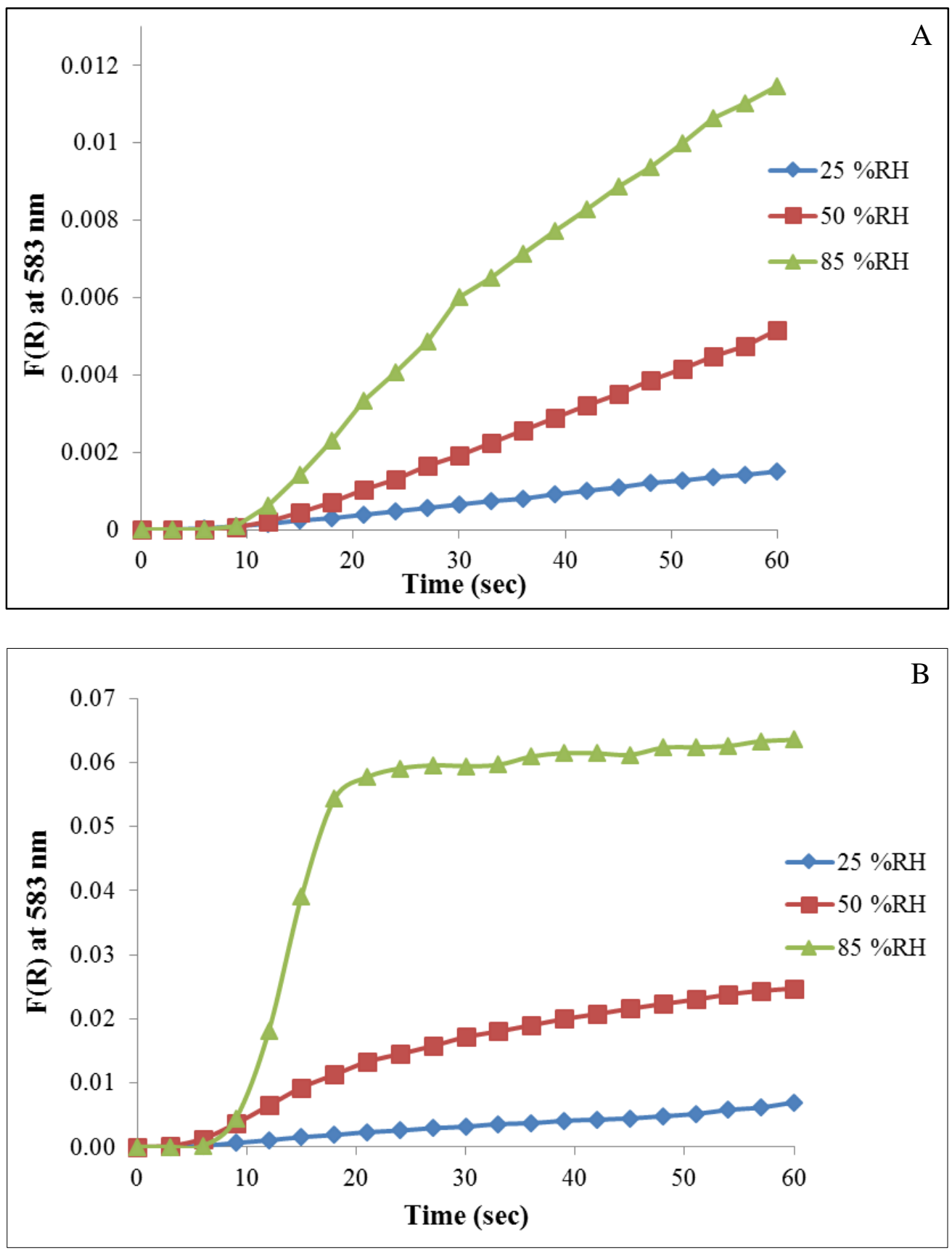

The larger observed signals at increasing \% $\mathrm{RH}$ may be attributed to the ability of the papers to adsorb water vapor, creating a more solution-like medium for the reaction between HCN and cobinamide, and possibly adding a proton acceptor for the HCN. It may also be attributed to 
index matching, as previously described. The water vapor in the air may also contribute to a smaller scattering cross-section for both types of paper as water fills the air-filled pores of the paper. $^{138}$

The large value of the binding constant for cyanide with $\mathrm{CN}\left(\mathrm{H}_{2} \mathrm{O}\right) \mathrm{Cbi}\left(\mathrm{i} . \mathrm{e} .10^{8}\right)$ implies that the cyanide binding should be irreversible. However, Figure 2.44 shows that the complex can slowly revert back to $\mathrm{CN}\left(\mathrm{H}_{2} \mathrm{O}\right) \mathrm{Cbi}$ when $\mathrm{HCN}$ is removed from the gas stream (cellulose paper). In this experiment, $5.0 \mathrm{ppm} \mathrm{HCN}$ was cycled on and off at 15 minute increments with an additional 60 minute absence of $\mathrm{HCN}$ at the end of the experiment. The flow and \% RH were held constant. Figure 2.45 shows a similar type of response for the glass fiber filter paper. Surprisingly, the rate of loss of cyanide was greatest at $50 \% \mathrm{RH}$. For both types of paper, the kinetics of the loss of cyanide is substantially slower than the kinetics of binding indicating that $\mathrm{k}_{\mathrm{f}}$ is larger than $\mathrm{k}_{\mathrm{r}}$. In terms of an end-of-service-life sensor, a brief exposure to HCN may not trigger the sensor due to insufficient change in the reflectance spectrum. However, the sensor would remain sensitive and respond rapidly upon a repeated exposure to $\mathrm{HCN}$ when going through environments of STEL and the Permissible Exposure Limit (PEL). Despite the potential reversibility of the sensor, ESLI standards require that an alarm be triggered to indicate $90 \%$ of the bed life is expended, an event that occurs only once in the lifetime of the carbon bed. ${ }^{54}$ The sensor response is not required to be linear or indicate a precise concentration, however the threshold response must be calibrated. 
Figure 2.44 - Effect of \% RH on Cbi cellulose filter paper to $5.0 \mathrm{ppm} \mathrm{HCN}$

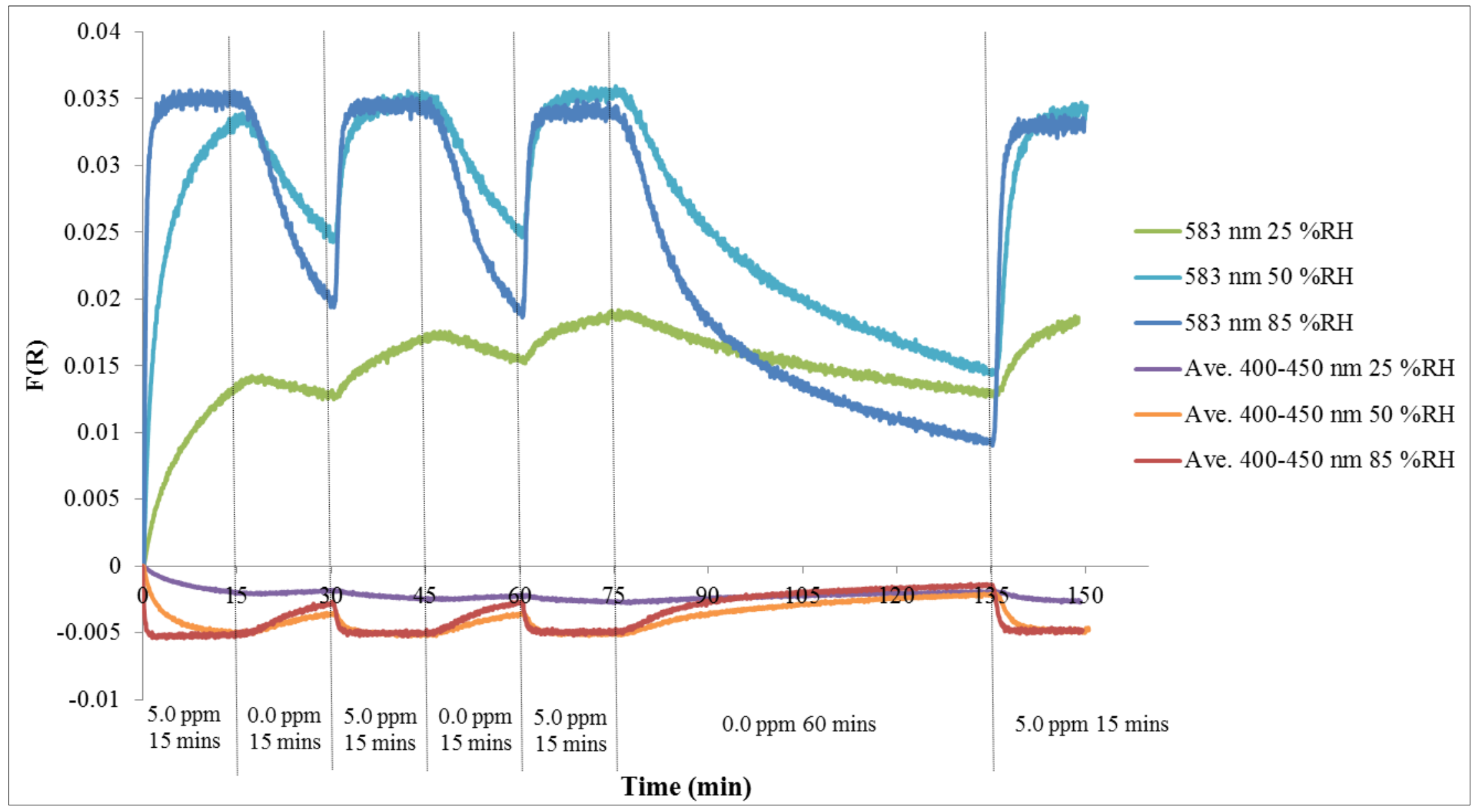


Figure 2.45 - Effect of \% RH on Cbi glass fiber filter paper to $5.0 \mathrm{ppm} \mathrm{HCN}$

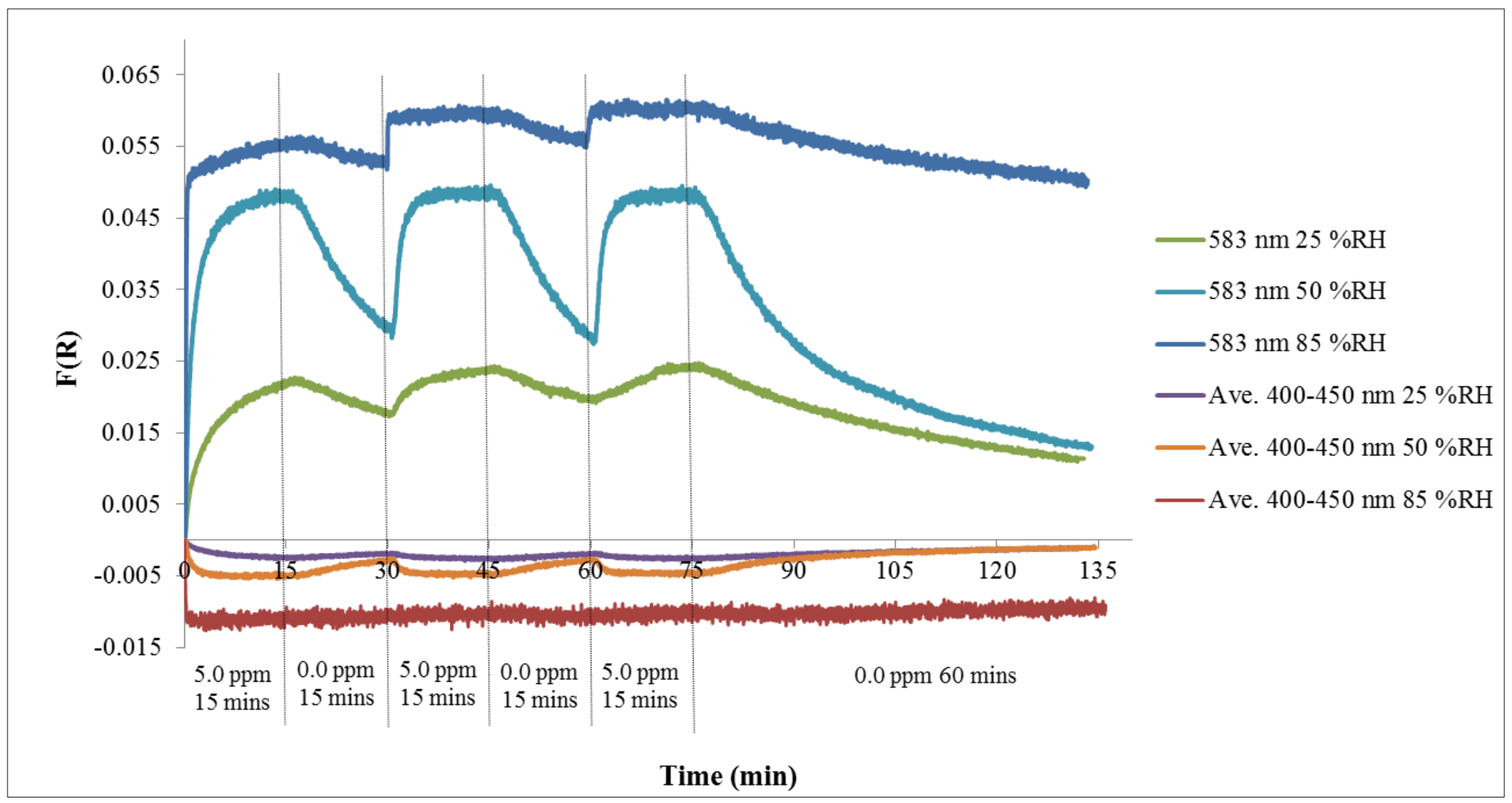




\subsection{Conclusion}

When $\mathrm{CN}\left(\mathrm{H}_{2} \mathrm{O}\right)$ Cbi was spotted onto cellulose and glass fiber filter paper, a rapid detection of low concentrations of $\mathrm{HCN}$ gas was successful. The combination of the diffuse reflectance setup and the impregnated filter papers allowed for the detection of the NIOSHrecommended STEL concentration for $\mathrm{HCN}$ gas within 10 seconds of $\mathrm{HCN}$ exposure. When the Kubelka-Munk function was applied, a more linear signal was observed as a function of time of $\mathrm{HCN}$ exposure and $\mathrm{HCN}$ concentration. The glass fiber paper resulted in larger $\mathrm{F}(\mathrm{R})$ values compared to cellulose filter paper. Paper was sensitive to moisture where a more rapid response occurs under conditions of higher humidity, but the observed baseline increase with increasing $\%$ RH must be accounted for.

Although this paper-based optochemical sensor is semi-quantitative due to the intrinsic scattering of paper, an ESLI could be developed that would indicate to the user (by use of an alarm or light signal) that the canister service-life has almost ended based on a threshold reflectance signal upon HCN detection. Paper offers many advantages over traditional detection methods for HCN discussed Section 1.1.5. Paper is widely available, simple, inexpensive, lightweight, and can be modified to fit a variety of applications. The availability of small photodetectors, inexpensive optical fibers, and low-power LED light sources suggest that a simple diffuse reflectance configuration could satisfy the size, cost, and power requirements for ESLIs, a drawback for electrochemical detectors. The small footprint of the proposed sensor makes it feasible to incorporate other sensing elements (for VOCs, halogens, CWAs, etc.) in a multiplexed fashion. The cobinamide sensing element has the potential to detect other compounds known to complex with cobinamide, such as ammonia and hydrogen sulfide. ${ }^{189}$ 


\section{Chapter 3: Cobinamide-Based Detection of Hydrogen Sulfide Gas}

\subsection{Introduction}

Hydrogen sulfide $\left(\mathrm{H}_{2} \mathrm{~S}\right)$ is one of the most common interfering substances for both aqueous $\mathrm{CN}^{-}$and gaseous $\mathrm{HCN}$ detection methods. ${ }^{190-192}$ The interference has been established for electrochemical and colorimetric detection, observed in both the NIOSH Analytical Methods (6010 and 6017) and in the Environmental Protection Agency (EPA) Method OIA-1677. ${ }^{70,80,193}$ Sulfide being the primary contributor, the "EPA Solutions to Analytical Chemistry Problems with Clean Water Act Methods" states that, "next to oil and grease, cyanide is the pollutant for which the most matrix interferences have been reported to the EPA". ${ }^{194}$ The positive interference is in part due to sulfide reacting with cyanide to form thiocyanate, or sulfide acidifying to hydrogen sulfide and colorimetric reagents erroneously detecting sulfide as cyanide. ${ }^{192}$ Interference of $\mathrm{H}_{2} \mathrm{~S}$ for $\mathrm{HCN}$ detection could cause either a false positive (end-of-service-life determined prematurely) or a false negative (end-of-service-life determined detrimentally too late).

Cobinamide is also reported to complex with $\mathrm{HS}^{-}$. In this chapter, the effects of cobinamide on paper when exposed to $\mathrm{H}_{2} \mathrm{~S}$ gas were explored. The purpose was to determine if $\mathrm{H}_{2} \mathrm{~S}$ would cause an interfering problem when detecting $\mathrm{HCN}$, or if a dual-purpose sensor could be established. A gas-flow system was modified from a setup used by NIOSH for respirator certification testing. ${ }^{195}$ In Chapter 2, glass fiber paper provided a higher signal compared to cellulose paper when exposed to HCN, therefore only this type of paper was used for immobilization of Cbi. Monocyanocobinamide, used in Chapter 2 for the detection of HCN, was not used for detection of $\mathrm{H}_{2} \mathrm{~S}$ because the addition of the first $\mathrm{CN}^{-}$ligand was not necessary to 
rapidly detect $\mathrm{HCN}$; two ligand binding sites were available to study the overall binding capabilities of $\mathrm{HS}^{-}$to Cbi. Therefore, aquohydroxocobinamide $\left[\mathrm{OH}\left(\mathrm{H}_{2} \mathrm{O}\right) \mathrm{Cbi}\right]$ was fixed onto the glass fiber paper and placed into the diffuse reflectance setup as previously described. The reflectance spectrum of the $\mathrm{OH}\left(\mathrm{H}_{2} \mathrm{O}\right)$ Cbi was monitored during exposure to 10.0 ppm hydrogen sulfide gas (NIOSH REL). Spectral changes due to the reaction between Cbi and sulfide (HS') were monitored as a function of time at several relative humidity values: 25,50 , and $85 \%$ relative humidity. Spectral shifts at higher humidity suggest reduction of the Cbi(III) compound.

\subsection{Background}

\subsubsection{Hydrogen Sulfide}

Hydrogen sulfide is extremely flammable, corrosive, and lethal, earning its place as the second most common cause of fatal gas inhalation in the workplace, behind $\mathrm{CO} .{ }^{115} \mathrm{H}_{2} \mathrm{~S}$ is denser than air and thus often found in low-lying and confined spaces such as natural gas wells, sulfur springs and lakes, sewers, well water, volcanoes, and areas of organic matter decomposition. ${ }^{196}$ $\mathrm{H}_{2} \mathrm{~S}$ is most commonly used and produced in oil and gas refining, waste water treatment, mining, tanning, and pulp and paper processing industries. ${ }^{196}$ Both acute and chronic $\mathrm{H}_{2} \mathrm{~S}$ exposure can occur in these facilities. The EPA has considered $\mathrm{H}_{2} \mathrm{~S}$ as a dominant impurity in natural gas and is said to make gas "sour", thus removal is necessary and may be accomplished by precipitation with metals or physical adsorption in solid bed absorbents. ${ }^{197}$ Workers may be routinely or accidently exposed to $\mathrm{H}_{2} \mathrm{~S}$ during the removal stage as well extraction, treatment, storage or refining stages. ${ }^{197} \mathrm{H}_{2} \mathrm{~S}$ is also commonly released in well blowouts during drilling, line releases, or leakage from abandoned wells. ${ }^{197}$ The 1990 Clean Air Act is a federal law designed to control and regulate air pollution. ${ }^{198} \mathrm{H}_{2} \mathrm{~S}$ was originally on the hazardous air pollutants list for this Act, however, controversially a "clerical error" was reportedly at fault for $\mathrm{H}_{2} \mathrm{~S}$ being added to this list 
and was hence removed in 1991. The removal was driven by oil and gas and chemical industries claiming $\mathrm{H}_{2} \mathrm{~S}$ is "accidently released" rather than a routine one. ${ }^{199,200}$

Known for its characteristic "rotten egg" smell, many exposed workers believe the distinct odor is a suitable means for detecting the presence of $\mathrm{H}_{2} \mathrm{~S}$. Individuals have a wide range of $\mathrm{H}_{2} \mathrm{~S}$ odor sensitivity, with reported detection thresholds of $0.5-300 \mathrm{ppb}$; it is estimated that $83 \%$ of the general population should be able to detect $\mathrm{H}_{2} \mathrm{~S}$ at $30 \mathrm{ppb} .^{201}$ Due to olfactory fatigue, a person can become "desensitized" to 15 minutes exposures of low concentrations or more rapidly at concentrations above the IDLH $(100+\mathrm{ppm})$. Although early odor of $\mathrm{H}_{2} \mathrm{~S}$ is beneficial, NIOSH and OSHA warn that this odor is not a reliable indicator especially at elevated $\mathrm{H}_{2} \mathrm{~S}$ concentrations, thus respiratory equipment is required. Recommended respirators include a powered air-purifying respirator (PAPR) with NIOSH-approved cartridges, or a self-contained breathing apparatus (SCBA). $\mathrm{H}_{2} \mathrm{~S}$ is especially dangerous to first responders who are unaware of the situation and not wearing adequate respiratory equipment. ${ }^{115}$ Although the exact number of fatalities associated with exposure to $\mathrm{H}_{2} \mathrm{~S}$ is not clear, it can be confidently stated that the number will increase with the surge in oil and gas related occupations in the United States, increasing the risk of $\mathrm{H}_{2} \mathrm{~S}$ exposure to workers. $\mathrm{H}_{2} \mathrm{~S}$ continues to be a controversial toxic compound, with hundreds of thousands of employees being exposed daily.

The NIOSH C REL for $\mathrm{H}_{2} \mathrm{~S}$ is 10 ppm (“C" = ceiling) with an IDLH of 100 ppm. ${ }^{202}$ This means that a person should not be exposed to concentrations above $10 \mathrm{ppm}_{2} \mathrm{~S}$ longer than 10 minutes during a 10-hour workday and 40-hour workweek. In 2011, the American Conference of Governmental Industrial Hygienists (ACGIH) recommended to decrease the REL to 1 ppm. ${ }^{203}$ Although not mandatory, this recommendation was based on recent data gathered on health effects of $\mathrm{H}_{2} \mathrm{~S}$ exposure. Depending on the concentration and length of exposure, $\mathrm{H}_{2} \mathrm{~S}$ is an 
irritant and asphyxiant. At low concentrations, $\mathrm{H}_{2} \mathrm{~S}$ can lead to personal stress and anxiety, while at high concentrations exposure can lead to loss of consciousness, permanent brain damage, or death. ${ }^{204} \mathrm{H}_{2} \mathrm{~S}$ affects the central nervous, respiratory and cardiovascular systems with common symptoms and physical properties summarized in Table 3.1 .

Table $3.1-\mathrm{H}_{2} \mathrm{~S}$ properties and symptoms

\begin{tabular}{|c|c|}
\hline Molecular Weight ${ }^{202}$ & $34.1 \mathrm{~g} / \mathrm{mol}$ \\
\hline Boiling Point ${ }^{202}$ & $-60^{\circ} \mathrm{C}$ \\
\hline Vapor Pressure & 13051 Torr at $21^{\circ} \mathrm{C}$ \\
\hline Conversion Factor ${ }^{202}$ & $1 \mathrm{ppm}=1.40 \mathrm{mg} / \mathrm{m}^{3}$ at $25^{\circ} \mathrm{C}$ \\
\hline Gas Density & $1.363 \mathrm{~kg} / \mathrm{m}^{3}$ \\
\hline $\mathbf{p K a}^{205^{*}, 206 *}$ & $\begin{array}{l}\mathrm{pKa}_{1}=6.98 \text { at } 25^{\circ} \mathrm{C} \\
\mathrm{pKa}_{2}=14.15^{*} \text { or } 19 \pm 2^{\ddagger}\end{array}$ \\
\hline $\begin{array}{c}\text { Lethal Blood } \\
\text { Concentrations }^{207}\end{array}$ & $1.7-3.75 \mathrm{mg} / \mathrm{L}$ \\
\hline $\begin{array}{l}\text { General Symptoms if } \\
\quad \text { Inhaled } 208\end{array}$ & $\begin{array}{l}\text { Upper respiratory symptoms, damage to lungs, skin, eyes (conjunctivitis) and } \\
\text { nose mucous membranes, neurological disorders (headaches, lack of } \\
\text { concentration, memory loss, sleep disturbances), cardiovascular } \\
\text { abnormalities (irregular heartbeat), pulmonary edema, cyanosis, } \\
\text { unconsciousness, coma and death. }\end{array}$ \\
\hline Concentration (ppm) ${ }^{196}$ & Symptoms/Effects ${ }^{196}$ \\
\hline $0.00011-0.00033$ & Typical concentrations in environment \\
\hline $0.01-1.5$ & $\begin{array}{l}\text { Odor threshold first noticeable; metabolic changes in exercising } \\
\text { individuals }{ }^{203}\end{array}$ \\
\hline $2-5$ (prolonged) & $\begin{array}{l}\text { Nausea, headaches, insomnia, irritability, bronchial constrict in asthma } \\
\text { patients. Easily noticeable odor. }{ }^{209}\end{array}$ \\
\hline $50-100$ (after $1 \mathrm{hr}$ ) & Conjunctivitis, respiratory tract irritation, loss of appetite \\
\hline $100-150^{209}$ & Olfactory fatigue/paralysis \\
\hline $300-700^{205}$ & $\begin{array}{l}\text { Staggering, irreversible damage to eye, rapid breathing; Death in } 30- \\
60 \text { minutes }\end{array}$ \\
\hline $1000+$ & Physical collapse, paralysis of respiration, instantaneous death \\
\hline
\end{tabular}

$\mathrm{H}_{2} \mathrm{~S}$ can be metabolized by the body in three distinct pathways: oxidation to sulfate, methylation, and reaction with metallo- or disulfide-containing proteins. ${ }^{209}$ The latter is largely considered the mechanism of $\mathrm{H}_{2} \mathrm{~S}$ toxicity. Generally, there is a lack of information regarding the toxicity of $\mathrm{H}_{2} \mathrm{~S}$, with disputes on if $\mathrm{H}_{2} \mathrm{~S}$ binds to cytochrome c oxidase, or if it causes reduction 
of intracellular ferric ion to ferrous ion. ${ }^{210,211}$ With a suspected manner like $\mathrm{HCN}, \mathrm{H}_{2} \mathrm{~S}$ may inhibit mitochondrial cytochrome oxidase, reducing oxidative phosphorylation during cellular respiration and disrupting the electron transport chain. $\mathrm{H}_{2} \mathrm{~S}$ is reported to be a more powerful inhibitor of cytochrome oxidase than $\mathrm{CN}^{-} .{ }^{209}$ Since $\mathrm{HCN}$ and $\mathrm{H}_{2} \mathrm{~S}$ are regarded to have similar reactivity for ferric heme iron, the same antidote kits (described in 2.2.1) are typically used for $\mathrm{H}_{2} \mathrm{~S}$ exposure with the absence of administration of sodium thiosulfate. When sodium nitrate is introduced to the body, complexation of $\mathrm{HS}^{-}$with methemoglobin to form sulfmethemoglobin occurs. $^{209}$

Similar to the hydroxocobalamin cyanide antidote kit described in Section 2.2.1, aquacobalamin has recently been shown to be an effective $\mathrm{H}_{2} \mathrm{~S}$ antidote in poisoned animal models. ${ }^{212}$ Due to cobinamide's unique advantages over cobalamin, the kinetics and mechanism of diaquocobinamide $\left[\left(\mathrm{H}_{2} \mathrm{O}\right)_{2} \mathrm{Cbi}(\mathrm{III})\right]$ with $\mathrm{H}_{2} \mathrm{~S}$ and aquohydroxocobinamide $\left[\mathrm{OH}\left(\mathrm{H}_{2} \mathrm{O}\right) \mathrm{Cbi}(\mathrm{III})\right]$ with NaHS were explored by Salnikov et al. and Brenner et al., respectively. ${ }^{115,189}$ Brenner et al. described diffuse optical spectroscopy (DOS) and continuous wave near-infrared spectroscopy (CWNIRS) to monitor toxicity and reversal of NaHS-induced rabbits by intravenous injection of cobinamide. Aquohydroxocobinamide was found most effective compared to dinitrocobinamide, sulfitocobinamide, and hydroxocobalamin (which was not significantly more effective than the placebo, saline). ${ }^{115}$ Salnikov et al. reported that cobinamide bound sulfide 100 times faster than cobalamin under the same conditions. ${ }^{189}$ A detailed explanation with UV-VIS spectra, mass spectrometry data, cyclic voltammograms, and ${ }^{1} \mathrm{H}$ NMR studies is referenced; the relevant key findings are summarized in Section 3.2.2. ${ }^{189}$

The most common and widely-available gas detectors for $\mathrm{H}_{2} \mathrm{~S}$ are voltammetric electrochemical air monitoring devices. Many manufacturers offer portable electrochemical 
detectors with detection ranges from $0-500$. ppm with detection limits of $0.5 \mathrm{ppm}$ and resolutions of 0.1 or $1 \mathrm{ppm} .{ }^{213}$ These detectors offer programmable alarms set at $10.0 \mathrm{ppm} \mathrm{H}_{2} \mathrm{~S}$ to alert the user to exit the scene or don a SCBA. ${ }^{203}$ Although manufacturers do not release the fabrication material of the electrodes or specific half-reactions, they are generally made of platinum or silver for sulfide detection. ${ }^{214,216} \mathrm{H}_{2} \mathrm{~S}$ is oxidized at the sensing electrode to a welldefined product (not reported), so the number of electrons transferred per sulfide is constant; current is proportional to sulfide concentration. A common type, produced by manufacturer MSA, is priced at $\$ 469.00$ and shown in Figure 3.1..$^{215}$

Figure 3.1 - MSA Altair $\mathrm{H}_{2} \mathrm{~S}$ detector (with permission)

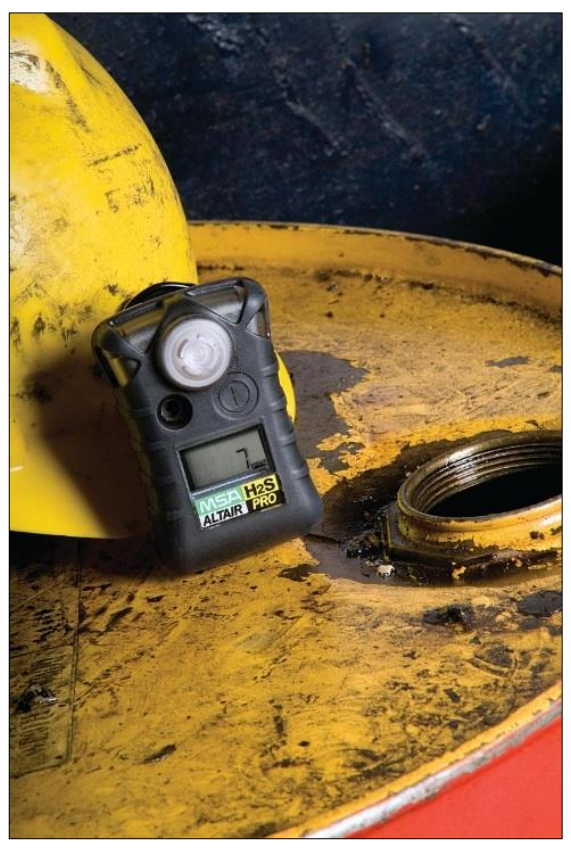

Additional gas-phase $\mathrm{H}_{2} \mathrm{~S}$ monitors include other electrochemical detectors (e.g., amperometric, potentiometric, coulometric), spectroscopic (e.g., UV-VIS, fluorescence), gas sampling tubes, and GC/MS. ${ }^{204,217}$ Although these detection methods are valuable in a laboratory setting, they offer drawbacks for field use. Table 3.2 compares these common $\mathrm{H}_{2} \mathrm{~S}$ detectors 
from the standpoint of portability. The detection of the sulfide ion ( $\mathrm{HS}^{-}$or $\left.\mathrm{S}^{2-}\right)$ in the context of biologically-relevant samples or aqueous solutions is outside the scope of this summary and reviews can be found elsewhere. ${ }^{204,205,218}$ However, the most common types of colorimetric detection of sulfide includes reaction with $\mathrm{N}, \mathrm{N}$-dimethyl-p-phenylenediamine sulfate in presence of iron(III) or zinc to form methylene blue, or use of crystal violet. ${ }^{219,220}$ Recent reviews $^{2}$ on chromogenic and fluorogenic chemosensors can be found elsewhere..$^{218,221}$ 
Table 3.2 - General comparison of common $\mathrm{H}_{2} \mathrm{~S}$ detection methods

\begin{tabular}{|c|c|c|c|c|c|c|c|}
\hline Detection & Selectivity & Sensitivity & Size & $\begin{array}{c}\text { Power } \\
\text { Requirements }\end{array}$ & $\begin{array}{c}\text { Sensor } \\
\text { Lifetime }\end{array}$ & $\begin{array}{l}\text { Detection } \\
\text { limit* }\end{array}$ & Cost \\
\hline $\begin{array}{l}\text { Gas sampling } \\
\text { tubes } 222\end{array}$ & Poor & Poor & $\begin{array}{l}\text { Small: } \\
\text { sufficient } \\
\text { for use } \\
\text { and } \\
\text { comfort }\end{array}$ & None & $\begin{array}{l}\text { Temperature } \\
\text { and humidity } \\
\text { sensitive; < } \\
3 \text { years } \\
\text { unopened }\end{array}$ & $>0.05 \mathrm{ppm}$ & Low \\
\hline Electrochemical & $\begin{array}{l}\text { Poor- } \\
\text { moderate if } \\
\text { mixtures } \\
\text { present } \\
\text { (dependent } \\
\text { on electrode } \\
\text { fabrication) }\end{array}$ & $\begin{array}{l}\text { Moderate- } \\
\text { high }\end{array}$ & $\begin{array}{l}\text { Very } \\
\text { small- } \\
\text { small }\end{array}$ & Low & $\begin{array}{l}\text { Low- } \\
\text { moderate } \\
\text { (sensitive to } \\
\text { humidity, } \\
\text { temperature) }\end{array}$ & ppb-ppm & $\begin{array}{l}\text { Low- } \\
\text { Moderate }\end{array}$ \\
\hline Spectroscopic & $\begin{array}{l}\text { Low- } \\
\text { Moderate } \\
\text { (selective to } \\
\text { class of } \\
\text { compounds) }\end{array}$ & $\begin{array}{l}\text { Moderate- } \\
\text { high }\end{array}$ & $\begin{array}{l}\text { Small: } \\
\text { sufficient } \\
\text { for use } \\
\text { and } \\
\text { comfort }\end{array}$ & $\begin{array}{l}\text { Low, may } \\
\text { require light } \\
\text { source and } \\
\text { spectrometer, } \\
\text { none if } \\
\text { colorimetric }\end{array}$ & $\begin{array}{l}\text { Moderate } \\
\text { with } \\
\text { calibration of } \\
\text { light source, } \\
\text { low if } \\
\text { indicator is } \\
\text { unstable }\end{array}$ & ppb-ppm & $\begin{array}{l}\text { Low- } \\
\text { moderate }\end{array}$ \\
\hline $\begin{array}{l}\text { Portable gas } \\
\text { chromatography } \\
\text { with TCD, ECD, } \\
\text { UV-VIS }{ }^{223,224}\end{array}$ & $\begin{array}{l}\text { Moderate; } \\
\text { environment } \\
\text { highly } \\
\text { contaminated } \\
\text { may cause } \\
\text { co-elution }\end{array}$ & $\begin{array}{l}\text { Moderate- } \\
\text { high }\end{array}$ & $\begin{array}{l}\text { Medium: } \\
35+ \\
\text { pounds }\end{array}$ & High & $\begin{array}{l}\text { Moderate } \\
\text { with } \\
\text { maintenance; } \\
8 \text { hr. field } \\
\text { operation } \\
\text { (batteries and } \\
\text { gas cylinder) }\end{array}$ & ppb-ppm & $\begin{array}{l}\text { Moderate } \\
\text { - high }\end{array}$ \\
\hline
\end{tabular}

* Concentration in terms of ppm or ppb refer to molecules per million molecules or molecules per billion molecules, respectively.

\subsubsection{Reaction(s) of Cobinamide and Sulfide}

The reaction of cobinamide with sulfide is not as straightforward as the reaction of cobinamide and cyanide. S-anions (e.g., HS- ligands) can act as both ligands and reducing agents in which coordination (thermodynamic factor) and reduction (kinetic factor) can occur. ${ }^{117} \mathrm{H}_{2} \mathrm{~S}$ is reported to react with $\left(\mathrm{H}_{2} \mathrm{O}\right)_{2} \mathrm{Cbi}(\mathrm{III})$ in three consecutive and rapid steps at $\mathrm{pH} 9.6$ (anaerobic conditions). ${ }^{189}$ The first is the formation of three different complexes between diaquacobinamide and $\mathrm{H}_{2} \mathrm{~S}$ : $(\mathrm{OH})(\mathrm{HS}) \mathrm{Cbi}(\mathrm{III}),\left(\mathrm{H}_{2} \mathrm{O}\right)(\mathrm{HS}) \mathrm{Cbi}(\mathrm{III})$, and $(\mathrm{HS})_{2} \mathrm{Cbi}(\mathrm{III})$, which is dependent on initial $\mathrm{H}_{2} \mathrm{~S}$ concentration. The second step is a short-lived intermediate via inner-sphere electron 
transfer with either $(\mathrm{OH})(\mathrm{HS}) \mathrm{Cbi}(\mathrm{III})$ or $\left(\mathrm{H}_{2} \mathrm{O}\right)(\mathrm{HS}) \mathrm{Cbi}(\mathrm{III})$ to form reduced cobinamide $[(\mathrm{H}) \mathrm{S}] \mathrm{Cbi}(\mathrm{II})$ or even super reduced cobinamide $(+1$ oxidation state). The third is the addition of a second $\mathrm{H}_{2} \mathrm{~S}$ molecule to the already reduced cobinamide. In acidic medium ( $\left.\mathrm{pH} 4.5\right)$, the reaction proceeds in only two steps. In alkaline medium and $\mathrm{H}_{2} \mathrm{~S}$ concentrations less than $1 \mathrm{mM}$, first order kinetics were observed, however at concentrations above $3 \mathrm{mM}$, two consecutive firstorder reactions are observed. When $\mathrm{H}_{2} \mathrm{~S}$ and $\left(\mathrm{H}_{2} \mathrm{O}\right)_{2} \mathrm{Cbi}(\mathrm{III})$ reactions were studied using mass spectral data in the negative mode, $\mathrm{m} / \mathrm{z}$ values did not correspond to either complex of $\mathrm{H}_{2} \mathrm{~S}$ with cobinamide. An m/z of 989.54 in the positive mode was hypothesized to be the reduced cobinamide compound ( +2 oxidation state) but other signals were unidentifiable. Thus, the product of reaction is thought to be unstable.

The specific UV-VIS spectral shifts observed for reaction between $\mathrm{H}_{2} \mathrm{~S}$ and cobinamide in the referenced work will be compared with the obtained results throughout this chapter (Section 3.5.6). However, the referenced observations were all performed in anaerobic conditions. In this study, experiments were attempted to simulate occupationally-relevant conditions, where aerobic conditions would exist.

The proposed mechanism is as follows (modified from Salnikov et al. $)^{189}$ : 


\section{Reaction 1:}

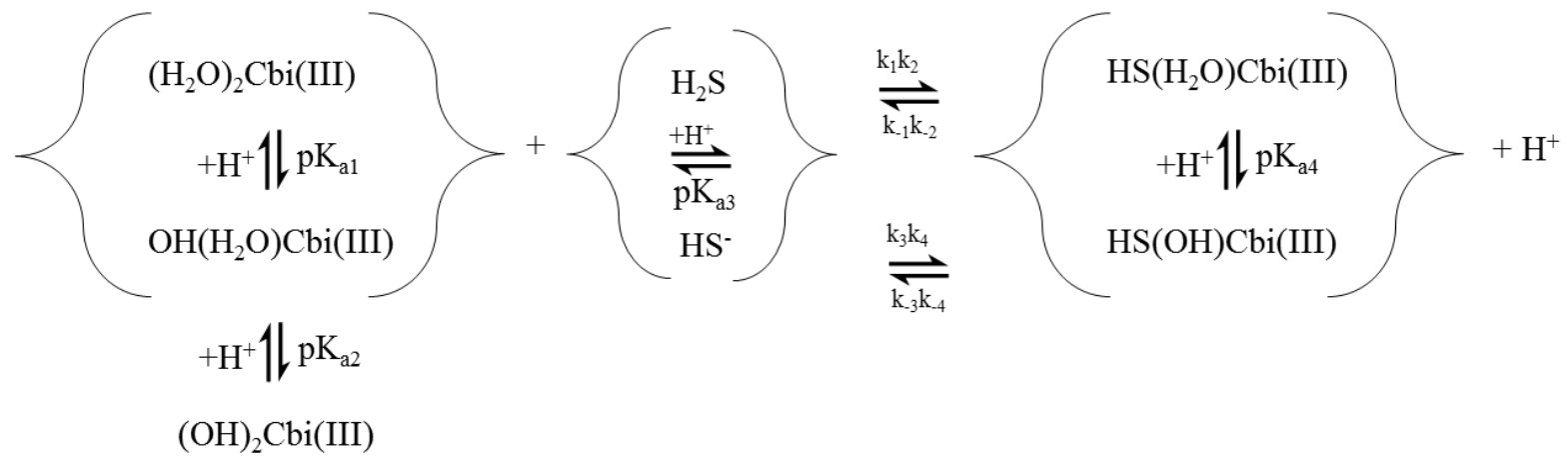

where $\mathrm{pK}_{\mathrm{a} 1}=5.9, \mathrm{pK}_{\mathrm{a} 2}=10.2, \mathrm{pK}_{\mathrm{a} 3}=7, \mathrm{pK}_{\mathrm{a} 4}>10.5$ (estimate),

The complexing of one $\mathrm{HS}^{-}$molecule occurs during Reaction 1, and is dependent of the initial $\mathrm{H}_{2} \mathrm{~S}$ concentration. The UV-VIS spectra red-shifts with increasing concentrations of $\mathrm{H}_{2} \mathrm{~S}$. The primary complex formed in Reaction 1 is $\mathrm{HS}^{-}\left(\mathrm{H}_{2} \mathrm{O}\right) \mathrm{Cbi}^{189}$

Reaction 2:

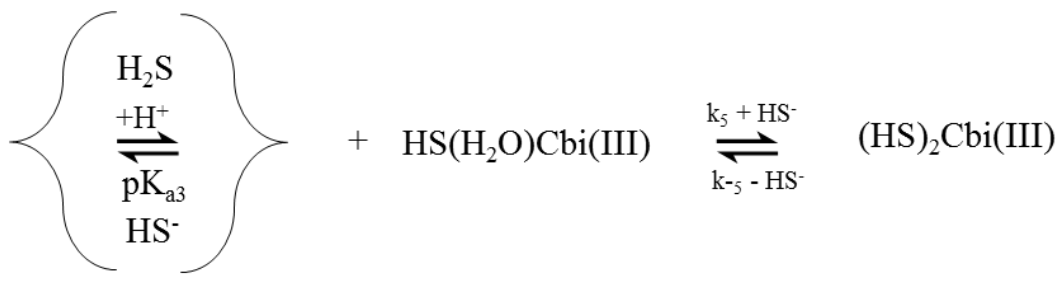

The second addition of an $\mathrm{H}_{2} \mathrm{~S}$ molecule to Cbi(III) occurs during Reaction 2.

(HS $)_{2} \mathrm{Cbi}(\mathrm{III})$ strongly hinders reduction of cobinamide and stabilizes the cobalt $3+$ oxidation state. Cobinamide can form a complex with $\mathrm{HS}^{-}, \mathrm{H} \dot{\mathrm{S}}$, and the dimer radical $\left(\dot{\mathrm{S} S \mathrm{~S}^{2-}}\right)$. 
Reaction 3:

$$
\mathrm{HS}\left(\mathrm{H}_{2} \mathrm{O}\right) \mathrm{Cbi}(\mathrm{III}) \underset{\mathrm{k}=6}{\stackrel{\mathrm{k}_{6}}{\rightleftharpoons}}(\mathrm{H} \dot{\mathrm{S}}) \mathrm{Cbi}(\mathrm{II})+\mathrm{H}_{2} \mathrm{O} \stackrel{\mathrm{pK}_{\mathrm{a} 5}}{\rightleftharpoons}(\dot{\mathrm{S}}) \mathrm{Cbi}(\mathrm{II})+\mathrm{H}^{+}
$$

where $\mathrm{pK}_{\mathrm{a} 5}=5.2$.

From electrochemical data, the authors conclude that an inner-sphere electron transfer process occurs with the formation of (HS) $\mathrm{Cbi}(\mathrm{II})$ in Reaction 3. Reduction can only occur with one $\mathrm{HS}^{-}$ complexed.

Reaction 4:

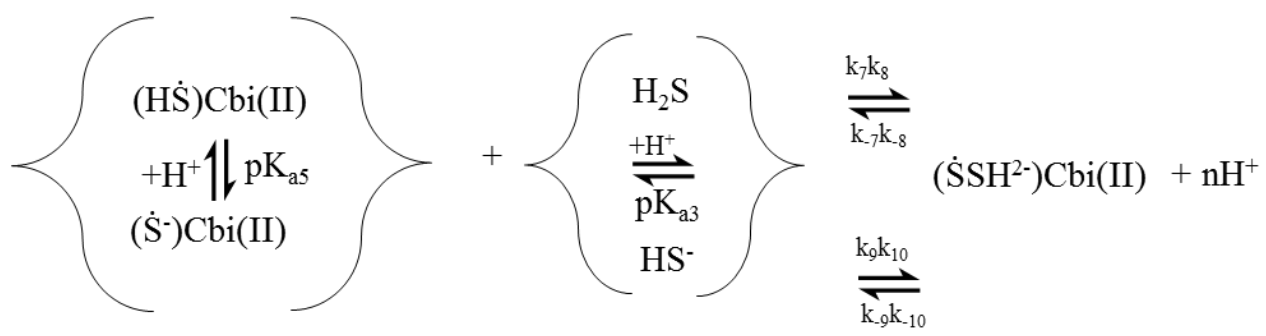

The authors conclude that the main product formed, independent of $\mathrm{pH}$, is the complex of $\mathrm{Cbi}$ (II) with $\mathrm{SSH}^{2-}$.

Because the reaction of sulfide involves the binding and reduction of $\mathrm{Cbi}$, it is challenging to retrieve a true binding constant for the reaction of sulfide with Cbi. Similarly, nitric oxide (NO) first reduces cobinamide to Cbi(II) (by a short-lived intermediate and electron transfer) and then binds to the $\mathrm{Cbi}(\mathrm{II})$ with a binding affinity of $4.6 \times 10^{6} \mathrm{M}^{-1} .181$ Therefore, it is 
difficult to compare the binding of cyanide and sulfide to $\mathrm{Cbi}$, since cyanide binds to cobinamide without any reduction step. Jann reported the binding affinity of sulfide to cobinamide is $5.27 \mathrm{x}$ $10^{8} .^{225}$ Dr. Gerry Boss's group attempted to calculate the affinity for the overall reaction of sulfide with Cbi by the overall spectral change and obtained a value of $6.8 \times 10^{5} \mathrm{M}^{-1}$ (unpublished data; personal conversation). This value is lower than $\mathrm{K}_{\mathrm{a}}$ for Cbi with $\mathrm{CN}^{-}\left(10^{14}\right)$.

In this study, identification of the specific products of the reaction between gaseous $\mathrm{H}_{2} \mathrm{~S}$ and $\mathrm{OH}\left(\mathrm{H}_{2} \mathrm{O}\right) \mathrm{Cbi}$ on paper is not a priority. The distinctive spectral shifts of $\mathrm{H}_{2} \mathrm{~S}$ and Cbi will be monitored as a function of $\mathrm{H}_{2} \mathrm{~S}$ exposure and \% RH. To have potential as an ESLI, reaction of gaseous $\mathrm{H}_{2} \mathrm{~S}$ and $\mathrm{Cbi}$ on paper must occur quickly at all \% RH values. The $\mathrm{C}$ REL of $\mathrm{H}_{2} \mathrm{~S}, 10.0$ ppm, is the concentration of interest.

\subsection{Materials}

Aquohydroxocobinamide $\left(\left[\mathrm{OH}\left(\mathrm{H}_{2} \mathrm{O}\right) \mathrm{Cbi}\right], \mathrm{Co}(\mathrm{III})\right)$ was synthesized from

hydroxocobalamin as described previously in literature. ${ }^{104}$ Sodium sulfide hydrated $\left(\mathrm{Na}_{2} \mathrm{~S} \times \mathrm{H}_{2} \mathrm{O}\right)$ was purchased from Fisher Scientific (flakes; technical) and dissolved in $1 \mathrm{mM} \mathrm{NaOH}$ (Fisher Scientific, certified). L-ascorbic acid was purchased from Fisher Scientific (99.2\%). Stock $\mathrm{H}_{2} \mathrm{~S}$ gas was purchased from Matheson at concentrations of $10.0( \pm 5 \%)$ ppm and $>99 \%$ pure $\mathrm{H}_{2} \mathrm{~S}$ (chemically pure). All gases were balanced in nitrogen. Gelman Sciences A/E Borosilicate Glass fiber filter paper (binder free, $330 \mu \mathrm{m}$ thick, and $1 \mu \mathrm{m}$ pore size) was used as the support medium. Deionized water $(18 \mathrm{M} \Omega-\mathrm{cm})$ was obtained from an in-line water system (Thermo Scientific Micropure) for dilution of $\mathrm{OH}\left(\mathrm{H}_{2} \mathrm{O}\right) \mathrm{Cbi}$. 


\subsection{Experimental Setup and Methods \\ 3.4.1 Preparation of Cobinamide Solution}

Aquohydroxocobinamide $\left[\mathrm{OH}\left(\mathrm{H}_{2} \mathrm{O}\right) \mathrm{Cbi}\right]$ was used as the initial reagent on glass fiber paper for the reaction with gas-phase $\mathrm{H}_{2} \mathrm{~S}$. A bench-top UV-VIS spectrometer (Thermo Scientific Evolution 300) was used to determine the concentration of $\mathrm{OH}\left(\mathrm{H}_{2} \mathrm{O}\right) \mathrm{Cbi}$ stock solutions using a molar extinction coefficient of $2.8 \times 10^{4} \mathrm{M}^{-1} \mathrm{~cm}^{-1}$ at $348 \mathrm{~nm} .{ }^{109}$ The $\mathrm{OH}\left(\mathrm{H}_{2} \mathrm{O}\right)$ Cbi stock solutions were diluted in deionized water and stored at $4^{\circ} \mathrm{C}$ for fixing onto the paper substrates. $\mathrm{Na}_{2} \mathrm{~S}$ and was prepared in $1 \mathrm{mM} \mathrm{NaOH}$. Absorbance spectra were obtained using the Thermo Scientific Evolution 300 UV-VIS spectrometer. Ascorbic acid was prepared in both aerobic and anaerobic conditions, where oxygen-free nitrogen $\left(\mathrm{N}_{2}\right)$ was used to sparge both the $\mathrm{OH}\left(\mathrm{H}_{2} \mathrm{O}\right) \mathrm{Cbi}$ and ascorbic acid solutions. $\mathrm{Na}_{2} \mathrm{~S}$ and ascorbic were used to compare the spectral shifts of reaction with $\mathrm{OH}\left(\mathrm{H}_{2} \mathrm{O}\right) \mathrm{Cbi}$ in solution and $\mathrm{H}_{2} \mathrm{~S}$ in gas-phase.

\subsubsection{Preparation of Cbi Sensor Substrate}

The preparation of the glass fiber paper circles was described Section 2.4.1 with the modification of pipetting $\mathrm{OH}\left(\mathrm{H}_{2} \mathrm{O}\right) \mathrm{Cbi}$ instead of the $\mathrm{CN}\left(\mathrm{H}_{2} \mathrm{O}\right)$ Cbi complex onto each paper circle. $15.00 \pm 0.02 \mu \mathrm{L}$ of $50.0 \pm 0.2 \mu \mathrm{M} \mathrm{OH}\left(\mathrm{H}_{2} \mathrm{O}\right)$ Cbi was pipetted onto each paper circle. In addition to $25 \% \mathrm{RH}$, some samples were tested at 50 and $85 \% \mathrm{RH}$ but an environmental chamber was not readily available. Therefore, the prepared Cbi-spotted papers were not incubated in an environmental chamber at the respective $\% \mathrm{RH}$ prior to the experiment, but were still equilibrated in the test setup for 30 minutes.

\subsubsection{Sensor Holder}

The holder designed to securely hold the $6.0 \mathrm{~mm}$ diameter paper circle was used for this portion of the research. For more information, refer back to Section 2.4.3. 


\subsubsection{Diffuse Reflectance Instrumentation}

The Ocean Optics USB4000 UV-VIS-ES spectrometer with the associated tungsten halogen light source and bifurcated fiber optic were also used for this portion of the research. Refer back to Section 2.4.4. Light reflected from the cobinamide-spotted glass fiber paper was detected by the spectrometer. Apparent absorbance values were converted to $F(R)$ values using the Kubelka-Munk function (Equation 2.6).

\subsubsection{Gas Flow System}

All $\mathrm{H}_{2} \mathrm{~S}$ exposure experiments were performed at the NIOSH/NPPTL facility in Pittsburgh, PA. The STP (with associated experimental equipment and setup) titled "Determination of CBRN Acid Gases (Hydrogen Sulfide) Service-Life Test, Air-Purifying Standard Test Procedure STP-CBRN-0305) can be found online. ${ }^{195}$ A modified version of this setup was used, but it is recommended to view this document for specific details. In short, a Miller Nelson Research Model 401 Flow-Temperature-Humidity Control System was used to control the airflow ( $10 \%$ of max flow $\mathrm{LPM} \pm 2 \%$ ), temperature $\left(20-30^{\circ} \mathrm{C} \pm 0.3 \%\right)$, and relative humidity (10-98\% $\pm 3 \%$ ) of the air supplied to the sensor, with laboratory compressed air and distilled water supplied to the unit. An EdgeTech ${ }^{\circledR}$ Dew Prime II Hygrometer (Model 2000) was used to verify the $\%$ RH ( 1 to $95 \% \pm 0.5 \%$ ). An Interscan ${ }^{\circledR}$ electrochemical instrument (Model RM-17-0) specific for $\mathrm{H}_{2} \mathrm{~S}$ was used with the detection range of 0.0-19.99 ppm (accuracy \pm 0.40 ppm, resolution $0.01 \mathrm{ppm}$ ). Brooks Mass Flow Controllers (accuracy of $\pm 7 \%$ of rate and $\pm 0.2 \%$ full scale) were used to automatically control all flow valves. Gas flow was controlled from a computer using a LabVIEW ${ }^{\circledR}$ virtual instrument program (National Instruments). Prior to the beginning of the experiment, the $\mathrm{H}_{2} \mathrm{~S}$ electrochemical detector was calibrated with $10.0 \mathrm{ppm}_{2} \mathrm{~S}$ calibration gas to ensure the sensor is exposed to $10.0 \mathrm{ppm}$. A photo of the sensor holder within 
the gas-flow setup can be seen in Figure 3.2. The electrochemical instruments are outside of the hood and not shown.

Figure 3.2 - Sensor flow setup

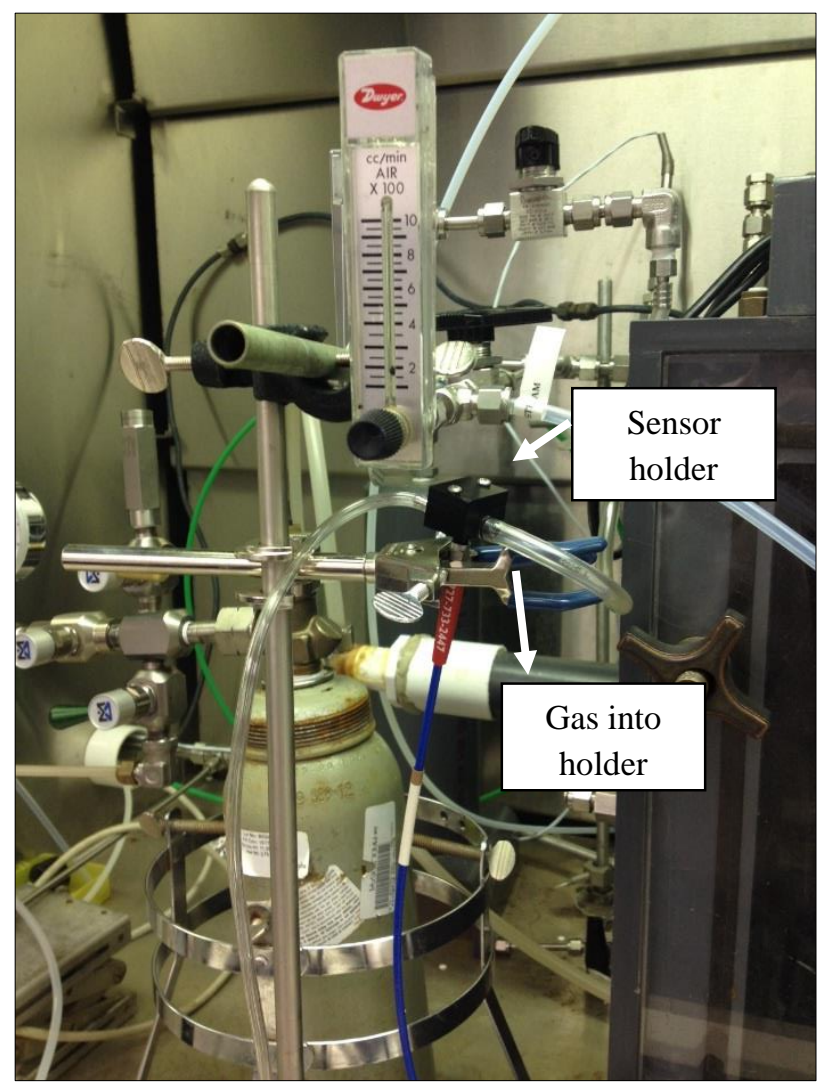

\subsubsection{System Optimization}

3.4.6.1 Instrument

The integration time for the miniature spectrometer was set to $300 \mathrm{~ms}$ with a boxcar width and scans-to-average set to 5 via the Oceanview ${ }^{\circledR}$ software (these values were explained in Section 2.4.6).

\subsubsection{Flow}

The flow rate over the paper was set to $1.01 \pm 0.04$ LPM to avoid backpressure build-up in the sensor holder. This was controlled with a Dwyer ${ }^{\circledR}$ Flowmeter (Series RMA-13 Rate- 
Master $\left.^{\circledR} ; 100-1000 \mathrm{cc} / \mathrm{min}, \pm 4 \%\right)$ and verified with a Sensidyne Gilian Gilibrator Flow Calibrator $^{\circledR}$.

The system was initially flushed with clean air at the desired $\% \mathrm{RH}\left(\right.$ no $\mathrm{H}_{2} \mathrm{~S}$ ) for 1 hour before each experiment. The system was evaluated by the electrochemical detector to ensure a reading of $0.0 \mathrm{ppm} \mathrm{H}_{2} \mathrm{~S}$. A blank paper circle was placed in the holder where the reflectance signal from the blank was defined as $100 \%$ reflectance at each wavelength. A piece of $\mathrm{OH}\left(\mathrm{H}_{2} \mathrm{O}\right) \mathrm{Cbi}$-immobilized paper was then placed in the holder and the appropriate reflectance spectrum recorded. In some experiments, the reflectance spectrum of $\mathrm{OH}\left(\mathrm{H}_{2} \mathrm{O}\right) \mathrm{Cbi}$-immobilized paper was designated as the "blank" when the goal was to monitor changes in the $\mathrm{OH}\left(\mathrm{H}_{2} \mathrm{O}\right) \mathrm{Cbi}$ spectrum. The paper circles were allowed to equilibrate with the desired $\% \mathrm{RH}$ for 30 minutes in the holder prior to beginning the experiment. Relative humidity levels of 25,50 , and $85 \% \mathrm{RH}$ at $25^{\circ} \mathrm{C} \pm 1{ }^{\circ} \mathrm{C}$ were tested, which are typical testing conditions for certification tests at NIOSH/NPPTL ( $\%$ RH conditions allowed with $\pm 5 \%$ range). All valves were controlled by LabVIEW $^{\circledR}$ software where average \%RH, temperature, upstream and downstream $\mathrm{H}_{2} \mathrm{~S}$ concentration, and start/end time were stored by the software.

\subsubsection{Volume and Concentration of Cobinamide}

$50.0 \pm 0.2 \mu \mathrm{M} \mathrm{OH}\left(\mathrm{H}_{2} \mathrm{O}\right) \mathrm{Cbi}$ was used as the concentration to immobilize onto each paper circle. Since this concentration was used when studying the binding of $\mathrm{CN}^{-}$(Chapter 2), it was similarly used to monitor effects of $\mathrm{H}_{2} \mathrm{~S}$ exposure. Correspondingly, $15.00 \mu \mathrm{L} \pm 0.02$ $\mathrm{OH}\left(\mathrm{H}_{2} \mathrm{O}\right) \mathrm{Cbi}$ was fixed onto each paper circle, which completely wicked over the surface of the paper without oversaturating or leaving $\mathrm{OH}\left(\mathrm{H}_{2} \mathrm{O}\right) \mathrm{Cbi}$ residue behind. The papers were allowed to fully dry at room temperature ( 1 hour). 


\subsection{Results and Discussion}

\subsubsection{Repeatability of $\mathrm{OH}\left(\mathrm{H}_{2} \mathrm{O}\right) \mathrm{Cbi}$ on Paper}

The average apparent absorbance of $\mathrm{OH}\left(\mathrm{H}_{2} \mathrm{O}\right)$ Cbi measured at $500 \mathrm{~nm}$ on glass fiber filter paper is $0.15 \pm 0.03(\mathrm{~F}(\mathrm{R})$ value equal to $0.083 \pm 0.02)$ with $17 \% \mathrm{RSD}$. These values are based on 7 glass fiber samples with \pm values calculated by sample standard deviation. Figure 3.3 shows the average absorbance of $50.0 \pm 0.2 \mu \mathrm{M} \mathrm{OH}\left(\mathrm{H}_{2} \mathrm{O}\right) \mathrm{Cbi}$ in solution (left y-axis) and on the glass fiber paper plotted as the diffuse reflectance spectrum (right y-axis). Variations in the two spectra are most likely due to the scattering of the paper, but the general $\mathrm{OH}\left(\mathrm{H}_{2} \mathrm{O}\right)$ Cbi spectra both in solution and on paper are similiar.

Figure 3.3 - Comparison of absorbance and Kubelka-Munk function to $\mathrm{OH}\left(\mathrm{H}_{2} \mathrm{O}\right) \mathrm{Cbi}$ on glass fiber paper

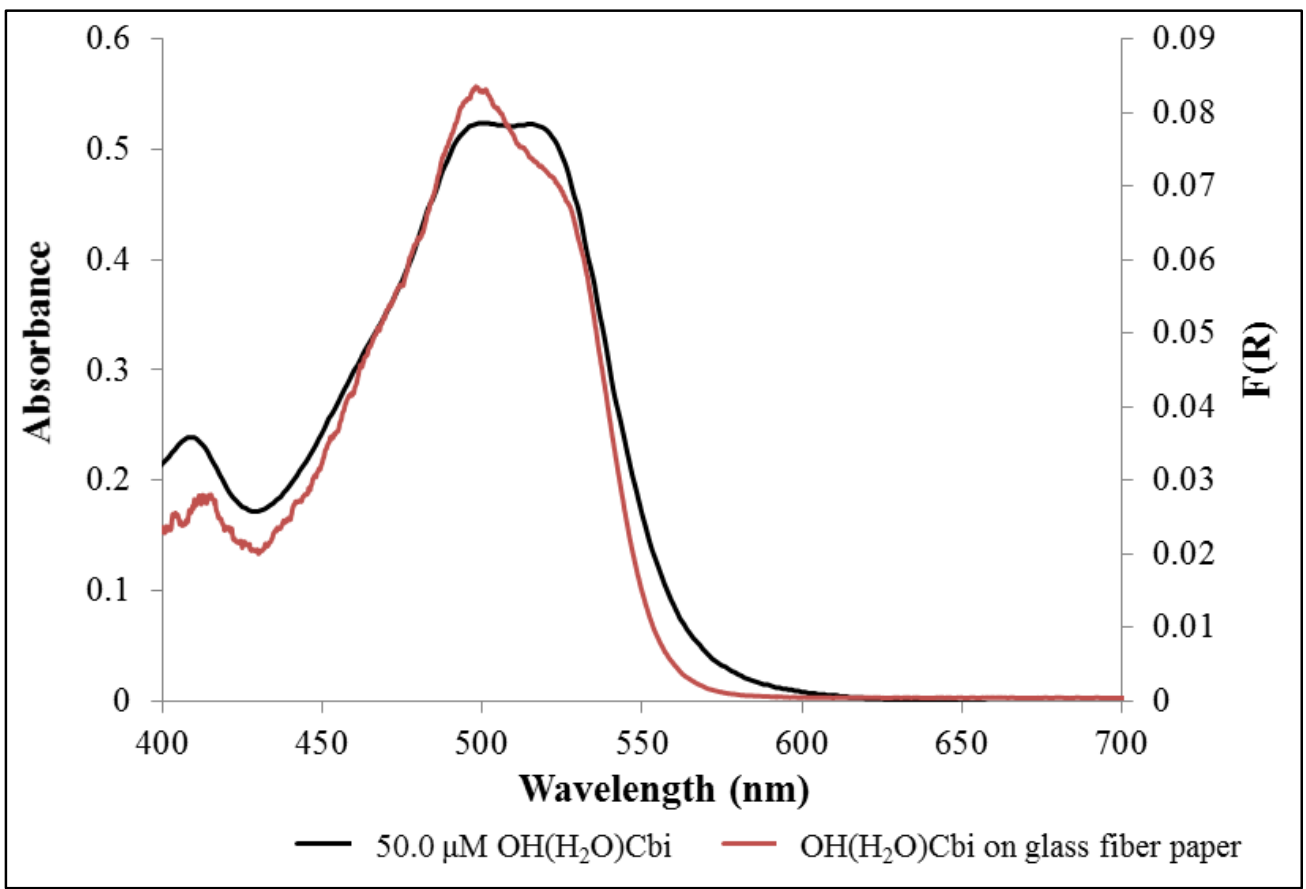




\subsubsection{UV-VIS Spectra of Cobinamide with $\mathrm{Na}_{2} \mathrm{~S}$ and Ascorbic Acid}

Using a benchtop spectrometer, $\mathrm{Na}_{2} \mathrm{~S}$ in $1 \mathrm{mM} \mathrm{NaOH}$ was incrementally added to a 50.0 $\mu \mathrm{M}$ aqueous solution of $\mathrm{OH}\left(\mathrm{H}_{2} \mathrm{O}\right) \mathrm{Cbi}$ in a cuvette. In the presence of $\mathrm{Na}_{2} \mathrm{~S}$, an increase in absorbance from 400-450 nm, an isosbestic point near $470 \mathrm{~nm}$, and a decrease in absorbance from 470-550 nm occurs. A slight increase in absorbance from $\sim 600-700 \mathrm{~nm}$ can also be observed. These characteristic spectral shifts are similar to those observed by Jann (2012) upon addition of $\mathrm{NaSH}$ to $\mathrm{OH}\left(\mathrm{H}_{2} \mathrm{O}\right) \mathrm{Cbi}(\mathrm{LOD} 1.88 \mu \mathrm{M})$, Ma et al. upon addition of $\mathrm{HS}^{-}$to $\mathrm{OH}\left(\mathrm{H}_{2} \mathrm{O}\right) \mathrm{Cbi}$, and Salnikov et al. upon addition of $\mathrm{H}_{2} \mathrm{~S}$ to $\mathrm{OH}\left(\mathrm{H}_{2} \mathrm{O}\right) \mathrm{Cbi}$ (anaerobic conditions). ${ }^{120,189,225}$ The spectral shifts differed from those of $\mathrm{Cbi}$ in the presence of $\mathrm{CN}^{-}$which produced a decrease from $400-450 \mathrm{~nm}$, an isosbestic point near 531, and increase at $583 \mathrm{~nm}$ (Chapter 2). Figure 3.4 shows the absorbance spectrum for $\mathrm{OH}\left(\mathrm{H}_{2} \mathrm{O}\right)$ Cbi when incremental concentrations of $1-300.0 \pm 0.2 \mu \mathrm{M} \mathrm{Na} 2 \mathrm{~S}$ were added to solution, where $\left[\mathrm{Na}_{2} \mathrm{~S}\right]_{\text {final }}$ was 300.0 $\mu \mathrm{M}$ and $\left[\mathrm{OH}\left(\mathrm{H}_{2} \mathrm{O}\right) \mathrm{Cbi}\right]_{\text {final }}$ was $47.5 \mu \mathrm{M}$ with final $\mathrm{pH}$ of 7.8. An observable pale-yellow color slowly develops upon addition of $\mathrm{Na}_{2} \mathrm{~S}$ to the Cbi solution. 
Figure 3.4 - Absorbance spectrum of $\mathrm{OH}\left(\mathrm{H}_{2} \mathrm{O}\right) \mathrm{Cbi}$ with $\mathrm{Na}_{2} \mathrm{~S}$

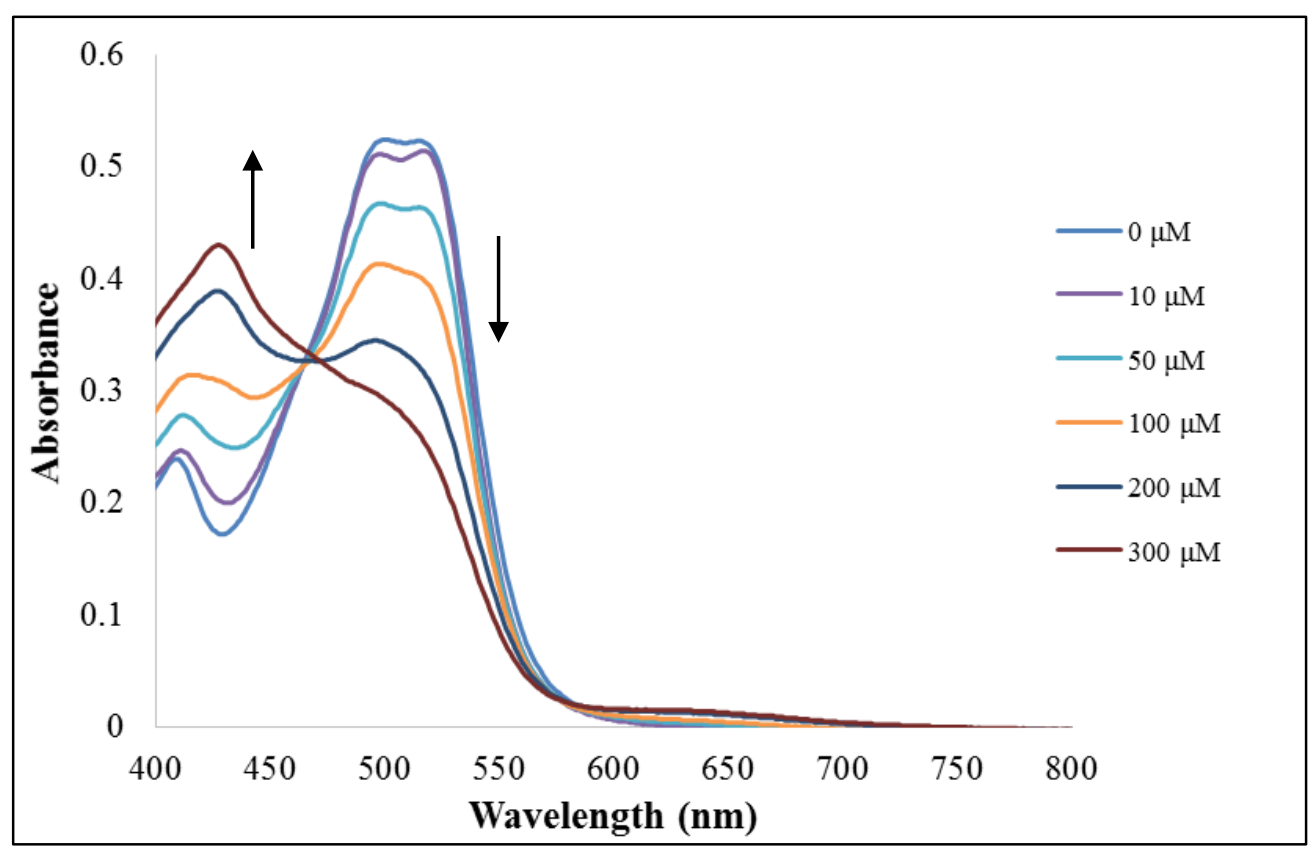

Ascorbic acid ( $1 \mathrm{M}$ in deionized $\mathrm{H}_{2} \mathrm{O}$ ), a reducing agent, was added in various molar ratios to $50.0 \pm 0.2 \mu \mathrm{M} \mathrm{OH}\left(\mathrm{H}_{2} \mathrm{O}\right) \mathrm{Cbi}$ to study the spectral shifts of reduction of $\mathrm{Cbi}\left(\mathrm{Co}^{3+}\right.$ to $\mathrm{Co}^{2+} ;$ Figure 3.5). Different spectral shifts are observed compared to addition of $\mathrm{Na}_{2} \mathrm{~S}$. The reaction of ascorbic acid with Cbi presumably involves reduction of the $\mathrm{Co}^{3+}$ species. The binding and reduction and associated spectral shifts of $\mathrm{Cbi}$ will be used to compare the gas-phase reaction with Cbi-immobilized paper and $\mathrm{H}_{2} \mathrm{~S}$. 
Figure 3.5 - Absorbance spectrum of $\mathrm{OH}\left(\mathrm{H}_{2} \mathrm{O}\right) \mathrm{Cbi}$ with ascorbic acid ("a.a."); aerobic conditions

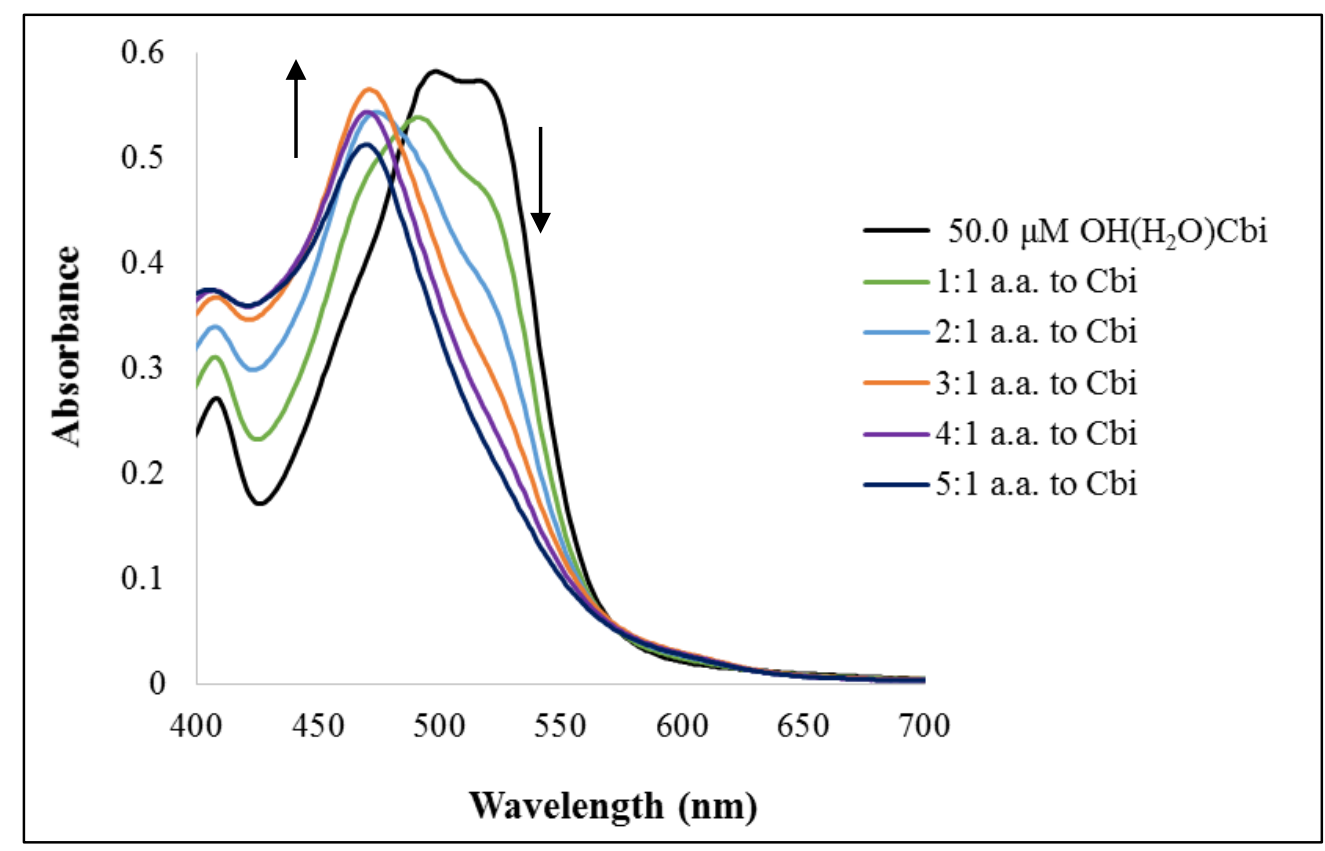

The increase from $400-450 \mathrm{~nm}$ and decrease from $470-550 \mathrm{~mm}$ is similar to that of $\mathrm{Na}_{2} \mathrm{~S}$ with Cbi at higher concentrations. Isosbestic peaks observed for ascorbic acid in solution with $\mathrm{Cbi}$ include $485 \mathrm{~nm}$ (which blue-shifts with increasing concentration of ascorbic acid), and $570 \mathrm{~nm}$. The absorbance peak at 468 is indicative of reduction of $\mathrm{Cbi}(\mathrm{III})$ to $\mathrm{Cbi}(\mathrm{II}) .{ }^{226} \mathrm{~A}$ visible color change of the cobinamide solution before and after addition of 5:1 ascorbic acid to Cbi could be visibly observed (Figure 3.6). The final $\mathrm{pH}$ after ascorbic acid is added to the Cbi solution in a $5: 1$ ratio is $\sim 3.5$. To verify the spectral shifts were a function of reduction of Cbi from ascorbic acid and not the decrease in $\mathrm{pH}$, a separate experiment was performed. $\mathrm{HCl}$ was added to 50.0 $\mu \mathrm{M} \mathrm{OH}\left(\mathrm{H}_{2} \mathrm{O}\right) \mathrm{Cbi}$ until a final $\mathrm{pH}$ of 2.5 was reached. Only a slight change in the Cbi spectrum is observed from 500-525 nm, which could indicate the conversion of $\mathrm{OH}\left(\mathrm{H}_{2} \mathrm{O}\right) \mathrm{Cbi}$ to $\left(\mathrm{H}_{2} \mathrm{O}\right)_{2} \mathrm{Cbi}$ (pKa 5.9). Results can be seen in Figure B.1. 
Figure 3.6 - 50.0 $\mu \mathrm{M} \mathrm{OH}\left(\mathrm{H}_{2} \mathrm{O}\right)$ Cbi before (A) and after addition (B) of 5:1 ascorbic acid.
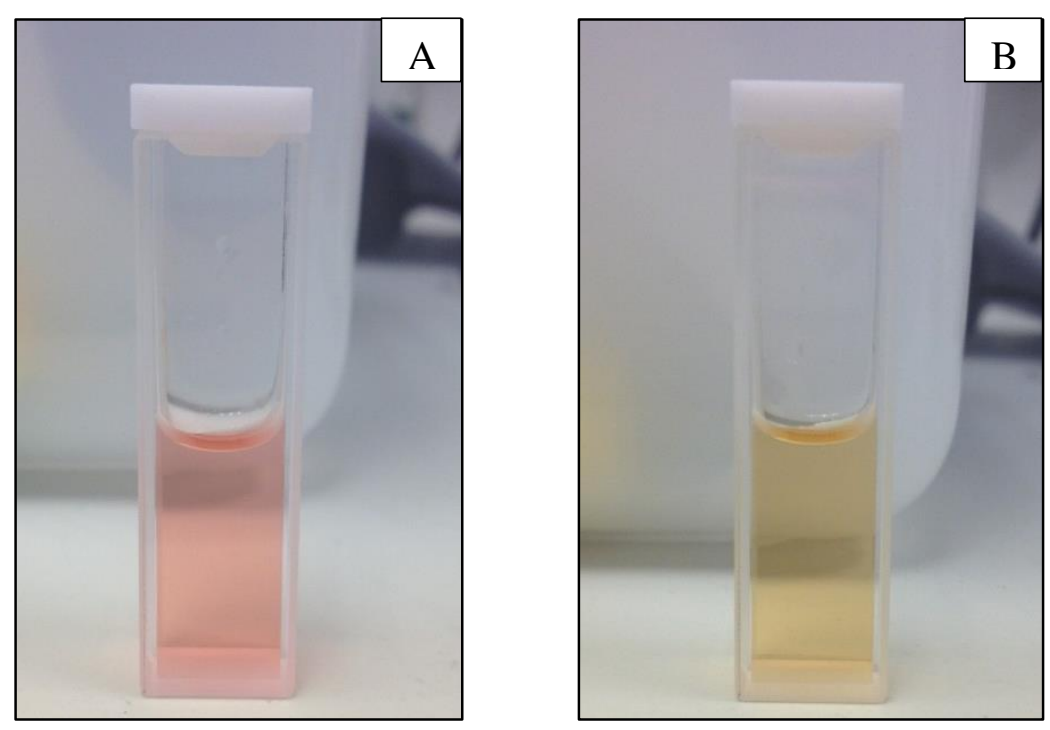

Additional experiments were performed to ensure the reaction with ascorbic acid under aerobic conditions was successfully reducing $\mathrm{Cbi}$, and oxidation effects from ambient conditions were not altering the spectra. Both $\mathrm{Cbi}$ and ascorbic acid solutions were deoxygenated by bubbling with oxygen-free $\mathrm{N}_{2}$. The UV-VIS spectrum for ascorbic acid under aerobic and anaerobic conditions are similar. The reaction is faster under anaerobic conditions (Figure 3.7), but still yields the general spectral shifts and solution color observed with aerobic conditions. Glucose and fructose, other reducing agents, cause similar spectral shifts under anaerobic conditions with an increase at $468 \mathrm{~nm}$, indicative of the reduction of $\mathrm{Cbi}(\mathrm{III})$ to $\mathrm{Cbi}(\mathrm{II})$, where a color change from red to yellow was also observed. ${ }^{226}$ 
Figure 3.7 - Absorbance spectrum of $\mathrm{OH}\left(\mathrm{H}_{2} \mathrm{O}\right)$ Cbi with ascorbic acid; anaerobic conditions

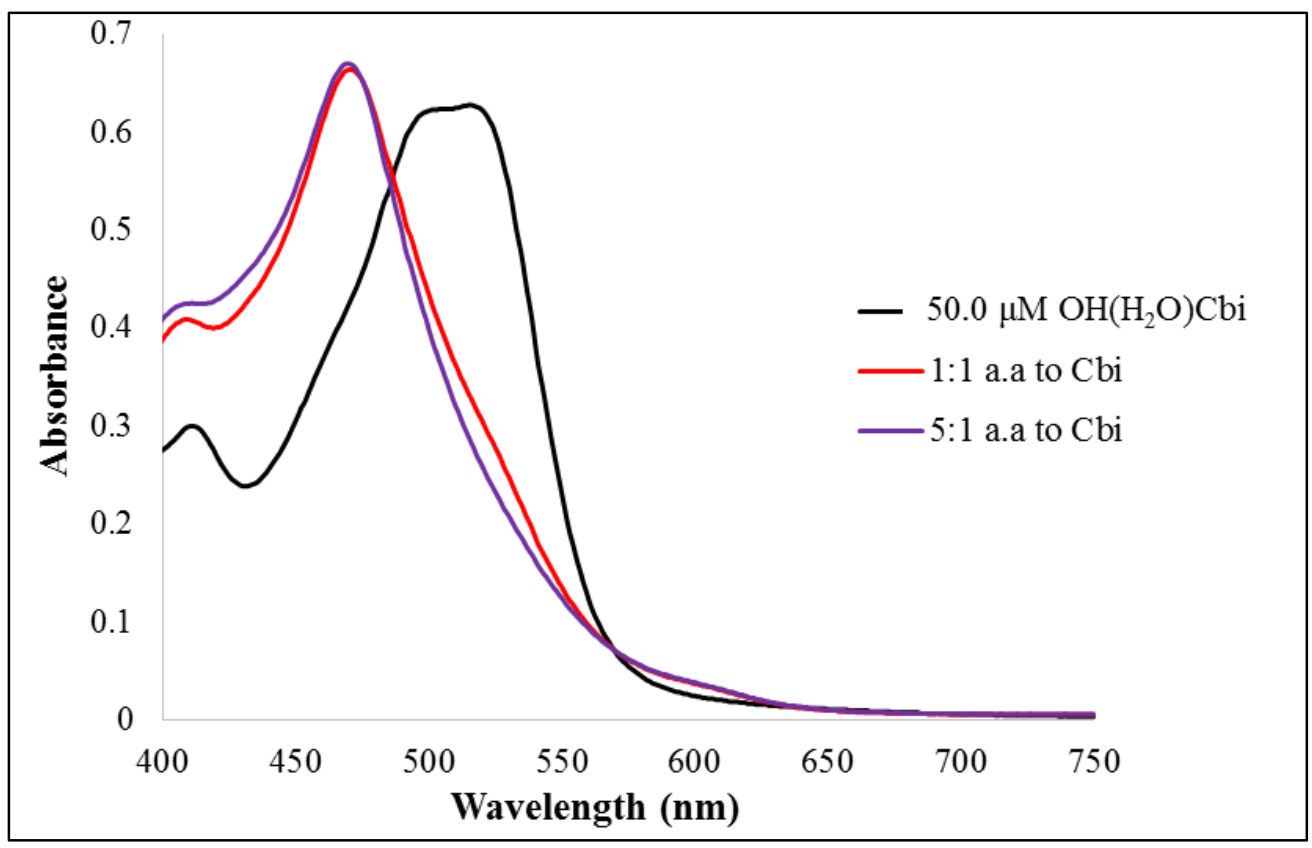

\subsubsection{Comparison of Absorbance and Diffuse Reflectance Spectra}

The absorbance spectrum of $\mathrm{OH}\left(\mathrm{H}_{2} \mathrm{O}\right)$ Cbi taken from a benchtop UV-VIS spectrometer is compared with the diffuse reflectance spectrum of $50.0 \mu \mathrm{M} \mathrm{OH}\left(\mathrm{H}_{2} \mathrm{O}\right) \mathrm{Cbi}$ on glass filter paper. In Figure 3.8a, the spectrum of the $50.0 \mu \mathrm{M} \mathrm{OH}\left(\mathrm{H}_{2} \mathrm{O}\right)$ Cbi solution (benchtop UV-VIS) is plotted when $50.0 \mu \mathrm{M}$ of $\mathrm{Na}_{2} \mathrm{~S}$ is present in the solution. When $\mathrm{OH}\left(\mathrm{H}_{2} \mathrm{O}\right) \mathrm{Cbi}$ was immobilized on paper and exposed to $10.0 \mathrm{ppm} \mathrm{H}_{2} \mathrm{~S}$ for 1 minute $(25 \% \mathrm{RH})$, similar spectral shifts to solution are observed: an increase in apparent absorbance (and F(R) values) at 400-450 nm, and decrease from 470-550 $\mathrm{nm}$ with an isosbestic point near $470 \mathrm{~nm}$ observed for both spectra (Figure $3.8 \mathrm{~b}$ ). The slight variation between the absorbance spectrum and diffuse reflectance spectrum may be attributed to the paper matrix, but the characteristic features of the binding of $\mathrm{HS}^{-}$and possible reduction of the Cbi complex are apparent by diffuse reflectance. Thus, the spectral shifts between the solution reaction and the solid $\mathrm{Cbi}-\mathrm{H}_{2} \mathrm{~S}$ gas reaction indicate that a gas-phase Cbi sensor is possible. 
Figure 3.8 - Addition of $50.0 \mu \mathrm{M} \mathrm{Na} 2 \mathrm{~S}$ to $\mathrm{OH}\left(\mathrm{H}_{2} \mathrm{O}\right)$ Cbi solution (A) and exposure of $10.0 \mathrm{ppm}$ $\mathrm{H}_{2} \mathrm{~S}$ for 5 minutes to $\mathrm{OH}\left(\mathrm{H}_{2} \mathrm{O}\right) \mathrm{Cbi}$ on paper (B).
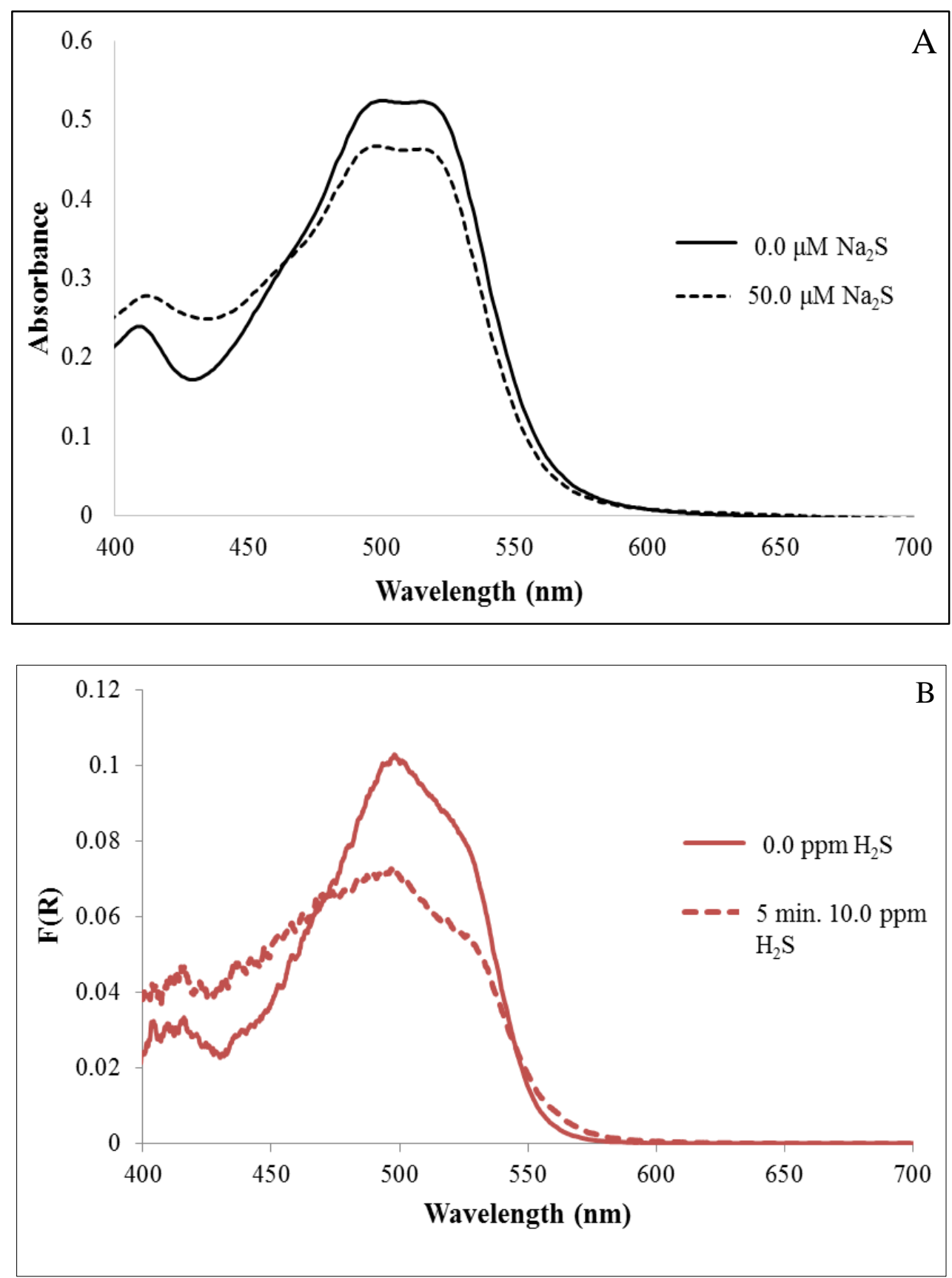

\subsubsection{Aquohydroxocobinamide Detection of $\mathrm{H}_{2} \mathrm{~S}$ Gas}

A piece of glass fiber paper fixed with $50.0 \mu \mathrm{M} \mathrm{OH}\left(\mathrm{H}_{2} \mathrm{O}\right) \mathrm{Cbi}$ was inserted into the diffuse reflectance sensor holder. Each paper was exposed to $10.0 \mathrm{ppm}_{2} \mathrm{~S}$ at 1.0 LPM. Figure 
3.9 shows the Kubelka-Munk response of $\mathrm{OH}\left(\mathrm{H}_{2} \mathrm{O}\right) \mathrm{Cbi}$ on glass fiber paper when exposed to $10.0 \mathrm{ppm} \mathrm{H}_{2} \mathrm{~S}$ after 1,5 , and 10 minutes at $25 \% \mathrm{RH}$.

Figure $3.9-\mathrm{OH}\left(\mathrm{H}_{2} \mathrm{O}\right) \mathrm{Cbi}$ on glass fiber filter paper response to $10.0 \mathrm{ppm} \mathrm{H}_{2} \mathrm{~S}$

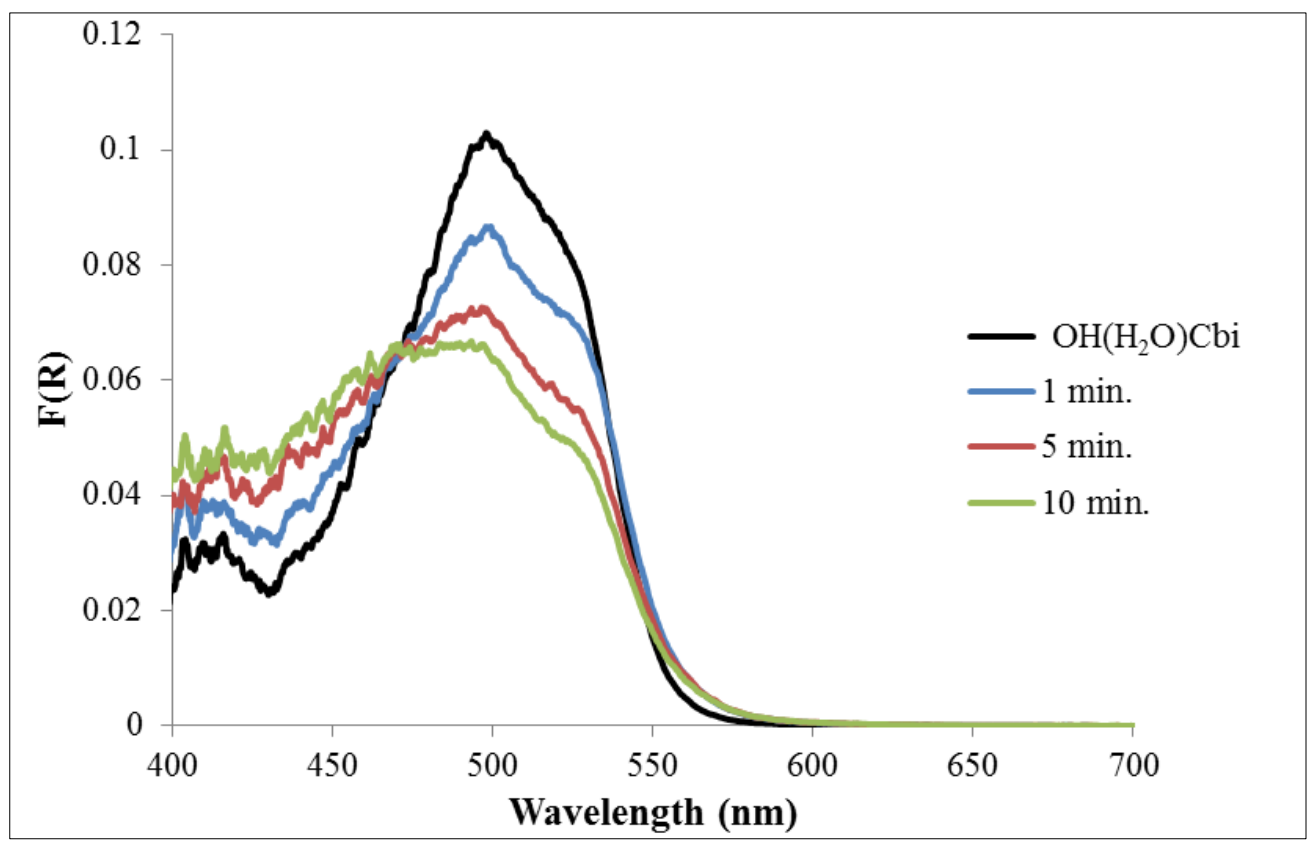

The increased signal from 400-450 nm and decreased signal from 470-550 nm are apparent and similar to spectral shifts found in solution and elsewhere in literature. ${ }^{189}$ Although not prominent, a slight increase is observed near $583 \mathrm{~nm}$ (characteristic for $\mathrm{HCN}$ detection). Additionally, the isosbestic point for $(\mathrm{CN})_{2} \mathrm{Cbi}$ at $531 \mathrm{~nm}$ is not observed for reaction with $\mathrm{H}_{2} \mathrm{~S}$. To more easily visualize these spectral shifts, the spectrum of $\mathrm{OH}\left(\mathrm{H}_{2} \mathrm{O}\right) \mathrm{Cbi}$ on glass fiber filter paper is considered the blank, creating difference spectra. The average Kubelka-Munk spectra for exposure to $10.0 \mathrm{ppm}$ can be observed in Figure $3.10(\mathrm{n}=3)$. 
Figure 3.10 - Difference spectra of $\mathrm{OH}\left(\mathrm{H}_{2} \mathrm{O}\right)$ Cbi on glass fiber filter paper response to $10.0 \mathrm{ppm}$ $\mathrm{H}_{2} \mathrm{~S}$

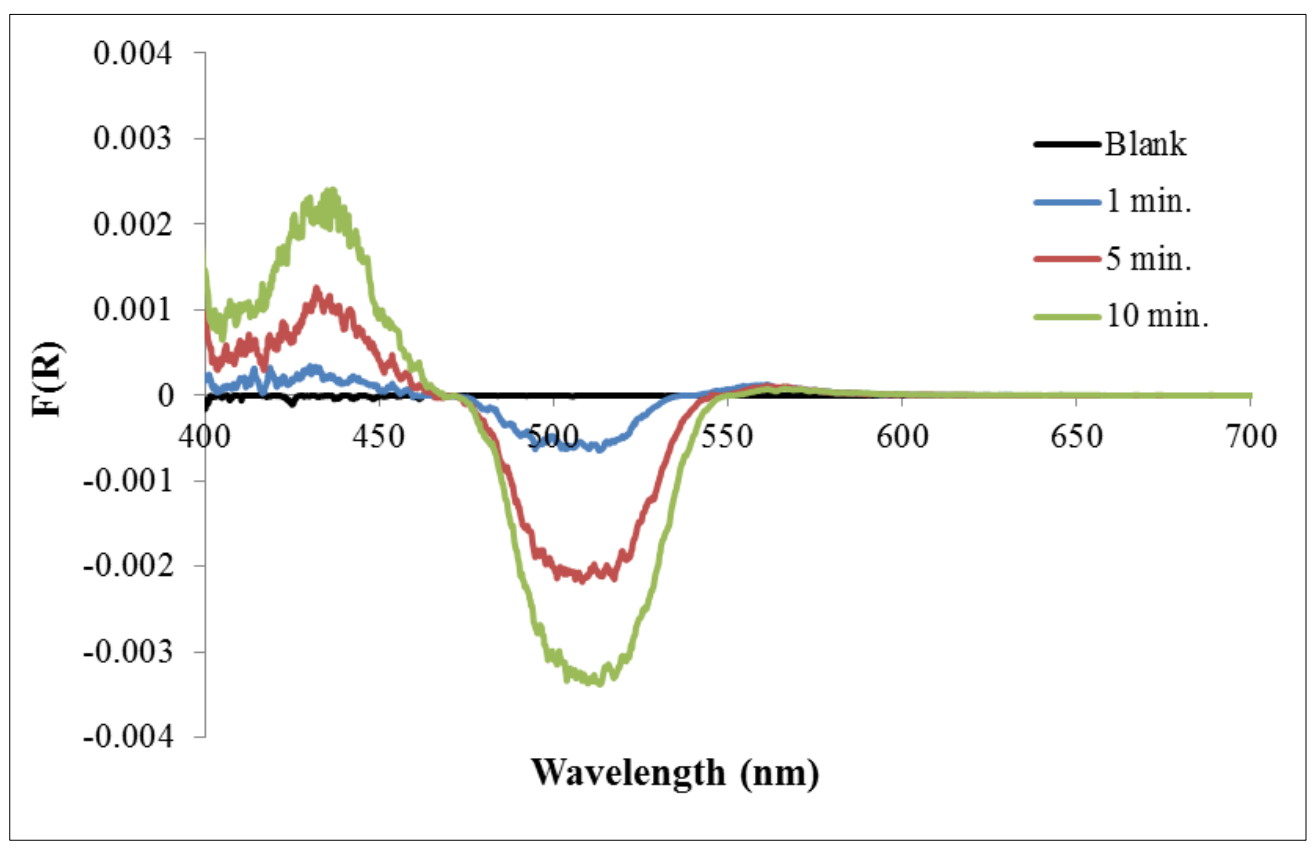

The average responses of $400-450 \mathrm{~nm}$ and $470-550 \mathrm{~nm}$ were monitored as a function of time exposed to $10.0 \mathrm{ppm} \mathrm{H}_{2} \mathrm{~S}$ exposure. Differently than results observed for $\mathrm{HCN}$, the resulting trend lines for $\mathrm{H}_{2} \mathrm{~S}$ were particularly noisy. A plot of $\mathrm{F}(\mathrm{R})$ vs. time can be observed in Figure 3.11 where a small signal is observed at 1 minute. The LINEST Excel statistical function provides a linear fit for $0-15$ minutes $\mathrm{H}_{2} \mathrm{~S}$ exposure with slope $1.63 \pm 0.05 \times 10^{-4}$ and $\mathrm{y}$ intercept $6.7 \pm 0.4 \times 10^{-4}$ with $R^{2}=0.997$ for the average of $F(R)$ values of $400-450 \mathrm{~nm}$. A slope of $-1.41 \pm 0.08 \times 10^{-4}$ and $y$-intercept of $-6 \pm 6 \times 10^{-5}$ with $\mathrm{R}^{2}=0.992$ was calculated for the average $F(R)$ values of 470-550 nm. Data for Figure 3.11 can be seen in Table B.1 (Appendix). Reaction to $\mathrm{H}_{2} \mathrm{~S}$ with Cbi appears slower than with $\mathrm{HCN}$ at $25 \% \mathrm{RH}$. 
Figure 3.11 - Average response of $\mathrm{OH}\left(\mathrm{H}_{2} \mathrm{O}\right) \mathrm{Cbi}$ on glass fiber filter paper to $10.0 \mathrm{ppm}_{2} \mathrm{~S}$ at various exposure times $(25 \% \mathrm{RH})$

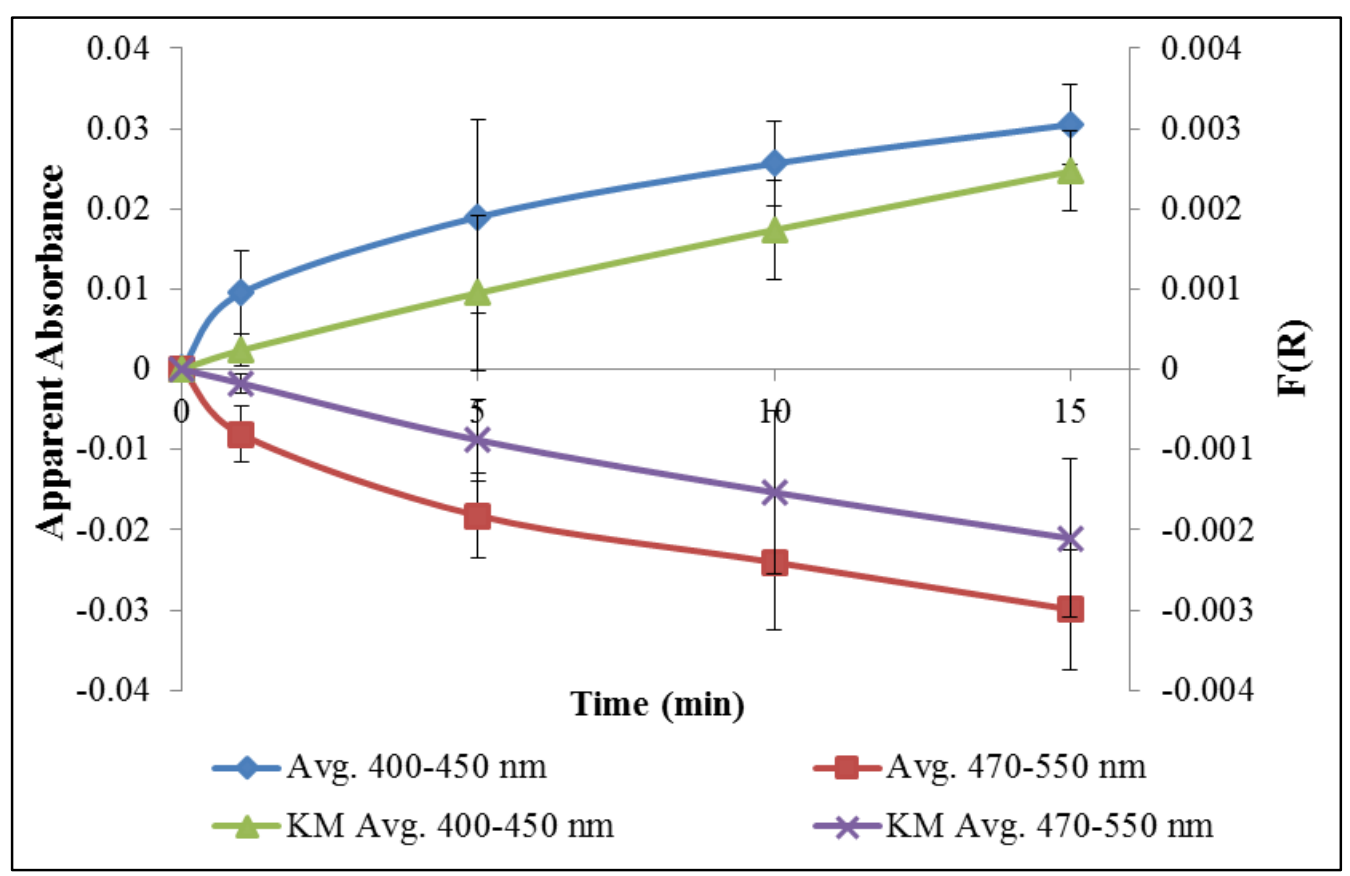

Spectra displaying a comparison of 10 minutes $\mathrm{HCN}$ exposure to 10 minutes of $\mathrm{H}_{2} \mathrm{~S}$ exposure at $25 \% \mathrm{RH}$ can be seen in Figure 3.12. The $(\mathrm{CN})_{2} \mathrm{Cbi}$ peak is clearly evident at $583 \mathrm{~nm}$ which is insignificant for $\mathrm{H}_{2} \mathrm{~S}$ exposure. The increase at $400-450 \mathrm{~nm}$ is characteristic of the presence of $\mathrm{H}_{2} \mathrm{~S}$. Additionally, the decrease at $531 \mathrm{~nm}$ can be used to identify the presence of $\mathrm{H}_{2} \mathrm{~S}$ since it is an isosbestic point for $(\mathrm{CN})_{2} \mathrm{Cbi}$. The significantly smaller $\mathrm{F}(\mathrm{R})$ values observed for $\mathrm{H}_{2} \mathrm{~S}$ exposure may be attributed to the intrinsically smaller $\mathrm{K}_{\mathrm{a}}$ value for $\mathrm{H}_{2} \mathrm{~S}$ reaction with $\mathrm{OH}\left(\mathrm{H}_{2} \mathrm{O}\right) \mathrm{Cbi}\left(10^{6}\right)$. 
Figure 3.12 - Comparison of Cbi response to $5.0 \mathrm{ppm} \mathrm{HCN}$ and $10.0 \mathrm{ppm} \mathrm{H}_{2} \mathrm{~S}$ on glass fiber filter paper

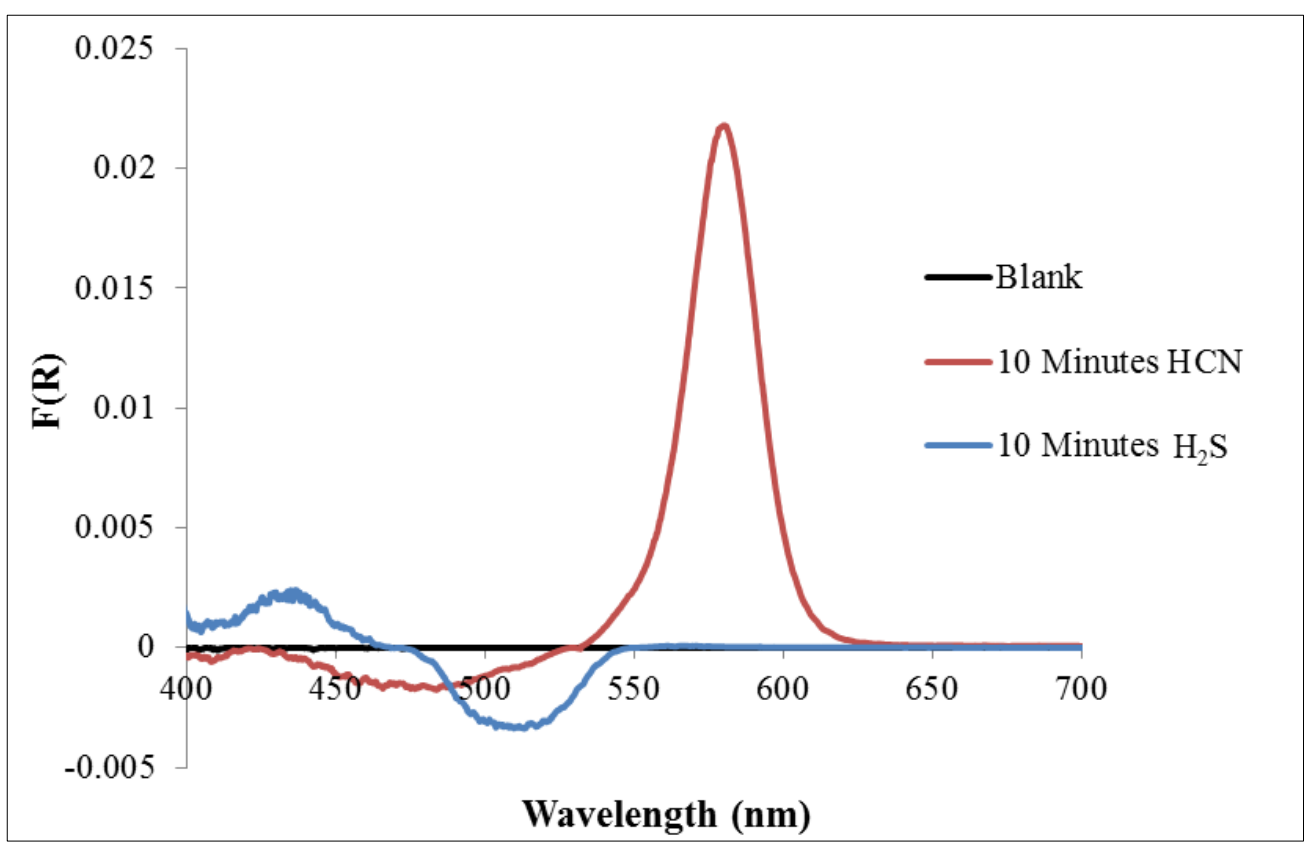

\subsubsection{Effect of Percent Relative Humidity}

The effect of \% RH on the Cbi-immobilized paper's detection for $\mathrm{H}_{2} \mathrm{~S}$ is observed for additional RH values of 50 and $85 \%$. Hypothesized from results of the HCN data, the water vapor in the challenge gas-air mixture should allow a faster reaction between $\mathrm{H}_{2} \mathrm{~S}$ and $\mathrm{OH}\left(\mathrm{H}_{2} \mathrm{O}\right) \mathrm{Cbi}$. These humidity values (including $\left.25 \% \mathrm{RH}\right)$ were evaluated because respirators are used in a wide range of climates with various levels of humidity. In this section, results of 10.0 ppm $\mathrm{H}_{2} \mathrm{~S}$ exposure at 50 and $85 \% \mathrm{RH}$ are presented first, followed by an overall discussion for all humidity values (Section 3.5.6).

\section{$50 \% R H$}

Figure 3.13 shows the difference spectra of $\mathrm{OH}\left(\mathrm{H}_{2} \mathrm{O}\right)$ Cbi on glass fiber filter paper (treated as the blank) when exposed to $10.0 \mathrm{ppm}_{2} \mathrm{~S}$ at $50 \% \mathrm{RH}$ for $1,5,10$, and 15 minutes. 
Figure 3.13 - Response of $\mathrm{OH}\left(\mathrm{H}_{2} \mathrm{O}\right) \mathrm{Cbi}$ on glass fiber filter paper to $10.0 \mathrm{ppm} \mathrm{H}_{2} \mathrm{~S}$ at $50 \% \mathrm{RH}$

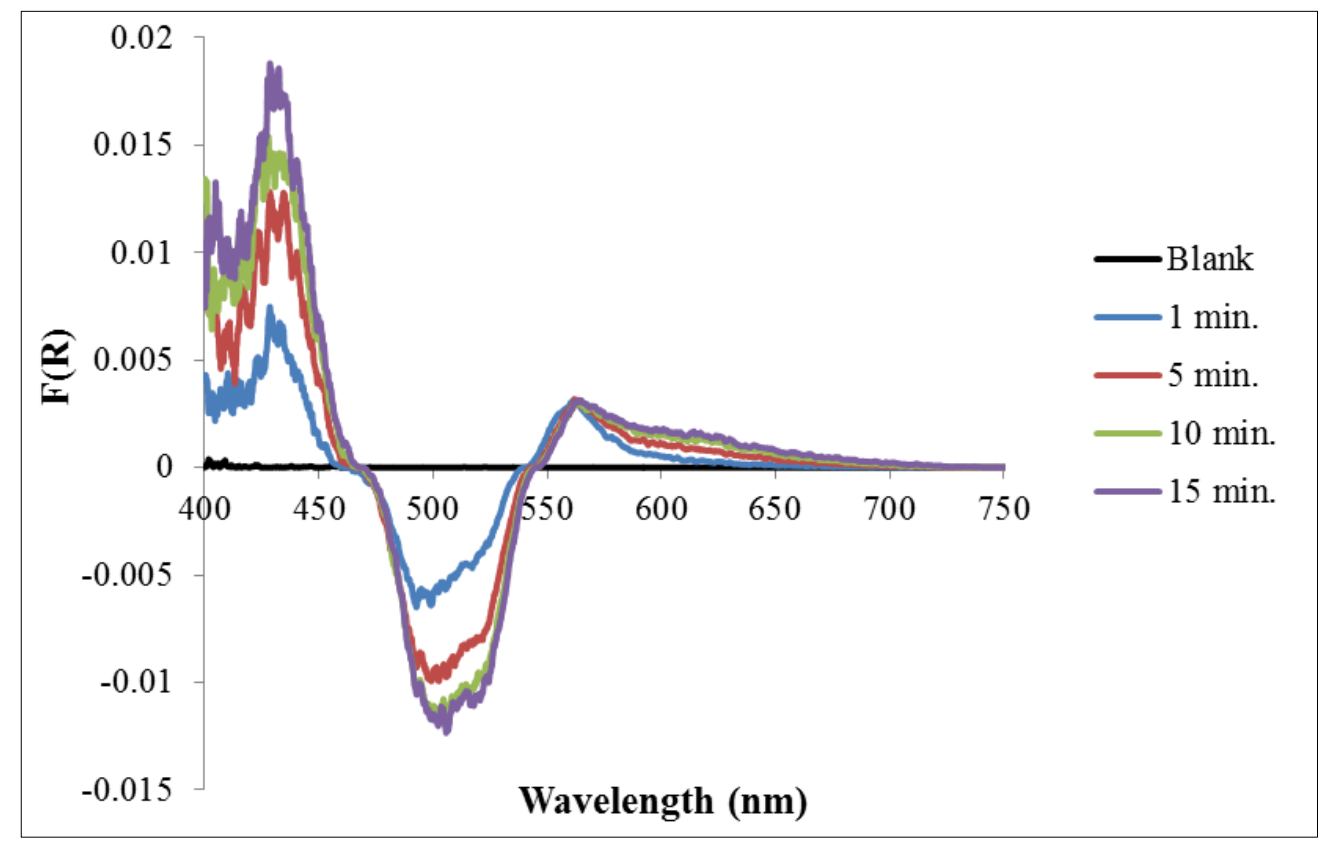

Similar spectral shifts to $25 \% \mathrm{RH}$ are observed, but at higher $\mathrm{F}(\mathrm{R})$ values as expected. A plot of $F(R)$ values (from difference spectra data) vs. time can be seen in Figure B.3, with data in Table B.2. The larger $F(R)$ values may be attributed to a larger amount of $\mathrm{HS}^{-}$binding to Cbi on paper due to water vapor adsorbed to the glass fiber paper's surface. 
Spectra displaying an overlay of 15 minutes $\mathrm{HCN}$ exposure to 15 minutes of $\mathrm{H}_{2} \mathrm{~S}$ exposure at $50 \%$ RH can be seen in Figure 3.14 (experiments conducted separately). The $(\mathrm{CN})_{2} \mathrm{Cbi}$ peak is clearly evident at $583 \mathrm{~nm}$, but is a slight peak in this wavelength range is also present upon $\mathrm{H}_{2} \mathrm{~S}$ exposure. However, characteristic spectral shifts for exposure to $\mathrm{H}_{2} \mathrm{~S}$ are apparent and different than those for $\mathrm{HCN}$.

Figure 3.14 - Comparison of Cbi response to $5.0 \mathrm{ppm} \mathrm{HCN}$ and $10.0 \mathrm{ppm} \mathrm{H}_{2} \mathrm{~S}$ at $50 \% \mathrm{RH}$

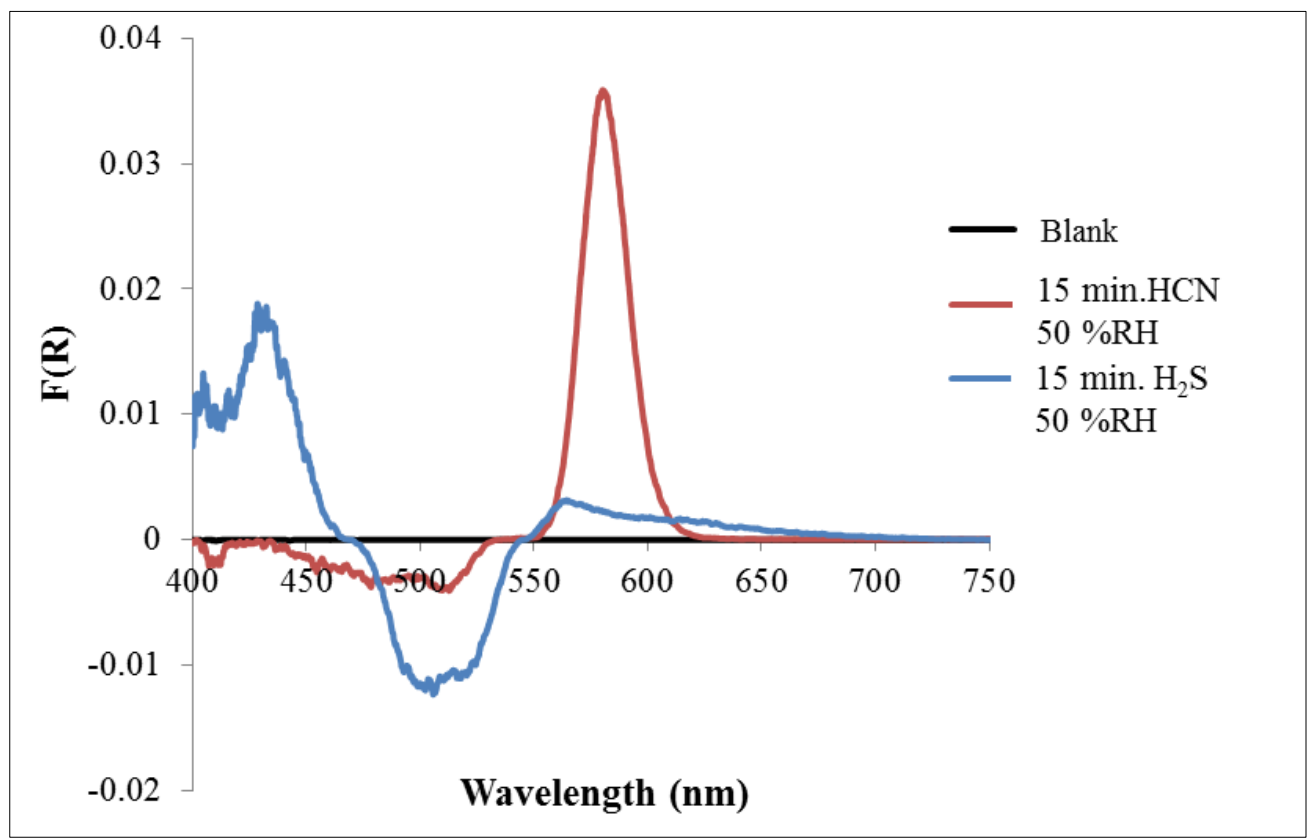

$85 \% R H$

Figure 3.15a shows the $\mathrm{F}(\mathrm{R})$ spectrum of $\mathrm{OH}\left(\mathrm{H}_{2} \mathrm{O}\right) \mathrm{Cbi}$ when exposed to $10.0 \mathrm{ppm}_{2} \mathrm{~S}$ at $85 \% \mathrm{RH}$. The spectral shifts for $85 \% \mathrm{RH}$ are remarkably different than those at lower $\% \mathrm{RH}$. Isosbestic points are observed near 460 and $560 \mathrm{~nm}$, which red-shift at longer exposure times. Similar to lower \%RH (and solution spectra), F(R) values from 400-450 nm increase and 470$550 \mathrm{~nm}$ decrease. Difference spectra can be observed in Figure 3.15b. Spectra for $\mathrm{H}_{2} \mathrm{~S}$ exposure 
at $85 \% \mathrm{RH}$ are similar to solution spectra for ascorbic acid reduction of $\mathrm{OH}\left(\mathrm{H}_{2} \mathrm{O}\right)$ Cbi from Cbi(III) to $\mathrm{Cbi}(\mathrm{II})$.

Figure 3.15 - Average response of $\mathrm{OH}\left(\mathrm{H}_{2} \mathrm{O}\right) \mathrm{Cbi}$ to $10.0 \mathrm{ppm}_{2} \mathrm{~S}$ at $85 \% \mathrm{RH}$ (A) difference spectra (B)
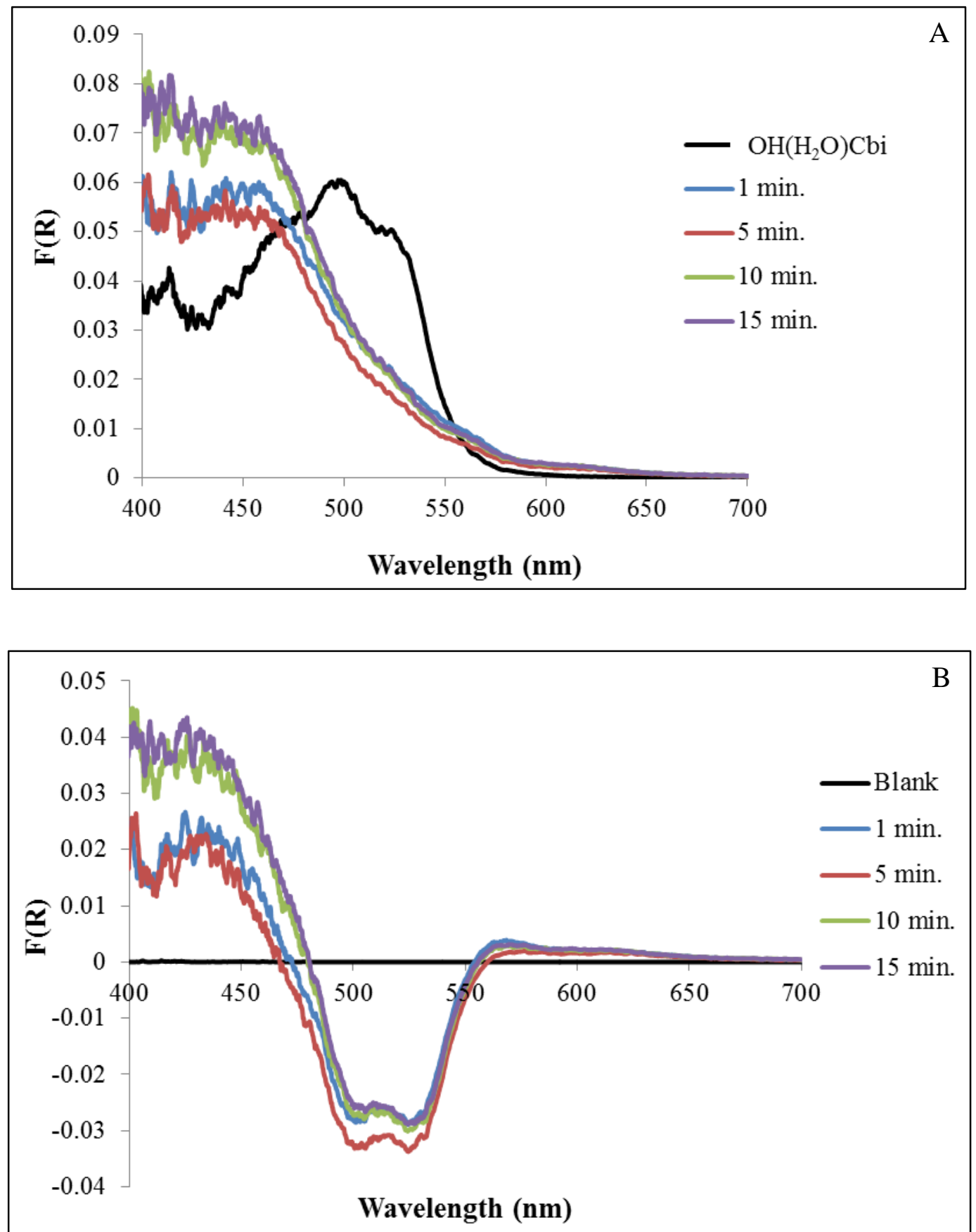
$\mathrm{F}(\mathrm{R})$ data for $85 \% \mathrm{RH}$ can be seen in Table B.3. The $\mathrm{F}(\mathrm{R})$ values are larger than those observed for 25 and $50 \% \mathrm{RH}$, as expected. This again may be attributed to a larger amount of HS- binding to Cbi on paper due to water vapor adsorbed to the paper's surface, and a more efficient reaction (possible reduction of $\mathrm{Co}^{3+}$ ).

Figure 3.16 compares the spectrum from $10.0 \mathrm{ppm} \mathrm{H}_{2} \mathrm{~S}$ and $5.0 \mathrm{ppm} \mathrm{HCN}$ exposure at $85 \% \mathrm{RH}$ after 15 minutes. The different spectral shifts suggests that Cbi could detect both gases simultaneously. Specifically, aquohydroxocobinamide $\left[\mathrm{OH}\left(\mathrm{H}_{2} \mathrm{O}\right) \mathrm{Cbi}\right]$ could be fixed on paper to detect both $\mathrm{HCN}$ and $\mathrm{H}_{2} \mathrm{~S}$ by the corresponding spectral shiftts. However, $\mathrm{HCN}$ appears to have a larger binding affinity compared to $\mathrm{H}_{2} \mathrm{~S}$, which could use up the Cbi binding sites.

Figure 3.16 - Comparison of Cbi response to $5.0 \mathrm{ppm} \mathrm{HCN}$ and $10.0 \mathrm{ppm}_{2} \mathrm{~S}$ at $85 \% \mathrm{RH}$

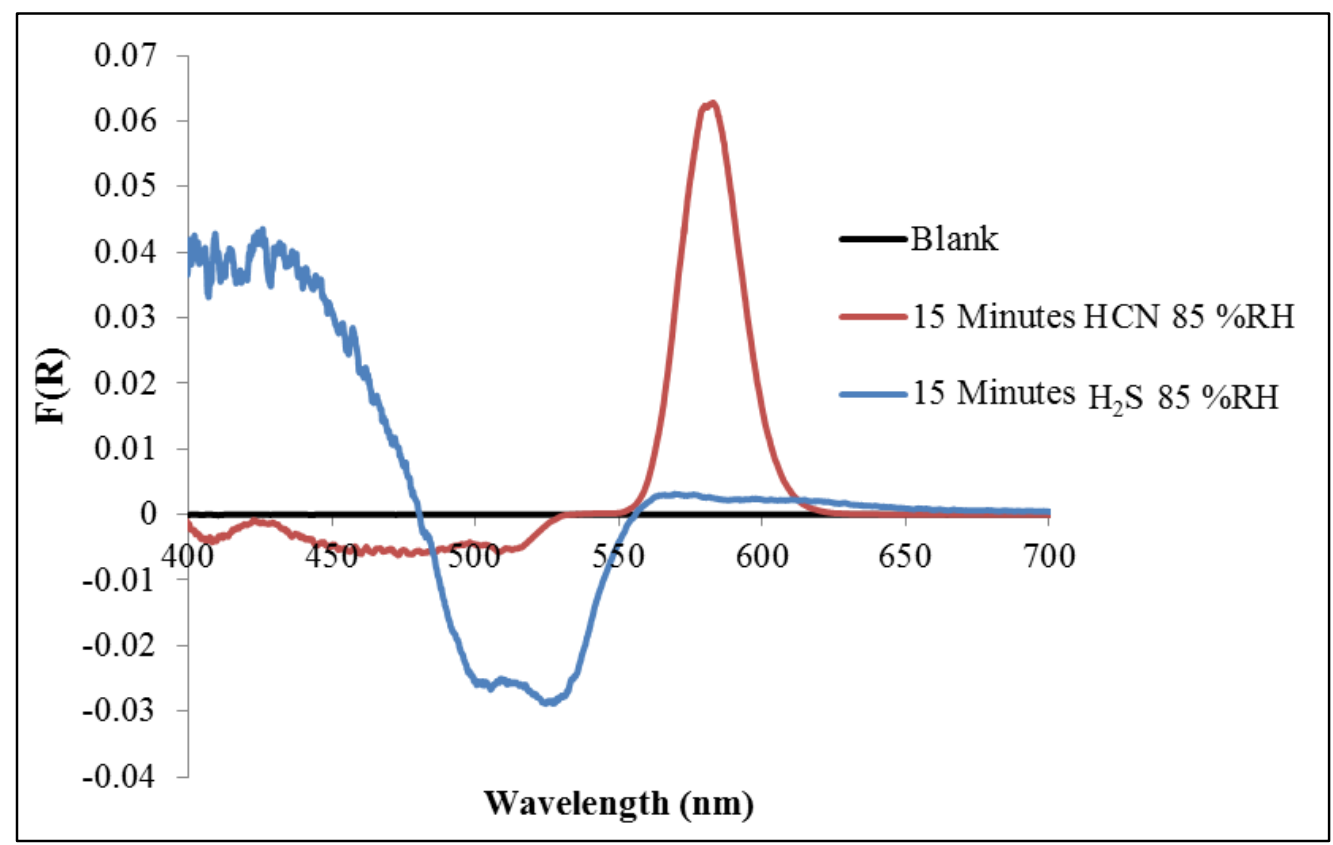

\subsubsection{Discussion - Data interpretation and Literature Comparison}

Although confirmation of the products after each \% RH exposure is not possible here, the UV-VIS spectra from $\mathrm{OH}\left(\mathrm{H}_{2} \mathrm{O}\right)$ Cbi reaction with $\mathrm{Na}_{2} \mathrm{~S}$ and ascorbic acid may be used to provide 
a hypothesis. The solution spectra of $\mathrm{Na}_{2} \mathrm{~S}$ and ascorbic acid (aerobic conditions) with $\mathrm{Cbi}$ (experiments separately), and the diffuse reflectance spectra when $10.0 \mathrm{ppm}_{2} \mathrm{~S}$ is exposed to the Cbi-immobilized paper is compared. $\mathrm{H}_{2} \mathrm{~S}$ exposure to 25 and $50 \% \mathrm{RH}$ result in spectral shifts with similar isosbestic points of $\mathrm{OH}\left(\mathrm{H}_{2} \mathrm{O}\right) \mathrm{Cbi}$ in solution with $\mathrm{Na}_{2} \mathrm{~S}(470 \mathrm{~nm})$, where $85 \% \mathrm{RH}$ is similar to the reaction of Cbi with ascorbic acid (isosbestic point $\sim 480 \mathrm{~nm}$ ). Results can be seen in Figure $3.17\left(\mathrm{OH}\left(\mathrm{H}_{2} \mathrm{O}\right) \mathrm{Cbi}\right.$ on glass fiber filter paper is the blank). 
Figure 3.17 - Comparison of $\mathrm{OH}\left(\mathrm{H}_{2} \mathrm{O}\right) \mathrm{Cbi}$ with $\mathrm{Na}_{2} \mathrm{~S}$, ascorbic acid, and 25/50\% RH exposure to $10.0 \mathrm{ppm} \mathrm{H}_{2} \mathrm{~S}(\mathrm{~A})$ or $85 \% \mathrm{RH}$ exposure (B)
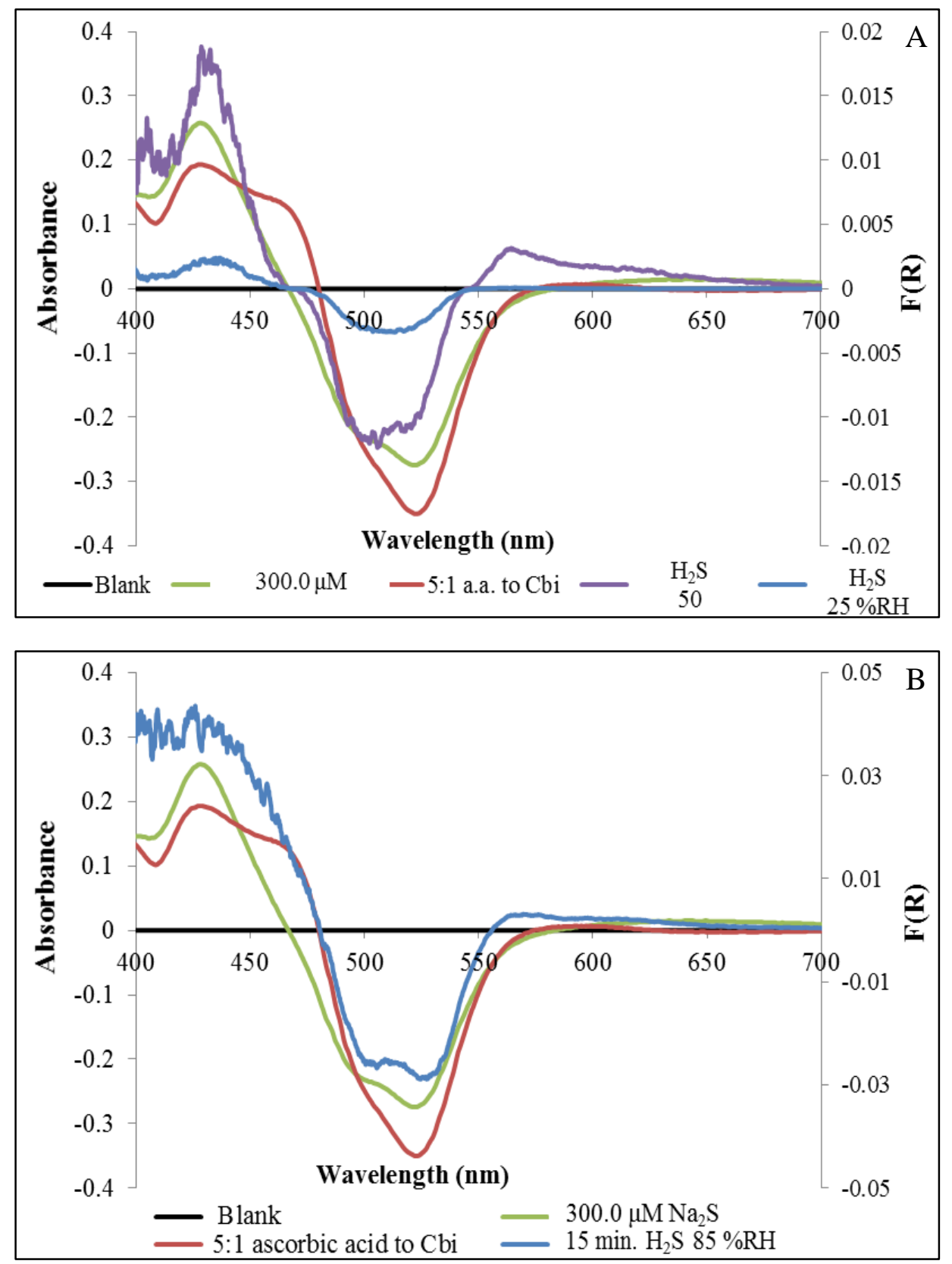

Additionally, Table 3.3 compares the spectral shifts of cobinamide after exposure to $\mathrm{H}_{2} \mathrm{~S}$ (aerobic and anaerobic conditions), $\mathrm{Na}_{2} \mathrm{~S}$ (aerobic), ascorbic acid (anaerobic and aerobic conditions), and sodium hydrosulfide (NaHS). 
Table 3.3 - Comparison of spectral shifts of Cbi exposed to $\mathrm{H}_{2} \mathrm{~S}, \mathrm{Na}_{2} \mathrm{~S}$, ascorbic acid, and $\mathrm{NaHS}$

\begin{tabular}{|c|c|c|c|c|}
\hline Analyte & pH & Reaction 1 & Reaction 2 & Reaction 3 \\
\hline $\begin{array}{l}\mathrm{H}_{2} \mathrm{~S}(<5 \mathrm{mM}) \\
\text { anaerobic }^{189}\end{array}$ & 9.6 & $\begin{array}{l}\text { Decrease: } 350,520 \mathrm{~nm} \\
\text { Increase: } 450 \mathrm{~nm} \\
\text { I.P. } 328,361,449,540 \mathrm{~nm} \\
\text { (Red-shift upon increasing } \\
\text { conc.) }\end{array}$ & $\begin{array}{c}\text { Abs. } \max \text { at } 314 \text {, } \\
468 \mathrm{~nm} \\
\text { I.P. } 330,370,493 \\
\mathrm{~nm}\end{array}$ & $\begin{array}{l}\text { Abs. decreases } \\
\text { at all } \\
\text { wavelengths }\end{array}$ \\
\hline $\begin{array}{c}\mathrm{H}_{2} \mathrm{~S}(>10 \mathrm{mM}) \\
\text { anaerobic }\end{array}$ & 9.6 & $\begin{array}{c}\text { Increase: } 316,355,550,590 \\
\mathrm{~nm} \\
\text { I.P. 333, 361, 449, } 540 \mathrm{~nm}\end{array}$ & $\begin{array}{l}\text { Abs. } \max \text { at } 314 \text {, } \\
\quad 468 \mathrm{~nm} \\
\text { I.P. } 400,507 \mathrm{~nm}\end{array}$ & $\begin{array}{c}\text { Abs. decreases } \\
\text { at all } \\
\text { wavelengths }\end{array}$ \\
\hline $\begin{array}{l}\mathrm{H}_{2} \mathrm{~S} \text { Low }(<5 \\
\mathrm{mM}) \\
\text { anaerobic }^{189}\end{array}$ & 4.5 & $\begin{array}{l}\text { Decrease: } 349,520 \mathrm{~nm} \\
\text { Increase: } 314,468 \mathrm{~nm}\end{array}$ & $\begin{array}{l}\text { Abs. decreases at } \\
\text { all wavelengths }\end{array}$ & \\
\hline $\mathrm{NaHS}^{225}$ & 4 & $\begin{array}{l}\text { Decrease: } 478.5-550 \mathrm{~nm} \\
\text { Increase: } 368.5-478\end{array}$ & - & - \\
\hline $\mathrm{H}_{2} \mathrm{~S}^{225}$ & & $\begin{array}{l}\text { Decrease: } 478.5-550 \mathrm{~nm} \\
\text { Increase: } 368.5-478 \mathrm{~nm}\end{array}$ & - & - \\
\hline $\begin{array}{c}\mathrm{Na}_{2} \mathrm{~S} \\
\text { Aerobic } \\
\text { (present work) }\end{array}$ & 7.8 & $\begin{array}{c}\text { Decrease: } 470-550 \mathrm{~nm} \\
\text { Increase: } 400-550 \mathrm{~nm}, 650 \mathrm{~nm} \\
\text { I.P. } 470,570 \mathrm{~nm}\end{array}$ & - & - \\
\hline $\begin{array}{l}\text { Ascorbic acid } \\
\text { (aerobic; 5:1 to } \\
\text { Cbi) } \\
\text { (present work) }\end{array}$ & $\sim 3.5$ & $\begin{array}{c}\text { Decrease: } 520 \\
\text { Increase: } 430,468 \mathrm{~nm} \\
\text { I.P. } 480,570 \mathrm{~nm}\end{array}$ & - & - \\
\hline $\begin{array}{l}\text { Ascorbic acid } \\
\text { (anaerobic; } 5: 1 \\
\text { to Cbi) } \\
\text { (present work) }\end{array}$ & $\sim 3.5$ & $\begin{array}{l}\text { Decrease: } 520 \\
\text { Increase: } 430,468 \mathrm{~nm} \\
\text { I.P. } 485,570 \mathrm{~nm}\end{array}$ & - & - \\
\hline
\end{tabular}

A comparison of the spectral shifts for 25,50 , and $85 \% \mathrm{RH}$ upon exposure to $10.0 \mathrm{ppm}$

$\mathrm{H}_{2} \mathrm{~S}$ can be seen in Figure 3.18. The resulting spectra are for exposure after 15 minutes. 
Figure 3.18 - Comparison of $\mathrm{OH}\left(\mathrm{H}_{2} \mathrm{O}\right) \mathrm{Cbi}$ on paper to $10.0 \mathrm{ppm}_{2} \mathrm{~S}$ at 25,50 , and $85 \% \mathrm{RH}$

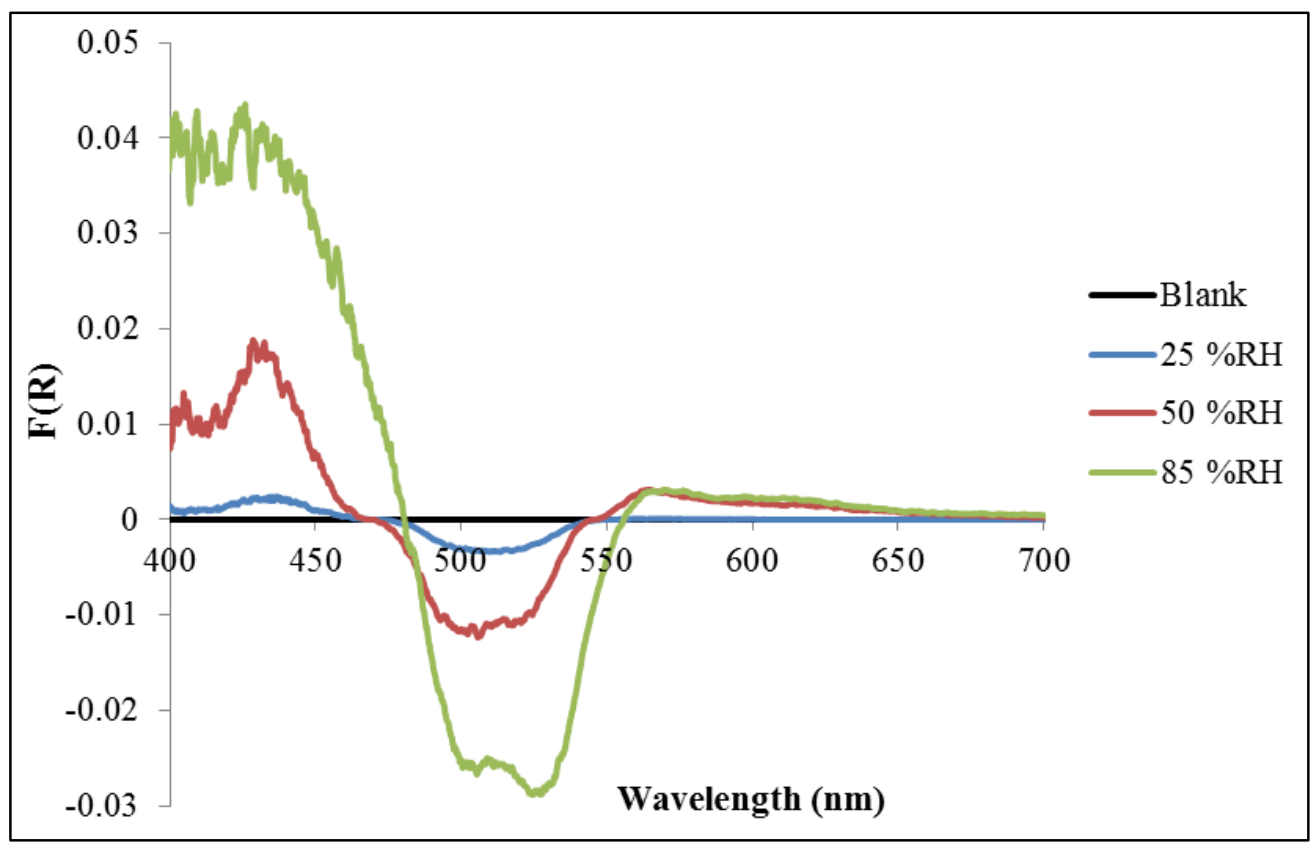

$25 \% R H$

The first step (binding of $\mathrm{HS}^{-}$to $\mathrm{Cbi}$ ) at low sulfide concentrations ( $<5 \mathrm{mM}$; $\left.\mathrm{pH} 9.5\right)$ is reported by Salnikov et al. to have a decrease in absorbance near $520 \mathrm{~nm}$, increase at $450 \mathrm{~nm}$, and isosbestic points at 449 and $540 \mathrm{~nm}$. High concentrations (>10 mM) were reported to have bands appear at 550 and $590 \mathrm{~nm}$, with isosbestic points at 449 and $540 \mathrm{~nm} .{ }^{189}$ Bands were reported to red-shift with increasing $\mathrm{H}_{2} \mathrm{~S}$ concentration. ${ }^{189}$ Exposure of the Cbi paper sensor to $10.0 \mathrm{ppm}_{2} \mathrm{~S}$ (from 1 to 15 minutes) at $25 \% \mathrm{RH}$ display spectral shifts similar to the first step of sulfide reaction with $\mathrm{OH}\left(\mathrm{H}_{2} \mathrm{O}\right)$ Cbi: the formation of compound $(\mathrm{HS})\left(\mathrm{H}_{2} \mathrm{O}\right)$ Cbi or possibly $(\mathrm{HS})_{2}$ Cbi. Spectral shifts found at this $\% \mathrm{RH}$ include isosbestic points at $470 \mathrm{~nm}$ and $\sim 545 \mathrm{~nm}$, with absorbance maximum at $435 \mathrm{~nm}$ and decrease at $\sim 520 \mathrm{~nm}$. These spectral shifts are similar to those observed by Salnikov et al., but the differences may be attributed to paper scattering, or the different environments that the experiments were formed in (e.g., anaerobic vs. aerobic, $\mathrm{pH}$ ). The observed spectral shifts, and absence of a maximum peak at $468 \mathrm{~nm}$, are similar to reaction 
with $\mathrm{Na}_{2} \mathrm{~S}$, and suggests the binding of one or two $\mathrm{HS}^{-}$groups to Cbi, but the reduction of Cbi(III) to Cbi(II) presumably did not take place.

$50 \% R H$

With exposure to $\mathrm{H}_{2} \mathrm{~S}$ at $50 \% \mathrm{RH}$, isosbestic points are observed near $460 \mathrm{~nm}$ and $~ 545$ $\mathrm{nm}$ which both red-shift upon longer time exposures. Low exposure times at $50 \% \mathrm{RH}$ display data signifying the first step of $\mathrm{H}_{2} \mathrm{~S}$ with $\mathrm{OH}\left(\mathrm{H}_{2} \mathrm{O}\right) \mathrm{Cbi}$ : the formation of compound $\mathrm{OH}(\mathrm{HS}) \mathrm{Cbi}$ or possibly the addition of the second $\mathrm{HS}^{-}$group, forming (HS) $)_{2} \mathrm{Cbi}$. Salnikov et al. reported the second step (reduction of Cbi through inner-sphere electron transfer) to have a maximum absorbance at $468 \mathrm{~nm}$ with isosbestic points at $493 \mathrm{~nm}$ (low $\mathrm{H}_{2} \mathrm{~S}$ concentrations) and $507 \mathrm{~nm}$ (high $\mathrm{H}_{2} \mathrm{~S}$ concentrations). ${ }^{189}$ These spectral shifts were not observed here for $50 \% \mathrm{RH}$, but is observed during the reduction of $\mathrm{OH}\left(\mathrm{H}_{2} \mathrm{O}\right)$ Cbi with ascorbic acid (Figure 3.5). The observed spectral shifts, isosbestic points, and absence of a peak at $468 \mathrm{~nm}$, are similar to the reaction with $\mathrm{Na}_{2} \mathrm{~S}$ and $25 \% \mathrm{RH} \mathrm{H}_{2} \mathrm{~S}$ exposure, which still suggests the binding of one or two $\mathrm{HS}^{-}$groups to Cbi, but the reduction of $\mathrm{Cbi}(\mathrm{III})$ to $\mathrm{Cbi}(\mathrm{II})$ presumably did not take place.

A small increase in signal at $583 \mathrm{~nm}$ is observed, which could potentially cause a false positive error when detecting $\mathrm{HCN}$. The formation of $\mathrm{Cbi}(\mathrm{II})$ by reduction using glucose shows a small increase at $\sim 600 \mathrm{~nm}$, while the formation of $\mathrm{Cbi}(\mathrm{I})$ shows an increase from $600-800 \mathrm{~nm}^{226}$ The increase at 400-450 $\mathrm{nm}$ and decrease from $470-550 \mathrm{~nm}$ are still characteristic for exposure to $\mathrm{H}_{2} \mathrm{~S}$, specifically the decrease at $531 \mathrm{~nm}$, which is an isosbestic point for $(\mathrm{CN})_{2} \mathrm{Cbi}$ formation when $\mathrm{HCN}$ is present.

$85 \% R H$

When $\mathrm{OH}\left(\mathrm{H}_{2} \mathrm{O}\right) \mathrm{Cbi}$ on paper is exposed to $10.0 \mathrm{ppm} \mathrm{H}_{2} \mathrm{~S}$ at $85 \% \mathrm{RH}$, isosbestic points are observed near 470 and $555 \mathrm{~nm}$. The isosbestic point red-shift upon increasing $\mathrm{H}_{2} \mathrm{~S}$ exposure 
times, which is also reported. ${ }^{189}$ Most notably, the increase near 417 and $468 \mathrm{~nm}$ (creating a broad peak here) is indicative of formation of Cbi (II). ${ }^{189,226}$ The results between solution spectra of ascorbic acid (both aerobic and anaerobic conditions) and gas-phase diffuse spectra are similar and the increase from $400-450 \mathrm{~nm}$ and decrease from $470-550 \mathrm{~nm}$ are apparent. Additionally, a small increase from $570-700 \mathrm{~nm}$ is observed, which was observed for glucose and fructose reduction of $\mathrm{Cbi}$, and thiocyanate reduction at high concentrations of both cobinamide(III) and cobalamin(III). ${ }^{106,226}$ The increasing absorbance/F(R) at the red end of the spectrum were also reported to increase with increasing $\mathrm{pH}$ and $\mathrm{H}_{2} \mathrm{~S}$ concentrations and can be seen in both aerobic and anaerobic environments of $\mathrm{OH}\left(\mathrm{H}_{2} \mathrm{O}\right) \mathrm{Cbi}$ and ascorbic acid in solution. ${ }^{189}$

Exposure to $10.0 \mathrm{ppm}_{2} \mathrm{~S}$ at $85 \% \mathrm{RH}$ display data possibly signifying all three steps of the reaction between $\mathrm{H}_{2} \mathrm{~S}$ and $\mathrm{OH}\left(\mathrm{H}_{2} \mathrm{O}\right) \mathrm{Cbi}$, including the reduction of Cbi due to charge transfer and possible formation of [HṠ]Cbi(II). The increase in signal at higher \%RH is most likely attributed to a higher concentration of $\mathrm{H}_{2} \mathrm{~S}$ reacting with cobinamide due to solubility in a water film on the paper's surface, and thus reduction of the $\mathrm{Co}(\mathrm{III})$ to $\mathrm{Co}(\mathrm{II})$. Control experiments performed with $\mathrm{OH}\left(\mathrm{H}_{2} \mathrm{O}\right)$ Cbi on glass fiber paper under conditions of $85 \% \mathrm{RH}$ and $0.0 \mathrm{ppm}_{2} \mathrm{~S}$ did not show changes to the Cbi spectrum. Thus, a higher \%RH allows a more efficient reaction between gaseous $\mathrm{H}_{2} \mathrm{~S}$ and $\mathrm{OH}\left(\mathrm{H}_{2} \mathrm{O}\right) \mathrm{Cbi}$. Similar to $50 \% \mathrm{RH}$, there is an increase in signal near $583 \mathrm{~nm}$. This could cause a false positive error when detecting HCN, but observation of 400-450 $\mathrm{nm}$ and $470-550 \mathrm{~nm}$ remain characteristic of $\mathrm{H}_{2} \mathrm{~S}$ exposure. Regardless, a false positive threshold must be incorporated into the ESLI.

The final reaction products as a function of exposure time or \%RH could not be identified without use of a mass spectrometer. Under anaerobic conditions, Salnikov et al. reported the $\mathrm{m} / \mathrm{z}$ values observed after reaction of Cbi with $\mathrm{H}_{2} \mathrm{~S}$ did not correspond with one or two $\mathrm{HS}^{-}$ions 
bound, as expected, nor did they correspond with the dimer produced in aerobic conditions $\left[\mathrm{Co}^{\mathrm{II}}\right]-\mathrm{S}-\mathrm{S}-\left[\mathrm{Co}^{\mathrm{II}}\right] \cdot{ }^{189,227}$ The reduced Cbi compound was observed in the positive mode, but the authors concluded that the product of the reaction was unstable and other reactions occurred.

The response of $\mathrm{H}_{2} \mathrm{~S}$ exposure to $\mathrm{OH}\left(\mathrm{H}_{2} \mathrm{O}\right) \mathrm{Cbi}$ on glass fiber paper at low $\% \mathrm{RH}$ are slower than for $5.0 \mathrm{ppm} \mathrm{HCN}$ exposure. The initial responses at each \% $\mathrm{RH}$ of $\mathrm{OH}\left(\mathrm{H}_{2} \mathrm{O}\right) \mathrm{Cbi}$ are compared by fitting the data with a linear regression line and comparing the slopes. Table 3.3 shows the slopes at the first two minutes for 25 and $50 \% \mathrm{RH}$, and the first 10 seconds for 85 $\% \mathrm{RH}$ (before the response began to plateau). A larger slope is observed with increasing \% RH, attributed to a faster response time.

Table 3.4 - Comparison of slopes for the initial response of $10.0 \mathrm{ppm}_{2} \mathrm{~S}$ to $\mathrm{OH}\left(\mathrm{H}_{2} \mathrm{O}\right) \mathrm{Cbi}$ at 25 , 50 and $85 \% \mathrm{RH}$

\begin{tabular}{|c|c|c|}
\hline & Linear regression & $\mathrm{R}^{2}$ \\
\hline $25 \% \mathrm{RH}$ & $\mathrm{y}=\mathbf{2 . 0} \times \mathbf{1 0}^{-4} \mathrm{x}-2.0 \times 10^{-5}$ & 0.72 \\
\hline $50 \% \mathrm{RH}$ & $\mathrm{y}=\mathbf{2 . 0} \times \mathbf{1 0}^{-3} \mathrm{x}-1.4 \times 10^{-3}$ & 0.92 \\
\hline $85 \% \mathrm{RH}$ & $\mathrm{y}=\mathbf{1 . 7 0}^{-10} \mathbf{1 0}^{-1} \mathrm{x}-1.2 \times 10^{-3}$ & 0.94 \\
\hline
\end{tabular}

\subsection{Conclusion}

Distinctive spectral changes were observed when $10.0 \mathrm{ppm}_{2} \mathrm{~S}$ was exposed to the $\mathrm{OH}\left(\mathrm{H}_{2} \mathrm{O}\right)$ Cbi-immobilized glass fiber paper-e.g. increase from 400 to $450 \mathrm{~nm}$ and decrease from 470 to $550 \mathrm{~nm}$. These spectral shifts were different from those observed during formation of $(\mathrm{CN})_{2} \mathrm{Cbi}$ (Chapter 2). Results found here were compared with recent published data of $\mathrm{H}_{2} \mathrm{~S}$ with $\mathrm{OH}\left(\mathrm{H}_{2} \mathrm{O}\right) \mathrm{Cbi}$, however, the referenced data was obtained under anaerobic conditions. In this study, experiments were attempted to simulate occupationally-relevant conditions, where aerobic conditions would exist. At lower \% RH, spectra were characteristic of formation of either 
$(\mathrm{HS})\left(\mathrm{H}_{2} \mathrm{O}\right) \mathrm{Cbi}$ or $(\mathrm{HS})_{2} \mathrm{Cbi}$. By increasing the amount of water vapor in the air, a faster reaction was observed leading to a more rapid response time and difference in the spectra. The higher signals observed were likely attributed to a combination of various complexes formed by reaction of $\mathrm{OH}\left(\mathrm{H}_{2} \mathrm{O}\right) \mathrm{Cbi}$ with $\mathrm{HS}^{-}$including the reduction of $\mathrm{Co}^{3+}$ to $\mathrm{Co}^{2+}$ and formation of [(HŚ)]Cbi(II). For all \% RH, exposure to $10.0 \mathrm{ppm}_{2} \mathrm{~S}$ was similar to the absorbance spectra observed for the addition of $\mathrm{Na}_{2} \mathrm{~S}$ and ascorbic acid, indicating reaction with the sulfide ion and/or reduction of Cbi. Thus, binding (of sulfide) and/or reduction of the $\mathrm{Co}^{3+}$ metal center of Cbi was apparent in the gas phase; however the unstable isosbestic points suggest formation of different species making identification difficult. The characteristic spectra, along with future data processing, make it possible to detect $\mathrm{H}_{2} \mathrm{~S}$ and $\mathrm{HCN}$ either independently or possibly simultaneously. Constructing a gas-flow system for use with both gases would be necessary. It should be mentioned, however, that $\mathrm{H}_{2} \mathrm{~S}$ (an acid gas) and $\mathrm{HCN}$ (classified as a CBRN gas) require different cartridges/canisters and it is not common for both to be present in the same environment.

\section{Chapter 4: Detection of $\mathrm{HCN}$ and $\mathrm{H}_{2} \mathrm{~S}$ Breakthrough from Respirator Canisters and Cartridges}

\subsection{Introduction}

To be an effective ESLI, the sensor must successfully detect a pre-determined gas concentration at a certain point within a carbon bed, signifying imminent and impending breakthrough. Before the paper sensor can be incorporated directly into a cartridge/canister wall for testing — which takes collaboration with manufacturers for proper placement without disruption of the carbon - it was placed in the downstream flow of a pair of cartridges/canisters to monitor breakthrough. This was done to establish detection of low gas concentrations breaking 
through the carbon bed. High concentrations of $\mathrm{HCN}$ and $\mathrm{H}_{2} \mathrm{~S}$ at various $\% \mathrm{RH}$ were directed through carbon beds that were specific for the protection against these gases. The $F(R)$ signal was simultaneously compared with a $\mathrm{HCN}$ - and $\mathrm{H}_{2} \mathrm{~S}$-specific electrochemical detector, which were also sampling air downstream of the carbon beds from a similar location to the paper sensor. The breakthrough curves (i.e. concentration of gas exiting a carbon bed vs. time of fixed contaminated airflow) were compared to study if the paper sensor was effective in monitoring breakthrough. ${ }^{32}$

\subsection{Background}

\subsubsection{Activated Carbon in Canisters}

Activated carbon refers to the class of carbon-based compounds (e.g., wood, coal, and coconut shells) used in the steam activation production process. Activation occurs by heating to $800-900^{\circ} \mathrm{C}$; the resulting carbon is highly porous, containing micro- $(<2 \mathrm{~nm})$, meso- $(2-50 \mathrm{~nm})$, and macropores (>50nm). ${ }^{228}$ Millions of these pores result in high surface areas up to 1500 $\mathrm{m}^{2} / \mathrm{g} .{ }^{229}$ Coconut or coal-based carbon is typically used in respiratory protection as it has high density with a large number of these small pores. ${ }^{230}$ Gases (adsorbate) are primarily removed by physical adsorption to the carbon (adsorbent) by van der Waals interactions as a result of intermolecular forces of attraction between molecules of the adsorbent and the adsorbate. The intensity of attraction varies with the type of sorbent and contaminant. Physical adsorption of smaller gases (e.g., $\mathrm{HCN}$ and $\mathrm{H}_{2} \mathrm{~S}$ ) and high-vapor pressure agents are weak and therefor reversible at room temperature. For this reason, activated carbon is often impregnated with chemicals to neutralize and enhance the removal of toxic gases by chemical adsorption, known as chemisorption. Chemisorption is the result of strong chemical interactions between the solid and adsorbed substance, and is frequently irreversible. ${ }^{231}$ Chemical adsorption typically results 
from electrostatic interactions or hydrogen bonding. Each gas and impregnant combination has a unique reaction designed to increase service-life. ${ }^{32}$ Jonas (1978) hypothesized the removal mechanism occurring in a sequence of steps shown in Figure 4.1, adapted from Jonas. ${ }^{16,232}$

Figure 4.1 - Reaction steps in gas adsorption by activated carbon

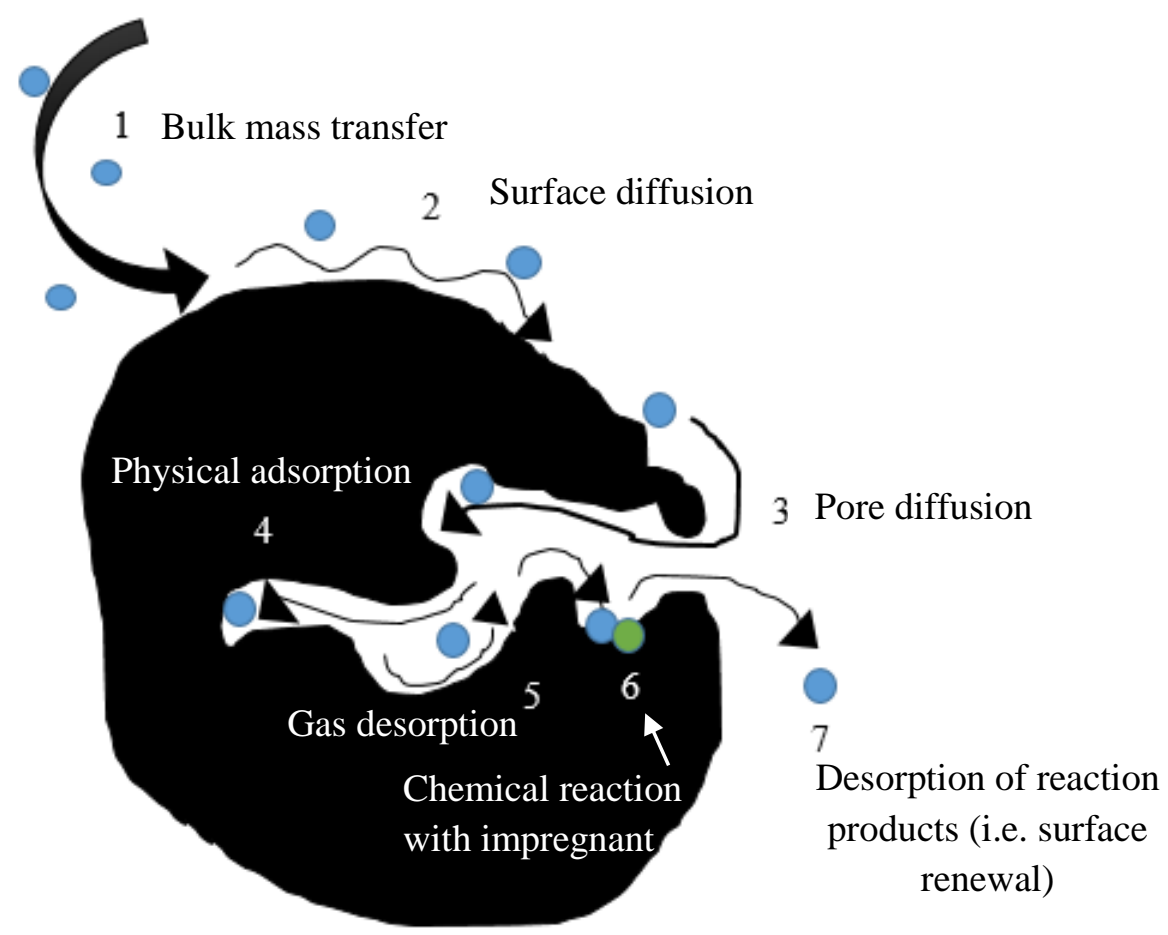

Graceffo et al. further simplified this mechanism by proposing that toxic gases are transferred from the bulk of the gas-air mixture to the external surface of adsorbent carbon (masstransfer). ${ }^{233}$ Then, pore diffusion occurs where the toxic species are either adsorbed by the carbon or reacted with the impregnants. ${ }^{233}$

The adsorbent becomes "exhausted" if both its adsorptive capacity and its impregnants are completely depleted-i.e. the carbon bed's end-of-service-life. ${ }^{232}$ Exhaustion is unavoidable as only a finite number of reaction sites exist. Factors that affect carbon bed service-life include the type and concentration of gas/vapor present, flow rate, temperature, and \%RH. Additionally, 
compounds that have molecular weight lower than $50 \mathrm{~g} / \mathrm{mol}$, a boiling point less than $20^{\circ} \mathrm{C}$, or index of refraction $\leq 1.40$ may not readily adsorb to the activated carbon. ${ }^{231}$

In this chapter, the effects of $\% \mathrm{RH}$ will be apparent in the context of toxic gas (i.e. reactive gas) carbon bed breakthrough. Water vapor is physically adsorbed onto the carbon bed surface and within the pores. For water-immiscible gases or vapors (e.g., organic vapors), competition for active sites occurs and causes a decreased service-life. For water-miscible gases or vapors (e.g., $\mathrm{HCN}$ and $\mathrm{H}_{2} \mathrm{~S}$ ), solubility aids in increased service-lives with the condensed water vapor in the pores.

When a carbon bed is exposed to a challenge vapor, a concentration gradient is established within the bed. ${ }^{54}$ As the carbon becomes saturated at a specific point within the bed, the concentration in this region approaches the challenge concentration (i.e. the concentration outside the cartridge) ${ }^{54}$ Upon repeated exposure, the concentration gradient (mass transfer zone) will move uniformly as a wavefront down the bed in the direction of the flow until it reaches the bed outlet. "Canister testing" involves passing a gas-air stream through a canister until the effluent stream shows penetration (i.e. breakthrough) at a predetermined concentration. ${ }^{234}$ For ESLIs, breakthrough testing can be used to confirm the sensor output at which triggers an alarm and the placement of the sensor to indicate $90 \%$ service-life exhaustion. A breakthrough curve is a plot of gas/vapor concentration as a function of time. The adsorption model for removal of the gas by activated carbon is considered to be second order in kinetics due to the reaction between an active site on the carbon and a free vapor molecule, but has been shown to exhibit this only in the linear or mid-portion of the curve where concentration rises rapidly against time. ${ }^{235}$ The first portion of this curve demonstrates that the active sites on the carbon are in excess and is pseudo- 
first-order kinetics with respect to vapor molecules. The rate of reaction, $\mathrm{R}$, has been postulated to be related to the rate constant $(k)$, impregnant concentration $(n)$, and gas concentration $(c):^{233}$

$$
\mathrm{R}=-k n c
$$

Correspondingly, as active sites on the carbon become depleted, vapor molecules are in excess and the curve displays pseudo-first-order kinetics with respect to active sites. ${ }^{235}$

Canister testing conditions were initially proposed during World War I, modified during World War II, and are still generally used today. Common parameters include flow rates of 32 and 60 LPM. These values were determined in 1918 and 1942, respectively, correlating to the average breathing rate for men at moderately heavy exercise. ${ }^{234}$ Also in 1942, $80 \% \mathrm{RH}$ was added to testing conditions to better represent tropical climates. Testing temperatures are typically made at or near room temperature. Most service-lives are not affected by minor variations in temperature, and external temperature does not generally affect the low heat conducting charcoal bed. For reproducibility purposes, an insulating apparatus can be incorporated into the testing setup. Lastly, 1,000 ppm has been the custom concentration for the gas of interest during canister testing. Unless service-times are too long-where 5,000 or 10,000 ppm can be used-1,000 ppm is still used today. ${ }^{234}$ Convenient canister service-lives for testing are typically under one hour. Longer lives are too time consuming while shorter ones are subject to uncertainty in determining the exact breakthrough point. ${ }^{234}$

\subsubsection{Neutralization by Impregnants}

The use of activated carbon as an adsorbent for toxic chemicals became popular in World War I where the introduction of gas warfare compelled the development of suitable respirators for personnel protection. ${ }^{229}$ The carbon used in German gas masks was impregnated with alkali 
or hexamethylene tetramine for protection against chemical warfare. ${ }^{236}$ This development encouraged the Allies to explore the use of impregnants. Subsequent developments provided soldiers and first-time responders with more advanced filter technology for protection against chemicals, biological agents, and nuclear agents. ${ }^{5}$

Chemical impregnants aid activated carbon in removal of volatile vapors and make cartridges more effective for filtering gases. One of the most important developments of carbon impregnation was copper as an impregnant, which was reported to triple the protection against $\mathrm{HCN} .{ }^{237}$ Nearing the end of World War I, a type of copper-impregnated carbon, called Whetlerite, was developed. The advancement and addition of divalent copper, silver, and hexavalent chromium impregnated carbon, called ASC Whetlerite, was further developed. This type of activated carbon is impregnated with copper oxide (6-8\% by volume), silver nitrate (0.2\%), chromium anhydride (2-3\%), and ammonium carbonate. ASC Whetlerite is superior at removing acidic or acid-forming gases such as cyanogen chloride, hydrogen cyanide, hydrogen sulfide, phosgene, and sarin. ${ }^{232,237}$

Incorporation of metals (in the form of alloys, oxides, halides, molybdates, etc.) can be used as catalysts to increase reaction with oxygen or water, or for reactions such as oxidation (e.g., platinum), decomposition (e.g., iron), hydration (e.g., aluminum), hydrolysis (e.g., copper) and reduction (e.g., nickel) of a toxic gas. ${ }^{234}$ Each impregnant/gas combination undergoes a unique reaction. $\mathrm{HCN}$ is weakly acidic and insufficiently removed by basic impregnants. HCN also has a low molecular weight and high volatility, which is inadequate for physical adsorption removal. Metal complexation with surface copper sites forms stable copper cyanides and sulfides and remove both $\mathrm{HCN}$ and $\mathrm{H}_{2} \mathrm{~S}$ by the reactions ${ }^{237}$ : 


$$
\begin{array}{rr}
4 \mathrm{HCN}_{(\mathrm{g})}+2 \mathrm{CuO}_{(\mathrm{s})} \rightarrow 2 \mathrm{Cu}(\mathrm{CN})_{(\mathrm{s})}+2 \mathrm{H}_{2} \mathrm{O}_{(\mathrm{aq})}+\mathrm{C}_{2} \mathrm{~N}_{2(\mathrm{~g})} \text { Equation } 4.2 \\
\mathrm{C}_{2} \mathrm{~N}_{2(\mathrm{~g})}+2 \mathrm{H}_{2} \mathrm{O}_{(\mathrm{aq})} \rightarrow\left(\mathrm{CONH}_{2}\right)_{2(\mathrm{aq})} \text { or polymerization } & \text { Equation } 4.3 \\
\mathrm{H}_{2} \mathrm{~S}_{(\mathrm{g})}+\mathrm{CuO}_{(\mathrm{s})} \rightarrow \mathrm{CuS}_{(\mathrm{s})}+\mathrm{H}_{2} \mathrm{O}_{(\mathrm{aq})} & \text { Equation } 4.4
\end{array}
$$

In the 1980's, there was concern regarding chromium as a potential human carcinogen. Considerable research, specifically by the U.S. Army, was performed to develop a chromiumfree impregnated carbon that still provided the same level of protection against toxic chemicals that the ASC carbon had offered. This new type of activated carbon - termed ASZM-TEDA—is impregnated with metal oxides such as copper (5-20\%), silver $(<0.5 \%)$, zinc $(<8 \%)$, molybdenum and/or vanadium salts (2-5\%; to replace chromium), along with triethylenediamine (TEDA, 1.0-7.5\%). ${ }^{238}$ The addition of an organic amine, such as TEDA, supports the increased removal of acidic gases such as cyanogen chloride, and is speculated to protect impregnants from degradation over time. Basic or base-forming gases (e.g., ammonia) are generally neutralized by acidic impregnants. ${ }^{232}$ Examples of chemical contaminants with respective impregnants used for neutralization can be observed in Table 4.1 (adapted from CBRN Protection) ${ }^{5}$ : 
Table 4.1 - Common chemical impregnants

\begin{tabular}{|c|c|}
\hline Gas/Vapor & Chemical Impregnant \\
\hline Acid gas, carbon disulfide & Potassium carbonate, copper oxide ${ }^{239}$ \\
\hline Aldehydes & Manganese (IV) oxide \\
\hline Ammonia & Phosphoric acid, nickel chloride, copper salts $^{239}$ \\
\hline Arsine, phosphine & Zinc oxide \\
\hline Hydrogen cyanide & Iron oxide \\
\hline Hydrogen mercaptans & Iron oxide, potassium permanganate \\
\hline Hydrogen sulfide & Sulfur, iodine ${ }^{239}$ \\
\hline Mercury & Copper/silver agents \\
\hline Phosgene, chlorine, and arsine & Zinc oxide \\
\hline Radioactive methyl iodide & \\
\hline
\end{tabular}

In this chapter, specific canisters and cartridges for $\mathrm{HCN}$ and $\mathrm{H}_{2} \mathrm{~S}$, respectively, were used for breakthrough studies. The cobinamide paper sensor was placed downstream of the carbon beds and simultaneously compared with previously established detection methods (i.e. gas-specific electrochemical sensors). Both downstream sensors actively monitored breakthrough and results were compared for a proof-of-concept study to determine if cobinamide fixed on paper could provide detection in a suitable amount of time.

\subsection{Experimental}

\subsubsection{Materials}

Aquohydroxocobinamide $\left.\left[\mathrm{OH}\left(\mathrm{H}_{2} \mathrm{O}\right) \mathrm{Cbi}\right], \mathrm{Co}(\mathrm{III})\right)$ was synthesized from hydroxocobalamin as described previously. ${ }^{104}$ Stock $\mathrm{H}_{2} \mathrm{~S}$ gas was purchased at concentrations of $1001 \pm 2 \%$ ppm (Butler Gas), $10.0 \pm 5 \%$ ppm (Greco Gas, Inc.), and $>99 \% \pm 2 \%$ (of certified value) chemically pure $\mathrm{H}_{2} \mathrm{~S}$ (Matheson). $\mathrm{HCN}$ calibration gases were purchased at concentrations of $10.1 \pm 5 \%$ (Matheson), $1001 \pm 2 \%$ (Greco Gas Inc.), and $1.99 \% \pm 2 \%$ of certified value $\left(\sim 20,000 \mathrm{ppm} \pm 2 \% ; 25.5 \mathrm{ft}^{3}\right)$. All gases were balanced in nitrogen. A cyanogen permeation tube (part no. SRT-2-006.50-2039, serial number 51213) was used with an emission rate of 5837 
ng/min at $30^{\circ} \mathrm{C}$. Gelman Sciences A/E Borosilicate Glass fiber filter paper (binder free, $330 \mu \mathrm{m}$ thick, and $1 \mu \mathrm{m}$ pore size) was used as the support media. Deionized water $(18 \mathrm{M} \Omega$-cm) was obtained from an in-line water system (Thermo Scientific Micropure). MSA ${ }^{\circledR}$ cartridges, and $3 \mathrm{M}^{\circledR}$ and Scott Safety ${ }^{\circledR}$ CBRN canisters were used.

\subsubsection{Preparation of Cobinamide Solution}

Monocyanocobinamide $\left[\mathrm{CN}\left(\mathrm{H}_{2} \mathrm{O}\right) \mathrm{Cbi}\right]$ and aquohydroxocobinamide $\left[\mathrm{OH}\left(\mathrm{H}_{2} \mathrm{O}\right) \mathrm{Cbi}\right]$ were prepared as discussed in Chapter 2.4.1 and 3.4.1, respectively. ${ }^{112}$ A bench-top UV-VIS spectrometer (Thermo Scientific Evolution 300) was used to determine the final concentration of cobinamide stock solutions using the molar extinction coefficient at $583 \mathrm{~nm}$ upon addition of excess $\mathrm{CN}^{-}$. The stock solutions were kept at $4^{\circ} \mathrm{C}$ and diluted in deionized water for fixing onto the paper substrates.

\subsubsection{Preparation of Sensor Substrate}

The preparation of the paper sensor substrate was explained in Chapter 2.4.2 and Chapter 3.4.1.

\subsubsection{Sensor Holder}

The paper substrate was housed in the sensor holder and was explained in detail in Chapter 2.4.3. The holder was integrated downstream of the canister flow. Air was pulled from the effluent gas over the Cbi paper sensor at 1.0 LPM $( \pm 5 \%)$ by a Gilian Air Sampling Pump.

\subsubsection{Diffuse Reflectance Instrumentation}

The bifurcated optical fiber, light source and spectrometer used for monitoring spectral shifts were explained in Chapter 2.4.4. 


\subsubsection{Gas Flow System and Instrumentation: HCN}

HCN breakthrough experiments were performed at the NIOSH/NPPTL facility in Pittsburgh, PA. The STP (with associated experimental equipment and setup) titled "Determination of CBRN Acid Gases (Hydrogen Cyanide) Service-Life Test, Air-Purifying Standard Test Procedure STP-CBRN-0303)" can be found online. ${ }^{240}$ In short, the Interscan ${ }^{\circledR}$ electrochemical HCN detector described in Chapter 2 was used to monitor HCN breakthrough from CBRN canisters and was placed downstream of the canisters to sample effluent flow. This downstream electrochemical detector was calibrated with $10.1 \mathrm{ppm} \mathrm{HCN}( \pm 5 \%)$. To verify the upstream gas concentration (i.e. challenge gas), a Photoacoustic Multi-Gas Monitor 1314A (California Analytical Instruments ${ }^{\circledR}$ ) with an optical filter for HCN (Model UA989) was used. This instrument uses infrared light to determine the concentration of the gas by use of optical filters for selecting the gas. The pulsating light that passes through the optical filter chopper is absorbed by the gas, causing the temperature to increase and decrease, simultaneously causing an increase and decrease in pressure. This acoustic signal is detected by two microphones mounted in the cell wall. Additionally, the instrument is fitted with a special filter to measure and compensate for water vapor, along with temperature and pressure. The photoacoustic instrument samples gas at $30 \mathrm{~mL} / \mathrm{min}$, with a response time of 13 seconds, and repeatability of $1 \%$ of measured value (according to manufacturer). Range for $\mathrm{HCN}$ is $0.8-8000 \pm 0.08 \mathrm{ppm}$. The instrument communicates via IEEE 488, RS-232 and CAN interfaces to a PC, and controlled by LabVIEW $^{\circledR}$. This instrument was calibrated with the $1001 \pm 2 \%$ ppm HCN calibration gas. The experimental setup can be seen in Figure C.1 (Appendix).

The gas-flow system was initially flushed with clean air at the desired \% RH (no $\mathrm{HCN}$ )

for 30 minutes before each experiment. The system was evaluated by the Interscan ${ }^{\circledR}$ to ensure a 
reading of $0.0 \mathrm{ppm} \mathrm{HCN}$. A blank paper circle was then placed in the sensor holder. The reflectance signal from the blank was defined as $100 \%$ reflectance at each wavelength. A piece of $\mathrm{CN}\left(\mathrm{H}_{2} \mathrm{O}\right) \mathrm{Cbi}$-impregnated paper was then placed in the holder and the appropriate reflectance spectrum recorded. In some experiments, the reflectance spectrum of $\mathrm{CN}\left(\mathrm{H}_{2} \mathrm{O}\right) \mathrm{Cbi}$-immobilized paper was designated as the "blank" when the goal was to monitor changes in the $\mathrm{CN}\left(\mathrm{H}_{2} \mathrm{O}\right) \mathrm{Cbi}$ spectrum. Air was pulled over the Cbi paper sensor at 1.0 LPM ( $\pm 5 \%)$ by a Gilian Air Sampling Pump (GilAir-3, Figure 4.2). The tubing from the test chamber to the sensor holder was 1.2 meters long, permitting a time delay of 2.3 seconds. A second pump was used to pull effluent air to a second sensor (RGB color sensor) with further explanation and results in Chapter 5.

Figure 4.2 - Experimental setup showing placement of the diffuse reflectance sensor and RGB color sensor

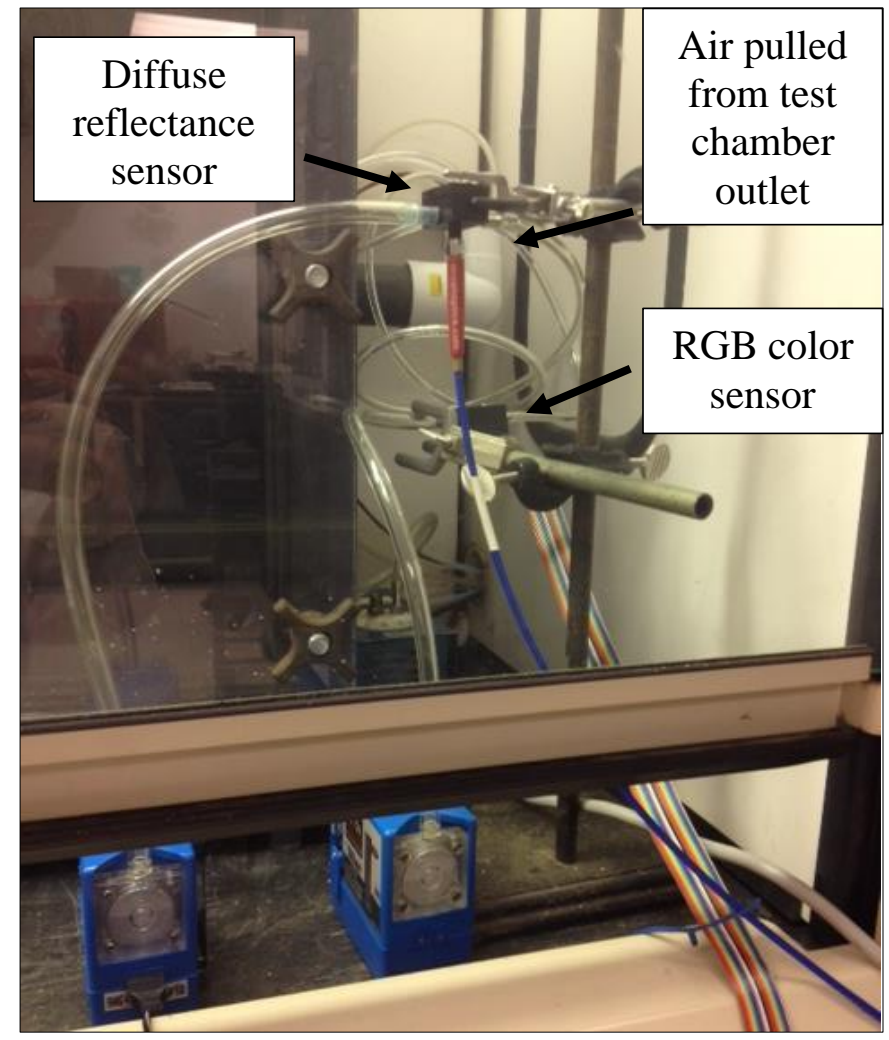


Apparent absorbance spectra were recorded at various time intervals throughout each experiment and at HCN breakthrough. All valves were controlled by LabVIEW ${ }^{\circledR}$ software where average \% RH, temperature, upstream challenge $\mathrm{HCN}$ concentration (Photoacoustic Gas Monitor), breakthrough concentration, and test time were stored by the software.

The CBRN canisters used were NIOSH-approved which provide protection for exposure to $\mathrm{HCN}$. Prior to the beginning of the experiment, the canister was mounted into a test fixture within the testing chamber. Each canister was housed in a 24 " x 24 " x 8 " air-tight metal box with door opening lined with gasket material. One opening located on the backside of the test chamber was used for entry of the challenge gas, where exit is forced through the canister. ${ }^{240}$

Caution: $\mathrm{HCN}$ is highly toxic. A Multilog 2000 personal air-monitoring device (Quest Technologies) was placed outside of the hood at all times and sampled ambient air during the experiments.

\subsubsection{Gas Flow System and Instrumentation: $\mathrm{H}_{2} \mathrm{~S}$}

All $\mathrm{H}_{2} \mathrm{~S}$ exposure experiments were performed at the NIOSH/NPPTL facility in Pittsburgh, PA. The STP (with associated experimental equipment and setup) titled "Determination of CBRN Acid Gases (Hydrogen Sulfide) Service-Life Test, Air-Purifying Standard Test Procedure STP-CBRN-0043A) can be found online and was described in Chapter

3. ${ }^{195}$ In short, two Interscan ${ }^{\circledR}$ instruments (Model RM-17-0 and RM-17-2) electrochemical sensor specific to $\mathrm{H}_{2} \mathrm{~S}$ were used with the detection range of 0.00-19.99 ppm (resolution $0.01 \mathrm{ppm}$ ) and 0-1000 ppm (resolution $1 \mathrm{ppm}$ ), respectively. One Interscan ${ }^{\circledR}$ was used to monitor the $\mathrm{H}_{2} \mathrm{~S}$ challenge concentration and was calibrated with $1000 \mathrm{ppm}_{2} \mathrm{~S}$ gas prior to the experiment. The other Interscan ${ }^{\circledR}$ was placed downstream of the canister to monitor effluent breakthrough 
concentrations and calibrated with $10.0 \mathrm{ppm}_{2} \mathrm{~S}$ gas. The experimental setup can be seen in Figure C.2.

The system was initially flushed with clean air at the desired $\% \mathrm{RH}\left(\mathrm{no} \mathrm{H}_{2} \mathrm{~S}\right)$ for 30 minutes before each experiment. The system was evaluated by the Interscan ${ }^{\circledR}$ to ensure a reading of $0.00 \mathrm{ppm} \mathrm{H}_{2} \mathrm{~S}$. A blank paper circle was then placed in the sensor holder. The reflectance signal from the blank was defined as $100 \%$ reflectance at each wavelength. A piece of $\mathrm{OH}\left(\mathrm{H}_{2} \mathrm{O}\right)$ Cbi-impregnated paper was then placed in the holder and the appropriate reflectance spectrum recorded. In some experiments, the reflectance spectrum of $\mathrm{OH}\left(\mathrm{H}_{2} \mathrm{O}\right) \mathrm{Cbi}$-immobilized paper was designated as the "blank" when the goal was to monitor changes in the $\mathrm{OH}\left(\mathrm{H}_{2} \mathrm{O}\right) \mathrm{Cbi}$ spectrum. Relative humidity levels of 25,50 , and $85 \% \mathrm{RH}$ at $25^{\circ} \mathrm{C} \pm 1{ }^{\circ} \mathrm{C}$ were tested, which are typical testing conditions for certification tests at NIOSH/NPPTL. Effluent air was pulled over the Cbi paper sensor at 1.0 LPM $( \pm 5 \%)$ by a Gilian Air Sampling Pump (GilAir-3). Apparent absorbance spectra were recorded at various time intervals throughout each experiment: 0 minutes, 10 minutes, 30 minutes, 45 minutes (for higher $\% \mathrm{RH}$ ), and at $10.0 \mathrm{ppm} \mathrm{H}_{2} \mathrm{~S}$ breakthrough (time varied for each pair or cartridges). All valves were controlled by LabVIEW ${ }^{\circledR}$ software where average \% RH, temperature, challenge $\mathrm{H}_{2} \mathrm{~S}$ concentration, breakthrough concentration, and test time were stored by the software.

Three pairs of cartridges for $\mathrm{H}_{2} \mathrm{~S}$ were tested at each $\% \mathrm{RH}(25,50$, and $85 \%)$. The cartridges used were NIOSH-approved and provide protection for exposure to $\mathrm{H}_{2} \mathrm{~S}$ (and other acid gases). Prior to the beginning of the experiment, the pair of cartridges were mounted into a test fixture within the testing chamber. The text fixture specifically fits the individual model of the cartridges. Each cartridge/canister was housed in a 12 " x 11 1/2” x 7" air-tight metal box described above (Section 4.3.6). Figures 4.3a and 4.3b show the testing chamber and the 
downstream placement of the sensor holder, respectively. The electrochemical detectors are outside of the hood and not shown. 
Figure $4.3-\mathrm{H}_{2} \mathrm{~S}$ cartridge testing chamber (A), with fiber optic, light source, spectrometer, and pump downstream of cartridges (B).
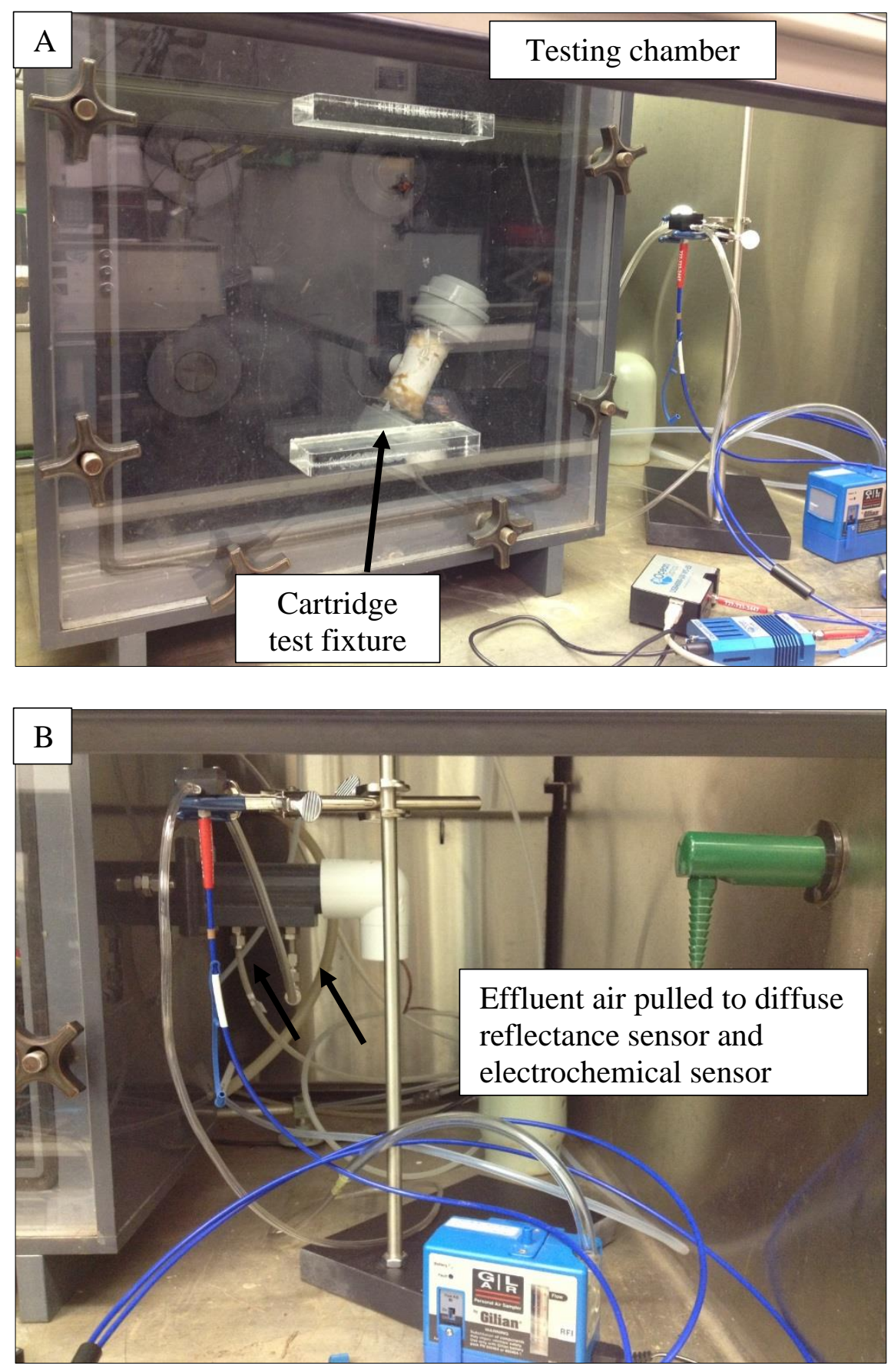

\subsubsection{Experimental Parameters: $\mathrm{HCN}$ and $\mathrm{H}_{2} \mathrm{~S}$}

Each test was run at a continuous airflow of 64 LPM with a challenge gas concentration of $1000 \mathrm{ppm} . \% \mathrm{RH}$ was within $\pm 5 \%$ of selected value, with temperatures of $25^{\circ} \mathrm{C} \pm 1^{\circ} \mathrm{C}$. Each 
flow meter, humidity monitor, and electrochemical gas detector was calibrated prior the start of the experiment. MFCs were used with accuracy of $\pm 0.7 \%$ of set point and $\pm 0.2 \%$ full scale (according to manufacturers). The Miller Nelson flow, temperature, and \% RH control had accuracies of $\pm 2 \%$ of full scale, $\pm 1^{\circ} \mathrm{C}$, and $10-98 \% \pm 3 \%$, respectively. Temperature was recorded by LabVIEW ${ }^{\circledR}$ using an Omega Type J Thermocouple $\left( \pm 2 \cdot 2^{\circ} \mathrm{C}\right)$.

No challenge gas was allowed to enter the testing chamber until the experiment starts. The diverter valve allowed the challenge gas to flow into the testing chamber or to waste. The LabVIEW $^{\circledR}$ program controls the valve and diverts the challenge gas to waste and stop the test upon reaching a pre-specified concentration by the Interscan ${ }^{\circledR}$. The test ran until breakthrough of 15.0 ppm $\mathrm{H}_{2} \mathrm{~S}$ or 4.7 ppm $\mathrm{HCN}$ was detected by the Interscan ${ }^{\circledR}$ detector. $\mathrm{H}_{2} \mathrm{~S}$ data will be presented in the context of $10.0 \mathrm{ppm}$, the $\mathrm{C}$ REL of $\mathrm{H}_{2} \mathrm{~S}$. After the completion of the experiment, the humidity was set to zero and clean air is passed through the system for 30 minutes. The downstream Interscan ${ }^{\circledR}$ is monitored to ensure a concentration of $0.00 \mathrm{ppm}$ prior to starting the next test.

\subsection{Results and Discussion \\ 4.4.1 HCN Breakthrough}

Initially, small amounts ( 100 mg) of activated carbon were extracted from a commercial CBRN canister and inserted into a glass tube for small-scale breakthrough studies (25.0 ppm $\mathrm{HCN}$ at $1.0 \mathrm{~L} / \mathrm{min}$ ). Although the dicyanocobinamide spectrum was observed, breakthrough occurred quickly and was likely attributed to the small amount of carbon (as to not cause resistance) and the uneven packing of the carbon in the tube - a process that is well established for large respirator cartridge companies but was found to be irreproducible here. Many groups use a variety of test bed lengths (typically $1-3 \mathrm{~cm}$ ) and diameters to produce their own rapid 
small scale column test (RSSCT). ${ }^{29,235,241}$ Additionally, researchers who design test beds often have information of the carbon they are using, or make their own, to provide known carbon parameters to breakthrough equations. Here, specific activated carbon information could not be retrieved due to proprietary reasons of the canister manufacturers. Information on the carbon would be necessary to make predictions on breakthrough time in CBRN canisters. Because laboratory resources were readily available for testing of NIOSH-approved CBRN canisters, the STP for certification testing of $\mathrm{HCN}$ was modified as described so that the $\mathrm{CN}\left(\mathrm{H}_{2} \mathrm{O}\right) \mathrm{Cbi}$ on glass fiber paper and electrochemical detector were simultaneously compared for HCN breakthrough.

CBRN canisters (Figure 4.4) are large and densely packed with ASZM-TEDA activated carbon, and are primarily used for first responders and military personnel where unknown contaminants and concentrations are likely. These canisters provide protection for toxic chemical warfare agents. NIOSH certifies CBRN canisters based on the minimum service-life per manufacturers' request $(15,30,45,60,90$, or 120 minutes $) .{ }^{240}$ This is in part due to the lengthy time for complete breakthrough of these CBRN canisters. NIOSH typically certifies CBRN canisters under designation "Capacity 1" with a test time of 15 minutes. Therefore, tests running to complete breakthrough are not regularly performed, and the time was unknown prior to beginning these experiments. 
Figure 4.4 - Comparison of two CBRN canisters

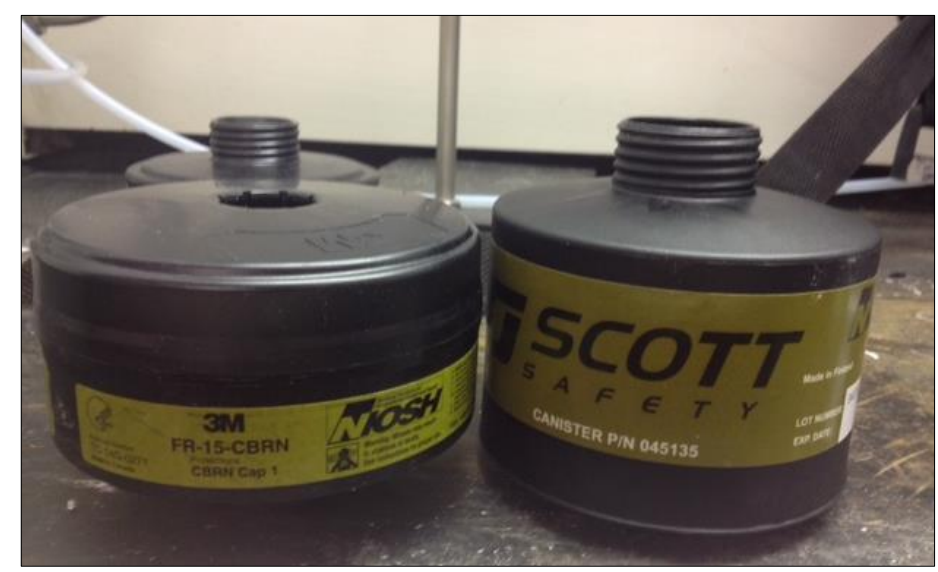

The first canister was placed in the test fixture and exposed to a challenge concentration of 1000 $\pm 2 \%$ ppm HCN. Breakthrough occurred almost immediately (2.6 minutes) for the first CBRN canister. The test was ceased by the electrochemical detection of $4.7 \mathrm{ppm}$ HCN (NIOSH STEL). An increase at $583 \mathrm{~nm}$ is observed prior to response by the electrochemical detector, indicating that the Cbi paper sensor detects the presence of $\mathrm{HCN}$ faster than the established method. The signal saturates quickly, within 2 minutes. A comparison of the Cbi paper sensor (plotted on the primary-axis as $F(R)$ values) with the electrochemical detector (plotted on the secondary-axis) can be observed in Figure 4.5. The "S-shaped" curve is characteristic of a carbon breakthrough curve, which is determined by vapor concentration, flowrate, and adsorption capacity of the carbon. The breakthrough curve is a reflection of the vapor front profile moving through the bed. ${ }^{28}$ The Cbi reflectance spectrum taken immediately at the end of the test $(4.7 \pm 2 \%$ ppm $\mathrm{HCN})$ is shown in Figure 4.6 where the peak $\mathrm{F}(\mathrm{R})$ signal at $583 \mathrm{~nm}$ is 0.041 . The average $\mathrm{F}(\mathrm{R})$ response of 700-750 $\mathrm{nm}$ is used as the reference in both figures. 
Figure 4.5 - Cbi paper sensor and electrochemical sensor breakthrough curves

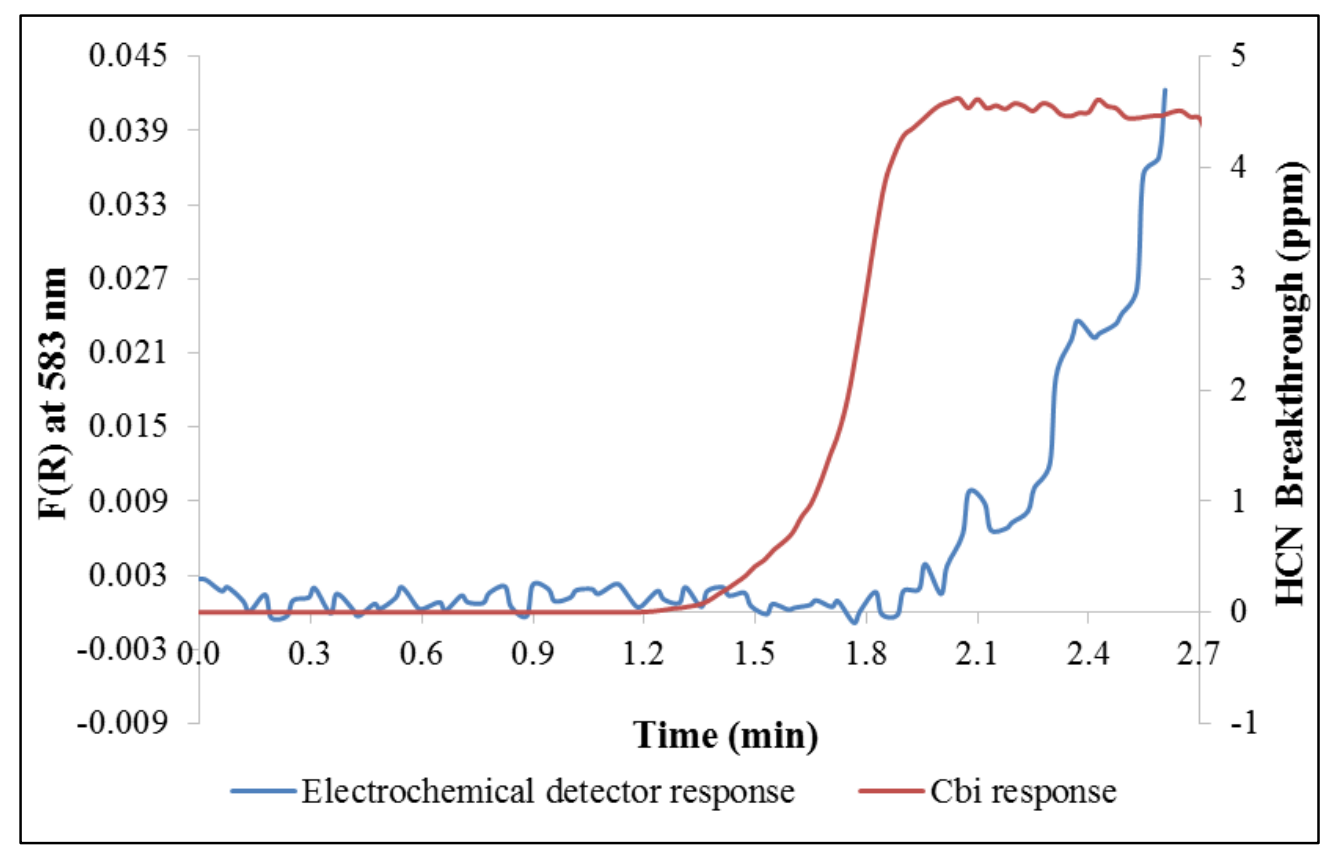

Figure 4.6-F(R) Cbi spectrum at breakthrough

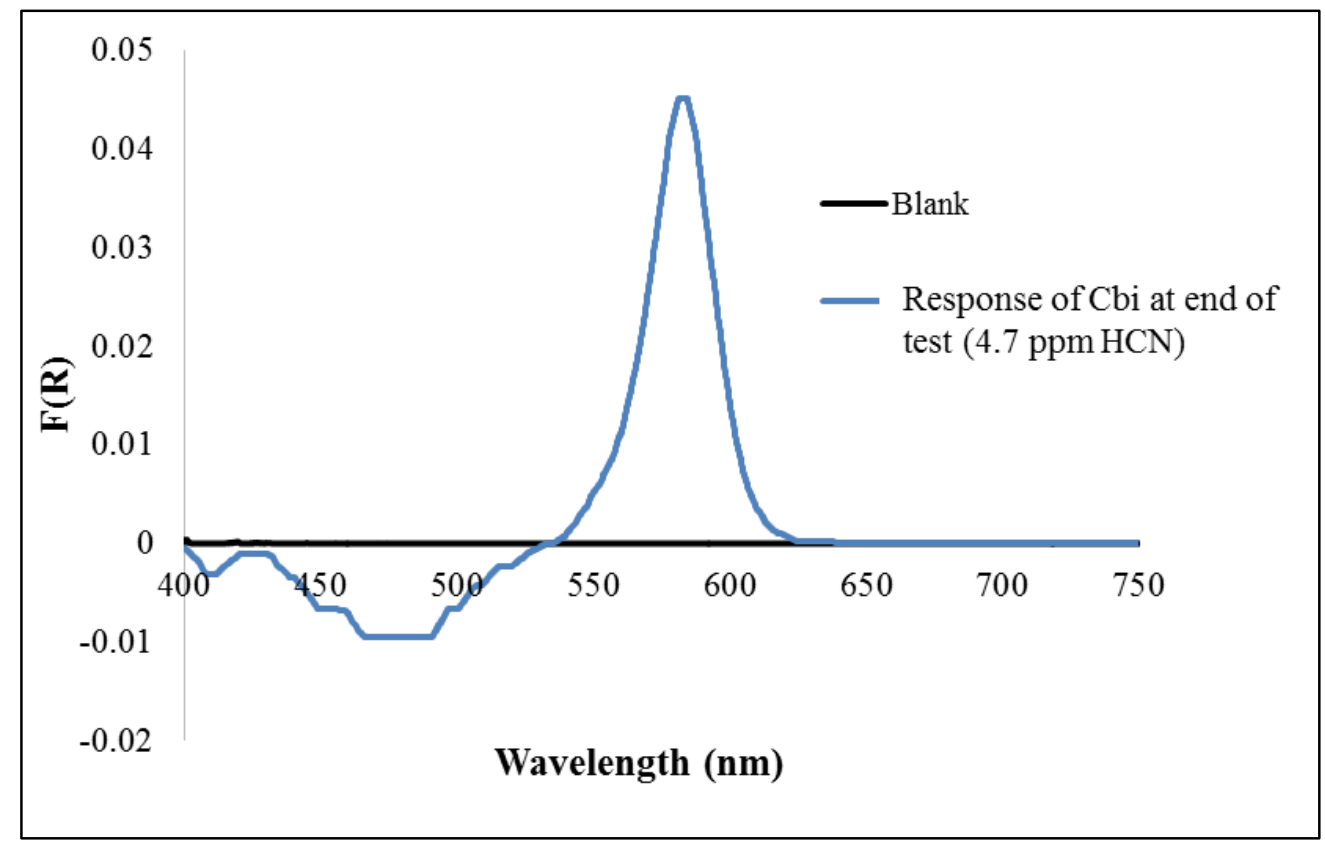

The test chamber is equipped with a total of four inlets for canister placement, which are capped off when not in use (Figure C.3). The test prematurely ends presumably because of a leak 
possibly because the canister was turned too tightly into the test chamber. The test chamber was rechecked/resealed and a different CBRN canister was used.

The second canister tested takes much longer to reach breakthrough. A comparison of the breakthrough curves for both the Cbi (primary-axis) and electrochemical detector (secondaryaxis) can be observed in Figure 4.7a (plotted as polynomial and moving average, respectively) and $4.7 \mathrm{~b}$ (both plotted as second derivatives from 40-140 minutes). The raw data from the electrochemical data can be seen in Figure C.4.

Figure 4.7 - Breakthrough curves for Cbi paper sensor (plotted as polynomial) and electrochemical detector (plotted as moving average) (A) and second derivatives of the polynomials (B)

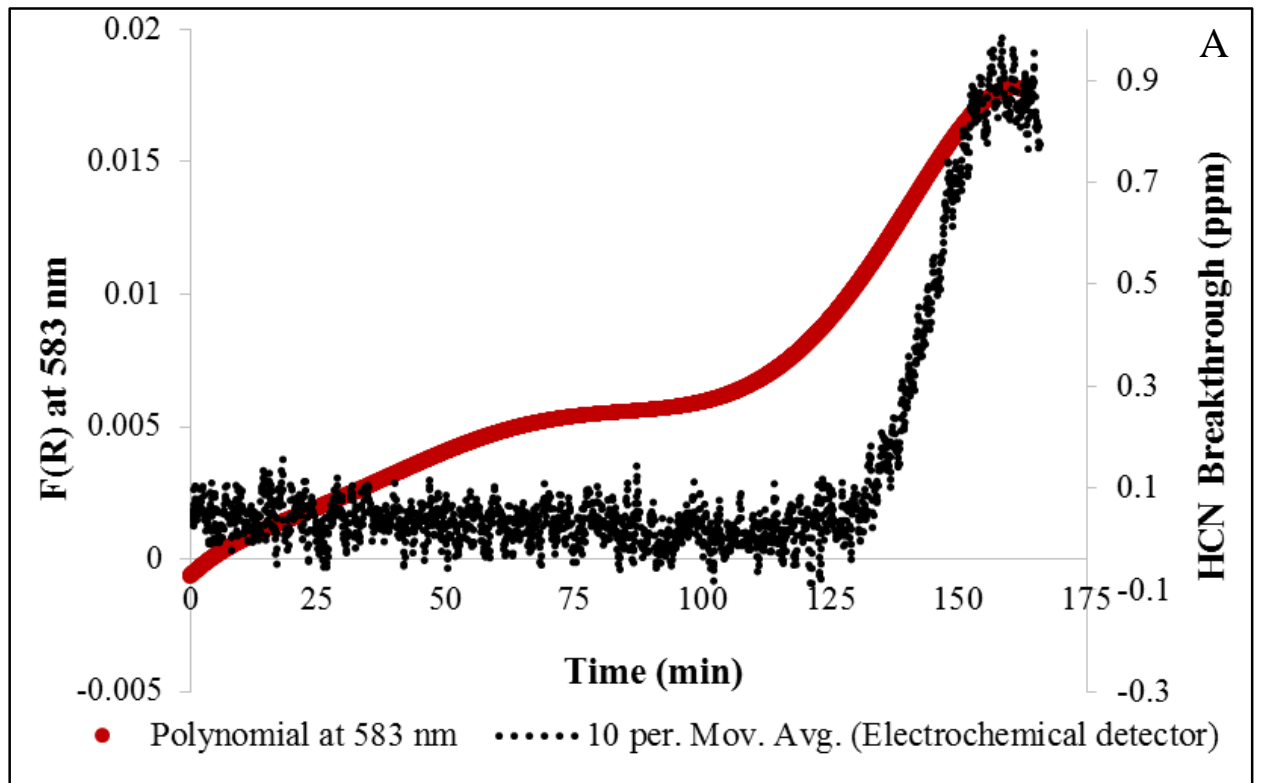




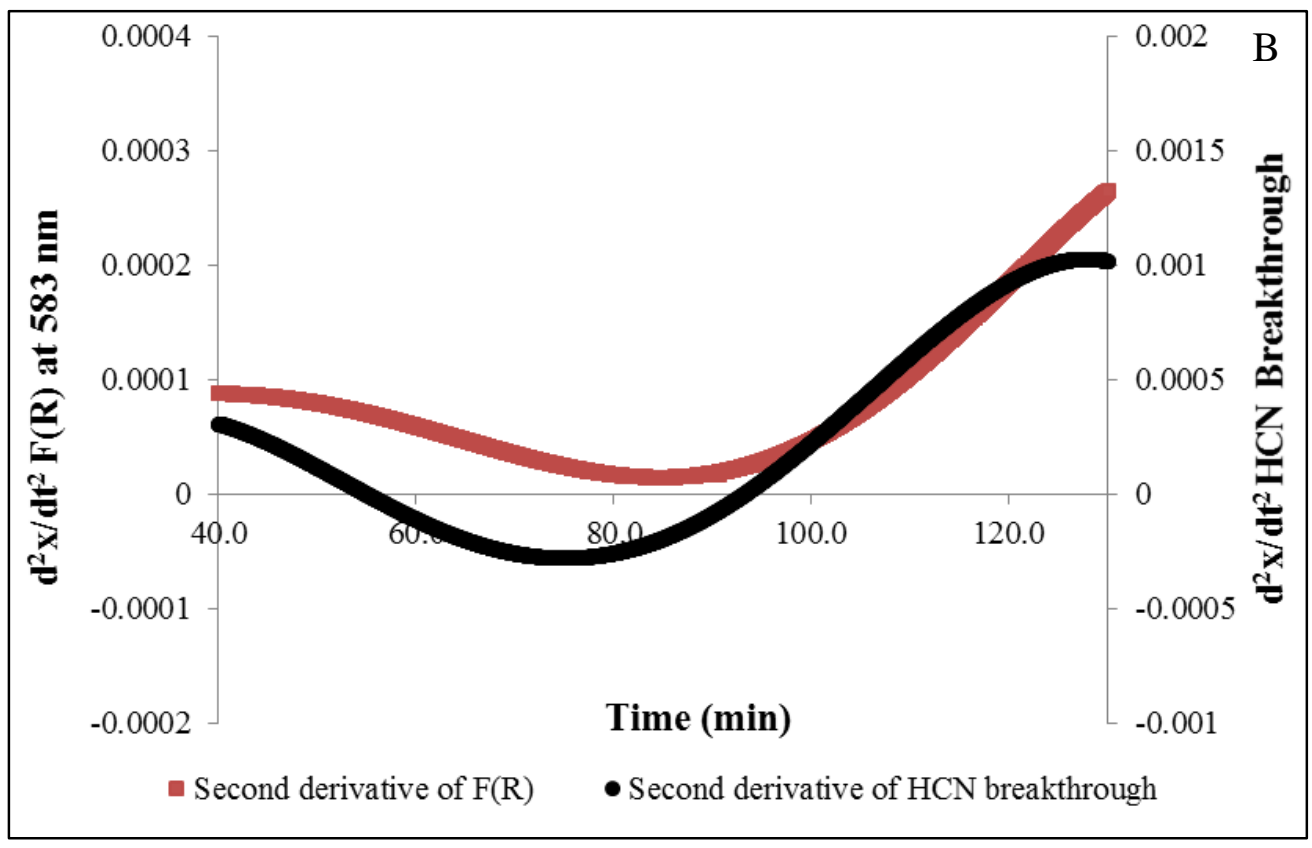

An increase in the $F(R)$ signal at $583 \mathrm{~nm}$ is observed throughout the majority of the test. A small amount of $\mathrm{HCN}$ is also observed to permeate through the canister carbon bed throughout the test as indicated by the electrochemical detector. This observation is common for canister testing and an explanation is not straightforward, but could be due to the vapor permeating through the channels of the carbon bed or the formation of chemical byproducts (e.g., cyanogen). The former is common in high-flow cartridge testing and varies significantly between brands and lots. Air channeling may be due to irregular sorbent granules in contact with the smooth canister wall and is reported to be a general drawback in design of canisters and reduces service-life. ${ }^{2}$ However, an increase in slope is apparent with time corresponding to the breakthrough of the canister detected by the electrochemical detector ( 120 minutes). A comparison of the second derivatives of both $\mathrm{F}(\mathrm{R})$ response at $583 \mathrm{~nm}$ and $\mathrm{HCN}$ breakthrough (determined by the electrochemical detector) shows the start of breakthrough for both detectors correlates well. Both sensors show a change slope, thus imminent breakthrough, near 90 minutes. 
The test was stopped after 163.8 minutes. This was not because $4.7 \mathrm{ppm} \mathrm{HCN}$ was detected, but because the HCN cylinder ran empty. A slow decrease in concentration began $~ 140$ minutes into the test until the challenge gas concentration reached $\sim 10 \mathrm{ppm} \mathrm{HCN}$ around 160 minutes. Breakthrough continued to occur through the CBRN canister so the testing was continued to show proof-of-concept of Cbi detection of $\mathrm{HCN}$ breakthrough. To reach the desired HCN challenge concentration (1000 ppm), a MFC pulled $3.45 \mathrm{~L} / \mathrm{min}$ from the $2 \% \mathrm{HCN}, 25.5 \mathrm{ft}^{3}$ gas cylinder. Theoretically, a new cylinder should have lasted 209.1 minutes at this flow rate; however, prior experiments may have been performed with this cylinder.

The large carbon bed of the CBRN canisters and lengthy breakthrough times make these tests not economically feasible to run as many replicate measurements as desired to breakthrough. Additionally, gas companies will not prepare concentrations of $\mathrm{HCN}$ in cylinders greater than $2 \%$, because cylinders above this concentration cannot be transported. Comprehensive conclusions cannot be made with the limited amount of breakthrough data for $\mathrm{HCN}$, however both the rapid and slow breakthrough test times show good correlation between the Cbi paper sensor and the electrochemical sensor upon HCN breakthrough.

The $F(R)$ responses at $t=0,15,30,60,105$ minutes, and at the end of the test (164 minutes) are shown in Figure 4.8. The distinctive spectral shifts for dicyanocobinamide are readily observed, specifically the increase at $583 \mathrm{~nm}$. The final concentration before the test was terminated was $\sim 1 \mathrm{ppm}$. The final $\mathrm{F}(\mathrm{R})$ value is similar to the $1.0 \mathrm{ppm} \mathrm{HCN}$ response observed for previous exposure experiments in Chapter 2 (Figures 2.28 and 2.29). 
Figure $4.8-\mathrm{F}(\mathrm{R})$ spectra during $\mathrm{HCN}$ breakthrough experiment

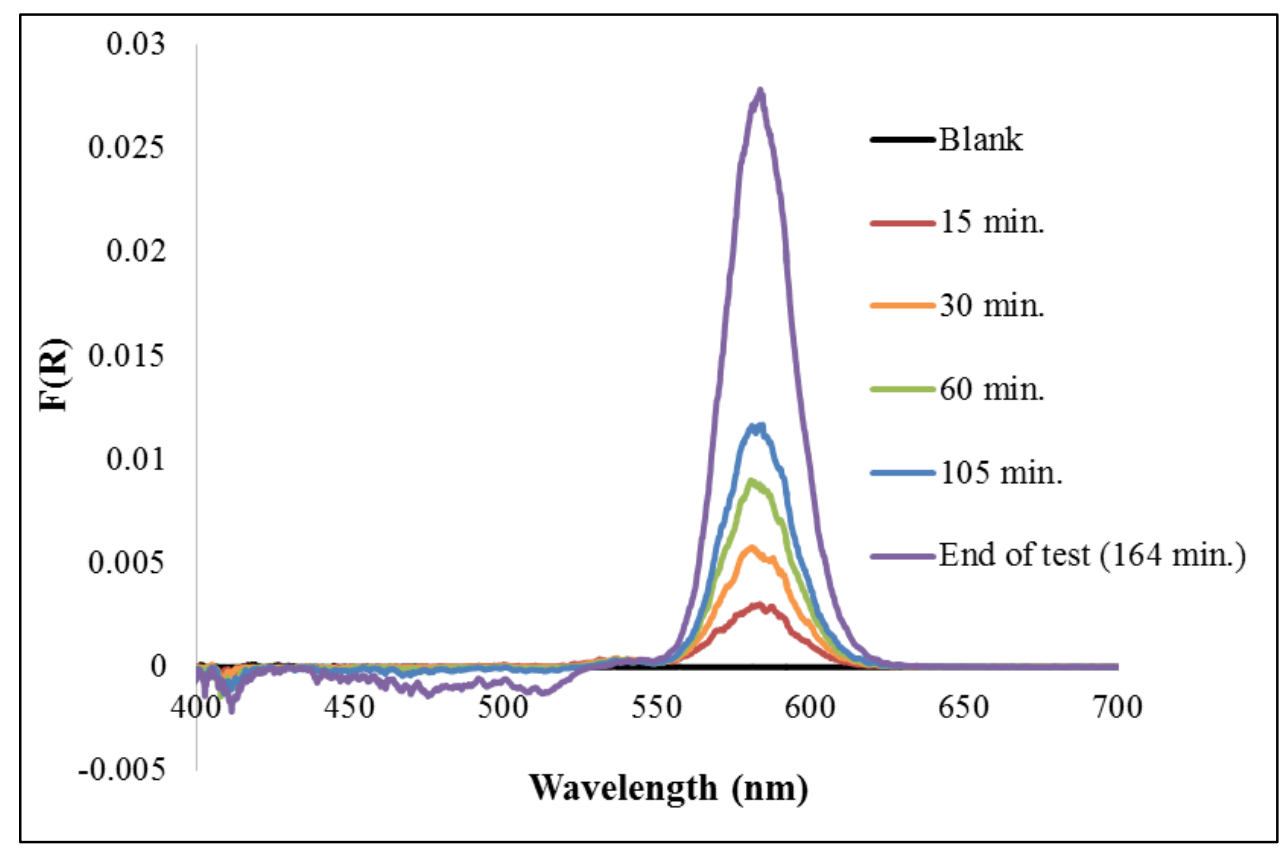

\section{Cyanogen}

A small increase near $545 \mathrm{~nm}$ is observed for the longer breakthrough experiment, along with a smaller decrease in response from 450-500 $\mathrm{nm}$ compared to direct exposure of Cbi to HCN. An expanded view near $545 \mathrm{~nm}$ of the breakthrough Cbi spectrum shown in Figure 4.9. 
Figure 4.9 - Expanded view of $\mathrm{F}(\mathrm{R})$ spectrum during $\mathrm{HCN}$ breakthrough experiment

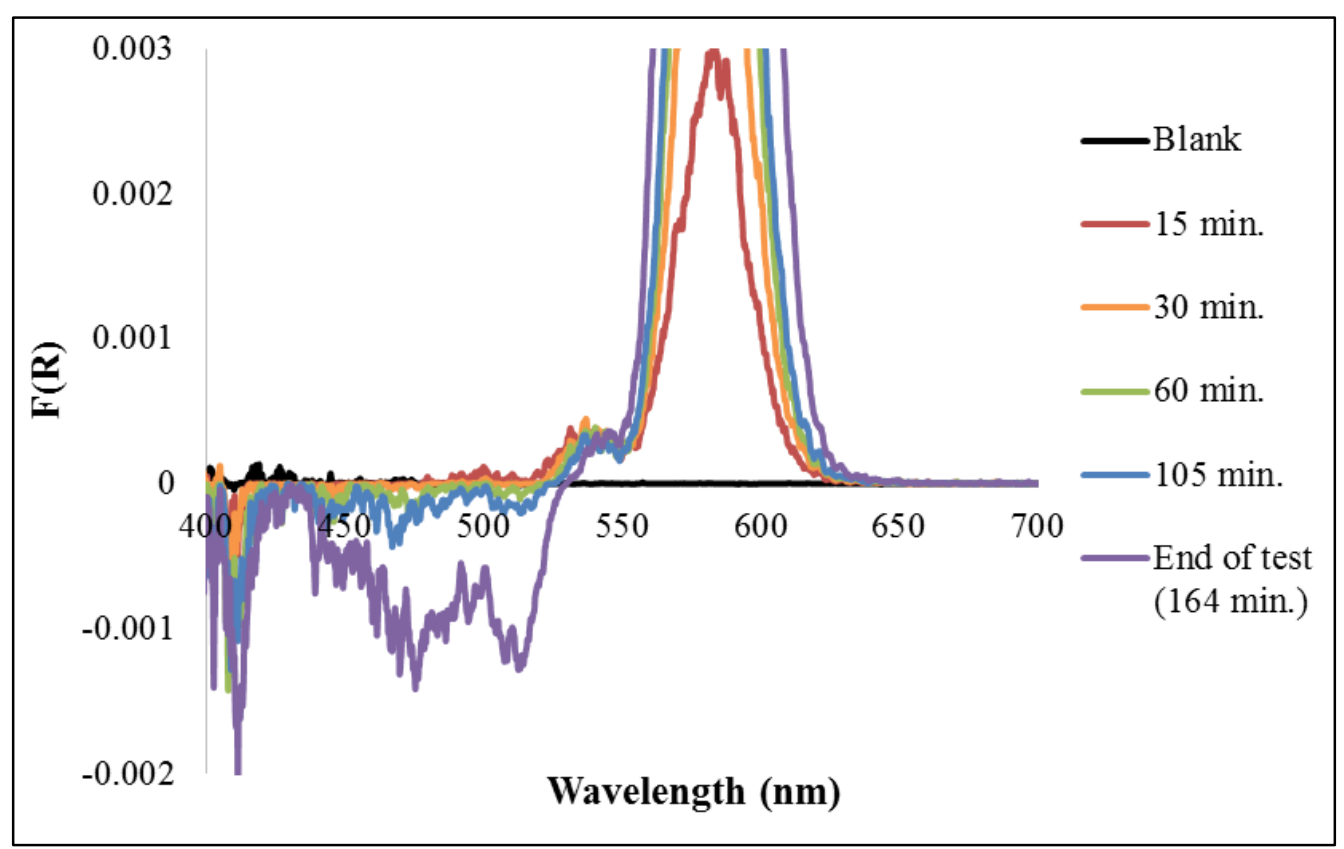

The small increase near $545 \mathrm{~nm}$ was not observed in any earlier experiments with HCN. One hypothesis is the attribution of this artifact to the presence of cyanogen $\left[(\mathrm{CN})_{2}\right]$. It is documented that $(\mathrm{CN})_{2}$ is an intermediate and/or byproduct of $\mathrm{HCN}$ neutralization and removal by activated carbon. ${ }^{242}$ Formation of cyanogen is reported to be due to the oxidation of $\mathrm{HCN}$ in the presence of copper (Equation 4.2) Therefore, a cyanogen Kim-TEK Trace Source ${ }^{\mathrm{TM}}$ permeation tube was used to expose $5.0 \pm 2 \%(\mathrm{CN})_{2}$ over the Cbi paper sensor at $0.49 \pm 0.01 \mathrm{~L} / \mathrm{min}$ at $30.00 \pm 0.01^{\circ} \mathrm{C}$ by using the following permeation tube calculator: ${ }^{243}$

$$
C_{p p m v}=\frac{E_{n g / \min } \times 22.41}{M W \times F_{p d}}
$$

where $\mathrm{C}_{\mathrm{ppmv}}$ is the generated concentration (ppm by volume), $\mathrm{E}_{\mathrm{ng} / \mathrm{min}}$ is the emission rate of component from the permeation tube, MW is the molecular weight of the component $(\mathrm{g} / \mathrm{mol})$, 22.41 is the volume (L) of 1 mole of gas at $\mathrm{STP}$, and $\mathrm{F}_{\mathrm{pd}}$ is the primary dilution flow rate 
(standard cubic centimeters, sccm). The cyanogen permeation tube was stored in an oven within a Kin-Tek Flexstream Gas Standards Generator ${ }^{\circledR}$. The flow rate was set to generate $5.0 \pm 0.1$ ppm cyanogen at an emission rate of $5837 \mathrm{ng} / \mathrm{min}$ at $30^{\circ} \mathrm{C}$. The average $\mathrm{F}(\mathrm{R})$ spectrum for 1,5 , and 10 minutes of exposure are shown in Figure $4.10(n=3)$.

$4.10-\mathrm{F}(\mathrm{R})$ spectra of $50.0 \mu \mathrm{M} \mathrm{CN}\left(\mathrm{H}_{2} \mathrm{O}\right) \mathrm{Cbi}$ on glass fiber filter paper to 5.0 ppm cyanogen

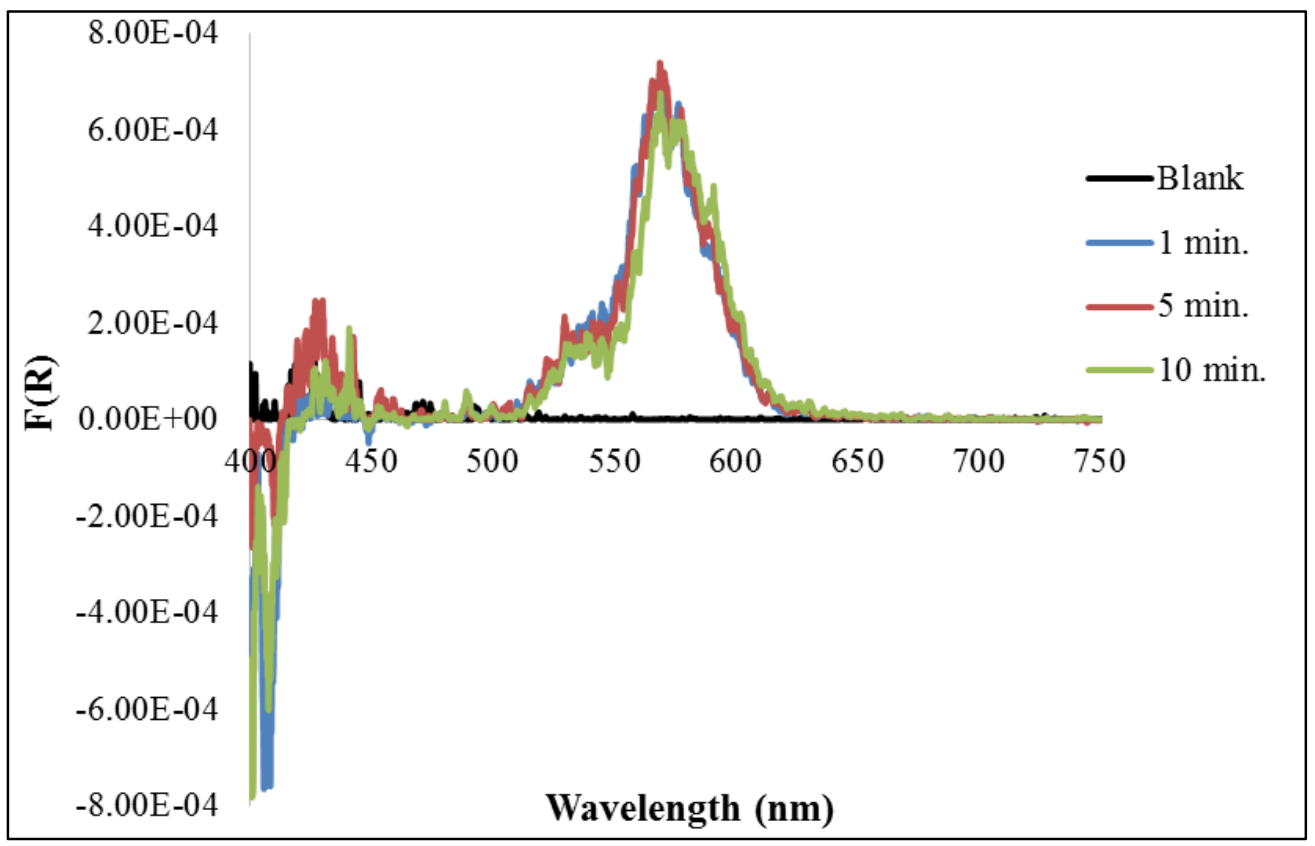

The distinctive isosbestic point at 531 for dicyanocobinamide is not observed. However, the small increase near $545 \mathrm{~nm}$ is apparent and the peak $F(R)$ is slightly blue shifted to shorter wavelengths to $\sim 568 \mathrm{~nm}$, compared to $583 \mathrm{~nm}$ for exposure to $\mathrm{HCN}$. Limited data is available for the reaction between cyanogen and Cbi. However, because the donor properties of the axial ligands to cobinamide are imperative, the shift to shorter wavelengths may be due to the more electronegative donor ligand, which are known to shift to shorter wavelengths. ${ }^{117}$ Additionally, there is an increase in signal from $400-450 \mathrm{~nm}$ and no change from $450-500 \mathrm{~nm}$, unlike that of formation of dicyanocobinamide. There is also little change in spectra after 1 minute of 
exposure. Figure 4.11a compares the Cbi spectrum after $5.0 \mathrm{ppm}(\mathrm{CN})_{2}$ exposure for 10 minutes, and the 15 minutes and 164 minutes (i.e. breakthrough) into the breakthrough experiment. The isosbestic point at $531 \mathrm{~nm}$ is not present in the cyanogen or 15 minutes into the experiment spectra, and the increase near $545 \mathrm{~nm}$ is apparent for both. Upon breakthrough of the canister, the isosbestic point near $531 \mathrm{~nm}$ is present and the Cbi spectra is similar to that of $(\mathrm{CN})_{2} \mathrm{Cbi}$. Figure $4.11 \mathrm{~b}$ compares the $5.0 \mathrm{ppm}(\mathrm{CN})_{2}$ spectra to that of $5.0 \mathrm{ppm} \mathrm{HCN}$ exposure to Cbi on glass fiber paper (Chapter 2). 
4.11 - Comparison of $\mathrm{CN}\left(\mathrm{H}_{2} \mathrm{O}\right) \mathrm{Cbi}$ on paper when exposed to 5.0 ppm cyanogen and after 15 and 164 minutes into $\mathrm{HCN}$ breakthrough experiment (A). Comparison of $\mathrm{CN}\left(\mathrm{H}_{2} \mathrm{O}\right) \mathrm{Cbi}$ on paper when exposed to $5.0 \mathrm{ppm}$ cyanogen and $5.0 \mathrm{ppm} \mathrm{HCN}$ (separate experiments) (B).
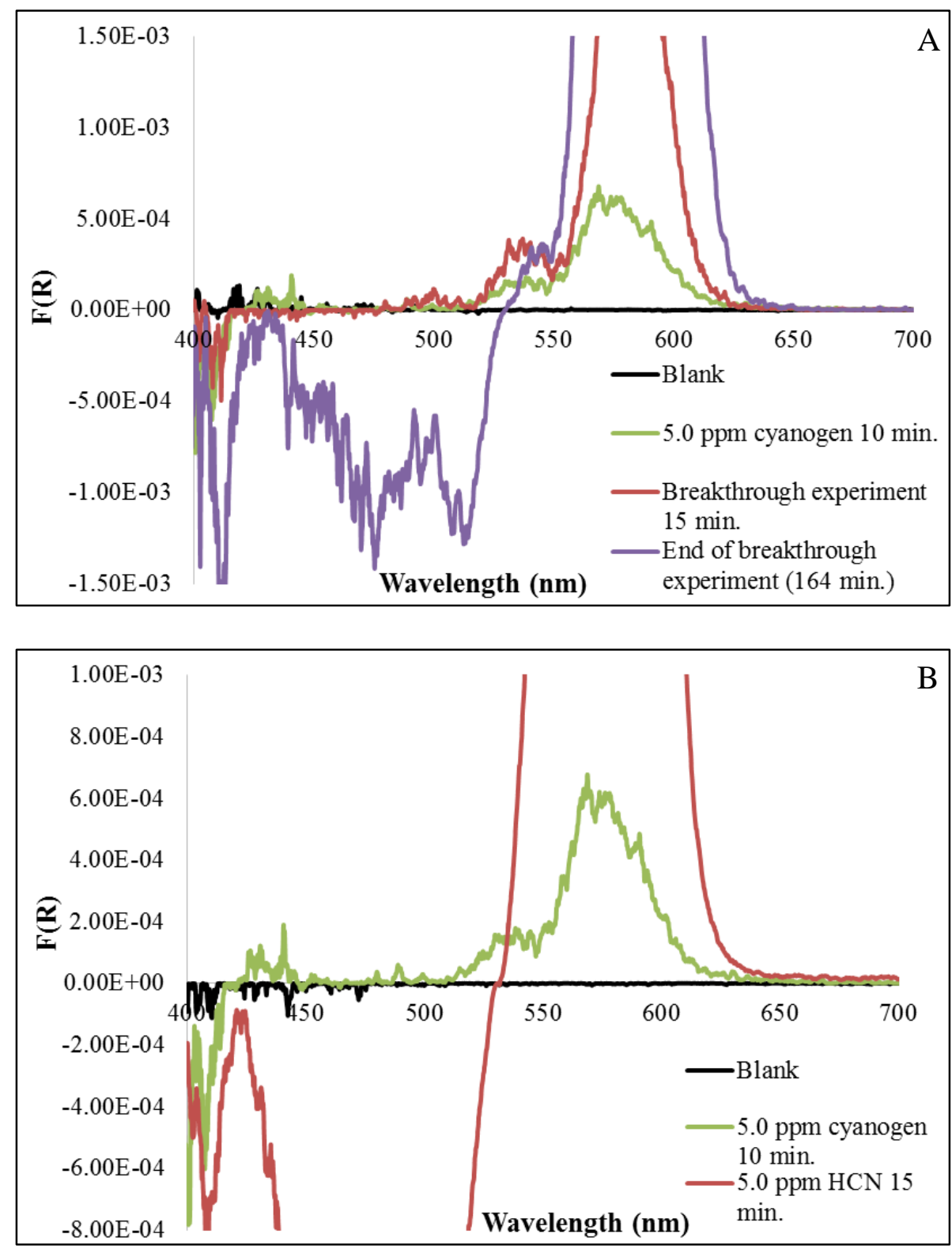

The distinctive dicyanocobinamide peak at $583 \mathrm{~nm}$ cannot be used to differentiate between HCN and $(\mathrm{CN})_{2}$ when using $\mathrm{CN}\left(\mathrm{H}_{2} \mathrm{O}\right)$ Cbi. However, the lack of isosbestic point at $531 \mathrm{~nm}$, increase near $545 \mathrm{~nm}$, and lack of response from 400-500 nm may be used to detect the additional presence of cyanogen. 


\subsection{2 $\mathrm{H}_{2} \mathrm{~S}$ Breakthrough}

\subsubsection{1 $25 \%$ RH}

Three pairs of cartridges were used for breakthrough testing of $\mathrm{H}_{2} \mathrm{~S}$ at $25 \% \mathrm{RH}$ with the Cbi paper sensor placed downstream of the effluent gas. The average $F(R)$ response at 10 minutes, 30 minutes, and at $10.0 \mathrm{ppm}$ breakthrough is shown in Figure $4.12(\mathrm{n}=3)$. The initial spectrum of $\mathrm{OH}\left(\mathrm{H}_{2} \mathrm{O}\right)$ Cbi was considered the blank.

Figure 4.12 - Average difference spectra of $\mathrm{OH}\left(\mathrm{H}_{2} \mathrm{O}\right)$ Cbi response to $\mathrm{H}_{2} \mathrm{~S}$ breakthrough at 25 $\%$ RH

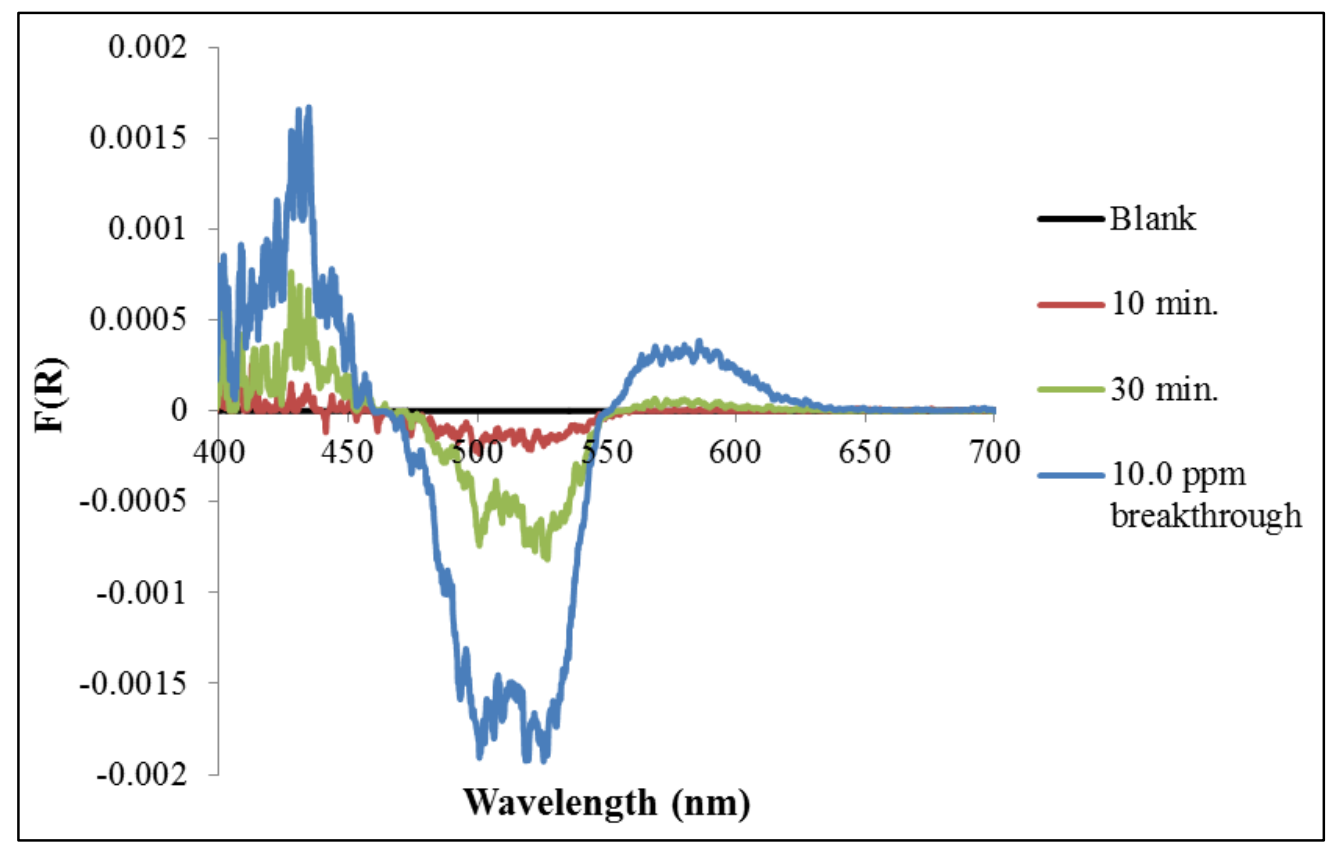


The $\mathrm{F}(\mathrm{R})$ spectrum is similar to that observed in Chapter 3 upon exposure of $10.0 \mathrm{ppm} \mathrm{H}_{2} \mathrm{~S}$ to $\mathrm{OH}\left(\mathrm{H}_{2} \mathrm{O}\right) \mathrm{Cbi}$ on paper. An increase near $575 \mathrm{~nm}$ is also present, which was observed when $\mathrm{OH}\left(\mathrm{H}_{2} \mathrm{O}\right)$ Cbi was exposed to $\mathrm{H}_{2} \mathrm{~S}$ (Chapter 3). Figure 4.13 shows one example of monitoring the $\mathrm{OH}\left(\mathrm{H}_{2} \mathrm{O}\right) \mathrm{Cbi}$ response at 400-450 (red line), 470-550 (green line), and $800 \mathrm{~nm}$ (used as reference, purple line) for the entirety of the experiment. These values were plotted as 6-order polynomials. The $\mathrm{F}(\mathrm{R})$ trends were simultaneously compared to the response from the $\mathrm{H}_{2} \mathrm{~S}$ specific electrochemical detector (blue line). This detector's response is plotted as the second derivative of the concentration vs. time response to easily visualize a change in slope, i.e. the start of breakthrough.

$4.13-\mathrm{F}(\mathrm{R})$ and electrochemical detector response to $\mathrm{H}_{2} \mathrm{~S}$ breakthrough at $25 \% \mathrm{RH}$

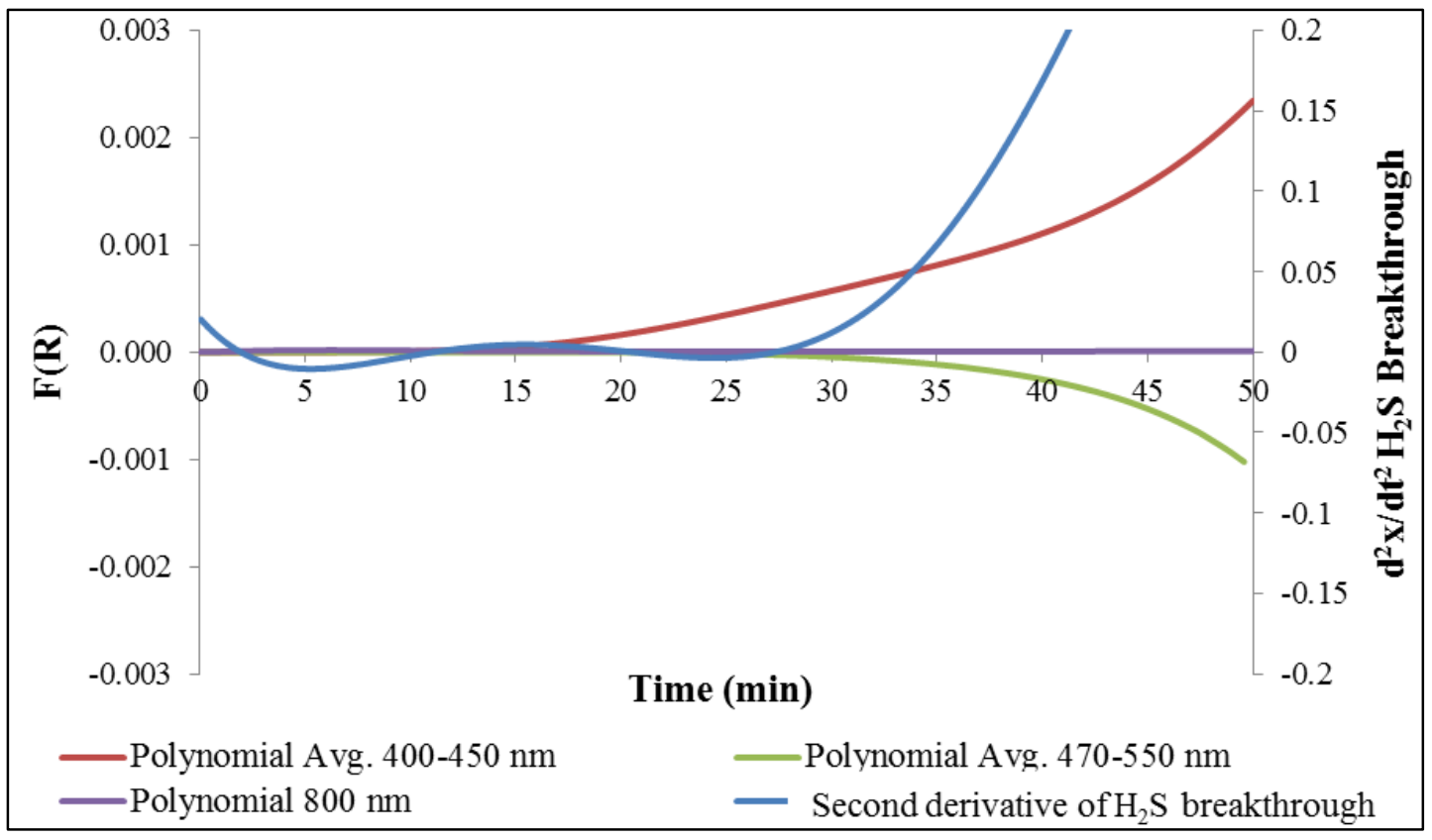


As previously mentioned, there is presumably a small amount of $\mathrm{H}_{2} \mathrm{~S}$ breaking through during the entirety of the experiment; the electrochemical detector's average response from time 0.025.0 minutes correlates to an average of $187 \mathrm{ppb} \mathrm{H}_{2} \mathrm{~S}$ (inset of Figure 4.14). The 400-450 nm response begins to increase $\sim 15$ minutes into the experiment, with the slope increasing around 40 minutes. The cumulative response is most likely attributed to the small amount of $\mathrm{H}_{2} \mathrm{~S}$ breaking through. The second derivative of the electrochemical sensor's response begins to change at 27.4 minutes (230 ppb). Table C.1 (Appendix) displays the slopes for the average F(R) polynomials between $400-450 \mathrm{~nm}$ and 470-550 nm between 20.0-30.0 minutes and upon $\mathrm{H}_{2} \mathrm{~S}$ breakthrough (beginning at $1.0 \mathrm{ppm} ; 36.3$ minutes). For this particular experiment, Figure 4.14 shows the electrochemical detector's response of concentration ( $\mathrm{ppm}$ ) versus time. This is a typical breakthrough curve for cartridges/canisters. The inset displays selected concentrations of $\mathrm{H}_{2} \mathrm{~S}$ at specific times throughout the experiment, including time of breakthrough $(10.0 \mathrm{ppm} \pm 2 \%)$.

Figure 4.14 - Electrochemical detector response to breakthrough of $\mathrm{H}_{2} \mathrm{~S}$ at $25 \% \mathrm{RH}$

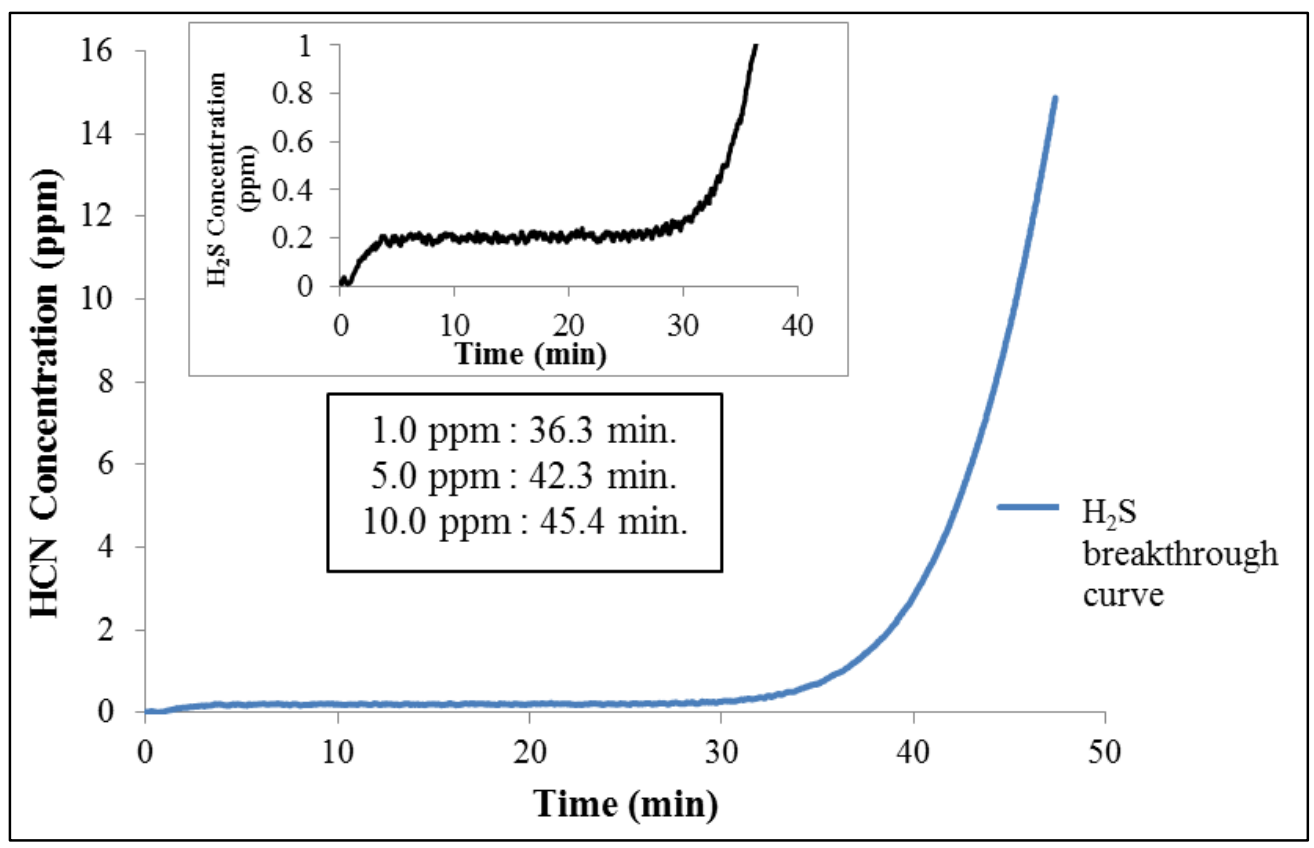


The average upstream $\mathrm{H}_{2} \mathrm{~S}$ concentration for this experiment is $1004 \pm 2 \%$ ppm at $64 \mathrm{LPM}$. The average $\% \mathrm{RH}$, is $25.7 \pm 0.5 \% \mathrm{RH}$.

\subsubsection{2 $50 \%$ RH}

Three pairs of cartridges were used for breakthrough testing of $\mathrm{H}_{2} \mathrm{~S}$ at $50 \% \mathrm{RH}$. The average response at 10 minutes, 30 minutes, and at $10.0 \mathrm{ppm}$ breakthrough are shown in Figure 4.15. The initial spectrum of $\mathrm{OH}\left(\mathrm{H}_{2} \mathrm{O}\right)$ Cbi is considered the blank. The $\mathrm{F}(\mathrm{R})$ values from $400-$ 450 and $470-550 \mathrm{~nm}$ for $50 \% \mathrm{RH}$ are higher than those for $25 \% \mathrm{RH}$, which was expected and observed previously.

4.15 - Average difference spectra of $\mathrm{OH}\left(\mathrm{H}_{2} \mathrm{O}\right) \mathrm{Cbi}$ response to $\mathrm{H}_{2} \mathrm{~S}$ breakthrough at $50 \% \mathrm{RH}$ $(\mathrm{n}=3)$

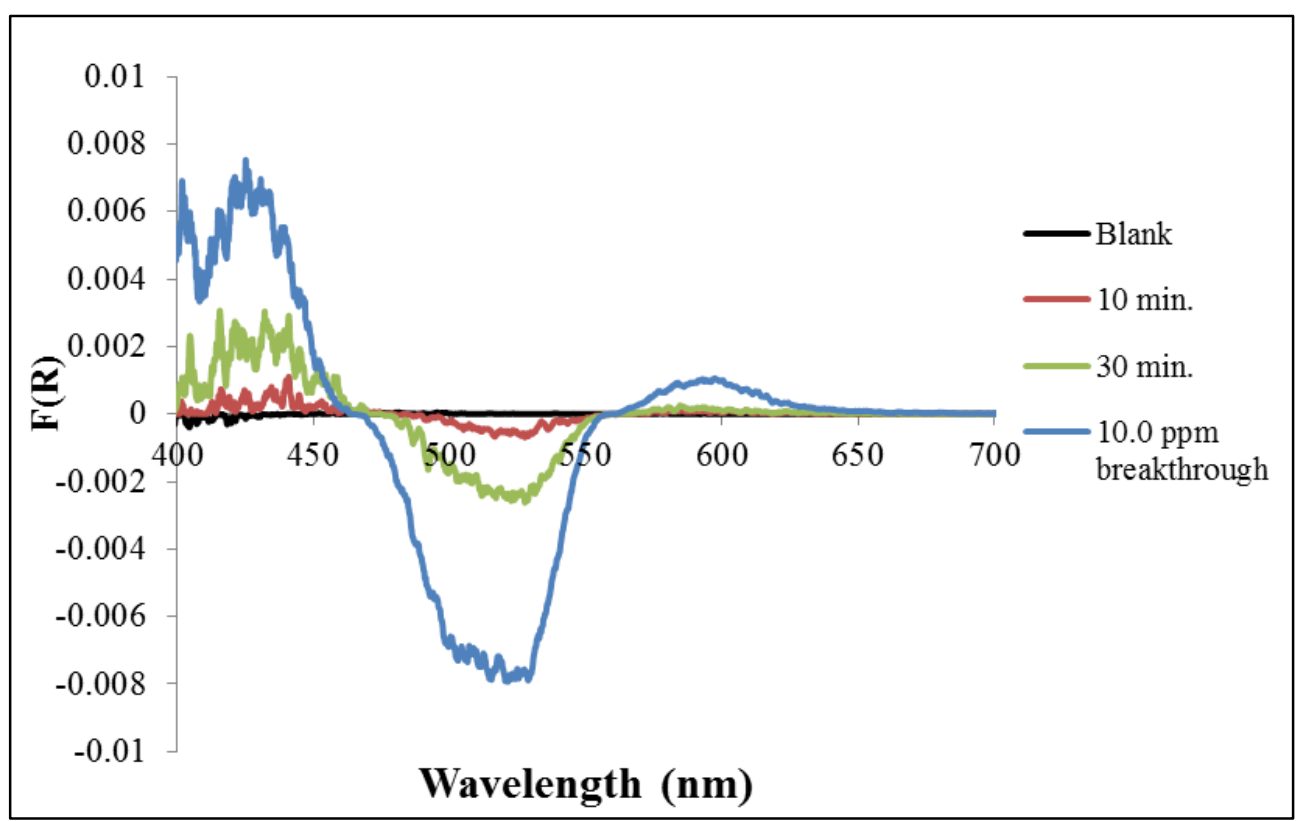


The $\mathrm{F}(\mathrm{R})$ spectrum observed at $10.0 \mathrm{ppm}_{2} \mathrm{~S}$ breakthrough is similar to that of 1 minute 10.0 ppm $\mathrm{H}_{2} \mathrm{~S}$ exposure (previously shown in Figure 3.13). Figure 4.16 compares the average $\mathrm{F}(\mathrm{R})$ response of 1 minute $10.0 \mathrm{ppm}_{2} \mathrm{~S}$ exposure to the breakthrough response. The spectral shifts are remarkably similar, however, the isosbestic point near $540 \mathrm{~nm}$ red shifts to $560 \mathrm{~nm}$, which was observed in Chapter 3 at longer exposure times (i.e. higher $\mathrm{H}_{2} \mathrm{~S}$ concentrations). This could be attributed to the cumulative response from the small amounts of $\mathrm{H}_{2} \mathrm{~S}$ breaking through and various reaction products of $\mathrm{H}_{2} \mathrm{~S}$ and $\mathrm{OH}\left(\mathrm{H}_{2} \mathrm{O}\right) \mathrm{Cbi}$, or the possibility of formation of chemical byproducts. Overall, the characteristic spectral shifts of $10.0 \mathrm{ppm}_{2} \mathrm{~S}$ exposure to the paper sensor and $\mathrm{H}_{2} \mathrm{~S}$ breaking through the cartridge at $50 \% \mathrm{RH}$ are similar.

4.16 - Comparison of average $\mathrm{F}(\mathrm{R})$ spectra at $\mathrm{H}_{2} \mathrm{~S}$ breakthrough (blue line) and exposure to 10.0 ppm $\mathrm{H}_{2} \mathrm{~S}$ (red line)

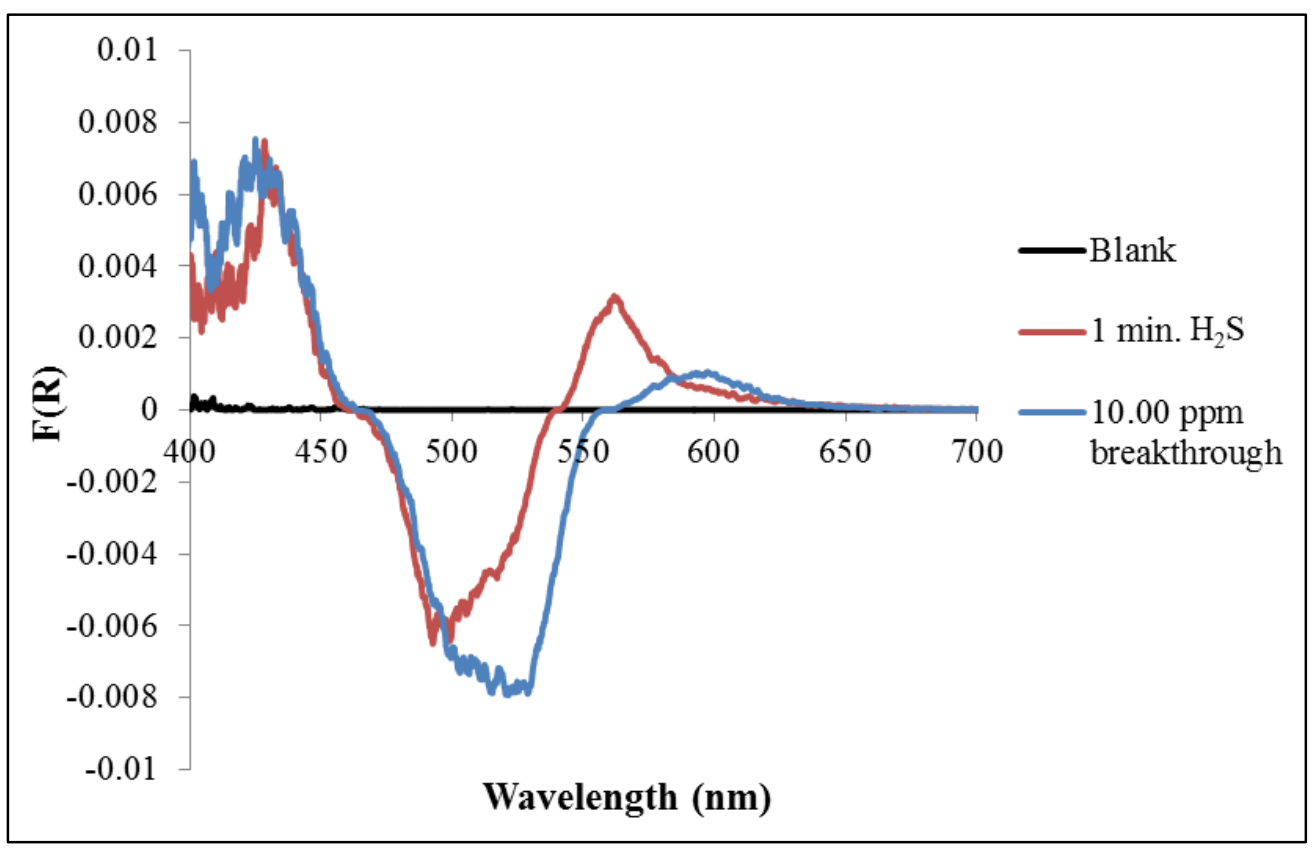


Figure 4.17 shows one example of monitoring the $\mathrm{OH}\left(\mathrm{H}_{2} \mathrm{O}\right) \mathrm{Cbi}$ response at 400-450, 470-550, and $800 \mathrm{~nm}$ (used as reference) for the entirety of the experiment at $50 \% \mathrm{RH}$. The $\mathrm{F}(\mathrm{R})$ values are plotted as 6-order polynomials, while the electrochemical detector's response is plotted as the second derivative of the concentration vs. time response.

$4.17-\mathrm{F}(\mathrm{R})$ and electrochemical detector response to $\mathrm{H}_{2} \mathrm{~S}$ breakthrough at $50 \% \mathrm{RH}$

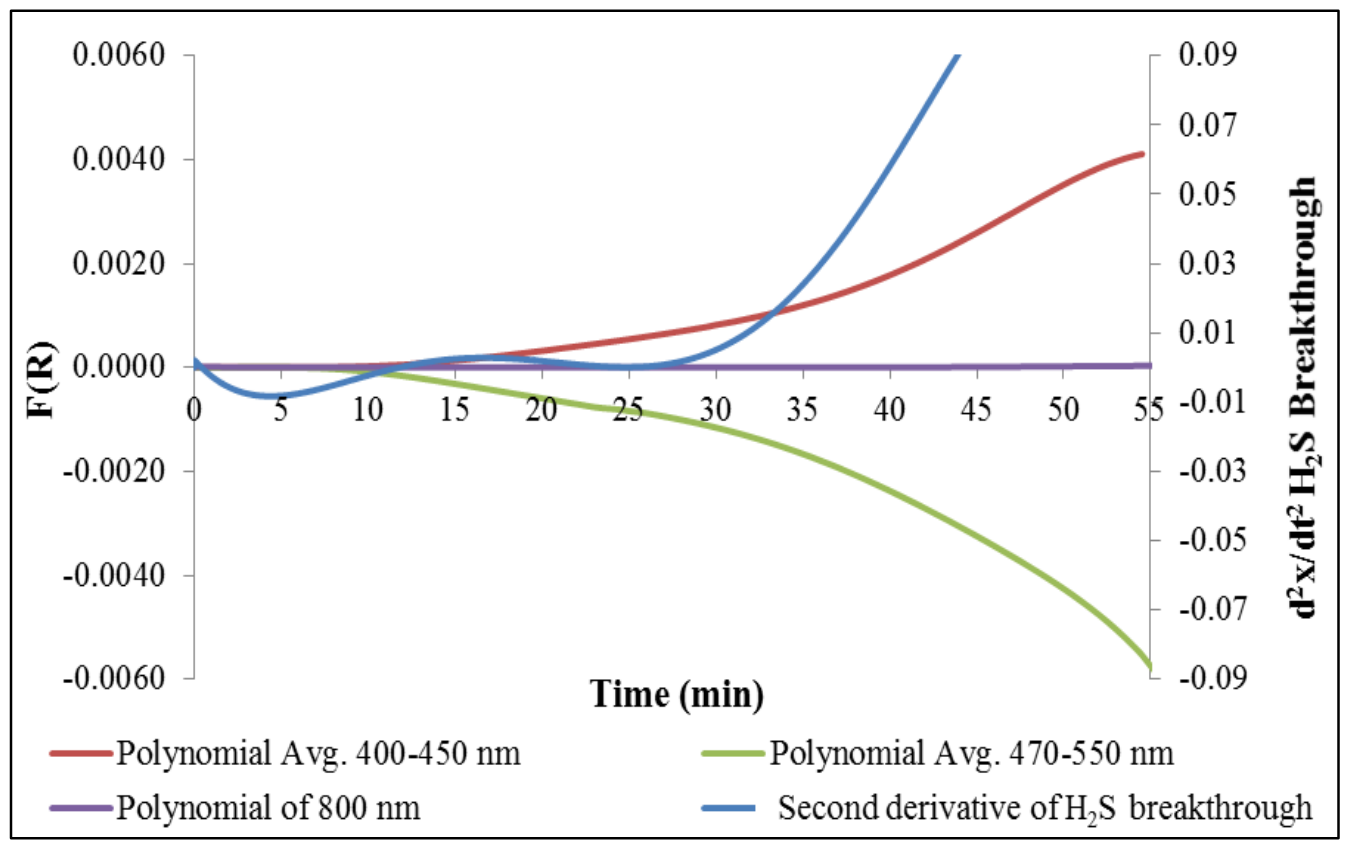


The electrochemical detector's average response from time 0.0-25.0 minutes yields an average concentration $174 \mathrm{ppb} \mathrm{H}_{2} \mathrm{~S}$. The $400-450 \mathrm{~nm}$ response begins to increase $\sim 15$ minutes into the experiment with the slope increasing around 40 minutes. The $470-550 \mathrm{~nm}$ response begins to decrease $\sim 10$ minutes into the experiment. The second derivative of the electrochemical detector's response begins to change near 26 minutes. For this particular experiment, Figure C.5 shows the raw electrochemical detector's response for concentration ( $\mathrm{ppm}$ ) versus time. The inset displays selected concentrations of $\mathrm{H}_{2} \mathrm{~S}$ at particular times throughout the experiment, including time of breakthrough $(10.0 \pm 2 \% \mathrm{ppm})$. Although the second derivative shows a slightly earlier response to $\mathrm{H}_{2} \mathrm{~S}$ breakthrough than $25 \% \mathrm{RH}$, the overall breakthrough time is longer for $50 \% \mathrm{RH}$. This was expected because of the solubility of $\mathrm{H}_{2} \mathrm{~S}$ and water in the carbon's pores, making service times of cartridges longer. Table C. 2 displays the slopes for the average $\mathrm{F}(\mathrm{R})$ polynomials between $400-450 \mathrm{~nm}$ and $470-550 \mathrm{~nm}$ between $20.0-30.0$ minutes and upon $\mathrm{H}_{2} \mathrm{~S}$ breakthrough (beginning at $1.0 \mathrm{ppm} ; 38.8$ minutes). The average upstream $\mathrm{H}_{2} \mathrm{~S}$ concentration for this experiment is $1004 \pm 2 \%$ ppm at $64 \mathrm{LPM}$. The average $\% \mathrm{RH}$ is $50.2 \pm 0.5$ $\%$ RH.

\subsubsection{3 $\quad 85 \%$ RH}

Three pairs of cartridges were used for breakthrough testing of $\mathrm{H}_{2} \mathrm{~S}$ at $85 \% \mathrm{RH}$. The average difference spectra at 10 minutes, 30 minutes, and at $10.0 \mathrm{ppm}$ breakthrough are shown in Figure C.6. The responses from $400-450 \mathrm{~nm}$ are similar to those observed for $50 \% \mathrm{RH}$, but responses for $470-550 \mathrm{~nm}$ are significantly higher than those for 25 and $50 \% \mathrm{RH}$. An increase in signal from $550-650 \mathrm{~nm}$ is observed that was similar to $10.0 \mathrm{ppm}_{2} \mathrm{~S}$ exposure at $50 \% \mathrm{RH}$ (Figure 3.13). Additionally, the isosbestic point red-shifts to a value similarly observed for 10.0 
ppm $\mathrm{H}_{2} \mathrm{~S}$ exposure at $85 \% \mathrm{RH}(560 \mathrm{~nm}$; Figure 3.16). This may be attributed to reduction of Cbi(III) to Cbi(II).

Figure 4.18 shows one example of monitoring the $\mathrm{OH}\left(\mathrm{H}_{2} \mathrm{O}\right)$ Cbi response at 400-450, 470-550, and $800 \mathrm{~nm}$ (used as reference) for the entirety of the experiment at $85 \% \mathrm{RH}$ which correlated well with the electrochemical detector. The $\mathrm{F}(\mathrm{R})$ values are plotted as 6-order polynomials, while the electrochemical detector's response is plotted as the second derivative of the concentration vs. time response. Breakthrough occurs at 65.9 minutes.

$4.18-\mathrm{F}(\mathrm{R})$ and electrochemical detector response to $\mathrm{H}_{2} \mathrm{~S}$ breakthrough at $85 \% \mathrm{RH}$

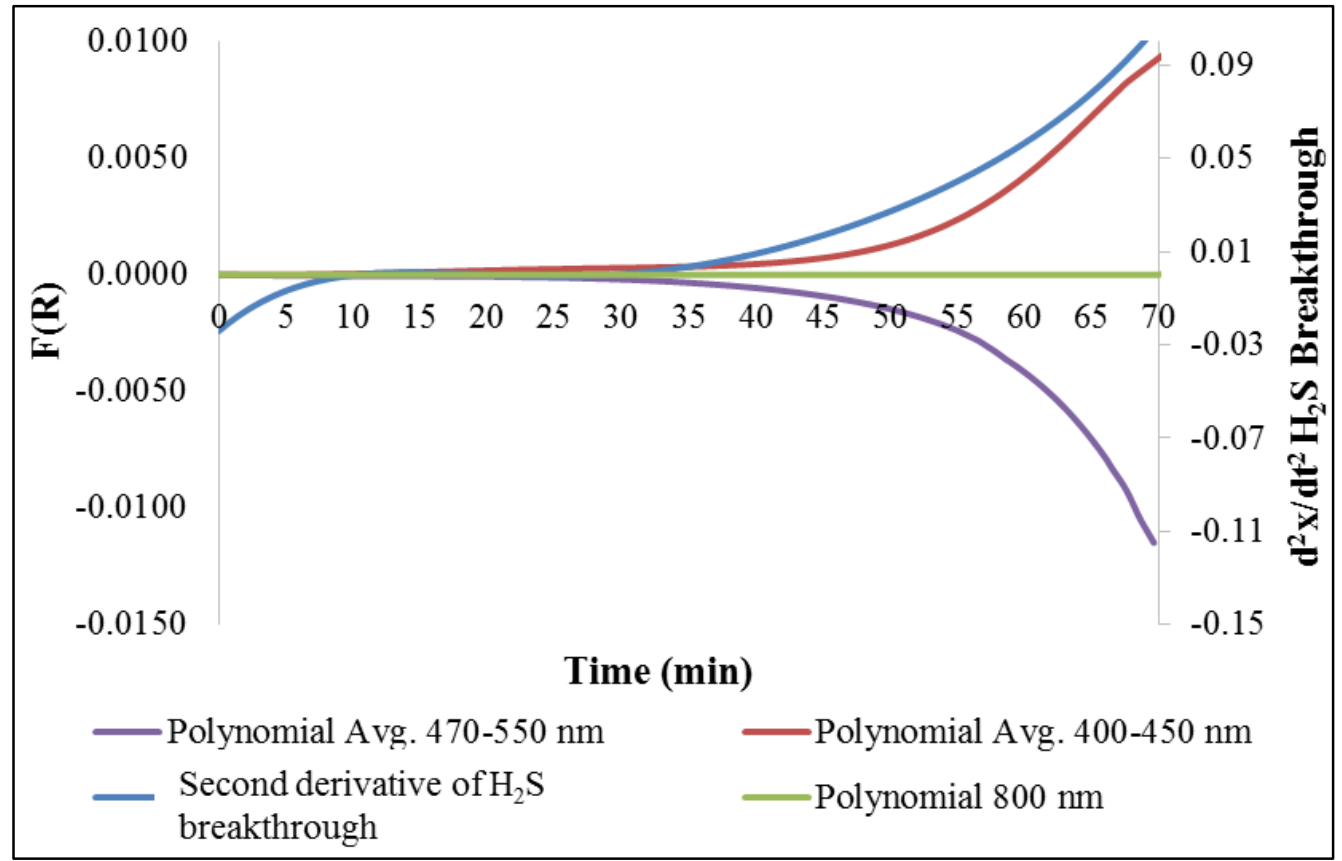

The electrochemical detector's average response from time 0.0-30.0 minutes results in an average concentration of $\sim 147 \mathrm{ppb} \mathrm{H}_{2} \mathrm{~S}$. The $\mathrm{F}(\mathrm{R})$ values for $400-450 \mathrm{~nm}$ response begins to increase $\sim 45$ minutes into the experiment, with the slope increasing simultaneously with the electrochemical detector. The 470-550 $\mathrm{nm}$ response begins to decrease $\sim 30$ minutes into the 
experiment. The second derivative of the electrochemical detector's response also begins to change near 30 minutes. For this particular experiment, Figure C.7 shows the raw electrochemical detector's response for concentration vs. time. The inset displays selected concentrations of $\mathrm{H}_{2} \mathrm{~S}$ at particular times throughout the experiment, including time of breakthrough. The average upstream $\mathrm{H}_{2} \mathrm{~S}$ concentration for this experiment is $1002 \pm 2 \% \mathrm{ppm}$ at 64 LPM. The average \% RH is $83.7 \pm 0.5 \% \mathrm{RH}$. Table C.3 displays the slopes for the average $\mathrm{F}(\mathrm{R})$ polynomials between $400-450 \mathrm{~nm}$ and $470-550 \mathrm{~nm}$ between $25.0-35.0$ minutes and upon $\mathrm{H}_{2} \mathrm{~S}$ breakthrough (1.0 ppm beginning at 48.8 minutes).

\subsubsection{Comparison of $\mathrm{H}_{2} \mathrm{~S}$ Breakthrough as a Function of \% RH}

A summary of approximate $\mathrm{Cbi} F(\mathrm{R})$ response times with correlating $\mathrm{H}_{2} \mathrm{~S}$ concentration can be seen in Table 4.2. The initial response refers to the approximate time where the $F(R)$ values began to increase, where the increase in slope refers to the time where a noticeable increase in the $F(R)$ breakthrough curve occurs. The comparison is made for the $F(R)$ responses of the breakthrough experiments shown in Figures 4.13, 4.17, and 4.18 for 25, 50, and $85 \%$ RH, respectively. The $\mathrm{H}_{2} \mathrm{~S}$ concentration are only approximately values, recorded from the Interscan ${ }^{\circledR}$ electrochemical detector $( \pm 2 \%)$ using LabVIEW ${ }^{\circledR}$. The increase in slope for the electrochemical detector is taken from the second derivative of the breakthrough curve. 
Table 4.2 - Summary of $\mathrm{F}(\mathrm{R})$ response times of Cbi on glass fiber paper, time corresponding to an increase in slope, and correlating $\mathrm{HCN}$ concentrations at each time

\begin{tabular}{|c|c|c|}
\hline & $\begin{array}{c}\text { Initial response / } \\
\text { increase in slope } \\
(\mathrm{min})\end{array}$ & $\begin{array}{c}\text { Correlating concentration } \\
\left.\text { (approximate conc. of } \mathrm{H}_{2} \mathrm{~S}\right)\end{array}$ \\
\hline $\mathbf{2 5} \% \mathbf{R H}$ & $15 / 40$ & $206 / 280 \mathrm{ppb}$ \\
\hline $400-450 \mathrm{~nm}$ & $30 / 40$ & $263 / 280 \mathrm{ppb}$ \\
\hline $470-550 \mathrm{~nm}$ & 27.4 & $230 \mathrm{ppb}$ \\
\hline Electrochemical detector & \multicolumn{2}{|}{} \\
\hline $\mathbf{5 0} \% \mathbf{R H}$ & $15 / 40$ & $171 \mathrm{ppb} / 1.38 \mathrm{ppm}$ \\
\hline $400-450 \mathrm{~nm}$ & $10 / 30$ & $195 / 267 \mathrm{ppb}$ \\
\hline $470-550 \mathrm{~nm}$ & 26 & $174 \mathrm{ppb}$ \\
\hline Electrochemical detector & \multicolumn{2}{|}{} \\
\hline $\mathbf{8 5} \% \mathbf{R H}$ & 30 & $120 \mathrm{ppb}$ \\
\hline $400-450 \mathrm{~nm}$ & 30 & $120 \mathrm{ppb}$ \\
\hline $470-550 \mathrm{~nm}$ & 30 & $120 \mathrm{ppb}$ \\
\hline Electrochemical detector & \multicolumn{2}{|c|}{}
\end{tabular}

Despite the $\mathrm{H}_{2} \mathrm{~S}$ concentrations being approximate, $\mathrm{OH}\left(\mathrm{H}_{2} \mathrm{O}\right)$ Cbi on paper successfully shows potential to detect low concentrations (ppb) of imminent carbon bed breakthrough. Although the overall breakthrough curves correlate well, the response times and change in slope times slightly differ from the electrochemical detector, presumably due to $\mathrm{H}_{2} \mathrm{~S}$ gas permeating through the carbon bed channels during the experiments. As mentioned, this is common in breakthrough experiments at such high flow (64 LPM) and concentrations (1000 ppm). It is exciting that Cbi on paper can detect such low concentrations of $\mathrm{H}_{2} \mathrm{~S}$, however the sensitivity may cause premature end-of-service-life determination of the respirator. Response times appear to correlate better at higher $\% \mathrm{RH}$, which be attributed to longer residence times of $\mathrm{H}_{2} \mathrm{~S}$ in the carbon bed due to solubility, as discussed below. 
Figure 4.19 summarizes the breakthrough times $\left(10.0 \mathrm{ppm}_{2} \mathrm{~S}\right)$ as a function of $\% \mathrm{RH}$ for average breakthrough curves at each \%RH with uncertainty in terms of S.D $(n=3)$.

4.19 - Electrochemical detector response to $\mathrm{H}_{2} \mathrm{~S}$ breakthrough for 25,50 , and $85 \% \mathrm{RH}$

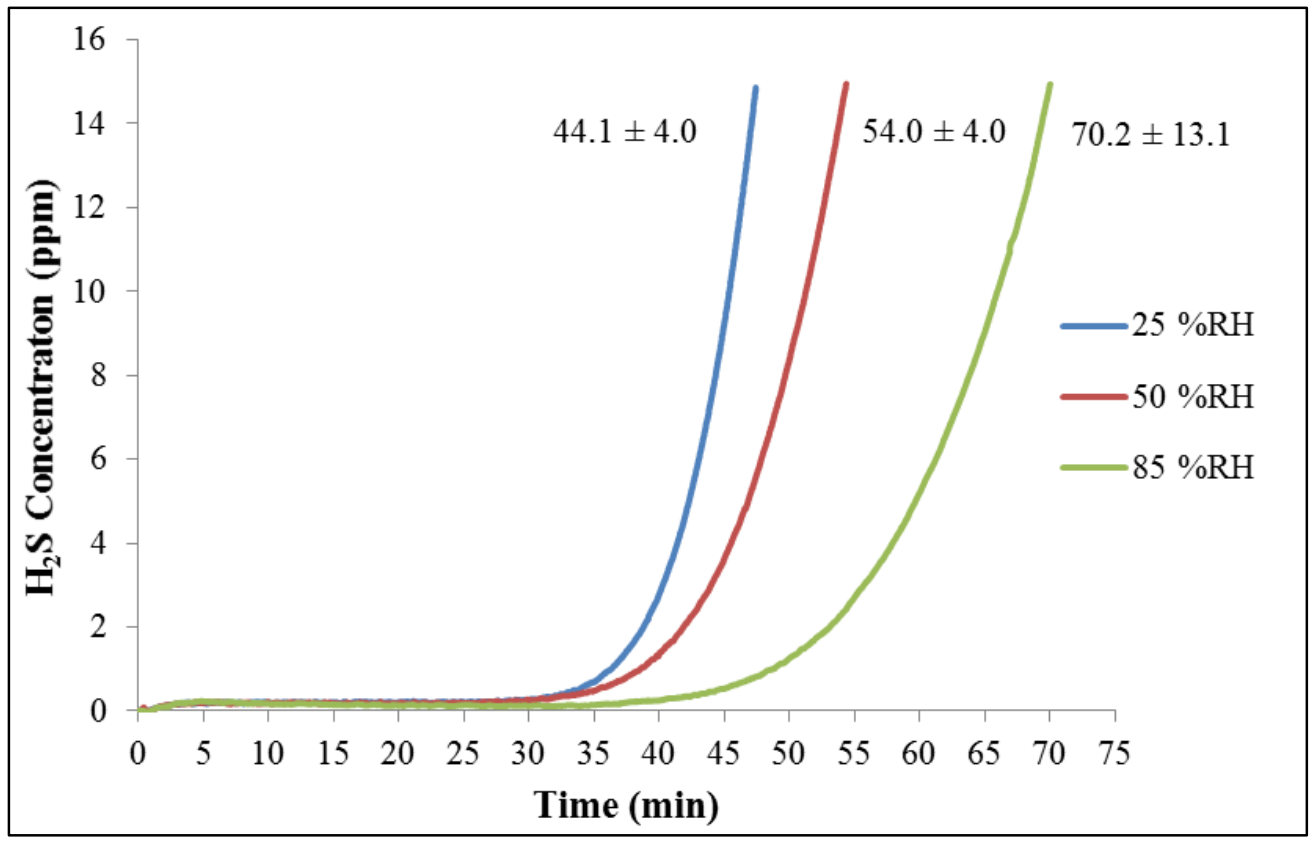

Although breakthrough begins at relatively the same time, service-life of the cartridges increases at elevated concentrations of water vapor in the air. Breakthrough time is longest for $85 \% \mathrm{RH}$. At higher $\% \mathrm{RH}$, a film of water is formed on the internal surface of activated carbon. ${ }^{244}$ The longer breakthrough time is expected because of the solubility of $\mathrm{H}_{2} \mathrm{~S}$ and water in the carbon's pores, making service times of cartridges longer. For organic vapors, the opposite effect occurs due to competition of active sites on the carbon. Shorter service-lives are observed with increasing $\%$ RH.

\subsubsection{Cbi Detection of Breakthrough a of Pre-Exhausted Cartridge}

Depending on usage, vapor concentration, breathing rate, and \% $\mathrm{RH}$, cartridges can last from minutes to weeks. Occupational workers often wear cartridges intermittingly over several 
days, donning and doffing upon entering and exiting contaminated areas during their 8-hour work shifts. An experiment was run to investigate the ability of the Cbi paper sensor to effectively detect breakthrough of $10.0 \mathrm{ppm}_{2} \mathrm{~S}$ through a previously exhausted cartridge where a gas/vapor formerly broke through and with redistribution, may offer a small amount of service-life remaining. The redistribution refers to a gas/vapor that has a tendency to migrate through the activated carbon during periods of storage or non-use. ${ }^{35}$ The pair of cartridges previously tested at $25 \% \mathrm{RH}$ (Section 4.3.2.1) was removed from the testing chamber upon completion of breakthrough and immediately stored in a clean, dry plastic bag for 18 hours (overnight). Figure 4.20 shows results of this experiment. $\mathrm{H}_{2} \mathrm{~S}$ breakthrough is plotted as the raw data from the electrochemical detector (i.e. not the second derivative). The average $F(R)$ response from $400-450 \mathrm{~nm}, 470-500 \mathrm{~nm}$, and $800 \mathrm{~nm}$ are plotted as 6-order polynomials.

$4.20-\mathrm{F}(\mathrm{R})$ and electrochemical detector response to $\mathrm{H}_{2} \mathrm{~S}$ breakthrough at $25 \% \mathrm{RH}$ for a pair of spent cartridges

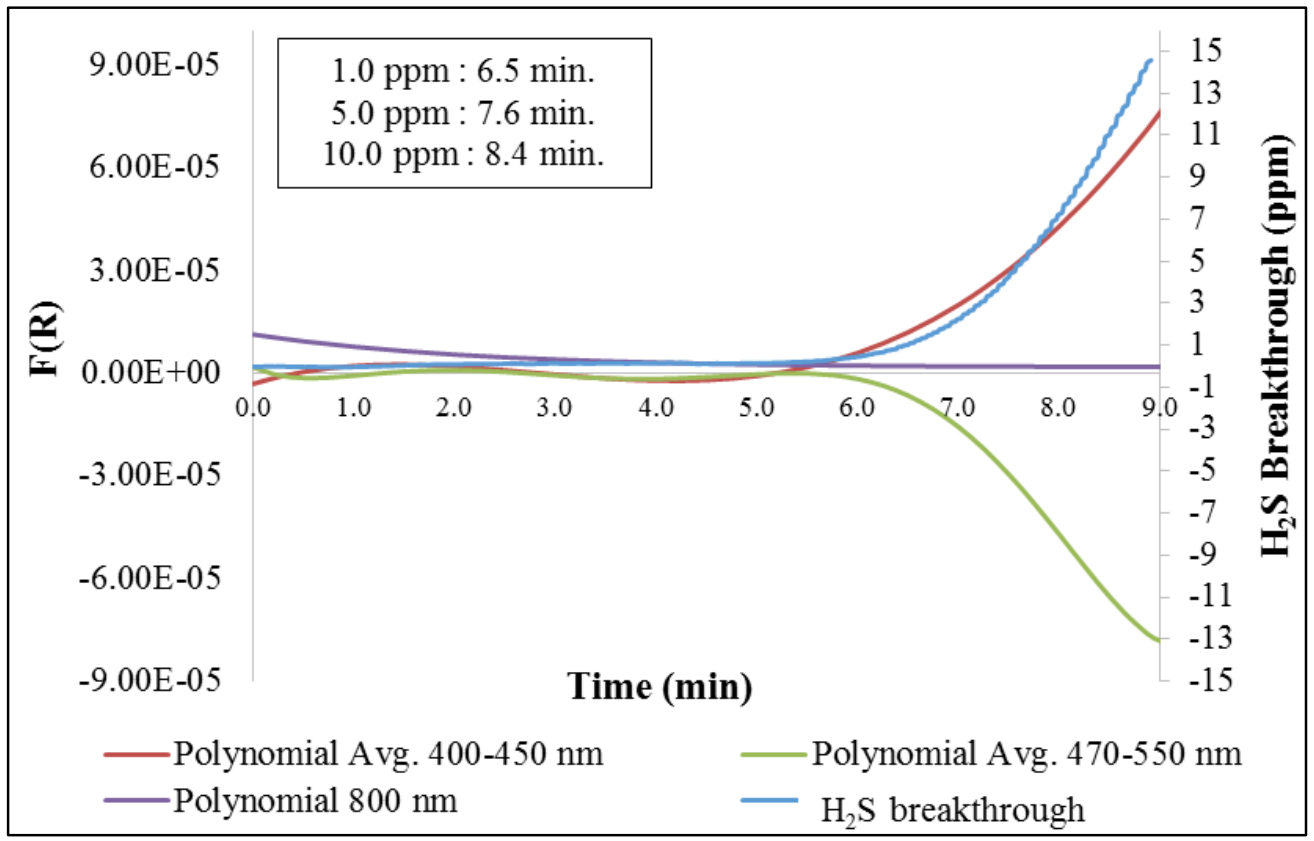


As expected, the $10.0 \pm 2 \% \mathrm{ppm}$ breakthrough time occurs rapidly (8.4 minutes) for a previously exhausted pair of cartridges. The $\mathrm{H}_{2} \mathrm{~S}$ that was adsorbed to the carbon probably re-distributed within the carbon bed overnight, allowing additional minutes to the service-life of the pair of cartridges. The results indicate that $\mathrm{OH}\left(\mathrm{H}_{2} \mathrm{O}\right)$ Cbi on paper can rapidly detect $\mathrm{H}_{2} \mathrm{~S}$ in cases where cartridges are worn with intermittent use and breakthrough occurs quickly.

\subsection{Conclusion}

Cobinamide was immobilized on glass fiber papers and placed in the downstream effluent flow of $\mathrm{H}_{2} \mathrm{~S}$ cartridges and $\mathrm{HCN}$ canisters. The $\mathrm{F}(\mathrm{R})$ signals from the paper sensor were simultaneously compared with commercial electrochemical detectors specific for these two gases, which were also placed downstream of the carbon beds. Replicate measurements were not possible for $\mathrm{HCN}$ due to the constraints of the experimental parameters (i.e. amount of $\mathrm{HCN}$ for breakthrough of canister), but preliminary data demonstrated that the $\mathrm{CN}\left(\mathrm{H}_{2} \mathrm{O}\right)$ Cbi could detect cyanogen (before breakthrough) and $\mathrm{HCN}$ (upon imminent breakthrough). The large carbon bed of the CBRN canisters and lengthy breakthrough times make these tests not economically feasible to run as many tests as desired to breakthrough. Additionally, gas companies will not prepare concentrations of $\mathrm{HCN}$ in cylinders greater than $2 \%$, because cylinders above this concentration cannot be transported. Comprehensive conclusions cannot be made with this limited amount of breakthrough data, however both the rapid and slow breakthrough test times show good correlation between the Cbi paper sensor and the electrochemical sensor upon HCN breakthrough.

The characteristic spectral shifts of $\mathrm{OH}\left(\mathrm{H}_{2} \mathrm{O}\right)$ Cbi reaction with $\mathrm{H}_{2} \mathrm{~S}$ were observed, where $400-450 \mathrm{~nm}$ increased and $470-550 \mathrm{~nm}$ decreased. At $85 \% \mathrm{RH}$, isosbestic points shifted towards longer wavelengths which was observed previously for higher $\mathrm{H}_{2} \mathrm{~S}$ concentrations. A small 
increase in signal near $600 \mathrm{~nm}$ was observed at all \% RH, which was also observed with exposure of $\mathrm{OH}\left(\mathrm{H}_{2} \mathrm{O}\right)$ Cbi to $\mathrm{H}_{2} \mathrm{~S}$. This increase would affect detection of $\mathrm{HCN}\left(\lambda_{\max }=583 \mathrm{~nm}\right)$; data processing would be necessary. The $\mathrm{H}_{2} \mathrm{~S}$ breakthrough trends of the Cbi paper sensor and electrochemical sensor were similar, indicating effectiveness in detecting imminent breakthrough from carbon beds and a proof-of-concept ESLI. A cumulative-like response was observed at lower \% RH, as low concentrations ( $\mathrm{ppb}$ ) of the gas permeate through the carbon bed through the first half of the experiment and could be detected both by the Cbi paper sensor and electrochemical sensor. This was not as easily observed for $85 \% \mathrm{RH}$, which could be attributed to the higher physical adsorption capacity of $\mathrm{H}_{2} \mathrm{~S}$ and $\mathrm{HCN}$ - both polar compounds - when higher amounts of water vapor are also adsorbed onto the carbon surface. Although a cumulative response may not be as prominent under normal working conditions ( $\sim 32 \mathrm{LPM},<50 \mathrm{ppm} \mathrm{H}_{2} \mathrm{~S}$ or $\mathrm{HCN}$ ), the sensitivity of Cbi for such low concentrations must be tuned, or the position in the respirator carbon bed optimized as to prevent premature end-of-service-life determination. However, a cumulative-like response is similar to that which a respirator user would experience upon small amounts of gas breaking though, the response/sensitivity of Cbi is also an advantage.

The effluent gas detection by the paper sensor was performed as an initial step towards integrating a miniaturized version of the sensor into a carbon bed. This would be challenging without collaboration of respirator manufacturers that could integrate the sensor during a manufacturing stage. Otherwise, cutting through the cartridge could compromise the integrity of the carbon bed and airflow movement through it, affecting canister/cartridge performance and breakthrough time. Working with manufacturers with a sensor prototype would be the next step forward. 


\section{Chapter 5: Color Sensor Prototype Development}

\subsection{Introduction}

For an ESLI to be marketable, it must be small, simple, light-weight, and cost-effective. A miniaturized ESLI prototype is developed to rapidly detect $\mathrm{HCN}$ at low concentrations in the visible spectral range of interest (400-700 nm), specifically where cobinamide yields characteristic absorbance spectra. The RGB color sensor is integrated into a test holder and controlled by a USB-powered microcontroller. An on-chip light emitting diode (LED) illuminates the sample, where the light reflected from the Cbi paper is detected by the color sensing photodiodes, where color formation is quantified from the optical reflectance.

Photodiodes allow separation of output RGB values. Total change in color (Cbi on paper preexposure as the reference) is calculated at specific time intervals, $\mathrm{HCN}$ concentrations, and relative humidity. This sensor has the potential to improve the current state of ESLIs which rely on subjective color-change determination by the user. Therefore, this sensor technology allows a more quantitative approach to determine end-of-service-life.

\subsection{Background}

Although color plays an integral role in our daily lives, sensors dedicated to color are relatively few in number in both the industrial and scientific worlds. ${ }^{245}$ A quick review of articles published in sensor-related peer-reviewed journals (Institute of Electrical and Electronics Engineers, Sensors and Actuators, etc.) yields a low percentage of color sensor applications compared to all articles. Unlike spectrometry, which separates incident light in a large number of narrow wavelength passbands, color sensors separates light by means of a set of colors, primarily red $(R)$, green $(G)$, and blue $(B)$, in the visible range. ${ }^{245}$ Although spectrometry is more accurate than colorimetry, miniaturization and fabrication of spectrometers is more difficult and 
expensive. Because of complex data analysis, complicated digital circuits are also usually required. ${ }^{245}$ Colorimetry offers a simpler and more cost-effective alternative to spectrometers with simpler standardization. Real-world applications include, but not limited to, chemistry (e.g., $\mathrm{pH}$ determination), the food and beverage industry (e.g., chemical reactions during wine storage), cosmetics, and printing and textile industries (e.g., quantify color variations in printed textile)..$^{245,246}$

Briefly, silicon-based color sensors (i.e. photodiodes) rely on the generation of an electron-hole pair upon photon excitement, where incident light is proportionately converted to an electric current. Specifically, photons with energy greater than the bandgap of silicon $(1.1 \mathrm{eV})$ generate the electron-hole pairs by being absorbed at certain depths depending on their energy. ${ }^{245}$ Depths are determined by the intrinsic diffusion layer of the photodiode or thickness of additional coatings (200-1100 nm) optimized for particular wavelength transmissions. ${ }^{247}$ For example, the shallower the diffusion layer, the shorter the wavelength (higher the frequency) detected. Thus, blue light is detected by a shallow diode near the silicon surface, green penetrates deeper and is detected by a middle diode, and red light by a deep diode ${ }^{248} \mathrm{~A}$ depiction of this type of RGB color sensor can be seen in Figure 5.1a (modified from Cambridge in Colour). ${ }^{249}$ Alternative to wavelength-dependent depth, photodiodes can also be deposited with red, green, or blue optical absorbance and/or interference filters obtained by depositing colored filter glass, polymer dyes, or synthetic gels to respond to a specific wavelength range. ${ }^{245}$ These deposits are typically impregnated with organic and inorganic dyes where absorbance filters absorb certain wavelengths and let others pass (Figure 5.1b), while interference filters reflect and destructively interfere with unwanted wavelengths. ${ }^{250}$ The photodiode array is often based on the Bayer Pattern (developed by Kodak in the 1970s), which uses a checkerboard pattern for arrangement 
of RGB color photodiodes. ${ }^{245}$ Colorimetric information is extracted by analyzing the photocurrents at different time intervals and transforming the current data to voltage (V).

Figure 5.1 - Pictorial representation of an RGB color sensor based on variations in photodiode depletion region (A) or with absorption filters (B)

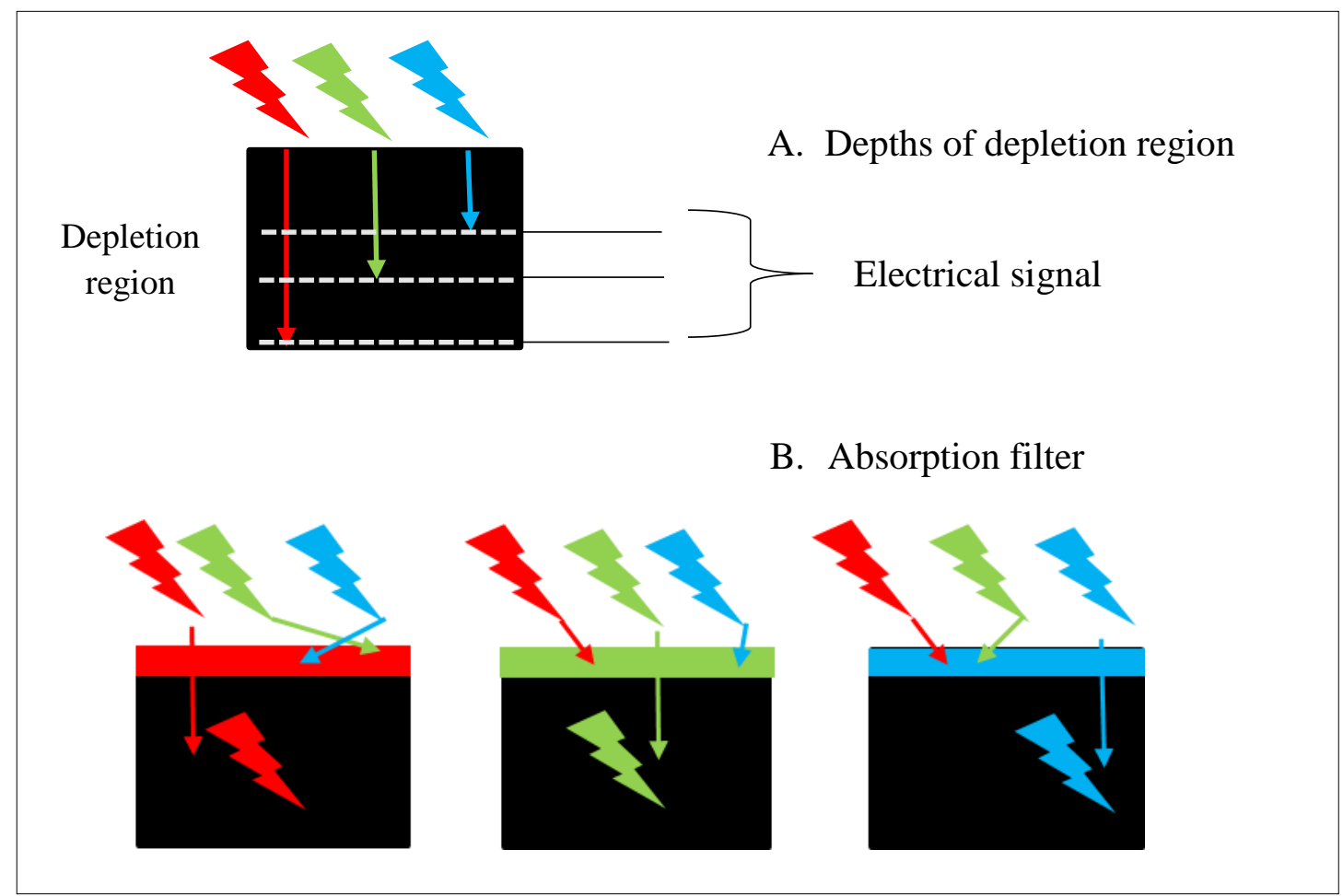

Generally photodiodes have quick responses with linearity over several orders of magnitude with lower detection limits in picowatt, several orders of magnitude lower than the human eye. Sensor output values, separated by RGB values, are in terms of counts or digital values (D.V.; particularly counts $/ \mu \mathrm{W} / \mathrm{cm}^{2}$ ). Amplifiers may be used to augment this signal. Dependent on the bit resolution, the data can be transformed into a standard color space using the Commission Internationale de l'Éclairage (CIE) color space such as CIE XYZ, and coloropponent space with light dimension (L), a (redness to greenness), and b (yellowness-blueness) color-opponent dimensions (i.e. CIE LAB), etc. ${ }^{251}$ The majority of color sensor data processing published in peer-reviewed journals are not in real-time: i.e. the sensor is exposed to the analyte and scanned (via a flatbed scanner) into a computer. The color analysis is performed by software 
(e.g., Adobe Photoshop, Adobe Illustrator) or on a smartphone application in terms of RGB values of 8-bit resolution (256-bit color scale with 255, 255, 255 corresponding to white, and 0, 0,0 corresponding to black). ${ }^{67,122,139-141}$ Data is frequently presented in terms of total color differences $(\Delta \mathrm{C})$ using the Euclidean distance equation:

$$
\Delta \mathrm{C}=\sqrt{(\Delta R)^{2}+(\Delta G)^{2}+(\Delta B)^{2}}
$$

Equation 5.1

where $\Delta \mathrm{R}, \Delta \mathrm{G}$, and $\Delta \mathrm{B}$ are the change in $\mathrm{R}, \mathrm{G}$, and $\mathrm{B}$ colors from reference values at a defined point in time, respectively. Data can be further presented using principle component analysis (PCA) and/or agglomerative hierarchical clustering (AHC) for multivariate statistical analysis. ${ }^{139,142}$

The RGB color sensor developed here is designed to be enclosed in a light-tight holder, which allows exposure of the $\mathrm{CN}\left(\mathrm{H}_{2} \mathrm{O}\right) \mathrm{Cbi}$ paper to $\mathrm{HCN}$ gas. The 16-bit color sensor is connected and controlled by a microcontroller, which converts data to real-time RGB readouts on a computer, and thus rapid color change analysis of the cobinamide metal-complex.

\subsection{Materials}

Refer to Section 2.3 for detailed information on materials used in Chapter 5.

\subsubsection{RGB Color Sensor}

An RGB color sensor was purchased from Adafruit ${ }^{\circledR}$ (adafruit.com; \$7.95) which incorporates a color sensor $\left(\operatorname{TCS} 34725\right.$, ams ${ }^{\circledR}$ ) with a neutral white, $4150^{\circ} \mathrm{K}$ temperature LED to illuminate the material of interest (i.e. the Cbi-immobilized paper). ${ }^{252}$ The on-chip LED eliminates the need for the cumbersome bifurcated fiber optic previously used in Chapters 2-4. The indium gallium nitride ( $\mathrm{InGaN}$ )-based LED has a viewing angle of $120^{\circ}$ with maximum 
illumination in the desired spectrum ranges $(400-700 \mathrm{~nm}){ }^{253} \mathrm{An}$ infrared (IR) blocking filter is integrated on-chip and located near the color sensing photodiodes. The manufacturer reports that this minimizes the IR spectral component and allows color measurements to be made more accurately. ${ }^{252}$ The photodiode color array is composed of three red, green, and blue-filtered photodiodes, as well as three clear (unfiltered) photodiode. Although specific information was unavailable due to proprietary reasons, the color sensor manufacturer reports to use absorption filters combined with interference filters over the RGB photodiodes for wavelength range specificity. The $4 \times 3$ color array is represented in Figure 5.2.

Figure 5.2 - Pictorial representation of the color array on the Adafruit ${ }^{\circledR}$ RGB color sensor

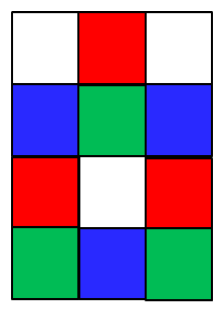

Four integrated analog-to-digital converters simultaneously convert the amplified photodiode currents to a 16-bit digital value. ${ }^{252}$ The results are then transferred to data registers and communicated to a microcontroller through a $400 \mathrm{kHz}, \mathrm{I}^{2} \mathrm{C}$ serial bus. ${ }^{252}$

The photodiodes are exposed to light for a certain amount of time and the current generated (stored in the capacitors) are converted to voltage, which is separated by respective RGB values. The sensor has a clock that runs at $425 \mathrm{~Hz}$, or $2.4 \mathrm{~ms}$ - the lowest integration time. The chip uses a 10-bit analog-to-digital converter (ADC) for this measurement, therefore the raw output values are between $0-1023\left(2^{10}=1024\right)$. The raw values are divided by the integration time to bring all values to a common scale, yielding the average amount of light detected per 
clock cycle per integration time. The sensor has a 3,800,000:1 dynamic range with adjustable integration time and gain for increased sensitivity. ${ }^{252}$ The integration time can be from 2.4 to 700 ms. An integration time of $700 \mathrm{~ms}$ yields 256 cycles, or 65535 max counts (i.e. 16-bit resolution). Increasing the integration time by four reduces the random error by two, therefore a 256 cycle experiment (700 ms integration time) will read $1 / 16^{\text {th }}$ the error of a 1-count reading (lowest integration time). The chip has a set of amplifiers between the capacitors and the ADC allowing for increased sensitivity (or "gain"), particularly in low light settings. Gain controls can be of 1 (no gain), 4, 16, or 60 . For maximum resolution, the 256-count reading would be multiplied by 60 . A disadvantage of increasing the gain is the amplification of the random noise along with the signal. The combination of integration time and gain selection is dependent on the application; here, accuracy is more important than speed (on order of ms), and light levels are not an issue. Integration time was increased to $700 \mathrm{~ms}$ while no gain was necessary.

\subsubsection{Sensor Wiring}

Header pins were soldered directly onto the sensor to ensure efficient electrical contact when connecting to the ribbon cable. The ribbon cable was soldered to the sensor pins and was used to connect the RGB color sensor and to the appropriate ports on the Arduino microcontroller (Figure 5.3). 
Figure 5.3 - Side view of RGB color sensor with soldered sensor pins (A), backside view of color sensor with soldered ribbon cable (B), connection of RGB color sensor to the microcontroller via the ribbon cable and breadboard $(\mathrm{C})$
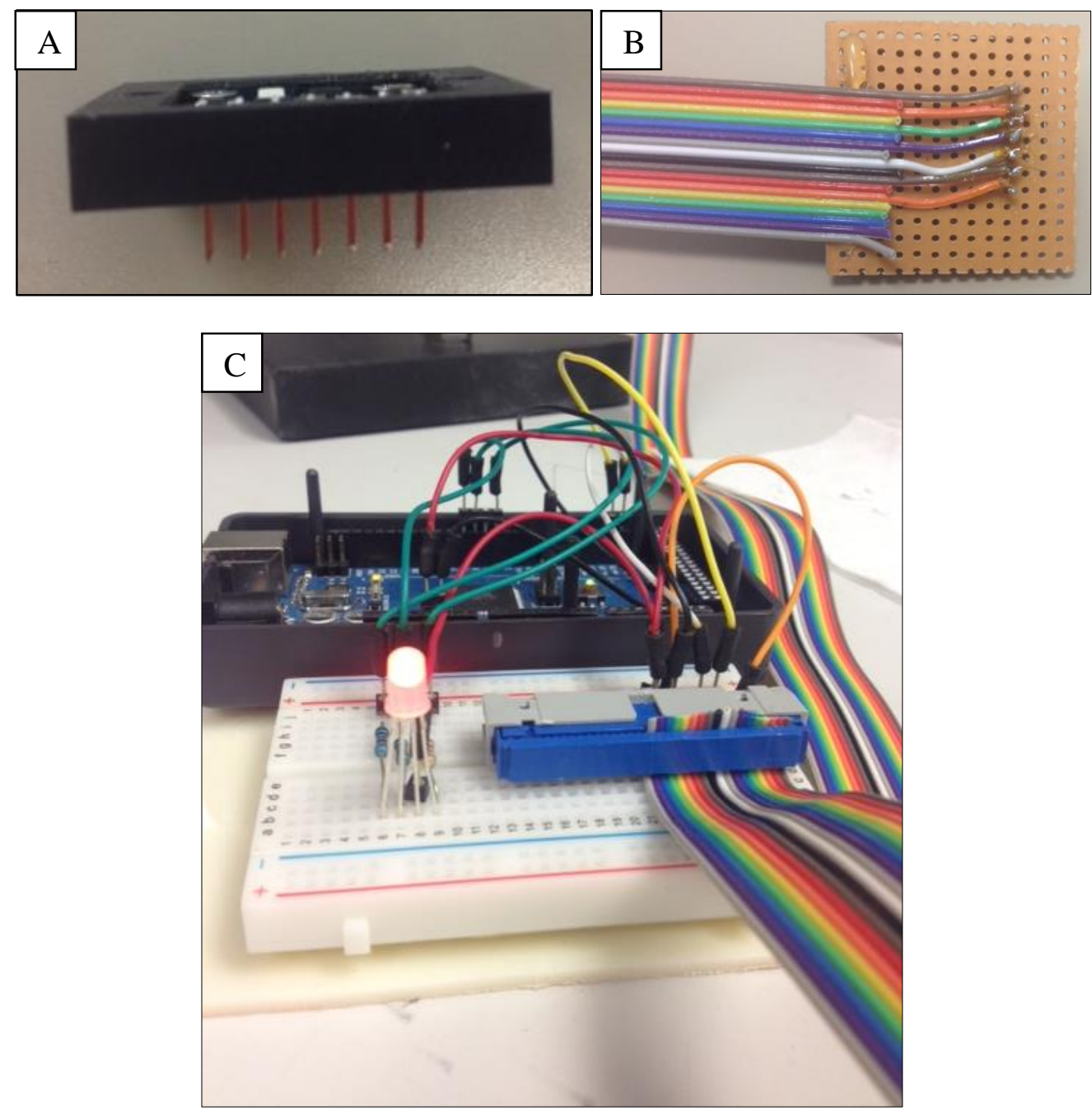

The accessory LED (on breadboard) was also connected through jumper wires and to the microcontroller. The LED is a diffused RGB ("tri-color LED”) with four pins. One pin is the common anode which is connected to $5 \mathrm{~V}$, and the three other pins (for separate color values) are grounded through the resistors (one $\mathrm{k} \Omega$ resistor and two $560 \Omega$ resistors).

The microcontroller was connected to a laptop via universal serial bus (USB) cable and controlled with its own software using Inter-Integrated Circuit $\left(\mathrm{I}^{2} \mathrm{C}\right)$ communication. A software 
sketch specific for the color sensor called "Color View" was downloaded from the Internet which displays data in separate R, G, B and clear light elements. The sketch was modified to delay RGB values to intervals of 6 seconds, and a calculation of the total change in color at each measurement. The sensor can also be modified to indicate when a minimum change in color is reached by flashing the LED (to simulate reaching end-of-service-life).

\subsubsection{Sensor Holder}

A sensor holder was designed to allow gas flow over the paper without exposing the RGB color sensor to corrosive gases. The material and design were similar to the sensor holder explained in Chapters 2-4, but modified to introduce a clear glass window for placement of the paper and detection of color change by the sensor directly below the paper. The sensor holder is made up of the following three components: the bottom to house the color sensor, the middle which houses the clear window and paper, and the top which screws on and holds all three pieces in place (Figure 5.4). 
Figure 5.4 - Top view of RGB color sensor in holder (A and B), middle section of sensor holder with glass window for LED illumination of Cbi paper and reflectance of color to the photodiodes (C)
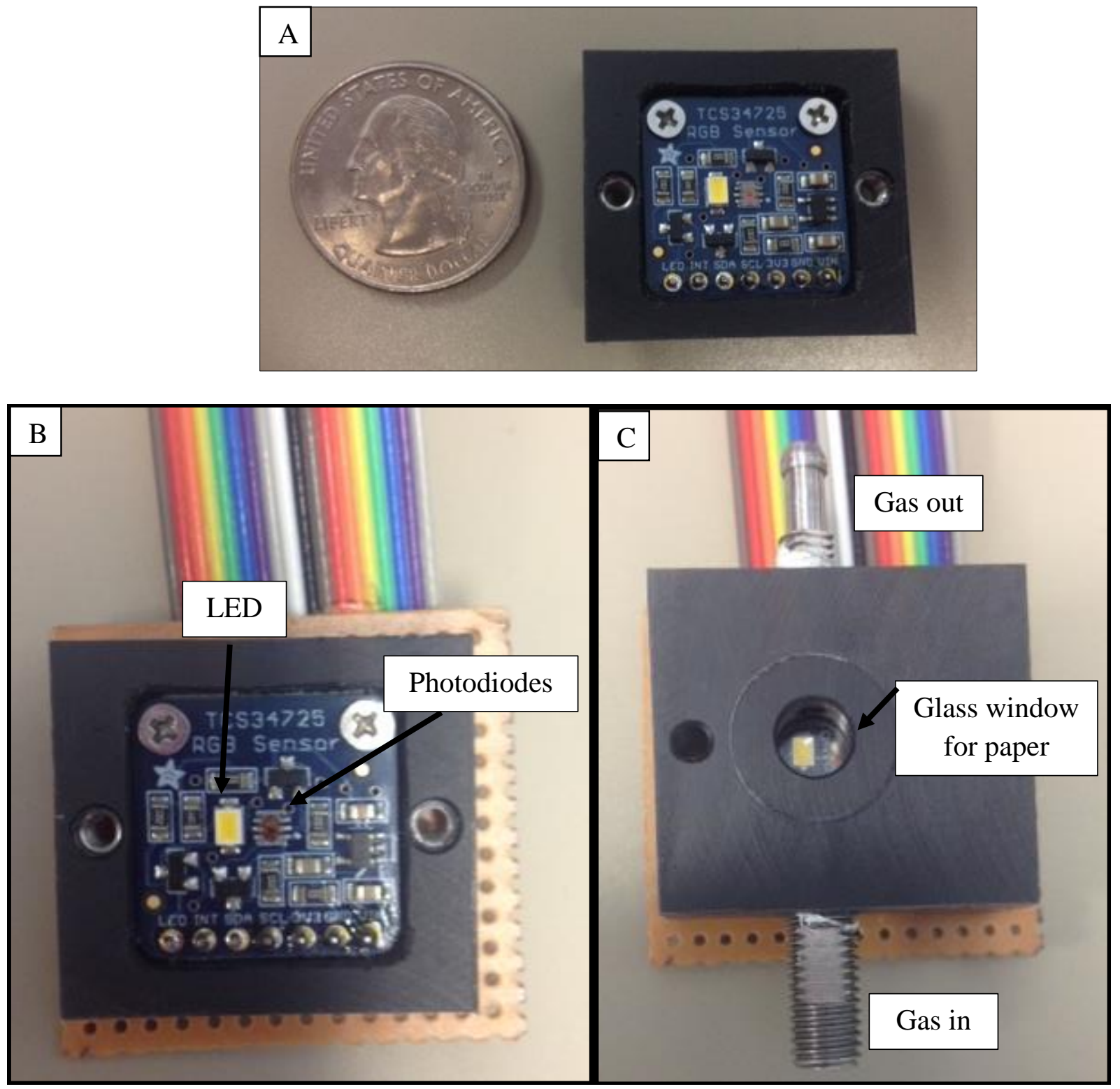

The complete RGB color sensor prototype - complete with the sensor holder, breadboard, and microcontroller — can be observed in Figure 5.5. 
Figure 5.5 - Complete RGB color sensor prototype

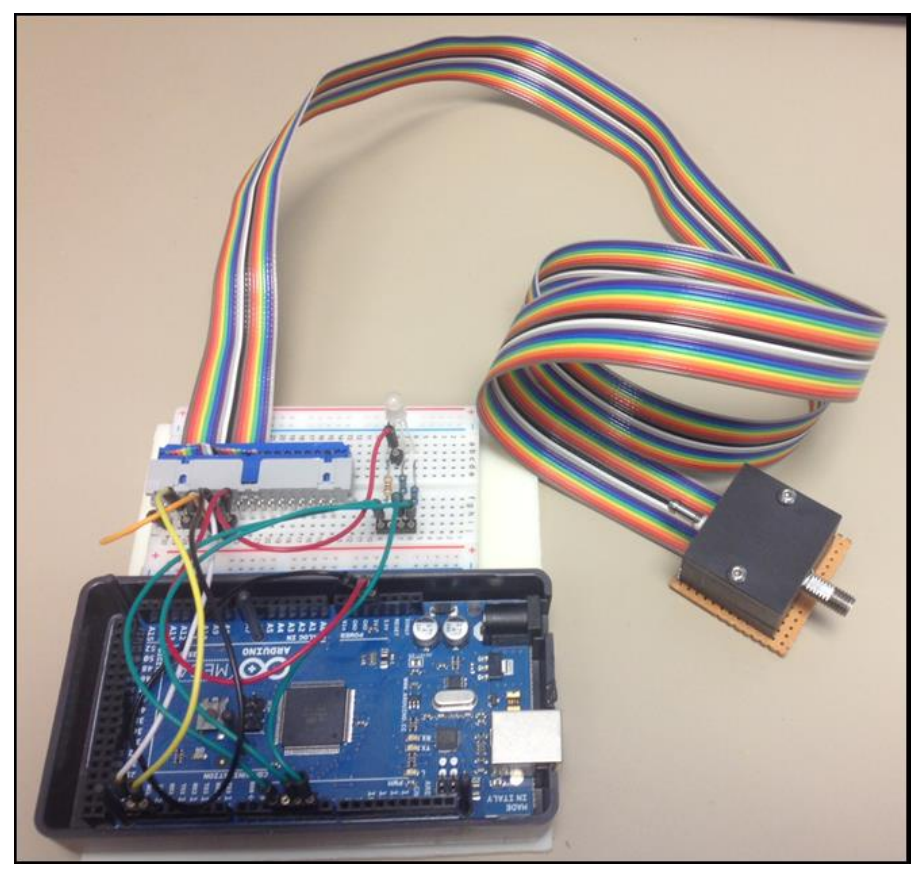

\subsection{Method}

\subsubsection{Cbi Concentration}

The volume and concentration of $\mathrm{CN}\left(\mathrm{H}_{2} \mathrm{O}\right) \mathrm{Cbi}$ to fix on the paper substrates were optimized. A volume of $15.0 \mu \mathrm{L}$ was used throughout Chapters 2-4; this volume was sufficient in loading Cbi onto the paper substrates while fully drying at room temperature in a short amount of time (1 hour). A concentration of $50.0 \pm 0.2 \mu \mathrm{M} \mathrm{CN}\left(\mathrm{H}_{2} \mathrm{O}\right) \mathrm{Cbi}$ was used throughout earlier chapters; this concentration was sufficient for the USB miniature spectrometer to quickly detect small changes in $\mathrm{F}(\mathrm{R})$ spectrum, but does not offer a significant contrasting color compared to the white background of the glass fiber paper when optimizing the RGB color sensor. A comparison of $\Delta \mathrm{C}$ of $50.0 \mu \mathrm{M}, 100.0 \mu \mathrm{M}, 200.0 \mu \mathrm{M}$, and $300.0 \mu \mathrm{M} \mathrm{CN}\left(\mathrm{H}_{2} \mathrm{O}\right) \mathrm{Cbi}$ when exposed to $5.0 \mathrm{ppm} \mathrm{HCN}$ was evaluated. 


\subsubsection{Repeatability}

The optimized concentration of $\mathrm{CN}\left(\mathrm{H}_{2} \mathrm{O}\right) \mathrm{Cbi}$ on glass fiber paper was compared across 30 samples using the RGB color sensor. 12 samples of blank glass fiber filter paper were also analyzed for their $\Delta \mathrm{C}$. Data was analyzed by average R, G, and B values, using SD, \% RSD, and $95 \%$ CI. All samples were prepared and tested under the same conditions.

\subsubsection{Robustness with LED}

The bifurcated optical fiber and associated Ocean Optics ${ }^{\circledR}$ spectrometer and tungsten halogen light source (Chapters 2-4) were used to determine the spectral responsivity at certain wavelengths of the on-chip LED. With the LED turned on, the common end of the bifurcated fiber optic was held as close as possible (and at different angles) to capture the average spectrum $(n=3)$ of the LED intensity detected by the spectrometer.

Additional experiments were performed to ensure the chip LED did not degrade or alter the Cbi spectrum when the paper sensor was placed in the sensor holder with the LED on for a period of time. Using the diffuse reflectance setup (bifurcated optical fiber, miniature spectrometer, and light source), an initial $F(R)$ spectrum was taken, after which the paper circle was inserted into the RGB color sensor holder for 60 minutes $(n=3)$. Final $F(R)$ spectra were taken immediately after in the diffuse reflectance setup. Total change in color after 60 minutes exposed to the chip-LED was calculated for $n=6$. 


\subsubsection{Drift}

Individual samples were placed in the RGB color sensor holder for 15 minutes (with LED turned on) to equilibrate the desired $\% \mathrm{RH}(25,50$, or $85 \%)$. Reference $\mathrm{R}, \mathrm{G}$, and B values were stored after this time, signifying $(t=0)$. A second 15 minute test was conducted (to mimic $\mathrm{HCN}$ exposure tests) and $\Delta \mathrm{C}$ values were obtained every 6 seconds. Average $\Delta \mathrm{C}$ values (in triplicate) were evaluated for each $\%$ RH.

\subsubsection{HCN Detection}

The experimental setup described in Chapter 2 was used for exposing the RGB color sensor to various concentrations of $\mathrm{HCN}$ and relative humidity. In Chapters 2-4, a flowrate of $1.00 \pm 0.01 \mathrm{LPM}$ was used to flow HCN over the paper held within the holder. However, paper movement in the color sensor holder was observed at this flowrate. Therefore, the flowrate was reduced to 0.75 LPM. Each paper was equilibrated with the desired \%RH for 15 minutes in the sensor holder. The Cbi paper was then exposed to HCN concentrations of 1.0, 3.0, 5.0, and 10.0 ppm, where $\Delta \mathrm{C}$ values were captured at $\mathrm{t}=0$ (when valve was turn to flow $\mathrm{HCN}$ towards sensor), 1, 5, 10, and 15 minutes (triplicate samples for each concentration). Experiments were performed at 25,50 , and $85 \% \mathrm{RH}$. The microcontroller program calculated $\Delta \mathrm{C}$ in intervals of 6 seconds using Equation 5.1. The reference $R G B$ value $\left(R_{1}, G_{1}, B_{1}\right)$ refers to the initial reading from the $\mathrm{CN}\left(\mathrm{H}_{2} \mathrm{O}\right) \mathrm{Cbi}$ color on glass fiber paper after equilibration with the appropriate $\% \mathrm{RH}$.

\subsection{Results and Discussion}

\subsubsection{Concentration of $\mathrm{Cbi}$ and Repeatability}

$\Delta \mathrm{C}$ of $50.0 \mu \mathrm{M}, 100.0 \mu \mathrm{M}, 200.0 \mu \mathrm{M}$, and $300.0 \mu \mathrm{M} \mathrm{CN}\left(\mathrm{H}_{2} \mathrm{O}\right) \mathrm{Cbi}$ when exposed to 5.0 ppm HCN were compared to evaluate the optimal concentration of Cbi to immobilize on the paper. Figure D.1 (Appendix) displays these results in terms of exposure time (minutes) to HCN 
where uncertainty is represented by S.D. (in triplicate measurements except $200.0 \mu \mathrm{M}$ with $\mathrm{n}=6$ ). The change in color is referenced to the RGB values of the Cbi on paper pre-exposure. As expected, $\Delta \mathrm{C}$ at a defined time interval increases with increasing concentration of Cbi on glass fiber paper. All concentrations performed similarly by an increasing change in color with increasing $\mathrm{HCN}$ time exposure. Cbi concentrations of $50.0 \mu \mathrm{M}$ and $100.0 \mu \mathrm{M}$ Cbi exhibited the lowest $\Delta \mathrm{C}$, while $300.0 \mu \mathrm{M}$ Cbi exhibited the highest. When $300.0 \mu \mathrm{M}$ was pipetted and allowed to dry on the individual paper pieces, areas of higher Cbi concentrations (rings) were observed around the outer edges of the paper causing inhomogeneous drying. Therefore, $200.0 \mu \mathrm{M}$ was chosen as the concentration to fix onto the paper pieces for $\mathrm{HCN}$ exposure.

Glass fiber filter paper was used as the sensor substrate for supporting Cbi. The average RGB values for 12 blank glass fiber paper (integration time of $700 \mathrm{~ms}$ ) and average RGB values for $200.0 \mu \mathrm{M} \mathrm{CN}\left(\mathrm{H}_{2} \mathrm{O}\right)$ Cbi on glass fiber paper $(\mathrm{n}=30)$ are shown in Table 5.1. RGB values are used to compute the average, 95\% CI, S.D., and \%RSD.

Table 5.1 - RGB values of blank glass fiber paper and $200.0 \mu \mathrm{M}$ Cbi on glass fiber paper

\begin{tabular}{|c|c|c|c|}
\hline Blank Glass Fiber Paper & R & G & B \\
\hline Average (D.V.) & 47110.2 & 51829.1 & 33808.5 \\
\hline 95 \% CI & 818.2 & 898.4 & 575.0 \\
\hline \% RSD & 2.6 & 2.6 & 2.6 \\
\hline $\mathbf{2 0 0 . 0} \boldsymbol{\mu M}$ Cbi on Glass Fiber Paper & R & G & B \\
\hline Average (D.V.) & 41531.2 & 41118.2 & 27373.5 \\
\hline 95 \% CI & 888.7 & 611.6 & 403.1 \\
\hline \%RSD & 5.7 & 4.0 & 3.9 \\
\hline
\end{tabular}

\subsubsection{LED}

The average UV-VIS spectrum of the on-chip LED is shown in Figure 5.6. The warmneutral white LED emitted a similar spectra shown in the datasheet with the distinctive InGaN LED peak observable at $\sim 450 \mathrm{~nm} .{ }^{253}$ When a mirror was placed directly over the chip-LED and 
photodiodes, the RGB values were recorded and normalized to the highest $\mathrm{R}, \mathrm{G}$, or B value. This spectral response is typically measured in amperes (A) of photocurrent generated per watt (W) of incident light power. A similar normalization approach was performed for blank glass fiber response $(n=12)$ and $200.0 \mu \mathrm{M} \mathrm{CN}\left(\mathrm{H}_{2} \mathrm{O}\right)$ Cbi on glass fiber paper $(\mathrm{n}=30)$ with results in Figure 5.7 and data in Table 5.2. The normalized data suggests a similar spectral response of the photodiodes when exposed to the white LED as function of wavelength, as well as the blank glass fiber paper and immobilized Cbi.

Figure 5.6 - Normalized response compared to the white LED spectrum (A) and comparison between spectral response of the photodiodes and response to paper as a function of maximum wavelength/color (B).

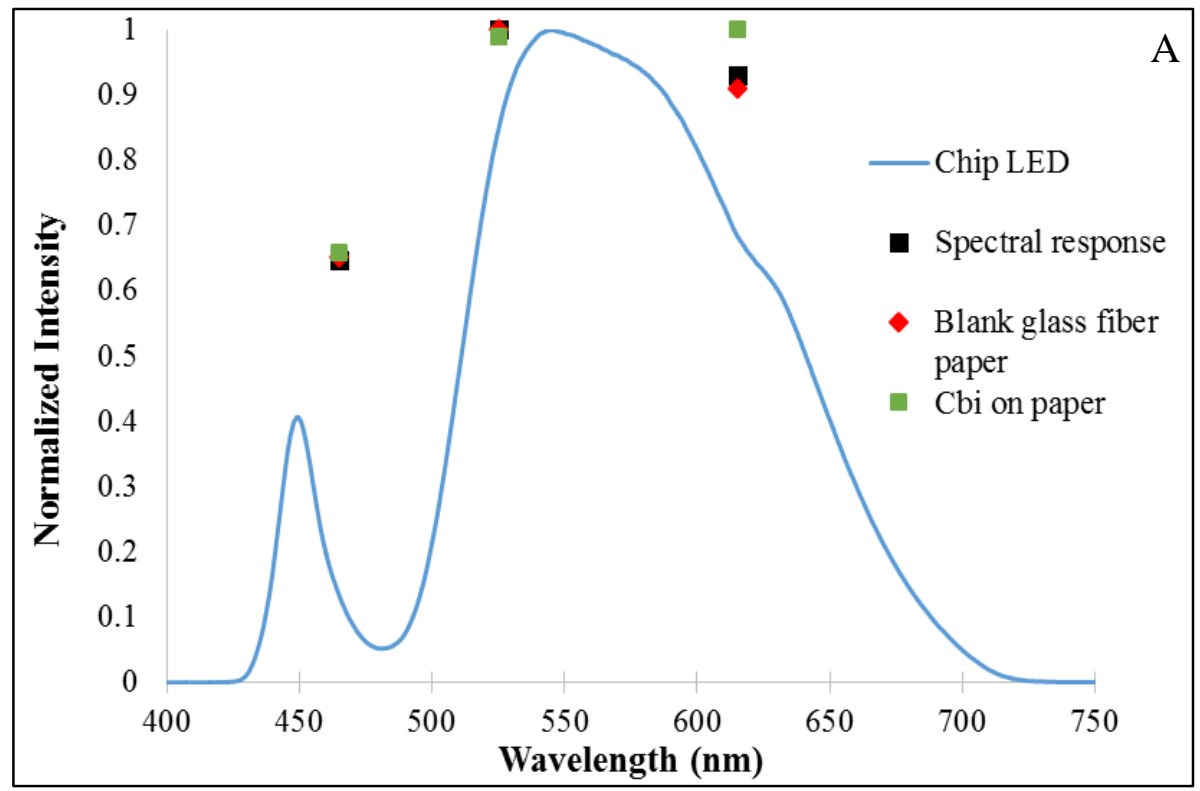




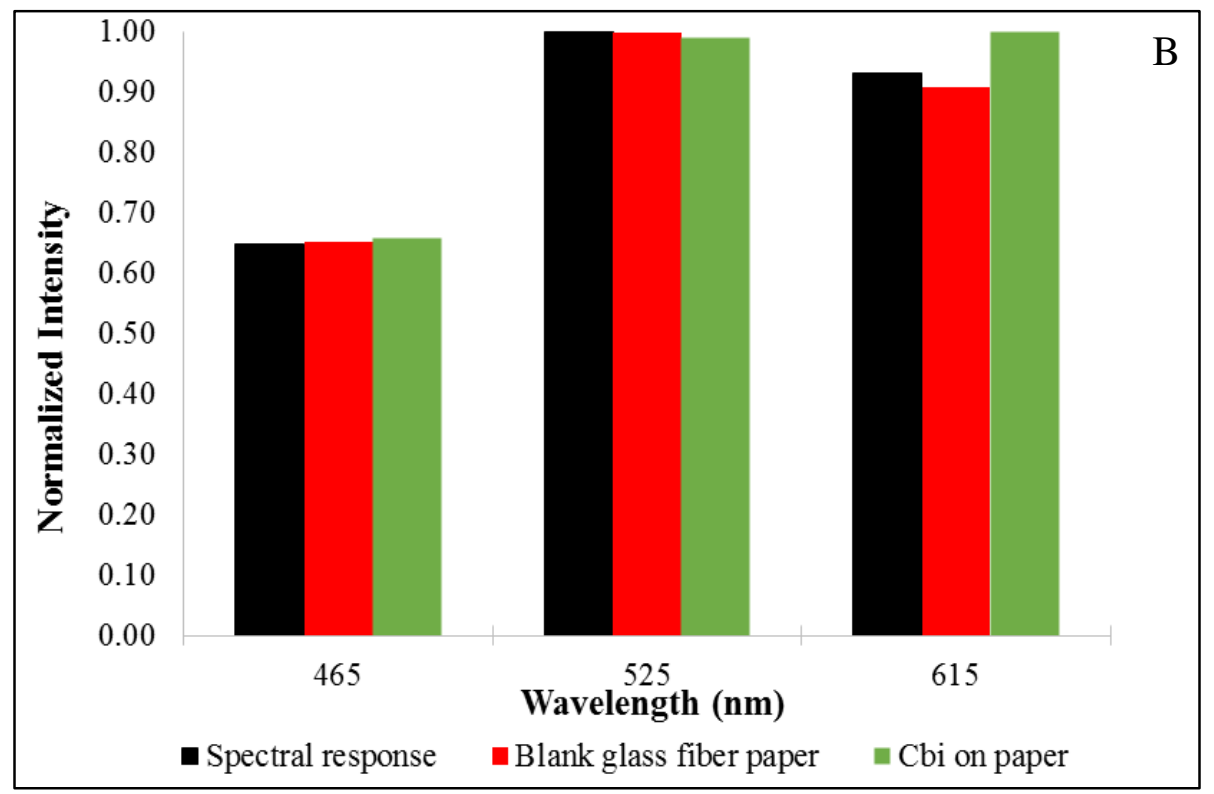

Table 5.2 - Normalized values for the spectral sensitivity of the RGB color sensor photodiodes, and response to paper as a function of wavelength max./color.

\begin{tabular}{|c|c|c|c|}
\hline $\begin{array}{c}\text { Wavelength } \\
\text { Max. }\end{array}$ & $\begin{array}{c}\text { Spectral sensitivity using } \\
\text { mirror }(\mathbf{n = 6})\end{array}$ & $\begin{array}{c}\text { Blank glass fiber } \\
(\mathbf{n = 1 2})\end{array}$ & $\begin{array}{c}\text { Cbi on paper } \\
(\mathbf{n = 3 0})\end{array}$ \\
\hline $465 \mathrm{~nm}(\mathrm{~B})$ & 0.65 & 0.65 & 0.66 \\
\hline $525 \mathrm{~nm}(\mathrm{G})$ & 1.00 & 1.00 & 0.99 \\
\hline $615 \mathrm{~nm}(\mathrm{R})$ & 0.93 & 0.91 & 1.00 \\
\hline
\end{tabular}

A study was conducted to ensure the chip LED did not degrade or alter the Cbi spectrum when the paper sensor was placed in the sensor holder for 1 hour. Using the diffuse reflectance setup (bifurcated optical fiber, spectrometer, and light source), an initial $F(R)$ spectrum for 200.0 $\mu \mathrm{M}$ Cbi-fixed paper was recorded, after which the paper circle was inserted into the RGB color sensor holder with LED on for 1 hour. Final $F(R)$ spectrum were taken immediately after in the diffuse reflectance setup. Figure D.2 shows the average $F(R)$ spectra of three Cbi paper samples taken before and after exposure to the chip LED for 1 hour. After 1 hour, the $F(R)$ values for Cbi from $\sim 400$ to $550 \mathrm{~nm}$ actually increases — as opposed to decreases which would be expected for degradation — but is most likely attributed to the variation in paper placement into the diffuse 
reflectance configuration, and not from the LED. The overall spectrum of Cbi remains the same. The total average $\Delta \mathrm{C}$ after 60 minutes of LED exposure is $195.6 \pm 24.8$ (uncertainty in $95 \% \mathrm{CI}$; $\mathrm{n}=6$ ) with data in Table D.1.

\subsubsection{Exposure to $\mathrm{HCN}$ \\ 5.5.3.1 $25 \%$ RH}

The Cbi paper was secured in the RGB color sensor holder and exposed to HCN. The average R, G, and B values for the response of Cbi paper exposed to $5.0 \mathrm{ppm} \mathrm{HCN}$ at $25 \% \mathrm{RH}$ is shown in Figure 5.7. The $\mathrm{R}$ and $\mathrm{G}$ values decrease, while the $\mathrm{B}$ values increase as a function of time. This increase and decrease trend is expected. Upon formation of $(\mathrm{CN})_{2} \mathrm{Cbi}$, an absorbance increase occurs from 531 to $600 \mathrm{~nm}$, while a decrease occurs from 420 to $531 \mathrm{~nm}$. The absorbance increase from 531 to $600 \mathrm{~nm}$ corresponds to the green-yellow-orange range in the UV-VIS spectrum; an increase in absorbance of the Cbi compound in this region would cause a decrease in the light reflected to the RGB color sensor, hence causing a decrease in the red and green-filtered photodiode response. An absorbance decrease from 420 to $531 \mathrm{~nm}$ corresponds to the blue-green region of the UV-VIS spectrum. An absorbance decrease causes an increase in reflectance/signal detected by the RGB color sensor. Therefore, an increase in the blue-filtered photodiode signal is observed. Overall, the red photodiode displayed the largest response, followed by the green photodiode and blue photodiode with change in color corresponding to $1910 \pm 130,880 \pm 110$, and $420 \pm 30$, respectively (uncertainty expressed by S.D.). These responses correlate well with the $(\mathrm{CN})_{2} \mathrm{Cbi}$ absorbance intensities at the appropriate wavelength ranges (Figure 2.33). 
Figure 5.7 - Response of the separate R, G, and B values upon 5.0 ppm HCN exposure at 25 $\% \mathrm{RH}$

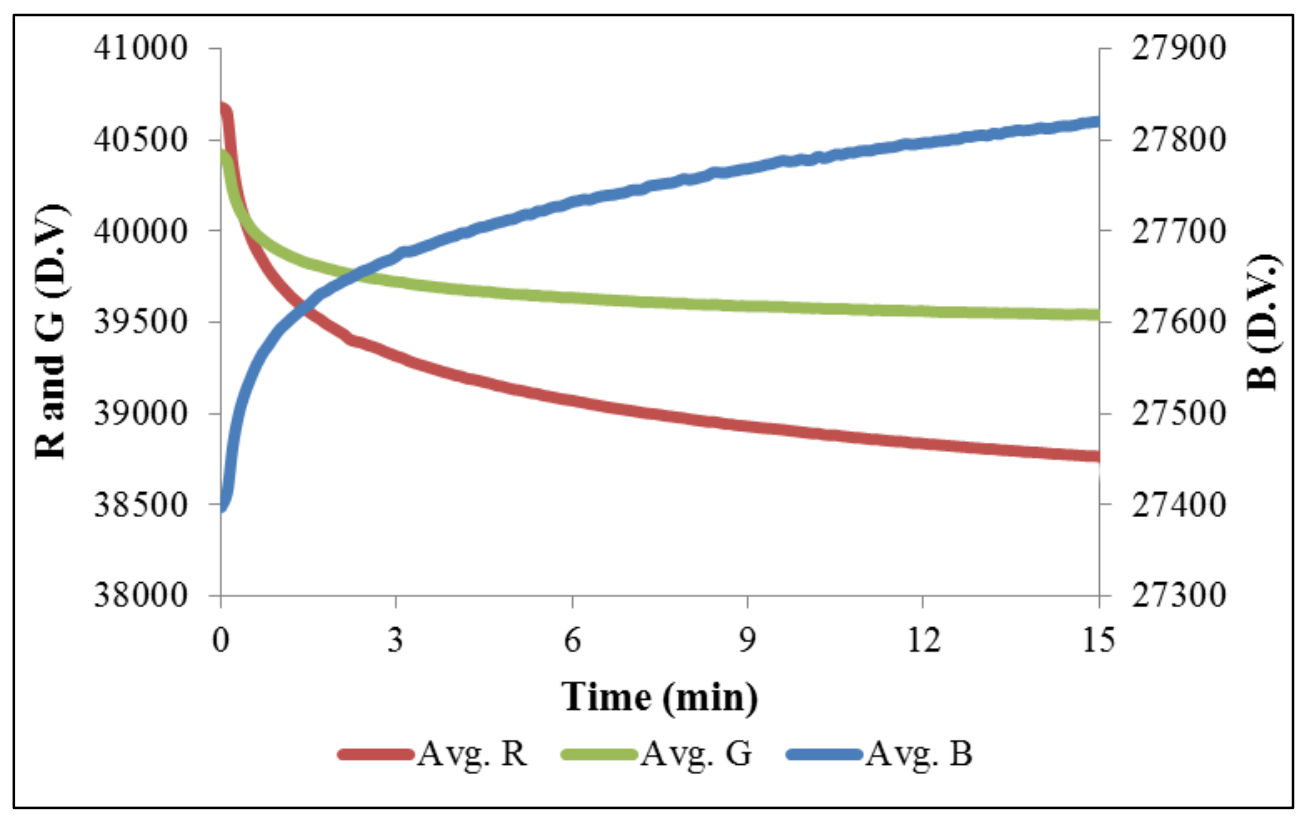

Additionally, 1.0, 3.0, and $10.0 \mathrm{ppm} \mathrm{HCN}$ were exposed to the Cbi paper at $25 \% \mathrm{RH} . \Delta \mathrm{C}$ values were computed every 6 seconds based on the initial RGB values for $\mathrm{CN}\left(\mathrm{H}_{2} \mathrm{O}\right) \mathrm{Cbi}$ on paper calculated by Equation 5.1. The $\Delta \mathrm{C}$ is observed to increase as a function of $\mathrm{HCN}$ concentration and slowly began to plateau over 15 minutes. The average $\Delta \mathrm{C}$ for each $\mathrm{HCN}$ concentration can be observed in Figure 5.8a $(\mathrm{n}=3)$. All concentrations at $25 \% \mathrm{RH}$ had similar response curves but at different $\Delta \mathrm{C}$ values. Exposure to $1.0 \mathrm{ppm} \mathrm{HCN}$ resulted in a slower linear response for the first $\sim 3$ minutes whereas $10.0 \mathrm{ppm}$ has a more rapid initial response. The RGB color sensor rapidly responded to 3.0 and $5.0 \mathrm{ppm} \mathrm{HCN}$. The average initial $\Delta \mathrm{C}$ values can be observed in Figure $5.8 \mathrm{~b}(\mathrm{n}=3)$. The $25 \% \mathrm{RH}$ blank is the average drift response of a Cbi paper exposed to $0.0 \mathrm{ppm} \mathrm{HCN}$ air at $25 \% \mathrm{RH}$ after 15 minutes of equilibration (final $\Delta \mathrm{C}=117.3 \pm$ 66.6, $\mathrm{n}=3$ ). Data for each concentration at $25 \% \mathrm{RH}$ can be seen in Table D.2. 
Figure 5.8 - RGB color sensor total change in color during HCN exposure at $25 \% \mathrm{RH}(\mathrm{A})$, expanded view of initial response (B)
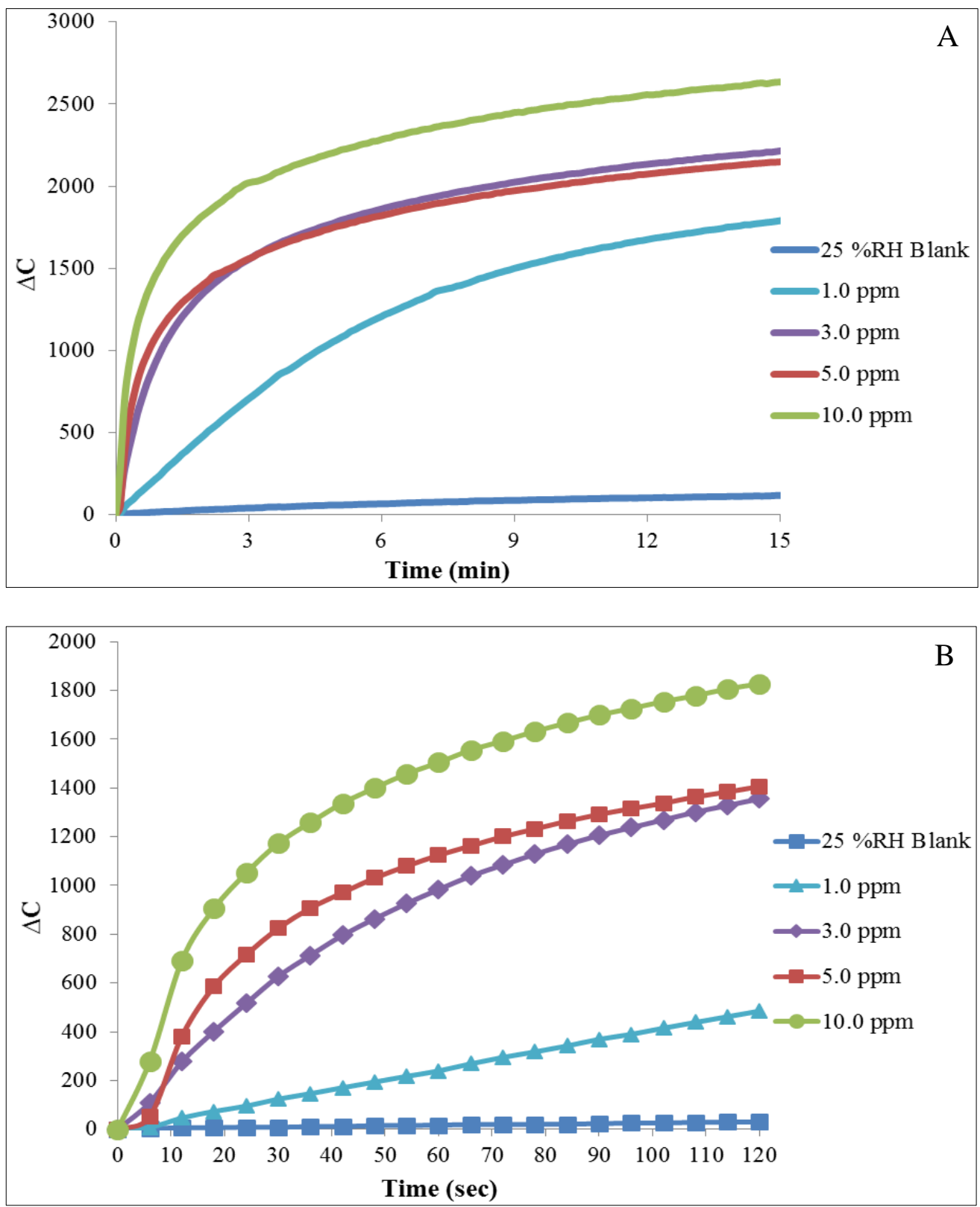

\subsubsection{2 $50 \% \mathrm{RH}$}

When the Cbi paper is exposed to $50 \% \mathrm{RH}$, the change in $\mathrm{R}, \mathrm{G}$, and B photodiode signals increase relative to the initial $\mathrm{CN}\left(\mathrm{H}_{2} \mathrm{O}\right) \mathrm{Cbi}$ on filter paper with larger $\Delta \mathrm{C}$ values than exposure to $25 \% \mathrm{RH}$. The average R, G, and B values for the response of Cbi paper exposed to $5.0 \mathrm{ppm}$ 
$\mathrm{HCN}$ at $50 \% \mathrm{RH}$ is shown in Figure D.2, where the total change in color after 15 minutes for the R, G, and B photodiodes are $3100 \pm 500,1700 \pm 500$, and $790 \pm 70$, respectively. The average computed total $\Delta \mathrm{C}$ for each $\mathrm{HCN}$ concentration can be seen in Figure $5.9(\mathrm{n}=3)$.

Figure 5.9 - RGB color sensor total change in color during $\mathrm{HCN}$ exposure at $50 \% \mathrm{RH}$

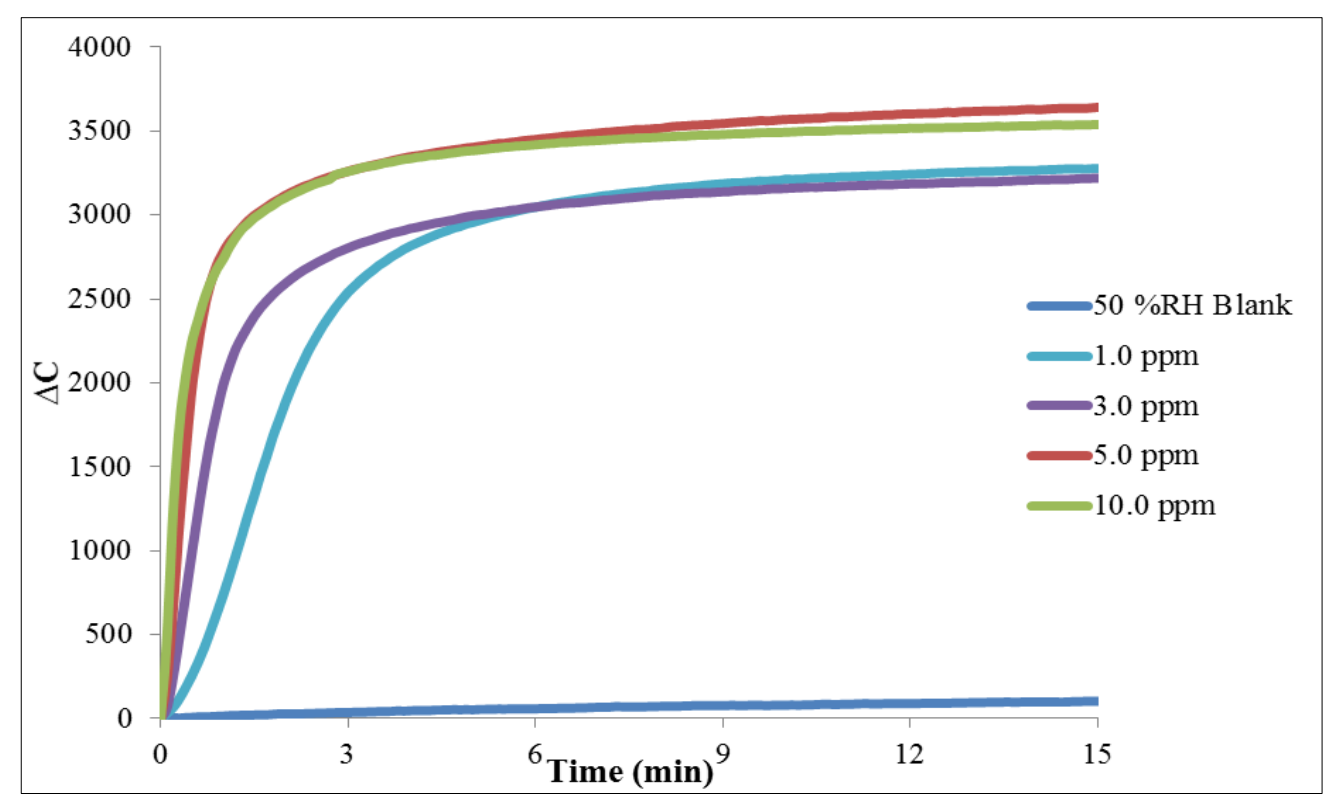

Exposure to $1.0 \mathrm{ppm}$ and $3.0 \mathrm{ppm} \mathrm{HCN}$ results in a plateau with $\mathrm{a} \sim \Delta \mathrm{C}=3200$, where the response to 5.0 and $10.0 \mathrm{ppm} \mathrm{HCN}$ plateaus around $\sim \Delta \mathrm{C}=3500$. The $\mathrm{RGB}$ color sensor rapidly responds to all four concentrations $\mathrm{HCN}$; the average initial responses can be observed in Figure D.3 $(\mathrm{n}=3)$. The $50 \% \mathrm{RH}$ blank is the average drift response of a Cbi paper exposed to $0.0 \mathrm{ppm}$ $\mathrm{HCN}$ air at $50 \% \mathrm{RH}$ after the paper had equilibrated for 15 minutes in the flowing stream. Data for each concentration at $50 \% \mathrm{RH}$ can be seen in Table D.3.

\subsubsection{85\% RH}

The average R, G, and B values for the response of Cbi paper exposed to $5.0 \mathrm{ppm} \mathrm{HCN}$ at $85 \% \mathrm{RH}$ is shown in Figure 5.10. The color-filtered photodiodes respond rapidly for all three 
colors, with the signal reaching steady-state within 2 minutes of HCN exposure. The plateau for the remainder of the experiment is stable. The total change in color after 15 minutes for the R, G, and B photodiodes are $3600 \pm 300,1500 \pm 100$, and $900 \pm 90$, respectively $(n=3)$.

Figure 5.10 - Response of the separate R, G, and B values upon 5.0 ppm HCN exposure at 85 $\% \mathrm{RH}$

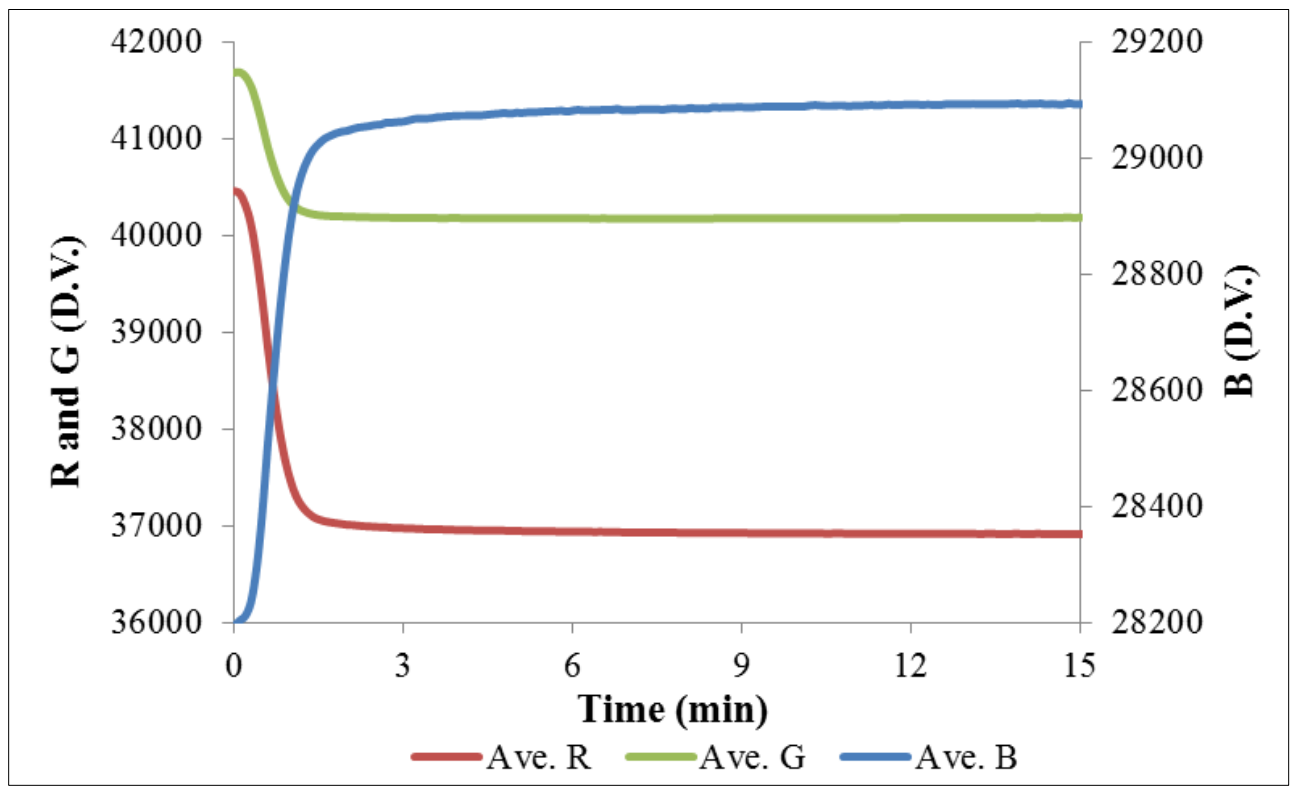

The average computed total $\Delta \mathrm{C}$ for each $\mathrm{HCN}$ concentration at $85 \% \mathrm{RH}$ can be observed in Figure $5.11(\mathrm{n}=3)$, with the data in Table D.4. Each concentration results in a plateau of similar $\Delta \mathrm{C}$ (3700-4200). 1.0 ppm $\mathrm{HCN}$ has a noticeable slower response compared to 3.0, 5.0, and 10.0 ppm HCN. 
Figure 5.11 - RGB color sensor total change in color during HCN exposure at $85 \% \mathrm{RH}(\mathrm{A})$, expanded view of initial response (B)
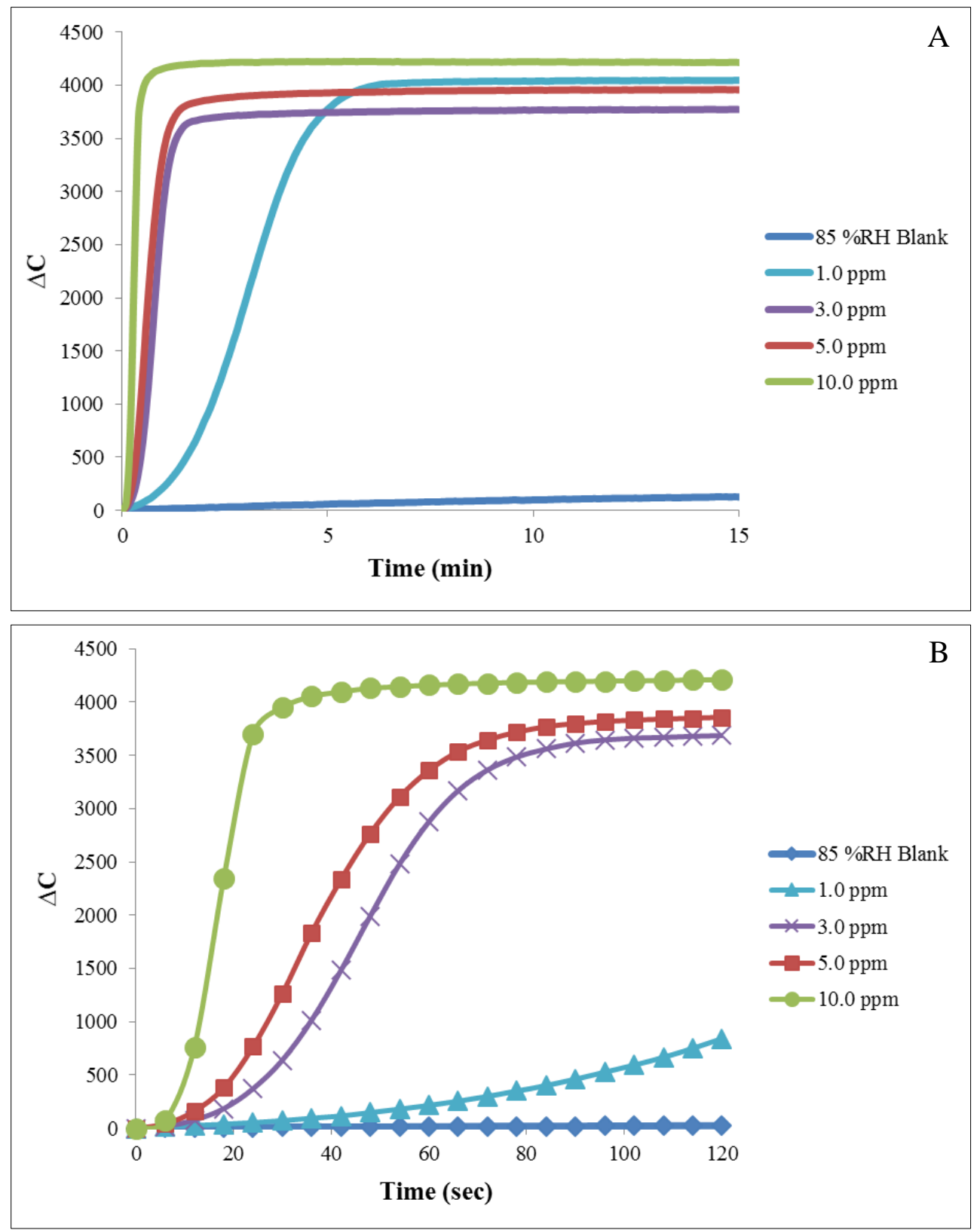

\subsubsection{Comparison of HCN Concentrations as a Function of \% RH}

The effect of $\% \mathrm{RH}$ on Cbi response to $\mathrm{HCN}$ was earlier studied using the bifurcated fiber optic setup in Chapter 2. Using the RGB color sensor, similar trends are found - i.e. the response $(\Delta \mathrm{C})$ increases with increasing $\% \mathrm{RH}$, resulting in a more sensitive and rapid response to all 
concentrations of $\mathrm{HCN}$. The response of $\mathrm{Cbi}$ on paper to $5.0 \mathrm{ppm} \mathrm{HCN}$ at 25,50 , and $85 \% \mathrm{RH}$ can be seen in Figure 5.12. For this experiment, the $\mathrm{HCN}$ is removed from the gas stream at $\mathrm{t}=$ 15 and 45 minutes and again added at 30 minutes. A decrease in $\Delta \mathrm{C}$ is observed at these intervals, which can be attributed to a slow, reversible removal of $\mathrm{CN}^{-}$from the $(\mathrm{CN})_{2} \mathrm{Cbi}$ compound and a resultant color closer to that of the reference (i.e. $\mathrm{CN}\left(\mathrm{H}_{2} \mathrm{O}\right) \mathrm{Cbi}$ on paper). $\Delta \mathrm{C}$ of 1.0, 3.0, and $10.0 \mathrm{ppm} \mathrm{HCN}$ as a function of \% RH can be seen in Figures D.5, D.7, and D.9, respectively. An expanded version of the initial $\Delta \mathrm{C}$ response to these concentrations can be seen in Figures D.6, D.8, and D.10, respectively.

Figure 5.12 - Average total change in color during $5.0 \mathrm{ppm} \mathrm{HCN}$ exposure at various \% RH; $\mathrm{HCN}$ was cycled on and off, $n=3$ (A), expanded view of initial response (B)

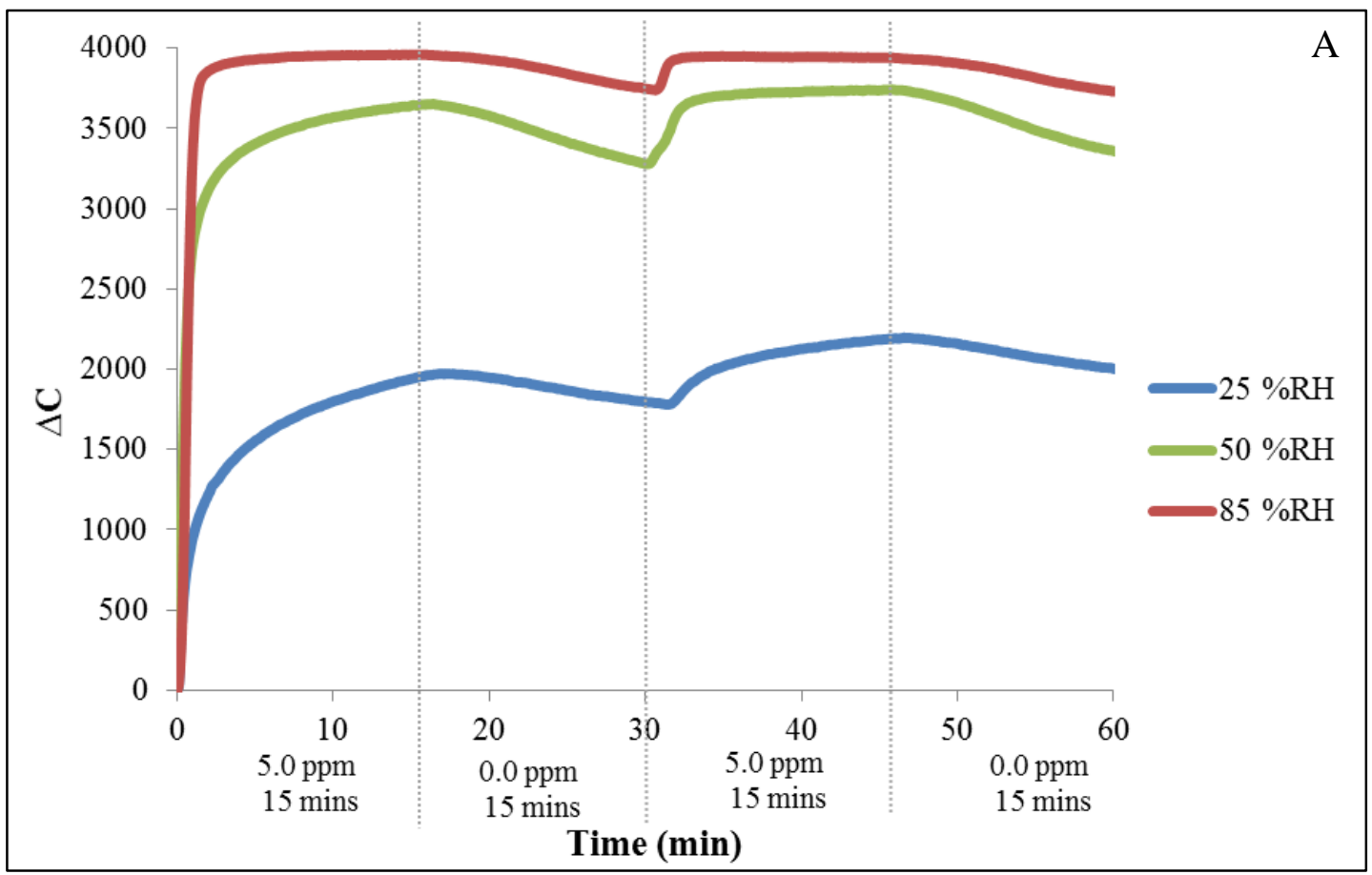




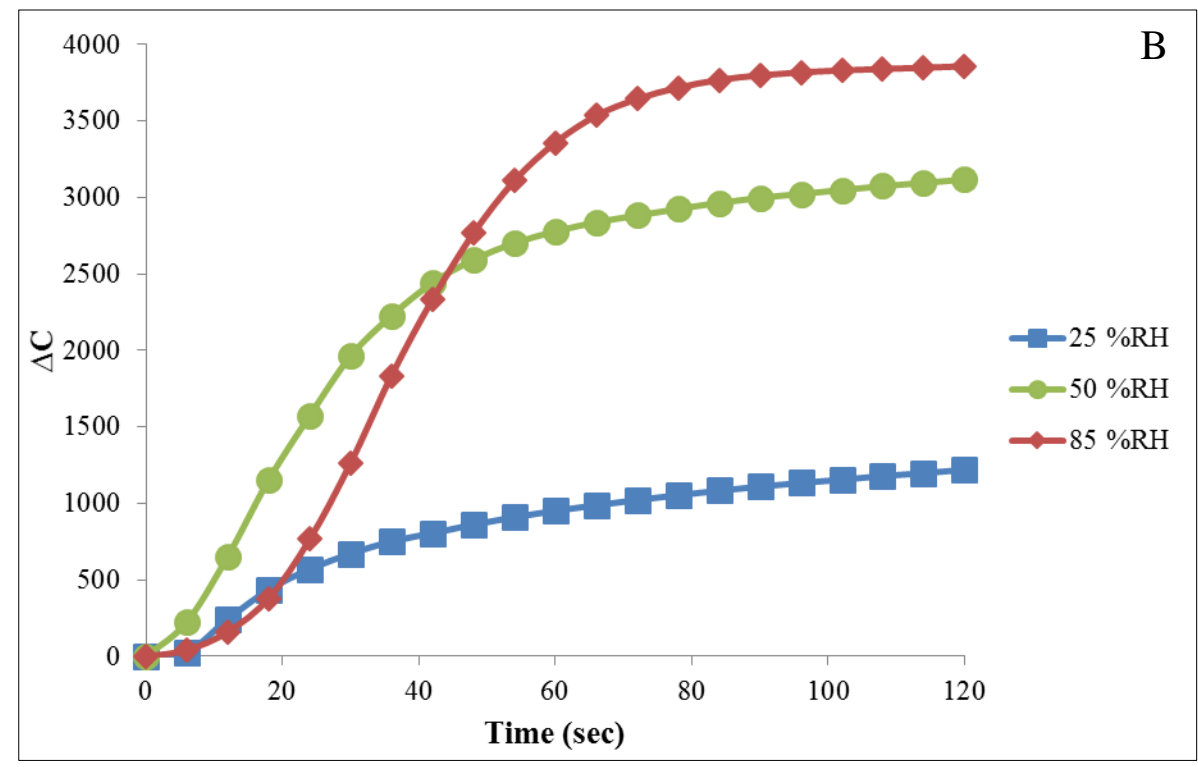

A distinct difference in the $\Delta \mathrm{C}$ is observed for the same $\mathrm{HCN}$ concentration under various \% $\mathrm{RH}$ levels. As discussed in Chapter 2, the increased signal may be attributed to water vapor adsorbed to the filter paper, allowing a more solution-like environment for the complexation reaction to take place.

In summary, higher $\Delta \mathrm{C}$ values are calculated by the RGB color sensor as a function of increasing both $\mathrm{HCN}$ concentration and/or \% RH. Table 5.3 summarizes these results for 1.0, 3.0, 5.0, and $10.0 \mathrm{ppm} \mathrm{HCN}$ for 1 and 15 minute $\mathrm{HCN}$ exposure at each \%RH level. Steady-state conditions are reached rapidly at higher $\% \mathrm{RH}$, and thus the difference in $\Delta \mathrm{C}$ values between 1 and 15 minute exposure times at higher $\mathrm{HCN}$ concentrations is reduced. $1.0 \mathrm{ppm} \mathrm{HCN}$ shows a different response trend (as seen in Table 5.3) where the $\Delta \mathrm{C}$ at 1 minutes decreases at $85 \% \mathrm{RH}$ exposure compared to 25 or $50 \% \mathrm{RH}$. This may be due to the photodiodes' response at higher $\%$ RH where the R, G, and B values increase, increase, and decrease, respectively (with regard to $\mathrm{CN}\left(\mathrm{H}_{2} \mathrm{O}\right) \mathrm{Cbi}$ on paper, no $\left.\mathrm{HCN}\right)$. This response is opposite of the photodiodes' response upon $\mathrm{HCN}$ exposure (i.e. decrease, decrease, and increase, respectively). Thus, at lower HCN concentrations/exposure times, the photodiode response may be affected. 
Table 5.3 - Comparison of HCN concentrations as a function of $\% \mathrm{RH}$

\begin{tabular}{|c|c|c|c|c|c|c|c|}
\hline & $\begin{array}{l}\text { Time } \\
(\min )\end{array}$ & $\begin{array}{c}\text { Average } \\
\Delta \mathrm{C} \mathrm{25 \%} \\
\mathrm{RH}(\mathbf{n}=\mathbf{3}) \\
\end{array}$ & $95 \%$ CI & $\begin{array}{c}\text { Average } \\
\Delta \text { C 50\% } \\
\text { RH }(\mathbf{n}=3) \\
\end{array}$ & 95\% CI & $\begin{array}{l}\text { Average } \\
\Delta \mathrm{C} \mathrm{85 \%} \\
\mathrm{RH}(\mathbf{n}=\mathbf{3}) \\
\end{array}$ & $95 \%$ CI \\
\hline \multicolumn{8}{|l|}{ Blank } \\
\hline & 1 & 17.2 & 28.03 & 15.7 & 29.8 & 14.2 & 11.9 \\
\hline & 15 & 117.3 & 165.5 & 103.1 & 122.4 & 127.0 & 51.9 \\
\hline \multicolumn{8}{|l|}{$\begin{array}{c}1.0 \\
\text { ppm }\end{array}$} \\
\hline & 1 & 239.7 & 138.0 & 733.6 & 746.8 & 215.2 & 165.7 \\
\hline & 15 & 1790.1 & 335.6 & 3277.6 & 45.4 & 4047.6 & 613.9 \\
\hline \multicolumn{8}{|l|}{$\begin{array}{c}\mathbf{3 . 0} \\
\text { ppm }\end{array}$} \\
\hline & 1 & 983.6 & 249.1 & 1983.9 & 162.4 & 2876.5 & 128.8 \\
\hline & 15 & 2214.4 & 299.1 & 3218.5 & 20.4 & 3772.5 & 247.1 \\
\hline \multicolumn{8}{|l|}{$\begin{array}{c}5.0 \\
\text { ppm }\end{array}$} \\
\hline & 1 & 1124.4 & 455.3 & 2778.0 & 1784.2 & 3358.0 & 563.9 \\
\hline & 15 & 2148.2 & 418.2 & 3645.4 & 1687.9 & 3957.6 & 921.5 \\
\hline \multicolumn{8}{|l|}{$\begin{array}{l}10.0 \\
\text { ppm }\end{array}$} \\
\hline & 1 & 1437.1 & 236.6 & 2737.6 & 242.4 & 4158.0 & 123.5 \\
\hline & 15 & 2519.4 & 402.8 & 3539.7 & 552.3 & 4214.5 & 68.5 \\
\hline
\end{tabular}

\subsubsection{Preliminary Findings for HCN Breakthrough}

Preliminary data was presented in Chapter 4.4.1 for the breakthrough and real-time detection of $\mathrm{HCN}$ from respirator canisters using $\mathrm{CN}\left(\mathrm{H}_{2} \mathrm{O}\right) \mathrm{Cbi}$-impregnated paper. Using the diffuse reflectance setup (bifurcated optical fiber coupled to the miniature spectrometer and light source) described in Chapter 2, initial findings indicated that low concentrations of HCN could be detected by Cbi upon imminent breakthrough of the canisters that correlated well the commercial electrochemical detector. The RGB color sensor was also simultaneously placed downstream of the CBRN canister alongside the bifurcated fiber optic sensor and electrochemical detector. Effluent air was pulled over the RGB sensor at $0.75 \mathrm{LPM}( \pm 5 \%)$ by a 
sampling pump. The resulting $\Delta \mathrm{C}$ from the RGB color sensor (secondary-axis) compared with the diffuse reflectance fiber optic configuration (primary-axis) is shown in Figure 5.13. The $F(R)$ at $583 \mathrm{~nm}$ for the fiber optic sensor is plotted as a 6-order polynomial.

Figure 5.13 - RGB color sensor response to $\mathrm{HCN}$ breakthrough from a respirator canister compared with the Cbi fiber optic sensor configuration

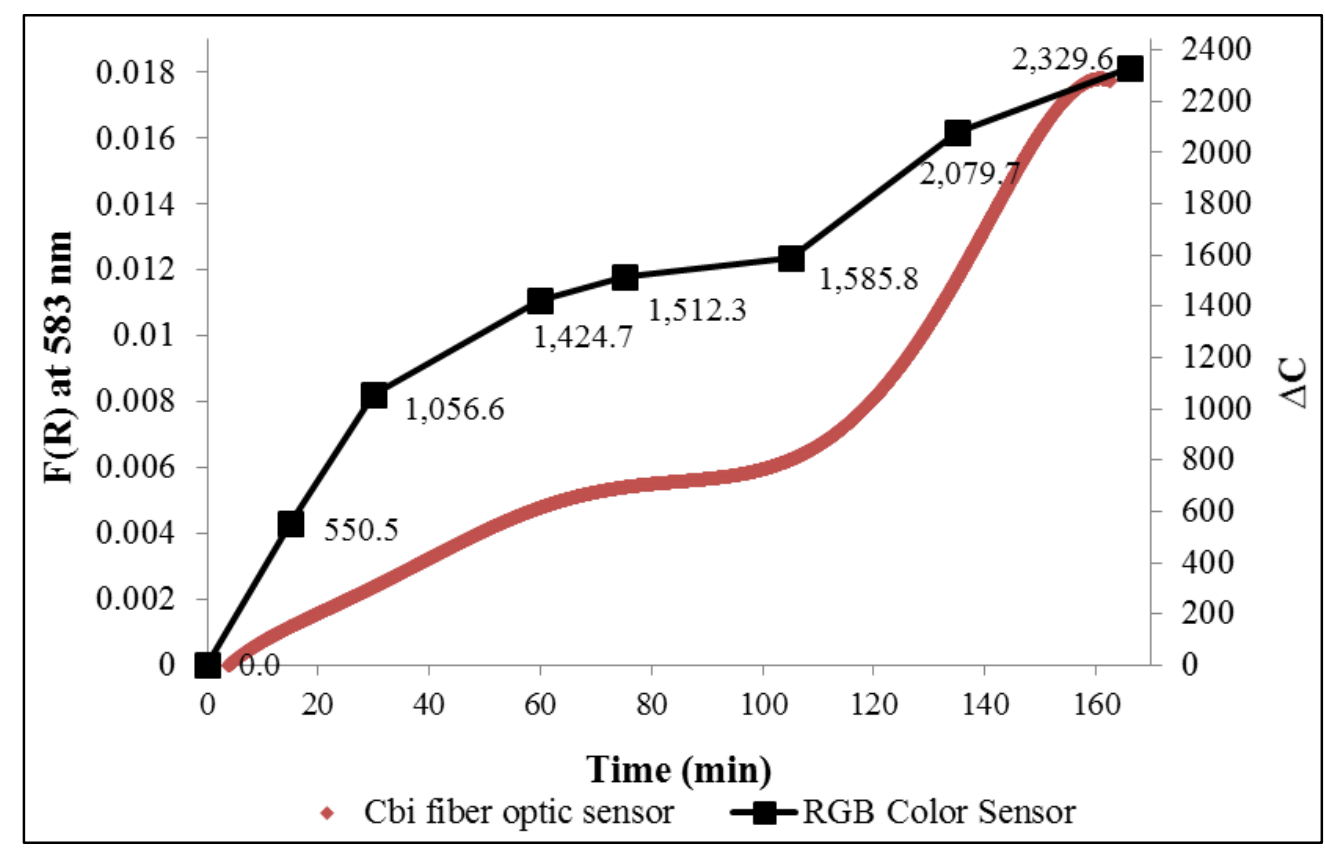

The response for both sensors correlate well upon breakthrough of HCN. At 115 minutes, the electrochemical detector (shown in Figure 4.7) indicates the start of breakthrough, where a change in slope is observed at this time for both Cbi sensors. Similar to previously described breakthrough experiments, the RGB color sensor responds to low concentrations of HCN permeating through the canister prior to breakthrough. The cumulative response would cause a premature warning signal to a respirator user, thus more experiments are required to either lower the sensitivity or include an increased threshold. However, unrealistically high concentrations of 
HCN were exposed to canisters during these breakthrough experiments, so a minimized presence of HCN prior to breakthrough would be expected.

\subsection{Conclusion}

The RGB color sensor is a promising low-power and inexpensive sensor to incorporate into respirator carbon beds. The RGB photodiodes demonstrated, in real-time, a rapid change in the red, green, and blue values of the $\mathrm{CN}\left(\mathrm{H}_{2} \mathrm{O}\right) \mathrm{Cbi}$ compound on filter paper upon exposure to $\mathrm{HCN}$ at various concentrations and \% RH. Total change in color from initial $\mathrm{CN}\left(\mathrm{H}_{2} \mathrm{O}\right) \mathrm{Cbi}$ on filter paper was calculated and yielded values that increased as a function of HCN concentration and $\% \mathrm{RH}$, where faster reaction kinetics may be attributed at higher \% RH. Using the total change in color values before and after exposure for each individual paper decreases the variability between paper sensors. The RGB color sensor also shows potential to detect low concentrations $(\mathrm{ppb})$ of $\mathrm{HCN}$ through a respirator canister that correlated well with both the fiber optic diffuse reflectance configuration and an $\mathrm{HCN}$-specific electrochemical detector. The color sensor offers an economical and quantitative approach to determining color-change of an end-ofservice-life indicator. 


\section{Chapter 6: Research Summary, Implications, and Future Work 6.1 Summary of Research}

Respirator users must be supplemented with an accurate method to determine end-ofservice-life of their canister or cartridge. Knowledge of end-of-service-life and imminent breakthrough informs the user to replace the spent carbon bed with a new one. Because commercially available end-of-service-life indicators are limited, software-based change-out schedules are typically used. However, accurate determination of service-life relies on the user's knowledge of the contaminant concentration, breathing rate, and environmental parameters to input these values into the software. ESLIs that are currently available are based on a usersubjective color change, which is disadvantageous when working in poorly-lit conditions, or when the user is color-blind. Additionally, the user must continuously monitor the side of the carbon bed to determine when to replace his/her cartridge.

To progress the availability of ESLIs, NIOSH has allocated funding directly towards the development of these sensors with the optimism that manufacturers would further mature the technology and bring novel ESLIs to the market. It is advantageous to start with a niche market - i.e. a smaller respirator or gas-specific market that the ESLI technology could be introduced to. Thus, a small and cost-effective ESLI was developed to show proof-of-concept that an optical diffuse reflectance-based sensor could detect hydrogen cyanide and hydrogen sulfide gases.

Cobinamide, a Vitamin $\mathrm{B}_{12}$ derivative, was immobilized on cellulose and glass fiber filter paper and used for detection of both $\mathrm{HCN}$ and $\mathrm{H}_{2} \mathrm{~S}$ gas: 
HCN

$\mathrm{CN}\left(\mathrm{H}_{2} \mathrm{O}\right)$ Cbi was able to rapidly detect $\mathrm{HCN}$ at various concentrations (1.0-10.0 ppm $\mathrm{HCN})$ and relative humidity $(25,50$, and $85 \% \mathrm{RH})$. The rapid binding of the second $\mathrm{CN}^{-}$causes a visible violet color to persist with a characteristic wavelength at $583 \mathrm{~nm}$. Response time was within 10 seconds, with increasing sensitivity at increased humidity. $\mathrm{CN}\left(\mathrm{H}_{2} \mathrm{O}\right)$ Cbi also showed promise towards the detection of imminent breakthrough at low $\mathrm{HCN}$ concentrations (ppm) from a CBRN canister. The compound also has potential to detect another toxic gas, cyanogen. Finally, an RGB color sensor was able to demonstrate, in real-time, a rapid change in the red, green, and blue values of the $\mathrm{CN}\left(\mathrm{H}_{2} \mathrm{O}\right) \mathrm{Cbi}$ compound on filter paper. Total change in color was calculated from these values, which rapidly increased upon exposure to $\mathrm{HCN}$ at various concentrations and \% RH.

\section{$\mathrm{H}_{2} \mathrm{~S}$}

$\mathrm{OH}\left(\mathrm{H}_{2} \mathrm{O}\right) \mathrm{Cbi}$ was immobilized on filter paper and was able to successfully detect NIOSH's recommended exposure limit to hydrogen sulfide (i.e. $10.0 \mathrm{ppm}_{2} \mathrm{~S}$ ) with similar spectral shifts as reported in literature. Additionally, $\mathrm{OH}\left(\mathrm{H}_{2} \mathrm{O}\right) \mathrm{Cbi}$ was also able to detect low concentrations ( $\mathrm{ppb}$ ) of $\mathrm{H}_{2} \mathrm{~S}$ upon imminent breakthrough from $\mathrm{H}_{2} \mathrm{~S}$-specific cartridges, which correlated well with a previously established electrochemical method. The reaction between gasphase $\mathrm{H}_{2} \mathrm{~S}$ and Cbi showed similar spectral shifts to those observed when sodium sulfide and ascorbic acid were in solution (separately) with Cbi (e.g., decrease at 400-450 nm, increase at $470-550 \mathrm{~nm}$ ). Thus binding (of sulfide) and/or reduction of the $\mathrm{Co}^{3+}$ metal center of Cbi on glass fiber filter paper was apparent in the gas-phase. 


\subsection{Research Implications and Future Work}

The experimental results serve as a pilot study for inexpensive, optical detection of two inorganic gases. The developed diffuse reflectance configuration involves a light source, miniature spectrometer, and bifurcated fiber optic. This configuration was chosen to reduce the footprint of a conventional absorbance setup (i.e. transmission through the sample), but is still too large and not yet realistic to be incorporated into the carbon bed of a cartridge/canister. Both types of sensors - the fiber optic configuration and RGB color sensor-require additional miniaturization. The availability of small photodetectors and micro-optical elements (e.g., lenses and gratings), inexpensive miniature optical fibers, and battery-powered LED light sources suggest that a simple diffuse reflectance configuration could satisfy the size, cost, and power requirements of ESLIs. Defining a narrow range of wavelengths may be done to use a miniature spectrometer. Regardless, the application of the Kubelka-Munk function and interpretation of reflectance data shows promise that cobinamide UV-VIS spectral shifts can not only be used in solution measurements, but also used for semi-quantitative rapid gas detection and identification.

Additionally, the RGB color sensor offers an alternative approach for monitoring color change. This approach is more accurate than relying on a respirator user's subjective color identification. This color sensor is cost-effective and could easily be further miniaturized. The $\Delta \mathrm{C}$ data could be used to inform the user to replace the cartridge/canister, and could also be configured with Bluetooth technology to alert the user or employer remotely. It is with anticipation that respirator manufacturers continually review emerging technology to further mature ESLI technology, such as the proposed reflectance color sensor research.

The presented experimental approach provides a template for further exploration into the development of ESLIs. The diffuse reflectance configuration is easily adaptable and could be 
used for a variety of sensor media immobilized with other colorimetric indicators for different gases. Here, the paper was not pre-treated/modified prior to immobilizing the chromophore, however imprinting a hydrophobic material (e.g., wax) can be done to assist in keeping the pipetted volume of solution in one area and immobilize color development, increasing sensitivity. Additionally, more extensive studies should be performed to determine photodegradation of the Cbi compound from the LED or other light source used with an optical sensor. Like other ESLI technologies, the effect of humidity needs further exploration. However results here for paper media show an increase in sensitivity during the cobinamide reaction with $\mathrm{HCN}$ and $\mathrm{H}_{2} \mathrm{~S}$. Reaction products of $\mathrm{Cbi}+\mathrm{H}_{2} \mathrm{~S}$ should be characterized through proper analytical instrumentation (e.g., mass spectrometry, benchtop UV-VIS, etc.). Additional gases may be further studied by Cbi detection such as ammonia and nitric oxide.

Other technologies of gas sensors can also be studied for their ability to be incorporated into a respirator carbon bed. For example, electrochemical sensors are small, simple, and inexpensive and show promise for use as an active ESLI. For optical sensors (studied here) and other potential ESLI technology, the robustness and effects of aging need careful consideration. The sensors may be dormant for long periods of time, and must work flawlessly upon respirator use.

In summary, it is critical for ESLI sensor research to continue so the technology matures and more sensors are available on the market. Unfortunately, the research-to-practice capabilities for ESLIs are dependent on monetary and marketability influences. Additionally, respirator manufacturers undertake multi-million dollar projects on the development of market-driven ESLIs, but will only allocate funds towards development if they determine it is cost-effective. Therefore, from a government agency's standpoint (i.e. NIOSH) with incomparable allocated 
funds towards this specific development, the respirator manufacturers may be the primary research entity for ESLIs. However, the publicity of exploring different gas-sensing technologies can establish collaborative efforts toward more commercially available end-of-service-life indicators. 


\section{References}

1. OSHA Regulations (Standards-29 CFR).

https://www.osha.gov/pls/oshaweb/owadisp.show_document?p_id=12716\&p_table=STA NDARDS (accessed 08/10/2015).

2. Bollinger, N. J.; Schutz, R. H., NIOSH Guide to Industrial Respiratory Protection. Cincinnati, OH, 1987; p 225.

3. NIOSH. NIOSH Interim Guidance on the Use of Chemical, Biological, Radiological and Nuclear (CBRN) Full Facepiece, Air-Puriying Respirators/Gas Masks Certified Under 42 CFR Part 84. http://www.cdc.gov/niosh/npptl/guidancedocs/interapr070805.html (accessed 09/23/2015).

4. $\quad 3 \mathrm{M}$ Cartridge Change Frequently Asked Questions (FAQs). http://multimedia.3m.com/mws/media/2598200/3m-cartridge-change.pdf (accessed 09/24/2015).

5. Richardt, A.; Dawert, T., CBRN Protection. Wiley-VCH Verlag GmbH \& Co. KGaA: Germany, 2013.

6. Nelson, T. J.; Janssen, L. L. Developing Cartridge Change Schedules: What are the Options? 3M Job Health Highlights [Online], 1999.

http://multimedia.3m.com/mws/media/2241810/developing-cartridge-change-schedulesoptions-1999.pdf (accessed 10/12/2015).

7. Cothran, T. Service Life Software for Organic Vapor Cartridges. 2001.

http://multimedia.3m.com/mws/media/277008O/service-life-software-for-organic-vaporcartridges.pdf (accessed 10/12/2015).

8. MSA. MSA Response Guide. http://webapps.msanet.com/responseguide/ (accessed 10/7/2015).

9. 3M Changeout Program.

http://solutions.3m.com/wps/portal/3M/en_US/Cartridge_Changeout_Program/CCOP/ (accessed 06/02/2013).

10. Honeywell Honeywell Safety Products. http://www.honeywellsafety.com/USA/Brands/North.aspx (accessed 10/7/2015).

11. Wheeler, A.; Robell, A. J., Performance of Fixed-Bed Catalytic Reactors with Poison in the Feed. Journal of Catalysis. 1969, 13, 299-305.

12. Nelson, G. O.; Harder, C. A., Respirator Cartridge Efficiency Studies IV. Effects of Steady-State and Pulsating Flow. American Industrial Hygiene Association Journal. 1972, 33 (12), 797-805.

13. Nelson, G. O.; Harder, C. A., Respirator Cartridge Efficiency Studies: V. Effect of Solvent Vapor. American Industrial Hygiene Association Journal. 1974, 35 (7), 391-410. 
14. Nelson, G. O.; Correia, A. N., Respirator Cartridge Efficiency Studies: VIII. Summary and Conclusions. American Industrial Hygiene Association Journal. 1976, 37 (9), 514 525.

15. Jonas, L. A.; Rehrmann, J. A., Predictive Equations in Gas Adsorption Kinetics. Carbon. 1973, 11, 59-64.

16. Jonas, L. A., Reaction Steps in Gas Sorption by Impregnated Carbon. Carbon. 1978, 16 (2), 115-119.

17. Jonas, L. A.; Rehrmann, J. A., The Rate of Gas Adsorption by Activated Carbon. Carbon. 1973, 12, 95-101.

18. Yoon, Y. H.; Nelson, J. H., Application of Gas Adsorption Kinetics I. A Theoretical Model for Respirator Cartridge Service Life. American Industrial Hygiene Association Journal. 1984, 45 (8), 509-516.

19. Yoon, Y. H.; Nelson, J. H., Application of Gas Adsorption Kinetics - II. A Theoretical Model for Respirator Cartridge Service Life and its Practical Applications. American Industrial Hygiene Association Journal. 1984, 45 (8), 517-524.

20. Yoon, Y. H.; Nelson, J. H., A Theoretical Study of the Effect of Humidity on Respirator Cartridge Service Life. American Industrial Hygiene Association Journal. 1988, 49 (7), $325-332$.

21. Yoon, Y. H.; Nelson, J. H., Breakthrough Time and Adsorption Capacity of Respirator Cartridges. American Industrial Hygiene Association Journal. 1992, 53 (5), 303-316.

22. Yoon, Y. H.; Nelson, J. H.; Lara, J., Respirator Cartridge Service-Life: Exposure to Mixtures. American Industrial Hygiene Association Journal. 1996, 57 (9), 809-819.

23. Wood, G. O., A Model for Adsorption Capacities of Charcoal Beds I. Relative Humidity Effects. American Industrial Hygiene Association Journal. 1987, 48 (7), 622-625.

24. Wood, G. O., A Model for Adsorption Capacticies of Charcoal Beds: II. Challenge Concentration Effects. American Industrial Hygiene Association Journal. 1987, 48 (8), 703-709.

25. Wood, G. O.; Moyer, E. S., A Review of the Wheeler Equation and Comparison of Its Applications to Organic Vapor Respirator Cartridge Breakthrough Data. American Industrial Hygiene Association Journal. 1989, 50 (8), 400-407.

26. (a) Wood, G. O.; Ackley, M. W., A Testing Protocol for Organic Vapor Respirator Canisters and Cartridges. American Industrial Hygiene Association Journal. 1989, 50 (12), 651-654; (b) Wood, G. O.; Moyer, E. S., A Review and Comparison of Adsorption Isotherm Equations Used to Correlate and Predict Organic Vapor Cartridge Capacities. American Industrial Hygiene Association Journal. 1991, 52 (6), 235-242.

27. Wood, G. O., Affinity Coefficients of the Polanyi/Dubinin Adsorption Isotherm Equations. A Review with Compilations and Correlations. Carbon. 2001, 39, 343-356. 
28. Wood, G. O., A Review of the Effects of Covapors on Adsorption Rate Coefficients of Organic Vapors Adsorbed onto Activated Carbon from Flowing Gases. Carbon. 2002, $40,685-694$.

29. Wood, G. O., Quantification and Application of Skew of Breakthrough Curves for Gases and Vapors Eluting from Activated Carbon Beds. Carbon. 2002, 40, 1883-1890.

30. Wood, G. O.; Lodewyckx, P., An Extended Equation for Rate Coefficients for Adsorption of Organic Vapors and Gases on Activated Carbons in Air-Purifying Respirator Cartridges. American Industrial Hygiene Association Journal. 2003, 64, 646650.

31. Lodewyckx, P.; Wood, G. O.; Ryu, S. K., The Wheeler-Jonas Equation: A Versatile Tool for the Prediction of Carbon Bed Breakthrough Times. Carbon. 2004, 42, 1351-1355.

32. Wood, G. O., Estimating Service Lives of Respirator Cartridges for Reactive Removal of Gases. In AIHA., 2004.

33. Wood, G. O.; Snyder, J. L., Estimating Service Lives of Organic Vapor Cartridges III: Multiple Vapors at All Humidities. American Industrial Hygiene Association Journal. 2007, 4 (5), 363-374.

34. Wood, G. O., Estimating Service Lives of Organic Vapor Cartridges II: A Single Vapor at All Humidities. Journal of Occupational and Environmental Hygiene. 2004, 1 (7), $472-492$.

35. Wood, G. O.; Snyder, J. L., Estimating Reusability of Organic Air-Purifying Respirator Cartridges. Journal of Occupational and Environmental Hygiene. 2011, 8, 609-617.

36. OSHA. Respirator Change Schedules. https://www.osha.gov/SLTC/etools/respiratory/change_schedule_mathmodel.html.

37. NIOSH, Determination of End of Service Life Indicator (ESLI) Test, Air-Purifying Respirators Standard Testing Procedure (STP). National Personal Protective Technology Laboratory, Pittsburgh, PA., 2005; p 6.

38. Rose-Pehrsson, S.; Williams, M. L. Integration of Sensor Technologies in Respirator Vapor Cartridges as End-of-Service Life Indicators: Literature and Manufacturers Review and Research Roadmap; 2005.

39. Favas, G., End-of-Service-Life (ESLI) for Respirator Cartridges. Part I: Literature Review. Department of Defence and Technology Organisation. Human Protection \& Performance Division: Australia, 2005.

40. Max, Y., Indicating Gas-Mask Canister. Google Patents: 1925.

41. 3M. 3M Organic Vapor Service Life Indicator Cartridges 6000i Series. http://solutions.3m.com/wps/portal/3M/en_US/3M-PPE-Safety-Solutions/PersonalProtective-Equipment/safety-products/organic-vapor-service-life/ (accessed 10/27/2015). 
42. Honeywell N Series Catridges and Filters.

http://www.honeywellsafety.com/Products/Respiratory_Protection/N_Series_Cartridges_

Filters.aspx $?$ site $=/ \&$ LangType $=1033($ accessed 2/23/2015).

43. 3M. 3M Mercury Vapor or Chlorine Acid Gas Cartridge, Respiratory Protection 6009, 60/Case.

http://solutions.3m.com.my/wps/portal/3M/en_MY/PPE_SafetySolutions_APAC/Safety/ Products/PoW-Product-

Catalog/?PC_Z7_U00M8B1A00H970I56CN7OT26E7000000_nid=GSK5R4BDP4gsF3

RH7CD92NglZPTQM018P0bl (accessed 10/26/2015).

44. King, B. H.; Ruminski, A. M.; Snyder, J. L.; Sailor, M. J., Optical-Fiber-Mounted Porous Silicon Photonic Crystals for Sensing Organic Vapor Breakthrough in Activated Carbon. Advanced Materials 2007, 19, 4530-4534.

45. Ruminski, A. M.; King, B. H.; Salonen, J.; Snyder, J. L.; Sailor, M. J., Porous SiliconBased Optical Microsensors for Volatile Organic Analytes: Effect of Surface Chemistry on Stability and Specificity. . Advanced Functional Materials 2010, 20, 2874-2883.

46. Garg, N.; Mohanty, A.; Lazarus, N. S.; Schultz, L.; Rozzi, T. R.; Santhanam, S.; Weiss, L.; Snyder, J. L.; Fedder, G. K.; Jin, R., Robust Gold Nanoparticles Stabilized by Trithiol for Applicaion in Chemiresistive Sensors. Nanotechnology. 2010, 21, 405501-405507.

47. Li, B.; Zhang, R.; Sauvé, G.; Cooper, J.; Iovu, M. C.; Santhanam, S.; Schultz, L.; Snyder, J. L.; Weiss, L. E.; Kowalewski, T.; Fedder, G. K.; McCullough, R. D.; Lambeth, D. N., Nanostructure Dependence of Conductive Polymer Chemical Sensors. In IEEE Sensors, Daegu, Korea., 2006.

48. Li, B.; Zhang, R.; Sauvé, G.; Cooper, J.; Iovu, M. C.; Santhanam, S.; Schultz, L.; Snyder, J. L.; Weiss, L. E.; Kowalewski, T.; Fedder, G. K.; McCullough, R. D.; Lambeth, D. N., Volatile Organic Compound Detection Using Nanostructured Copolymers. Nano Letters. 2006, $6(8), 1598-1602$.

49. Li, B.; Santhanam, S.; Schultz, L.; Jeffries-EL, M.; Iovu, M. C.; Sauvé, G.; Cooper, J.; Zhang, R.; Revelli, J. C.; Kusne, A. G.; Snyder, J. L.; Kowalewski, T.; Weiss, L. E.; McCullough, R. D.; Fedder, G. K.; Lambeth, D. N., Inkjet Printed Chemical Sensor Array Based on Polythiophene Conductive Polymers. Sensors and Actuators B: Chemical 2007, 123, 651-660.

50. $\quad$ Lazarus, N. S.; Bedair, S. S.; Lo, C.-C.; Fedder, G. K., CMOS-MEMS Capacitive Humidity Sensor. Journal of Microelectromechanical Systems. 2010, 19 (1), 183-191.

51. Pinet, É.; Côté, J.-S. In Birefringent Porous Glass Fiber-Optic Sensor as a Low-Cost End-of-Service-Life Indicator (ESLI) for Organic Vapor Respiratory Cartridges, Optical Fiber Sensors, Cancun, 2006/10/23; Optical Society of America: Cancun, 2006; p WA3.

52. Caron, S.; Bernard, P.; Vernon, M.; Lara, J., Porous Glass Optical Fiber Sensor as an End-of-Service-Life Indicator for Respiratory Cartridges. Sensors and Actuators B: Chemical 2004, 102 (2), 198-206. 
53. Park, J.; Zhang, G.-Z.; Zellers, E. T., Personal Monitoring Instrument for the Selective Measurement of Multiple Organic Vapors. American Industrial Hygiene Association Journal. 2000, 61 (2), 192-204.

54. Maclay, G. J.; Findlay, M. W.; Stetter, J. R., A Prototype Active End-of-Service-Life Indicator for Respiratory Cartridges. Applied Occupational and Environmental Hygiene. 1991, 6 (8), 677-682.

55. Moyer, E. S.; Findlay, M. W.; Maclay, G. J.; Stetter, J. R., Preliminary Evaluation of an Active End-of-Service-Life Indicator for Organic Vapor Cartridge Respirators. American Industrial Hygiene Association Journal. 1993, 54 (8), 417-426.

56. Office of Environmental Health Hazard Chronic Toxicity Summary for Hydrogen Cyanide. http://oehha.ca.gov.

57. Agency for Toxic Substance and Disease Registry Medical Management Guidelines for Hydrogen Cyanide. http://www.atsdr.cdc.gov/MMG/MMG.asp?id=1141\&tid=249 (accessed 04/30/2015).

58. Garcia, R.; Shepherd, G., Cyanide Poisoning and its Treatment. Pharmacotherapy 2004, 10, 1358-1365.

59. CDC Hydrogen Cyanide. http://www.cdc.gov/NIOSH/ipcsneng/neng0492.html (accessed $1 / 10 / 15)$.

60. Leybell, I. Cyanide Toxicity. http://emedicine.medscape.com/article/814287overview\#aw2aab6b2b3 (accessed 04/28/2015).

61. OPCW Guidelines for Schedules of Chemicals. http://www.opcw.org/chemical-weaponsconventions/annex-on-chemicals/a-guidelines-for-schedules-of-chemicals/ (accessed 06/10/2013).

62. Shoebridge, T. Carbon Monoxide and Hydrogen Cyanide Make Todays Fires More Dangerous. http://www.firefighternation.com/article/firefighter-safety-and-health/carbonmonoxide-hydrogen-cyanide-make-today-s-fires-more-dangerous (accessed 04/28/2015).

63. Rochford, R. Hydrogen Cyanide: New Concerns for Firefighting and Medical Tactics. http://www.fireengineering.com/articles/2009/06/hydrogen-cyanide-new-concerns-forfirefighting-and-medical-tactics.html (accessed 09/10/2013).

64. Anseeuw, K.; Delvau, N.; Burillo-Putze, G.; De Laco, F.; Geldner, G.; Holmström, P.; Lambert, Y.; Sabbe, M., Cyanide Poisoning by Fire Smoke Inhalation: A European Expert Consensus. European Journal of Emergency Medicine. 2013, 20, 2-9.

65. Brenner, M. M., S.B.; Lee, J.; Kim, J.; Mukai, D.; Goodman, S.; Kreuter, K.A.; Ahdout, R.; Mohammad, O.; Sharma, V.S.; Blackledge, W.; Boss, G.R., Comparison of Cobinamide to Hyroxocobalamin in Reversing Cyanide Physiologic Effects in Rabbits using Diffuse Optical Spectroscopy Monitoring. Journal of Biomedical Optics 2010, 15 (1), 017001-1-017001-7. 
66. CDC Hydrogen Cyanide (AC): Systemic Agent.

http://www.cdc/gov/niosh/ershdb/emergencyresponsecard_29750038.html (accessed 09/10/2013).

67. CDC Documentation for Immediately Dangerous to Life or Health Concentrations. http://www.cdc.gov/niosh/idlh/intridl4.html (accessed 07/05/2013); (b) OSHA. Hydrogen Sulfide. https://www.osha.gov/SLTC/hydrogensulfide/standards.html (accessed 05/05/2015).

68. ILPI STEL. http://www.ilpi.com/msds/ref/stel.html (accessed 04/28/2015).

69. Aristatek Hydrogen Cyanide Poisoning from Inhalation of Smoke Produced in Fires. http://www.aristatek.com/newsletter/0604April/TechSpeak.pdf (accessed 04/30/2015).

70. OI Analytical Cyanide Analysis Guide. http://www.oico.com/documentlibrary/2968broc.pdf (accessed 05/13/2015).

71. Xu, Z.; Chen, X.; Kim, H. N.; Yoon, J., Sensors for the Optical Detection of Cyanide Ion. Chemical Society Reviews. 2009, 39, 127-137.

72. Porter, T. L.; Delinger, W.; Veneda, R., A Solid-State Sensor Platform for the Detection of Hydrogen Cyanide Gas. Sensors and Actuators B: Chemical 2007, 123, 313-317.

73. Randviir, E. P.; Banks, C. E., The Latest Developments in Quantifying Cyanide and Hydrogen Cyanide. Trends in Analytical Chemistry. 2015, 64, 75-85.

74. Ma, J.; Dasgupta, P., Recent Developments in Cyanide Detection: A Review. Analytica Chimica Acta 2010, 673, 117-125.

75. O'Dell, J. W., Determination of Total Cyanide by Semi-Automated Colorimetry. In Method 335.4, 1.0 ed.; Office of Research and Development, Ed. Environmental Monitoring Systems Laboratory: Cincinnatti, OH, 1993; pp 1-16.

76. Männel-Croisé, C.; Zelder, F., Side Chains of Cobalt Corrinoids Control the Sensitivity and Selectivity in the Colorimetric Detection of Cyanide. Inorganic Chemistry 2009, 48, $1272-1274$.

77. Chamjangali, M. A.; Soltanpanah, S.; Bagherian, G.; Amin, A. H., Development of a Simple and Inexpensive Optical Absorption One-Shot Sensor Membrane for Detection and Determination of Cyanide Ions in Water Samples. Journal of the Chinese Society. 2011, 58, 118-125.

78. Männel-Croisé, C.; Zelder, F., Complex Samples Cyanide Detection with Immobilized Corrinoids. Applied Materials and Interfaces. 2012, 4, 725-729.

79. Untang, M.; Shiowatana, J.; Siripinyanond, A., A Simple Cyanide Test Kit for Water and Fruit Juices. Analytical Methods 2010, 2, 1698-1701.

80. NIOSH Manual of Analytical Methods Hydrogen Cyanide: Method 6010. http://www.cdc.gov/niosh/docs/2003-154/pdfs/6010.pdf (accessed 05/13/2015). 
81. Gotor, R.; Costero, A. M.; Gil, S.; Parra, M.; Martinez-Manez, R.; Sancenon, F.; Gavina, P., Selective and Sensitive Chromogenic Detection of cyanide and HCN in Solution and In Gas Phase. Chemical Comunications 2013, 49, 5669-5671.

82. International Sensor Technology Electochemical Sensors. http://www.intlsensor.com/pdf/electrochemical.pdf (accessed 05/26/2015).

83. To'th, K.; Pungor, E., Determination of cyanides with ion-selective membrane electrodes. Analytica Chimica Acta 1970, 51 (2), 221-230.

84. Pletcher, D.; Valdes, E. M., Determination of Cyanide Based on a Gold Microband Electrode. Analytica Chimica Acta 1991, 248 (1), 173-176.

85. Safavi, A.; Maleki, N.; Shahbaazi, H. R., Indirect Determination of Cyanide Ion and Hydrogen Cyanide by Adsorptive Stripping Voltammetry at a Mercury Electrode. Analytica Chimica Acta 2004, 503 (2), 213-221.

86. Grainger. Hydrogen Cyanide Detectors. http://www.grainger.com/category/ecatalog/N1z0dep1 (accessed 04/29/2015).

87. Mil-Ram. Hydrogen Cyanide HCN Gas Detector. http://www.milram.com/public/ta_2102_hcn_page.html.

88. MSA. ALTAIR Pro Snigle-Gas Detector. http://us.msasafety.com/Portable-GasDetection/Single-or-Two-Gas/ALTAIR\%26reg\%3B-Pro-Single-GasDetector/p/000080000200001512 (accessed 04/29/2015).

89. Delphian Detection Technology Sensor Technology. http://delphian.com/sensor-tech.htm (accessed 05/26/2015).

90. Yang, M.; He, J.; Hu, X.; Yan, C.; Cheng, Z., CuO Nanostructures As Quartz Crystal Microbalance Sensing Layers for Detection of Trace Hydrogen Cyanide Gas.

Environmental Science and Technology. 2011, 2011, 6088-6094.

91. Desharnais, B.; Huppe, G.; Lamarche, M.; Mireault, P.; Skinner, C. D., Cyanide Quantification in Post-Mortem Biological Matrices by Headspace GC-MS. Forensic Science International. 2012, 222 (1-3), 346-351.

92. Cordero, S. R.; Beshay, M.; Low, A.; Mukamal, H.; Ruiz, D.; Lieberman, R. A., A Distributed Fiber Optic Chemical Sensor for Hydrogen Cyanide Detection. SPIE Proceedings. 2005, 5993, 1-7.

93. Sensidyne. Hydrogen Cyanide Gas Detector Tube. http://www.sensidyne.com/colorimetric-gas-detector-tubes/detector-tubes/112sbhydrogen-cyanide.php (accessed 04/29/2015).

94. Vashist, S. K. A Review of Microcantilevers for Sensing Applications. http://www.azonano.com/article.aspx?ArticleID=1927\#_Sensing_Applications_Of_Micr ocantil (accessed 05/26/2015). 
95. NIOSH. Determination of End-of-Service-Life Indicator (ESLI) Drop Test, Air-Purifying Respirators Standard Testing Procedure (STP). National Personal Protective Technology Laboratory. Pittsburgh, PA., 2005.

96. García-Romeo, D.; Pellejero, I.; Urbiztondo, M. A.; Sesé, J.; Pina, M. P.; Martínez, P. A.; Calvo, B.; Medrano, N., Portable Low-Power Electronic Interface for Explosive Detection Using Microcantilevers. Sensors and Actuators B: Chemical 2014, 200 (0), 3138.

97. Yang, M.; He, J.; Hu, X.; Yan, C.; Cheng, Z., Synthesis of Nanostructured Copper Oxide Via Oxalate Precursors and Their Sensing Properties for Hydrogen Cyanide Gas. Analyst 2013, 138 (6), 1758-1763.

98. Magnusson, R.; Nyholm, S.; Åstot, C., Analysis of Hydrogen Cyanide in a Case of Attempted Cyanide Poisoning. Forensic Science International. 2012, 222, e7-e12.

99. Myerson, J. Introduction to FTIR. 2006. (accessed 06/09/2015).

100. Interscan Detector Tubes and When to Use Them. http://www.gasdetection.com/knowledge-base/best-practices/detector-tubes-and-when-touse-them/ (accessed 05/26/2015).

101. Pitschmann, V.; Kobliha, Z.; Tušarová, I.; Bártová, L.; Vetchý, D.; Bobál, P., A New Detection Tube to Detect Hydrogen Cyanide in the Air. Chemical Industry and Chemical Engineering Quarterly. 2014, 20 (2), 155-161.

102. Roberson, R. Common Questions Revolving Around Detector Tube Accuracy. http://www.sensidyne.com/library/detector-tubes/Tech\%20CornerDetector\%20Tubes/FAQDetectorTubeAccuracy.pdf (accessed 05/26/2015).

103. Reig, A. J.; Conrad, K. S.; Brunold, T. C., Combined Spectroscopic/Computational Studies of Vitamin B 12 Precursors: Geometric and Electronic Structures of Cobinamides. Inorganic Chemistry 2012, 51, 2867-2879.

104. Broderick, K. E.; Potluri, P.; Zhuang, S.; Scheffler, I. E.; Sharma, V. S.; Pilz, R. B.; Boss, G. R., Cyanide Detoxification by the Cobalamin Precursor Cobinamide. Experimental Biology and Medicine 2006, 231, 641-649.

105. George, P.; Irvine, D. H.; Glauser, S. C., The Influence of Chelation in Determining the Reactivity of the Iron in Hemoproteins, and the Cobalt in Vitamin $\mathrm{B}_{12}$ Derivatives. Annals of the New York Academy of Sciences 1960, 88 (2), 393-415.

106. Dereven'kov, I. A.; Salnikov, D. S.; Makarov, S. V.; Surducan, M.; Silaghi-Dumitrescu, R.; Boss, G. R., Comparative Study of Reaction of Cobalamin and Cobinamide with Thiocyanate. Journal of Inorganic Biochemistry 2013, 125, 32-39.

107. Skoog, D. A.; West, D. M.; Holler, F. J.; Crouch, S. R., Fundamentals of Analytical Chemistry. 9 ed.; Brooks/Cole, Cengage Learning: 2014. 
108. Ma, J.; Dasgupta, P.; Zelder, F. H.; Boss, G. R., Cobinamide Chemistries for Photometric Cyanide Determination. A Merging Zone Liquid Core Wavequide Cyanide Analyzer Using Cyanoaquacobinamide. Analytica Chimica Acta 2012, 736, 78-84.

109. Blackledge, W. C.; Blackledge, C. W.; Griesel, A.; Mahon, S. B.; Brenner, M.; Pilz, R. B.; Boss, G. R., New Facile Method to Measure Cyanide in Blood. Journal of Analytical Chemistry 2010, 82, 4216-4221.

110. Brenner, M.; Mahon, S. B.; Lee, J.; Kim, J.; Mukai, D.; Goodman, S.; Kreuter, K. A.; Ahdout, R.; Mohammad, O.; Sharma, V. S.; Blackledge, W.; Boss, G. R., Comparison of Cobinamide to Hyroxocobalamin in Reversing Cyanide Physiologic Effects in Rabbits using Diffuse Optical Spectroscopy Monitoring. Journal of Biomedical Optics 2010, 15 (1), 017001-1-017001-7.

111. Baldwin, D. A.; Betterton, E. A.; Pratt, J. M., The Chemistry of Vitamin B12. Part 20. Diaquocobinamide: pK Values and Evidence for Conformatinal Isomers. J. Chem. Soc. Dalton Trans. 1983, 217-223.

112. Ford, S. H.; Nichols, A.; Shambee, M., The Preparation and Characterization of the diaquo- Forms of Several Incomplete Corrinoids Cobyric Acid, Cobinamide, and Three Isomeric Cibinic Acid Pentaamines. Journal of Inorganic Biochemistry 1991, 41, 235244.

113. Brenner, M.; Mahon, S. B.; Lee, J.; Kim, J.; Mukai, D.; Goodman, S.; Kreuter, K. A.; Ahdout, R.; Mohammad, O.; Sharma, V. S.; Blackledge, W.; Boss, G. R., Comparison of Cobinamide to Hyroxocobalamin in Reversing Cyanide Physiologic Effects in Rabbits using Diffuse Optical Spectroscopy Monitoring. Journal of Biomedical Optics 2010, 15, 017001-1-017001-7.

114. Chan, A.; Jiang, J.; Fridman, A.; Guo, L. T.; Shelton, G. D.; Liu, M.-T.; Green, C.; KHaushalter, K. J.; Patel, H. H.; Lee, J.; Yoon, D.; Burney, T.; Mukai, D.; Mahon, S. B.; Brenner, M.; Pilz, R. B.; Boss, G. R., Nitrocobinamide, A New Cyanide Antidote That Can Be Administered by Intramuscular Injection. Journal of Medicinal Chemistry. 2015, 58, 1750-1759.

115. Brenner, M.; Benavides, S.; Mahon, S. B.; Lee, J.; Yoon, J.; Mukai, D.; Viseroi, M.; Chan, A.; Jiang, J.; Narula, N.; Azer, S. M.; Alexander, C.; Boss, G. R., The Vitamin B12 Analog Cobinamide is an Effective Hydrogen Sulfide Antidote in a Lethal Rabbit Model. Clinical Toxicology 2014, 52, 490-497.

116. Broderick, K. E.; Gingh, V.; Zhuang, S.; Kambo, A.; Chen, J. C.; Sharma, V. S.; Pilz, R. B.; Boss, G. R., Nitric Oxide Scavenging by the Cobalamin Precursor Cobinamide. Journal of Biological Chemistry 2005, 280, 8678-8686.

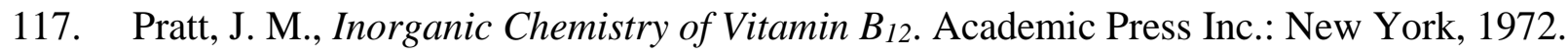

118. Ma, J.; Dasgupta, P. K.; Blackledge, W.; Boss, G. R., Temperature Dependence of Henry's Law Constant for Hydrogen Cyanide. Generation of Trace Standard Gaseous Hydrogen Cyanide. Environmental Science and Technology. 2010, 44 (8), 3028-3034. 
119. Männel-Croisé, C.; Probst, B.; Zelder, F., A Straightforward Method for the Colorimetric Detection of Endogenous Biological Cyanide. Analytical Chemistry 2009, 81, 94939498.

120. Ma, J.; Dasgupta, P. K.; Blackledge, W.; Boss, G. R., Cobinamide-Based Cyanide Analysis by Multiwavelength Spectrometry in a Liquid Core Waveguide. Analytical Chemistry 2010, 82, 6244-6250.

121. Ma, J.; Ohira, S.; Mishra, S. K.; Puanngam, M.; Dasgupta, P. K., Rapid Point of Care Analyzer for the Measurement of Cyanide in Blood. Analytical Chemistry 2011, 83, 4319-4324.

122. Janzen, M. C.; Ponder, J. B.; Bailey, D. P.; Ingison, C. K.; Suslick, K. S., Colorimetric Sensor Arrays for Volatile Organic Compounds. Analytical Chemistry 2006, 78, 35913600 .

123. Pierre, A. C., The Sol-Gel Encapsulation of Enzymes. Biocatalysis and Biotransformation 2004, 22 (3), 145-170.

124. El-Ashgar, N. M.; El-Basioni, A. I.; El-Nahhal, I. M.; Zourob, S. M.; El-Agez, T. M.; Taya, S. A., Sol-Gel Thin Films Immobilized with Bromocresol Purple pH-Sensitive Indicator in Presence of Surfactants. Analytical Chemistry 2012, 2012, 1-11.

125. Bhatia, R. B.; Brinker, C. J.; Gupta, A. K.; Singh, A. K., Aqueous Sol-Gel Process fo Protein Encapsulation. Chemistry of Materials 2000, 12 (8), 2434-2441.

126. Mosquera, M. J.; Dde los Santos, D. M.; Valdez-Castro, L.; Esquivias, L., New Route for Producing Crack-Free Xerogels: Obtaining Uniform Pore Size. Journal of NonCrystalline Solids 2008, 354, 645-650.

127. Kappert, E. J.; Pavlenko, D.; Malzbender, J.; Nijmeijer, A.; Benes, N. E.; Tsai, P. A., Formation and Prevention of Fractures in Sol-Gel-Derived Thin Films. Soft Materials 2015, 11 (5), 882-890.

128. Scherer, G. W., Recent Progress in Drying of Gels. Journal of Non-Crystalline Solids 1992, 147, 565-574.

129. Liana, D. D.; Raguse, B.; Gooding, J. J.; Chow, E., Recent Advances in Paper-Based Sensors. Sensors 2012, 12, 11505-11526.

130. Lu, Y.; Shi, W.; Quin, J.; Lin, B., Fabrication and Characterization of Paper-Based Microfluidics Prepared in Nitrocellulose Membrane By Wax Printing. Analytical Chemistry 2010, 82, 329-335; (b) Nie, Z.; Nijhuis, C. A.; Gong, J.; Chen, X.; Kumachev, A.; Martinez, A. W.; Narovlyansky, M.; Whitesides, G. M., Electrochemical Sensing in Paper-Based Microfluidic Devices. Lab on a Chip 2009, 10, 477-483.

131. (a) Arena, A.; Donato, N.; Saitta, G.; Bonavita, A.; Rizzo, G.; Neri, G., Flexible Ethanol Sensors on Glossy Paper Substrates Operating at Room Temperature. Sensors and Actuators B: Chemical 2010, 145, 488-494; (b) Nie, Z.; Nijhuis, C. A.; Gong, J.; Chen, X.; Kumachev, A.; Martinez, A. W.; Narovlyansky, M.; Whitesides, G. M., 
Electrochemical Sensing in Paper-Based Microfluidic Devices. Lab on a Chip 2010, 10, 477-483.

132. Nery, E. W.; Kubota, L. T., Sensing Approaches on Paper-Based Devices: A Review. Analytical and Bioanalytical Chemistry 2013, 405, 7573-7595.

133. Comer, J. P., Semiquantitative Specific Test Paper for Glucose in Urine. Analytical Chemistry 1956, 28 (11), 1748-1750.

134. NIH A Timeline of Pregnancy Testing. http://history.nih.gov/exhibits/thinblueline/timeline.html (accessed 04/27/2015).

135. Martinez, A. W.; Phillips, S. T.; Whitesides, G. M., Diagnostics for the Developing World: Microfluidic Paper-Based Analytical Devices. Analytical Chemistry 2010, 82 (1), $3-10$.

136. Thuo, M. M.; Martinez, R. V.; Lan, W. J.; Liu, X.; Barber, J.; Atkinson, M. B.; Bandarage, D.; Bloch, J. R.; Whitesides, G. M., Fabrication of Low-Cost Paper-Based Microfluidic Devices by Embossing or Cut-and-Stack Methods. Chemistry of Materials 2014, 26, 4230-4237.

137. Martinez, A. W.; Phillips, S. T.; Carriho, E.; Thomas, S. W.; Sindi, H.; Whitesides, G. M., Simple Telemedicine for Developing Regions; Camera Phones and Paper-Based Microfluidic Devices for Real-Time, Off-Site Diagnosis. Analytical Chemistry 2008, 80, 3699-3707.

138. Ellerbee, A. K.; Phillips, S. T.; Siegel, A. C.; Mirica, K. A.; Martinez, A. W.; Striehl, N.; Prentiss, M.; Whitesides, G. M., Quantifying Colorimetric Assays in Paper-Based Microfluidic Devices by Measuring the Transmission of Light Through Paper. Analytical Chemistry 2009, 81, 8447-8452.

139. Soga, T.; Jimbo, Y.; Suzuki, K.; Citterio, D., Inkjet-Printed Paper-Based Colorimetric Sensor Array for the Discrimination of Volatile Primary Amines. Journal of Analytical Chemistry 2013, 85, 8973-8978.

140. Feng, L.; Musto, C. J.; Suslick, K. S., A Simple and Highly Sensitive Colorimetric Detection Method for Gaseous Formaldehyde. Journal of American Chemical Society 2010, 132, 4046-4047.

141. Lim, S. H.; Feng, L.; Kemling, J. W.; Musto, C. J.; Suslick, K. S., An Optoelectronic Nose for Detection of Toxic Gases. Nature Chemistry 2009, 1, 562-566.

142. Sen, A.; Albarella, J. D.; Carey, J. R.; Kim, P.; McNamara, W. B., III, Low-Cost Colorimetric Sensor for the Quantitative Detection of Gaseous Hydrogen Sulfide. Sensors and Actuators B: Chemical 2008, 134, 234-237.

143. Martinez, A. W.; Phillips, S. T.; Butte, M. J.; Whitesides, G. M., Patterned Paper as a Platform for Inexpensive, Low-Volume, Portable Bioassays. Angewandte Chemie International Edition 2007, 46 (8), 1318-1320. 
144. Jokerst, J. C.; Adkins, J. A.; Bisha, B.; Mentele, M.; Goodridge, L. D.; Henry, C. S., Development of a Paper-Based Analytical Device for Colorimetric Detection of Select Foodborne Pathogens. Analytical Chemistry 2012, 84, 2900-2907.

145. Ratnarathorn, N.; Chailapakul, O.; Henry, C. S.; Dungchai, W., Simple Silver Nanoparticle Colorimetric Sensing for Copper by Paper-Based Devices. Talanta 2012, 99, 552-557.

146. Hossain, S. M. Z.; Brennan, J. D., B-Galactosidase-Based Colorimetric Paper Sensor for Determination of Heavy Metals. Analytical Chemistry 2011, 83, 8772-8778.

147. Jarujamrus, P.; Tian, J.; Li, X.; Siripinyanond, A.; Shiowatana, J.; Shen, W., Mechanisms of Red Blood Cells Agglutination in Antibody-Treated Paper. Analyst 2012, 137, 22052210 .

148. Klasner, S. A.; Price, A. K.; Hoeman, K. W.; Wilson, R. S.; Bell, K. J.; Culbertson, C. T., Paper-Based Microfluidic Devices for Analysis of Clinically Relevant Analytes Present in Urine and Saliva. Analytical and Bioanalytical Chemistry 2010, 397, 1821-1829.

149. Hecht, E., Optics. 4 ed.; Addison Wesley: Boston, 2002.

150. Zhao, W.; Ali, M. M.; Aguirre, S. D.; Brookk, M. A.; Li, Y., Paper-Based Bioassays Using Gold Nanoparticle Colorimetric Probes. Analytical Chemistry 2008, 80, 84318437.

151. Bănică, F.-G., Chemical Sensors and Biosensors. John Wiley \& Sons: United Kingdom, 2012.

152. Samuels, A. C.; Zhu, C.; Williams, B. R.; Ben-David, A.; Miles, R. W.; Hulet, M., Improving the Linearity of Infrared Diffuse Reflection Spectroscopy Data for Quantitative Analysis: An Application in Quantifying Organophosphorous Contamination in Soil. Journal of Analytical Chemistry 2006, 78, 408-415.

153. Monico, L.; Janssens, K.; Miliani, C.; Van der Snickt, G.; Brunetti, B. G.; Guidi, M. C.; Radepont, M.; Cotte, M., Degradation Process of Lead Chromate in Paintings by Vincent van Gogh Studied by Means of Spectromicroscopic Methods. Artificial Aging of Model Samples of Co-Precipitates of Lead Chromate and Lead Sulfate. Journal of Analytical Chemistry 2013, 85, 860-867.

154. Yu, B.; Sha, A.; Nagarajan, V. K.; Ferris, G. G., Diffuse Reflectance Spectroscopy of Epithelial Tissue with a Smart Fiber-Optic Probe. Biomedical Optics Express 2014, 5 (3), 675-689.

155. Lee, S. J.; Han, S. W.; Choi, H. J.; Kim, K., Phase Behavior of Organic-Inorganic Crystal: Temperature-Dependent Diffuse Reflectance Infrared Spectroscopy of Silver Sterate. European Physical Journal D 2001, 16, 293-296.

156. Osawa, M., The Measurement of Meat Pigments by Fibre-Optic Reflectance Spectrophotometry Using the Kubelka-Munk Equation. Meat Science. 1995, 40, 63-77. 
157. Džimbeg-Malčić, V.; Barbarić-Mikočević, Ž.; Itrić, K. Kubelka-Munk Theory in Describing Optical Properties of Paper (I) Technical Gazette [Online], 2011, p. 117-224.

158. Shimadzu Diffuse Reflectance Measurement. http://www.shimadzu.com/an/spectro/uv/accessory/solidsample/solid.html (accessed 06/03/2015).

159. Lab Sphere, Integrating Sphere Theory and Applications. New Hampshire.

160. Ocean Optics FOIS-1 Integrating Sphere. http://oceanoptics.com/product/fois-1integrating-sphere/ (accessed 06/1/2015).

161. Taylor, A. E. F. Illumination Fundamentals. 2000, p. 1-48. http://optics.synopsys.com/lighttools/pdfs/illuminationfund.pdf (accessed 06/01/2015).

162. Ocean Optics Fibers and Probes. http://oceanoptics.com/wpcontent/uploads/Ocean_Optics_Fibers_Probes.pdf (accessed 05/28/2015).

163. Fibers. http://oceanoptics.com/product-category/fibers/ (accessed 11/20).

164. Momin, S. A.; Narayanaswamy, R., Optosensing of Chlorine Gas Using a Dry Reagent Strip and Diffuse Reflectance Spectrophotometry. Analytica Chimica Acta 1991, 244, 7179.

165. Lobnik, A., Absorption-Based Sensors. In Optical Chemical Sensors., Baldini, F.; Chester, A. N.; Homola, J.; Martellucci, S., Eds. Springer Netherlands, 2006; Vol. 224, p 520 .

166. Barrón, V.; Torrent, J., Diffuse Reflectance Spectroscopy. In Methods of Soil Analysis. Part 5: Mineralogical Methods, Ulery, A. L.; Drees, L. R., Eds. Soil Science Society of America.: 2008.

167. Tolvaj, L.; Mitsui, K.; Varga, D., Validity Limits of Kubelka-Munk Theory for DRIFT Spectra of Photodegraded Solid Wood. Wood Science and Technology 2011, 45, 135146.

168. Luiz, V. H. M.; Pezza, L.; Pezza, H. R., Determination of Nitrite in Meat Products and Water Using Dapsone with Combined Spot Test/Diffuse Reflectance on Filter Paper. Food Chemistry 2012, 134, 2546-2551.

169. Gaffney, J. S.; Marley, N. A.; Smith, K. J., Characterization of Fine Mode Atmospheric Aerosols by Raman Microscopy and Diffuse Reflectance FTIR. Physical Chemistry A. 2015, 119, 4524-4532.

170. Brimmer, P. J.; Griffiths, P. R., Angular Dependence of Diffuse Reflectance Infrared Spectra. Part III: Linearity of Kubelka-Munk Plots. Applied Spectroscopy 1988, 42 (2), 242-247.

171. Juang, R.-H.; Storey, D. E., Quantitative Determination of the Extent of Neutralization of Carboxylic Acid Functionality in Carbopol ${ }^{\circledR}$ 974P NF by Diffuse Reflectance Fourier 
Transform Infrared Spectrometry Using Kubelka-Munk Function. Pharmaceutical Research. 1998, 15 (11), 1714-1720.

172. Myrick, M. L.; Simcock, M. N.; Baranowski, M.; Brooke, H.; Morgan, S. L.; McCutcheon, J. N., The Kubelka-Munk Diffuse Reflectance Formula Revisited. Applied Spectroscopy Reviews 2014, 46 (2), 140-165.

173. Džimbeg-Malčić, V.; Barbarić-Mikočević, Ž.; Itrić, K., Kubelka-Munk Theory in Describing Optical Properties of Paper (II). Tehnički vjesnik 2012, 19 (1).

174. Averett, L. A.; Griffiths, P. R., Method to Improve Linearity of Diffuse Reflection MidInfrared Spectroscopy. Analytical Chemistry 2006, 78, 8165-8167.

175. Arena, M. P.; Porter, M. D.; Fritz, J. S., Rapid, Specific Determination of Iodine and Iodide by Combined Solid-Phase Extraction/Diffuse Reflectance Spectroscopy. Analytical Chemistry 2002, 74, 185-190.

176. Yang, L.; Kruse, B., Revised Kubelka-Munk Theory. I. Theory and Application. Journal of the Optical Society of America A 2004, 21 (10), 1933-1941.

177. Yang, L.; Kruse, B.; Miklavcic, S. J., Revised Kubelka-Munk Thoery. II. Unified Framework for Homogenous and Inhomogenous Optical Media. Journal of the Optical Society of America A 2004, 21 (10), 1942-1952.

178. Messerschmidt, R. G., Complete Elimination of Specular Reflectance in Infrared Diffuse Reflectance Measurements. Applied Spectroscopy 1985, 39 (4), 737-739.

179. Nayra, S. K.; Fang, X. S.; Boult, T., Separation of Reflection Components Using Color and Polarization. International Journal of Computer Vision. 1997, 21 (3), 163-186.

180. Wolff, L. B. In Using Polarization to Separate Reflection Components., Institute of Electrical and Electronics Engineers., San Diego, CA., San Diego, CA., 1989; pp 363369.

181. Sharma, V. S.; Pilz, R. B.; Boss, G. R.; Magde, D., Reactions of Nitric Oxide with Vitamin $B_{12}$ and Its Precursor, Cobinamide. Biochemistry 2003, 42 (29), 8900-8908.

182. Copco, A. Oil-Free Rotary Tooth Compressors. http://www.atlascopco.us/usus/ (accessed 04/21/2015).

183. Compresco A Guide to International Paper Sizes. http://www.copresco.com/techn11.pdf (accessed 04/23/2015).

184. Dupont Delrin- An Industry-Leading, High-Performace Acetal Resin. http://www.dupont.com/products-and-services/plastics-polymersresins/thermoplastics/brands/delrin-acetal-resin.html (accessed 04/23/2015).

185. Ocean Optics Glossary. http://oceanoptics.com/glossary/\#averaging (accessed 04/21/2015).

186. Bell, S., Forensic Chemistry. 2 ed.; Pearson Education: 2013; p 13-40. 
187. Jensen, H. W.; Legakis, J.; Dorsey, J., Rendering of Wet Materials. In Rendering Techniques., Springer Vienna: 1999; pp 273-281.

188. Department of Health and Human Services, Components for Evaluation of DirectReading Monitors for Gases and Vapors. NIOSH, Ed. 2012; pp 77-81.

189. Salnikov, D. S.; Makarov, S. V.; van Eldik, R.; Kucherenko, P. N.; Boss, G. R., Kinetics and Mechanism of the Reaction of Hydrogen Sulfide with Diaquacobinamide in Aqueous Solution. Eur. J. inorg. Chem. 2014, 4123-4133.

190. Bond, A. M.; Heritage, I. D.; Wallace, G. G.; McCormick, M. J., Simultaneous Determination of Free Sulfide and Cyanide by Ion Chromatography with Electrochemical Detection. Analytical Chemistry 1982, 54, 582-585.

191. Ghanavati, M.; Azad, R. R.; Mousavi, S. A., Amperometric Inhibition Biosensor for the Determination of Cyanide. Sensors and Actuators B: Chemical 2014, 190, 858-864.

192. Wilmot, J. C.; Solujić, L.; Milosavljević, E. B.; Hendrix, J. L.; Rader, W. S., Formation of Thiocyanate During Removal of Sulfide as Lead Sulfide Prior to Cyanide Determination. Analyst 1996, 121, 799-801.

193. EPA. Method OIA-1677 Available Cyanide by Flow Injection, Ligand Exchange, and Amperometry. Office of Water. Ed. 1999; p 22.

194. NIOSH Manual of Analytical Methods Hydrogen Cyanide: Method 6017. http://www.cdc.gov/niosh/docs/2003-154/pdfs/6017.pdf (accessed 05/13/2015).

195. NIOSH. Determination of Hydrogen Sulfide Service-Life Test, Air-Purifying Respirators with Cartridges Standard Test Procedure (STP). National Personal Protective Technology Laboratory, Pittsburgh, PA. http://www.cdc.gov/niosh/npptl/stps/pdfs/TEBAPR-STP-0043A.pdf (accessed 05/05/2015).

196. United States Department of Labor. Hydrogen Sulfide. https://www.osha.gov/SLTC/hydrogensulfide/standards.html (accessed 05/05/2015).

197. EPA. Report to Congress on Hydrogen Sulfide Air Emissions Associated with the Extraction of Oil and Natural Gas. Agency, Department of Environmental Protection Agency. Research Triangle Park, NC., 1993; pp 1-79.

198. EPA. Summary of the Clean Air Act. http://www2.epa.gov/laws-regulations/summaryclean-air-act (accessed 05/06/2015).

199. Skrtic, L. Hydrogen Sulfide, Oil and Gas, and People's Health. University of California, Berkeley., Berkeley, 2006.

200. EPA. Modifications to the 112(b)1 Hazardous Air Pollutants. http://www.epa.gov/ttn/atw/pollutants/atwsmod.html (accessed 05/06/2015).

201. Maine Department of Health \& Human Services. Ambient Air Guidelines for Hydrogen Sulfide 2006, p. 1-15. 
http://www.maine.gov/dep/waste/publications/documents/ambientairguidelines.pdf (accessed 06/27/2015).

202. CDC Hydrogen Sulfide. http://www.cdc.gov/niosh/npg/npgd0337.html (accessed 05/05/2015).

203. Wanek, R. Monitoring $\mathrm{H}_{2} \mathrm{~S}$ to Meet New Exposure Standards. 2011. https://ohsonline.com/articles/2011/09/01/monitoring-h2s-to-meet-new-exposurestandards.aspx (accessed 06/23/15).

204. Hu, X.; Mutus, B., Electrochemical Detection of Sulfide. Reviews in Analytical Chemistry. 2013, 32 (3), 247-256.

205. Lawrence, N. S.; Davis, J.; Compton, R. G., Analytical Strategies for the Detection of Sulfide: A Review. Talanta 2000, 52, 771-784.

206. Hughes, M. N.; Centelles, M. N.; Moore, K. P., Making and Working with Hydrogen Sulfide: The Chemistry and Generation of Hydrogen Sulfide in vitro and its Measurement in vivo: A Review. Free Radical Biology \& Medicine 2009, 47, 1346-1353.

207. WHO. Hydrogen Sulfide. http://www.euro.who.int/_data/assets/pdf_file/0019/123076/AQG2ndEd_6_6Hydrogens ulfide.PDF (accessed 05/06/2015).

208. Mousa, H. A.-L., Short-Term Effects of Subchronic Low-Level Hydrogen Sulfide Exposure on Oil Field Workers. Environmental Health and Preventive Medicine 2015, $20,12-17$.

209. Beauchamp, R. O., Jr.,; Bus, J. S.; Popp, J. A.; Boreiko, C. J.; Andjelkovich, D. A., A Critical Review of the Literature on Hydrogen Sulfide Toxicity. Critical Reviews in Toxicology 1984, 13 (1), 25-97.

210. Truong, D. H.; Eghbal, M. A.; Hindmarsh, W.; Roth, S. H.; O'Brien, P. J., Molecular Mechanisms of Hydrogen Sulfide Toxicity. Drug Metabolism Reviews. 2006, 38, 733744.

211. Kabil, O.; Banerjee, R., Redox Biochemistry of Hydrogen Sulfide. Journal of Biological Chemistry. 2010, 285 (29), 21903-21907.

212. Truong, D. H.; Mihajlovic, A.; Gunness, P.; Hindmarsh, W.; O'Brien, P. J., Prevention of Hydrogen Sulfide $\left(\mathrm{H}_{2} \mathrm{~S}\right)$ - Induced Mouse Lethality and Cytotoxicity by Hydroxocobalamin (Vitamin $\mathrm{B}_{12 \mathrm{a}}$ ). Toxicology 2007, 242, 16-22.

213. Industrial Scientific Industrial Scientific Gas Detectors: Hydrogen Sulfide. https://www.indsci.com/services/training/general-gas-education/common-chemicals/h2s/ (accessed 05/15/2015).

214. O'Mahony, A. M.; Dickinson, E. J. F.; Aldous, L.; Hardacre, C.; Compton, R. G., Electrochemical Oxidation of Hydrogen Sulfide at Platinum Electrodes in room Temperature Ionic Liquids: Evidence for Significant Accumulation of $\mathrm{H}_{2} \mathrm{~S}$ at the $\mathrm{Pt} / 1$ - 
Butyl-3-methylimidazolium Trifluoromethylsulfonate Interface. Journal of Physical Chemistry C 2009, 113, 10997-11002.

215. MSA Gas Monitors MSA Altair Pro Single-Gas Detector- Hydrogen Sulfide. http://www.msagasmonitors.com/10074136.html (accessed 05/15/2015).

216. Henderson, R. E. Using Electrochemical Sensors for Toxic Gas Measurement. www.gasmonitors.com (accessed 05/14/2015).

217. Kolluru, G. K.; Shen, X.; Bir, S. C.; Kevil, C. G., Hydrogen Sulfide Chemical Biology: Pathophysiological Roles and Detection. Nitric Oxide 2013, 35, 5-20.

218. Li, J.; Yin, C.; Huo, F., Chromogenic and Fluorogenic Chemosensors for Hydrogen Sulfide: Review of Detection Mechanisms Since the Year 2009. Royal Society of Chemistry Advances 2015, 5, 2191-2206.

219. Lawrence, N. S.; Davis, J.; Jiang, L.; Jones, T. G. J.; Davis, S. N.; Compton, R. G., Selective Determination of Thiols: A Novel Electroanalytical Approach. Analyst 2000, 125 (4), 661-663.

220. Sarlak, N.; Anizadeh, M., Simultaneous Kinetic Spectrophotometric Determination of Sulfide and Sulfite Ions by Using an Optode and the Partial Least Squares (PLS) Regression. Sensors and Actuators B: Chemical 2011, 160 (1), 644-649.

221. Shimamoto, K.; Hanaoka, K., Fluorescent Probes for Hydrogen Sulfide (H2S) and Sulfane Sulfur and Their Applications to Biological Studies. Nitric Oxide 2015, 46, 72 79.

222. Sensidyne. Colorimetric Gas Detector Tube Handbook. http://www.intecconinc.com/files/datasheet/Datasheet_Sensidyne_Detector_Tube_Handb ook.pdf (accessed 05/04/2015).

223. Posner, J. C., Portable Gas Chromatography. NIOSH, Ed. 1998; pp 75-81.

224. Ho, C. K.; Kelley, M.; Itamura, M. T.; Hughes, R. C. Review of Chemical Sensors for InSitu Monitoring of Volatile Contaminants. 2001. (accessed 06/04/2015).

225. Jann, L. L. Development of a New Method to Measure Hydrogen Sulfide Using the Vitamin B12 Precursor Cobinamide. UCSD, San Diego, 2012.

226. Dereven'kov, I. A.; Salnikov, D. S.; Shpagilev, N. I.; Makarov, S. V.; Tarakanova, E. N., Reactions of Cobinamide with Glucose and Fructose. Macroheterocycles 2012, 5 (3), 260-265.

227. Toohey, J. I., Hydrosulfide Derivatives of Cobalamins. Journal of Inorganic Biochemistry 1993, 49 (3), 189-199.

228. Rouquerol, J.; Avnir, D.; Fairbridge, C. W.; Everett, D. H.; Haynes, J. H.; Pernicone, N.; Ramsay, J. D. F.; Swing, K. S. W.; Unger, K. K. Recommendations for the Characterization of Porous Solids.; Great Britain., 1994; pp 1739-1759. 
229. Cameron Carbon. Activated Carbon: Manufacture, Structure and Properties. 2006, p. 11. http://www.cameroncarbon.com/documents/carbon_structure.pdf (accessed 06/11/2015).

230. Tsai, W.; Chang, C.; Ho, C.; Chen, L., Adsorption Properties and Breakthrough Model of 1,1-dichloro-1-fluoroethane on Activated Carbons. Journal of Hazardous Materials. 1999, 69, 53-66.

231. EPA. Section 6.0: Carbon Adsorbers., p. 36. http://www.epa.state.oh.us/portals/27/engineer/eguides/carbon.pdf (accessed $06 / 12 / 2015)$.

232. Tien, C., Adsorption Calculations and Modelling. . Elsevier Inc.: 1995.

233. Graceffo, L. A.; Chatterjee, S. G.; Moon, H.; Tien, C., A Model for the Retention of Toxic Gases by Impregnated Carbon. Carbon. 1989, 27 (3), 441-456.

234. Pierce, W. C. Testing of Gas Mask Charcoal and Canister.; 1946.

235. Sansone, E. B.; Tewari, Y. B.; Jonas, L. A., Prediction of Removal of Vapors from Air by Adsorption on Activated Carbon. ACS 1979, 13 (12), 1511-1513.

236. Patterson, A. M. Impregnated Charcoals.; 1919.

237. Grabenstetter, R. J.; Blacet, F. E. Impregnation of Charcoal.; 1946.

238. Tolles, E. Method and Apparatus for Removing Hydrogen Cyanide, Cyanogen, and Cyanogen Chloride from Air. 4,801,311, 1989.

239. 3M. Reuse of Organic Vapor Chemical Cartridges. http://multimedia.3m.com/mws/media/150751O/reuse-of-organic-vapor-chemicalcartridges-technical-data.pdf (accessed 11/20/2015).

240. NIOSH., Determination of CBRN Acid Gases (Hydrogen Cyanide) Service Life Test, Air-Purifying Respirators Standard Test Procedure (STP). NPPTL., Ed. Pittsburgh, 2005.

241. Zhang, H.; Cheng, D., Mathematical Model for a Fixed Bed Adsorptive Reactor. Carbon 2000, 38, 877-880.

242. Alves, B. R.; Clark, A. J., An Examination of the Products Formed on Reaction of Hydrogen Cyanide and Cyanogen with Copper, Chromium (6+) and Copper-Chromium (6+) Impregnated Activated Carbons. Carbon 1986, 24 (3), 287-294.

243. Kin-Tek Flexstream User's Manual; 2010.

244. Ho, N. Modeling Hydrogen Sulfide Adsorption by Activated Carbon Made From Anaerobic Digestion By-Product. University of Toronto., 2012.

245. Puiu, P. D., Optical Nano-and Microsystems for Bioanalytics. In Springer Series on Chemical Sensors and Biosensors, Urban, G., Ed. Springer: Berlin, 2012; Vol. 10, pp 347. 
246. de la Torre, C.; Muñiz, R.; Pérez, M. A., A New, Lost-Cost, On-Line RGB Colorimeter for Wine Industry Based on Optical Fibers. In XIX IMEKO World Congress, Portugal, 2009; pp 2554-2558.

247. Hamamatsu. Si Photodiodes - Chapter 02.

https://www.hamamatsu.com/resources/pdf/ssd/e02_handbook_si_photodiode.pdf (accessed 12-9-2015).

248. Polzer, A.; Gaberl, W.; Zimmermann, H., Wavelength Detection with Integrated FilterLess BiCMOS RGB Sensor. Electronics Letters 2011, 47 (10), 614-615.

249. Cambridge in Colour Digital Camera Sensors. http://www.cambridgeincolour.com/tutorials/camera-sensors.htm (accessed 08/22/2015).

250. Light Filtration. http://www.olympusmicro.com/primer/lightandcolor/filter.html (accessed 12/15/2015).

251. Avago Technologies, Reflective Color Sensing with Avago Technologies' RGB Color Sensor. 2015.

252. Adafruit. Overview of Adafruit TCS34725. https://learn.adafruit.com/adafruit-colorsensors/overview (accessed 07/31/2015).

253. Everlight Datasheet Low Power LED. http://media.digikey.com/pdf/Data\%20Sheets/Everlight\%20PDFs/45-21_XK2CBXXXXXXXXX_2T.pdf (accessed 07/31/2015). 


\section{Appendix A - Tables and Figures for Chapter 2}

\section{Figures}

Figure A.1 - Cracked sol-gel monoliths (without Cbi)

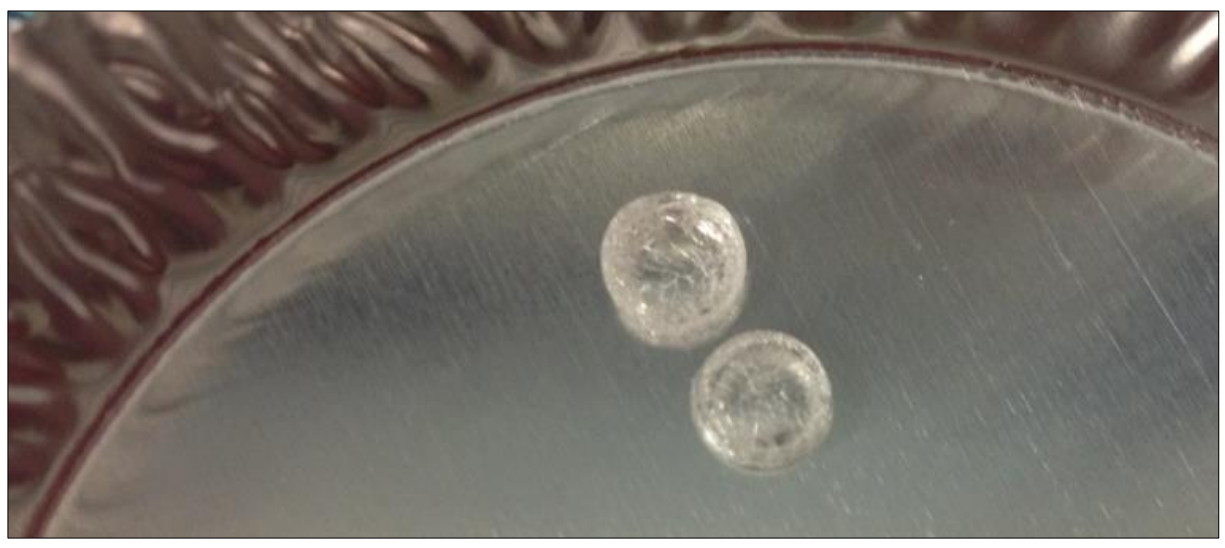

Figure A.2 - Sensor holder top view (A) and side view (B)

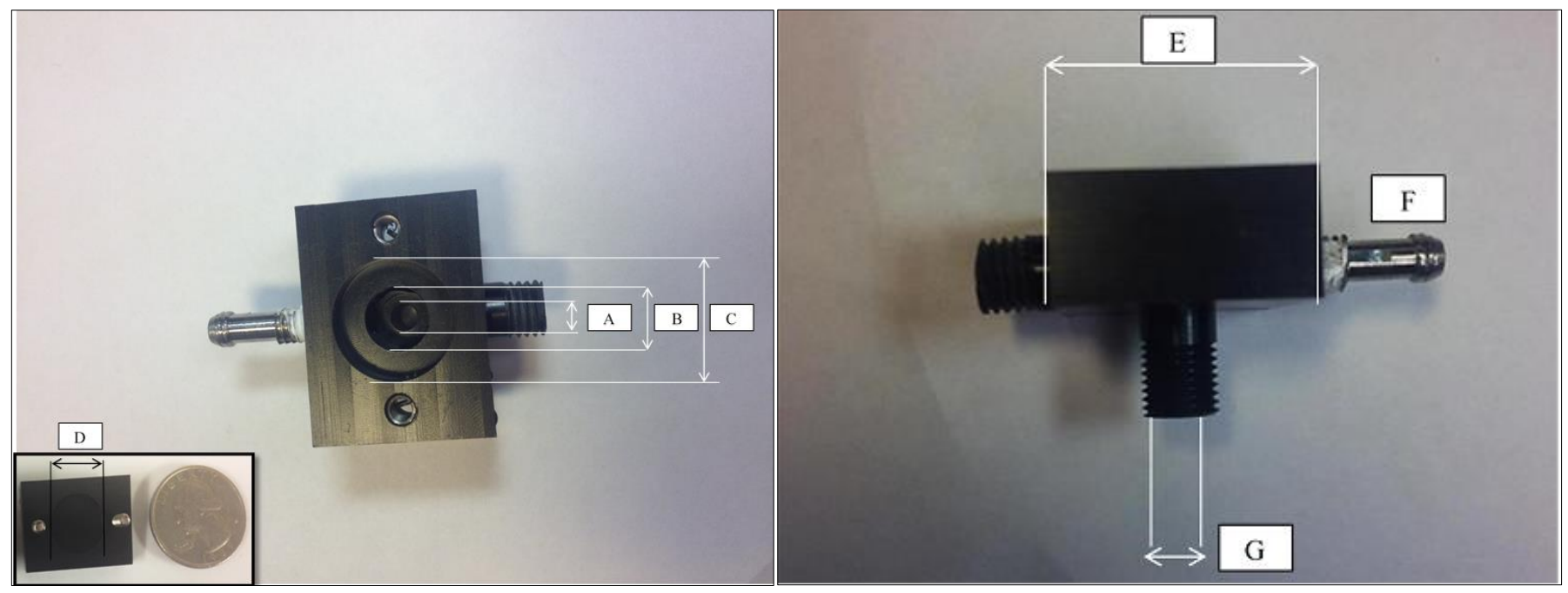


Figure A.3 - Comparison of $\mathrm{CN}\left(\mathrm{H}_{2} \mathrm{O}\right) \mathrm{Cbi}$ on cellulose and glass fiber filter paper to $5.0 \mathrm{ppm}$ $\mathrm{HCN}$

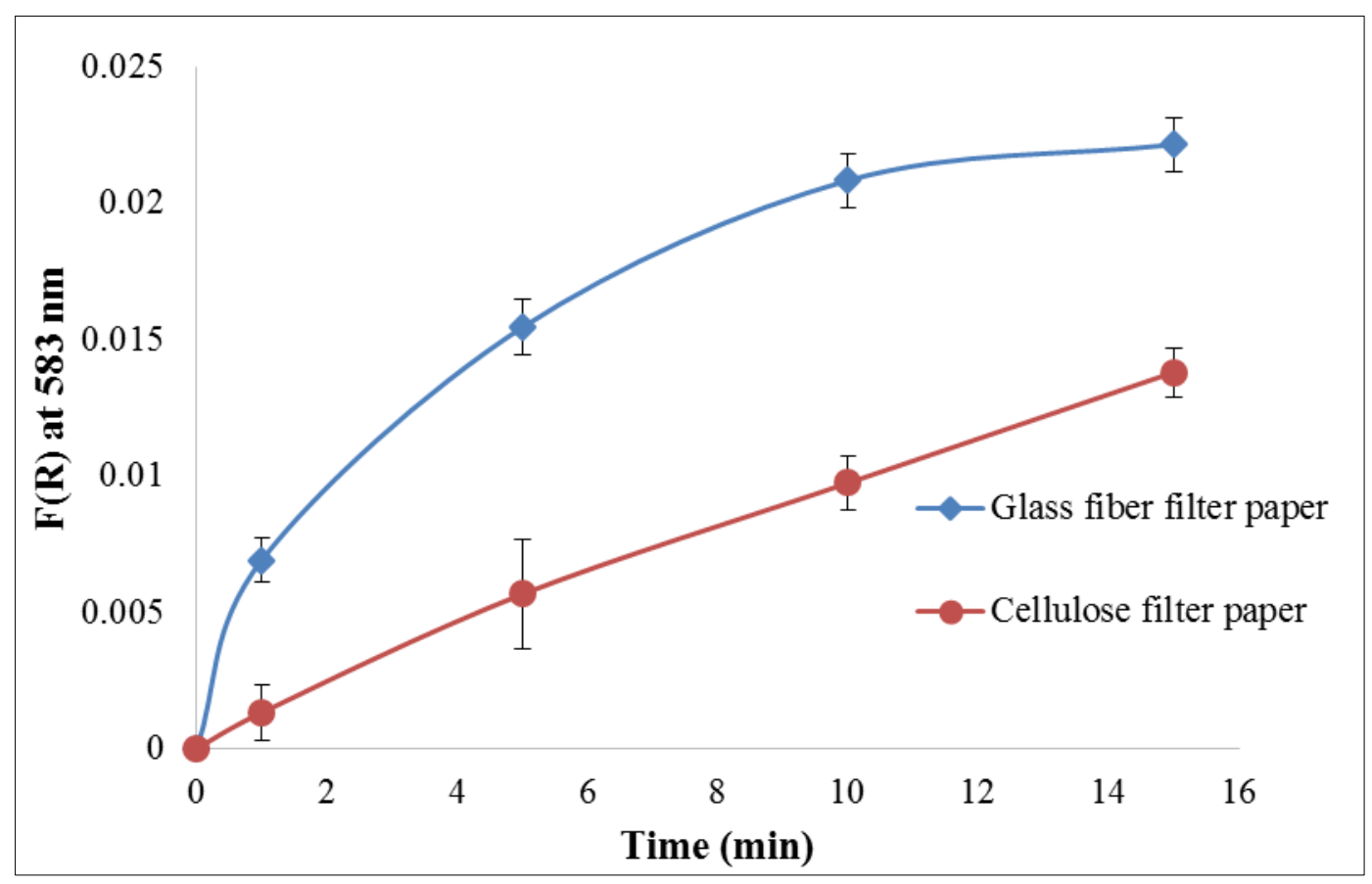

\section{Tables}

Table A.1 - Sensor holder dimensions

\begin{tabular}{|c|c|}
\hline Letter & Measurement $(\mathrm{mm})$ \\
\hline A & 3.0 \\
\hline B & 7.6 \\
\hline C & 12.7 \\
\hline D & 12.7 \\
\hline E & 23.8 \\
\hline F & 11.5 \\
\hline G & 3.0 \\
\hline
\end{tabular}


Table A.2. - Reproducibility plan for 6 months; "x" represents that absorbance was taken by the Ocean Optics miniature spectrometer

\begin{tabular}{|l|l|l|l|l|l|l|}
\hline $\begin{array}{l}\text { Fresh } \\
\text { Cbi }\end{array}$ & 1 Month & $\begin{array}{l}\text { 1 Month w/ } \\
\text { HCN }\end{array}$ & $\begin{array}{l}\text { 3 } \\
\text { Months }\end{array}$ & $\begin{array}{l}\text { 3 Months with } \\
\text { HCN }\end{array}$ & $\begin{array}{l}\text { 6 } \\
\text { Months }\end{array}$ & $\begin{array}{l}\text { 6 Months with } \\
\text { HCN }\end{array}$ \\
\hline 1 & $\mathrm{x}$ & $\mathrm{x}$ & & & & \\
\hline 2 & $\mathrm{x}$ & & $\mathrm{x}$ & & $\mathrm{x}$ & $\mathrm{x}$ \\
\hline 3 & $\mathrm{x}$ & & $\mathrm{x}$ & & $\mathrm{x}$ & \\
\hline 4 & $\mathrm{x}$ & & $\mathrm{x}$ & & & \\
\hline 5 & $\mathrm{x}$ & $\mathrm{x}$ & $\mathrm{x}$ & & $\mathrm{x}$ & \\
\hline 6 & $\mathrm{x}$ & & $\mathrm{x}$ & & $\mathrm{x}$ & \\
\hline 7 & $\mathrm{x}$ & & $\mathrm{x}$ & & $\mathrm{x}$ & \\
\hline 8 & $\mathrm{x}$ & & $\mathrm{x}$ & & $\mathrm{x}$ & \\
\hline 9 & $\mathrm{x}$ & & & & & \\
\hline 10 & $\mathrm{x}$ & $\mathrm{x}$ & $\mathrm{x}$ & $\mathrm{x}$ & & \\
\hline 11 & & & $\mathrm{x}$ & $\mathrm{x}$ & & \\
\hline 12 & & & $\mathrm{x}$ & $\mathrm{x}$ & & \\
\hline 13 & & & & & $\mathrm{x}$ & $\mathrm{x}$ \\
\hline 14 & & & & $\mathrm{~N}=10$ & $\mathrm{~N}=3$ & $\mathrm{x}$ \\
\hline 15 & & & $\mathrm{~N}=3$ & & & $\mathrm{~N}=9$ \\
\hline
\end{tabular}

Table A.3 - Apparent absorbance and F(R) data for cellulose filter paper exposed to $5.0 \mathrm{ppm}$ HCN (Figure 2.22)

\begin{tabular}{|c|c|c|c|c|}
\hline $\begin{array}{c}\text { Time } \\
(\mathbf{m i n})\end{array}$ & Abs. at 583 nm & 95\% CI Abs. & F(R) & $\begin{array}{c}\text { 95\% CI } \\
\text { F(R) }\end{array}$ \\
\hline $\mathbf{0}$ & 0.0005 & 0.0002 & $3 . \mathrm{E}-06$ & $8 . \mathrm{E}-06$ \\
\hline $\mathbf{1}$ & 0.02 & 0.01 & 0.001 & 0.001 \\
\hline $\mathbf{5}$ & 0.05 & 0.02 & 0.006 & 0.002 \\
\hline $\mathbf{1 0}$ & 0.06 & 0.02 & 0.010 & 0.001 \\
\hline $\mathbf{1 5}$ & 0.07 & 0.02 & 0.0138 & 0.0009 \\
\hline
\end{tabular}


Table A.4 - Apparent absorbance and $\mathrm{F}(\mathrm{R})$ values for cellulose filter paper exposed to $\mathrm{HCN}$ concentration for 5 minutes (Figure 2.23)

\begin{tabular}{|c|c|c|c|c|}
\hline HCN ppm & Abs at 583 nm & Abs. 95\% CI & F(R) at 583 nm & F(R) 95\% CI \\
\hline $\mathbf{0 . 0}$ & 0.0008 & 0.0005 & 1.7 E-06 & 3. E-07 \\
\hline $\mathbf{1 . 0}$ & 0.02 & 0.02 & 0.001 & 0.001 \\
\hline $\mathbf{3 . 0}$ & 0.04 & 0.02 & 0.003 & 0.001 \\
\hline $\mathbf{5 . 0}$ & 0.05 & 0.02 & 0.006 & 0.002 \\
\hline $\mathbf{7 . 0}$ & 0.05 & 0.02 & 0.008 & 0.001 \\
\hline $\mathbf{1 0 . 0}$ & 0.07 & 0.02 & 0.012 & 0.001 \\
\hline $\mathbf{1 5 . 0}$ & 0.07 & 0.02 & 0.014 & 0.001 \\
\hline
\end{tabular}

Table A.5 - Glass fiber filter data for 5.0 ppm HCN $25 \%$ RH (Figure 2.30)

\begin{tabular}{|c|c|c|c|c|}
\hline Time (min) & Ave Abs. at 583 nm & Abs 95\% CI & F(R) & F(R) 95\% CI \\
\hline $\mathbf{0}$ & 0.0006 & 0.0001 & 1. E-06 & 1. E-06 \\
\hline $\mathbf{1}$ & 0.051 & 0.008 & 0.007 & 0.001 \\
\hline $\mathbf{5}$ & 0.08 & 0.01 & 0.015 & 0.001 \\
\hline $\mathbf{1 0}$ & 0.09 & 0.01 & 0.021 & 0.001 \\
\hline $\mathbf{1 5}$ & 0.09 & 0.01 & 0.022 & 0.001 \\
\hline
\end{tabular}


Table A.6 - Glass fiber data for 1 and 15 minute HCN exposure (Figures 2.31 and 2.32)

\begin{tabular}{|c|c|c|c|c|}
\hline \multicolumn{5}{|c|}{ 1 Minute HCN Exposure } \\
\hline HCN Concentration (ppm) & Abs. at 583 nm & Abs. 95\% CI & F(R) & F(R) 95\% CI \\
\hline 0.0 & 0.0006 & 0.0001 & 0.000001 & $2 . \mathrm{E}-08$ \\
\hline 1.0 & 0.017 & 0.005 & 0.0008 & 0.0009 \\
\hline 3.0 & 0.041 & 0.004 & 0.004 & 0.001 \\
\hline 5.0 & 0.051 & 0.008 & 0.007 & 0.001 \\
\hline 7.0 & 0.06 & 0.01 & 0.010 & 0.001 \\
\hline 10.0 & 0.079 & 0.007 & 0.0167 & 0.0009 \\
\hline \multicolumn{5}{|c|}{15 Minute HCN Exposure } \\
\hline HCN Concentration (ppm) & Abs. at 583 nm & Abs. 95\% CI & $\mathbf{F}(\mathbf{R})$ & $\mathbf{F}(\mathbf{R}) \mathbf{9 5 \%}$ CI \\
\hline 0.0 & 0.0006 & 0.0001 & 0.000001 & $2 . \mathrm{E}-08$ \\
\hline 1.0 & 0.048 & 0.005 & 0.006 & 0.001 \\
\hline 3.0 & 0.071 & 0.006 & 0.013 & 0.001 \\
\hline 5.0 & 0.09 & 0.01 & 0.022 & 0.001 \\
\hline 7.0 & 0.105 & 0.008 & 0.029 & 0.001 \\
\hline 10.0 & 0.13 & 0.01 & 0.0456 & 0.0009 \\
\hline
\end{tabular}

Table A.7 - Comparison of cellulose and glass fiber to 5.0 ppm HCN (Figure 2.36)

\begin{tabular}{|c|c|c|c|c|}
\hline Time (min) & $\begin{array}{c}\mathbf{F}(\mathbf{R}) \text { at 583 } \\
\text { nm Cellulose } \\
\text { F.P. }\end{array}$ & $\begin{array}{c}\mathbf{9 5 \%} \mathbf{C I} \\
\mathbf{n = 3}\end{array}$ & $\begin{array}{c}\mathbf{F}(\mathbf{R}) \text { at 583 } \\
\text { nm Glass } \\
\text { Fiber F.P. }\end{array}$ & $\begin{array}{c}\mathbf{9 5 \%} \text { CI } \\
\mathbf{n = 6}\end{array}$ \\
\hline 0 & $7.4 \times 10^{-7}$ & $6.6 \times 10^{-8}$ & 1. E-06 & 1. E $10-6$ \\
\hline 1 & 0.0013 & 0.001 & 0.007 & 0.001 \\
\hline 5 & 0.0057 & 0.002 & 0.015 & 0.001 \\
\hline 10 & 0.0097 & 0.001 & 0.021 & 0.001 \\
\hline 15 & 0.0138 & 0.0009 & 0.022 & 0.001 \\
\hline
\end{tabular}


Table A. 8 - Average F(R) Cbi response on cellulose filter paper for 25, 50, and $85 \%$ RH (Figure 2.40)

\begin{tabular}{|c|c|c|c|c|c|c|}
\hline Time & $\mathbf{F}(\mathbf{R}) \mathbf{a t}$ & $\mathbf{9 5 \%}$ & $\mathbf{F}(\mathbf{R}) \mathbf{a t}$ & $\mathbf{9 5 \%}$ & $\mathbf{F}(\mathbf{R}) \mathbf{a t}$ & $\mathbf{9 5 \%}$ \\
$\mathbf{( m i n})$ & $\mathbf{5 8 3} \mathbf{~ n m}$ & $\mathbf{C I}$ & $\mathbf{5 8 3} \mathbf{~ m}$ & $\mathbf{C I}$ & $\mathbf{5 8 3} \mathbf{~ m}$ & $\mathbf{C I}$ \\
& $\mathbf{2 5 \%} \mathbf{~ R H}$ & $\mathbf{N = 3}$ & $\mathbf{5 0 \%} \mathbf{R H}$ & $\mathbf{N = 3}$ & $\mathbf{8 5 \%} \mathbf{R H}$ & $\mathbf{N = 3}$ \\
\hline $\mathbf{0}$ & $4 \mathrm{E}-07$ & $9 \mathrm{E}-08$ & $7 \mathrm{E}-06$ & $7 \mathrm{E}-08$ & $9 \mathrm{E}-06$ & $2 \mathrm{E}-07$ \\
\hline $\mathbf{1}$ & 0.0013 & 0.001 & 0.005 & 0.001 & 0.0115 & 0.0009 \\
\hline $\mathbf{5}$ & 0.006 & 0.002 & 0.0248 & 0.0009 & 0.0309 & 0.0009 \\
\hline $\mathbf{1 0}$ & 0.010 & 0.001 & 0.0330 & 0.0009 & 0.035 & 0.001 \\
\hline $\mathbf{1 5}$ & 0.0136 & 0.0009 & 0.035 & 0.001 & 0.036 & 0.001 \\
\hline $\mathbf{6 0}$ & 0.030 & 0.001 & \multicolumn{5}{|l}{} \\
\hline
\end{tabular}

Table A.9 - Average F(R)Cbi Response on glass fiber filter paper for 25, 50, and 85\% RH (Figure 2.41)

\begin{tabular}{|c|c|c|c|c|c|c|}
\hline $\begin{array}{c}\text { Time } \\
\text { (min) }\end{array}$ & $\begin{array}{c}\mathbf{F}(\mathbf{R}) \text { at } \\
\mathbf{5 8 3} \mathbf{~ n m} \\
\text { for 25\% } \\
\mathbf{R H}\end{array}$ & $\begin{array}{c}\mathbf{9 5 \%} \\
\text { CI N=6 }\end{array}$ & $\begin{array}{c}\mathbf{F}(\mathbf{R}) \text { at } \\
\mathbf{5 8 3} \mathbf{~ n m} \\
\text { for 50\% } \\
\mathbf{R H}\end{array}$ & $\begin{array}{c}\mathbf{9 5 \%} \\
\mathbf{C I} \mathbf{N}=\mathbf{3}\end{array}$ & $\begin{array}{c}\mathbf{F}(\mathbf{R}) \mathbf{a t} \\
\mathbf{5 8 3} \mathbf{~ n m} \\
\text { for 85\% } \\
\mathbf{R H}\end{array}$ & $\begin{array}{c}\mathbf{9 5 \%} \\
\mathbf{C I} \mathbf{N = 3}\end{array}$ \\
\hline $\mathbf{0}$ & $1 \mathrm{E}-06$ & $3 \mathrm{E}-08$ & $1 \mathrm{E}-06$ & $7 \mathrm{E}-08$ & $1 \mathrm{E}-05$ & $7 \mathrm{E}-06$ \\
\hline $\mathbf{1}$ & 0.007 & 0.001 & 0.026 & 0.002 & 0.060 & 0.004 \\
\hline $\mathbf{5}$ & 0.015 & 0.001 & 0.040 & 0.001 & 0.062 & 0.003 \\
\hline $\mathbf{1 0}$ & 0.021 & 0.001 & 0.041 & 0.001 & 0.062 & 0.003 \\
\hline $\mathbf{1 5}$ & 0.022 & 0.001 & 0.042 & 0.001 & 0.063 & 0.003 \\
\hline
\end{tabular}


Table A.10 - Average initial response for cellulose paper (Figure 2.43a)

\begin{tabular}{|c|c|c|c|}
\hline $\begin{array}{c}\text { Time } \\
(\mathbf{s})\end{array}$ & $\begin{array}{c}\text { F(R) at 583 } \\
\text { nm for 25\% } \\
\mathbf{R H}\end{array}$ & $\begin{array}{c}\mathbf{F}(\mathbf{R}) \text { at 583 } \\
\text { nm for 50\% } \\
\mathbf{R H}\end{array}$ & $\begin{array}{c}\mathbf{F}(\mathbf{R}) \text { at 583 } \\
\text { nm for 85\% } \\
\mathbf{R H}\end{array}$ \\
\hline $\mathbf{0}$ & $4 \mathrm{E}-06$ & $9 \mathrm{E}-06$ & $8 \mathrm{E}-06$ \\
\hline $\mathbf{3}$ & $4 \mathrm{E}-06$ & $5 \mathrm{E}-06$ & $1 \mathrm{E}-05$ \\
\hline $\mathbf{6}$ & $5 \mathrm{E}-05$ & $2 \mathrm{E}-05$ & $1 \mathrm{E}-05$ \\
\hline $\mathbf{9}$ & $9 \mathrm{E}-05$ & $6 \mathrm{E}-05$ & 0.0001 \\
\hline $\mathbf{1 2}$ & 0.0002 & 0.0002 & 0.0006 \\
\hline $\mathbf{1 5}$ & 0.0002 & 0.0005 & 0.0014 \\
\hline $\mathbf{1 8}$ & 0.0003 & 0.0007 & 0.0023 \\
\hline $\mathbf{2 1}$ & 0.0004 & 0.0010 & 0.0033 \\
\hline $\mathbf{2 4}$ & 0.0005 & 0.0013 & 0.0041 \\
\hline $\mathbf{2 7}$ & 0.0006 & 0.0017 & 0.0049 \\
\hline $\mathbf{3 0}$ & 0.0007 & 0.0019 & 0.0060 \\
\hline $\mathbf{3 3}$ & 0.0008 & 0.0022 & 0.0065 \\
\hline $\mathbf{3 6}$ & 0.0008 & 0.0026 & 0.0071 \\
\hline $\mathbf{3 9}$ & 0.0009 & 0.0029 & 0.0077 \\
\hline $\mathbf{4 2}$ & 0.0010 & 0.0032 & 0.0083 \\
\hline $\mathbf{4 5}$ & 0.0011 & 0.0035 & 0.0089 \\
\hline $\mathbf{4 8}$ & 0.0012 & 0.0039 & 0.0094 \\
\hline $\mathbf{5 1}$ & 0.0013 & 0.0042 & 0.010 \\
\hline $\mathbf{5 4}$ & 0.0014 & 0.0045 & 0.0106 \\
\hline $\mathbf{5 7}$ & 0.0014 & 0.0047 & 0.0110 \\
\hline $\mathbf{6 0}$ & 0.0015 & 0.0052 & 0.0115 \\
\hline
\end{tabular}

Table A.11 - Average initial response for glass fiber paper (Figure 2.43b)

\begin{tabular}{|c|c|c|c|}
\hline $\begin{array}{c}\text { Time } \\
(\mathbf{s})\end{array}$ & $\begin{array}{c}\text { F(R) at 583 } \\
\text { nm for 25\% } \\
\text { RH }\end{array}$ & $\begin{array}{c}\text { F(R) at 583 } \\
\text { nm for 50\% } \\
\text { RH }\end{array}$ & $\begin{array}{c}\text { F(R) at 583 } \\
\text { nm for 85\% } \\
\text { RH }\end{array}$ \\
\hline $\mathbf{0}$ & $5 \mathrm{E}-07$ & $3 \mathrm{E}-05$ & $2 \mathrm{E}-05$ \\
\hline $\mathbf{3}$ & $2 \mathrm{E}-06$ & 0.0002 & $4 \mathrm{E}-05$ \\
\hline $\mathbf{6}$ & 0.0002 & 0.0013 & 0.0002 \\
\hline $\mathbf{9}$ & 0.0006 & 0.0037 & 0.0045 \\
\hline $\mathbf{1 2}$ & 0.0011 & 0.0065 & 0.0181 \\
\hline $\mathbf{1 5}$ & 0.0016 & 0.0093 & 0.0391 \\
\hline $\mathbf{1 8}$ & 0.0019 & 0.0113 & 0.0543 \\
\hline $\mathbf{2 1}$ & 0.0023 & 0.0133 & 0.0577 \\
\hline $\mathbf{2 4}$ & 0.0026 & 0.0145 & 0.0591 \\
\hline $\mathbf{2 7}$ & 0.0030 & 0.0158 & 0.0596 \\
\hline $\mathbf{3 0}$ & 0.0032 & 0.0172 & 0.0594 \\
\hline $\mathbf{3 3}$ & 0.0036 & 0.0180 & 0.0596 \\
\hline $\mathbf{3 6}$ & 0.0037 & 0.0190 & 0.0609 \\
\hline $\mathbf{3 9}$ & 0.0041 & 0.0200 & 0.0615 \\
\hline $\mathbf{4 2}$ & 0.0043 & 0.0208 & 0.0614 \\
\hline $\mathbf{4 5}$ & 0.0045 & 0.0216 & 0.0612 \\
\hline $\mathbf{4 8}$ & 0.0048 & 0.0223 & 0.0623 \\
\hline $\mathbf{5 1}$ & 0.0052 & 0.0230 & 0.0624 \\
\hline $\mathbf{5 4}$ & 0.0058 & 0.0238 & 0.0626 \\
\hline $\mathbf{5 7}$ & 0.0062 & 0.0244 & 0.0633 \\
\hline
\end{tabular}




\begin{tabular}{|l|l|l|l|}
\hline $\mathbf{6 0}$ & 0.0070 & 0.0247 & 0.0635 \\
\hline
\end{tabular}

\section{Appendix B - Tables and Figures for Chapter 3}

\section{Figures}

Figure B1. $-1 \mathrm{M} \mathrm{HCl}$ addition to $50.0 \mu \mathrm{M} \mathrm{OH}\left(\mathrm{H}_{2} \mathrm{O}\right) \mathrm{Cbi}$

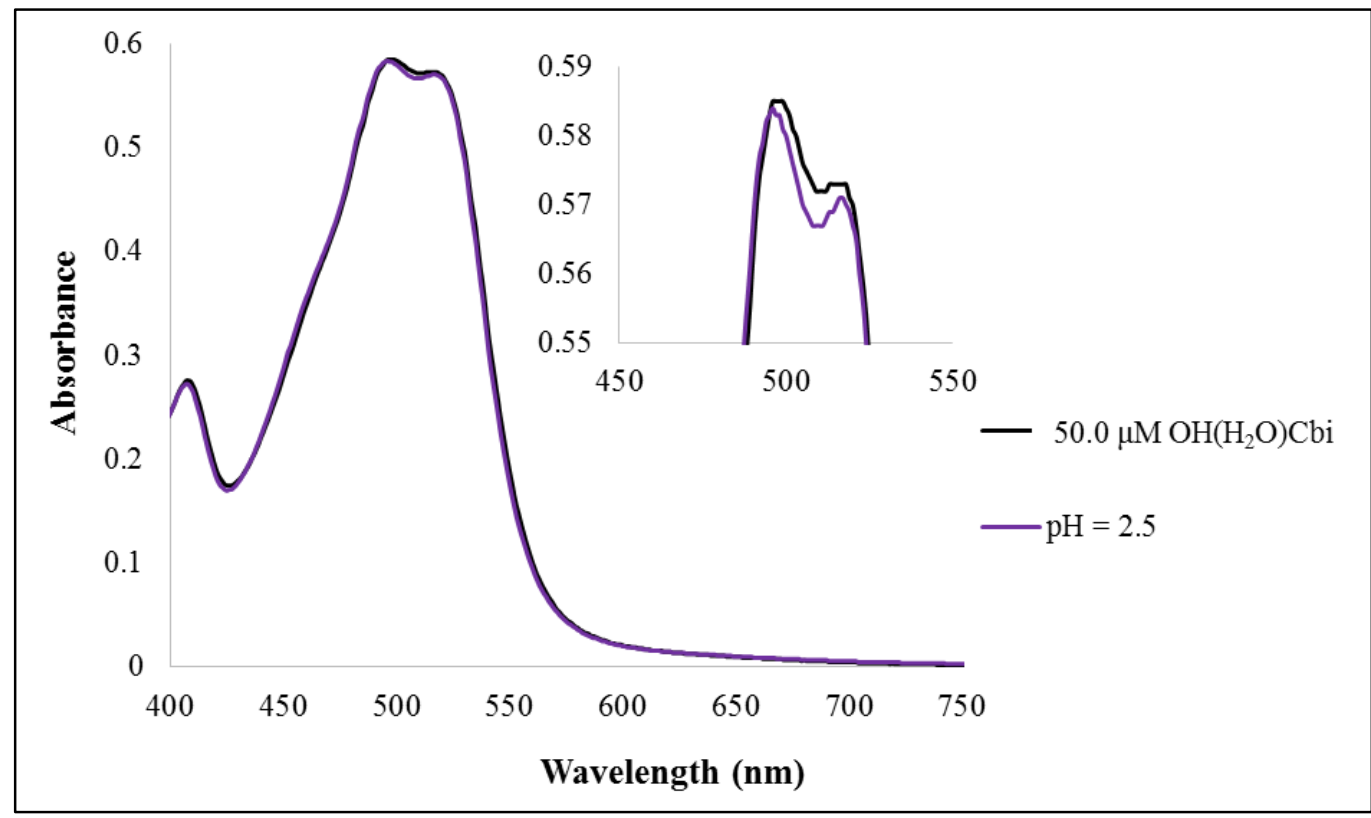


Figure B.2. - Response of $\mathrm{OH}\left(\mathrm{H}_{2} \mathrm{O}\right) \mathrm{Cbi}$ on glass fiber paper to $10.0 \mathrm{ppm} \mathrm{H}_{2} \mathrm{~S}$ at $50 \% \mathrm{RH}$

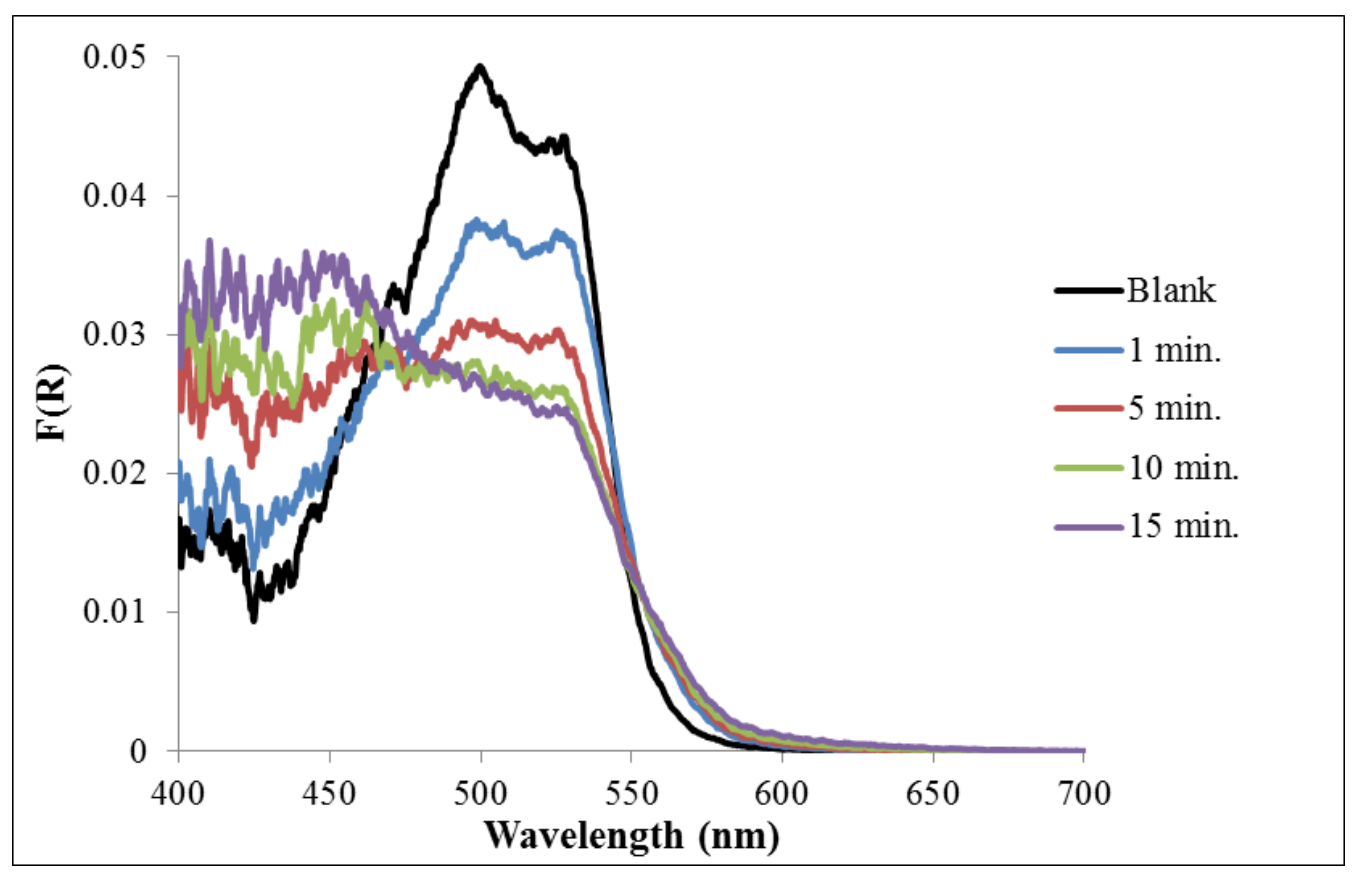

Figure B.3 - Average $\mathrm{F}(\mathrm{R})$ response of $\mathrm{OH}\left(\mathrm{H}_{2} \mathrm{O}\right)$ Cbi to $10.0 \mathrm{ppm}_{2} \mathrm{~S}$ at various exposure times $(50 \% \mathrm{RH})$

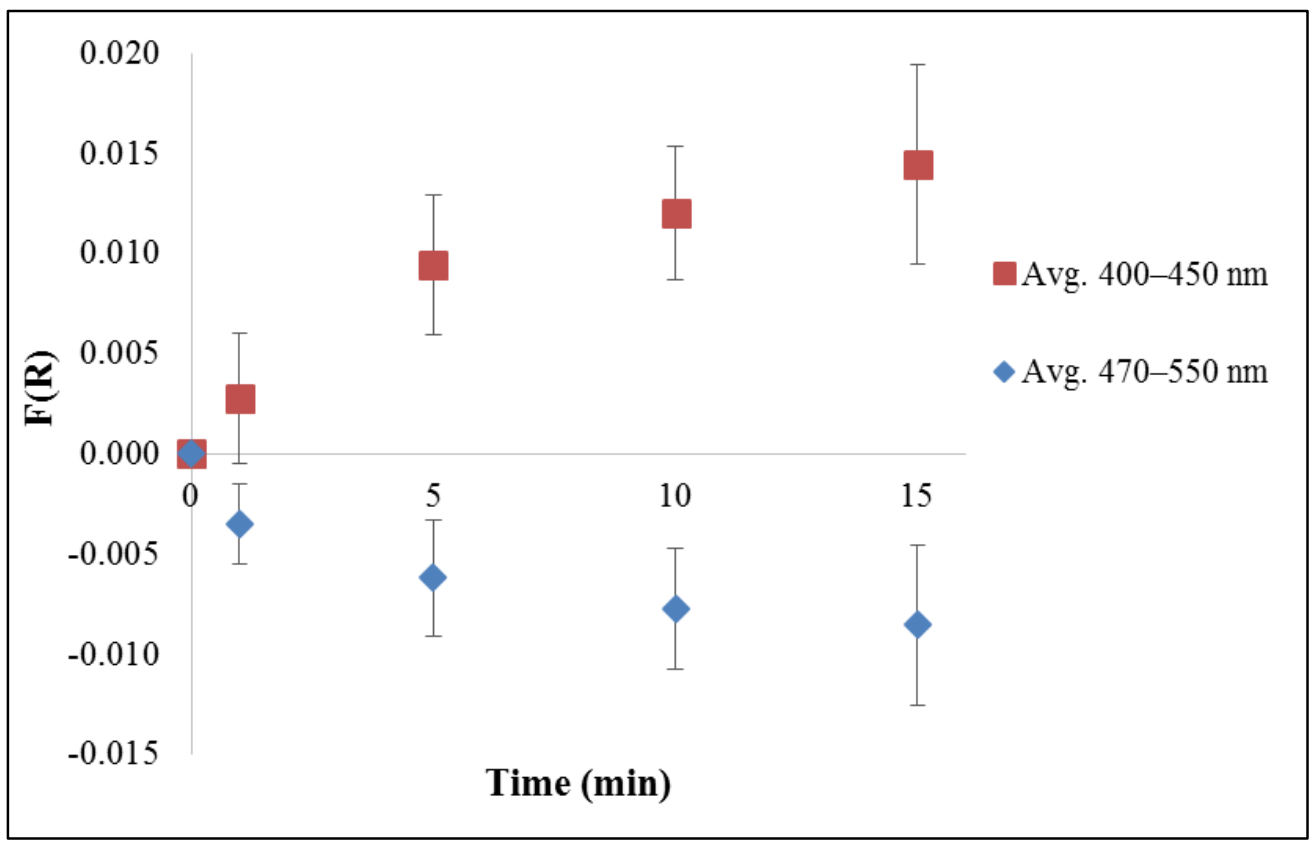




\section{Tables}

Table B.1 - Response of $\mathrm{OH}\left(\mathrm{H}_{2} \mathrm{O}\right) \mathrm{Cbi}$ on glass fiber paper to $10.0 \mathrm{ppm} \mathrm{H}_{2} \mathrm{~S}$ at $25 \% \mathrm{RH}$ ( $\mathrm{n}=3$; Figure 3.9)

\begin{tabular}{|c|c|c|c|c|}
\hline $\begin{array}{c}\text { Time } \\
(\mathbf{m i n})\end{array}$ & $\begin{array}{c}\mathbf{4 0 0}-\mathbf{4 5 0} \mathbf{~ n m} \text { Apparent } \\
\text { Abs. }\end{array}$ & $\begin{array}{c}\mathbf{9 5 \%} \\
\text { CI }\end{array}$ & $\begin{array}{c}\mathbf{4 7 0}-\mathbf{5 5 0} \mathbf{~ n m} \text { Apparent } \\
\text { Abs. }\end{array}$ & $\begin{array}{c}\mathbf{9 5 \%} \\
\text { CI }\end{array}$ \\
\hline $\mathbf{0}$ & 0.0002 & 0.0001 & 0.0001 & 0.0001 \\
\hline $\mathbf{1}$ & 0.010 & 0.005 & -0.008 & 0.004 \\
\hline $\mathbf{5}$ & 0.02 & 0.01 & -0.018 & 0.005 \\
\hline $\mathbf{1 0}$ & 0.026 & 0.005 & -0.024 & 0.008 \\
\hline $\mathbf{1 5}$ & 0.031 & 0.005 & -0.030 & 0.007 \\
\hline $\mathbf{T i m e}$ & $\mathbf{F}(\mathbf{R}) \mathbf{4 0 0 - 4 5 0} \mathbf{~ n m}$ & $\mathbf{9 5 \%}$ & $\mathbf{F}(\mathbf{R}) \mathbf{4 7 0}-\mathbf{5 5 0} \mathbf{~ n m}$ & $\mathbf{9 5 \%}$ \\
$(\mathbf{m i n})$ & & $\mathbf{C I}$ & & $\mathbf{C I}$ \\
\hline $\mathbf{0}$ & $8 . \mathrm{E}-07$ & $1 . \mathrm{E}-07$ & $9 . \mathrm{E}-08$ & $1 . \mathrm{E}-08$ \\
\hline $\mathbf{1}$ & 0.0002 & 0.0002 & -0.0002 & 0.0001 \\
\hline $\mathbf{5}$ & 0.001 & 0.001 & -0.0009 & 0.0005 \\
\hline $\mathbf{1 0}$ & 0.0017 & 0.0006 & -0.002 & 0.001 \\
\hline $\mathbf{1 5}$ & 0.0025 & 0.0005 & -0.002 & 0.001 \\
\hline
\end{tabular}

Table B.2 - Response of $\mathrm{OH}\left(\mathrm{H}_{2} \mathrm{O}\right) \mathrm{Cbi}$ on glass fiber paper to $10.0 \mathrm{ppm} \mathrm{H}_{2} \mathrm{~S}$ at $50 \% \mathrm{RH}$ ( $\mathrm{n}=3$; Figure 3.13)

\begin{tabular}{|c|c|c|c|c|}
\hline Time (min) & F(R) 400-450 $\mathbf{~ n m}$ & $\mathbf{9 5 \%} \mathbf{C I}$ & $\mathbf{F}(\mathbf{R}) \mathbf{4 7 0}-\mathbf{5 5 0} \mathbf{~ n m}$ & $\mathbf{9 5 \%} \mathbf{C I}$ \\
\hline 0 & $8 . \mathrm{E}-07$ & $1 . \mathrm{E}-07$ & $9 . \mathrm{E}-08$ & $1 . \mathrm{E}-08$ \\
\hline 1 & 0.003 & 0.003 & -0.003 & 0.002 \\
\hline 5 & 0.009 & 0.003 & -0.006 & 0.003 \\
\hline 10 & 0.012 & 0.003 & -0.008 & 0.003 \\
\hline 15 & 0.014 & 0.005 & -0.009 & 0.004 \\
\hline
\end{tabular}


Table B.3 - Response for $\mathrm{OH}\left(\mathrm{H}_{2} \mathrm{O}\right) \mathrm{Cbi}$ on glass fiber paper to $10.0 \mathrm{ppm}_{2} \mathrm{~S}$ at $85 \% \mathrm{RH}(\mathrm{n}=3)$

\begin{tabular}{|c|c|c|c|c|}
\hline Time (min) & F(R) 400-450 nm & $\mathbf{9 5 \%} \mathbf{C I}$ & $\mathbf{F}(\mathbf{R}) \mathbf{4 7 0 - 5 5 0 ~} \mathbf{~ n m}$ & $\mathbf{9 5 \%} \mathbf{C I}$ \\
\hline 0 & $8 . \mathrm{E}-07$ & $1 . \mathrm{E}-07$ & $9 . \mathrm{E}-08$ & $1 . \mathrm{E}-08$ \\
\hline 1 & 0.02 & 0.01 & -0.019 & 0.007 \\
\hline 5 & 0.02 & 0.01 & -0.024 & 0.008 \\
\hline 10 & 0.03 & 0.01 & -0.018 & 0.01 \\
\hline 15 & 0.038 & 0.009 & -0.017 & 0.01 \\
\hline
\end{tabular}

\section{Appendix C - Tables and Figures for Chapter 4}

\section{Figures}

Figure C.1 - HCN experimental flow setup

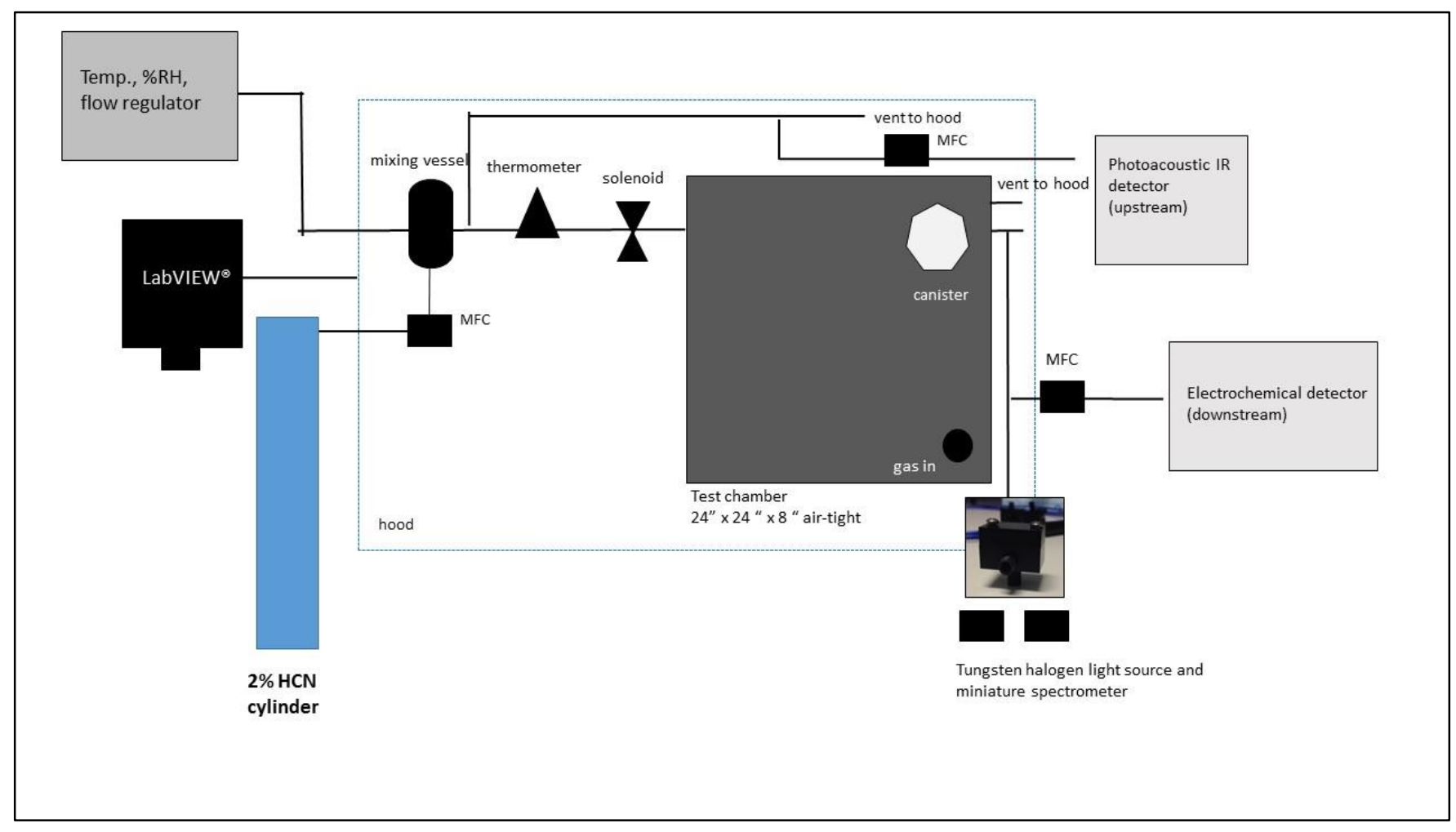


Figure C. $2-\mathrm{H}_{2} \mathrm{~S}$ experimental flow setup

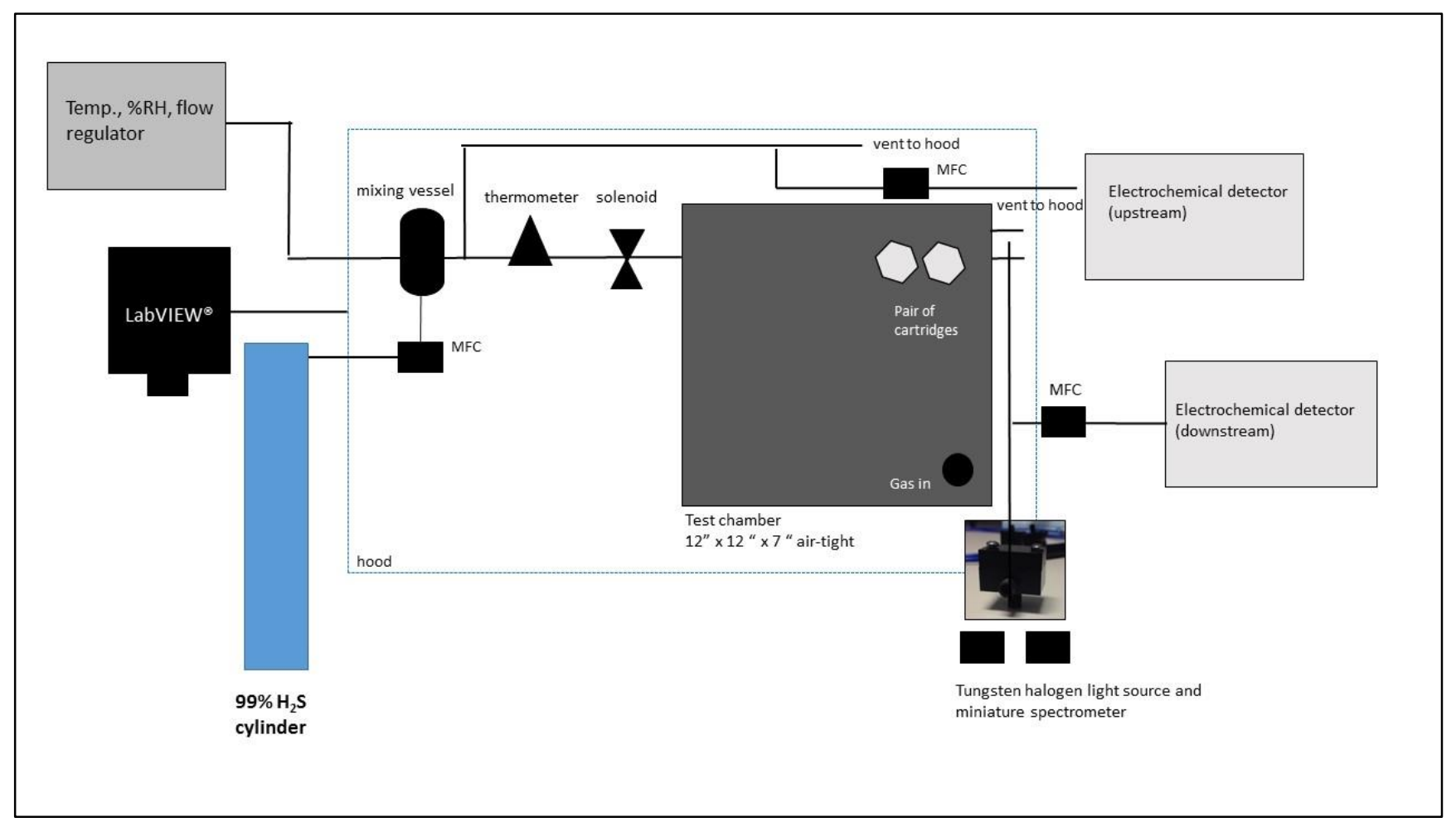


Figure C.3 - Inside of $\mathrm{HCN}$ test chamber (A and B)
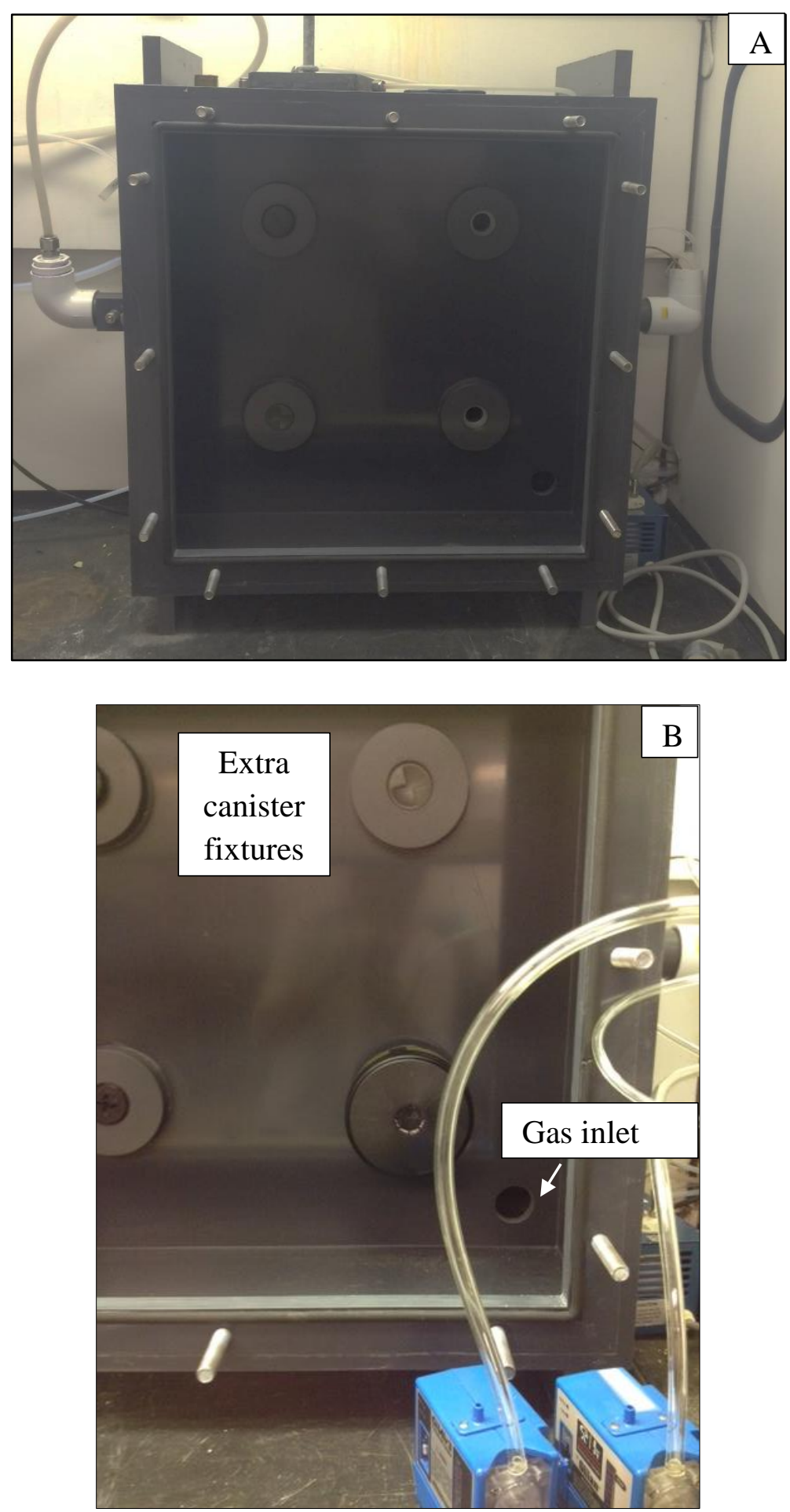
Figure C.4 - Raw electrochemical data to breakthrough of $\mathrm{HCN}$ canister

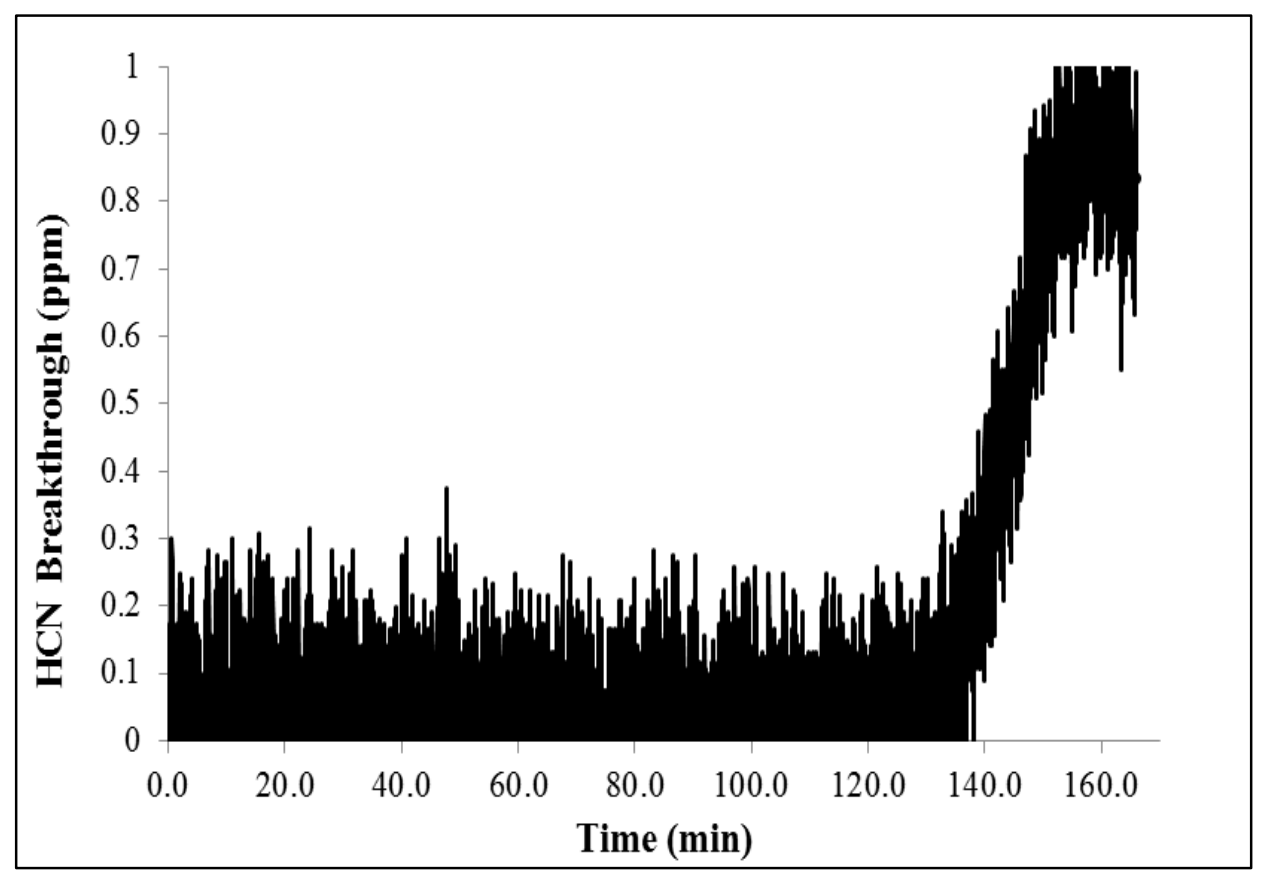

Figure C.5 - Electrochemical detector response to breakthrough of $\mathrm{H}_{2} \mathrm{~S}$ at $50 \% \mathrm{RH}$

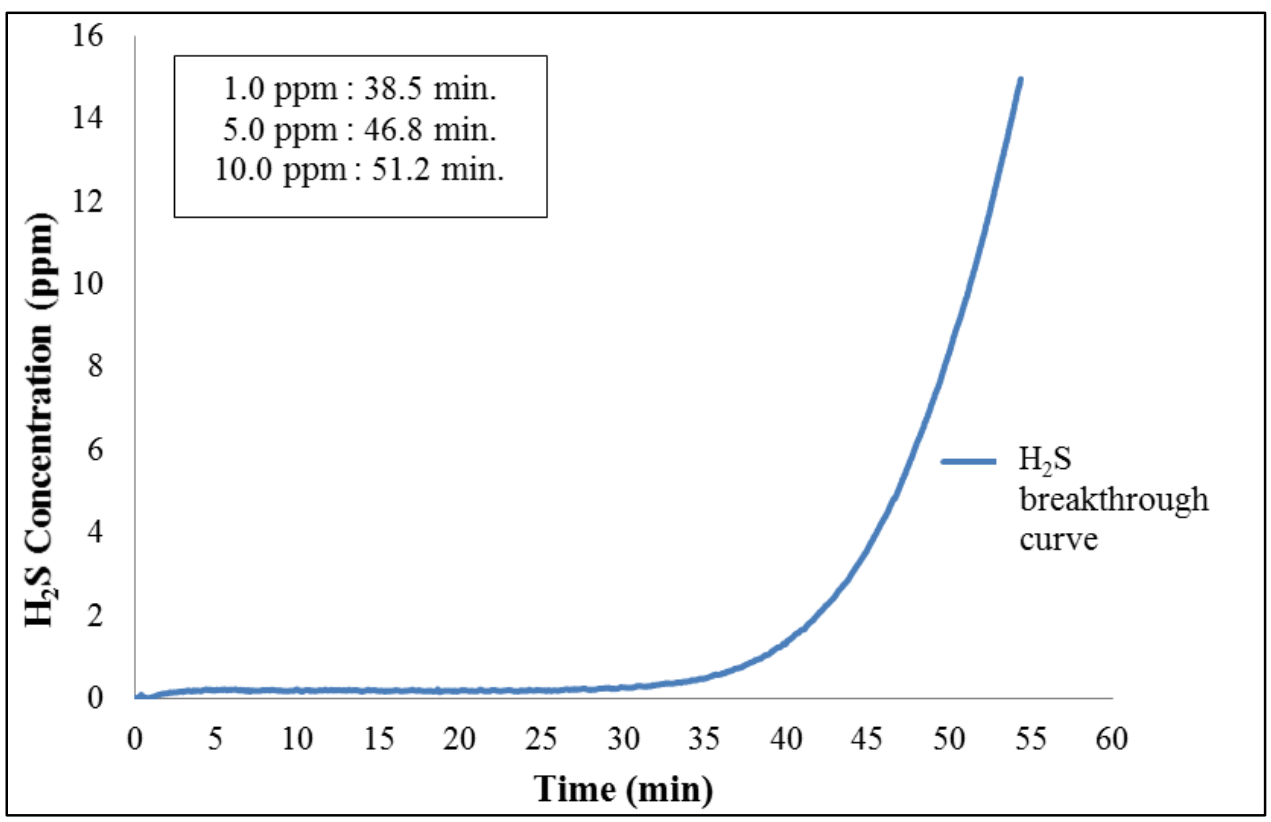


Figure C.6- Average difference spectra of $\mathrm{OH}\left(\mathrm{H}_{2} \mathrm{O}\right)$ Cbi response to $\mathrm{H}_{2} \mathrm{~S}$ breakthrough at 85 $\% \mathrm{RH}(\mathrm{n}=3)$

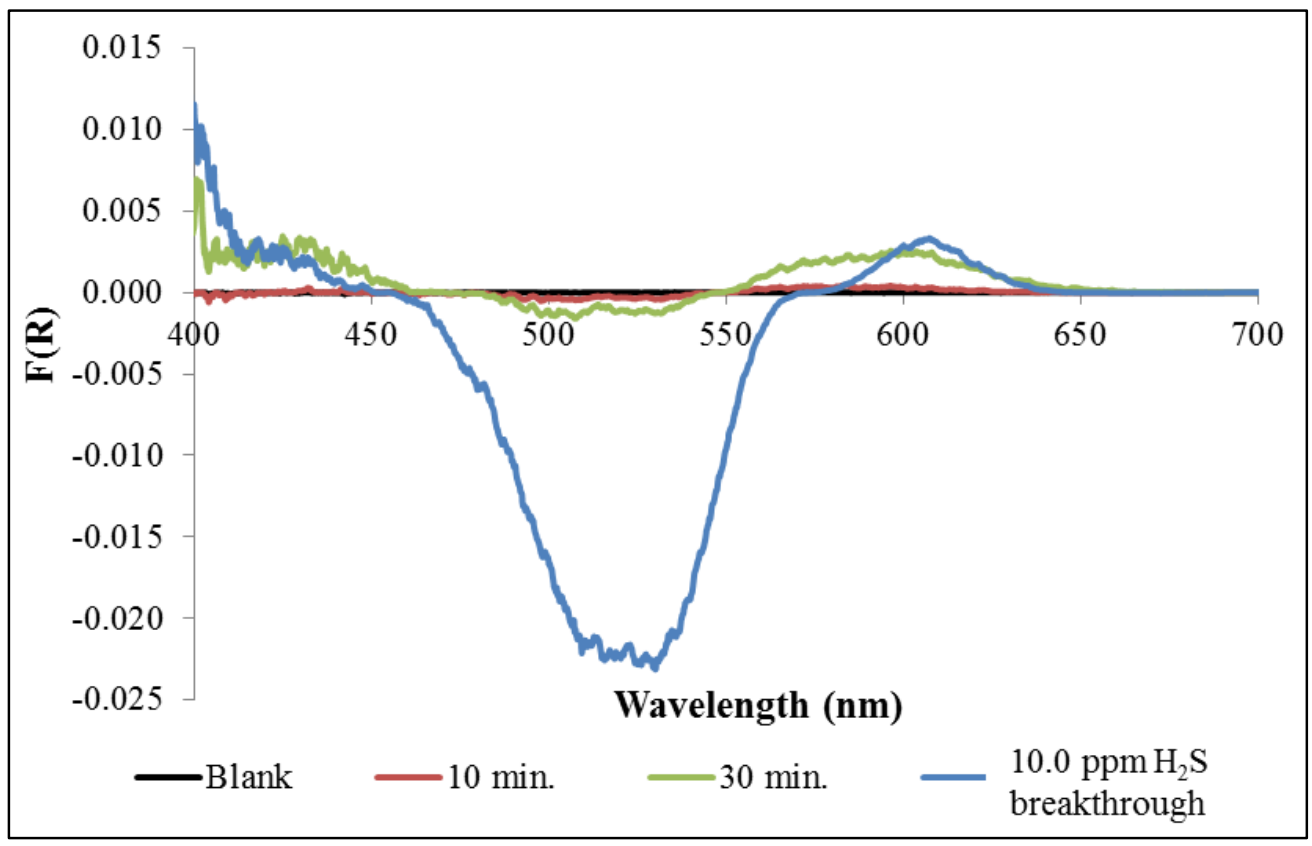

Figure C.7 - Electrochemical detector response to breakthrough of $\mathrm{H}_{2} \mathrm{~S}$ at $85 \% \mathrm{RH}$

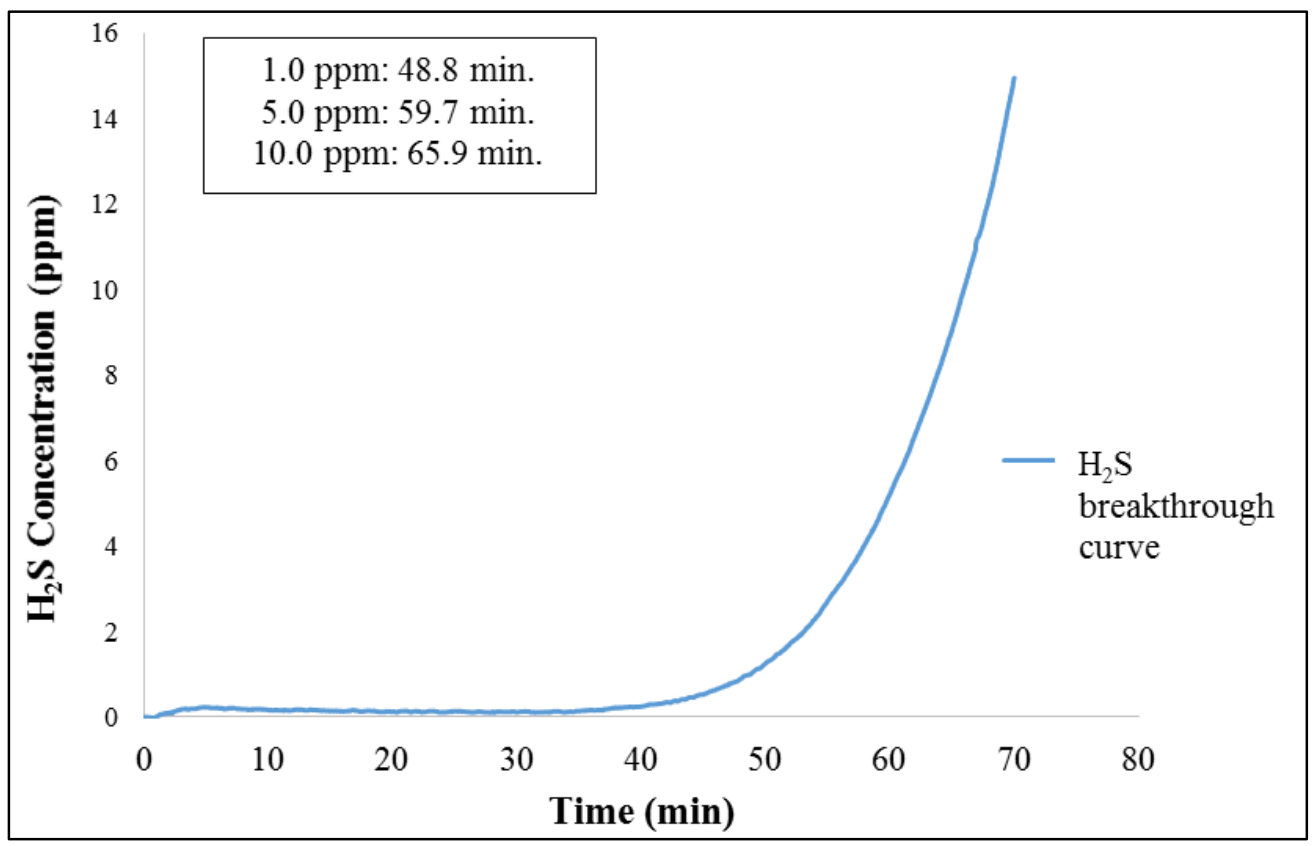




\section{Tables}

Table C. 1 - Slopes as a function of time into experiment ( $25 \% \mathrm{RH})$

\begin{tabular}{|c|c|c|}
\hline & \multicolumn{2}{|c|}{ Time into experiment (min.) } \\
\hline Wavelength range & $20.0-30.0$ & $36.3+(i . e .1 .0 \mathrm{ppm}+)$ \\
\hline $400-450 \mathrm{~nm}$ & $\mathrm{y}=7.4 \mathrm{E}-7 \mathrm{x}^{2}+\mathbf{4 . 3 E}-6 \mathbf{x}-2.2 \mathrm{E}-4$ & $\mathrm{y}=5.0 \mathrm{E}-6 \mathrm{x}^{2}-\mathbf{3 . 4 E}-5 \mathbf{x}+6.3 \mathrm{E}-3$ \\
\hline $470-550 \mathrm{~nm}$ & $\mathrm{y}=-3.7 \mathrm{E}-7 \mathrm{x}^{2}+\mathbf{1 . 4 E}-5 \mathrm{x}-1.4 \mathrm{E}-4$ & $\mathrm{y}=-5.0 \mathrm{E}-6 \mathrm{x}^{2}+\mathbf{3 . 8 E}-4 \mathbf{x}-7.0 \mathrm{E}-3$ \\
\hline
\end{tabular}

Table C. 2 - Slopes as a function of time into experiment (50\%RH)

\begin{tabular}{|c|c|c|}
\hline & \multicolumn{2}{|c|}{ Time into experiment (min.) } \\
\hline Wavelength range & $20.0-30.0$ & $38.3+(1.0 \mathrm{ppm}+)$ \\
\hline $400-450 \mathrm{~nm}$ & $\mathrm{y}=1.0 \mathrm{E}-6 \mathrm{x}^{2}-\mathbf{2 . 7 E}-\mathbf{6} \mathbf{x}-3.7 \mathrm{E}-5$ & $\mathrm{y}=-3.7 \mathrm{E}-6 \mathrm{x}^{2}+\mathbf{2 . 0 E}-\mathbf{4 x}-5.8 \mathrm{E}-3$ \\
\hline $470-550 \mathrm{~nm}$ & $\mathrm{y}=-1.5 \mathrm{E}-6 \mathrm{x}^{2}+\mathbf{2 . 0 E}-\mathbf{5} \mathrm{x}-4.3 \mathrm{E}-4$ & $-4.6 \mathrm{E}-6 \mathrm{x}^{2}+\mathbf{2 . 3 E}-\mathbf{4} \mathbf{x}-4.0 \mathrm{E}-3$ \\
\hline
\end{tabular}

Table C.3 - Slopes as a function of time into experiment ( $85 \% \mathrm{RH})$

\begin{tabular}{|c|c|c|}
\hline & \multicolumn{2}{|c|}{ Time into experiment (mins) } \\
\hline Wavelength range & $25.0-35.0$ & $48.8+(1.0 \mathrm{ppm}+)$ \\
\hline $400-450 \mathrm{~nm}$ & $\mathrm{y}=2.4 \mathrm{E}-7 \mathrm{x}^{2}-\mathbf{4 . 5 E}-\mathbf{6} \mathbf{x}+2.1 \mathrm{E}-4$ & $\mathrm{y}=1.2 \mathrm{E}-6 \mathrm{x}^{2}+\mathbf{5 . 0 E}-5 \mathbf{x}-6.1 \mathrm{E}-34$ \\
\hline $470-550 \mathrm{~nm}$ & $\mathrm{y}=-1.5 \mathrm{E}-5 \mathrm{x}^{2}+\mathbf{1 . 4 E}-3 \mathrm{x}-3.2 \mathrm{E}-2$ & $\mathrm{y}=-2.4 \mathrm{E}-5 \mathrm{x}^{2}+\mathbf{2 . 4 E}-3 \mathrm{x}-6.1 \mathrm{E}-2$ \\
\hline
\end{tabular}




\section{Appendix D - Tables and Figures for Chapter 5}

\section{Figures}

Figure D. $1-\Delta \mathrm{C}$ of various Cbi concentrations as a function of $5.0 \mathrm{ppm} \mathrm{HCN}$ exposure time

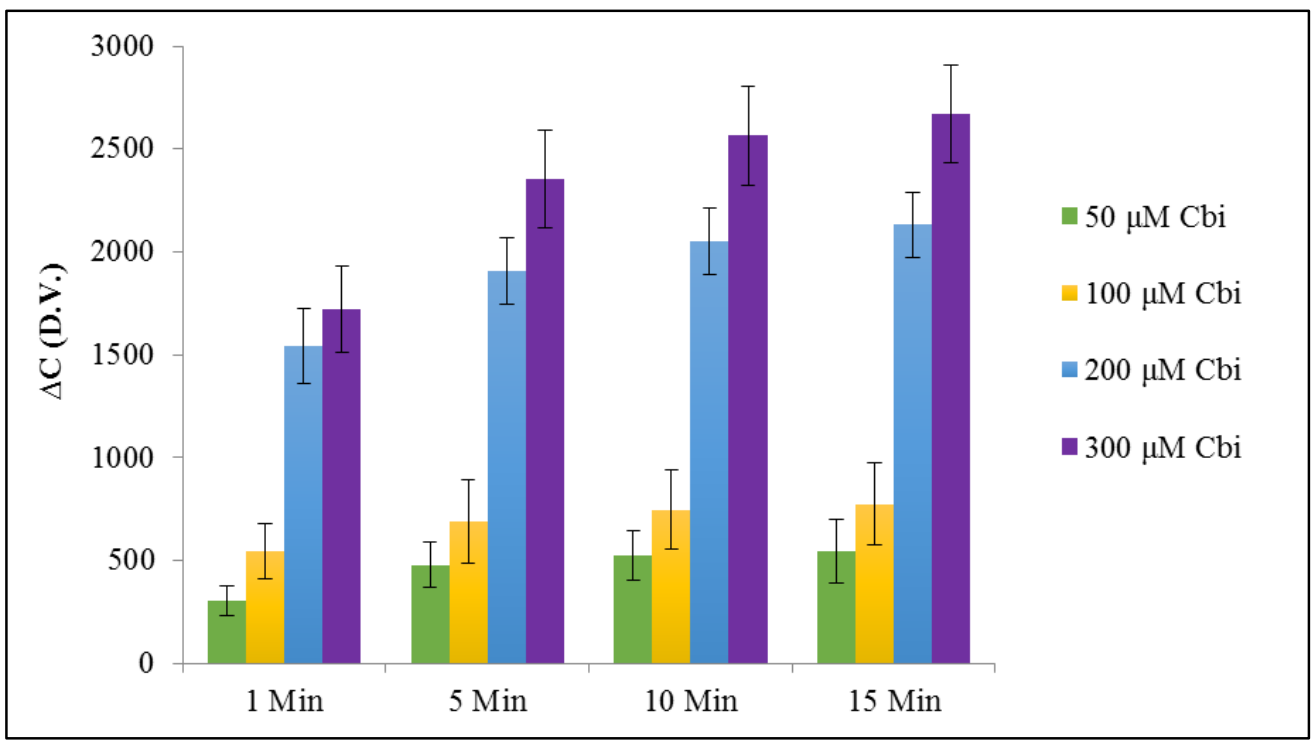

Figure D.2 - Kubelka-Munk spectrum of Cbi on glass fiber paper before (blue line) and after LED exposure (red line) for 1 hour $(n=3)$

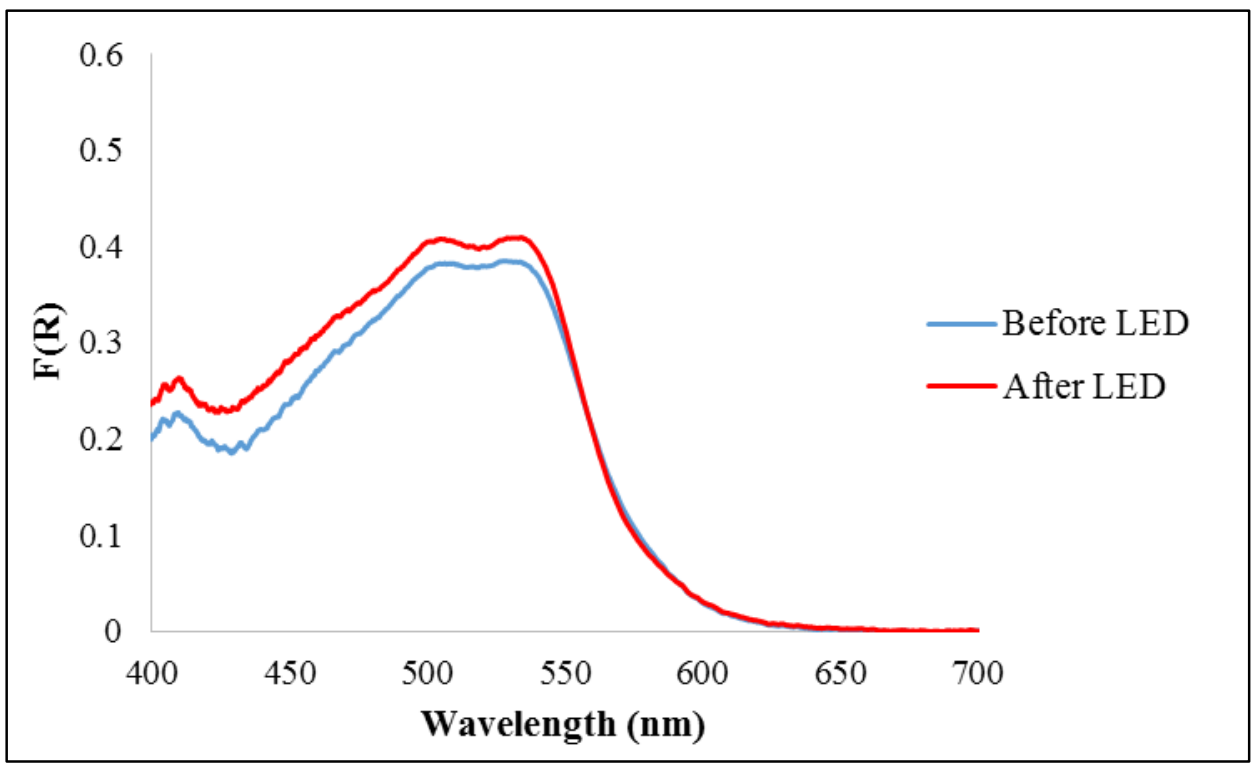


Figure D.3 - Response of the separate R,G, and B values upon $5.0 \mathrm{ppm}$ HCN exposure at 50 $\% \mathrm{RH}$

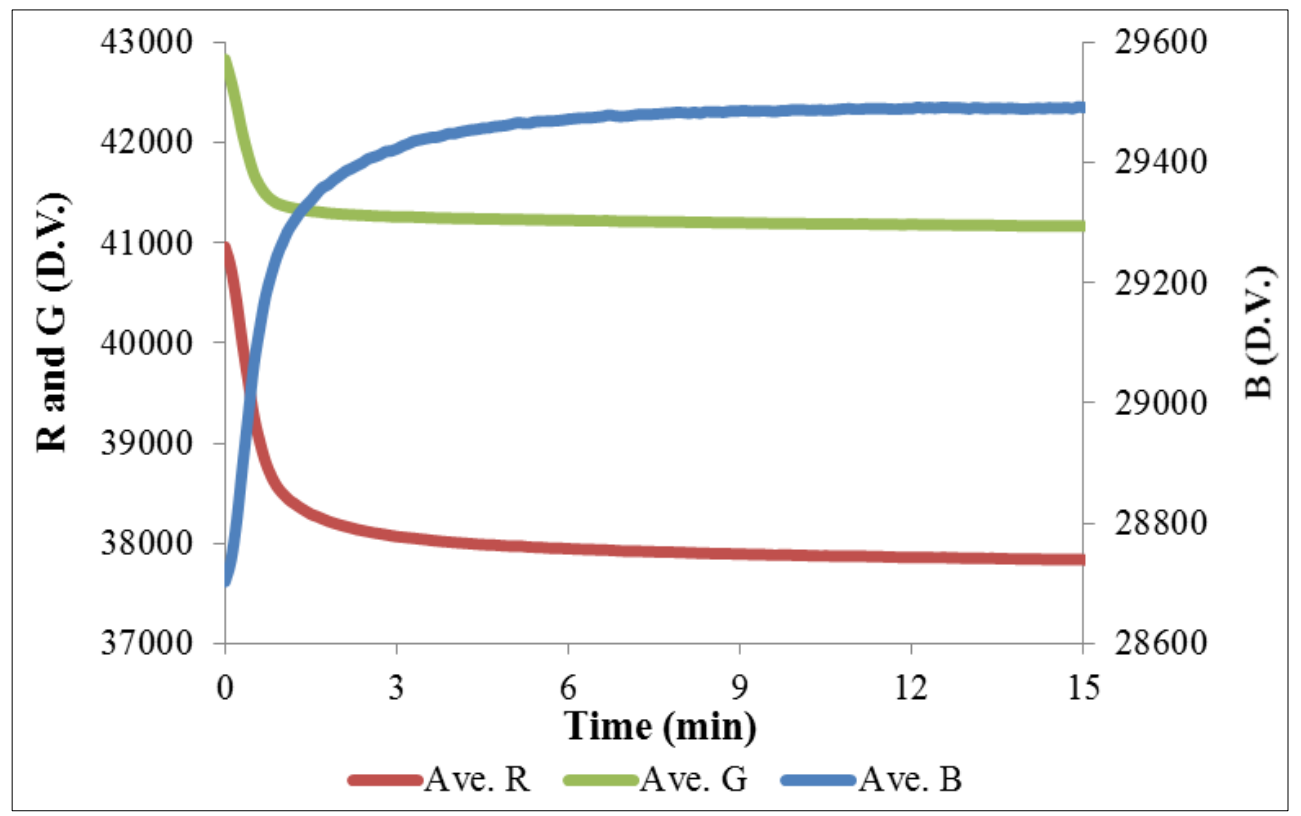

Figure D.4 - Initial $\Delta \mathrm{C}$ response for $50 \% \mathrm{RH}$

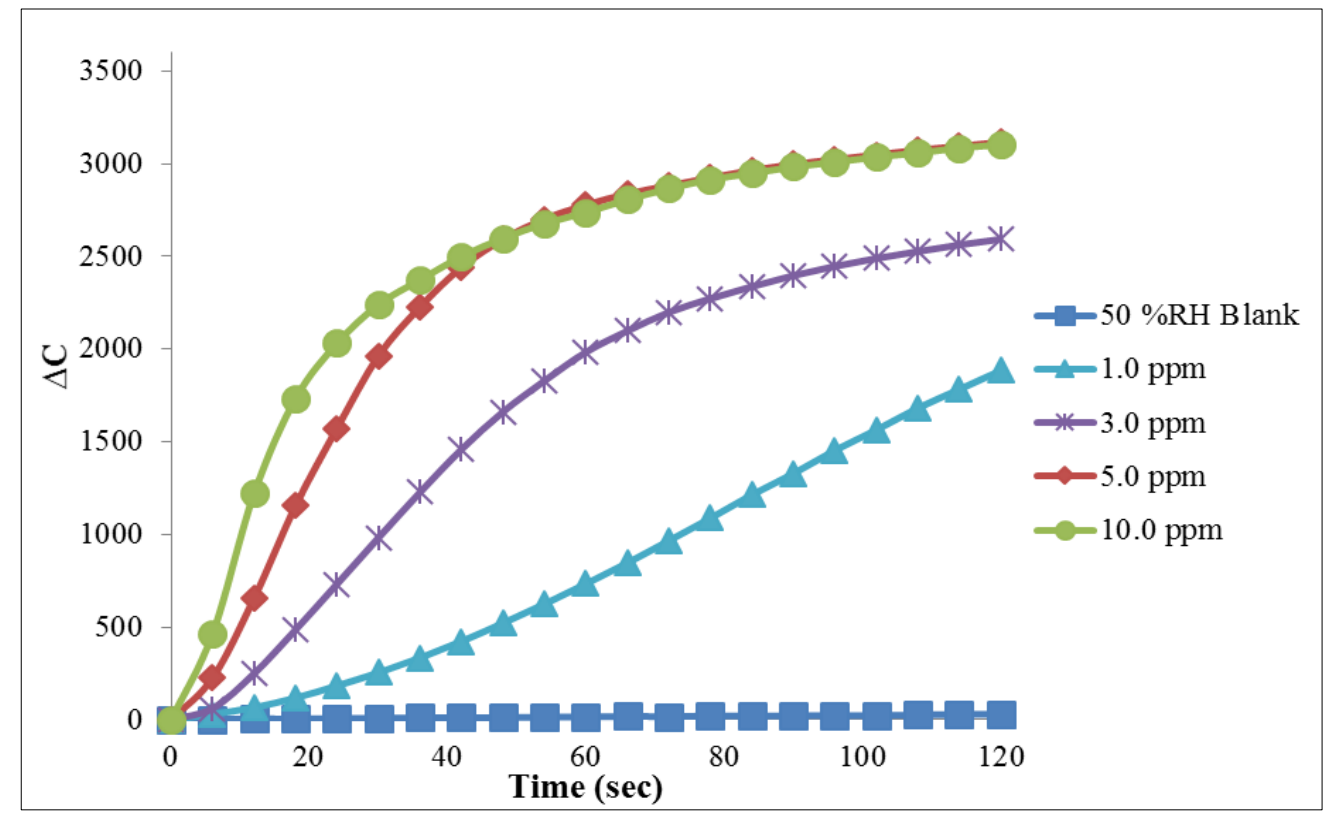


Figure D.5 - Total $\Delta \mathrm{C}$ for $1.0 \mathrm{ppm} \mathrm{HCN}$ at 25,50 , and $85 \% \mathrm{RH}$

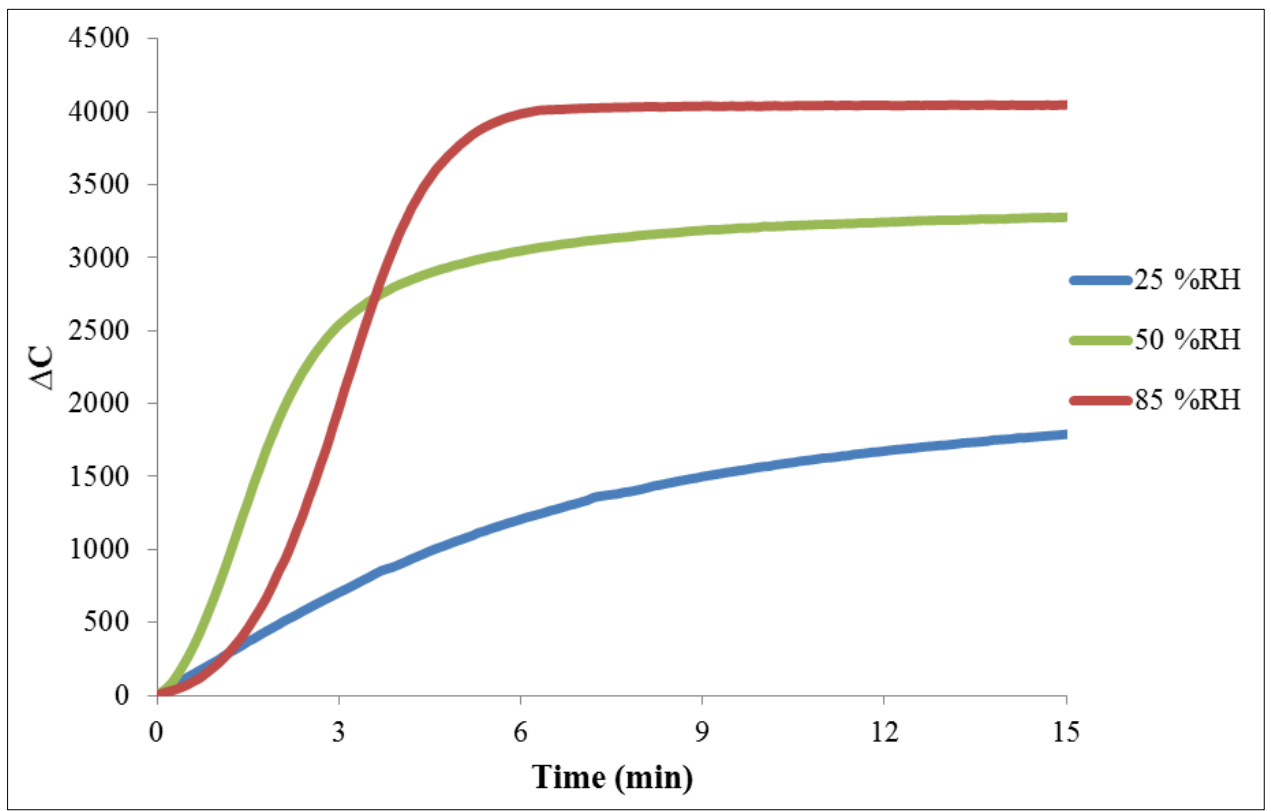

Figure D.6 - Initial total $\Delta \mathrm{C}$ for $1.0 \mathrm{ppm} \mathrm{HCN}$ at 25,50 , and $85 \% \mathrm{RH}$

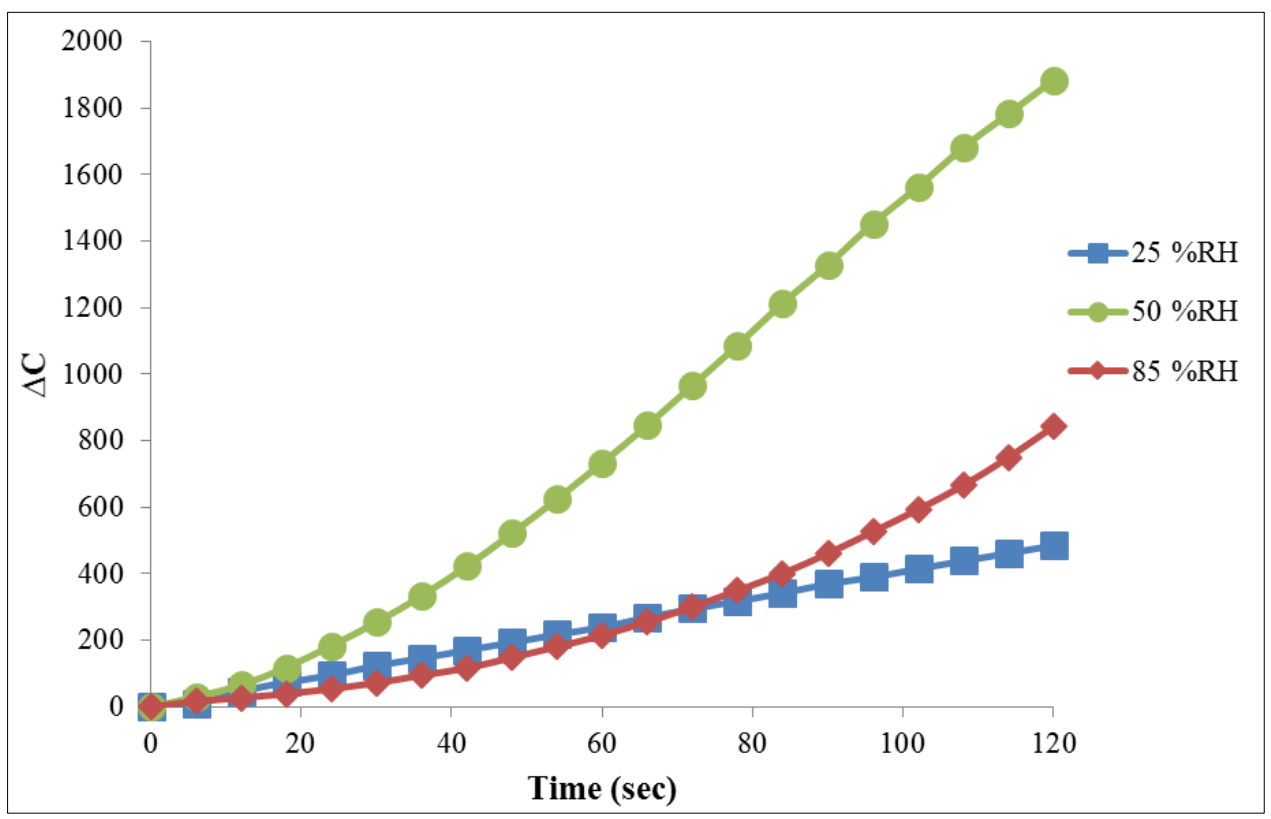


Figure D.7 - Total $\Delta \mathrm{C}$ for $3.0 \mathrm{ppm} \mathrm{HCN}$ at 25,50 , and $85 \% \mathrm{RH}$

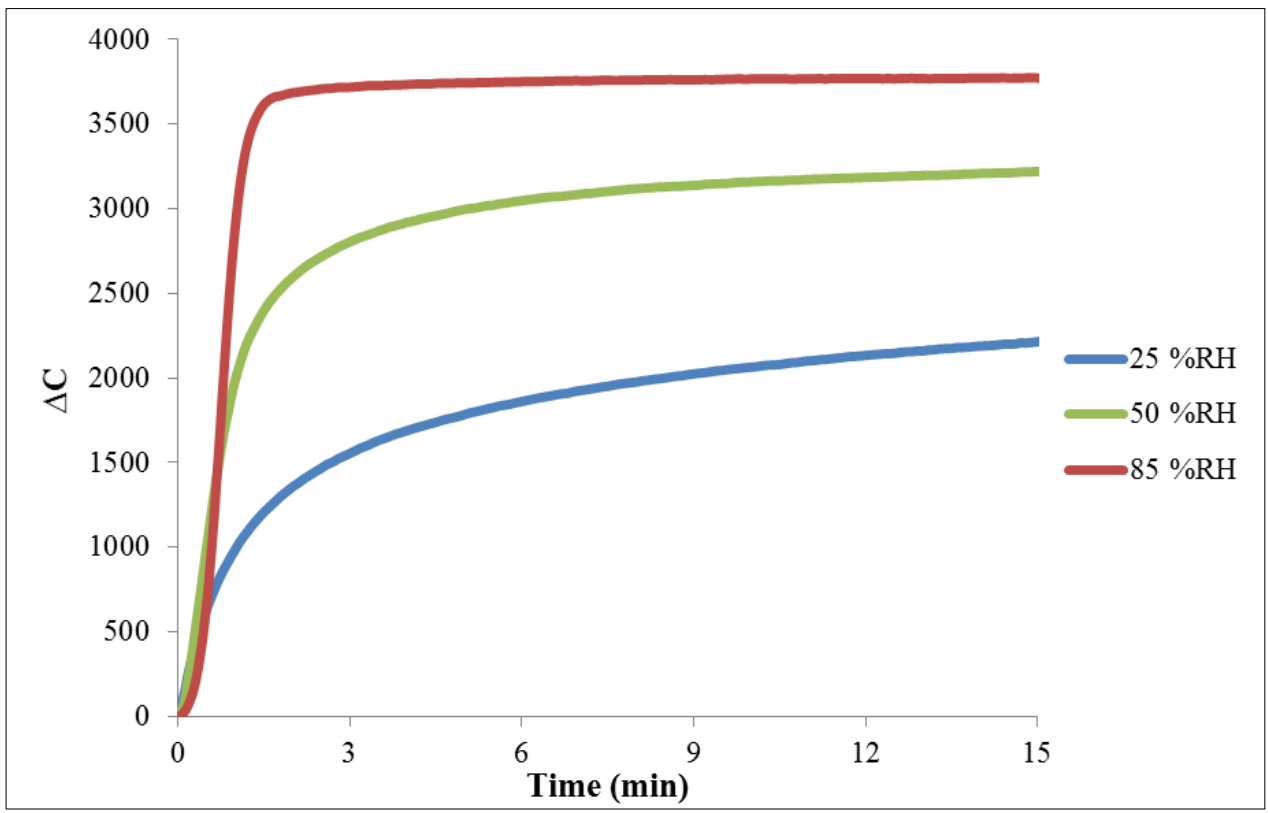

Figure D.8 - Initial $\Delta \mathrm{C}$ for $3.0 \mathrm{ppm} \mathrm{HCN}$ at 25,50 , and $85 \% \mathrm{RH}$

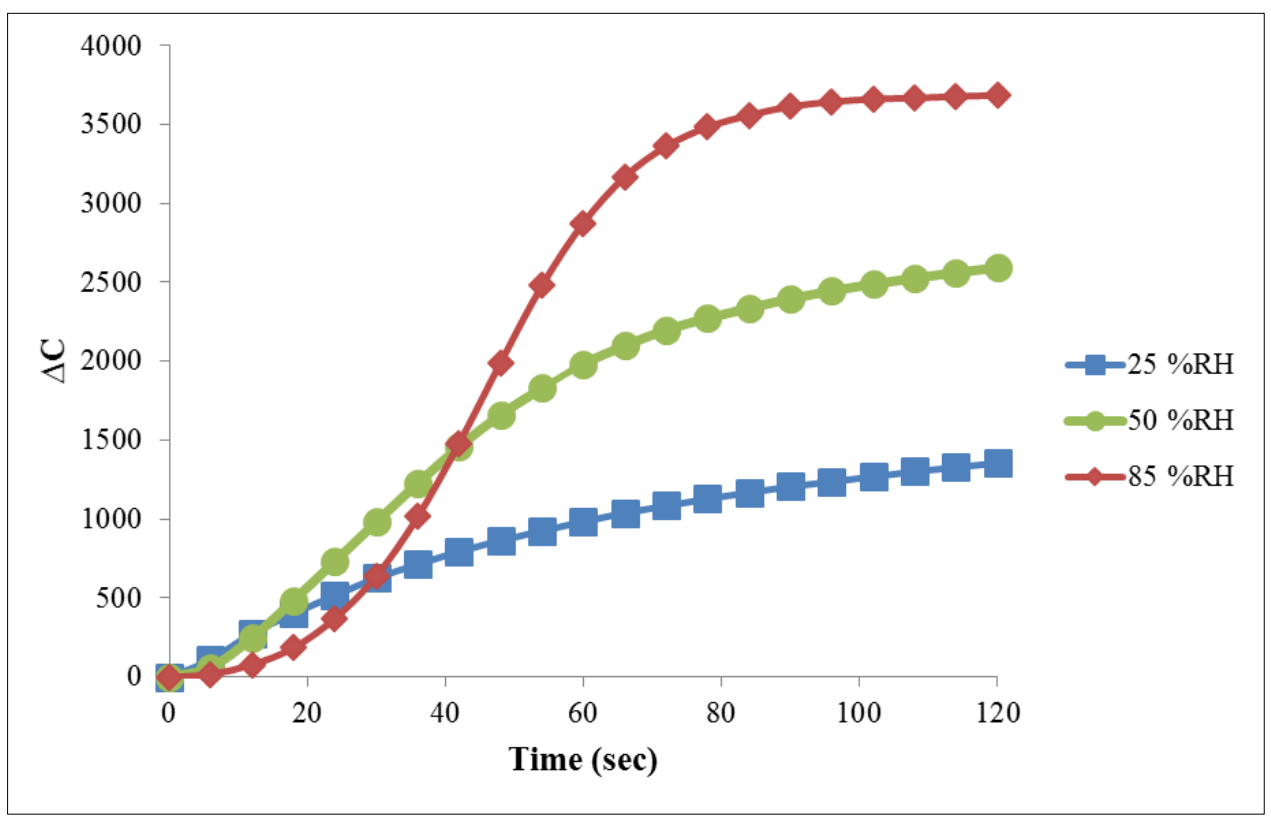


Figure D.9 - Total $\Delta \mathrm{C}$ for $10.0 \mathrm{ppm} \mathrm{HCN}$ at 25,50 , and $85 \% \mathrm{RH}$

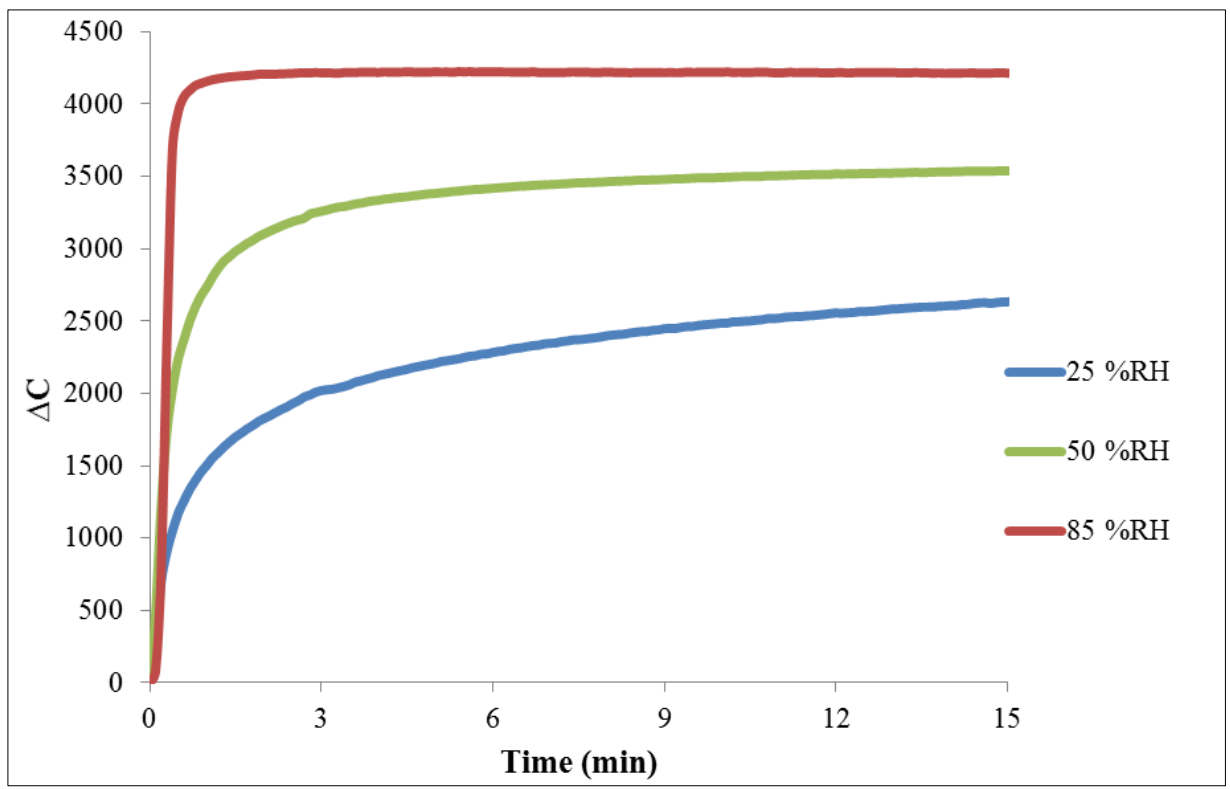

Figure D.10 - Initial $\Delta \mathrm{C}$ for $10.0 \mathrm{ppm} \mathrm{HCN}$ at 25,50 , and $85 \% \mathrm{RH}$

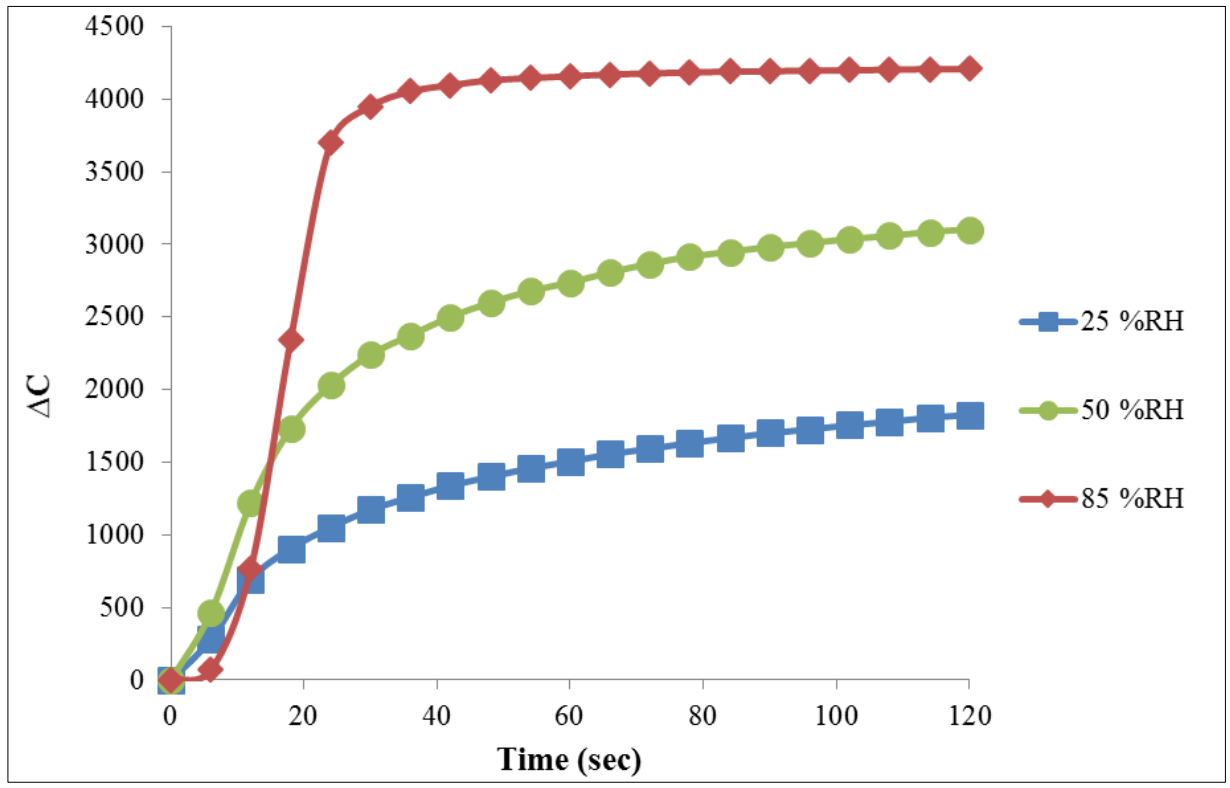




\section{Tables}

Table D. $1-\Delta \mathrm{C}$ for $\mathrm{CN}\left(\mathrm{H}_{2} \mathrm{O}\right) \mathrm{Cbi}$ on paper at $0.0 \mathrm{ppm} \mathrm{HCN}$ over 60 minutes

\begin{tabular}{|c|c|c|c|c|}
\hline Sample number & $\mathbf{R}$ & $\mathbf{G}$ & B & $\Delta \mathbf{C}$ \\
\hline \multicolumn{5}{|l|}{1} \\
\hline $\mathrm{t}=0 \mathrm{~min}$ & 42834 & 41729 & 28150 & \\
\hline$t=60 \mathrm{~min}$ & 42961 & 41912 & 28169 & 223.6 \\
\hline \multicolumn{5}{|l|}{2} \\
\hline $\mathrm{t}=0 \mathrm{~min}$ & 40180 & 40708 & 27028 & \\
\hline $\mathrm{t}=60 \mathrm{~min}$ & 40260 & 40890 & 27100 & 211.4 \\
\hline \multicolumn{5}{|l|}{3} \\
\hline $\mathrm{t}=0 \mathrm{~min}$ & 40904 & 41746 & 27744 & \\
\hline $\mathrm{t}=60 \mathrm{~min}$ & 41050 & 41832 & 27759 & 170.1 \\
\hline \multicolumn{5}{|l|}{4} \\
\hline $\mathrm{t}=0 \mathrm{~min}$ & 40487 & 40374 & 27180 & \\
\hline $\mathrm{t}=60 \mathrm{~min}$ & 40519 & 40581 & 27150 & 211.6 \\
\hline \multicolumn{5}{|l|}{5} \\
\hline $\mathrm{t}=0 \mathrm{~min}$ & 41261 & 41504 & 27634 & \\
\hline $\mathrm{t}=60 \mathrm{~min}$ & 41322 & 41681 & 27599 & 190.5 \\
\hline \multicolumn{5}{|l|}{6} \\
\hline $\mathrm{t}=0 \mathrm{~min}$ & 38770 & 39427 & 26332 & \\
\hline \multirow[t]{4}{*}{$\mathrm{t}=60 \mathrm{~min}$} & 38829 & 39580 & 26302 & 166.7 \\
\hline & & & Average $\Delta \mathbf{C}$ & 195.6 \\
\hline & & & S.D. & 23.7 \\
\hline & & & $95 \%$ CI & 24.8 \\
\hline
\end{tabular}


Table D. 2 - RGB color sensor response to $25 \% \mathrm{RH}$ at various concentrations of $\mathrm{HCN}$

\begin{tabular}{|c|c|c|c|c|c|}
\hline & Time (min) & Average $\Delta C(n=3)$ & SD & \%RSD & 95\% CI \\
\hline \multicolumn{6}{|l|}{ Blank } \\
\hline & 1 & 17.2 & 11.3 & 65.5 & 28.0 \\
\hline & 5 & 58.6 & 38.0 & 64.8 & 94.4 \\
\hline & 10 & 92.9 & 55.1 & 59.5 & 126.9 \\
\hline & 15 & 117.3 & 66.6 & 56.8 & 165.5 \\
\hline \multicolumn{6}{|l|}{$1.0 \mathrm{ppm}$} \\
\hline & 1 & 239.7 & 55.6 & 23.2 & 138.0 \\
\hline & 5 & 1065.4 & 76.6 & 7.2 & 190.6 \\
\hline & 10 & 1567.7 & 95.4 & 6.1 & 236.9 \\
\hline & 15 & 1790.1 & 135.1 & 7.5 & 335.6 \\
\hline \multicolumn{6}{|l|}{$3.0 \mathrm{ppm}$} \\
\hline & 1 & 983.6 & 100.3 & 10.2 & 249.1 \\
\hline & 5 & 1783.7 & 130.6 & 7.3 & 324.4 \\
\hline & 10 & 2063.9 & 133.8 & 6.5 & 332.3 \\
\hline & 15 & 2214.4 & 120.4 & 5.4 & 299.1 \\
\hline \multicolumn{6}{|l|}{$5.0 \mathrm{ppm}$} \\
\hline & 1 & 1124.4 & 183.3 & 16.3 & 455.3 \\
\hline & 5 & 1755.8 & 178.2 & 10.1 & 442.7 \\
\hline & 10 & 2009.1 & 171.8 & 8.6 & 425.8 \\
\hline & 15 & 2148.2 & 168.3 & 7.8 & 418.2 \\
\hline \multicolumn{6}{|l|}{$10.0 \mathrm{ppm}$} \\
\hline & 1 & 1437.1 & 95.23 & 9.0 & 236.6 \\
\hline & 5 & 2129.0 & 115.6 & 5.3 & 287.3 \\
\hline & 10 & 2403.8 & 117.7 & 4.8 & 292.5 \\
\hline & 15 & 2519.4 & 162.1 & 5.1 & 402.8 \\
\hline
\end{tabular}


Table D.3. - RGB color sensor response to $50 \% \mathrm{RH}$ at various concentrations of $\mathrm{HCN}$

\begin{tabular}{|c|c|c|c|c|c|}
\hline & Time (min) & Average $(n=3)$ & SD & \%RSD & 95\% CI \\
\hline \multicolumn{6}{|l|}{ Blank } \\
\hline & 1 & 15.7 & 12.0 & 76.4 & 29.8 \\
\hline & 5 & 52.6 & 29.1 & 55.3 & 72.3 \\
\hline & 10 & 79.2 & 40.3 & 50.9 & 100.2 \\
\hline & 15 & 103.1 & 49.3 & 47.8 & 122.4 \\
\hline \multicolumn{6}{|l|}{$1.0 \mathrm{ppm}$} \\
\hline & 1 & 733.6 & 300.6 & 41.0 & 746.8 \\
\hline & 5 & 2956.2 & 47.8 & 1.6 & 118.7 \\
\hline & 10 & 3213.7 & 149.6 & 4.7 & 36.2 \\
\hline & 15 & 3277.6 & 173.9 & 2.3 & 45.4 \\
\hline \multicolumn{6}{|l|}{$3.0 \mathrm{ppm}$} \\
\hline & 1 & 1983.9 & 65.4 & 3.3 & 162.4 \\
\hline & 5 & 2996.9 & 32.7 & 1.1 & 81.3 \\
\hline & 10 & 3158.5 & 18.8 & 0.6 & 46.6 \\
\hline & 15 & 3218.5 & 8.19 & 0.3 & 20.4 \\
\hline \multicolumn{6}{|l|}{$5.0 \mathrm{ppm}$} \\
\hline & 1 & 2778.0 & 718.2 & 25.9 & 1784.2 \\
\hline & 5 & 3404.1 & 647.4 & 19.0 & 1608.3 \\
\hline & 10 & 3569.0 & 658.7 & 18.5 & 1636.5 \\
\hline & 15 & 3645.4 & 679.4 & 18.7 & 1687.9 \\
\hline \multicolumn{6}{|l|}{10.0 ppm } \\
\hline & 1 & 2737.6 & 97.6 & 3.6 & 242.4 \\
\hline & 5 & 3383.5 & 216.3 & 6.4 & 537.5 \\
\hline & 10 & 3493.9 & 222.2 & 6.4 & 551.9 \\
\hline & 15 & 3539.7 & 222.3 & 6.3 & 552.3 \\
\hline
\end{tabular}


Table D.4 - RGB color sensor response to $85 \% \mathrm{RH}$ at various concentrations of $\mathrm{HCN}$

\begin{tabular}{|c|c|c|c|c|c|}
\hline & Time (min) & Average $(n=3)$ & S.D. & \% RSD & $95 \% \mathrm{CI}$ \\
\hline \multicolumn{6}{|l|}{ Blank } \\
\hline & 1 & 14.2 & 4.8 & 33.7 & 11.9 \\
\hline & 5 & 59.1 & 12.9 & 21.9 & 32.1 \\
\hline & 10 & 99.5 & 20.7 & 20.8 & 51.5 \\
\hline & 15 & 127.0 & 20.9 & 16.4 & 51.9 \\
\hline \multicolumn{6}{|l|}{$1.0 \mathrm{ppm}$} \\
\hline & 1 & 215.2 & 66.7 & 31.0 & 165.7 \\
\hline & 5 & 3774.8 & 79.2 & 2.1 & 196.8 \\
\hline & 10 & 4038.5 & 268.8 & 6.7 & 667.9 \\
\hline & 15 & 4047.6 & 247.1 & 6.1 & 613.9 \\
\hline \multicolumn{6}{|l|}{$3.0 \mathrm{ppm}$} \\
\hline & 1 & 2876.5 & 51.9 & 1.8 & 128.8 \\
\hline & 5 & 3743.1 & 98.0 & 2.6 & 243.5 \\
\hline & 10 & 3767.8 & 92.6 & 2.5 & 230.0 \\
\hline & 15 & 3772.5 & 99.5 & 2.6 & 247.1 \\
\hline \multicolumn{6}{|l|}{$5.0 \mathrm{ppm}$} \\
\hline & 1 & 3358.0 & 227.0 & 6.8 & 563.9 \\
\hline & 5 & 3928.7 & 388.1 & 9.9 & 964.1 \\
\hline & 10 & 3954.2 & 377.3 & 9.5 & 937.3 \\
\hline & 15 & 3957.6 & 370.9 & 9.4 & 921.5 \\
\hline \multicolumn{6}{|l|}{10.0 ppm } \\
\hline & 1 & 4158.0 & 49.7 & 1.2 & 123.5 \\
\hline & 5 & 4223.7 & 41.1 & 0.97 & 102.1 \\
\hline & 10 & 4220.3 & 38.6 & 0.92 & 96.0 \\
\hline & 15 & 4214.5 & 27.6 & 0.65 & 68.5 \\
\hline
\end{tabular}

